FCNyM - UNLP

Dinámica del crecimiento óseo facial en poblaciones humanas del sur de Sudamérica

- $4=3$

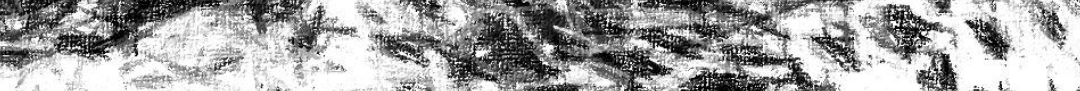

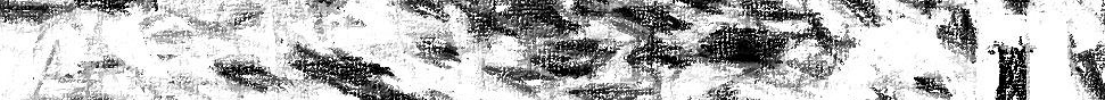

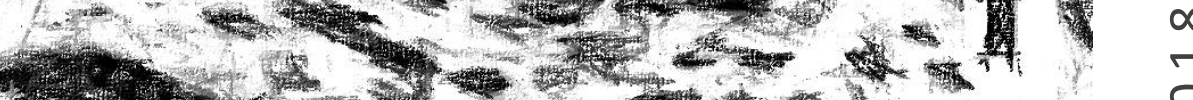
(6)

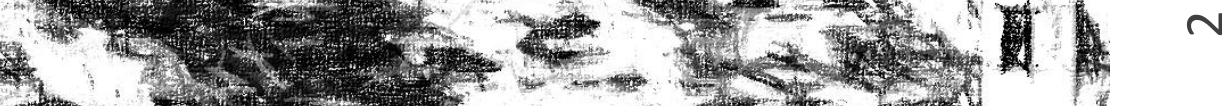

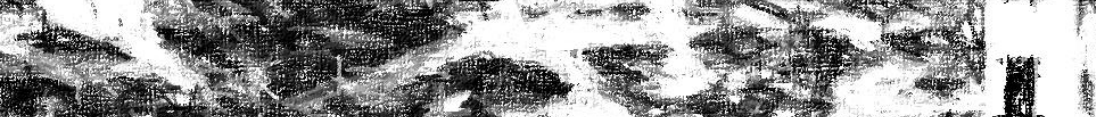

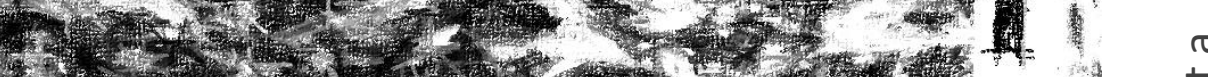

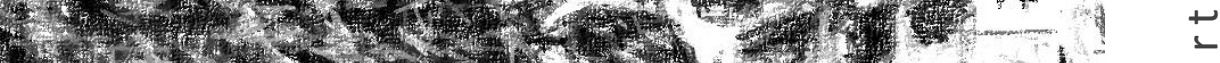

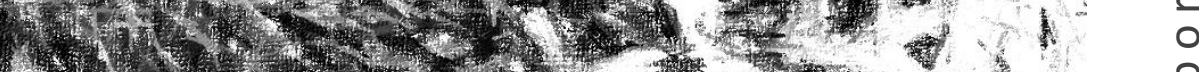

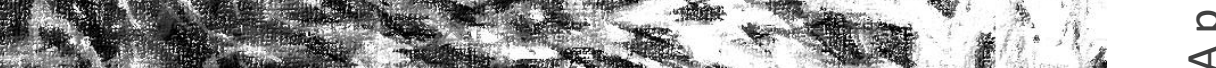

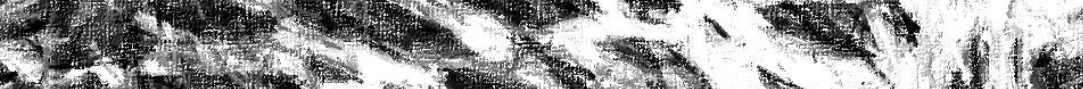
-17.

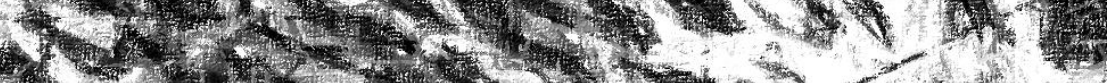

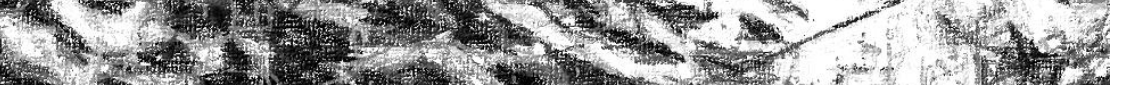

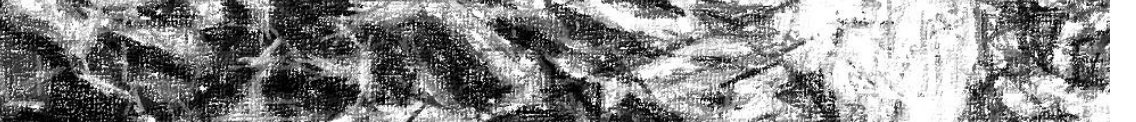

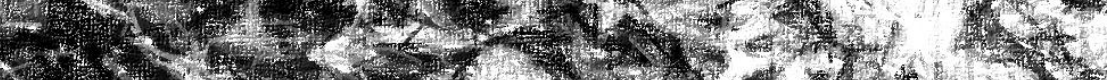

W

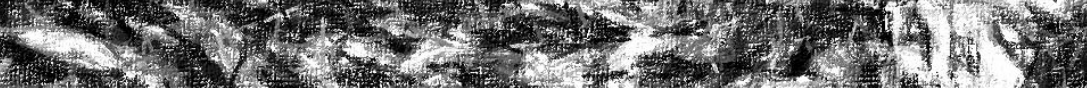

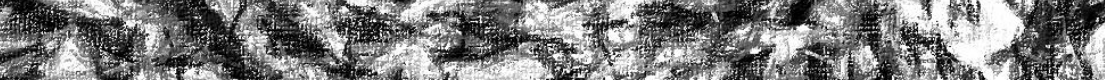

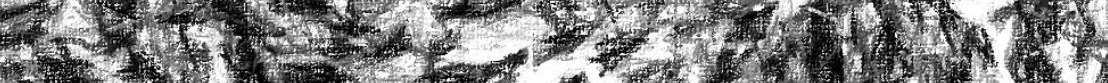
1.

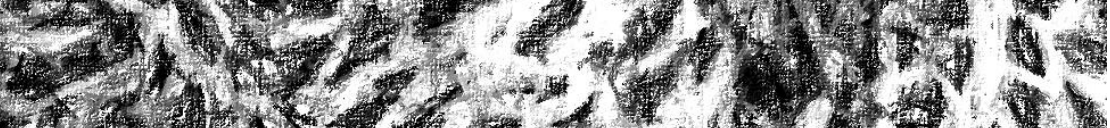

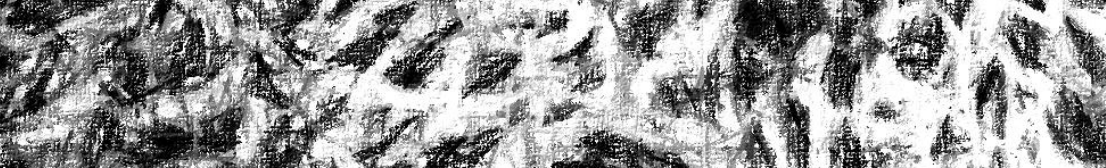
7.

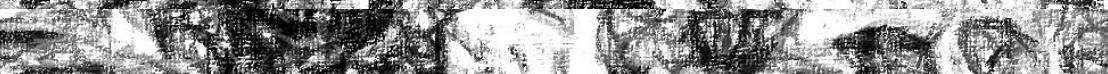

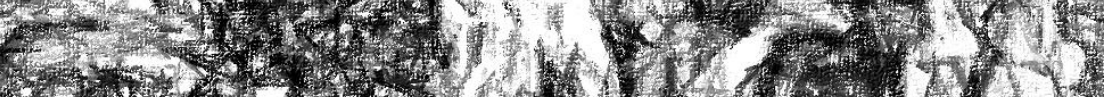

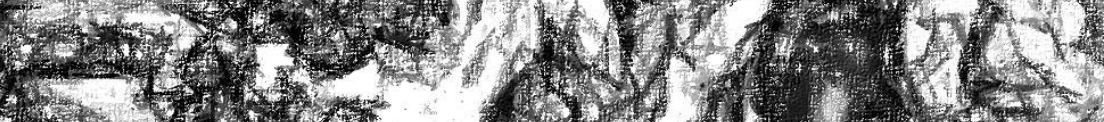
4.7.7.7. s.6.

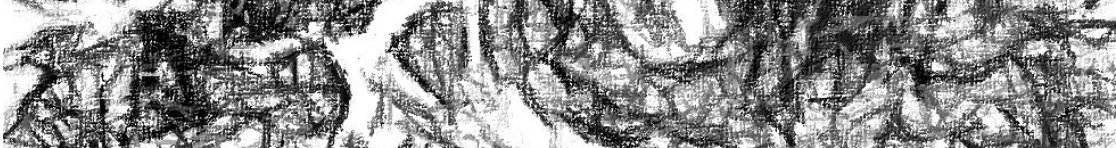

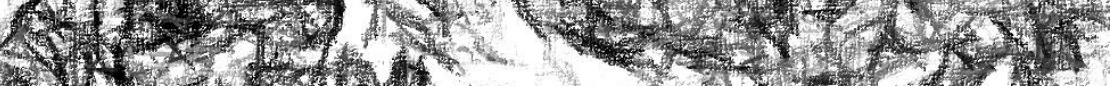
1.7.

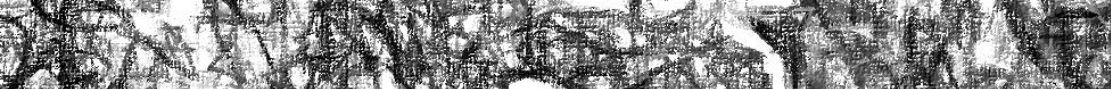

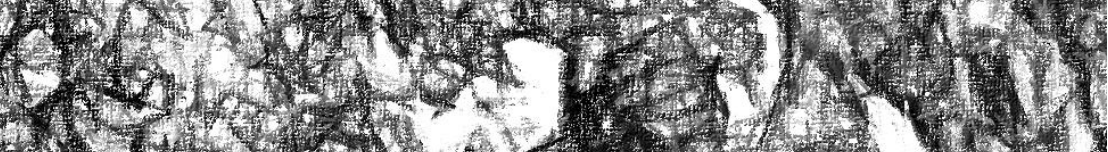
M. 7.t.

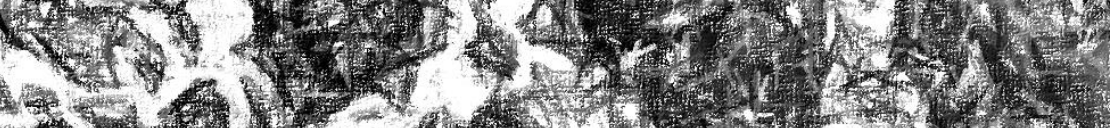

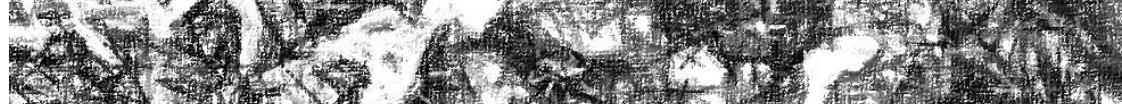

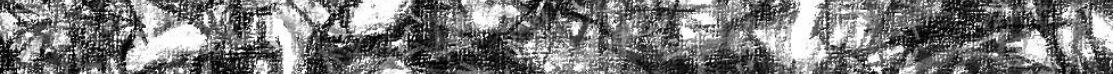

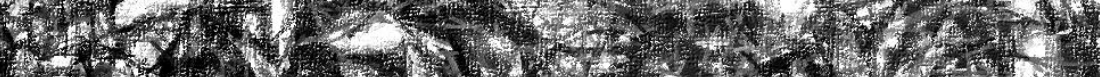
4.7.

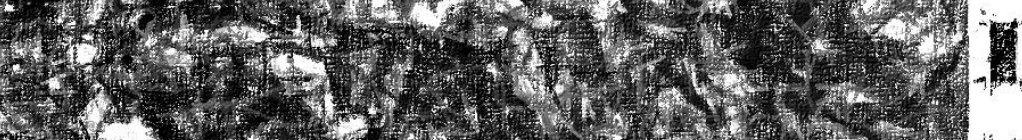

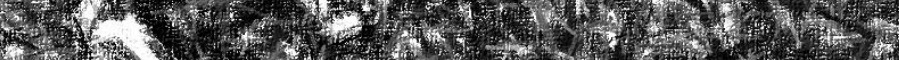
1.7.

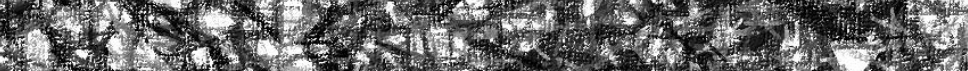

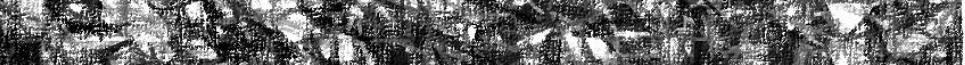

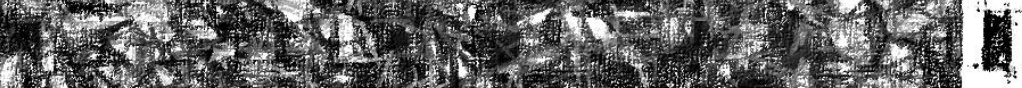




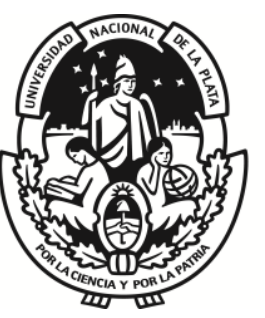

Universidad Nacional de La Plata

Facultad de Ciencias Naturales y Museo

\section{Dinámica del crecimiento óseo facial en poblaciones humanas del sur de Sudamérica}

Lic. Natalia Brachetta Aporta

2018

Directoras: Dra. Valeria Bernal y Dra. Paula Natalia Gonzalez

Tesis presentada para optar por el título de Doctor en Ciencias Naturales 
A mi papá, Roberto 


\section{Agradecimientos}

A Valeria Bernal y Paula Gonzalez. Gracias por enseñarme y por ayudarme a ordenar mis ideas y preguntas, y por acompañarme a pensar otras tantas nuevas. Por ser parte de mis vicisitudes y ayudarme a superar aquellos obstáculos que el proyecto de tesis me fue deparando. Gracias por guiarme en esto de crecer en la ciencia.

A mi familia. Por estar y ser parte de lo que soy. A mi mamá y mi abuela, Gladys y Fifi, por el amor y las esperanzas que siempre depositaron en mí. A mi hermano Lautaro y a Ana, que a pesar de tenerlos lejos, siempre los sentí cerca. A Silvia, por hacerme un lugar en su corazón. Y a muchos miembros más, quienes cada uno a su manera me brindaron cariño.

A la gente del equipo, con quienes compartí tantos buenos momentos. A Ivan Perez, quien con su perspectiva analítica y sencillez en el ejemplo, me ayudó en más de una oportunidad a resolver inconvenientes. A Guido Rocatti, Vir Cobos y Nahuel Muñoz, con quienes pasé buenos momentos dentro y fuera del laboratorio, siempre rodeada de risas y comida. Gracias por ayudarme a aminorar mis preocupaciones y darme ánimos. A Barby Postillone, Jimena Barbeito y Flor Gordón, por las visitas al 132, compartiendo siempre buena onda y consejos. A Marien Béguelin, por la buena onda y por recibirme en Roca con el mayor de los lujos. A mis asesores informáticos, Fede Lotto y Leandro Arístide. Difícilmente hubiera podido emplear programas como el R y el Avizo sin ustedes. Gracias por las charlas y por los mates compartidos. A Lumi Menéndez, por las energías y las cervezas, por meterme en la cabeza que haga una especialización que me deparó tantas buenas sorpresas. A Mirsha Quinto, por la calidez y la comida mexicana. A las nuevas generaciones, que llenan con entusiasmo el 132: Noelia Bonfili, Bruno Moscardi, Mariana Vallejo, Leandro Koch y Joaquín del Río.

A las amistades, platenses y mendocinas. Todas y cada una de ellas, que de una u otra manera me ayudaron y acompañaron a transitar este largo camino recorrido. A Eliana Coturel, siempre presente para darme ánimos y alejar mis frustraciones. Por intervenir artísticamente estas páginas y ayudarme en las traducciones. A Eluney Aguilar y Analía Agüero, porque a través de los años han sido mis confidentes y mi sosiego. Gracias a todos, por el amor y las risas, por el apoyo y los recuerdos.

A quienes me ensañaron la magia del microscopio: a Enrique Portiansky, por su paciencia en enseñarme a usarlo y a modificarlo para mis objetivos. A los chicos del laboratorio 143, por ayudarme en la obtención de las fotos. 
A Cayetana Martinez-Maza, por guiarme en el reconocimiento de las superficies de modelado óseo y ayudarme a poner a punto la técnica para hacer réplicas. Por los trabajos compartidos y el conocimiento brindado.

A Fabián Tricárico, por metalizarme cientos de moldes y permitirme explorar algunos al MEB. Gracias por la predisposición con la que siempre me recibiste en el Museo Argentino de Ciencias Naturales.

A Diego Gobbo, por adentrarme en el mundo de ArcGIS. Por automatizar el relevamiento de datos. Si no fuera por él, todavía estaría contando celdas.

A Rocío García-Mancuso y Barby Desántolo. Por compartir sus experiencias y ofrecerme ayuda en todo momento. Gracias por el apoyo.

A Mariano Del Papa y Andrés Di Bastiano, por permitirme acceder en más de una oportunidad a las muestras depositadas en el Museo de La Plata.

$Y$ a todos aquellos con quienes me fui topando en las diversas encrucijadas de la tesis y me aportaron toda la ayuda que estaba a su alcance. $\mathrm{O}$ que simplemente tiraron una piedra en el estanque, movilizándome a cambiar. Gracias.

A Lucas A. D’Addona, por ser mi apoyo constante, mi compañero de vida. Por mostrarme la mitad del vaso lleno cuando yo me centro en la vacía. Porque desde la facultad venimos pateando las piedras del camino juntos. Gracias por ayudarme con la tesis y hacerla parte tuya, por llevar adelante todo lo que yo dejé de lado por ella.

Esta tesis está dedicada a mi papá, Luis Roberto Brachetta. Por ser mi pilar en esta vida y la motivación para seguir avanzando. Porque supo entenderme, apoyarme y acompañarme a través de los años. Por el amor que me dejó y que tanto añoro. A él le debo poder haber llegado hasta acá.

Esta tesis fue posible gracias al soporte otorgado por la Facultad de Ciencias Naturales y Museo (FCNyM), la Universidad Nacional de La Plata (UNLP) y el Consejo Nacional de Investigaciones Científicas y Técnicas (CONICET). 


\section{Resumen}

La variación morfológica craneofacial resulta, en parte, de procesos del desarrollo que involucran interacciones mecánicas y espaciales que actúan a distintos niveles de organización a lo largo de la ontogenia de los individuos. Los principales determinantes de la forma y tamaño del cráneo incluyen factores, tanto locales como globales, vinculados a la interacción entre el tejido óseo y órganos (e.g. cerebro, músculos) y estructuras asociadas (i.e. dientes), y a respuestas compensatorias a modificaciones producidas en regiones anatómicas específicas. La acción conjunta de estos factores durante el crecimiento y desarrollo estimula o inhibe la diferenciación y actividad de las células involucradas en los procesos de formación y reabsorción de hueso -i.e. osteoblastos y osteoclastosque constituyen el modelado óseo, produciendo diferencias en tamaño y forma observables anatómicamente entre individuos y poblaciones. Por lo tanto, para comprender el origen y mantenimiento de los patrones de variación observable a nivel morfológico resulta especialmente relevante el estudio de los procesos a nivel tisular y celular. En este contexto, el objetivo general de este trabajo es contribuir al conocimiento de la variación intra-específica en los procesos de modelado óseo y su relación con la variación morfológica dentro y entre poblaciones humanas.

Se analizaron los patrones de modelado óseo en el esqueleto facial de individuos subadultos y adultos de dos muestras del sur de Sudamérica procedentes del Noroeste de Argentina (Pampa Grande, Salta) y Patagonia (Valle inferior del río Chubut). Los cambios en la forma y el tamaño del cráneo durante la ontogenia y entre muestras fueron evaluados a partir del empleo de coordenadas tridimensionales de landmarks y semilandmarks, y reconstrucciones tridimensionales de los espacios funcionales correspondientes a los senos maxilar y frontal, al orbital y el endocráneo. Se emplearon técnicas de la morfometría geométrica, adecuadas para cuantificar la dirección y magnitud de los cambios en el arreglo espacial de los rasgos morfológicos. Para el análisis de los patrones de modelado óseo de la superficie facial y su integración con datos morfométricos se desarrolló una aproximación metodológica novedosa que combina estadística espacial y univariada. La metodología propuesta consiste en la cuantificación de la distribución espacial y extensión de las áreas de formación y reabsorción ósea. Esto permitió, en primer lugar, contar con criterios claros y explícitos para la estimación de datos en las áreas con ausencia de información histológica mediante técnicas de interpolación espacial e imputación de datos perdidos. A partir de la obtención de mapas de modelado completos fue posible aplicar análisis estadísticos para resumir y analizar la información del modelado óseo dentro y entre muestras. Asimismo, esta aproximación posibilitó la integración de conjuntos de datos que capturan distintos niveles de variación fenotípica (e.g. histológico y morfológico) empleando estadística multivariada. La información generada sobre la variación ontogenética en ambos conjuntos de datos fue utilizada, asimismo, para discutir implicancias 
derivadas de las formulaciones de los modelos clásicos de Moss y Enlow sobre los procesos que operan durante el crecimiento y desarrollo craneofacial. Por otro lado, a fin de controlar la variación introducida por el observador en los análisis histológicos de superficies óseas y proveer así mayor confiabilidad a las observaciones, se desarrolló el primer protocolo para el análisis sistemático del error de medición de las superficies de formación y reabsorción ósea.

Los resultados de los análisis histológicos obtenidos para Pampa Grande y Chubut indican que el patrón de modelado óseo se mantiene constante a través de la ontogenia para las regiones de la glabela, supraorbital, proceso frontal del maxilar y gran parte del hueso malar, caracterizado por la predominancia de formación. Por el contrario, el cuerpo del maxilar y el borde orbital del malar exhibieron cambios en el patrón de modelado, con un incremento en la presencia de áreas de formación con la edad para ambas poblaciones. Asimismo, se encontraron diferencias entre las muestras analizadas, observándose una mayor presencia de reabsorción en los individuos de la muestra de cazadores-recolectores de Chubut, especialmente en las regiones de mayor impacto local de cargas masticatorias. Por el contrario, la región de la glabela y el supraorbital no exhibió diferencias entre muestras. Estos resultados apoyan una diferenciación en los patrones de modelado entre la región facial superior y la media, indicando que desde el punto de vista histológico estas dos regiones presentan un comportamiento modular. Se detectaron además, áreas con una extensión espacial más limitada que podrían corresponder a módulos de menor jerarquía asociados a factores locales biomecánicos. En general, el análisis comparativo realizado en este trabajo permite señalar que la región facial, especialmente la región media, no exhibe un patrón de modelado único en las poblaciones humanas.

A partir del análisis de la covariación entre el modelado óseo y la forma de las estructuras faciales se estableció que los cambios ontogenéticos en la forma de la glabela y el supraorbital no se asocian a diferencias en la extensión y distribución espacial de las actividades de modelado óseo entre individuos. Este resultado sugiere que los cambios en forma a lo largo de la ontogenia serían modelados por la tasa de formación ósea antes que por cambios en la distribución espacial de los dos tipos de actividad celular. Por el contrario, la variación en la forma del malar y del maxilar con la edad se asoció a cambios en el patrón de modelado óseo a lo largo de la ontogenia, aunque en el caso del malar no se corresponde con las expectativas del modelo de crecimiento craneofacial planteado por Enlow. Sobre la base de estos resultados se infiere que las diferencias en la forma de la región facial superior entre las dos muestras analizadas serían resultado de una mayor tasa de actividad de formación en la muestra de Chubut, lo que conduciría al mayor desarrollo de la glabela y los supraorbitales. Por otro lado, las diferencias en los patrones de modelado habrían contribuido a la diferenciación morfológica de la región facial media entre las dos muestras analizadas. En 
particular, la diferenciación en los patrones de modelado entre muestras se observó en edades más tempranas para el malar que para el maxilar.

Estos resultados han permitido generar nuevas preguntas de investigación que requieren futuros estudios para el abordaje de aspectos metodológicos vinculados a la identificación de distintos tipo de superficies óseas en condiciones tafonómicas diversas; y que incluyan un número mayor de muestras, balanceadas por sexo, que incorporen la representación de todos los rangos etarios, y procedan de poblaciones expuestas a diferentes factores ecológicos. Esto permitirá discutir con mayor profundidad los factores que modelan la variación morfológica craneofacial a nivel intra e inter-poblacional. 


\section{Abstract}

Morphological craniofacial variation is partially a consequence of developmental processes. These processes involve both mechanical and spatial interactions that act at different levels of organization throughout the ontogeny of individuals. The main factors that regulate the shape and size skull can be classified according to their extension, as local or global factors. These factors are associated to the interaction among bone tissue, organs (e.g. brain, muscles) and related structures (i.e. teeth), and to compensatory responses to changes produced in specific anatomical regions. Altogether, these interactions and compensatory responses stimulate or inhibit cell differentiation and activity involved in the process of bone formation and resorption -i.e. osteoblast and osteoclast- that constitute bone modeling, generating differentiations in size and shape anatomically observable among individuals and populations. Therefore, the study of the processes at tissue and cellular level is especially relevant in order to understand the origin and preservation of the patterns of variation observable at the morphological level. In this context, the main objective of this work is to contribute to the knowledge of intra-specific variation in bone modeling process, and their relation to morphological variation within and among human populations.

Bone modeling patterns from facial skeleton of subadults and adults were analyzed. Samples were taken from two localities of Argentina, one from the Northwest Region (Pampa Grande, Salta) and another from central Patagonia (Lower Valley of Chubut River). The changes in the shape and size of the skull during ontogeny and between samples were evaluated with two methodologies: three-dimensional coordinates of landmarks and semilandmarks, and three-dimensional reconstructions of the functional spaces of the maxillary and frontal sinuses, the orbital and the endocranium. The geometric morphometric techniques employed in this study were selected because they are adequate to quantify the direction and magnitude of changes in the spatial arrangement of morphological features. On the other hand, a novel methodological approach was developed for the analysis of bone modeling patterns and its integration with morphometric data. This method consists in the quantification of the spatial distribution and extension of the areas of bone formation and resorption. The methodology allows the application of clear and explicit criteria for estimations of missing histological data by spatial interpolation and imputations techniques. The complete modeling maps obtained made possible to apply statistical analyses to summarize and analyze bone modeling data within and between samples. Also, this approach allowed the integration of data from different levels of phenotypic variation (e.g. histological and morphological) using multivariate statistics. The information gathered from both data sets was also employed to discuss 
implications derived from classic models of Moss and Enlow about the processes that took place during craniofacial growth and development. On the other hand, in order to control the variation introduced by the observer in the histological analysis of bone surfaces and provide greater reliability to the observations, the first protocol for a systematic analysis of the measurement error of bone formation and resorption surface was developed.

Histological results from Pampa Grande and Chubut indicated that the bone modeling pattern is constant through ontogeny for glabella, supraorbital, frontal process of maxilla and most of malar surface, with formation principally. In contrast, the body of maxilla and the malar rim of orbital display bone modeling changes with an increase in the presence of formation areas with age for both populations. The samples showed different reabsorption activity between localities, with an extra activity on individuals from the hunter-gatherers sample of Chubut, especially in the regions of greatest local impact of chewing loads. In contrast, the glabella and supraorbital region do not exhibit differences between samples. These results support a differentiation in bone modeling patterns between the upper and middle face, which indicates a modular behavior from a histological perspective. In addition, more limited areas of differentiation were detected that could correspond to modules of lower hierarchy associated with biomechanical local factors. Overall, the comparative analyses carried out indicated that the facial region, especially the middle face, does not exhibit a unique bone modeling pattern in human populations.

From the covariation analyses between bone modeling and the form of facial structures, it was established that the ontogenetic changes in the shape of glabella and supraorbital are not associated to differences in the extension and spatial distribution of the bone modeling activities among individuals. This result is interpreted as that ontogenetic changes in shape would be modeled by the bone formation rate rather than spatial distribution changes of both types of cell activity. In contrast, maxillary and malar shape variation within age was associated with changes in the bone modeling pattern through the ontogeny, even though the malar shape variation is not consistent with the expectations from the growth craniofacial model of Enlow. Based on these results it is possible to infer that the differences in shape in the upper face between both samples would be result of a higher formation rate in the Chubut sample, which would lead to a greater development of the glabella and supraorbitals. On the other hand, the differences in modeling patterns would have contributed to the morphological differentiation in the middle face between the two samples analyzed. In particular, the differentiation in modeling patterns between samples was observed at younger ages for the malar than for the maxilla. 
These results allow generating new research questions that require future studies to address methodological aspects linked to the identification of different types of bone surfaces in different taphonomic conditions. Future studies should include a greater number of samples, balanced by sex, with all the age ranges represented, and from populations exposed to different ecological factors. This will to allow discuss in greater depth the factors that model the craniofacial morphological variation at intra- and inter-population level. 


\section{Índice}

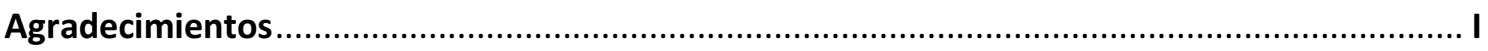

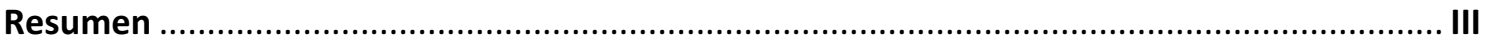

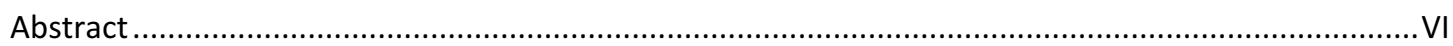

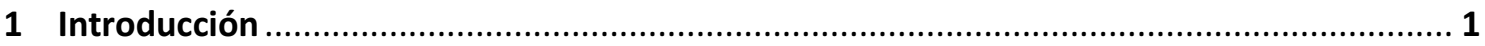

1.1. Antecedentes, planteo y relevancia del problema en estudio ....................................................... 1

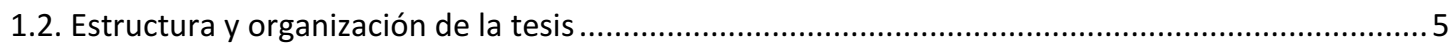

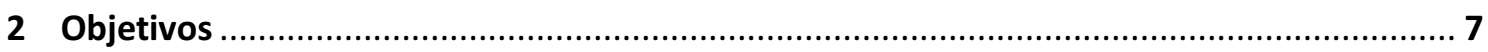

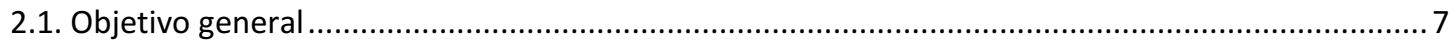

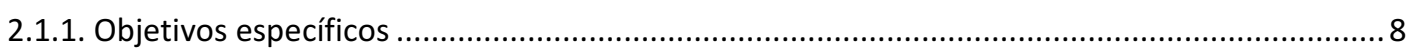

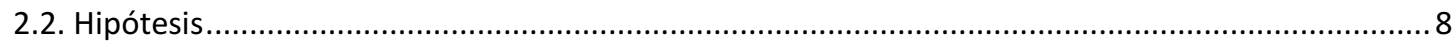

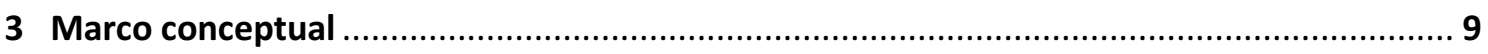

3.1. Aproximación desde la biología evolutiva del desarrollo a la variación fenotípica ....................... 10

3.1.1. Estructuración de la variación fenotípica ....................................................................... 11

3.1.2. Enfoque middle-out a los fenotipos complejos .............................................................. 12

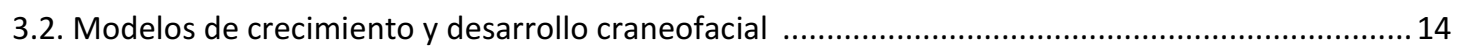

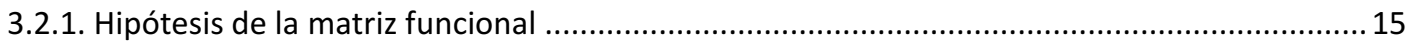

3.2.2. El control regional del desarrollo óseo ....................................................................... 17

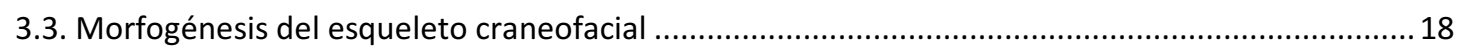

3.3.1. Origen embriológico y osificación del cráneo.................................................................. 18

3.3.2. Procesos histológicos de crecimiento y desarrollo craneofacial ...........................................20

3.4. Regiones del cráneo: desarrollo y función ........................................................................ 24

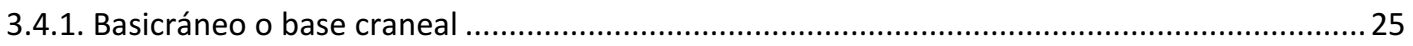

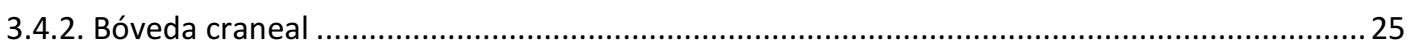

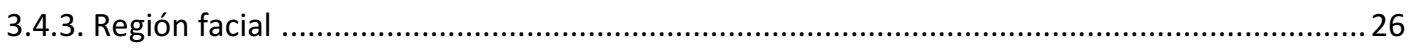

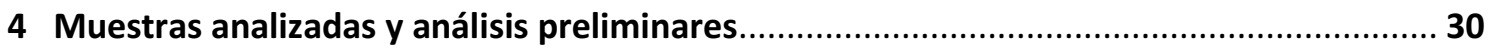

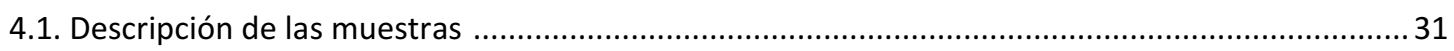

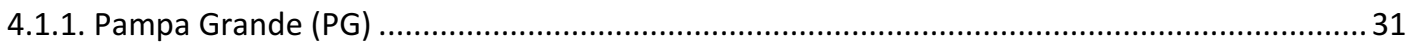

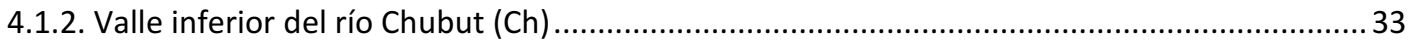

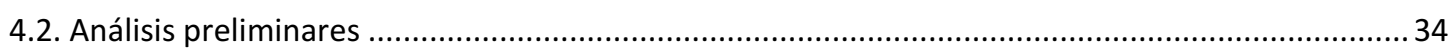

4.2.1. Composición sexual y etaria de las muestras ................................................................. 34 


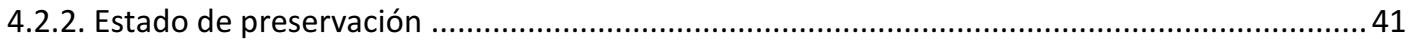

4.2.3. Indicadores de adecuación fisiológica y salud bucal ...................................................... 43

5 Métodos para el análisis histológico de superficies óseas ................................................. 46

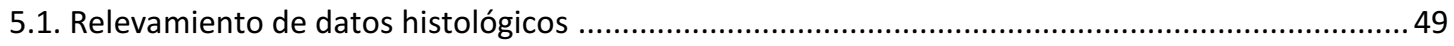

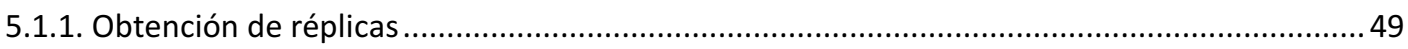

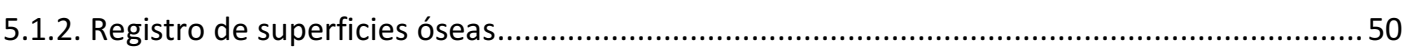

5.2. Análisis del error de observación en el registro de superficies óseas .......................................5 54

5.2.1. Metodología para el análisis del error de observación ....................................................... 54

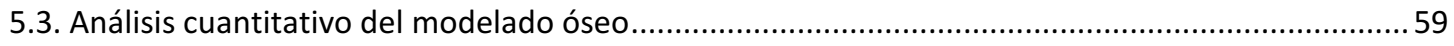

5.3.1. Estimación de los datos perdidos en mapas de modelado óseo ..........................................6 61

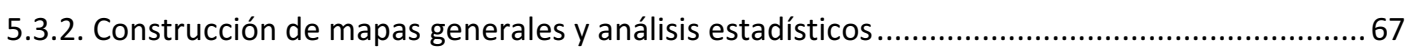

6 Métodos para el análisis de la morfología craneofacial ..........................................69

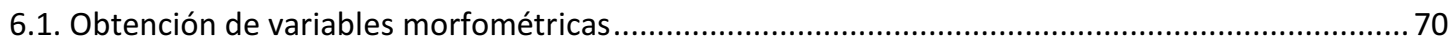

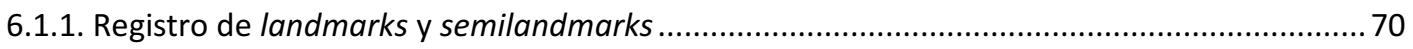

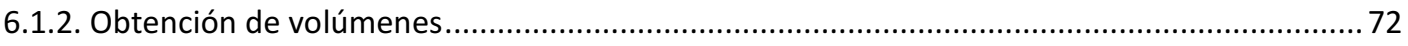

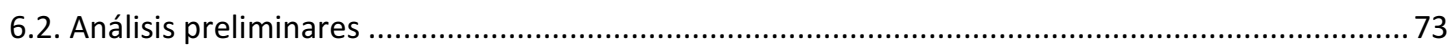

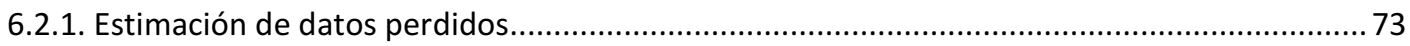

6.2.2. Análisis del error de observación en la digitalización de landmarks y semilandmarks ........... 75

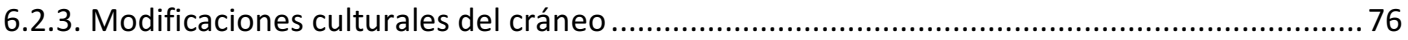

6.3. Métodos multivariados para el análisis de la morfología craneofacial ..................................... 77

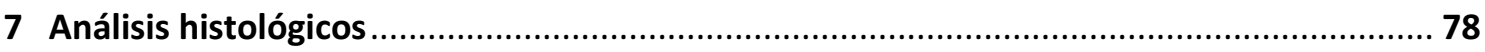

7.1. Completitud de la información histológica de las superficies faciales ........................................ 79

7.2. Patrones de modelado óseo: mapas generales en individuos subadultos y adultos .....................85

7.2.1. Patrones generales de modelado óseo en la muestra de Pampa Grande............................ 85

7.2.2. Patrones generales de modelado óseo en la muestra de Chubut ........................................89

7.3. Variación individual de los patrones de modelado óseo ......................................................93

7.3.1. Patrones de modelado óseo individuales en la muestra de Pampa Grande .........................93

7.3.2. Patrones de modelado óseo individuales en la muestra de Chubut ................................... 101

7.4. Variación inter-muestral de los patrones de modelado óseo de la región facial.........................112

7.4.1. Comparación de los patrones generales de modelado óseo de los individuos subadultos ...112

7.4.2. Comparación de los patrones generales de modelado óseo de los individuos adultos .........113 


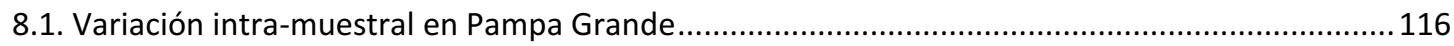

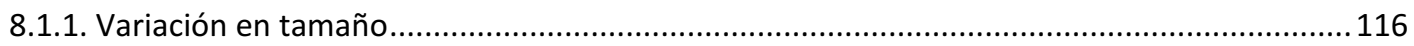

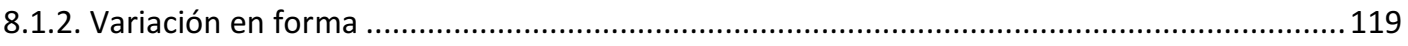

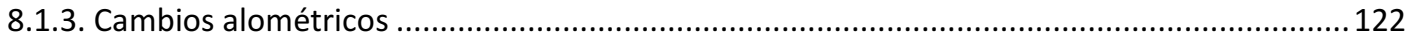

8.2. Variación intra-muestral en Chubut............................................................................... 124

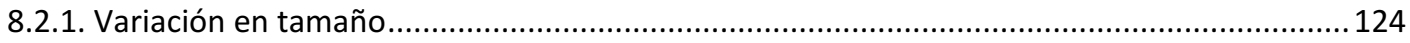

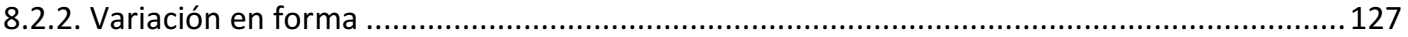

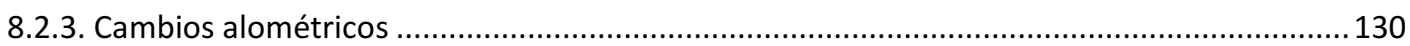

8.3. Variación inter-muestral entre Pampa Grande y Chubut ...................................................... 131

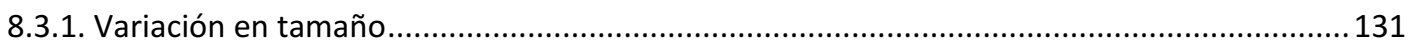

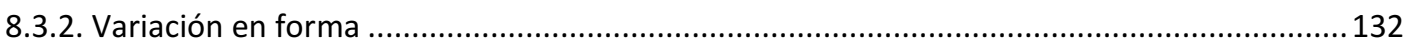

9 Integración de datos histológicos y morfológicos ............................................... 135

9.1. Variación en los patrones de modelado óseo y la morfología facial en la muestra de Pampa Grande.......

9.1.1. Variación en tamaño, forma y modelado óseo

9.2. Variación en los patrones de modelado óseo y la morfología facial en la muestra de Chubut .... 150

9.2.1. Variación en tamaño, forma y modelado óseo 150

9.3. Resultados destacados.

10 Discusión

10.1. Desarrollo de una aproximación metodológica cuantitativa para el análisis de los patrones de

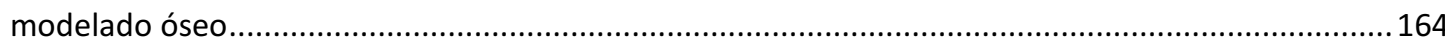

10.2. Variación intra e inter-poblacional en los patrones de modelado óseo .................................... 169

10.3. Integración de datos craneofaciales histológicos y morfométricos ........................................... 175

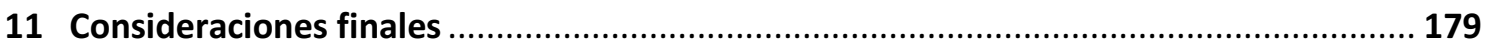

Anexo 1 Planilla registro de individuos............................................................. 183

Anexo 2 Definición de landmarks, semilandmarks y curvas digitalizados en el cráneo ..... 185

Anexo 3 Elaboración de réplicas de alta resolución .................................................. 198

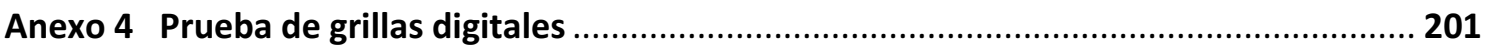

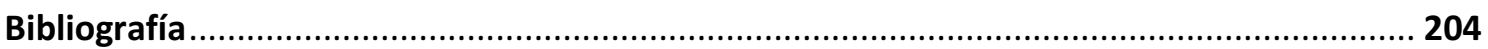




\section{Introducción}

Problema de estudio

\section{Contenido}

1.1. Antecedentes, planteo y relevancia del problema en estudio

1.2. Estructura y organización de la tesis

En el presente capítulo se presenta el problema de estudio abordado en el trabajo de tesis, introduciendo la problemática en torno a las dinámicas de crecimiento óseo facial humano. Se expone la importancia de la información histológica en los estudios orientados a determinar los procesos de crecimiento y desarrollo involucrados en la variación morfológica craneofacial. Al finalizar, se hace una breve presentación de los capítulos subsiguientes.

\subsection{Antecedentes, planteo y relevancia del problema de estudio}

Las estructuras morfológicas complejas, como el cráneo, se originan durante el desarrollo de los organismos a partir de la integración de agregados o condensaciones celulares de diverso origen embriológico que se diferencian para producir componentes morfogenéticos semiindependientes (Atchley y Hall, 1991). El tamaño relativo de estos componentes está controlado por diversos parámetros derivados de procesos que ocurren a nivel celular, tales como el número inicial, el arreglo espacial y la tasa de división de las células. Asimismo, la matriz extracelular sobre la cual migran las células define el tiempo, la dirección, la velocidad y el destino final de cada célula (Franz-Odendaal, 2011). En conjunto, estos parámetros celulares y extracelulares determinan la forma de las estructuras morfológicas a lo largo de la ontogenia, a través de eventos secuenciados en el tiempo y anidados estructuralmente en niveles jerárquicos mayores. Los cambios en forma, por lo tanto, son resultado de la acción de diversos factores genéticos, epigenéticos y ambientales que tienen influencia sobre las condensaciones celulares (Atchley y Hall, 1991; Hall, 2003; Bastir, 2008; Hallgrimsson y Lieberman, 2008; Franz-Odendaal, 2011). Estos factores pueden tener efectos globales -e.g. hormonas, ambiente- extendiéndose a múltiples rasgos, o locales -e.g. moléculas de acción autocrina o paracrina, interacciones epigenéticas entre tejidos y órganos- con una acción limitada espacialmente afectando un número acotado de rasgos (Mitteroecker y Bookstein, 2008; Parker, 2011). Particularmente para el cráneo se ha sugerido que los principales 
determinantes de su forma y tamaño serían factores, tanto locales como globales, vinculados a la interacción entre el tejido óseo y órganos (e.g. cerebro, músculos) y estructuras asociadas (i.e. dientes), y a respuestas compensatorias a reorganizaciones espaciales producidas en regiones anatómicas específicas (Moss y Young, 1960; Enlow y Hans, 1996; Daegling, 2010). La acción conjunta de estos factores durante el desarrollo puede estimular o inhibir la diferenciación y actividad de las células involucradas en los procesos de formación y reabsorción de hueso -i.e. osteoblastos y osteoclastos- que constituyen el modelado óseo, así como desencadenar movimientos pasivos -i.e. desplazamientos de crecimiento- producto del movimiento de tejidos adyacentes (Enlow y Hans, 1996). El modelado óseo actúa en consecuencia, manteniendo las proporciones espaciales y relaciones funcionales del hueso durante el crecimiento, compensando los desplazamientos y modelando la forma del hueso. En base a ello, es que se considera que la distribución del modelado en superficie es un indicador importante del patrón de crecimiento craneofacial (Bromage, 1982; Enlow y Hans, 1996; O'Higgins y Jones, 1998). Los cambios espaciales y temporales en la actividad de osteoclastos y osteoblastos modelan el crecimiento y desarrollo del cráneo durante la ontogenia, originando las diferencias en tamaño y forma observables entre individuos y poblaciones (Lieberman, 2011a,b).

El estudio sobre los procesos de desarrollo que subyacen a la variación morfológica dentro y entre especies actuales y extintas se ha basado, principalmente, en análisis a nivel macroestructural o anatómico. Desde esta aproximación se han analizado, especialmente, los cambios en forma y tamaño de las estructuras anatómicas durante la ontogenia mediante el empleo de técnicas morfométricas y de análisis estadísticos multivariados. Dado que el diseño de estos estudios es, salvo excepciones, comparativo y transversal el análisis morfológico sólo permite evaluar un subconjunto de los posibles procesos y mecanismos del desarrollo a través de los cuales podrían originarse las diferencias morfológicas observadas. En particular, se ha focalizado en el rol de las modificaciones en la extensión del crecimiento y dirección de las trayectorias ontogenéticas en el establecimiento de los patrones de variación entre poblaciones y especies (Ackermann y Krovitz, 2002; Mitteroecker y Bookstein, 2008; Gonzalez et al., 2011; Freidline et al., 2015; Klingenberg, 2016). La extensión de las trayectorias varía como resultado tanto de modificaciones en la tasa de crecimiento como en la edad de finalización del mismo. Ambos procesos generarán cambios en forma manteniendo constantes los patrones alométricos (i.e. cambios en forma asociados al tamaño). Por otro lado, las diferencias en las trayectorias de cambio en forma a lo largo de la ontogenia entre grupos reflejan modificaciones de los patrones alométricos. Los patrones observados a nivel 
anatómico pueden resultar de diversos procesos que ocurren a nivel histológico y por lo tanto, el análisis de este nivel resulta relevante para comprender las dinámicas de crecimiento asociadas a la diferenciación poblacional.

A pesar de su rol fundamental en el establecimiento de los patrones morfológicos en las estructuras óseas, el análisis a nivel histológico ha sido escasamente explorado (Desántolo y Bernal, 2016), aun cuando desde la década de 1960 se ha reconocido la posibilidad de estudiar los procesos de modelado y remodelado óseo a partir de los rasgos microestructurales característicos que éstos generan sobre las superficies del hueso (Enlow, 1963; Boyde, 1972; Bromage, 1989; Enlow y Hans, 1996). Hasta el presente, estos estudios han abordado, principalmente, el análisis comparativo del esqueleto craneofacial en primates a nivel interespecífico (e.g. Enlow, 1966; O’Higgins et al., 1991; Martinez-Maza et al., 2006, 2016; McCollum, 2008; Lacruz et al., 2015a,b). En tanto que el estudio de los procesos de modelado óseo en poblaciones humanas modernas se ha limitado a la información disponible sobre los cambios ontogenéticos en los patrones de formación y reabsorción en el esqueleto facial de un número reducido de muestras (Enlow, 1963; Enlow y Bang, 1965; Kurihara et al., 1980; McCollum, 2008; Martinez-Maza et al., 2013; Brachetta-Aporta et al., 2014). En particular, los análisis se han centrado en individuos menores de 14 años (Enlow y Bang, 1965; Kurihara et al., 1980; Enlow y Hans, 1996; McCollum, 2001, 2008; Martinez-Maza et al., 2013), mientras que la información disponible para subadultos mayores de 14 años de edad y adultos es reducida (McCollum, 2001; 2008; Martinez-Maza et al., 2013; Brachetta-Aporta et al., 2014). Asimismo, se observa un mayor énfasis en el estudio de la región facial en relación con otras regiones del cráneo. Esto se debe a que es la región anatómica con mayor complejidad desde el punto de vista del desarrollo y funcional, y presenta un crecimiento extendido que acompaña el patrón de crecimiento somático, alcanzando el tamaño y forma adultos con posterioridad al neurocráneo (Moss y Young, 1960; Cheverud, 1995, 2007; Opperman, 2000; Opperman et al., 2005; Lieberman, 2011b). En este sentido, se ha planteado que la región facial sería más susceptible a la influencia del ambiente durante la ontogenia (Cheverud, 1995; Sperber, 2001; Opperman et al., 2005).

Diversos trabajos previos coinciden en señalar que los patrones de modelado óseo difieren entre los individuos subadultos y adultos, indicando que las dinámicas generales de crecimiento se modifican a lo largo de la ontogenia (McCollum, 2001; 2008; Kranioti et al., 2009; Martinez-Maza et al., 2013; Brachetta-Aporta et al., 2014). En particular, para los individuos subadultos se ha señalado que la región facial superior -i.e. que incluye proceso frontal del maxilar, proceso frontal del malar, glabela, arco supraorbitario y cavidad orbital- se 
caracteriza por el predominio de formación ósea, con pequeñas áreas de reabsorción principalmente a lo largo del borde orbital (Enlow y Bang, 1965; Martinez-Maza et al., 2013). Este patrón general se mantendría en los individuos adultos, aunque con incremento de la extensión y distribución de las áreas de reabsorción (Martinez-Maza et al., 2013; BrachettaAporta et al., 2014). En la región facial media -conformada por el cuerpo del maxilar y del malar- se registraron cambios a lo largo de la ontogenia postnatal en la superficie anterior del maxilar, caracterizándose por la presencia de áreas de formación ósea durante el período de desarrollo de la dentición decidua; seguido por un período, entre los 2 y 14 años, en el que predomina la reabsorción ósea, aunque la distribución y extensión varía entre los distintos estudios (Enlow y Bang, 1965; Kurihara et al., 1980; McCollum, 2008; Martinez-Maza et al., 2013). Por otro lado, para el malar de los individuos subadultos se ha observado principalmente actividad de depositación (Enlow y Bang, 1965; Martinez-Maza et al., 2013). Los escasos estudios realizados en individuos adultos indican que las superficies externas tanto del maxilar como del malar se caracterizan por presentar una mayor proporción de formación, con pequeñas áreas de reabsorción ósea en el borde del masetero del malar y en la fosa canina del maxilar (Martinez-Maza et al., 2013; Brachetta-Aporta et al., 2014). Aún resta por estudiar en profundidad si estos patrones de modelado son comunes a la especie, o si por el contrario existen diferencias poblacionales (McCollum, 2008; Brachetta-Aporta et al., 2014).

En menor medida aún, se ha avanzado en la integración de la información a nivel histológico con la variación en la morfología craneofacial tanto a escala inter-específica como intra-específica. Esto puede deberse, en parte, a las distintas tradiciones de investigación en las que se han desarrollado estos estudios. Por un lado, el análisis de la morfología realizado desde aproximaciones vinculadas a la anatomía y la biología evolutiva, y por otro lado, el análisis de las dinámicas de modelado óseo en el marco de estudios sobre el crecimiento normal y patológico de la región facial (Boyde, 1972; Enlow y Hans, 1996; Monteiro y dos Reis, 1999; Carlson, 2005; Bastir et al., 2006, 2010). Otro aspecto que ha dificultado su integración ha sido el metodológico, mientras los análisis morfológicos tienen un fuerte énfasis en el registro de variables cuantitativas y el empleo de métodos estadísticos, el análisis histológico de las superficies óseas ha sido, hasta el presente, de carácter descriptivo y cualitativo (O'Higgins y Jones, 1998; Brachetta-Aporta et al., 2014, 2016; Martinez-Maza et al., 2016; Freidline et al., 2017). Los escasos trabajos que analizan la morfología facial y los patrones de modelado óseo sobre las mismas muestras se han limitado a realizar evaluaciones descriptivas de la correspondencia entre ambos tipos de datos, destacándose por la ausencia de métodos que permitan combinar la información en análisis estadísticos conjuntos. 
Considerando lo arriba expuesto, en este trabajo se propone analizar los patrones de modelado óseo en el esqueleto facial de individuos subadultos y adultos de dos poblaciones sudamericanas procedentes del Noroeste de Argentina y Patagonia con el objetivo de contribuir al conocimiento de la variación intra-específica en los procesos de modelado óseo y su relación con la variación morfológica dentro y entre poblaciones humanas. Estas muestras proceden de poblaciones que presentan un conjunto de características ecológicas y evolutivas singulares que las hace particularmente relevantes para el desarrollo de este estudio. Fueron seleccionadas debido a que representan los extremos de la variación morfológica craneofacial presente en las poblaciones de Sudamérica (Perez y Monteiro, 2009; González-José et al., 2005; Barbeito-Andrés et al., 2011; Gonzalez et al., 2011; Menéndez et al., 2014). Los cráneos correspondientes a la muestra de Pampa Grande (Noroeste de Argentina) se caracterizan por su tamaño reducido y rasgos gráciles, mientras que los individuos correspondientes a la muestra del Valle inferior del río Chubut (Patagonia) presentan cráneos de gran tamaño y robustez (Bernal et al., 2006). Estos rasgos característicos están presentes en los individuos desde edades tempranas y muestran una tendencia a acentuarse marcadamente a lo largo de la ontogenia (Barbeito-Andrés et al., 2011; Gonzalez et al., 2011). Ambas muestras proceden, además, de poblaciones con dietas disímiles, una basada principalmente en la ingesta de proteínas de origen animal y otra basada en una mayor incorporación de hidratos de carbono procedentes de vegetales tanto domésticos como silvestres (Gómez Otero y Novellino, 2011; Lema, 2011). Estas diferencias ecológicas han sido señaladas como una de las principales causas de diferenciación de la morfología facial en poblaciones sudamericanas (González-José et al., 2005; Perez y Monteiro, 2009; Barbeito-Andrés et al., 2011; Perez et al., 2011; Menéndez et al., 2014). Desde el punto de vista genético, los estudios recientes sobre ADN antiguo también remarcan la existencia de diferencias en la composición haplotípica entre las poblaciones que habitaron el Noroeste de Argentina y Patagonia (Postillone, 2016).

En lo concerniente a lo metodológico, el presente trabajo avanza en el desarrollo de una aproximación metodológica novedosa para la cuantificación de la información histológica y la integración con datos generados a partir de técnicas de antropología virtual y morfometría geométrica en $3 \mathrm{D}$ que permiten describir los patrones de variación en tamaño y forma del esqueleto facial.

\subsection{Estructura y organización de la tesis}

El presente trabajo de tesis se estructura de la siguiente manera: en el capítulo 2 se presentan los objetivos propuestos y las hipótesis planteadas. En el capítulo 3 se introducen las 
aproximaciones conceptuales a la morfología craneofacial humana. En primer lugar, se realiza una breve revisión de los conceptos teóricos adoptados en el marco de la biología evolutiva del desarrollo. En segundo lugar, se presentan las bases biológicas del crecimiento y desarrollo craneofacial, recapitulando los principales modelos que explican el desarrollo del esqueleto facial humano, su morfogénesis y las regiones en las que se divide al cráneo. El capítulo 4 refiere a las muestras empleadas en el estudio. Se presentan los criterios de selección utilizados para la conformación de cada muestra y los resultados de los análisis preliminares efectuados para establecer la composición sexual y etaria, y el estado de preservación de las muestras. En los capítulos 5 y 6 se exponen los abordajes metodológicos adoptados. El capítulo 5 incluye una descripción del procedimiento histológico empleado para el análisis de superficie óseas, con una breve revisión de los antecedentes metodológicos. Se introduce también la propuesta metodológica elaborada para superar las limitaciones analíticas que se desprenden de las aproximaciones vigentes. El capítulo 6 presenta la metodología empleada para el análisis de la morfología craneofacial. Se describen las variables relevadas mediante técnicas de la morfometría geométrica y tradicional, los análisis morfológicos preliminares efectuados y los métodos multivariados aplicados en capítulos posteriores. Los capítulos 7, 8 y 9 presentan los resultados obtenidos. El capítulo 7 corresponde a los resultados del análisis histológico, incluyendo los patrones de modelado óseo registrados en las trayectorias ontogenéticas, y las variaciones en el patrón entre muestras. El capítulo 8 corresponde a los resultados de los análisis morfométricos efectuados sobre la superficie craneofacial y los espacios funcionales para evaluar la variación intra e inter-muestral. El capítulo 9 contiene los resultados del análisis conjunto de los datos de modelado óseo y de la morfología craneofacial para cada una de las muestras. En el capítulo 10 se discuten los resultados más relevantes de la tesis. En primer lugar, se hace referencia a la aproximación metodológica implementada en los análisis histológicos de superficie. A continuación, se retoman las hipótesis planteadas y se discuten en función de los resultados obtenidos y los antecedentes. Por último, el capítulo 11 corresponde a las consideraciones finales, en el que se destacan los principales aportes del trabajo desarrollado y las perspectivas futuras que se desprenden del mismo. 


\section{Objetivos}

Presentación de los objetivos e hipótesis

\section{Contenido}

2.1. Objetivo general

2.1.1. Objetivos específicos

2.2. Hipótesis

\subsection{Objetivo general}

La variación fenotípica, en forma y tamaño, es influenciada por factores genéticos, epigenéticos y ambientales, y resulta de interacciones mecánicas y espaciales que actúan a distintos niveles de organización a lo largo de la ontogenia de los individuos. En este sentido, la morfología característica de las distintas estructuras craneofaciales resultaría de cambios en el número, tamaño y arreglo espacial de las células (i.e. osteoblastos y derivados, y osteoclastos) que constituyen el tejido óseo. A pesar de la importancia que presenta el análisis de los patrones de variación a nivel histológico para comprender los mecanismos que contribuyen a la diferenciación morfológica facial dentro y entre poblaciones humanas, hasta el presente, su estudio no ha sido abordado de forma sistemática. En este sentido, el objetivo general del presente trabajo es contribuir al conocimiento de los procesos y mecanismos de desarrollo, a nivel histológico, involucrados en la diferenciación de la morfología craneofacial dentro y entre poblaciones humanas.

La aproximación empleada integra el estudio de los patrones de modelado óseo y los patrones de variación en tamaño y forma del esqueleto facial. En este sentido, se analizan de manera conjunta datos generados a partir de imágenes tridimensionales de tomografías computadas y técnicas de la morfometría geométrica, adecuadas para cuantificar la dirección y magnitud de los cambios en el arreglo espacial de los rasgos morfológicos durante la ontogenia, y datos derivados del análisis histológico de superficies óseas, que permiten establecer la distribución espacial y extensión de las áreas de formación y reabsorción ósea. 


\subsubsection{Objetivos específicos}

En primer lugar, desde una perspectiva metodológica se propone:

- Desarrollar métodos para el análisis de los patrones de modelado óseo de la superficie facial y la integración de datos histológicos y morfométricos.

Asimismo, se plantea:

- Describir la distribución y extensión de las áreas de formación y reabsorción ósea (i.e. patrones de modelado óseo) en el esqueleto facial de individuos subadultos y adultos correspondientes a muestras de poblaciones prehistóricas de Pampa Grande (Salta, Noroeste Argentino) y valle del río Chubut (Chubut, Patagonia Argentina).

- Analizar los patrones de modelado óseo facial durante la ontogenia en individuos subadultos y adultos correspondientes a las muestras de Pampa Grande y valle del río Chubut.

- Analizar la variación en forma y tamaño del cráneo, y el volumen de espacios funcionales dentro y entre las muestras.

- Evaluar la asociación entre la variación en los patrones de modelado óseo y la variación en la morfología facial en las muestras estudiadas.

- Discutir la acción de procesos y mecanismos de crecimiento involucrados en la diferenciación de la morfología craneofacial dentro y entre poblaciones.

\subsection{Hipótesis}

Con base en información biológica derivada de trabajos previos se plantean y evalúan las siguientes hipótesis:

- Los patrones de modelado óseo del esqueleto facial no se mantienen constantes a través de la ontogenia de los individuos.

- Los patrones de modelado óseo del esqueleto facial difieren entre las poblaciones humanas modernas.

- La distribución y extensión de las áreas de formación y reabsorción ósea se asocia con la variación en la morfología del esqueleto facial en la ontogenia. 
Marco conceptual

Aproximación conceptual para el estudio de la variación morfológica craneofacial

\section{Contenido}

3.1. Aproximación desde la biología evolutiva del desarrollo a la variación fenotípica

3.1.1. Estructuración de la variación fenotípica

3.1.2. Aproximación middle-out a los fenotipos complejos

3.2. Modelos de crecimiento y desarrollo craneofacial

3.2.1. Hipótesis de la matriz funcional

3.2.2. El control regional del desarrollo óseo

Principio de las contrapartes

Principio de la V

3.3. Morfogénesis del esqueleto craneofacial

3.3.1. Origen embriológico y osificación del cráneo

3.3.2. Procesos histológicos de crecimiento y desarrollo craneofacial

Modelado óseo

Remodelado óseo

Desplazamientos

3.4. Regiones del cráneo: desarrollo y función

3.4.1. Basicráneo o base craneal

3.4.2. Bóveda craneal

3.4.3. Región facial

Región facial superior

Región facial media

El estudio de la variación morfológica craneofacial intra e inter-poblacional requiere el empleo de un marco que articule conceptos teóricos de la biología evolutiva del desarrollo (Hall, 2003), hipótesis acerca de aspectos estructurales y funcionales que intervienen en el crecimiento y desarrollo del cráneo (Moss y Young, 1960; Enlow y Hans, 1996), con los procesos -i.e. serie de 
acciones que conducen a un patrón particular- y mecanismos -i.e. acciones químicas o físicas causales que dan origen al fenómeno de interés- morfogenéticos que actúan a diferentes niveles de complejidad, desde el celular al anatómico, durante la ontogenia de los organismos (Moss, 1997b; Hallgrimsson y Lieberman, 2008). En el presente trabajo se adopta un marco conceptual que integra las aproximaciones mencionadas cuyas bases son presentadas en los siguientes apartados.

\subsection{Aproximación desde la biología evolutiva del desarrollo a la variación fenotípica}

La biología evolutiva del desarrollo constituye una aproximación conceptual para explicar la evolución morfológica de los organismos surgida a partir de diversas críticas de la teoría evolutiva darwiniana y sintética (Arthur, 2002). Sus comienzos pueden plantearse hacia la década de 1950, pero no es sino hasta mediados de 1980 que se expande y consolida, en gran medida como resultado del descubrimiento de genes que regulan el desarrollo.

Esta aproximación permite vincular los procesos que median la generación de rasgos fenotípicos complejos durante la ontogenia de los individuos con la producción de variación fenotípica a escala evolutiva (Atchley y Hall, 1991; Hall, 2003; Hallgrimsson y Hall, 2011). A lo largo del desarrollo del individuo se produce una creciente complejidad fenotípica -desde el nivel molecular al organismo-, como producto de la interacción entre factores genéticos y nogenéticos, incluyendo estos últimos factores ambientales internos y externos (Hall, 2003). En particular, la generación de estructuras morfológicas involucra un incremento en el número de células así como cambios en sus propiedades -división y diferenciación-, y el establecimiento de nuevos niveles jerárquicos de organización -i.e. morfogénesis- (Atchley y Hall, 1991). Cada uno de los niveles -e.g. nivel molecular, celular, tisular- presenta propiedades emergentes que resultan de las interacciones entre los elementos que se producen durante el desarrollo por encima del nivel genético o secuencia de ADN (Hallgrimsson y Hall, 2011). En este sentido, Waddington propuso en 1957 el concepto de epigenética para demarcar, mediante el prefijo epi, el conjunto de mecanismos que actúan por encima del nivel del gen y contribuyen a la formación de rasgos fenotípicos durante el desarrollo (Jamniczky et al., 2010; Hallgrimsson y Hall, 2011). En consecuencia, la perspectiva evo-devo remarca la importancia de estudiar los procesos de desarrollo en el mapeo genotipo-fenotipo para comprender la variación fenotípica.

La contribución de los procesos del desarrollo en la evolución morfológica es relevante en dos sentidos. Por un lado, los cambios observados a nivel fenotípico resultan de modificaciones en los procesos de desarrollo que median entre el genotipo y el fenotipo (Hall, 
2003). En este sentido, su estudio permite conocer los mecanismos del desarrollo por los cuales ocurre el cambio evolutivo. Por otro lado, los procesos que originan el fenotipo durante la ontogenia pueden sesgar la magnitud y la dirección de la evolución fenotípica, es decir, el potencial de cambio evolutivo o evolucionabilidad de los organismos (Hendrikse et al., 2007). Esta capacidad es en gran parte función de la habilidad de los sistemas de desarrollo de producir variación en rasgos fenotípicos sobre la que luego actúa la selección natural. Desde una perspectiva evo-devo, la generación de variación no es aleatoria, ya que las mutaciones no tienen efectos directos sobre el fenotipo sino que el desarrollo determina de qué manera la variación genética se traslada a variación fenotípica.

Como se expone en el siguiente apartado, la estructuración de la variación en el mapeo genotipo-fenotipo puede facilitar o limitar el cambio evolutivo en conjuntos de rasgos.

\subsubsection{Estructuración de la variación fenotípica}

Las estructuras anatómicas tienden a organizarse jerárquicamente y de manera anidada. Están conformadas por unidades estructurales semi-independientes, denominadas módulos (Olson y Miller 1958, en O'Higgins et al., 2006; Klingenberg, 2008). Los módulos exhiben una elevada integración interna debido a la presencia de numerosas interacciones, tales como aquellas establecidas entre tejido muscular y óseo, mientras que las interacciones entre módulos (e.g. módulo facial y neurocráneo) son menores o más débiles (Fig. 3.1; Bastir, 2008; Klingenberg, 2008). La integración es entendida como la tendencia de los rasgos fenotípicos a variar de forma coordinada debido a la influencia de factores genéticos, del desarrollo, funcionales o evolutivos comunes (Cheverud, 1996; Hallgrimsson et al., 2009; Klingenberg, 2014). A nivel del individuo se reconocen dos modos principales de integración, funcional y del desarrollo, mientras la integración genética y evolutiva son definidas a escala poblacional (Cheverud, 1996). En particular, la integración funcional es resultado de las interacciones entre componentes vinculados a una función común, que permiten garantizar el correcto desenvolvimiento del organismo. La integración del desarrollo, por otro lado, refiere a las interacciones que se establecen entre rasgos durante el crecimiento y desarrollo del organismo. Entre los factores que contribuyen a dicha integración se encuentra el efecto pleiotrópico de los genes sobre caracteres distintos, y las interacciones epigenéticas, tanto físicas como químicas (e.g. hormonales, factores de crecimiento), que se establecen a lo largo de la ontogenia y promueven la integración morfológica (Cheverud, 1982; Lieberman, 2011b).

Dado que los conjuntos de rasgos altamente integrados tienden a variar de manera coordinada y relativamente independiente de otros, la estructura de variación originada en el 
desarrollo puede favorecer o limitar la evolución morfológica en ciertas direcciones (Hendrikse et al., 2007; Klingenberg, 2010a,b). La asociación de rasgos durante el desarrollo resulta en la herencia conjunta de elementos o componentes morfológicos, causando la evolución coordinada de los rasgos que se encuentran bajo la influencia de procesos del desarrollo comunes, aunque no estén directamente bajo el efecto de la selección (Cheverud, 1995). Por otro lado, la modularidad facilita la evolución relativamente independiente de conjuntos de rasgos débilmente integrados. Ambas propiedades de los sistemas de desarrollo, integración y modularidad, contribuyen a estructurar la generación de variación fenotípica y por lo tanto, influyen en la evolucionabilidad de los rasgos.

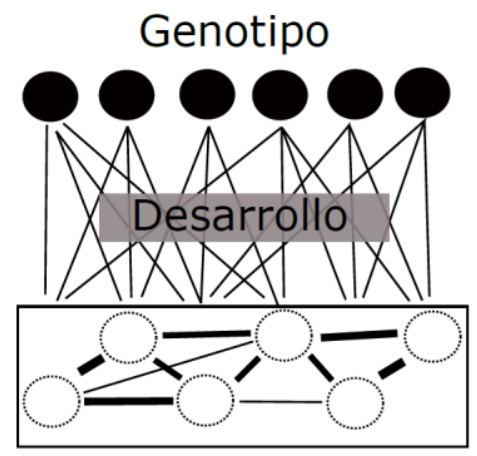

Fenotipo integrado

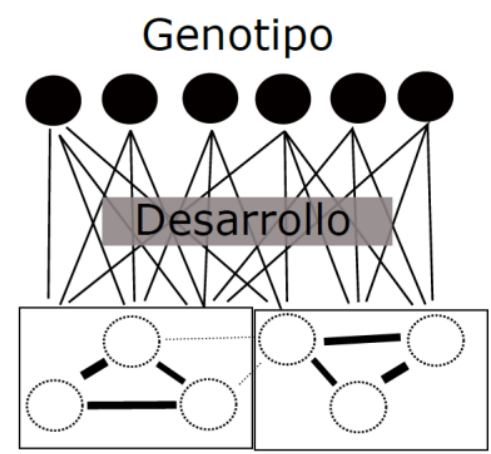

Fenotipo modular

Fig. 3.1. Integración fenotípica y modularidad

\subsubsection{Enfoque middle-out a los fenotipos complejos}

La variación observada en los fenotipos complejos resulta de procesos que operan, en parte, a escalas de organización jerárquica menores. Los estudios en el marco de la biología evolutiva del desarrollo se han centrado en la identificación de los procesos del desarrollo que vinculan la variación genética con el resultado fenotípico, atendiendo especialmente al nivel genético y molecular. Esta aproximación presenta dificultades debido a que en la mayoría de los casos el conocimiento sobre estos procesos es limitado, y a que omite la influencia de procesos epigenéticos que tienen lugar por encima del nivel molecular. En este sentido, se plantea como alternativa la adopción de un enfoque middle-out, es decir, identificar los procesos del desarrollo que son determinantes particularmente importantes en la estructuración de la variación de los rasgos de interés (Hallgrimsson y Lieberman, 2008).

Para comprender el origen y mantenimiento de los patrones de variación observable a nivel morfológico resultan especialmente relevantes conocer los procesos a nivel tisular y celular (Atchley y Hall, 1991; Hall, 2003). En efecto, las células son consideradas unidades morfogenéticas fundamentales, desde las cuales la morfología de los organismos es construida 
(Atchley y Hall, 1991; Hall, 2003). El desarrollo del organismo está caracterizado por el incremento en la especificidad celular y la reorganización de conglomerados celulares que resultan en la diferenciación morfológica observada, por lo que las alteraciones a nivel celular contribuirán a la variación a nivel anatómico (Abzhanov et al., 2004; Jamniczky et al., 2010). En consecuencia, una aproximación a los mecanismos epigenéticos que parta desde un nivel celular, pero integrando los procesos desencadenados en niveles superiores (i.e. tisular, de órgano; Hallgrimsson y Hall, 2011), confiere la posibilidad de analizar los procesos que subyacen a la variación morfológica (Fig. 3.2).

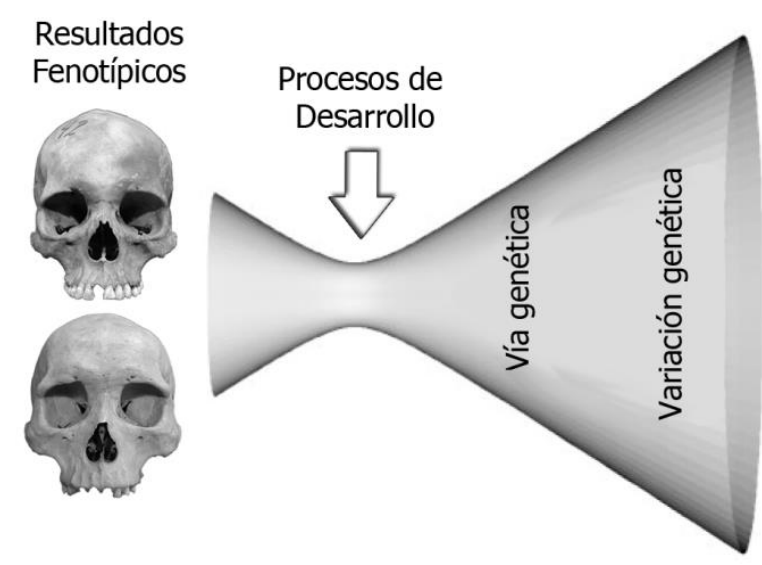

Fig. 3.2. Representación del enfoque middle-out. Los cráneos corresponden a individuos adultos de Pampa Grande (superior) y valle inferior del río Chubut (inferior). Modificado de Hallgrimsson y Lieberman (2008)

Tomando en consideración los conceptos expuestos previamente, en este trabajo de tesis se abordará el estudio de la variación morfológica facial a nivel intra e interpoblacional teniendo en cuenta especialmente los procesos de crecimiento y desarrollo a nivel de los individuos y su influencia en la diferenciación a nivel poblacional. En particular, el cráneo es analizado como una estructura compleja, conformada por elementos anatómicos que se organizan de forma modular y presentan diferentes niveles de integración (Hallgrimsson y Hall, 2011). Los elementos óseos que componen el cráneo, de acuerdo al mapeo genotipo-fenotipo diferencial y a la variación en las funciones en las que están involucrados, son agrupados en módulos de jerarquía variable (Cheverud 1995, 1996; Pucciarelli et al. 2003). Particularmente, se considera que la variación morfológica de las estructuras óseas craneofaciales es influenciada por factores genéticos, epigenéticos y ambientales, y resulta de interacciones mecánicas y espaciales -i.e. desplazamientos- y procesos de modelado óseo -i.e. formación y 
reabsorción celular- que actúan a niveles de organización menores (Frost, 1987; Enlow y Hans, 1996; Bastir et al., 2006; McCollum, 2008; Maggiano, 2012).

En los próximos apartados se detallan los mecanismos de crecimiento y desarrollo pre y postnatal a nivel anatómico e histológico, y se describen los diferentes módulos craneofaciales.

\subsection{Modelos de crecimiento y desarrollo craneofacial}

Los procesos y mecanismos que operan durante el crecimiento -i.e. incremento de tamaño con la edad- y desarrollo -i.e. cambios de forma con la edad- prenatal y postnatal del cráneo en humanos han sido objeto de profundas controversias. A partir de estudios realizados hacia fines del siglo XIX y principios del XX, se reconoció la influencia de dos procesos en el crecimiento craneofacial: la depositación en superficies óseas y el crecimiento del cartílago. No se produjo un acuerdo en cuanto a la importancia relativa de cada proceso (i.e. centros de crecimiento primarios o activos, y secundarios o pasivos), otorgándose una preponderancia diferente a uno y a otro en las explicaciones. Ambos procesos fueron considerados en principio, como respuestas predeterminadas genéticamente. Posteriormente, a mediados del siglo XX, el énfasis se centró en la plasticidad del desarrollo del cráneo, otorgándose mayor importancia a aspectos funcionales. Con ello, la inmutabilidad de los procesos fue cediendo el espacio a una nueva forma de concebir el crecimiento craneofacial, basado en interacciones epigenéticas entre factores intrínsecos y extrínsecos al esqueleto (Carlson, 2005).

Actualmente, la morfogénesis craneofacial es considerada multifactorial, reconociéndose la importancia de factores genéticos y ambientales y la intervención de múltiples mecanismos del desarrollo (Sperber, 2001). En conjunto con los mecanismos óseos vinculados al crecimiento y desarrollo del hueso, se reconoce la participación de los centros cartilaginosos como motores del crecimiento craneofacial, a la vez que se considera el crecimiento regulado por tejidos blandos circundantes y espacios funcionales (Moss y Young, 1960; Moss, 1997a; Carlson, 2005). Las suturas del cráneo, consideradas previamente como centros primarios de crecimiento, se reconocen en la actualidad como centros de crecimiento óseo secundario y se vinculan a diversas funciones, tales como la absorción de fuerzas y la articulación entre huesos otorgando relativo movimiento (Wagemans et al., 1988; Carlson, 2005).

A continuación se resumen los principales modelos sobre la biología del crecimiento y desarrollo craneofacial, con particular atención en los procesos epigenéticos que sustentan los cambios morfológicos craneofaciales. 


\subsubsection{Hipótesis de la matriz funcional}

Moss y colaboradores propusieron la distinción de dos componentes principales en el crecimiento y desarrollo del cráneo, una matriz funcional y una unidad esquelética (hipótesis de la matriz funcional; Moss y Young, 1960; Moss y Salentijn, 1969; Moss, 1997a,b). La matriz funcional refiere a los tejidos blandos, dientes y espacios o cavidades involucradas en una función particular (e.g. masticación). Se puede distinguir una matriz funcional capsular y una matriz funcional perióstica (Moss y Salentijn, 1969; Moss, 1997a). La matriz funcional capsular comprende los órganos y espacios anatómicos amplios, mientras que la matriz funcional periosteal corresponde al ambiente local inmediato (e.g. músculos, vasos sanguíneos, nervios; Moss y Salentijn, 1969). Por otra parte, la unidad esquelética incluye la estructura de soporte y protección de la matriz funcional (e.g. hueso, cartílago, tendones), y se diferencia en unidades microesqueléticas y macroesqueléticas. Las unidades microesqueléticas corresponden a regiones anatómicas que forman parte de unidades óseas mayores, por ejemplo, la tuberosidad del hueso maxilar; mientras que las unidades macroesqueléticas son unidades mayores compuestas por huesos adyacentes (Moss y Salentijn, 1969; Carlson, 2005).

En este contexto, se diferencian dos cápsulas matriciales principales, la neurocraneal y la orofacial. Cada una abarca unidades esqueléticas y matrices funcionales diferentes, asociadas a la masa neural (i.e. cerebro, leptomeninges y fluido cerebroespinal) y al espacio oronasofaríngeo, respectivamente. El límite de cada una está dado por la piel, la duramadre y las mucosas (Moss y Salentijn, 1969). Asimismo, es posible dividirlas en cápsulas submatriciales. En este sentido, la cápsula neurocraneal se diferencia en la submatriz frontal, parietal y occipital, cada una con centros de osificación independientes. Por otro lado, la cápsula orofacial se diferencia parcialmente en las submatrices orbital, nasal, oral y masticatoria. La submatriz orbital es relativamente independiente y se asocia a los globos oculares y a las unidades microesqueléticas del borde orbital. Las submatrices nasal y oral se encuentran más asociadas entre sí que con el resto, e incluyen sus respectivas cavidades y las unidades esqueléticas maxilar, nasal, premaxilar y palatino. Finalmente, la submatriz masticatoria incluye los músculos de la masticación (e.g. masetero) y parte de los huesos malar y temporal (Cheverud, 1982).

Las diferentes unidades esqueléticas y capsulares se encuentran integradas, a través de numerosas interacciones. En particular, se pueden diferenciar interacciones primarias, que ocurren entre una matriz funcional dada y el entorno óseo inmediato; e interacciones secundarias entre una matriz funcional y otras unidades, mediadas de manera indirecta por 
componentes del cráneo compartidos (Moss, 1997b; Lieberman, 2011b). En este sentido, las cápsulas tienen un efecto primario fuerte en las unidades esqueléticas adyacentes, y menor o secundario, en las unidades esqueléticas más distantes (Lieberman, 2011b). Asimismo, se pueden diferenciar niveles de interacción asociados a cada unidad esquelética. Variaciones funcionales de la matriz perióstica -e.g. por actividad muscular- pueden inducir cambios locales en las unidades microesqueléticas, activando la acción celular asociada a la depositación ósea (i.e. modelado y remodelado óseo), así como expansiones primarias de las cápsulas matriciales y de la traslación por crecimiento de las estructuras óseas -i.e. desplazamientos- pueden producir cambios de tamaño y forma en unidades macroesqueléticas (Moss y Salentijn, 1969; Moss, 1997a; Carlson, 2005).

Diversos aspectos en torno a la hipótesis de la matriz funcional permanecen aún sin resolver. Por un lado, este modelo no cuenta con una explicación sobre los mecanismos que median la recepción de un estímulo epigenético y su traducción en señales celulares de respuesta (Moss, 1997b). Es decir, se reconoce por ejemplo, que las células óseas establecen una red funcional en las que se incluyen diferentes tipos celulares, los cuales se coordinan para dar respuesta a estímulos externos; sin embargo, no es claro cómo cada célula detecta e interpreta el estrés, o cómo establece comunicación con las restantes células a fin de generar una respuesta (Franz-Odendaal, 2011). Por otro lado, el énfasis en el rol de las matrices funcionales para explicar el crecimiento de las unidades esqueléticas subestima la importancia de las interacciones que se establecen entre los diferentes componentes (Daegling, 2010).

Esto condujo en la década de 1970 al desarrollo de la teoría del servosistema o servosystem, por Alexandre Petrovic, basada en una consideración multifactorial del desarrollo craneofacial. En base a un modelo cibernético aplicado a la mandíbula, Petrovic y colaboradores representan diferentes factores como parte de un sistema estructurado en el que se integran factores extrínsecos del sistema con factores biomecánicos y funcionales locales. Por ejemplo, a medida que el cóndilo mandibular y la sutura son afectados directa e indirectamente por el sistema de hormonas, su crecimiento se produce en respuesta compensatoria y adaptativa a los factores extrínsecos, incluyendo funciones locales y el crecimiento de otras áreas del complejo craneofacial. Los estudios de Petrovic incorporaron gran parte de los conceptos de la hipótesis de la matriz funcional reconociendo que no todos los tejidos craneofaciales son similares en cuanto a su capacidad de expresar el potencial de crecimiento intrínseco y de responder a factores funcionales epigenéticos y extrínsecos (Carlson, 2005). 


\subsubsection{El control regional del desarrollo óseo}

A la aproximación holística del crecimiento craneofacial de Moss, basado en interrelaciones morfogenéticas entre componentes blandos y duros, Enlow contribuyó con una perspectiva particular, basada en el equilibrio funcional y estructural del hueso (Enlow, 1963; Enlow y Hans, 1996; Moss, 1997b; Daegling, 2010). Enlow consideró que a medida que el hueso crece, se producen desequilibrios como resultado de los cambios en tamaño y posición, generando la necesidad de establecer nuevas adaptaciones por parte de los huesos así como de las estructuras adyacentes. En consecuencia, se producen ajustes a fin de preservar el equilibrio óseo (Enlow y Hans, 1996). Enlow propuso dos principios para explicar cómo se suceden los ajustes: el principio de las contrapartes y el de la V (Enlow, 1963; Enlow et al., 1988; Enlow y Hans, 1996).

\section{Principio de las contrapartes}

Enlow plantea que el crecimiento de los componentes óseos craneofaciales se relaciona mediante un aumento proporcionado y equilibrado entre partes adyacentes. De acuerdo a esta propuesta, el cráneo consistiría en una serie de partes que crecen y se desarrollan organizadas espacialmente en contrapartes. En este sentido, las distintas contrapartes se compensan de manera activa y constante, permitiendo ajustes en el desarrollo que conducen al equilibrio (Enlow et al., 1988; Enlow y Hans, 1996). Asimismo, los límites entre partes representan zonas de mayor remodelado (o modelado, de acuerdo a Frost, 1987) y desplazamiento (Enlow et al., 1988).

Este principio propone la división del cráneo en dos series mayores limitadas antero-posteriormente por el plano pterigomaxilar o plano maxilar posterior (Fig. 3.3). Las partes y contrapartes dentro de cada compartimiento estarían altamente integradas, pero serían relativamente independientes entre compartimentos (Lieberman, 2011b). Asimismo, sería posible diferenciar contrapartes

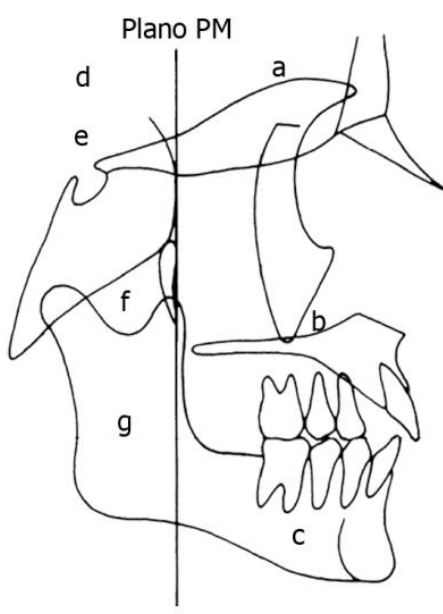

Fig. 3.3. Contrapartes craneofaciales. Plano PM: plano pterigomaxilar. Partes anteriores al plano PM: a. Fosa craneal anterior; b. Complejo nasomaxilar; c. Cuerpo mandibular. No figura el lóbulo frontal. Partes posteriores al plano PM: d. Lóbulo temporal; e. Fosa craneal media; f. Nasofaringe; g. Rama mandibular. Esquema modificado de Enlow y Hans (1996) en sentido sagital o lateral (Bastir et al., 2006). 


\section{Principio de la V}

El principio de la $V$ desarrollado por Enlow vincula el crecimiento de los huesos craneofaciales con sus desplazamientos (Fig. 3.4; Enlow, 1963; Enlow y Hans, 1996). Este principio debe su nombre a la analogía entre el crecimiento óseo con la letra "V". Muchos de los huesos craneofaciales tienen una configuración en $\mathrm{V}$, en los que se deposita hueso en la parte interior y se reabsorbe en la superficie externa (Enlow y Hans, 1996). El hueso nuevo se va formando en dirección a la apertura de la $V$, alargándose las ramas; mientras que el hueso viejo asociado al lado externo de la V- es reabsorbido (Fig. 3.4c). En consecuencia, las proporciones se mantienen constantes (Enlow, 1963; Enlow y Hans, 1996).

a)

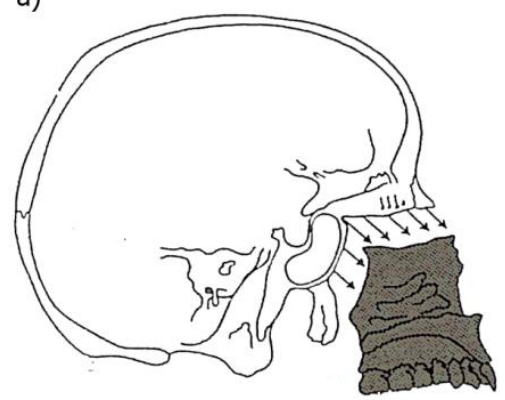

b)

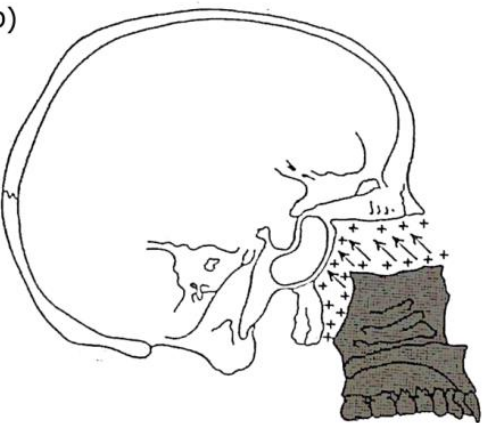

c)

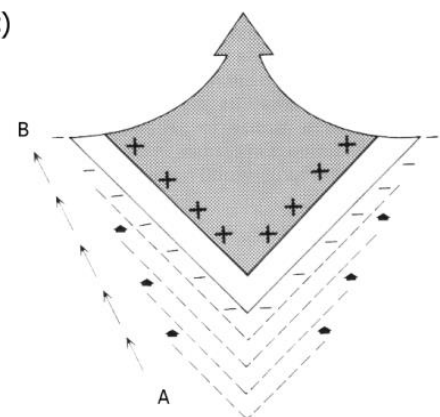

Fig. 3.4. Crecimiento de los huesos craneofaciales: a) Desplazamiento de la región maxilar hacia abajo y adelante, alejándose del cráneo, por el crecimiento expansivo de tejido de la región media facial. b) Crecimiento de hueso nuevo (+) en dirección opuesta al desplazamiento. c) Esquematización de la $V$, con crecimiento progresivo de A a B acompañado por depositación interna (+) y reabsorción externa (-). Modificados de Enlow y Hans (1996)

\subsection{Morfogénesis del esqueleto craneofacial}

\subsubsection{Origen embriológico y osificación del cráneo}

El cráneo se origina principalmente de mesénquima derivado de células de la cresta neural (e.g. huesos de la cara y de la bóveda, huesos nasal y lagrimal), y del mesodermo paraxial (e.g. región occipital y partes posteriores de la cápsula ótica; Sadler, 1996; Franz-Odendaal, 2011). El tejido óseo derivado del mesénquima puede producirse por un proceso de osificación intramembranosa, diferenciándose el hueso directamente del mesénquima (e.g. huesos planos de la bóveda, maxilar, malar, partes de la mandíbula); o por osificación endocondral, donde la forma del hueso parte de la forma previa del cartílago hialino diferenciado del mesénquima (e.g. huesos de la base del cráneo; Sadler, 1996; Martin et al., 2015). Una vez iniciada la osificación, el hueso crece por acumulación de masa ósea debido a la adición de tejido a lo 
largo de las suturas y mediante la generación de tejido nuevo en la superficie (Martin et al., 2015). En la Figura 3.5 se resume el conjunto secuencial de procesos a nivel celular, cada uno de los cuales involucra diferentes procesos epigenéticos que ocurren durante el desarrollo craneofacial.

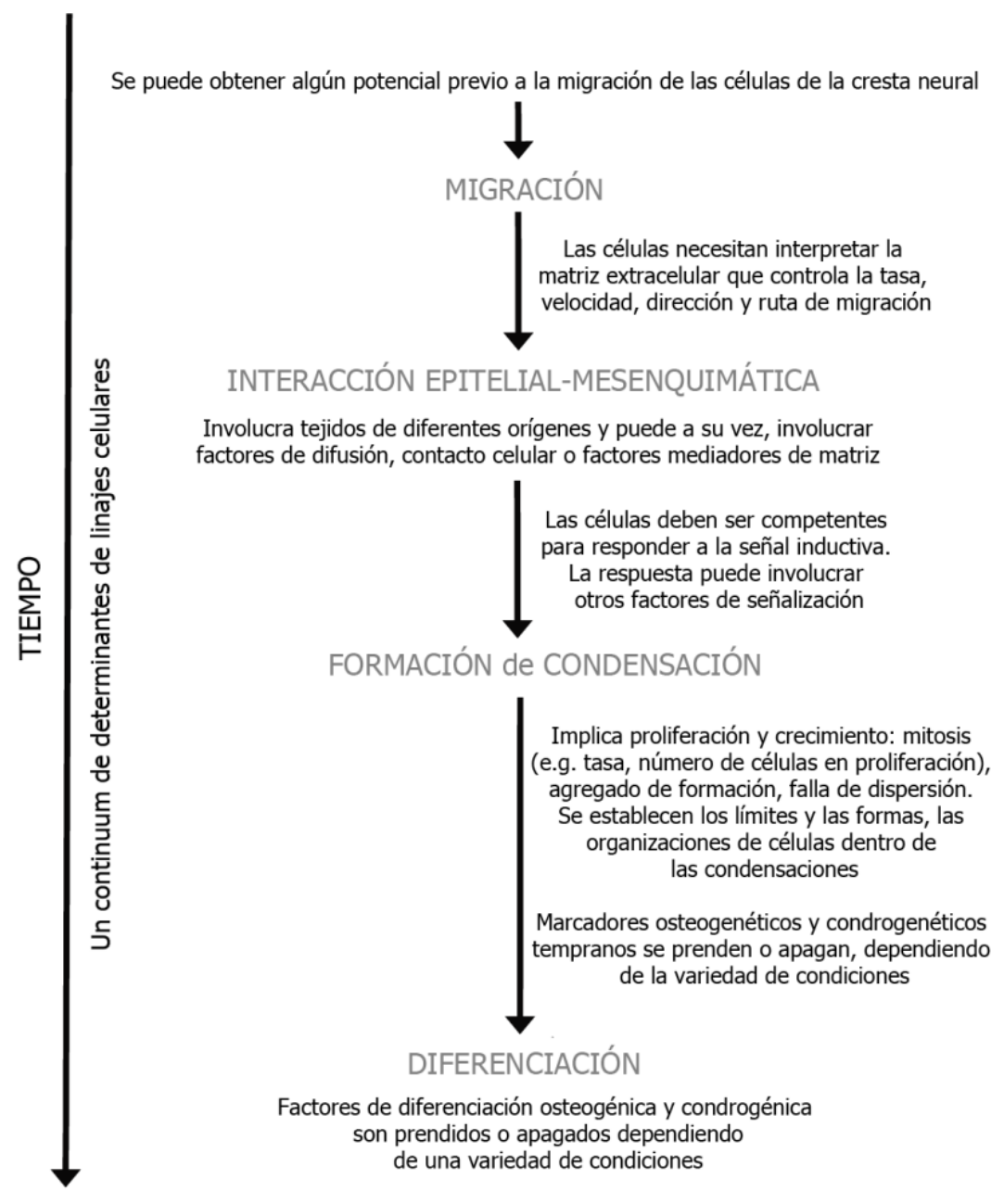

Fig. 3.5. Fases del desarrollo craneofacial (en gris), junto a los procesos epigenéticos involucrados (centrado en los derivados de la cresta neural). Alteraciones en la secuencia pueden resultar en modificaciones morfológicas óseas o cartilaginosas. Modificado de Franz-Odendaal (2011)

Después de la primer mineralización, el hueso se reconfigura en forma y tamaño, tanto a nivel del periostio como del endostio (Martin et al., 2015). Particularmente, el hueso altera su organización histológica en función del tiempo y la velocidad con que se forma. Así, el hueso que se forma rápidamente -ya sea trabecular o compacto-, se caracteriza por presentar fibras de colágeno y osteocitos distribuidos de manera irregular, en una matriz que se mineraliza a elevada velocidad. Este tipo de hueso se denomina fibroso o woven, y es característico durante el crecimiento o cuando se reparan fracturas. Posteriormente, el hueso se reabsorbe y se 
sustituye por un hueso cuya disposición es organizada, el hueso lamelar o lamellar. El hueso lamelar presenta una disposición ordenada en capas concéntricas, donde se disponen las fibras de colágeno y el mineral asociado, confiriéndole resistencia al tejido. Su formación y renovación es lenta, produciéndose cierto retraso entre depositación y mineralización de la matriz (Shapiro, 2008; García-Gil et al., 2016).

\subsubsection{Procesos histológicos de crecimiento y desarrollo craneofacial}

A lo largo de la ontogenia de los individuos, los componentes óseos cambian de tamaño, forma y posición relativa bajo la influencia conjunta del modelado óseo -mediante formación y reabsorción celular- y de desplazamientos entre las unidades particulares que interactúan durante el crecimiento (Frost, 1987; Enlow y Hans, 1996; McCollum, 2008; Maggiano, 2012).

El crecimiento de los huesos del cráneo ocurre por depositación y reabsorción ósea en las superficies perióstica y endóstica (i.e. modelado óseo; Enlow, 1963; Frost, 1987; Enlow y Hans, 1996; Stout y Crowder, 2012). Dado que las áreas de depositación y reabsorción difieren a lo largo del hueso, el aumento de tamaño no se produce de manera uniforme en todas las direcciones, es decir que el crecimiento de los huesos no es isométrico (Maggiano, 2012). En consecuencia, el crecimiento es acompañado por modificaciones en la geometría estructural de todo hueso (Martin et al., 2015). Una vez alcanzada la madurez ósea, el hueso mantiene su forma y tamaño mediante el remodelado óseo, el cual permite recambiar tejido viejo por nuevo. En adultos puede haber modelado óseo, pero asociado a reparaciones de fracturas y patologías (Parfitt, 2002; Stout y Crowder, 2012).

Existen algunas controversias respecto a cómo se definen a los procesos de modelado y remodelado óseo. Históricamente, se ha empleado el término remodelado tanto para describir los procesos de cambio durante el crecimiento, como los asociados a la regeneración o a las respuestas a diversos estímulos (e.g. biomecánicos, patologías; Enlow, 1963; Maggiano, 2012). Esta definición es particularmente usada en estudios clínicos y de crecimiento craneofacial (e.g. Enlow, 1963; Kurihara et al., 1980; Bromage, 1989; O’Higgins y Jones, 1998; McCollum, 2008; Kranioti et al., 2009); mientras que en otros campos se adoptó la diferenciación de modelado y remodelado propuesta en la década de 1970 por Frost (Frost, 1987; MartinezMaza et al., 2006; Maggiano, 2012; Martin et al., 2015). Más recientemente, Maggiano (2012) propuso que el término remodelado sea abandonado en favor del de modelado para referir a procesos ocurridos por la acción de las membranas periósticas y endósticas antes que por la acción de conglomerados locales de osteoblastos y osteoclastos (i.e. Unidad Básica Multicelular, BMU por su sigla en inglés). En consecuencia, dado que el análisis histológico 
empleado en esta tesis se basa en la observación de superficies, el término modelado óseo se aplicará para referir a los procesos de formación y reabsorción en general; mientras que cuando el interés sea hacer hincapié en diferencias ontogenéticas, se empleará modelado para individuos subadultos y remodelado para adultos. Asimismo, modelado y remodelado óseo serán entendidos como procesos fisiológicos del desarrollo y mantenimiento del hueso, mientras que se empleará patrones de modelado óseo para describir la distribución espacial de las actividades de formación y reabsorción ósea.

\section{Modelado óseo}

El modelado óseo se caracteriza por la actividad coordinada de células formadoras de hueso i.e. osteoblastos- y células que reabsorben hueso -i.e. osteoclastos- (Stout y Crowder, 2012). En el modelado óseo, las actividades de formación y reabsorción se encuentran desacopladas, siendo predominante la formación. Una característica distintiva del modelado es que los procesos de "activación" celular, "reabsorción" y "formación" ósea no siguen un orden preestablecido, pudiendo progresar desde la activación a la formación ósea y luego revertir a reabsorción cuando sea necesario, o viceversa (Maggiano, 2012). Por lo tanto, las BMU resultan más difíciles de definir en el modelado que en el remodelado óseo.

A causa de su crecimiento diferencial -producto de aumentos diferentes en distintas direcciones, con tasas regionales cambiantes-, el hueso no solo alcanza un tamaño y forma particular, sino que también se desplaza a una nueva posición anatómica, lejana de la original (Enlow y Hans, 1996; Maggiano, 2012). El desplazamiento de una región por modelado óseo se denomina deriva cortical (i.e. drift, en inglés; Enlow, 1962, 1963; Frost, 1987). El hueso mantiene sus proporciones a medida que se desplaza si las actividades de formación y reabsorción ósea ocurren de forma espejada entre las superficies perióstica y endóstica (Enlow, 1963; Enlow y Hans, 1996; Maggiano, 2012; Martin et al., 2015). Por el contrario, si las actividades de depositación y reabsorción no se mantienen simétricas en cuanto a sus tasas 0 distribución, el espesor y la forma del hueso pueden modificarse (Enlow y Hans, 1996; Lieberman, 2011b).

\section{$\underline{\text { Remodelado óseo }}$}

El remodelado es un proceso permanente de recambio óseo, característico en individuos adultos; en el cual, las actividades de formación y reabsorción ósea se encuentran coordinadas y acopladas temporal y espacialmente, manteniendo la estructura ósea (Maggiano, 2012; Stout y Crowder, 2012). El proceso de remodelado óseo se encuentra en constante ajuste, a fin 
de mantener la integridad ósea (e.g. ante envejecimiento del tejido o en respuesta mecánica), la homeostasis de calcio plasmático y la hematopoyesis (Parfitt, 2002). Dado que el tiempo de formación ósea es aproximadamente 10 veces mayor que el de reabsorción, se estima que por cada BMU existiría una relación de 10:1 entre cantidad de osteoblastos y osteoclastos para mantener el balance de formación y reabsorción en el hueso normal (Stout y Crowder, 2012).

El remodelado comienza con la aparición de osteoclastos en los sitios de activación o iniciación, como respuesta a factores sistémicos y biomecánicos percibidos por los osteocitos (Parfitt, 2002). Los osteoclastos derivan de células madres o stem cell hematopoyéticas, que se diferencian por influencia de citoquinas CSF-1 (i.e. del inglés, factor 1 estimulador de colonia). Con la presencia de citoquina OPG (osteoprotegerina) que se une a los RANK ligando (RANK-L) presentes en osteoblastos o sus precursores, se inhibe la producción de osteoclastos. A continuación, los osteoclastos formados reabsorben el hueso, liberando diferentes factores de crecimiento contenidos en la matriz ósea (e.g. IGF, TGF- $\beta$, PDGF), desencadenando la activación de los osteoblastos y la apoptosis de los osteoclastos. Los osteoblastos comienzan a secretar matriz orgánica, compuesta de colágenos tipo I y otras proteínas nanocolágenas, proteoglicanos y agua. Posteriormente, se mineraliza la matriz por depositación de cristales de fosfato de calcio (Stout y Crowder, 2012; Martin et al., 2015).

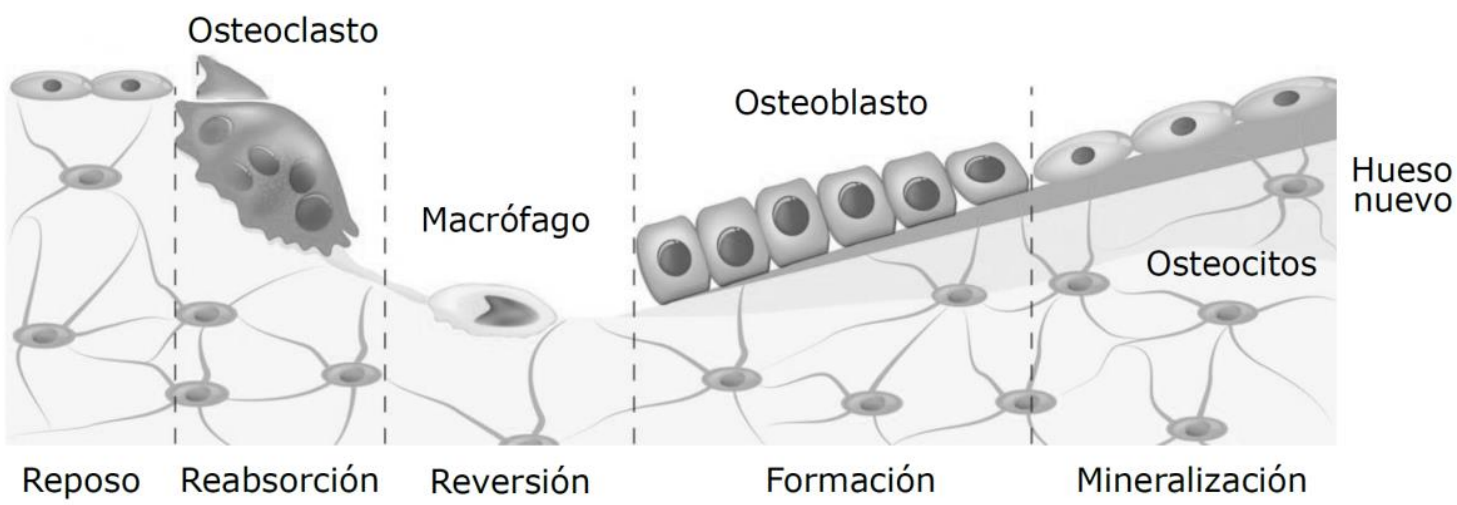

Fig. 3.6. Fases del modelado y remodelado óseo. La imagen fue modificada de designua / 123rf

En resumen, modelado y remodelado óseo ocurren en las superficies de todos los huesos como respuesta a diversas demandas metabólicas que se suceden a lo largo de la vida del individuo (e.g. crecimiento, homeostasis, reparación; Parfitt, 2002; Stout y Crowder, 2012). Dichas demandas pueden generar efectos irreversibles en la estructura ósea, de acuerdo a la magnitud de las tensiones externas así como del momento en que ocurren. Particularmente, los períodos más sensibles en el desarrollo óseo son el prenatal y la adolescencia, momentos 
en que diferentes perturbaciones pueden producir cambios en los procesos de crecimiento, modelado, remodelado y adaptación ósea (Gosman, 2012). En general, se reconoce una mayor sensibilidad ósea a insuficiencias nutricionales asociadas a restricciones proteicas y deficiencia materna de vitamina D, así como a variaciones en las cargas mecánicas (Gosman, 2012; Martin et al., 2015; D’Addona et al., 2016).

\section{$\underline{\text { Desplazamientos }}$}

Durante el crecimiento del cráneo se producen desplazamientos pasivos de los huesos como consecuencia de la expansión de los tejidos blandos circundantes -desplazamientos primariosasí como por el movimiento de otros elementos esqueléticos que están en contacto a través de suturas -desplazamientos secundarios- (Fig. 3.7a; Enlow y Hans, 1996). Se diferencian de los desplazamientos activos, producto del propio crecimiento del hueso mediante modelado óseo -deriva cortical o drift- (Fig. 3.7b; Enlow, 1962, 1963; Frost, 1987).

Un tipo particular de movimiento que suele diferenciarse de los desplazamientos, es la rotación de crecimiento. En general, se diferencian rotaciones por remodelado y rotaciones por desplazamiento (Enlow y Hans, 1996). Las rotaciones ocurren cuando un campo con actividades de formación y reabsorción en superficies opuestas se encuentra adyacente a otro campo con disposición opuesta (Fig. 3.7c; Lieberman, 2011b). Este tipo de movimiento permitiría por ejemplo, la correcta oclusión entre los arcos dentales del maxilar y la mandíbula (Björk, 1955; McNamara et al., 1976; Enlow y Hans, 1996). Sin embargo, es un tipo de desplazamiento discutido en tanto que se considera que las rotaciones registradas por análisis de $r x$ pueden ser en realidad artefactos generados por la obtención de mediciones angulares (al menos para el basicráneo; Bastir, 2008).

a)

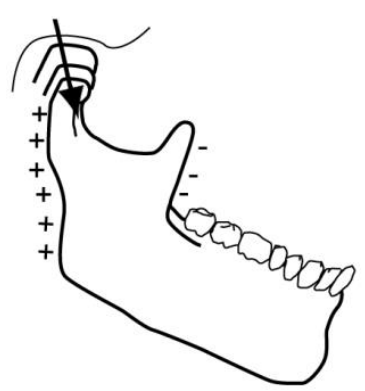

b)

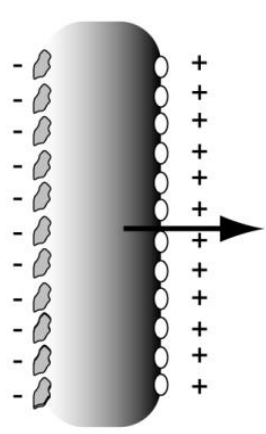

c)

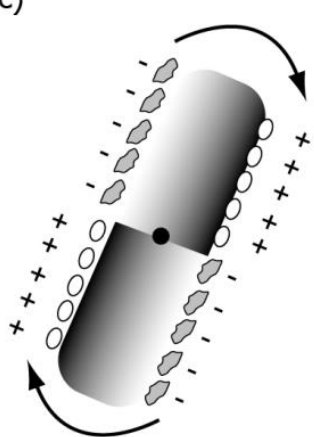

Fig. 3.7. Tipos de desplazamientos óseos: a) desplazamiento, b) deriva cortical y c) rotación. Las flechas indican la dirección del movimiento, (+) formación ósea y (-) reabsorción ósea. Modificado de Lieberman (2011b) 


\subsection{Regiones del cráneo: desarrollo y función}

El cráneo de los mamíferos puede diferenciarse en módulos, relativamente autónomos a nivel genético y fenotípico, pero que mantienen interacciones sustanciales a lo largo del desarrollo prenatal y posnatal (Lieberman, 2011b). Así, mientras los diferentes componentes óseos, órganos y cavidades crecen y se desarrollan, se comparten estructuras y funciones, resultando el cráneo en una región fuertemente integrada (Moss y Young, 1960; Lieberman, 2011a,b; Klingenberg, 2013).

Diferentes procesos de cohesión se suceden a lo largo del desarrollo craneofacial, manteniéndose un equilibrio espacial y funcional con los tejidos blandos y cavidades funcionales asociadas (Moss y Young, 1960; Enlow y Hans, 1996). De esta manera, en primer lugar alcanzan la madurez los componentes neurales y ópticos, asociados al desarrollo del cerebro y de los orbitales; a continuación, la región facial media y parte de la base craneal, asociados a los componentes respiratorios y óticos, respectivamente; y finalmente, aquellos vinculados a la masticación (i.e. componente alveolar) (Humphrey, 1998; Sardi y RamírezRozzi, 2007; Franz-Odendaal, 2011). En consecuencia, existen diferencias en las trayectorias de crecimiento que generan diferencias en el grado de integración e interacción entre las regiones y componentes (Lieberman, 2011b). Por ejemplo, dado el desarrollo intermedio de la región facial media, resulta influenciada por el sistema respiratorio, así como por aquellos componentes que se desarrollaron más tempranamente (i.e. alrededor de los 3 años) y los que continúan su desarrollo (i.e. con cambios en las tasas de crecimiento en edades posteriores a los 14 años; Humphrey, 1998; Sardi y Ramirez-Rozzi, 2007). Estas interacciones diferenciales pueden dar lugar a niveles altos de variación, sin comprometer la función (Lieberman, 2011a).

En general, el cráneo se diferencia en tres regiones principales: el basicráneo, la bóveda craneal y la región facial (Cheverud, 1996; Lieberman, 2011b). La delimitación de cada partición es realizada en función de diferencias en los procesos de desarrollo (e.g. trayectorias de crecimiento, integración funcional; Cheverud, 1982; Sperber, 2001; Lieberman, 2011b). A continuación se describirá cada región en asociación a los tejidos blandos y espacios funcionales circundantes, con especial hincapié en la región facial. 


\subsubsection{Basicráneo o base craneal}

La base craneal está compuesta por los huesos occipital, temporal, esfenoides y etmoides, y es principalmente de osificación endocondral (Sadler, 1996; Lieberman, 2011b). La diferenciación y crecimiento del condrocráneo estarían sujetas principalmente a influencias genéticas $y$ epigenéticas, con mínimo impacto del ambiente (Sperber, 2001). Es una región de integración muy importante, dado que interactúa directamente con el cerebro y la región facial (Cheverud, 1996; Lieberman, 2011b).

Se puede diferenciar una fosa craneal posterior, una media y una anterior (Fig. 3.8) A su vez, presenta una sincondrosis que actúa de bisagra entre las tres fosas, disponiéndolas en ángulos relativos entre sí. En humanos, el ángulo de la base craneal presenta la máxima flexión, incluso en comparación con otros primates (Lieberman,

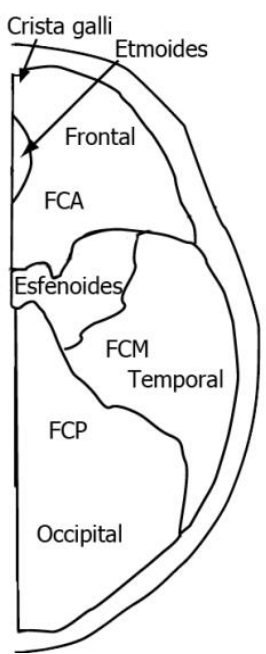

Fig. 3.8. Esquema lateral del basicráneo. FCA: Fosa craneal anterior, FCM: Fosa craneal media, FCP: Fosa craneal posterior. Modificado de Lieberman (2011b) 2011b).

\subsubsection{Bóveda craneal}

Los huesos de la bóveda, en conjunto con el basicráneo, encapsulan al cerebro; razón por la cual se suele agrupar a ambas regiones como neurocráneo (Lieberman, 2011b). Sin embargo, la bóveda craneal tiene un origen embriológico diferente y su osificación es principalmente intramembranosa (Sadler, 1996; Lieberman, 2011b). En su desarrollo, interactúa fuertemente con el cerebro, ya que los huesos de la bóveda forman la duramadre (i.e. membrana que rodea al cerebro), a partir de las membranas pericraneal y endocraneal. A su vez, la expansión del cerebro genera tensiones en la duramadre, las cuales estimulan la depositación ósea entre las suturas de la bóveda (Sperber, 2001; Lieberman, 2011b).

Dado su origen intramembranoso, los huesos de la bóveda (i.e. parietales, gran parte del occipital y frontal, temporal, esfenoide) exhiben una disposición diploe, con tablas externas e internas de hueso lamelar y una capa intermedia de hueso trabecular. El mayor crecimiento de la bóveda se produce en las suturas sagital, coronal, lambdoidea y escamosa (Lieberman, 2011b). 


\subsubsection{Región facial}

Tradicionalmente definida como viscerocráneo, es la región más compleja y derivada en humanos (Sadler, 1996; Lieberman, 2011b). Presenta numerosos componentes, que deben ajustarse estructural y funcionalmente a lo largo del crecimiento, lo que genera numerosas interacciones a nivel interno. Dada la cantidad de cápsulas presentes (e.g. orbital, cavidad nasal y oral), se establecen interacciones entre unidades vecinas, en las que se incluyen a su vez, el efecto de fuerzas mecánicas generadas por el crecimiento de órganos y de las funciones de respiración y masticación (Lieberman, 2011b). Asimismo, la región facial debe ajustarse a las regiones basicraneal y neurocraneal, en una interacción que resulta desigual dadas las diferencias en sus trayectorias de crecimiento. Mientras que el basicráneo y el neurocráneo alcanzan el tamaño adulto alrededor de los 6-7 años, la región facial superior continúa su desarrollo hasta alrededor de los 12 años y las regiones faciales media e inferior hasta el término de la adolescencia, alrededor de los 18 años (Humphrey, 1998; Sperber, 2001; Lieberman, 2011b). En este sentido, es probable que la influencia del neurocráneo y basicráneo sea mayor sobre la región facial que viceversa (Lieberman, 2011b).

En la región facial se encuentran diversos espacios funcionales -cavidades o cápsulas craneofaciales- que se asocian estructuralmente dado que comparten las paredes intramembranosas (Moss y Young, 1960; Sperber, 2001). En líneas generales, pueden diferenciarse tres cavidades principales: las cavidades orbitales, la cavidad nasal y la cavidad oral. En asociación con estas, se encuentra la cavidad craneal anterior, que corresponde al basicráneo (Lieberman, 2011b). Las cavidades orbitales se establecen tempranamente en el desarrollo, creciendo inicialmente en asociación con las órbitas, aunque continuando de manera independiente a ellas y en asociación al frontal y el maxilar (Enlow y Hans, 1996; Sperber, 2001; Lieberman, 2011b). Hacia los dos primeros años de vida postnatal, las órbitas han completado la mitad de su crecimiento, y alcanzan las dimensiones adultas alrededor de los 7 años (Sperber, 2001). El techo de los orbitales constituye el piso de la cavidad craneal anterior, razón por la cual el frontal no solo crece en respuesta al desarrollo del lóbulo frontal del cerebro, sino también al de los orbitales (Moss y Young, 1960; Enlow y Hans, 1996; Lieberman, 2011b). El desarrollo orbital y el de la cavidad nasal ocurren de manera asociada. Al nacimiento, la cavidad nasal se localiza casi enteramente entre las órbitas; posteriormente, el cartílago del tabique nasal continúa creciendo hasta los 6 años, bajando el piso de la cavidad por debajo de las órbitas. Hacia esta edad se completa el desarrollo del paladar, componente evolutivo de la división oronasal (Sperber, 2001). La cavidad oral se conforma en su techo por los huesos paladar y maxilar, en la parte anterior, y por el paladar blando, en la parte posterior 
(Lieberman, 2011b). En asociación con la cavidad oral, se sitúan los dientes, cuya secuencia de desarrollo y erupción influye en el crecimiento del arco alveolar (Sperber, 2001).

Por otra parte, en la región facial media se produce un proceso de pneumatización, a través del cual los osteoclastos remueven hueso, generando espacios o senos. Se presentan cuatro senos paranasales: frontal, etmoidal, esfenoidal y maxilar (Enlow y Hans, 1996; Lieberman, 2011b). Existe controversia en cuanto a su funcionalidad y presentan gran variación estructural, pudiendo estar ausentes o presentar altos niveles de asimetría (O’Higgins et al., 2006; Lieberman, 2011b).

Se han propuesto diversas subdivisiones de la región facial sobre la base de criterios anatómicos y funcionales. En general, cada una de estas divisiones se caracteriza por presentar límites poco claros (Cheverud, 1982; Sperber, 2001; Lieberman, 2011b). Tradicionalmente, una de las divisiones más empleadas es la que diferencia tres regiones anatómicas en función del desarrollo e interacción entre las unidades estructurales. En este sentido, se diferencia una región facial superior, que abarca la zona alrededor de los globos oculares y debajo del lóbulo frontal del cerebro; la región facial media, que incluye la región nasal y parte del aparato masticatorio (i.e. maxilar y dentición asociada); y la región facial inferior, compuesta por la mandíbula y su dentición.

El presente trabajo de tesis analiza los patrones de modelado óseo de las dos primeras regiones (i.e. región facial superior y media), por este motivo se describen a continuación con mayor detalle, complementando la caracterización de las regiones facial superior y media, y bases que sustentan la división en estos módulos.

\section{$\underline{\text { Región facial superior }}$}

Incluye las cavidades orbitales y áreas circundantes, incluyendo la glabela y el supraorbital, el borde orbital del malar, el proceso frontal del maxilar y la región superior al foramen infraorbitario (Fig. 3.9a). Esta región integra la submatriz capsular orbital, caracterizada por su relativa independencia y por estar asociada a una matriz perióstica conformada por el borde orbital (i.e. partes del frontal, malar y maxilar; Cheverud, 1982). La fosa craneal anterior también queda integrada a esta región, dado que su piso óseo es el techo orbital (Sperber, 2001). La trayectoria de crecimiento de esta región finaliza con anterioridad a la región facial media (Humphrey, 1998; Sperber, 2001; Sardi y Ramirez-Rozzi, 2007). 


\section{$\underline{\text { Región facial media }}$}

Conformada por el cuerpo del maxilar y del malar (Fig. 3.9b,c). Esta región integra el complejo nasomaxilar, definido según el principio de las contrapartes, así como las submatrices oral y masticatoria, de la cápsula orofacial (Cheverud, 1982; Enlow et al., 1988). La región facial media se encuentra fuertemente influenciada por las cargas masticatorias, mediadas por la dentición y la musculatura asociada (Cheverud, 1982; Herring, 2011; Lieberman, 2011b).

a)

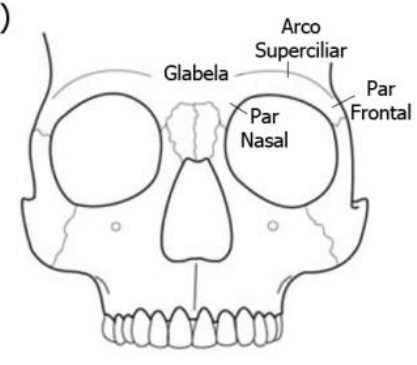

b)

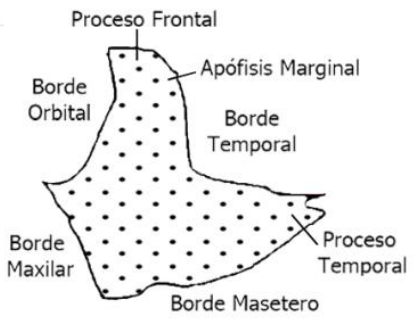

c)

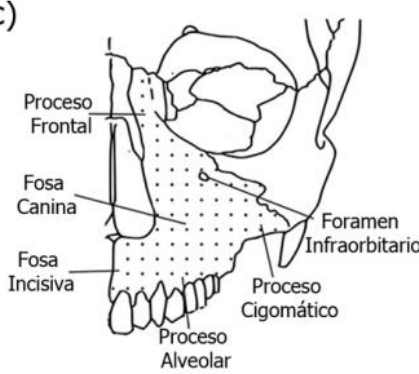

Fig. 3.9. Rasgos anatómicos generales de la región facial superior y media: a) glabela y componentes del supraorbital, b) malar, c) maxilar anterior. Modificado de Lieberman (2011b)

La región facial en general, pero principalmente la región facial media, se ve fuertemente influenciada por el rol de las cargas mecánicas. La dentición anterior -i.e. incisivos y caninos-, y la posterior -i.e. premolares y molares-, generan cargas masticatorias diferenciales. En particular, las etapas de incisión y trituración en las que se produce el corte y ruptura mecánica de los alimentos tienen un fuerte impacto en la región facial media que se incrementa y extiende durante el desarrollo postnatal (O'Higgins et al., 2012). Las funciones de incisión y trituración se producen de manera bilateral y unilateral respectivamente y generan una importante fuerza de mordida en un lugar único (i.e. punto de mordida). Asimismo, la trituración es un proceso frecuente y repetitivo, durante el cual se acumulan grandes tensiones (Lieberman, 2011b). Para realizar ambas funciones actúan diferentes músculos que permiten llevar a cabo la masticación a la vez que contribuyen al balance del cráneo. Se pueden diferenciar cinco músculos principales vinculados a la masticación: el temporal, el masetero, los pterigoides lateral y medial, y el digástrico (Fig. 3.10).

En general, aún no resulta muy claro cómo las tensiones producidas durante la incisión y la trituración afectan al cráneo. Esto se debe en parte a los múltiples huesos y factores (e.g. órganos, espacios funcionales, diferencias de magnitud en la fuerza muscular) que intervienen en el desarrollo craneofacial (Lieberman, 2011b). Sin embargo, se ha planteado la existencia de un gradiente de magnitud en la tensión, en el que las mayores tensiones ocurren en el proceso 
alveolar, en las áreas de inserción muscular y, posiblemente, en el paladar. Las tensiones decrecerían en proporción al aumento de la distancia con respecto a la fila dental (Lieberman, 2011b; Toro-Ibacache y O'Higgins, 2016), siendo las tensiones producidas durante la masticación típicamente moderadas para la región facial media (Lieberman, 2011b).
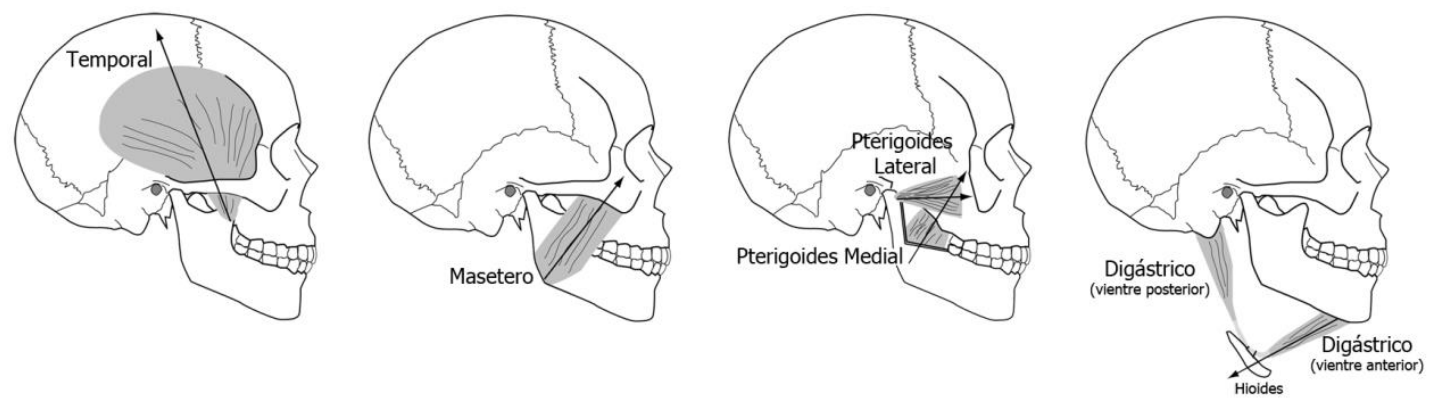

Fig. 3.10. Principales músculos con rol en las cargas masticatorias. Las flechas indican la orientación aproximada del vector de fuerza. El pterigoides medial se visualiza gracias a la eliminación de una porción de la rama mandibular. Modificado de Lieberman (2011b) 


\section{Muestras analizadas y análisis preliminares}

Descripción y criterios de selección de las muestras empleadas

\section{Contenido}

4.1. Descripción de las muestras

4.1.1. Pampa Grande (PG)

4.1.2. Valle inferior del río Chubut (Ch)

4.2. Análisis preliminares

4.2.1. Composición sexual y etaria de las muestras

Estimación de la edad en subadultos

Estimación de edad y sexo en adultos

4.2.2. Estado de preservación

4.2.3. Indicadores de adecuación fisiológica y salud bucal

Las poblaciones humanas originarias del sur de Sudamérica se caracterizan por presentar un elevado grado de variación craneofacial, incluso entre grupos geográficamente cercanos (Sardi et al., 2005; Pucciarelli et al., 2006; Perez et al., 2011). Con el objetivo de estudiar los procesos de desarrollo a nivel histológico involucrados en la variación morfológica, se seleccionaron dos muestras de poblaciones originarias procedentes de Argentina. Para ello se siguieron criterios de diferenciación genética, ecológica (i.e. dieta y temperatura) y morfológica (i.e. tamaño y forma) (González-José et al., 2005; Carnese et al., 2010; Barbeito-Andrés et al., 2011; Perez et al., 2011; Menéndez et al., 2014; Postillone, 2016). La selección de los individuos en cada muestra incluyó diferentes rangos etarios con el fin de conformar series ontogenéticas que abarquen desde la etapa infantil a adulto medio. Asimismo, en el muestreo se consideró el estado de preservación de las superficies óseas y de salud bucal.

A continuación se describen las muestras seleccionadas en relación con su procedencia geográfica, y sus características morfológicas, ecológicas y genéticas. Asimismo, se realiza una caracterización del perfil de edad y sexo de cada muestra, del estado de preservación ósea y de los indicadores de adecuación fisiológica y salud bucal. Debido a que las prácticas de curaduría de las colecciones del Museo de La Plata implicaron la separación del cráneo y la 
mandíbula en la mayoría de los casos, los análisis se realizaron sólo sobre el cráneo (Baldini et al., 1998; Béguelin y Gómez, 2011).

\subsection{Descripción de las muestras}

Se analizó un total de 71 individuos adultos y subadultos correspondientes a muestras osteológicas procedentes de sitios arqueológicos del Noroeste Argentino (Pampa Grande) y centro-este de Patagonia argentina (valle inferior del río Chubut) (Tabla 4.1). Los restos analizados forman parte de la colección osteológica dela División Antropología del Museo de La Plata.

Tabla 4.1. Composición de la muestra

\begin{tabular}{cccc}
\hline Muestras & Subadultos & Adultos & Totales \\
\hline Pampa Grande & 15 & 17 & 32 \\
$\begin{array}{c}\text { Valle inferior } \\
\text { del río Chubut }\end{array}$ & 20 & 19 & 39 \\
\hline Totales & 35 & 36 & 71 \\
\hline
\end{tabular}

El análisis de los restos óseos humanos se efectuó bajo estrictas normas ético-legales y de conservación preventiva, en concordancia con lo sugerido por la Asociación de Antropología Biológica Argentina a través de "Ética del Estudio de Restos Humanos" (AABA, Salta 2007) y el "Código Deontológico para el Estudio, Conservación y Gestión de Restos Humanos de Poblaciones del Pasado" (AABA, 2014), y la legislación nacional vigente acerca del manejo de materiales culturales y bioantropológicos (Ley 25.517/01 de Restitución de Restos AborígenesDecreto Reglamentario 701/2010 y la Ley Nacional N 25.743 de Protección del Patrimonio Arqueológico y Paleontológico). Asimismo, las actividades que involucraron la manipulación directa de los restos óseos fueron efectuadas bajo protocolos de conservación preventiva orientadas a evitar el empleo de tratamientos invasivos (Anexos 1 y 3 ).

\subsubsection{Pampa Grande (PG)}

La muestra se conformó a partir de sucesivas excavaciones realizadas a principios del siglo XX por J.B. Ambrosetti y F. Aparicio, y posteriormente entre los años 1969 y 1971, por A.R. González (González, 1972; Baldini et al., 1998; Dejean et al., 2014). Los restos óseos proceden de entierros en urna y directos hallados en numerosas cavernas de las serranías de Las Pirguas, departamento Guachipas, provincia de Salta (González, 1972; Baffi et al., 1996). Pampa Grande corresponde a las Sierras Subandinas que se ubican entre la zona Valliserrana (entre 2500- 
$3000 \mathrm{msnm}$ ) y las Selvas Occidentales, con una temperatura anual media entre $16^{\circ}$ y $18^{\circ}$ (Baldini et al., 1998). A nivel fitogeográfico, la zona incluye las provincias de las Yungas, Monte y Altoandina. La provincia de las Yungas se caracteriza por la presencia de selva tropical, con exceso de agua. La provincia del Monte ocupa la región de los suelos de desierto y presenta principalmente estepas arbustivas. Finalmente, la provincia Altoandina abarca las regiones de mayor altura, con temperaturas medias menores a los $7{ }^{\circ} \mathrm{C}$ y presencia de estepas herbáceas, en su mayor parte, y arbustivas ( $D^{\prime}$ Antoni, 1971). A partir de los hallazgos materiales asociados, los sitios fueron asignados a la cultura Candelaria, correspondiente al periodo formativo temprano del Noroeste Argentino (entre 1500 y 1400 años AP; González, 1972; Baldini et al., 2003). Esta cronología coincide con la establecida a partir de un fechado radiocarbónico que indicó una antigüedad de $1720 \pm 50$ años AP (Lema, 2009).

En cuanto a la dieta, las evidencias arqueobotánicas recuperadas en contextos domésticos de Pampa Grande y obtenidas a partir de macro y microrestos vegetales indican el acceso a una gran variedad de plantas así como el empleo de diferentes modos de cocción. El maíz es uno de los vegetales más recurrentes en el registro arqueológico, acompañado de la presencia de porotos domesticados y silvestres, distintas variedades de zapallos, maíz, algarroba y pimientos (e.g. Phaseolus vulgaris, Zea mays, Prosopis sp., Cucurbita maxima sp., Geoffroea decorticans, Lagenaria siceraria; Lema, 2011). La diversidad de plantas domesticadas, silvestres y formas híbridas halladas en Pampa Grande sugiere que en el área, las poblaciones del formativo habrían tenido una estrategia productiva de carácter hortícola (Lema, 2010). Con respecto a la fauna, los restos hallados sugieren el consumo de camélidos, tanto de formas silvestres como domesticadas, roedores y, en menor proporción, dasipódidos y peces (V. Lema com. pers.). Con relación a los análisis bioarqueológicos, a partir de indicadores óseos de malnutrición y enfermedades infecciosas se planteó que la población del lugar habría estado bajo estrés nutricional, con una dieta carente de vitaminas C y D, y rica en carbohidratos (Baffi et al., 1996). El elevado porcentaje de carbohidratos en la dieta fue inferido a partir del análisis de las caries dentales, observándose esta patología en el 43,2\% de los individuos adultos (Baffi et al., 1996).

Respecto a la morfología craneal, en contraste con poblaciones ubicadas más al sur del continente sudamericano, esta muestra se caracteriza por presentar rasgos menos robustos, con cráneos de menor tamaño (Gonzalez et al., 2010; Barbeito-Andrés et al., 2011; Menéndez et al., 2014). Asimismo, a partir del análisis de la anatomía craneana y la fuerza de palanca en relación con la mordida se han inferido niveles bajos de fuerza de mordida, en comparación a otras poblaciones prehistóricas procedentes del noroeste, centro y sur de Argentina 
(Menéndez et al., 2014). Finalmente, se ha descrito la presencia de modificaciones culturales del cráneo con una importante frecuencia de la variante tabular (Salceda, 1984; Cocilovo y Varela, 2010).

Con relación a la composición genética de la población, los estudios de ADN antiguo señalan que PG presenta mayor diversidad en comparación a zonas aledañas, con una alta frecuencia de los haplogrupos B y D (Carnese et al., 2010; Dejean et al., 2014). Se ha hipotetizado que tal diversidad genética estaría asociada a la presencia de individuos correspondientes a distintos grupos poblacionales (Baffi y Torres, 1993; Dejean et al., 2014), aunque los individuos de esta muestra exhiben gran homogeneidad morfológica (Perez y Monteiro, 2009).

\subsubsection{Valle inferior del río Chubut (Ch)}

La muestra fue conformada principalmente a partir de las recolecciones que realizaran Francisco P. Moreno (1876-77) y Santiago Pozzi (1893), en las zonas aledañas a Gaiman y Trelew (Lehmann-Nitsche, 1910). El valle inferior del río Chubut se ubica en la provincia fitogeográfica de Monte, caracterizada por un clima semiárido, con temperaturas templadas (aproximadamente $12{ }^{\circ} \mathrm{C}$ ), escasas precipitaciones y fuertes vientos; siendo el río Chubut una importante fuente de agua dulce, con gran diversidad de recursos (Gordón, 2011). Con respecto a la cronología, las dataciones radiocarbónicas realizadas directamente sobre los restos óseos y las variantes de modificación cultural presente en los cráneos (i.e. tabular erecta planofrontal y planolámbdica) permiten asignar a la muestra al Holoceno tardío, entre 2600 y 200 años AP (Perez, 2006; Gómez Otero y Novellino, 2011; Gordón, 2011).

Las poblaciones que habitaron el área se habrían caracterizado por ser grupos de cazadores-recolectores de relativa movilidad y baja densidad demográfica, con una dieta que incluía la incorporación de recursos terrestres, marinos y fluviales (i.e. guanaco, pequeños animales, huevos, moluscos, pescados, plantas; Gómez Otero y Novellino, 2011). Hacia el Holoceno tardío final (1500-400 años AP) se habría producido un incremento demográfico gradual con disminución de la movilidad residencial e intensificación, asociada a cambios en las tecnologías de procesamiento (e.g. morteros) y almacenamiento de recursos (Bernal et al., 2007; Gómez Otero y Novellino, 2011). Los valores de isótopos estables del colágeno son consistentes con una dieta basada principalmente en la incorporación de recursos animales terrestres $\left(\delta^{13} \mathrm{C}\right.$ : -19 a $-16 ; \delta^{15} \mathrm{~N}$ : 13-15; Gómez Otero, 2007). El bajo porcentaje de caries en la muestra, $<4 \%$, es también consistente con una baja ingesta de hidratos de carbono (Bernal et al., 2007). Por otro lado, los niveles de desgaste dental relativamente elevados observados en 
la muestra podrían vincularse a la abrasividad y textura (e.g. dureza) de los alimentos, así como a la presencia de partículas abrasivas incorporadas con la dieta (e.g. arena asociada a los alimentos, procesamiento con herramientas de piedra, cocción directa sobre las cenizas; Bernal et al., 2007). Con relación a la morfología craneofacial, la muestra se caracteriza por presentar cráneos de gran tamaño y marcada robustez, con un desarrollo pronunciado de las estructuras óseas (e.g. mayor espesor de la bóveda, arcos superciliares prominentes, arcos cigomáticos de gran robustez; Sardi et al., 2005; Bernal et al., 2006; Perez et al., 2007; Gonzalez et al., 2010; Barbeito-Andrés et al., 2011). Sin embargo, la magnitud de la fuerza de mordida estimada a partir de variables morfométricas indica valores relativamente bajos en comparación a otras poblaciones prehistóricas del sur de Sudamérica (Menéndez et al., 2014).

Con respecto a la composición genética, la información proveniente de ADN mitocondrial antiguo indica la predominancia del haplogrupo $D$ en las muestras del centro de Patagonia (Postillone, 2016; Crespo et al., 2017).

\subsection{Análisis preliminares}

\subsubsection{Composición sexual y etaria de la muestra}

\section{Estimación de la edad en subadultos}

Durante el proceso de crecimiento y desarrollo se producen diferentes eventos morfofuncionales que se asocian con la edad (Humphrey, 1998; Franklin, 2010; GarcíaMancuso, 2014). En este sentido, los distintos componentes craneofaciales presentan trayectorias de crecimiento particulares, caracterizadas por momentos de aceleración y desaceleración del crecimiento hasta alcanzar la madurez (Sardi y Ramírez-Rossi, 2007). Estas trayectorias de crecimiento pueden presentar diferencias dentro y entre poblaciones vinculadas tanto al origen de la población como al sexo de los individuos (Franklin, 2010). En consecuencia, las estimaciones de la edad biológica de individuos subadultos en muestras arqueológicas varían en función de las características propias de la población de la que procede la muestra (e.g. ancestría, sexo de los individuos, características ambientales), de los estándares usados para desarrollar los métodos de estimación, así como del entrenamiento del observador, entre otros.

El desarrollo de las piezas dentales ha sido tradicionalmente empleado para estimar la edad de los individuos subadultos a partir de restos óseos. Esto se debe a la buena preservación de las piezas dentales aún en condiciones post-depositacionales desfavorables, a que la secuencia 
y el tiempo de erupción son menos susceptibles a los cambios ambientales, así como a la mayor precisión en las estimaciones etarias obtenidas con relación a otros indicadores óseos (Bernal, 2008; Franklin, 2010). Por consiguiente, se decidió utilizar el desarrollo dental para estimar la edad en los individuos subadultos. Cabe aclarar que no se realizó la estimación del sexo en los subadultos, debido a su bajo nivel de exactitud dado que los rasgos morfológicos dimórficos del cráneo aún no se han desarrollado (Ferembach et al., 1977).

La estimación de la edad se realizó empleando los métodos estándar basados en la formación (i.e. desarrollo de la corona, raíz y ápice del diente) y erupción de la dentición decidua y permanente (Buikstra y Ubelaker, 1994; AlQahtani et al., 2010). A fin de evaluar diferencias en la asignación etaria obtenida a partir de distintos estándares de referencia, se emplearon dos estándares construidos sobre muestras de diferente procedencia geográfica. Se empleó el estándar de Ubelaker (1978), que toma de referencia a grupos étnicos de Norteamérica (Buikstra y Ubelaker, 1994), y el de AlQahtani y colaboradores (2010), basado en radiografías dentales de individuos de origen europeo y asiático. Se realizaron estimaciones a partir de la observación directa de los cráneos (Anexo 1), en los que sólo se pudo registrar la erupción dental, y de imágenes digitales de tomografías computadas (TC) en las que se registró, además, la formación (Fig. 4.1). Se identificó el grado de formación de cada diente en relación con el desarrollo de su corona, raíz y ápice, empleando las referencias de Moorrees y colaboradores (1963) para dientes uni- y multiradiculares (Buikstra y Ubelaker, 1994; AlQahtani, 2008).

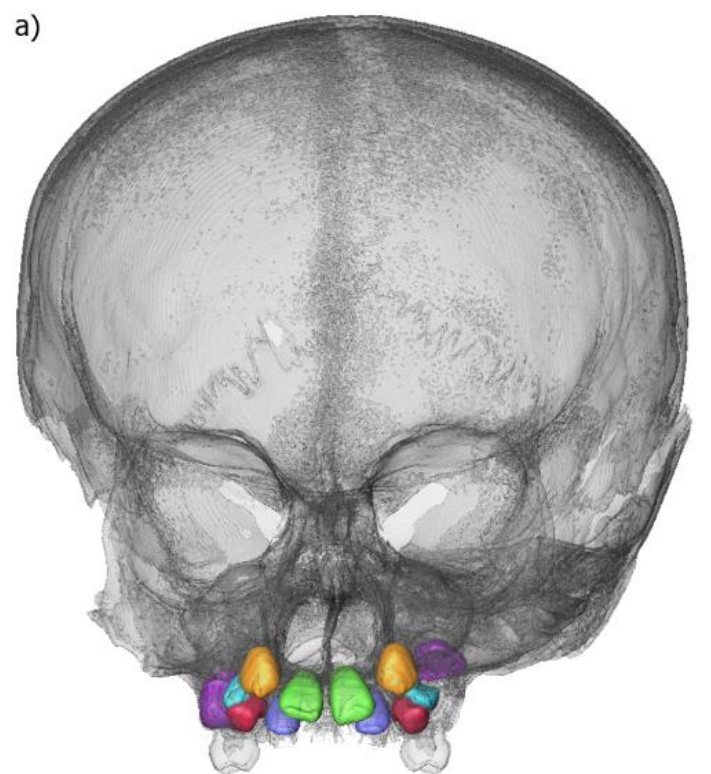

b)

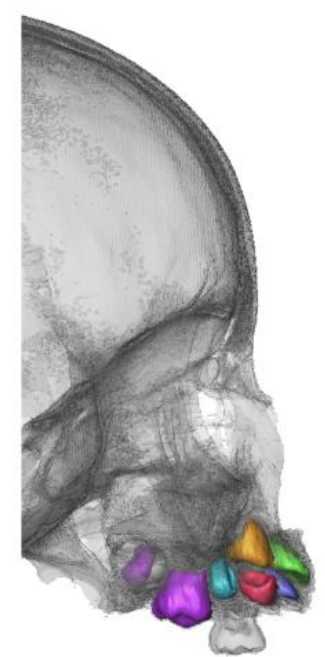

Fig. 4.1. Visualización de la dentición superior en tomografía computada en norma anterior (a) y lateral (b). Incisivos 1 (verde), incisivos 2 (azul), caninos (amarillo), premolar 1 (rojo), premolar 2 (celeste), molares (violeta), molares deciduos (sin color) 
De forma complementaria a las dos estimaciones de edad basadas en estándares mencionadas más arriba se desarrolló un procedimiento que permite obtener una distribución continua de los individuos en función del grado de desarrollo dental con el fin de establecer un ordenamiento de los individuos que no requiere asignarlos a rangos de edad discretos. Para ello se realizó un Análisis de Componentes Principales (ACP) a partir de las variables que describen el grado de formación dental de la totalidad de los dientes permanentes del maxilar (Incisivos 1 y 2-I1, 12; Canino-C; Premolares 1 y 2-PM1, PM2; Molares 1, 2 y 3-M1, M2, M3). Los dientes deciduos fueron excluidos de este análisis dado que la mayoría se encontraban perdidos post-mortem o reemplazados por los permanentes. Se asignó a cada pieza dental un valor entre 1 y 14 en función del estadío de desarrollo alcanzado, partiendo desde un estadío inicial de formación de la cúspide y finalizando con el cierre del ápice de la raíz (Buikstra y Ubelaker, 1994). A las piezas que aún no se encontraban en formación se les asignó 0 . Las observaciones fueron efectuadas sobre las piezas dentales del lado izquierdo, empleándose piezas del lado derecho en casos de pérdida post-mortem.

Para realizar el ACP es necesario que todos los individuos presenten una matriz completa de datos, lo que implica que haya información sobre el desarrollo dental para los 8 dientes permanentes de cada individuo. Dado que algunos individuos presentaban dientes perdidos post-mortem fue necesario imputar los datos correspondientes al grado de formación utilizando la información disponible para el resto de los individuos de la muestra. El método de imputación empleado consiste en los siguientes pasos: los valores perdidos son inicialmente reemplazados por el promedio para dicha variable en la muestra; se realiza un análisis de componentes principales (ACP) inicial para estimar los valores perdidos mediante una regresión; el mismo procedimiento se repite hasta alcanzar la convergencia (Hammer et al., 2001). Para realizar la imputación se incluyeron datos dentales de tres individuos (PG17771 de 6,5 años, PG17779 de 6,5 años, Ch1213 de 17 años) que presentaban entre el 87-100\% de piezas dentales observables, pero que fueron excluidos de la muestra general ya que presentaron un mal estado de preservación ósea para efectuar análisis histológicos. Tanto la imputación como el ACP fueron efectuados con el programa Past 3.15 (Hammer et al., 2001). Sobre los scores del primer componente principal (CP1) se efectuó una correlación con las edades estimadas a partir de los estándares de Ubelaker (1978) y AlQahtani y colaboradores (2010), a fin de evaluar la asociación entre desarrollo dental y asignación etaria.

Los resultados obtenidos indican discrepancias en cuanto a las asignaciones etarias realizadas de acuerdo a la técnica (i.e. observación directa o TC) y estándar empleados. La posibilidad de evaluar mediante TC el grado de formación de la corona, raíz y ápice de los 
dientes en oclusión permitió una mayor exactitud en la asignación al estadio de desarrollo dental. La Figura 4.2 muestra el número de individuos asignados a cada edad, en función de la técnica usada. Con el empleo de TC se incrementaron las asignaciones de edad a intervalos menores a 5 años, así como entre los 6 y 9 años. Asimismo, se observaron diferencias en las asignaciones otorgadas a los individuos de acuerdo al tipo de estándar de referencia (Fig. 4.2). Esto puede deberse a diferentes factores, entre ellos a que el estándar de AlQahtani y colaboradores (2010) asigna edades empleando valores con decimales, a diferencia del de Ubelaker (1978) en que los intervalos están generados en números enteros. A su vez, el estándar de AlQahtani y colaboradores (2010) presenta una continuidad en los intervalos registrados desde la etapa uterina y los 24 años, manteniendo el mismo intervalo de corte durante el desarrollo postnatal; mientras que Ubelaker (1978) amplía los intervalos de edad a partir de los 12 años, omitiendo algunas edades intermedias entre los 12 y los 35 años. Finalmente, los estándares de referencia empleados son conformados a partir de muestras cuya ancestría difiere entre sí, pudiendo responder la variación a diferencias poblacionales. En consecuencia, se decidió emplear para los subadultos una estimación de edad final promediada entre ambos estándares (Tabla 4.2).

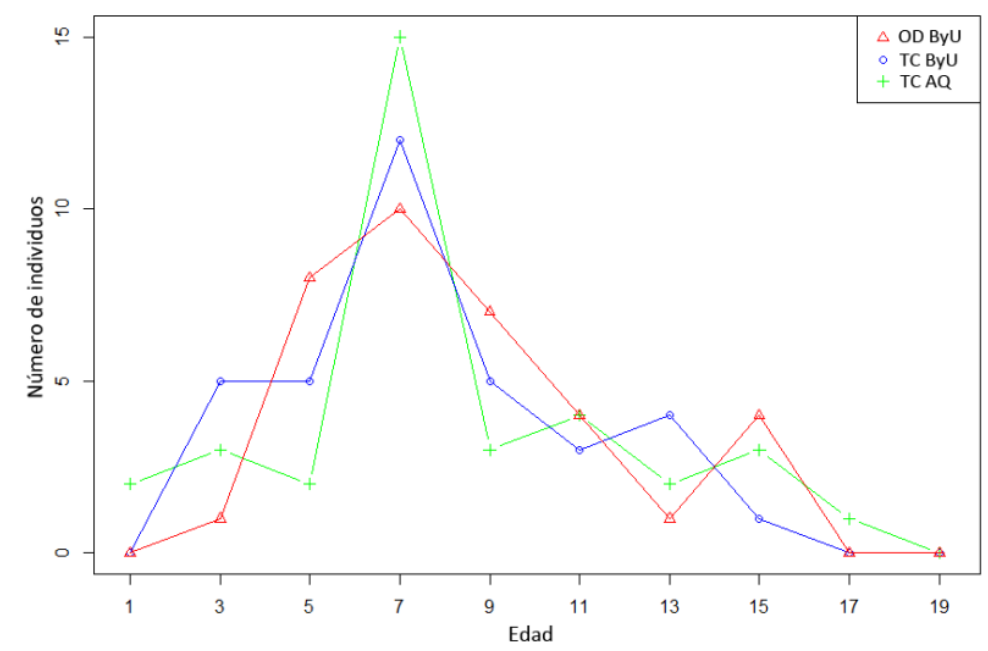

Fig. 4.2. Edades estimadas en subadultos. Referencias: OD ByU: observación directa con estándar de Buikstra y Ubelaker (1994); TC ByU: observación desde tomografía computada con estándar de Buikstra y Ubelaker (1994); TC AQ: observación desde tomografía computada con estándar de AlQahtani (2008)

Los resultados del ACP para la muestra de PG indican que dos primeros componentes (CP1 y CP2) dieron cuenta del 98,28\% de la variación. En el CP1 los individuos se ordenan en función del incremento en el desarrollo dental (Fig. 4.3a). Las piezas dentales que más contribuyeron 
en el CP1 fueron el segundo premolar (PM2) y el segundo molar (M2); seguidos del M1, canino (C) e incisivos (I1 y I2), mientras el M3 y el PM1 fueron los que menos contribuyeron.

Para la muestra de Ch, los dos primeros componentes sumaron el 98,29\% de la variación total. En el CP1 los individuos se distribuyen de acuerdo al grado de desarrollo dental (Fig. 4.3b). Al igual que en PG, el M2 y PM2 fueron los dientes que más contribuyeron en el CP1, seguidos por M3, PM1, C e 12. Los que menos contribuyeron fueron M1 e I1.

a)

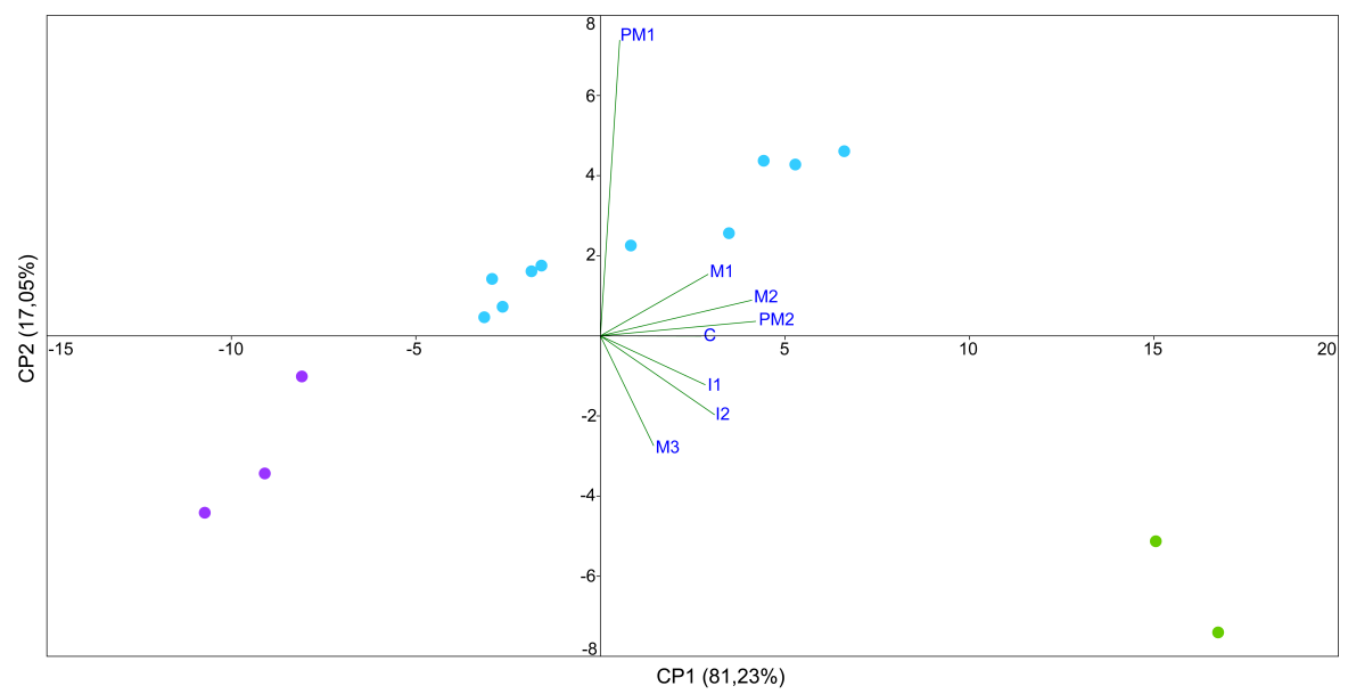

b)

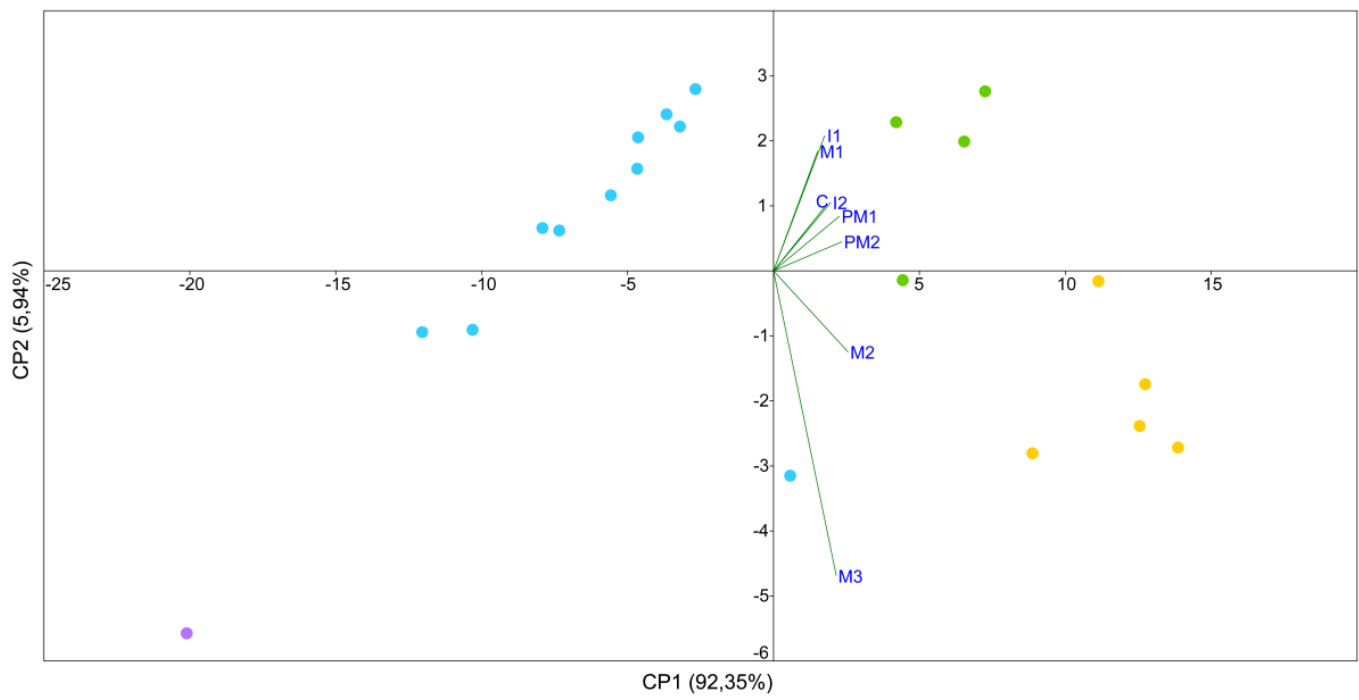

Fig. 4.3. Distribución de los subadultos de PG (a) y Ch (b) en función del desarrollo dental. Los vectores indican la contribución de cada pieza dental permanente en los CP1 y CP2. Rango de edad: menos de 4,4 años (violeta); de 4,5 a 10,4 años (celeste); de 10,5 a 14,4 años (verde); de 14,5 a 18 años (amarillo) 
La Figura 4.4 presenta las correlaciones entre la edad estimada y el grado de desarrollo dental representado en el CP1. Tanto para PG como para Ch se obtuvo una correlación del 0,97 y significativa $(p<0.001)$. Sin embargo, en ambos casos se observó una diferenciación en el desarrollo dental en individuos que habían sido asignados a una misma categoría etaria, en particular en los individuos asignados a los 8 años en PG y a edades comprendidas entre los 7 y los 10 en la muestra de Ch.

a)

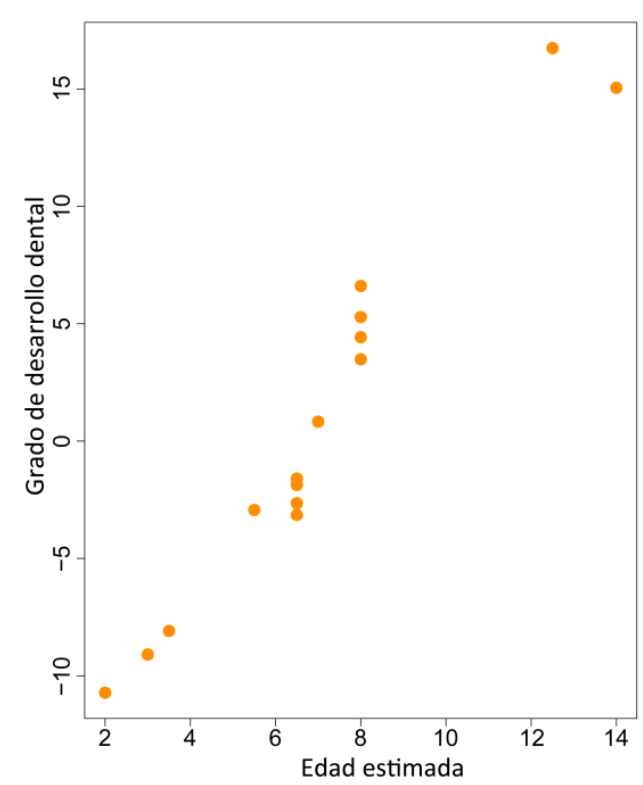

b)

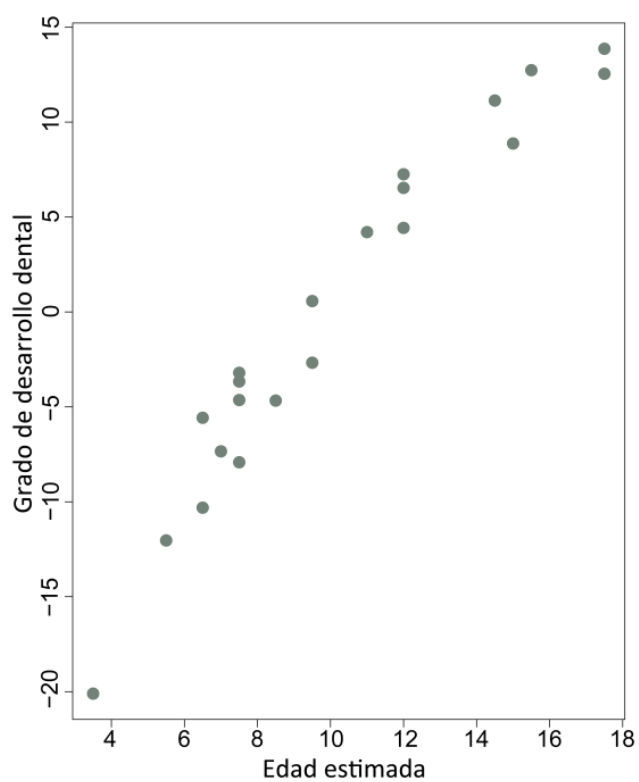

Fig. 4.4. Correlación entre las edades estimadas y el grado de desarrollo dental para PG (a) y Ch (b)

A partir de los resultados obtenidos para el grado de desarrollo dental, se agruparon los subadultos en rangos discretos de acuerdo al desarrollo y erupción dental de los molares y del PM2 (Tabla 4.2).

Tabla 4.2. Edad estimada para subadultos

\begin{tabular}{ccccc}
\hline \multicolumn{2}{c}{ Desarrollo y erupción } & Grupos y rango etario & \multicolumn{2}{c}{ Subadultos } \\
\cline { 4 - 5 } Molares & PM2 & PG & Ch \\
\hline Desarrollo del M1 & Ausencia del PM2 & $\begin{array}{c}\text { Grupo 1: } \\
\text { incluye hasta 4,4 años }\end{array}$ & 4 & 1 \\
\hline $\begin{array}{c}\text { Erupción del M1 y } \\
\text { desarrollo del M2 }\end{array}$ & Desarrollo del PM2 & $\begin{array}{c}\text { Grupo 2: } \\
\text { de 4,5 a 10,4 años }\end{array}$ & 9 & 11 \\
\hline $\begin{array}{c}\text { Erupción del M2 y } \\
\text { desarrollo de } \\
\text { corona del M3 }\end{array}$ & $\begin{array}{c}\text { Desarrollo final y } \\
\text { erupción del PM2 }\end{array}$ & $\begin{array}{c}\text { Grupo 3: } \\
\text { de 10,5 a 14,4 años }\end{array}$ & 2 \\
\hline $\begin{array}{c}\text { Desarrollo de raíz y } \\
\text { erupción del M3 }\end{array}$ & - & $\begin{array}{c}\text { Grupo 4: } \\
\text { de 14,5 a 18 años }\end{array}$ & - \\
\hline \multicolumn{2}{c}{ Total de individuos } & 15 \\
\hline
\end{tabular}




\section{Estimación de edad y sexo en adultos}

La estimación de edad y sexo en muestras arqueológicas presenta una serie de dificultades, vinculadas a la variación de las poblaciones humanas (asociada a factores genéticos y ambientales), la estructura anatómica disponible, la exactitud de los indicadores empleados y la experiencia del observador, entre otros (Buikstra y Ubelaker, 1994; Franklin, 2010; Desántolo e Inda, 2016). En particular, para adultos se reconoce que las estimaciones de edad son menos precisas (i.e. rangos de edad amplios) que en subadultos, dado que los indicadores clave dependen más de la degeneración ósea que del desarrollo biológico (Franklin, 2010). Por otra parte, los indicadores empleados para estimar el sexo también se ven afectados por factores individuales (e.g. edad, estado de salud y nutrición). Por ejemplo, se reconoce para el cráneo una tendencia a adquirir rasgos masculinos con la edad (Buikstra y Ubelaker, 1994).

Particularmente, para la estimación de la edad en individuos adultos, se consideró la obliteración de la sutura esfenobasilar y el grado de obliteración de las suturas ectocraneales de la región antero-lateral (Meindl y Lovejoy, 1985; Buikstra y Ubelaker, 1994). La elección del sistema antero-lateral se basó en que es mejor predictor de la edad que otros sistemas de suturas ectocraneales (Meindl y Lovejoy, 1985). Los grupos de edad empleados fueron: Adulto Joven (20-34 años, denominado Grupo 5 en este trabajo), Adulto Medio (35-49 años, denominado Grupo 6 en este trabajo) y Adulto Mayor (+50 años, incluido en el Grupo 6) (Buikstra y Ubelaker, 1994). La estimación de sexo se realizó a partir de rasgos morfológicos del cráneo, considerando el grado de desarrollo de la glabela, el margen supraorbital, el proceso mastoides y la cresta nucal (Buikstra y Ubelaker, 1994). Tanto la edad como el sexo fueron relevados en adultos por observación directa del cráneo (Anexo 1).

En la Tabla 4.3 se detalla la composición sexual y etaria de los individuos adultos de las dos muestras analizadas.

Tabla 4.3. Edad y sexo estimados para adultos

\begin{tabular}{lcccccc}
\hline \multirow{2}{*}{ Individuos } & \multicolumn{2}{c}{ PG } & & \multicolumn{2}{c}{ Ch } \\
\cline { 2 - 4 } \cline { 6 - 7 } \cline { 5 - 6 } & Femenino & Masculino & & Femenino & Masculino \\
\hline Adulto Joven (G5) & 5 & 3 & & 4 & 3 \\
Adulto Medio (G6) & 6 & 2 & & 5 & 5 \\
Adulto Mayor (G6) & - & 1 & & 1 & 1 \\
\hline Total & 11 & 6 & & 10 & 9 \\
\hline
\end{tabular}




\subsubsection{Estado de preservación}

El estado de preservación de los huesos es un factor importante a considerar cuando se realizan análisis histológicos de superficie dado que se puede producir pérdida de las microestructuras características de las superficies de formación y reabsorción ósea (MartínezMaza et al., 2010). La preservación depende tanto de la integridad ósea de los restos como de la influencia de factores tafonómicos (González, 2013; Knüsel y Robb, 2016). Respecto a la integridad ósea, después de la muerte del individuo los huesos pierden gradualmente su contenido de colágenos, lo que genera que se vuelvan frágiles y quebradizos, incrementándose las posibilidades de pérdida ósea (Knüsel y Robb, 2016). Entre los factores tafonómicos que pueden alterar la microestructura ósea, algunos operan antes del entierro (i.e. bioestratinomía) y otros, con posterioridad a la depositación (i.e. diagénesis; Kontopoulos et al., 2016). Particularmente, la preservación de los restos óseos arqueológicos depende de la exposición a diferentes factores ambientales (e.g. humedad, temperatura, tipo de suelo), así como a la acción microbial, de raíces y de animales, o antrópica (e.g. pisoteo, defleshing, quema; Stout, 1978; Kontopoulos et al., 2016).

Si bien existe una variedad de factores que pueden influir en la preservación ósea, la histomorfología de los huesos hallados en contextos arqueológicos en general se preserva bien (Stout, 1978). Sin embargo, existe un tipo de alteración tafonómica que genera inconvenientes en el análisis de superficies: la abrasión (Bromage, 1984). El aspecto que adquieren las superficies óseas expuestas a la abrasión es similar al observado en situaciones de quiescencia celular, lo que dificulta la identificación del origen de las superficies de aspecto liso cuando son observadas al microscopio (Boyde, 1972; Martinez-Maza, 2007). Asimismo, se pierden los rasgos que definen las superficies de formación y reabsorción, alterando la frecuencia y distribución de cada actividad en el patrón de modelado óseo (Brachetta-Aporta et al., 2018).

En este trabajo se evaluó la preservación de los restos considerando la integridad ósea y de las alteraciones tafonómicas presentes (Anexo 1). En particular, se evaluó: porcentaje de pérdida ósea en el cráneo, presencia de fracturas y fragmentaciones post-depositacionales (i.e. rotura con y sin separación de hueso, respectivamente), presencia de carbonato, de óxido de manganeso y de óxido de cobre, y marcas de raíces, animales y antrópicas (Buikstra y Ubelaker, 1994; Lyman, 1994; Barrientos et al., 2007; Knüsel y Robb, 2016). Asimismo, se registró el grado de meteorización, considerando un intervalo de 0 a 5 en función del incremento gradual del agrietamiento, escisión y exfoliación de la superficie (Behrensmeyer, 1978; Knüsel y Robb, 2016). Los individuos con valores de meteorización mayores a 3 fueron 
excluidos de los análisis dado que el incremento de la exfoliación genera texturas óseas ásperas y frágiles que pueden deteriorarse fácilmente con el procedimiento de replicado de las superficies.

Con relación a la integridad ósea, en la Figura 4.5 se presenta la frecuencia de individuos con pérdida ósea por norma y porcentaje de pérdida, agrupados por muestra y categorías de edad. En general, las estructuras observadas en norma inferior fueron las más afectadas, presentando mayor frecuencia de individuos con pérdida ósea; seguida por las de la norma lateral. Para la norma posterior también se registraron algunos individuos con $75-100 \%$ de pérdida ósea. La muestra Ch presentó mayor frecuencia de individuos con pérdida ósea, principalmente en subadultos. En PG los individuos subadultos también presentaron mayor pérdida ósea que los adultos.
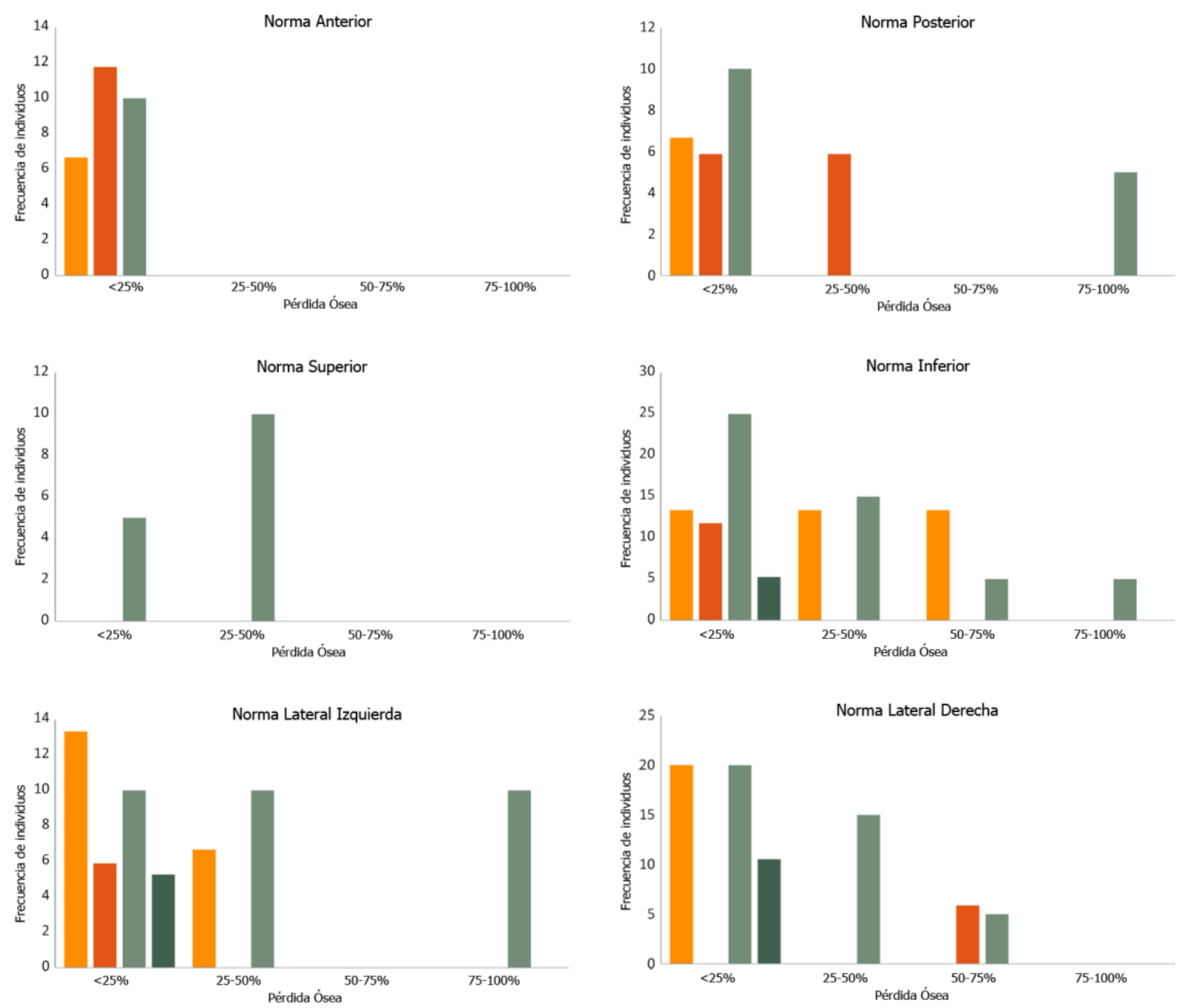

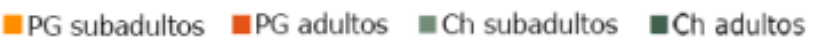

Fig. 4.5. Frecuencia de individuos por rango de pérdida ósea registrada para cada muestra y grupo de edad 
Respecto a la presencia de fracturas y fragmentaciones post-depositacionales en la región facial, ambas muestras presentaron una mayor prevalencia de fragmentaciones. Para PG, se registró fragmentación en el 53\% de los individuos y fracturas en el 18,7\%; en tanto en Ch, el porcentaje de fragmentaciones fue del $44 \%$ y el de fracturas, del $12,8 \%$. Entre las regiones óseas más afectadas, el malar y la porción anterior del maxilar fueron las más recurrentes en ambas muestras.

Por otro lado, se registró mayor prevalencia de marcas químicas y biológicas en la muestra Ch. Las principales marcas corresponden a manganeso (presente en el 15,6\% de los individuos de PG y en el $35,9 \%$ de $\mathrm{Ch}$ ) y a raíces (presente en el $12,5 \%$ de los individuos de PG y en el 25,6\% de Ch). Asimismo, se registraron 3 individuos con marcas antrópicas, dos correspondientes a PG y uno de Ch. Finalmente, en relación con el grado de meteorización, los individuos de Ch exhiben una preservación menor en comparación a los de PG (Fig. 4.6).

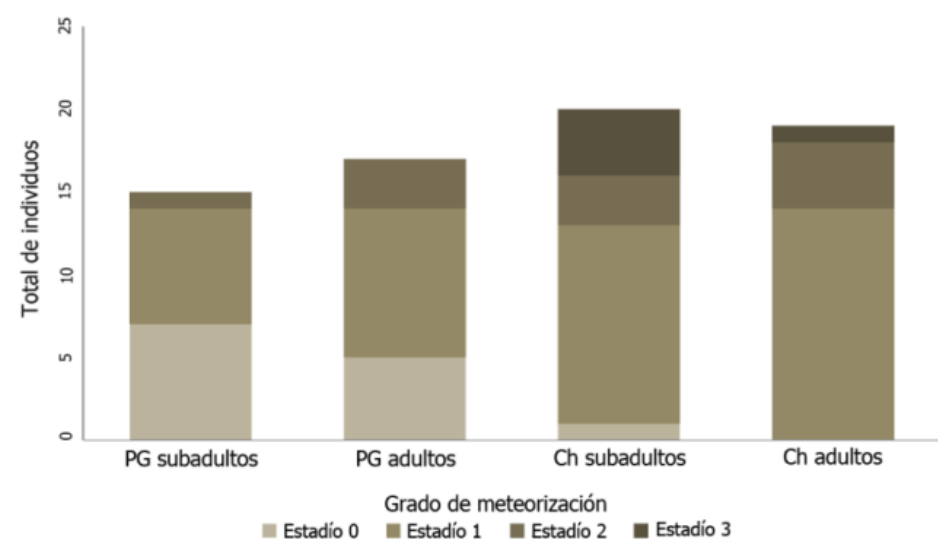

Fig. 4.6. Distribución de individuos por grado de meteorización

\subsubsection{Indicadores de adecuación fisiológica y salud bucal}

El modelado óseo facial puede estar afectado por distintas patologías, así como por la dureza y abrasividad de la dieta (Enlow y Hans, 1996). Con el fin de evaluar la influencia de estas variables se relevaron diversos indicadores de adecuación fisiológica y salud bucal del maxilar. Uno de los indicadores empleados en este sentido es el desgaste dental, el cual permite obtener información acerca de la dureza y abrasividad de la dieta (e.g. asociada al tipo de alimentos y a los abrasivos externos incorporados con la comida), así como del empleo de los dientes como instrumentos. Asimismo, existen otros indicadores vinculados a procesos infecciosos o degenerativos, los cuales otorgan información del estado de salud bucal del individuo (L'Heureux, 2014). 
Particularmente, en este trabajo se registró: el grado de desgaste de la superficie oclusal de los diente; la presencia de fracturas dentales, caries, abscesos, periodontitis y labiación; y el número de pérdidas dentales ante-mortem (Buikstra y Ubelaker, 1994) (Anexo 1). El desgaste fue registrado empleando las escalas ordinales propuestas por Smith (1984) y Scott (1979), para la dentición anterior y posterior respectivamente. El registro de las lesiones cariosas fue realizado en aquellos casos en que la desmineralización provocó una cavidad (Hillson, 2001). Estas variables fueron registradas para los lados derecho e izquierdo del maxilar.

Para la obtención de réplicas de alta resolución empleadas en el análisis paleohistológico, se excluyeron aquellos individuos que presentaban remodelado alveolar debido a abscesos, pérdida dental ante-mortem y altos grados de desgaste en la dentición superior.

Con relación al grado de desgaste, en la Tabla 4.4 se observan los resultados obtenidos para subadultos. De las piezas dentales analizadas, la mayoría corresponde a la dentición posterior. Los individuos de PG presentaron menores grados de desgaste que los de $\mathrm{Ch}$, tanto en la dentición decidua como permanente.

Tabla 4.4. Medias del desgaste oclusal en subadultos

\begin{tabular}{ccccccccc}
\hline Muestra & Dentición & $\mathrm{M}^{2}$ & $\mathrm{M}^{1}$ & $\mathrm{PM}^{2}$ & $\mathrm{PM}^{1}$ & $\mathrm{C}$ & $\mathrm{I}^{2}$ & $\mathrm{I}^{1}$ \\
\hline \multirow{2}{*}{$\mathrm{PG}$} & Decidua & 3,07 & 4,17 & $\mathrm{x}$ & $\mathrm{x}$ & - & - & - \\
& Permanente & 3 & 2 & 1 & - & 1 & - & 2 \\
\hline \multirow{2}{*}{$\mathrm{Ch}$} & Decidua & 13 & 20,09 & $\mathrm{x}$ & $\mathrm{x}$ & 2 & 3 & - \\
& Permanente & 9,4 & 8,94 & 1,67 & 2,67 & 3,5 & 2 & 4 \\
\hline
\end{tabular}

$\mathrm{x}$ : los premolares se encuentran ausentes en la dentición decidua

En la Figura 4.7 se presentan los resultados obtenidos para el grado de desgaste en la dentición anterior y premolares (a), y en los molares (b) de individuos adultos. Los resultados indican en todos los casos, mayores grados de desgaste en la muestra Ch.
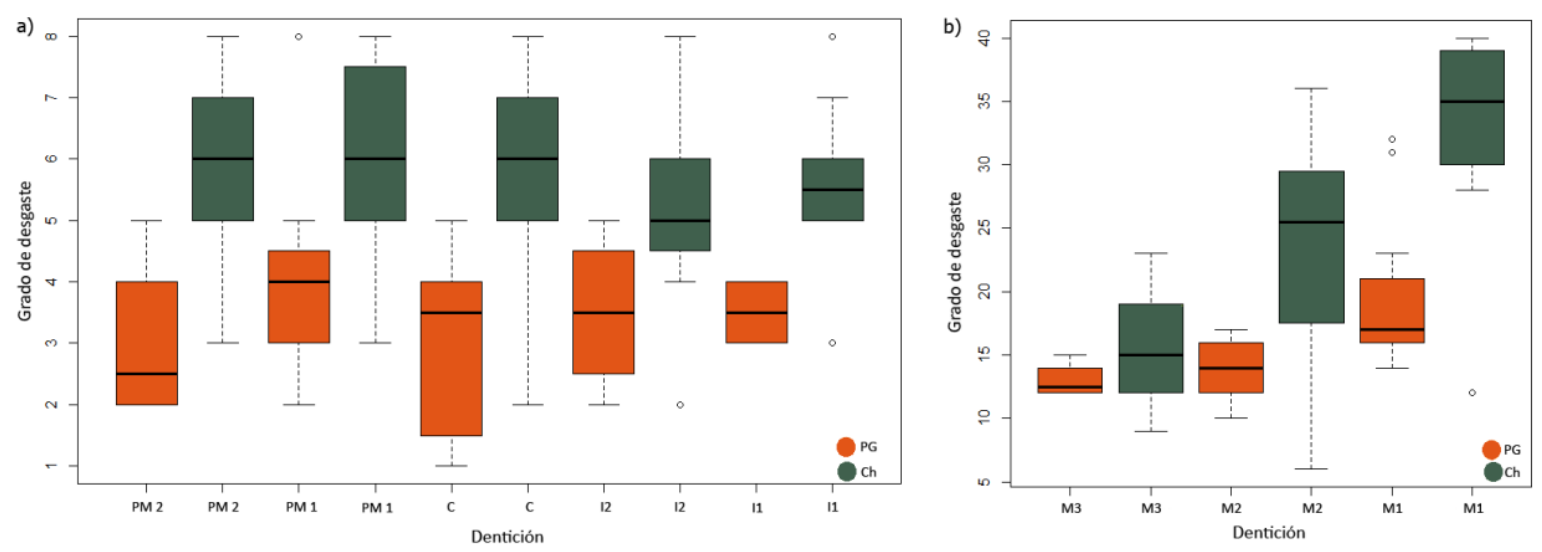

Fig. 4.7. Grado de desgaste en adultos: a) dentición anterior y premolares, b) molares 
La Tabla 4.5 resume las frecuencias de caries y fracturas registradas en ambas muestras. Los individuos subadultos de PG presentaron los porcentajes más elevados para ambas variables. En los adultos se observó una mayor prevalencia de caries en PG, mientras que las fracturas presentaron una frecuencia similar en ambas muestras (Tabla 4.5).

Tabla 4.5. Porcentaje de caries y fracturas

\begin{tabular}{lccccc}
\hline \multirow{2}{*}{ Estado bucal } & \multicolumn{2}{c}{ Subadultos } & & \multicolumn{2}{c}{ Adultos } \\
\cline { 2 - 3 } & PG & Ch & & PG & Ch \\
\hline Total de dientes & 70 & 133 & & 105 & 212 \\
Caries (\%) & 5,71 & 3,76 & & 6,67 & 3,77 \\
Fracturas (\%) & 10 & 2,25 & & 3,81 & 3,77 \\
\hline
\end{tabular}

Con respecto al estado alveolar, en los individuos subadultos no se registró labiación ni periodontitis, y sólo se registraron 2 abscesos en la muestra de Ch. La Figura 4.8 presenta el porcentaje de abscesos, periodontitis y labiación registrado en los individuos adultos. Los individuos de PG presentaron menor frecuencia de abscesos, pero mayor de periodontitis. La frecuencia de labiación fue similar en ambas muestras.

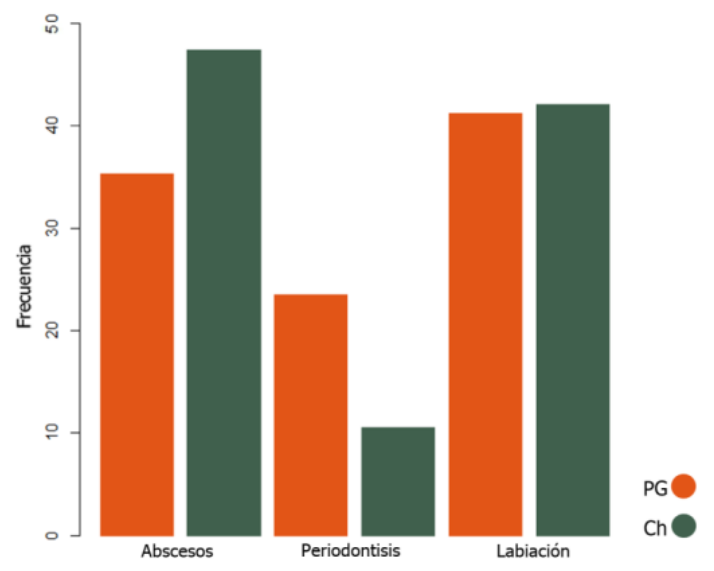

Fig. 4.8. Porcentaje de indicadores de salud bucal en adultos 


\section{Métodos para el análisis histológico de superficies óseas}

Descripción de los procedimientos empleados en el análisis de superficies óseas.

Revisión de los métodos tradicionales y formulación de alternativas.

\section{Contenido}

5.1. Relevamiento de datos histológicos

5.1.1. Obtención de réplicas

5.1.2. Registro de superficies óseas

Superficie de reabsorción ósea

Superficie de formación ósea

Superficie de reposo (resting surface)

Otras microestructuras

5.2. Análisis del error de observación en el registro de superficies óseas

5.2.1. Metodología para el análisis del error de observación

Topografía de superficies óseas

Fracción de área

5.3. Análisis cuantitativo del modelado óseo

5.3.1. Estimación de los datos perdidos en mapas de modelado óseo

Estimación de la forma general a partir de mapas de modelado óseo

Exploración de la estructura espacial

Evaluación de las estimaciones obtenidas por interpolación espacial

Evaluación de las estimaciones obtenidas por imputación de datos

5.3.2. Construcción de mapas generales y análisis estadísticos

La reconstrucción de los patrones de modelado óseo registrados a partir del relevamiento de rasgos histológicos sobre las superficies óseas requiere de una serie de pasos que incluyen la obtención de réplicas de la superficie del hueso, su observación al microscopio, la delimitación de criterios para identificar los distintos rasgos microestructurales que definen cada tipo de actividad de modelado óseo, la construcción de mapas de modelado óseo a partir de la información relevada y el análisis comparativo de los patrones obtenidos. Desde su 
formulación a principios de la década de 1970, los estudios histológicos de superficies han propuesto y discutido las ventajas y limitaciones de distintas aproximaciones para algunos de los procedimientos mencionados, mientras otros aspectos han recibido menos atención.

La técnica de análisis de superficies mediada por réplicas obtenidas a partir del empleo de silicona y resina epoxi fue propuesta por Grundy en 1971. Posteriormente, numerosos trabajos evaluaron tanto diferentes combinaciones de los materiales empleados para hacer las réplicas como las posibles aplicaciones de la técnica (Bromage, 1985). Asimismo, se han evaluado alternativas metodológicas relacionadas al empleo de diferentes microscopios (Boyde y Jones, 1996; Bromage y Boyde, 2008; Martinez-Maza et al., 2010). Inicialmente, las superficies fueron observadas mediante microscopio electrónico de barrido (MEB; Boyde, 1972; Boyde y Jones, 1972). Más recientemente, se ha explorado la utilidad del microscopio óptico de luz incidente (MLI) y del microscopio confocal (Martinez-Maza et al., 2006). El MLI presenta la ventaja de un funcionamiento sencillo que no requiere la intervención de un técnico especialista como en el MEB; a su vez, permite analizar réplicas de mayor tamaño y su costo resulta menor (MartinezMaza et al., 2010). Con microscopio confocal es posible observar la superficie de manera directa, y por lo tanto no requiere la elaboración de réplicas de las superficies óseas para efectuar el análisis (Bromage y Boyde, 2008).

La obtención del patrón de modelado a partir de la observación de superficies óseas depende de la correcta identificación de las microestructuras asociadas a la actividad celular. Diferentes factores pueden alterar la identificación de tales microestructuras y por lo tanto, interferir en la inferencia de los procesos subyacentes que les dan origen. Por un lado, el grado de expresión y por ende, la posibilidad de visualizar la actividad celular, dependerá de si las células se encontraban en estado activo o en reposo al momento del deceso del individuo (Boyde, 1972; Boyde y Jones, 1972). Por otro lado, las condiciones externas a las que estuvo expuesta la superficie ósea (i.e. alteraciones tafonómicas) pueden eliminar las marcas características de los distintos tipos de actividad celular (Bromage, 1984; 1989). Finalmente, debe tenerse en cuenta que el proceso de registro de los datos está sujeto al error introducido por el observador, y que es necesario controlarlo a fin de garantizar la confiabilidad de las reconstrucciones efectuadas (Arnqvist y Mårtensson, 1998). Este último aspecto no ha sido evaluado sistemáticamente y por lo tanto, no se conoce en qué medida puede afectar la identificación del tipo de actividad celular así como la extensión asignada a cada una.

El análisis de superficies óseas de restos arqueológicos y fósiles presenta una dificultad adicional debido a la pérdida de información (i.e. marcas de formación y reabsorción ósea) 
como consecuencia de las alteraciones producidas por procesos tafonómicos (Bromage, 1984, 1989). Esto resulta en una distribución fragmentaria y heterogénea de las estructuras asociadas al modelado óseo que dificulta los análisis comparativos posteriores (Bromage y Boyde, 2008; Gunz et al., 2009). Por lo tanto, se requiere la aplicación de técnicas que permitan reconstruir las áreas sin información. El procedimiento empleado generalmente se basa en la expansión hacia las áreas sin datos de la información de depositación o reabsorción más próxima registrada, bajo el supuesto de que la actividad de modelado en las superficies óseas ocurre en grandes áreas (Bromage, 1982, 1989; Bromage y Boyde, 2008). Esto se sustenta en el reconocimiento de que los osteoblastos presentan una conformación en dominio, caracterizada por la continuidad de las fibras de colágeno en una dirección preferente como resultado de la agregación de 20 a 60 osteoblastos (Boyde, 1972; Boyde y Jones, 1972). Respecto a los osteoclastos, la presencia de unidades funcionales denominadas pseudópodos, les conferirían cierta movilidad espacial en la superficie ósea (Boyde, 1972).

Una vez obtenidos los patrones de modelado óseo individuales, los análisis posteriores se orientan a realizar estudios comparativos tanto a nivel intra como inter-grupal. Estos estudios se han basado principalmente en caracterizaciones cualitativas, con detalladas descripciones de los rasgos observados, las cuales resultan difíciles de emplear en análisis comparativos. Algunas opciones para facilitar la caracterización del patrón de modelado se han basado en el empleo de esquemas (e.g. faciales, base del cráneo), donde se referencian los distintos tipos de actividad celular observados (i.e. mapas de modelado óseo). Estos mapas de modelado óseo pueden representarse sobre la forma original del hueso cuando se analizan pocos individuos (Bromage, 1989; Lacruz et al., 2015a,b) o bien, sobre una forma base predeterminada común para todos los especímenes (Martinez-Maza et al., 2013, 2016; McCollum, 2008; Kranioti et al., 2009). Esto último facilita la comparación entre individuos aunque conduce a la pérdida de variación en la forma de los huesos analizados. Otras opciones para organizar la información consisten en establecer grupos integrados por un número menor de especímenes en los cuales se divide la muestra (e.g. por edad, sexo; Wealthall, 2002; McCollum, 2008; Martinez-Maza et al., 2013), seleccionar al individuo considerado más representativo o de mayor relevancia en cada grupo (Bromage, 1989; Lacruz et al., 2015b), y excluir la alternancia de actividades en la caracterización general, salvo que representen áreas cercanas a zonas de inversión -reversals- (i.e. con una marcada separación entre un tipo de actividad y otro; Lacruz et al., 2013). Tanto la selección de individuos particulares como la generación de mapas comunes a la muestra se ven afectadas por valoraciones personales en función de la información presente (e.g. seleccionar el individuo que exhibe mayor porcentaje 
de datos relevados, otorgar mayor preponderancia a una actividad celular cuando predomina en extensión con respecto a la otra). En general, estos procedimientos no están basados en criterios explícitos, lo que dificulta su replicabilidad y la consideración de la variación intragrupal (Brachetta-Aporta et al., 2018).

En este capítulo se presentan y discuten las alternativas metodológicas exploradas a fin de superar las limitaciones mencionadas anteriormente. En particular, se propuso un abordaje para evaluar el error de observación que permita generar criterios para identificar y minimizar el sesgo introducido en el reconocimiento de las estructuras de modelado óseo; y una aproximación cuantitativa para la construcción de mapas de modelado y su posterior análisis. En este sentido, se incorporaron herramientas estadísticas que permiten describir la estructuración espacial de los datos, estimar los datos perdidos a partir de criterios replicables, y analizar conjuntamente un gran número de especímenes incorporando la variación interindividual en la caracterización de los distintos grupos estudiados.

\subsection{Relevamiento de datos histológicos}

\subsubsection{Obtención de réplicas}

Se analizaron las superficies óseas correspondientes a la región facial (Fig. 5.1) mediante la elaboración de impresiones que capturan con alta precisión la microestructura ósea, denominadas réplicas de alta resolución. Brevemente, el procedimiento consiste en la limpieza del material mediante el empleo de cepillos de cerdas suaves y alcohol $60 \%$. Posteriormente, se genera un molde negativo en silicona de baja viscosidad que sirve de base para la generación del molde positivo en resina epoxi. El molde positivo es luego metalizado para su observación al microscopio (Anexo 3). En este trabajo se

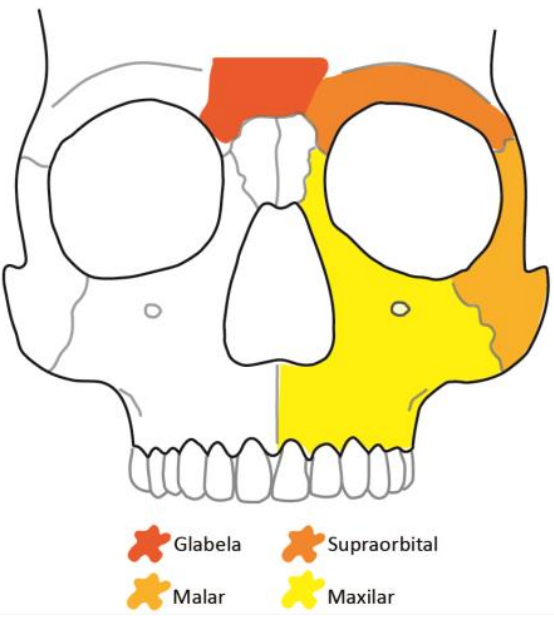

Fig. 5.1. Regiones faciales replicadas empleó silicona Coltène ${ }^{\circledR}$ y resina epoxi Tolken ${ }^{\circledR}$.

Se obtuvieron réplicas de la superficie ósea de la glabela, el supraorbital, el malar y la región anterior del maxilar superior (Fig. 5.1). Se replicó el lado izquierdo, aunque en los casos en que la preservación o alteraciones óseas impedían su estudio la réplica fue realizada del lado derecho. Las réplicas fueron posteriormente metalizadas en oro-paladio en el metalizador Termo VG Scientific SC7620, del Museo Argentino de Ciencias Naturales Bernardino Rivadavia. 
Para el relevamiento se empleó un microscopio Olympus CX31 (objetivo de 20x NA 0.40) modificado para luz de incidencia. Sobre la región metalizada de las réplicas, se trazó una grilla de $5 \times 5 \mathrm{~mm}$, empleando un marcador indeleble de trazo fino, para guiar la observación sistemática al microscopio. Los datos relevados fueron registrados en mapas construidos manualmente y luego escaneados y convertidos a imágenes digitales (Fig. 5.2).
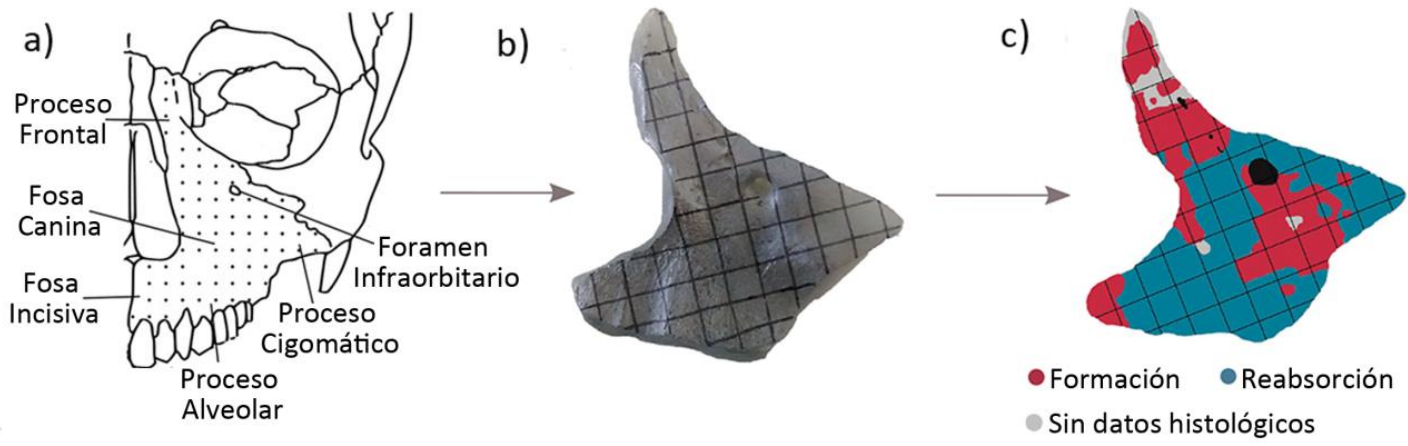

Fig. 5.2. Pasos del relevamiento histológico en el maxilar: a) Delimitación de la superficie a replicar; b) Réplica de alta resolución de maxilar (región anterior); c) Registro de información histológica

\subsubsection{Registro de superficies óseas}

En base a descripciones previamente publicadas (Boyde, 1972; Bromage, 1984; MartinezMaza, 2007; Martinez-Maza et al., 2010) se registraron dos tipos de superficies: reabsorción ósea, resultado de la actividad de los osteoclastos; y formación ósea, producto de la actividad de los osteoblastos. Existe un tercer tipo de superficie -superficie de reposo o resting surfaceasociada a la mineralización de la matriz ósea y otros rasgos microestructurales identificables al microscopio -e.g. marcas de vascularización y tafonómicas-, que no se incluyeron en el análisis.

\section{$\underline{\text { Superficie de reabsorción ósea }}$}

Las superficies de reabsorción ósea se identifican a partir de la presencia de depresiones de distinto tamaño, denominadas lagunas de Howship (Boyde, 1972; Martinez-Maza et al., 2010). Las lagunas se encuentran agrupadas entre sí (i.e. topografía lagunar), con una disposición general desordenada producto de la orientación de los pseudópodos de los osteoclastos (Martinez-Maza, 2007). Aquellas superficies de reabsorción activa presentan lagunas profundas con bordes bien definidos, y pueden presentar algunas fibras de colágeno dispersas y desordenadas, como resultado de la exposición del hueso lamelar (Iamellae) a diferentes profundidades; mientras que cuando la reabsorción procede lentamente o ha finalizado, las lagunas son poco profundas y sus bordes menos definidos acompañados de una superficie muy lisa (Boyde, 1972; Boyde y Jones, 1972). La reabsorción puede proceder sobre superficies 
mineralizadas o previo al avance del frente de mineralización, actuando directamente sobre áreas activas de formación (Boyde, 1972).

Dado que en huesos secos la abrasión puede alterar fácilmente la superficie ósea, resulta difícil establecer si el estado de la reabsorción ósea era activo o estaba en reposo al momento del deceso del individuo (Bromage, 1984; McCollum, 2008). En consecuencia, sólo se identificó su presencia (Fig. 5.3).
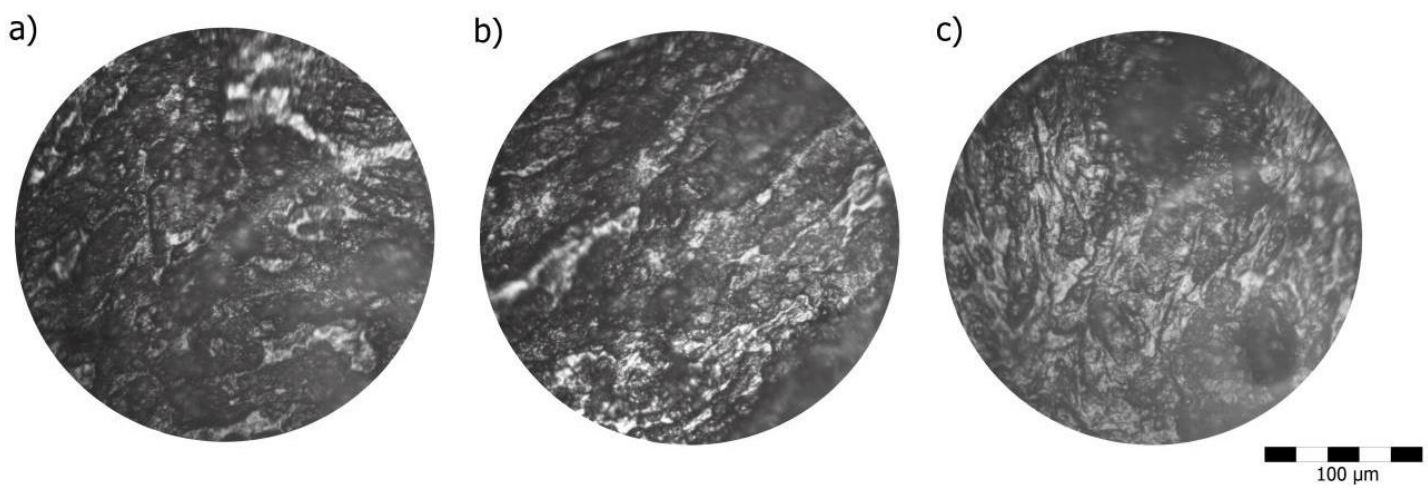

Fig. 5.3. Superficies de reabsorción ósea en subadulto (a), adulto joven (b) y adulto medio (c)

\section{Superficie de formación ósea}

Las superficies de formación, también denominadas superficies de depositación (Fig. 5.4), están caracterizadas por la presencia de estructuras alargadas, correspondientes a las fibrillas de colágeno que conforman haces de fibras paralelos, dispuestos con una orientación preferente (Martinez-Maza et al., 2010). En general, son grandes áreas en las que posteriormente a la síntesis de las fibras de colágeno se continúa un frente de mineralización. En áreas de mineralización activa, los segmentos de haces de fibras de colágeno se distinguen claramente entre sí, incluso las fibras individuales que constituyen los haces también se distinguen con claridad (Boyde, 1972). Dentro de las superficies de modelado óseo, se considera a la formación como la superficie más afectada por los procesos de fosilización, como consecuencia de la abrasión (Bromage, 1984).

a)

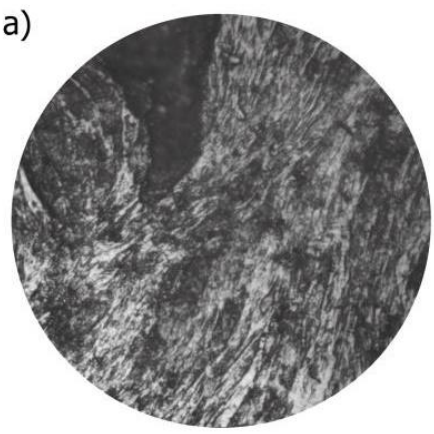

b)

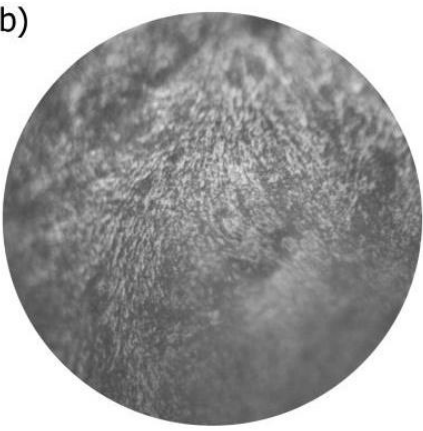

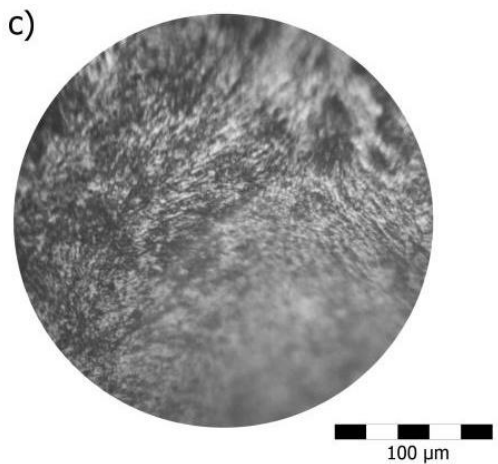

c)

Fig. 5.4. Superficies de formación ósea en adulto joven (a) y adulto medio (b y c) 


\section{Superficie de reposo (resting surface)}

Al igual que la superficie de formación, las superficies de reposo constituyen grandes áreas donde se pueden presentar fibras de colágeno uniformes pero anastomosadas y menos delineadas; donde la mineralización progresiva genera capas de matriz sobre las que no se genera nueva depositación (Boyde, 1972; Martinez-Maza et al., 2010). En general, estas superficies son de aspecto liso y el detalle de las fibras de colágeno está oscurecido con un "barniz" relativamente suave como consecuencia del avance y mineralización de la sustancia fundamental (Boyde, 1972). Son superficies asociadas a períodos de quiescencia (Boyde, 1972; Boyde y Jones, 1972). Estas superficies son similares a aquellas generadas por abrasión, producto de los diferentes procesos tafonómicos a los que se ve expuesto el material (e.g. compactación en el sedimento, limpieza, manipulación; Bromage, 1984). Como consecuencia de estas alteraciones, las fibras de colágeno que no han completado su mineralización son sencillamente removidas (Boyde, 1972).

Considerando la ambigüedad en los procesos que pueden dar origen a las superficies lisas y brillantes, no se incluyó la superficie de reposo como categoría en el análisis (Fig. 5.5).
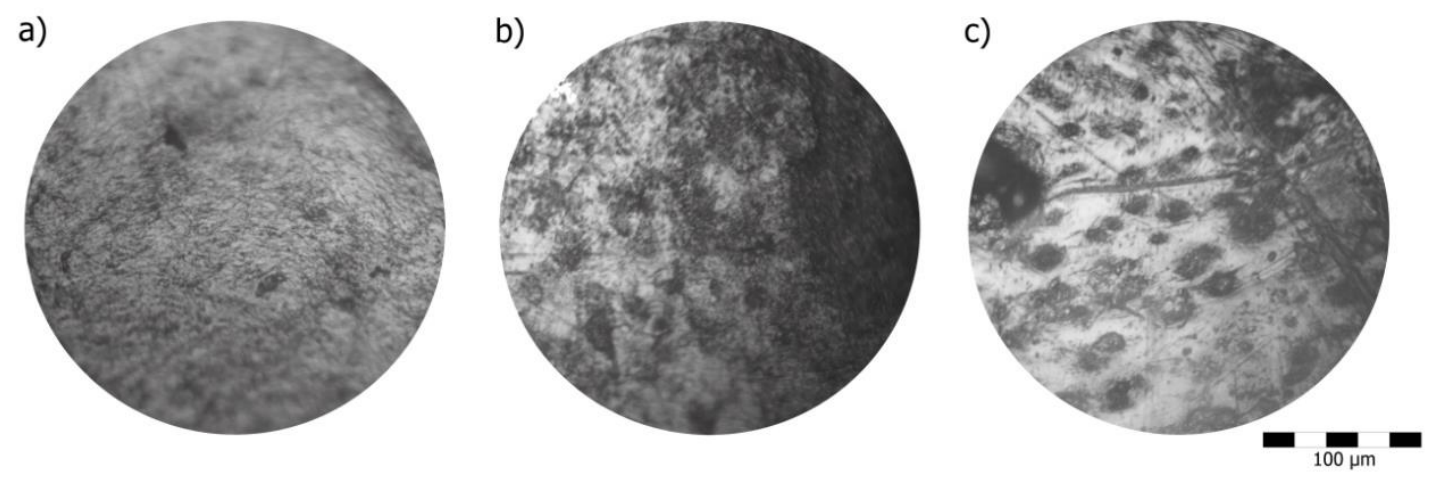

Fig. 5.5. Superficies de reposo en subadultos (a-c)

\section{Otras microestructuras}

El tejido óseo presenta vascularizaciones e inervaciones que dejan marcas visibles en su estructura. Así, es posible observar poros aislados producto de la entrada de capilares, principalmente en las regiones de la glabela y arcos supraorbitales (Martinez-Maza, 2007). Por otra parte, también pueden encontrarse hoyos o lagunas en la superficie mineralizada, producto de la inserción de fibras de Sharpey (Boyde, 1972; Jones y Boyde, 1974). En general, estas pueden identificarse por la presencia de varios hoyos de tamaño uniforme que no se encuentran agrupados entre si (Fig. 5.6). A nivel de la superficie craneofacial, las fibras de 
Sharpey se asocian con la inserción de tendones y ligamentos, y son observables, por lo general, en la glabela y los arcos supraorbitales (Jones y Boyde, 1974; Martinez-Maza, 2007).

Otras marcas presentes en las superficies de los huesos resultan de alteraciones tafonómicas (Fig. 5.6). En este sentido, se puede registrar fragmentaciones, superficies erosionadas, marcas dejadas por elementos punzantes (e.g. asociadas a la limpieza del material), marcas fúngicas y bacterianas, entre otras (Bromage, 1984; Fernández-Jalvo y Marín Monfort, 2008; Martinez-Maza et al., 2010).

Estas variantes de microestructuras no fueron relevadas dado que no contienen información sobre los procesos de interés para los objetivos del presente trabajo.

a)

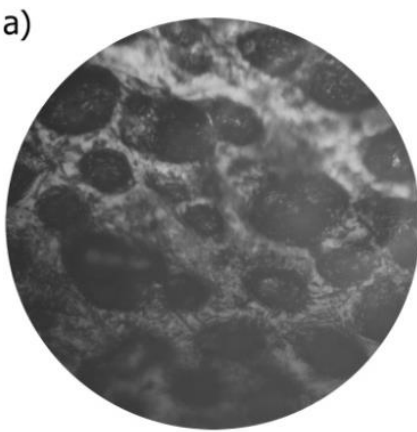

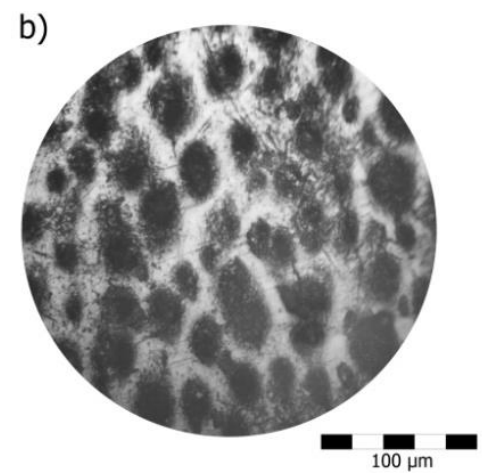

c)

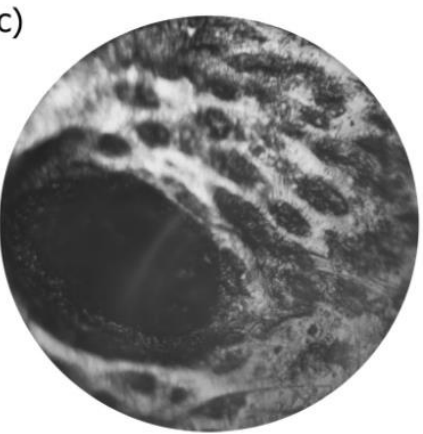

f)

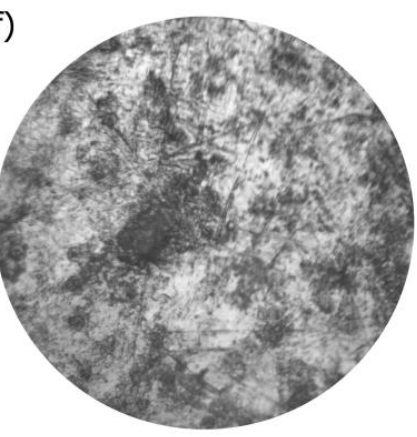

d)

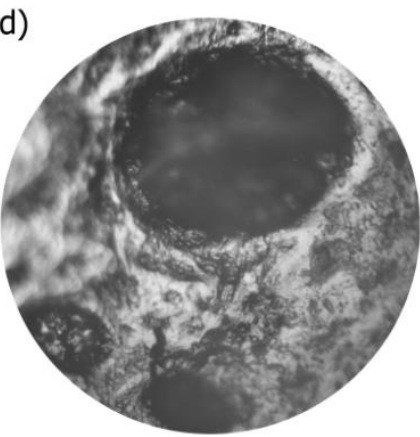

g)

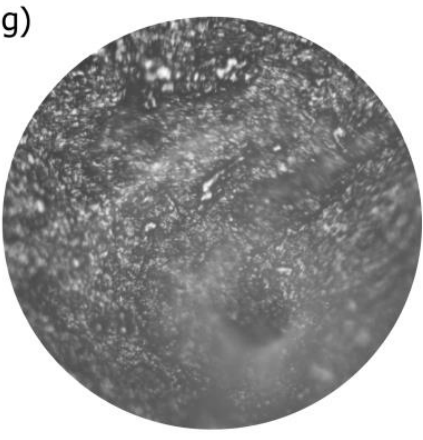

e)

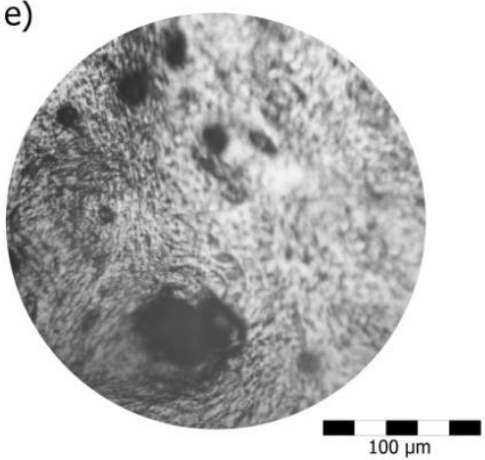

h)

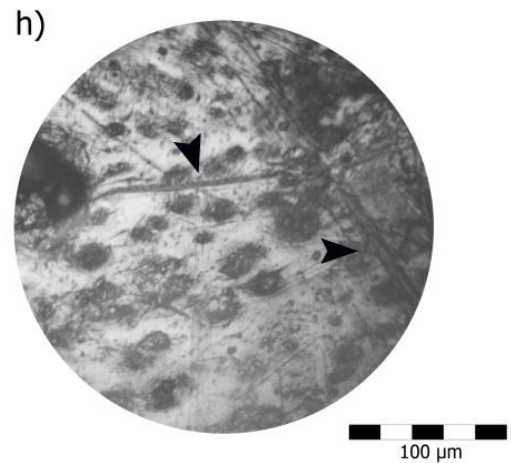

Fig. 5.6. Marcas de microestructuras: probables fibras de Sharpey ( $a$ y b), vasos o inervaciones (c-d), erosión ( $\mathrm{f}$ g $\mathrm{g}$, marcas de instrumentos ( $h$, flechas negras) 


\subsection{Análisis del error de observación en el registro de superficies óseas}

En general, la confiabilidad y repetibilidad de las observaciones histológicas se fundamentan en el aprendizaje continuo y guiado para la identificación de rasgos microestructurales, acompañado de una revisión de los procesos biológicos que los subyacen (Krause, 2001; Peña Amaro, 2007; Stout y Crowder, 2012). Sin embargo, la determinación de posibles fuentes de error que alteren la correcta identificación de las estructuras y su impacto en los resultados, carecen aún de la debida atención (Brachetta-Aporta, 2016). En efecto, el error de observación (i.e. diferencias en la identificación y medición repetida de una misma variable) es un factor que debe considerarse (Gonzalez et al., 2004; Perez et al., 2004; Muñoz-Muñoz y Perpiñán, 2010).

La identificación del tipo de superficie ósea y su extensión pueden verse influenciadas por distintas fuentes de error. La preparación de los materiales (e.g. técnica empleada para la elaboración de las réplicas o a los materiales usados), el instrumental utilizado (e.g. tipo de microscopio), la forma de la estructura (e.g. diferencias de relieve entre las réplicas) o aquellas fuentes inherentes al observador (e.g. grado de entrenamiento, diferencias en los criterios entre observadores), pueden alterar la correcta identificación de la actividad celular así como dificultar la reproducibilidad del análisis (Arnqvist y Mårtensson, 1998; Muñoz-Muñoz y Perpiñán, 2010). Esto es particularmente importante en análisis de muestras que exhiben bajos niveles de variación, incrementándose el efecto del error de medición en los resultados (Arnqvist y Mårtensson, 1998). En consecuencia, es necesario reconocer, evaluar y controlar cada una de las posibles fuentes de error, para incrementar de esta manera la exactitud (i.e. aproximación del valor observado al real) y la precisión (i.e. menor dispersión causada por la varianza introducida) en el relevamiento de los datos (Perez et al., 2004). A partir de estas consideraciones, se evaluó el error intra-observador en el relevamiento de las superficies óseas, teniendo en cuenta la concordancia en la identificación de las actividades de formación y reabsorción ósea, así como la extensión relevada para cada tipo de actividad. Para ello, se elaboró un diseño experimental de bloques completos aleatorios con medidas repetidas para cada variable registrada (Zar, 1999).

\subsubsection{Metodología para el análisis del error de observación}

Como base para la evaluación del error, se seleccionaron las réplicas de la glabela, el malar y el maxilar anterior izquierdo, correspondientes a un individuo adulto joven femenino de la muestra de Pampa Grande. A partir de las grillas realizadas en cada réplica se obtuvieron un total de 133 celdas (glabela=38, malar=38 y maxilar=57) sobre las que se realizó el análisis. La 
enumeración de las celdas se obtuvo considerando los ejes de coordenadas $(x, y)$, comenzando por la celda inferior izquierda.

El relevamiento de los datos se organizó en 3 bloques, realizándose la observación de las réplicas en tres ocasiones (serie 1 , serie 2 y serie 3 ) con un intervalo de 7 días entre repeticiones sobre la misma réplica. La aleatoriedad de las observaciones se estableció cambiando la celda por la que se iniciaba el registro en cada serie. Como resultado, se obtuvieron para cada serie los mapas correspondientes a glabela, malar y maxilar, con la información de modelado óseo (i.e. áreas de formación y reabsorción). Cada mapa fue digitalizado y se estableció una escala en $\mathrm{mm}^{2}$ para las imágenes obtenidas.

Posteriormente, se realizaron dos análisis complementarios, uno orientado a evaluar el error en la identificación del tipo de superficie y el otro, el error en la extensión asignada a cada tipo de superficie. En el primero, denominado aquí Topografía de superficies óseas, las variables de formación y reabsorción fueron relevadas como discretas; mientras en el segundo, denominado Fracción de área, las variables fueron consideradas como continuas. En cada análisis, las comparaciones se efectuaron por celda y por tipo de superficie, para evaluar conjuntamente la concordancia en la ubicación espacial y en la identificación de las superficies de formación y reabsorción. Las comparaciones se realizaron de a pares de series consecutivas (serie 1 con serie 2 , serie 2 con serie 3 ), dado que se espera un incremento de la concordancia a través del tiempo, producto de la experiencia progresiva del observador.

\section{$\underline{\text { Topografía de superficies óseas }}$}

Para este análisis las variables de formación y reabsorción fueron registradas en cada celda de forma discreta, estableciendo su presencia (1) o ausencia (0). El error de observación en el registro de estas variables se calculó a través del índice Kappa ( $k$ ) (Cohen, 1960) y la prueba McNemar (McNemar, 1947), utilizando el paquete estadístico irr en R 3.1.1 (R Core Team, 2014). El índice Kappa ( $k$ ) indica el grado de acuerdo de dos medidas sobre un mismo objeto (en este caso, el valor otorgado por celda entre series) por encima del esperado por azar; y sus valores oscilan entre -1 y 1 , siendo 0 cuando la concordancia es por azar. La hipótesis nula de esta prueba es que las observaciones son independientes, por lo tanto, el rechazo de la hipótesis indica que las observaciones repetidas presentan mayor acuerdo que el esperado por azar. Por el contrario, la prueba McNemar evalúa si las proporciones pareadas son diferentes, centrándose en las discordancias. De esta manera, el índice Kappa se centra en la diagonal de concordancia, mientras que la prueba McNemar se centra en los marginales, evaluando su homogeneidad o heterogeneidad entre repeticiones (Fig. 5.7) (Azzimonti Renzo, 2005; 
Benavente et al., 2006). La hipótesis nula en este caso es que las frecuencias marginales son iguales. Ambos estadísticos presentan problemas asociados a la correspondencia de sus resultados con lo efectivamente observado. De esta manera, se podría observar una concordancia alta en el registro de superficies óseas asociada a un índice Kappa bajo o bien, resultados similares para proporciones de discordancia análogas, independientemente del total de las observaciones en la prueba McNemar (Feinstein y Cichetti, 1990; Lantz y Nebenzahl, 1996; Azzimonti Renzo, 2005; Benavente et al., 2006). Como solución a ambos problemas, para el índice Kappa se calcularon los resultados junto con los valores mínimos $\left(k_{\min }\right)$ y máximos $\left(k_{\max }\right)$ asociados; mientras que para la prueba McNemar se consideró la corrección de continuidad de -1 para su cálculo, utilizada para los casos en que la suma de los valores marginales es menor a 10 (Lantz y Nebenzahl, 1996; Benavente et al., 2006).

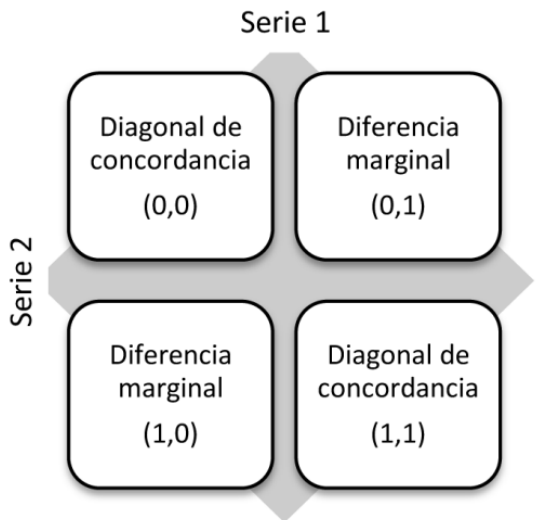

Fig. 5.7. Esquema representativo de la tabla de dimensión $2 \times 2$ para comparar las series

Los resultados del error de observación en la identificación del tipo de superficie se presentan en la Tabla 5.1. Los valores para el índice Kappa fueron significativos en todos los casos, principalmente para la actividad de formación ósea. Esto indica que la concordancia entre pares de observaciones fue mayor a la esperada por azar. Se registró un incremento en la concordancia a lo largo de las series. Con respecto a las regiones óseas analizadas, los valores más bajos de concordancia fueron registrados para la superficie de reabsorción en el maxilar.

En relación con la prueba McNemar (Tabla 5.1), se observaron diferencias según el tipo de superficie. Para la formación ósea las diferencias marginales fueron menores en el primer par de series, mientras que para la reabsorción las menores diferencias se hallaron entre el segundo par de observaciones. Considerando todos los valores por región ósea, las diferencias marginales fueron consistentemente menores entre las series 2 y 3 . Un detalle que cabe 
destacar respecto es que para ninguna región se encontraron valores significativos a excepción de la superficie de reabsorción en el maxilar entre las series 1 y 2 , indicando que en este caso las frecuencias marginales fueron heterogéneas.

Tabla 5.1. Resultados del análisis de Topografía de superficies óseas

\begin{tabular}{|c|c|c|c|c|c|}
\hline \multirow{2}{*}{\multicolumn{2}{|c|}{ Observaciones }} & \multicolumn{2}{|c|}{ Serie 1 - Serie 2} & \multicolumn{2}{|l|}{ Serie 2 - Serie 3} \\
\hline & & $k\left(k_{\min }-k_{\max }\right)$ & McNemar & $k\left(k_{\min }-k_{\max }\right)$ & McNemar \\
\hline \multirow{4}{*}{ Formación } & Glabela & $0,88 * * *(-0,027-0,895)$ & 0,5 & $0,94 * * *(-0,013-0,947)$ & 0 \\
\hline & Malar & $0,59 * * *(-0,118-0,597)$ & 3,12 & $0,83 * * *(-0,041-0,843)$ & 0 \\
\hline & Maxilar & $0,75 * * *(-0,065-0,758)$ & 0 & $0,89 * * *(-0,027-0,895)$ & 0 \\
\hline & Total & $0,74 * * *(-0,068-0,748)$ & 0,24 & $0,89 * * *(-0,027-0,895)$ & 0,57 \\
\hline \multirow{4}{*}{ Reabsorción } & Glabela & $0,54 * * *(-0,055-0,792)$ & 0 & $0,77^{* * *}(-0,027-0,895)$ & 0 \\
\hline & Malar & $0,73 * * *(-0,055-0,792)$ & 2,25 & $0,77 * * *(-0,041-0,843)$ & 0 \\
\hline & Maxilar & $0,23 * * *(-0,187-0,426)$ & $6,72 * * *$ & $0,39 * *(-0,151-0,508)$ & 2,4 \\
\hline & Total & $0,44 * * *(-0,108-0,623)$ & 1,88 & $0,58 * * *(-0,081-0,706)$ & 1,25 \\
\hline
\end{tabular}

${ }^{*} \alpha<0,05 ;{ }^{* *} \alpha<0,01 ;{ }^{* * *} \alpha<0,001$

\section{Fracción de área}

Para este análisis las variables fueron consideradas como continuas a partir del cálculo del área que ocupaba cada tipo de superficie por celda. Este cálculo se realizó por serie para cada región ósea y para las tres en conjunto. La extensión de las áreas en $\mathrm{mm}^{2}$ se estimó mediante el programa ImageJ 1.47v (Abràmoff et al., 2004).

Se calculó el error intra-observador a través del análisis del Coeficiente de Correlación Intraclase (CCI) y del ANOVA de medidas repetidas (Zar, 1999) utilizando los paquetes estadísticos psy y base del programa R 3.1.1 (R Core Team, 2014). El CCl permite evaluar la concordancia entre dos o más observaciones, estimando la proporción de la variación total que se debe a la variación existente entre los componentes de la muestra (siendo en este caso, las diferencias en el tipo de superficie ósea registrada por celda) (Fig. 5.8). El grado de concordancia varía entre 0 (sin acuerdo) a 1 (acuerdo total), considerándose los valores mayores a 0,74 como excelente acuerdo (Fleiss, 1981; Müller y Büttner, 1994). Por otro lado, el ANOVA de medidas repetidas estima cuánto de la variación total se debe a la variación entre grupos (en este caso, entre series) y a la variación residual (introducida, por ejemplo, por errores de medición; Fig. 5.8); mientras que la variación entre objetos queda eliminada al ser una constante en el mismo conjunto de datos (Norman y Streiner, 1998). Dado que la varianza 
entre las series se calcula como la diferencia entre los valores medios de cada serie, es posible evaluar la existencia de sesgos (i.e. valores que se apartan sistemáticamente) que afectarían la precisión de las identificaciones (Muñoz-Muñoz y Perpiñán, 2010). La hipótesis nula a evaluar es que no existen diferencias entre las observaciones repetidas de una variable.

Fig. 5.8. Componentes asociados a la variación total en el registro de superficies óseas

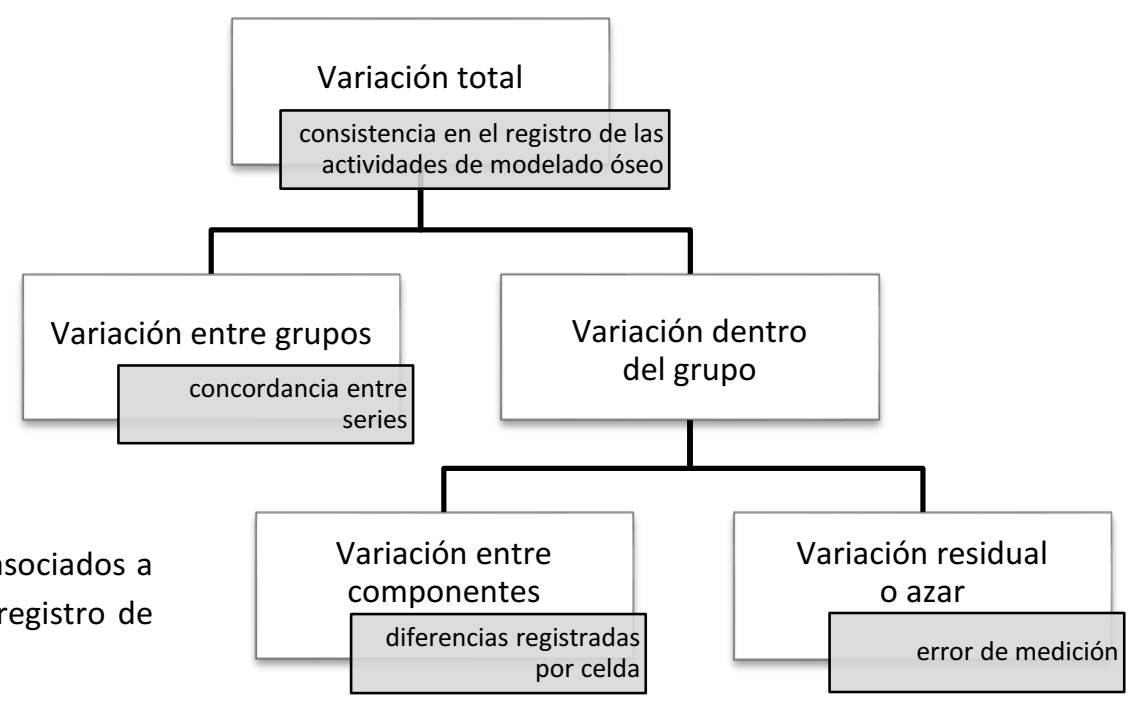

En la Tabla 5.2 se presentan los resultados del análisis de Fracción de área. El CCI mostró altos niveles de acuerdo en la identificación del área de cada tipo superficie, siendo en su mayoría excelentes (Fleiss, 1981). Se obtuvo una mayor concordancia en el registro con las sucesivas repeticiones, observándose los mayores incrementos en el registro de la superficie de formación en la glabela y en la superficie de reabsorción en el malar y el maxilar. Cabe destacar que el mayor incremento en el acuerdo entre observaciones se obtuvo para la reabsorción en el maxilar, el acuerdo fue moderado entre las series 1 y 2 y excelente entre las series 2 y 3 . Por otra parte, los resultados obtenidos para el análisis de ANOVA de medidas repetidas (Tabla 5.2) mostraron resultados diferentes para cada tipo de superficie. Respecto a la identificación de superficies de formación, si bien los valores totales no fueron significativos, al considerar cada una de las regiones se obtuvieron valores significativos para el malar y el maxilar entre el primer par de series. Por el contrario, en la identificación de la superficie de reabsorción, los valores obtenidos para la comparación entre las series 2 y 3 fueron significativos para un nivel de $p<0,05$. Al realizar el análisis para cada región ósea, sólo el maxilar presentó valores significativos para la superficie de reabsorción, con un nivel de $p<0,01$ entre las series 1 y 2 , y de $p<0,05$ entre las series 2 y 3 . A pesar de la disparidad de los resultados, los valores obtenidos para cada región ósea mostraron un aumento de la precisión con las repeticiones. 
Tabla 5.2. Resultados del análisis de Fracción de área

\begin{tabular}{|c|c|c|c|c|c|c|c|}
\hline \multirow{2}{*}{\multicolumn{2}{|c|}{ Observaciones }} & \multicolumn{3}{|c|}{ Serie 1 - Serie 2} & \multicolumn{3}{|c|}{ Serie 2 - Serie 3} \\
\hline & & $\mathrm{CCl}$ & $F$ & $p$ & $\mathrm{CCl}$ & $F$ & $p$ \\
\hline \multirow{4}{*}{ Formación } & Glabela & 0,84 & 1,57 & 0,218 & 0,91 & 3,88 & 0,056 \\
\hline & Malar & 0,88 & 12,54 & 0,0011 & 0,91 & 0,1 & 0,756 \\
\hline & Maxilar & 0,84 & 5,05 & 0,029 & 0,9 & 0 & 0,998 \\
\hline & Total & 0,84 & 0,92 & 0,34 & 0,91 & 0,38 & 0,537 \\
\hline \multirow{4}{*}{ Reabsorción } & Glabela & 0,7 & 0,49 & 0,489 & 0,69 & 0,45 & 0,505 \\
\hline & Malar & 0,8 & 0,93 & 0,34 & 0,91 & 0,15 & 0,704 \\
\hline & Maxilar & 0,58 & 12,9 & 0,0007 & 0,76 & 9,08 & 0,004 \\
\hline & Total & 0,73 & 2,76 & 0,099 & 0,85 & 4,61 & 0,034 \\
\hline
\end{tabular}

\subsection{Análisis cuantitativo del modelado óseo}

Tradicionalmente, los estudios sobre patrones de modelado óseo han adoptado aproximaciones cualitativas, tanto para estimar la información perdida en mapas individuales como para integrar los datos de formación y reabsorción ósea registrados en varios individuos (Bromage, 1982, 1989; Martinez-Maza et al., 2006, 2013, 2016; Kranioti et al., 2009; Lacruz et al., 2013, 2015b). En el marco de esta aproximación, las áreas de las superficies óseas que presentan datos perdidos son reemplazadas simplemente por la extensión de la información de formación y reabsorción registrada en áreas adyacentes dado que se considera que el proceso de modelado óseo ocurre en grandes áreas (Bromage, 1982, 1989). Para la integración de los datos de formación y reabsorción ósea registrados en varios individuos (i.e. la construcción de mapas de modelado óseo común) se determina la representatividad de los tipos de superficie considerando la predominancia o extensión de las mismas en cada individuo (C Martinez-Maza com. pers.). En ambos procedimientos, el criterio bajo el cual se realiza la expansión e integración no siempre resulta explícito y reproducible incrementando el sesgo en la determinación de los patrones de modelado óseo (e.g. tipo de actividad, extensión y localización).

Los análisis cualitativos presentan diversas desventajas. Por un lado, es difícil establecer comparaciones entre varios individuos y muestras a partir de la observación directa de descripciones y mapas de modelado óseo. Por otro lado, no permiten tener en cuenta e incorporar en los análisis la variación interna del grupo (McCollum, 2008). En consecuencia, existe una subestimación de la variación en cuanto a la distribución de las áreas de formación y reabsorción ósea, disminuyendo la exactitud de las inferencias.

Con el objetivo de superar los problemas mencionados se desarrolló un procedimiento cuantitativo orientado a proporcionar estimaciones objetivas y replicables para la 
reconstrucción de las superficies óseas (Brachetta-Aporta et al., 2018). El procedimiento consiste de una serie de pasos que permiten: 1) estimar las áreas con datos perdidos a partir de la información propia del individuo, así como de la proveniente del grupo (e.g. especie, edad, sexo); y 2) estimar la distribución de las áreas de modelado óseo para las muestras estudiadas considerando la variación intra-muestral. Para ello se emplearon técnicas de estadística espacial y univariada, ofreciendo criterios explícitos en cada uno de los supuestos en los que se basa la construcción de los mapas. Asimismo, se elaboró un protocolo semiautomático que facilita el registro y procesamiento de la información de modelado óseo mediante el empleo de programas de computación. La utilidad del empleo de programas de sistema de información geográfica ha sido demostrada previamente para la identificación sistemática de microestructuras en análisis histológicos de corte en huesos humanos (CambraMoo et al., 2012, 2014; Rose et al, 2012). En la presente tesis, se empleó el programa ArcGIS 10 (con licencia de FCNyM) a fin de identificar y procesar la información relevada en los mapas de modelado óseo.

El procedimiento fue desarrollado y validado en una muestra de maxilares de individuos subadultos y adultos de Pampa Grande y fue luego aplicado a todos los casos incluidos en este trabajo. En la Tabla 5.3 se detalla la sub-muestra utilizada.

Tabla 5.3. Resumen de las muestras de maxilar utilizadas. Las cruces indican qué individuos se emplearon para cada análisis

\begin{tabular}{|c|c|c|c|c|}
\hline \multirow[t]{2}{*}{ Individuos } & \multirow{2}{*}{$\begin{array}{l}\text { Superficie con datos } \\
\text { registrados }(\%)\end{array}$} & \multicolumn{2}{|c|}{$\begin{array}{c}\text { Estimación de datos perdidos. } \\
\text { Datos procedentes del }\end{array}$} & \multirow{2}{*}{$\begin{array}{c}\text { Construcción del } \\
\text { mapa general }\end{array}$} \\
\hline & & Individuo & Grupo & \\
\hline \multicolumn{5}{|l|}{ Subadultos } \\
\hline 17769 & 92,98 & & & $x$ \\
\hline 17774 & 93,33 & & & $x$ \\
\hline 17780 & 98,43 & & & $x$ \\
\hline 17783 & 96,67 & $x$ & & $x$ \\
\hline 17787 & 97,33 & $x$ & & $x$ \\
\hline \multicolumn{5}{|l|}{ Adultos } \\
\hline 17688 & 41,07 & & & $x$ \\
\hline 17690 & 59,43 & & $x$ & $x$ \\
\hline 17724 & 88,89 & & & $x$ \\
\hline 17726 & 33,19 & & & $x$ \\
\hline 17744 & 86,93 & $x$ & & $x$ \\
\hline
\end{tabular}

La superficie se calculó de acuerdo al tamaño original de las réplicas 


\subsubsection{Estimación de los datos perdidos en mapas de modelado óseo}

La estimación de datos perdidos implica una serie de pasos secuenciales que incluyen: la construcción de una forma base o general para el relevamiento común de toda la muestra, sobre la cual registrar los datos de modelado óseo y que permita conservar la ubicación espacial de la información de cada individuo; la evaluación de la estructuración espacial de los datos para obtener información acerca de la proporción de cada tipo de superficie y su distribución; y la implementación de procedimientos para estimar los datos perdidos, ya sea con datos procedentes del mismo individuo mediante interpolación espacial o con datos procedentes de otros individuos mediante algoritmos de imputación.

\section{Estimación de la forma general a partir de mapas de modelado óseo individuales}

Los mapas de modelado óseo generados para cada individuo y sobre los cuales se registra la información observada al microscopio, representan la forma original copiada a través de la réplica de alta resolución. En este sentido, los mapas de modelado óseo presentan diferencias de forma y tamaño asociadas a las características de las regiones replicadas de cada individuo. A fin de generar una forma consenso común para cada grupo de edad (i.e. subadultos y adultos, Tabla 5.3) de la muestra, se aplicó el método de Superposición Procrustes Generalizado por mínimos cuadrado y el de deformación thin plate spline (deformación de placa delgada; Bookstein, 1989). Mediante la superposición Procrustes se eliminó toda información de tamaño, posición y orientación de los mapas digitalizados, pero manteniendo la información de forma (i.e. shape, en inglés) (Bookstein, 1991). El procedimiento permitió centrar, escalar y rotar las imágenes a partir de un conjunto de puntos de referencia (i.e. landmarks) minimizando la suma de las diferencias cuadradas entre los puntos de las configuraciones originales y el consenso de la muestra (Rohlf y Slice, 1990). Luego, para ajustar los mapas individuales al consenso, se empleó el método de deformación thin plate spline para transformar cada una de las imágenes rotadas a la forma media -resultante de la superposición- que es utilizada para representar las estructuras faciales de los individuos analizados dentro de cada muestra (Bookstein, 1991).

Los pasos seguidos para la generación de los mapas de modelado óseo homologados y el relevamiento del tipo de actividad ósea fueron:

1. Generación de un archivo de tipo .tps que contiene las imágenes digitalizadas de las réplicas del maxilar del grupo a analizar (Fig. 5.9a)

2. Digitalización de 8 puntos de referencia a lo largo del contorno de cada imagen (Fig. 5.9b) 
3. Realización de la Superposición Procrustes Generalizada, para centrar, escalar y rotar las imágenes de acuerdo a la configuración de puntos de referencia (Fig. 5.9b)

4. Obtención de una forma consenso para el maxilar, estimada en función del contorno máximo sobre el cual se integran todas las formas rotadas (Fig. 5.9c)

5. Generación de una grilla digital que abarque la forma consenso (Fig. 5.9d). El tamaño de las celdas se estableció en función de la posibilidad de contener información de un solo tipo de dato (i.e. formación, reabsorción o datos perdidos; Anexo 4)

6. Cuantificación automática de la información contenida en cada celda del mapa rotado asignando los siguientes valores: -1, para superficies de reabsorción ósea; 1 , para superficies de formación ósea; 0, para superficies con datos perdidos. En caso de que una celda contuviera más de un tipo de información, se seleccionó aquel que ocupara la mayor superficie dentro de la celda.

a)

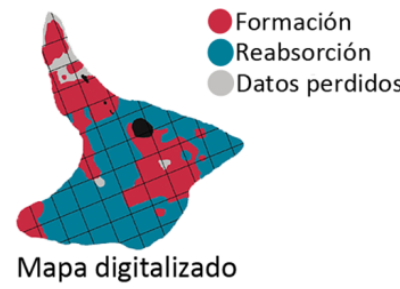

b)

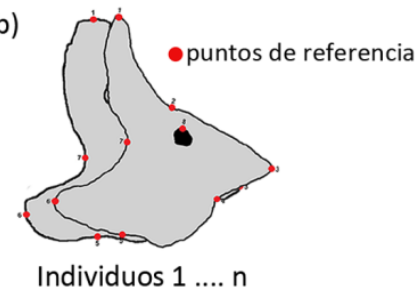

c)

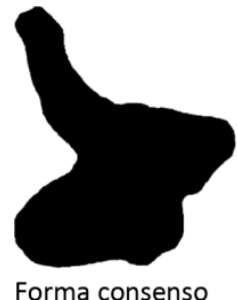

d)

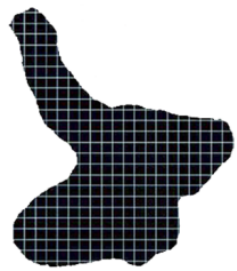

Grilla digital

Fig. 5.9. Superposición de mapas digitalizados y grilla. Referencias en el texto

El procedimiento se realizó empleando los programas tpsUtil v1.46, tpsDig2 v2.17 y tpsSuper v2.03 (Rohlf, 2015) para la generación del archivo .tps, la digitalización de los puntos de referencia y la superposición de los mapas. La generación de la grilla y el relevamiento de la información contenida en cada celda se realizaron empleando el programa ArcGIS 10 (con licencia de FCNyM).

\section{Exploración de la estructura espacial}

Con el objetivo de determinar el método de estimación de datos perdidos más adecuado, se exploró la estructura espacial de los datos en los mapas de modelado óseo de 3 individuos $(17774,17787,17783)$ que presentaban más del 93\% de las celdas con información histológica (Tabla 5.3). Este análisis permite establecer si la distribución de los mismos responde a procesos aleatorios o si, por el contrario, hay un patrón en la distribución de los tipos de superficie. Sólo en el segundo caso sería posible estimar los datos perdidos con la información presente en los mapas. 
La estructura espacial del tipo de actividad ósea registrada en las celdas se evaluó mediante el coeficiente de correlación espacial I de Moran (Fortin y Dale, 2005). El coeficiente I de Moran refleja la asociación entre las unidades relevadas en un intervalo de distancia dado, y generalmente toma valores entre $-1 \mathrm{y}+1$. Los valores positivos indican similitud entre las celdas para una clase de distancia mientras que los valores negativos indican que la información entre celdas difiere. El número de clases de distancia empleado para el cálculo del coeficiente I de Moran se basó en la fórmula:

$$
D=1+3.3 \times \log 10(n)
$$

Donde $n$, es el tamaño de la muestra dado por el número de las celdas de la grilla (Legendre y Legendre, 1998). Las unidades de distancia fueron estimadas en celdas.

En la Figura 5.10, se muestran los correlogramas espaciales generados a partir de contrastar los resultados del coeficiente I de Moran sobre las clases de distancia. Existe una autocorrelación espacial positiva para distancias cercanas, lo que indica que celdas vecinas tienden a mostrar el mismo tipo de dato (i.e. tipo de superficie). A medida que se incrementa la distancia, la información entre las celdas tiende a diferir.
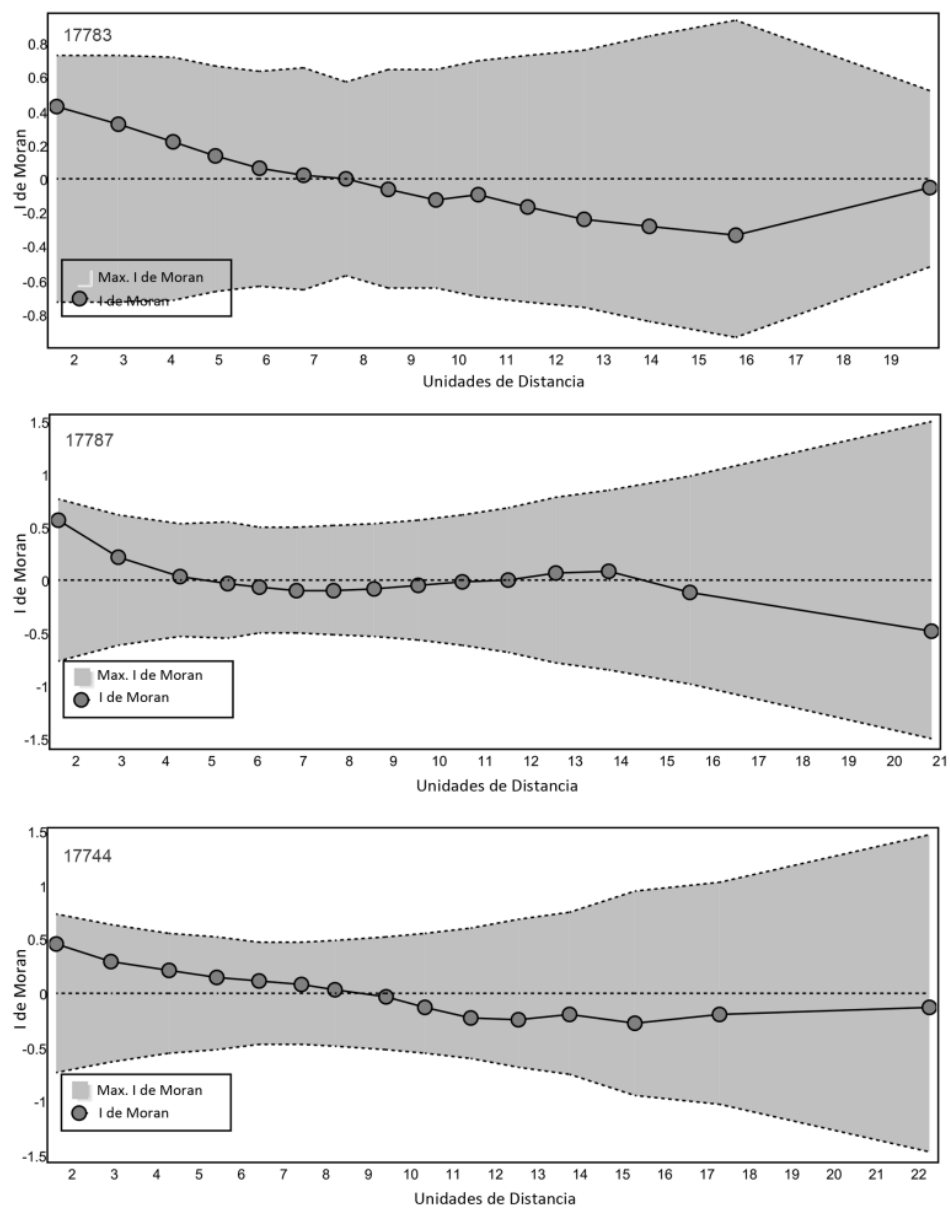

Fig. 5.10. Correlaciones espaciales. El eje horizontal representa las clases de distancia, el eje vertical muestra los coeficientes de Moran estimados para cada clase de distancia 
Dado que las celdas cercanas mostraron una tendencia a presentar el mismo tipo de superficie ósea se consideró que el patrón espacial del modelado óseo se puede describir a partir del método de interpolación basado en el criterio de Inverse Distance Weighting (Distancia Inversa Ponderada, IDW por sus siglas en inglés). A partir de la interpolación IDW se obtuvieron valores para las celdas sin datos utilizando el promedio ponderado de los valores cercanos conocidos. Estos valores se ponderan en proporción inversa a la distancia, es decir, como la raíz cuadrada de la distancia entre celdas. En este sentido, la fórmula de la interpolación IDW puede expresarse como:

$$
z\left(x_{0}\right)=\frac{\sum_{j=1}^{m} z\left(x_{j}\right) d_{i j}^{-k}}{\sum_{j=1}^{m} d_{i j}^{-k}}
$$

Donde $\hat{z}\left(x_{0}\right)$ es el valor de la variable $z$ en las ubicaciones perdidas, $z\left(x_{j}\right)$ es el valor de la variable en $j$ ubicaciones relevadas, $m$ es el número de vecinos, $d_{i j}$ es la distancia entre la ubicación sin datos $i$ y la ubicación con datos $j$, el exponente $k$ es un valor real entre 0 y 1 (Fortin y Dale, 2005). Los valores de interpolación se obtuvieron empleando el programa Past 3.02a (Hammer et al., 2001; Brachetta-Aporta et al., 2018). Posteriormente, el procedimiento se sistematizó en ArcGIS 10 (Brachetta-Aporta y Gobbo, 2017).

\section{Evaluación de las estimaciones obtenidas por interpolación espacial}

Se procedió a evaluar la fiabilidad de las estimaciones de los datos perdidos obtenidas por IDW mediante la eliminación aleatoria de la información en un número progresivo de celdas en los mismos individuos utilizados para el análisis de la estructuración espacial (17774, 17787, 17783). La evaluación se realizó a partir de la eliminación del 25, 50, 75 y $90 \%$ de las celdas (Fig. 5.11). A continuación, se calculó la concordancia entre los valores obtenidos por IDW para cada simulación y las estimaciones obtenidas con toda la información originalmente disponible mediante un análisis de CCI (Coeficiente de Correlación de Intraclase; Müller y Büttner, 1994). Se emplearon los programas Past 3.02a (Hammer et al., 2001) y el paquete psy en R 3.1.1 ( $R$ Core Team, 2014) para los cálculos de IDW y CCI, respectivamente.

Los resultados del $\mathrm{CCl}$ (Tabla 5.4) mostraron una concordancia excelente cuando se compararon los valores obtenidos por IDW con los datos originales para las pruebas en que se había eliminado aleatoriamente un 25,50 y $75 \%$ de la información original, y buena para el 90\% (Fleiss, 1981). La información gráfica presentada en la Fig. 5.11 muestra correspondencia con estos resultados. Se observa que a medida que se elimina un mayor porcentaje de celdas 
con información presente, la configuración de los mapas de modelado óseo obtenida por interpolación difiere de la distribución de las áreas de formación y reabsorción ósea presentes en el mapa original. Incluso se registraron parches de actividad que se pierden en las sucesivas interpolaciones (para una descripción detallada de los cambios, ver Brachetta-Aporta et al., 2018). En efecto, la estructuración espacial que originalmente exhibe un patrón agregado e irregular se transforma en gradiente (Fortin y Dale, 2005). Es decir, las interpolaciones realizadas con el total de la información disponible dieron como resultado una distribución espacial en mosaico (i.e. heterogénea), dada la presencia de parches de formación o reabsorción ósea en algunas regiones del maxilar. Con la eliminación del 90\% de las celdas con datos presentes, el mapa de modelado óseo mostró áreas continuas y uniformes (i.e. homogéneas). A su vez, superficies que presentaban originalmente sólo formación o reabsorción, tendieron a mostrar valores intermedios al eliminar por lo menos el $75 \%$ de las celdas con datos.
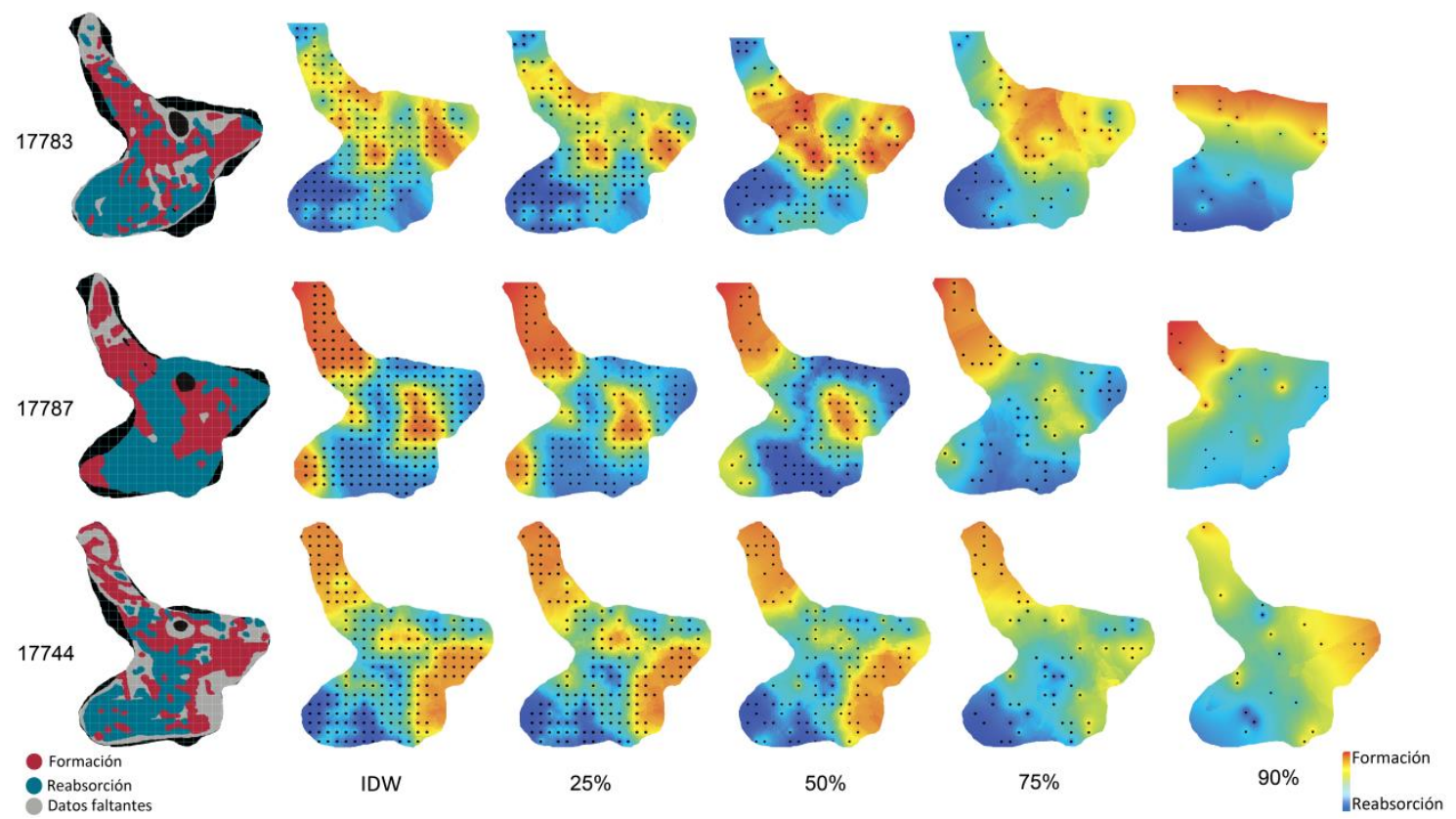

Fig. 5.11. Evaluación de la interpolación de los mapas de modelado óseo. La primera columna representa cada mapa individual deformado a la forma consenso. La segunda columna representa los mapas de color obtenidos a partir de la interpolación con el total de datos presentes. El resto de las columnas muestran los mapas de color obtenidos a partir de las interpolaciones realizadas sobre un porcentaje aleatorio de celdas faltantes. Los puntos en los mapas representan el centro de cada celda (total de celdas: 273 ) 
Tabla 5.4. Concordancia de los valores interpolados y originales. Los valores representan el $\mathrm{CCl}$ obtenido para cada comparación

\begin{tabular}{ccccc}
\hline \multirow{2}{*}{ Individuos } & \multicolumn{4}{c}{ Porcentaje de celdas con información eliminadas } \\
\cline { 2 - 5 } & 25 & 50 & 75 & 90 \\
\hline 17783 & 0,94 & 0,87 & 0,79 & 0,73 \\
17787 & 0,99 & 0,96 & 0,85 & 0,64 \\
17774 & 0,97 & 0,94 & 0,83 & 0,64 \\
\hline
\end{tabular}

\section{Evaluación de las estimaciones obtenidas por imputación de datos perdidos}

El método de interpolación es adecuado para estimar los datos perdidos a partir de información presente en áreas vecinas. Sin embargo, la estimación de datos perdidos empleando información de áreas que no se encuentran próximas puede conducir a errores por introducción de información procedente de áreas anatómicamente diferentes sujetas a demandas biomecánicas y procesos de desarrollos disímiles (e.g. proceso frontal y alveolar del maxilar). Una alternativa, es la imputación de los datos perdidos a partir de la información procedente de otros individuos pertenecientes a la muestra en estudio. En este caso, es importante considerar la similitud de los individuos a emplear (e.g. mismo grupo etario).

Se evaluó la performance de este procedimiento de imputación de datos perdidos a partir de una muestra de 5 individuos adultos (Tabla 5.3; 17690, 17688, 17724, 17726 y 17744). Del total de información relevada para uno de los individuos (17690), se eliminó la información correspondiente a la fosa canina y el proceso alveolar, dos áreas adyacentes en el cuerpo del maxilar. Los datos perdidos fueron estimados a partir de un algoritmo de imputación múltiple para datos sin distribución normal, el Predictive Mean Matching (PMM; van Buuren y Groothuis-Oudshoorn, 2011). El PMM funciona a partir de la estimación de una regresión lineal con los datos presentes, con los que establece posteriormente una distribución predictiva, generando de manera iterativa valores para todos los casos (faltantes y presentes), sobre los cuales se determina una relación entre valores presentes y predichos. El análisis se efectuó empleando el paquete mice en el programa R 3.1.1 (R Core Team, 2014).

La Figura 5.12 presenta la estimación de los datos perdidos para el individuo 17690, tras la eliminación de la información registrada alrededor de la fosa canina y el proceso alveolar del maxilar. La reconstrucción del área perdida por interpolación (5.12a) difiere de la obtenida por imputación (5.12b). En la primera se observan áreas con reabsorción ósea en la región posterior del proceso alveolar que no están presentas en la estimación obtenida por imputación. Estos resultados remarcan la importancia de reconocer la existencia de regiones 
anatómicas que presentan patrones de actividad característicos para la selección del método a implementar en la estimación de datos perdidos.
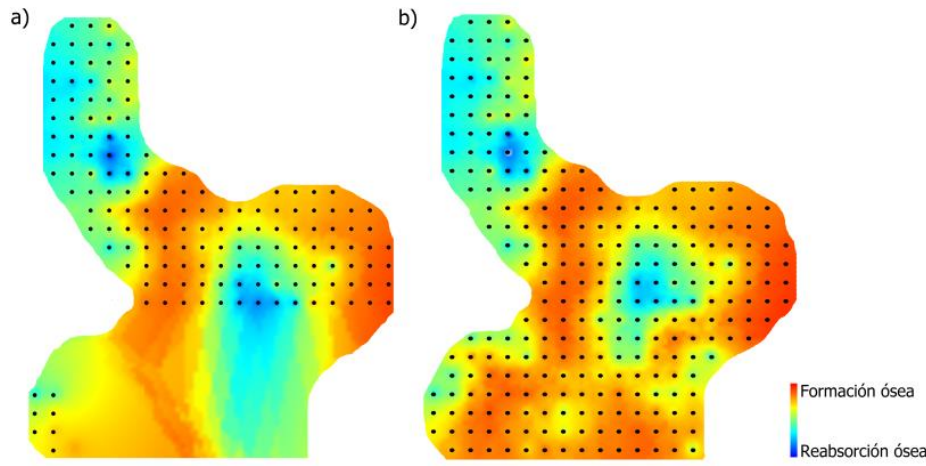

Fig. 5.12. Estimación de datos perdidos para fosa canina y proceso alveolar: a) interpolación del área a partir de datos adyacentes; b) imputación del área a partir de los datos presentes para la misma región en la muestra de referencia

\subsubsection{Construcción de mapas generales y análisis estadísticos}

La construcción de mapas de modelado óseo homologados posibilitó integrar posteriormente la información obtenida para cada mapa de modelado óseo individual en uno común. Se denominó a este tipo de mapa como "mapa general", para diferenciarlo de los mapas de modelado óseo comunes obtenidos por procedimientos cualitativos.

Para la integración de la información en mapas generales, se obtuvieron medidas de tendencia central y dispersión para cada celda utilizando los valores de tipo de superficie obtenidos mediante interpolación espacial e imputación. Dado el número reducido de individuos que caracterizan los estudios paleohistológicos, se utilizó la mediana como medida de tendencia central y el rango intercuartil, como medida de dispersión. Ambas medidas tienen la ventaja de ser más robustas frente a valores atípicos, los cuales tienen un mayor impacto en muestras reducidas. Los resultados fueron representados en mapas de colores para la mediana y en escala de grises para el rango. Se emplearon paquetes maptools, RColorBrewer y classInt del programa R 3.1.1 (R Core Team, 2014; Brachetta-Aporta et al., 2018). Este procedimiento fue posteriormente sistematizado en ArcGIS 10.

La Figura 5.13 presenta el mapa general correspondiente a la región maxilar para subadultos (a) y adultos (b) de PG. El mapa de color representa el patrón de modelado óseo resultante a partir de la integración de los datos registrados por individuo. El mapa en escala de grises representa las regiones de mayor variación (oscuros) y de menor variación (claros) 
entre los maxilares. La interpretación en conjunto permite describir no sólo el tipo de actividad de modelado óseo que predomina, sino también la variación intra-grupal.
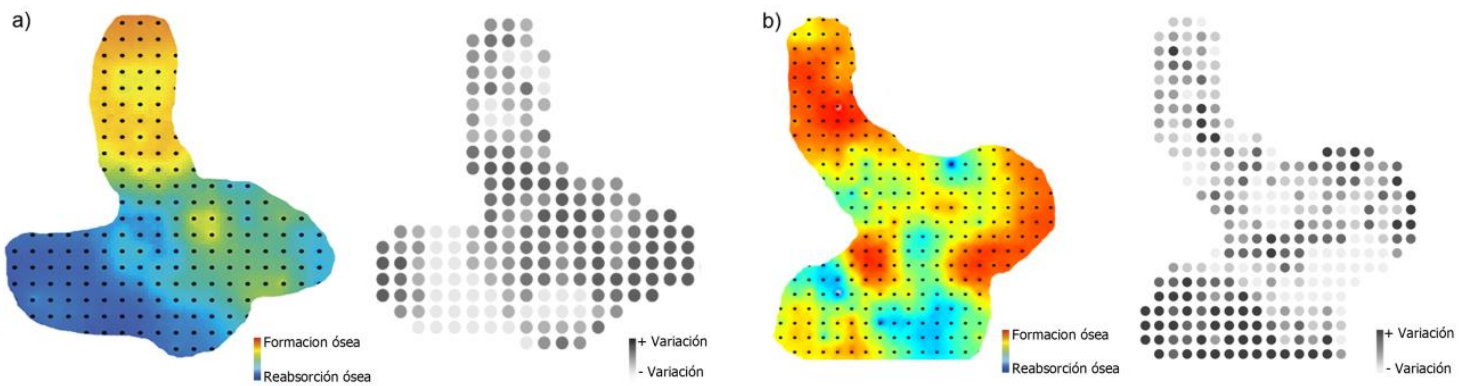

Fig. 5.13. Mapa general del patrón de modelado óseo de subadultos (a) y adultos (b). El mapa de color muestra el consenso obtenido para todos los individuos de la muestra en función del cálculo de la mediana, mientras que el mapa en escala de grises representa el rango de variación registrado.

La obtención de valores para cada celda posibilitó a su vez, la aplicación de análisis multivariados para analizar los cambios en los patrones de modelado con la edad y evaluar su relación con la variación en la morfología craneofacial -tamaño y forma facial, y tamaño de los espacios funcionales- entre los individuos de cada muestra. A partir de la información de los mapas de modelado óseo individuales completos, se efectuó un Análisis de Componentes Principales a fin de resumir la información de modelado óseo por hueso. Los score de los componentes principales que resumieron el $80 \%$ de la variación registrada fueron posteriormente empleados como variables dependientes en análisis de regresión con el desarrollo dental (score dental) y el tamaño (tamaño centroide y volúmenes) como variables independientes. La covariación entre la forma (i.e. shape) de las regiones óseas y los patrones de modelado fue evaluada mediante análisis de Partial Least Squares (PLS). Se emplearon los programas Past (Hammer et al., 2001), MorphoJ (Klingenberg, 2011) y R (paquete geomorph; R Core Team, 2014). 


\section{Métodos para el análisis de la morfología craneofacial}

Descripción del procedimiento empleado para el análisis morfométrico

\section{Contenido}

6.1. Obtención de variables morfométricas

\subsubsection{Registro de landmarks y semilandmarks}

\subsubsection{Obtención de volúmenes}

\subsection{Análisis preliminares}

\subsubsection{Estimación de datos perdidos}

\subsubsection{Análisis del error de observación en la digitalización de landmarks y} semilandmarks

\subsubsection{Modificaciones culturales del cráneo}

6.3. Métodos multivariados para el análisis de la morfología craneofacial

La descripción y análisis de la morfología craneofacial requiere de técnicas cuantitativas que permitan caracterizar los patrones de variación en tamaño (i.e. size) y forma (i.e. shape), y su covariación (i.e. cambios alométricos), a lo largo de las trayectorias ontogenéticas de los individuos (Mosimann, 1970; Klingenberg, 2009, 2016). Las técnicas empleadas tradicionalmente se han basado en medidas lineales, ángulos y volúmenes que permiten registrar la variación de los rasgos de interés (Monteiro y dos Reis, 1999; Adams et al., 2013). Las medidas lineales y los volúmenes resultan adecuados para describir el tamaño de las estructuras craneofaciales. En particular, los volúmenes representan una medida escalar de tres dimensiones, en la que la noción de distancia física se encuentra implícita como una integral de área de varias secciones transversales de un espacio u órgano (Monteiro y dos Reis, 1999). Los volúmenes resultan útiles para demarcar espacios integrados en la morfología craneofacial, como los espacios funcionales, cuyas morfologías pueden presentar niveles altos de variación, dificultando la definición de variables adecuadas para describir su forma (Zelditch et al., 2004; O'Higgins et al., 2006). Sin embargo, dadas las limitaciones de las medidas tradicionales para capturar la forma y preservar las relaciones espaciales entre rasgos, se ha propuesto el empleo de coordenadas cartesianas para describir las estructuras anatómicas de interés en el marco de la denominada morfometría geométrica (Adams et al., 2013). 
La morfometría geométrica es una herramienta adecuada para analizar la morfología craneofacial ya que posibilita la integración de numerosos rasgos anatómicos de manera simultánea en el análisis, evitando la redundancia de información, y la visualización de la variación en forma preservando las relaciones espaciales entre variables (Klingenberg, 2013). A diferencia de las medidas lineales que contienen información tanto de forma como de tamaño, las técnicas de morfometría geométrica permiten diferenciar las características geométricas del objeto de las de tamaño. En este contexto, forma refiere a shape cuando sólo incluye a las propiedades geométricas o a form, si se incluyen además las propiedades de tamaño en la descripción del objeto (i.e. form es el producto de shape y tamaño; Monteiro y dos Reis, 1999; Mitteroecker et al., 2013). A su vez, la referencia de tamaño también presenta diferencias entre la morfometría tradicional y geométrica. Si bien en ambos casos se refiere a las dimensiones de un objeto, en morfometría geométrica se emplea el tamaño centroide (CSz por su denominación en inglés, Centroid Size), que no está afectado por los cambios en forma, como variable de tamaño (Bookstein, 1989, 1991; Mitteroecker et al., 2013).

En este trabajo las estructuras anatómicas craneofaciales fueron descriptas y analizadas mediante la combinación de técnicas de la morfometría geométrica y el empleo de volúmenes. A partir de imágenes de tomografía computada de los cráneos, se obtuvieron datos correspondientes a puntos anatómicos homólogos -i.e. landmarks-, así como de curvas y superficies -i.e. semilandmarks-, y se obtuvieron los volúmenes de diferentes espacios funcionales, mediante la segmentación de las cavidades correspondientes (i.e. senos maxilar y frontal, cápsula orbital y endocráneo). En los siguientes apartados se describen los métodos empleados en el análisis de la morfología craneofacial.

\subsection{Obtención de variables morfométricas}

\subsubsection{Registro de landmarks y semilandmarks}

Para los análisis morfométricos se emplearon imágenes digitales reconstruidas a partir de tomografías computadas de los cráneos. Las TC consisten en una serie de cortes bidimensionales a partir de los cuales se puede generar una reconstrucción tridimensional de la estructura de interés (Fig. 6.1a). Se obtuvieron en tomógrafos multislice de centros de diagnóstico por imágenes de la ciudad de La Plata (CIMED y Mon), cuyas resoluciones y tamaños de voxels fueron de $1024 \times 1024$ y 0,165×0,165×0,33 mm para CIMED, y de $512 \times 512$ y 0,345 $\times 0,345 \times 0,33 \mathrm{~mm}$ para Mon. Mediante el empleo del programa Avizo 8.0, se obtuvieron las representaciones tridimensionales de las superficies craneofaciales, así como de los senos 
maxilar y frontal, la cápsula orbital y el endocráneo. Se digitalizaron 190 landmarks y 337 semilandmarks de contorno y superficie, y 9 coordenadas de puntos en estructuras internas del cráneo (Anexo 2, Fig. 6.1b). Respecto a los landmarks y los semilandmarks de contorno, la digitalización se realizó manualmente mediante el programa Avizo 8.0, a fin de garantizar su ubicación sobre las curvas de interés. Por el contrario, para la digitalización de semilandmarks de superficie se siguió un protocolo semiautomático que facilita el procedimiento (Gunz y Mitteroecker, 2013). Este protocolo consiste en la digitalización del total de coordenadas de puntos de superficie sobre un individuo de referencia (i.e. próximo a la forma media de la muestra) a fin de generar una malla de puntos (i.e. mesh) que posteriormente se proyecta sobre el resto de los individuos (i.e. blanco). La malla de puntos utiliza como referencia los landmarks y semilandmarks de contorno colocados en los individuos blanco y, mediante la función Thin Plate Spline (TPS) se proyectan los semilandmarks de superficie sobre estos individuos. La función TPS minimiza la bending energy, la cual representa la flexión necesaria para deformar una configuración particular en función de la referencia (Mitteroecker y Gunz, 2009). Este procedimiento se realizó con los paquetes geomorph y Morpho del programa $R$ ( $R$ Core Team, 2014).

Las configuraciones de landmarks y semilandmarks son posteriormente trasladadas al origen, escaladas a una dimensión igual a uno y rotadas para minimizar las distancias de las coordenadas de puntos entre configuraciones, eliminando así los parámetros de posición, tamaño y orientación (Monteiro y dos Reis, 1999; Zelditch et al., 2004). En este trabajo se empleó el Análisis Procrustes Generalizado por cuadrados mínimos (Rohlf y Slice, 1990). Asimismo, a fin de reducir los efectos de su localización arbitraria inicial, los semilandmarks fueron deslizados por el método de TPS, minimizando la bending energy entre la configuración objetivo y la de referencia (Mitteroecker y Gunz, 2009; Klingenberg, 2013). En particular, los semilandmarks digitalizados sobre curvas fueron deslizados a lo largo de la línea tangente a la curva, mientras que los semilandmarks de superficie se deslizaron en el plano tangencial (Gunz y Mitteroecker, 2013). Se optó por el método TPS en lugar de un ajuste por cuadrados mínimos para los semilandmarks ya que es considerado un criterio más conservador, dado que no se deslizan de manera independiente de los otros semilandmarks o de los landmarks (Gunz et al., 2005; Gunz y Mitteroecker, 2013). Las coordenadas de landmarks y semilandmarks superpuestas y deslizadas a través de estos procedimientos fueron utilizadas como variables de forma. 
El tamaño centroide, definido como la raíz cuadrada de la suma de las distancias cuadradas de todos los puntos respecto a su centro de gravedad, fue empleado como variable para describir el tamaño de las estructuras craneofaciales (Bookstein, 1989, 1991).
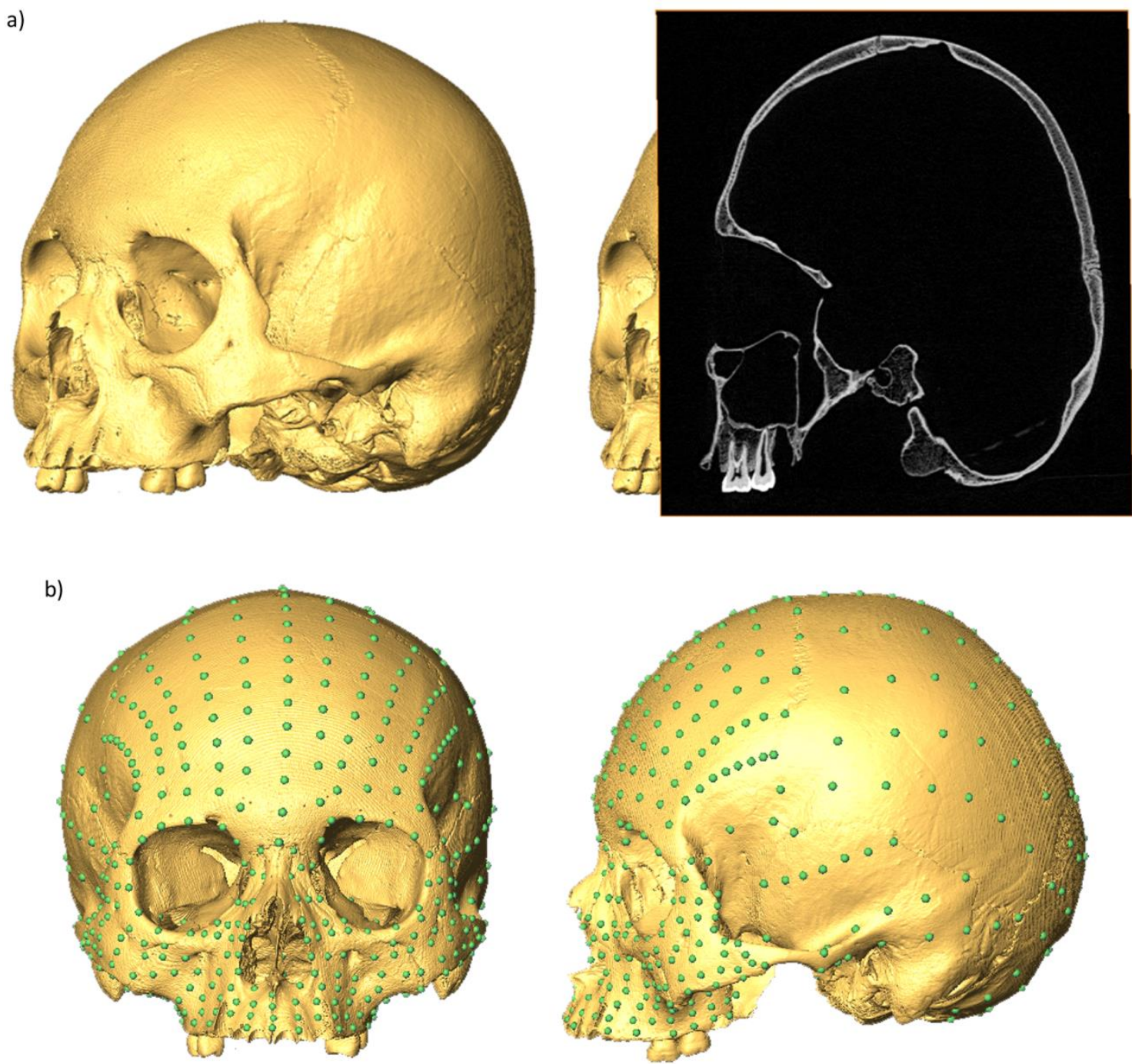

Fig. 6.1. Imagen tridimensional del cráneo a partir de tomografía computada: a) reconstrucción completa (izquierda) y visualización de un corte (derecha), b) landmarks y semilandmarks (verde) digitalizados en norma anterior (izquierda) y lateral (derecha)

\subsubsection{Obtención de volúmenes}

El segundo tipo de dato morfométrico que se obtuvo fueron los volúmenes de las distintas cavidades craneofaciales: seno maxilar izquierdo, seno frontal, cápsula orbital izquierda y endocráneo (Fig. 6.2). Para ello, se segmentaron cada una de las cavidades a partir de las imágenes de TC empleando la función multi-thresholding en el programa Avizo 8.0. Este procedimiento permite que los voxels (i.e. píxeles tridimensionales) de cada corte de una imagen de TC puedan ser asignados a la estructura de interés. Una vez segmentada cada 
cavidad, se calculó el volumen representado en la reconstrucción virtual tridimensional con la función surface area volume (Neubauer et al., 2009; Ito et al., 2015). Se evaluaron los cambios en tamaño de las cavidades en relación con la edad de los individuos, y al tamaño craneal total y facial.
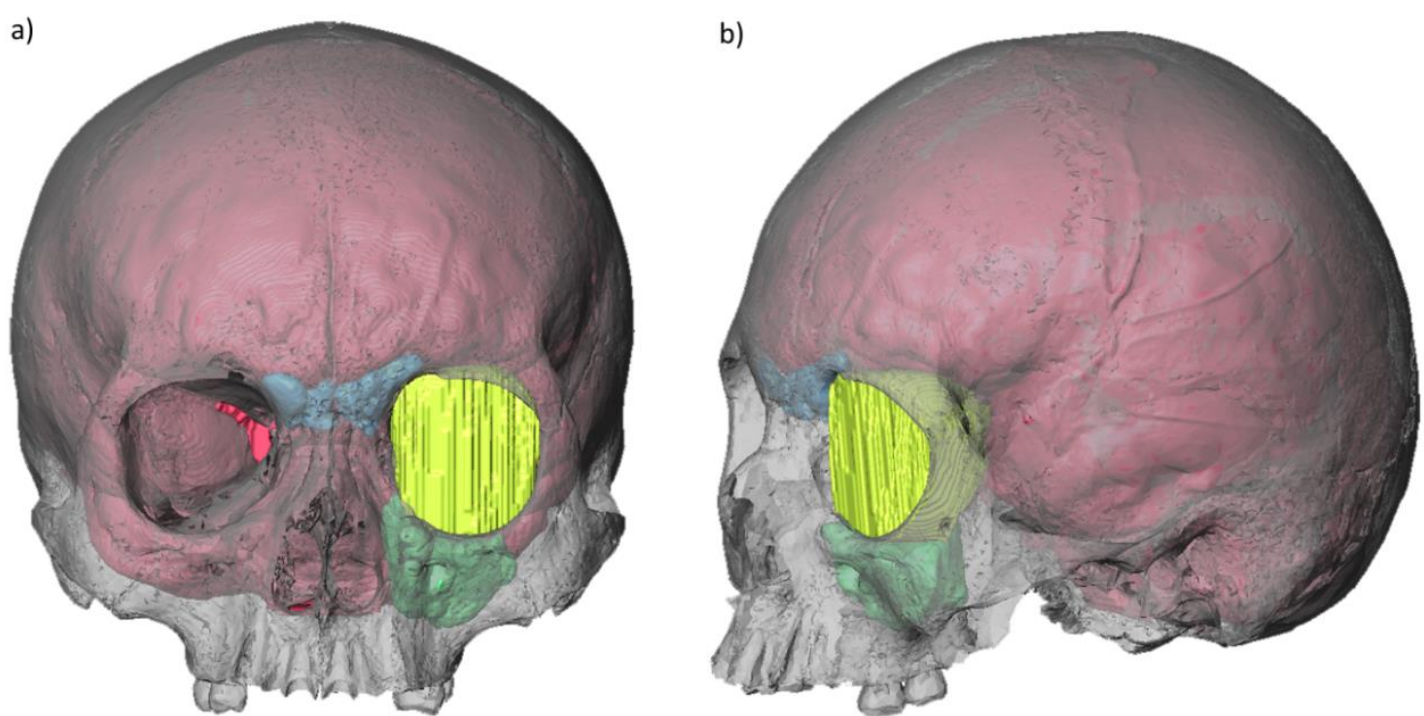

Fig. 6.2. Segmentación de las cavidades craneofaciales en vista frontal (a) y lateral (b): cerebro (rojo), seno frontal (azul), orbital (amarillo) y seno maxilar (verde). La segmentación del orbital se extendió anteriormente hasta el diámetro vertical anterior (Jeong y Ahn, 2015)

\subsection{Análisis preliminares}

\subsubsection{Estimación de datos perdidos}

Las muestras analizadas presentaron distintos tipos de alteraciones tafonómicas, incluyendo pérdida ósea (ver Capítulo 4). Esto resulta en la obtención de matrices de coordenadas de puntos landmarks y semilandmarks incompletas, limitando la posibilidad de realizar análisis comparativos mediante técnicas estadísticas (Gunz et al., 2009). Asimismo, los factores tafonómicos pueden deformar la morfología craneofacial y afectar la ubicación de los landmarks y semilandmarks (Gunz et al., 2004).

Para incluir la mayor cantidad de individuos posibles y así incrementar el tamaño de las muestras se realizaron reconstrucciones virtuales de las superficies dañadas cuando estas eran reducidas y en los casos en que el área afectada fue extensa, se aplicó un método para la imputación de datos perdidos. La reconstrucción virtual se realizó mediante la función multithresholding del programa Avizo 8.0. Las superficies ausentes se reconstruyeron de forma manual (Fig. 6.3), y posteriormente fueron adicionadas al resto del cráneo con el programa 
MeshLab 1.3. De esta manera se obtuvo un modelo completo del cráneo sobre el que luego fueron digitalizados los puntos (Gunz et al., 2009).

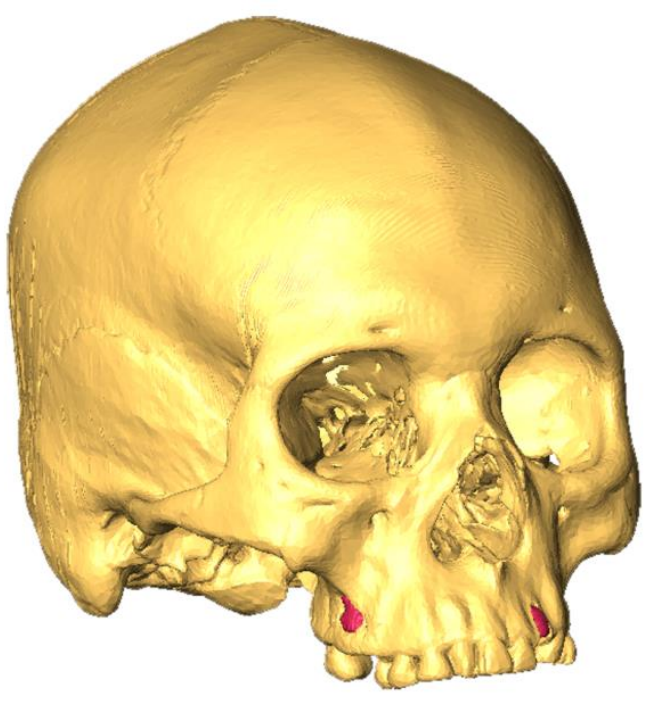

Fig. 6.3. Ejemplo de reconstrucción virtual de superficies dañadas. En rojo se señalan los sectores faciales reconstruidos

En aquellos individuos que presentaban grandes extensiones del cráneo con pérdida ósea o deformación plástica, se procedió a efectuar una reconstrucción geométrica mediante la función TPS (Neeser et al., 2009). En primer lugar se digitalizaron las coordenadas de puntos y posteriormente se trataron como datos perdidos aquellos landmarks y semilandmarks que se encontraban en las superficies dañadas. Luego, los datos perdidos fueron sustituidos empleando la información de todos los individuos mediante el criterio de bending energy (Neeser, 2007; Gunz et al., 2009). La imputación fue efectuada por muestra y rango de edad. El procedimiento se realizó a través del paquete geomorph para R (R Core Team, 2014). Del total de individuos seleccionados para este estudio debieron imputarse coordenadas de puntos de 9 individuos subadultos y 3 adultos de PG, y 12 individuos subadultos y 7 adultos de $\mathrm{Ch}$. El número de coordenadas de puntos perdidos que fue necesario imputar resultó mayor en subadultos que en adultos.

En los casos en que no fue posible registrar datos de volúmenes, se estimaron los datos perdidos mediante el algoritmo de imputación múltiple Predictive Mean Matching (van Buuren y Groothuis-Oudshoorn, 2011). Las imputaciones fueron efectuadas con paquete mice en el programa R 3.1.1. (R Core Team, 2014). El 2,56\% del total de datos volumétricos relevados para la muestra Ch debieron ser imputados con este procedimiento ya que estaban ausentes por pérdida ósea. 


\subsubsection{Análisis del error de observación en la digitalización de landmarks y semilandmarks}

En el capítulo anterior se discutió la importancia del análisis del error de observación en el registro de superficies óseas. La digitalización de coordenadas de puntos (landmarks y semilandmarks) también está sujeta a diversas fuentes de error. Brevemente, el error de observación implica todas aquellas diferencias entre medidas repetidas de una misma variable, lo que conduce a un incremento de la varianza en la muestra analizada (Arnqvist y Mårtensson, 1998; Perez et al., 2004). El error en el registro de los landmarks y semilandmarks debe ser controlado a fin de no incrementar el sesgo en los análisis (Muñoz-Muñoz y Perpiñán, 2010). Particularmente, es importante reconocer que existen diferentes fuentes de error vinculadas al análisis morfométrico, por ejemplo: el instrumental empleado (e.g. calidad de las imágenes de TC, programas informáticos utilizados), la técnica empleada (e.g. digitalización directa o mediada por programa), la definición de las coordenadas de puntos a digitalizar (e.g. diferencias entre los tipos de landmarks; ver Bookstein, 1991) y el grado de entrenamiento del observador (Arnqvist y Mårtensson, 1998; Muñoz-Muñoz y Perpiñán, 2010)

A fin de evaluar la influencia del error intra-observador en la digitalización de landmarks y semilandmarks, se seleccionaron aleatoriamente 15 individuos distribuidos entre ambas muestras ( $P G$ y $\mathrm{Ch}$ ), correspondientes a subadultos y adultos. Se efectuaron dos series, en las cuales se digitalizaron 53 landmarks, en el lado izquierdo del cráneo. A partir de estas variables se realizaron análisis de componentes principales para cada serie. La concordancia en la posición de los individuos a lo largo de los dos primeros componentes (CP1 y CP2) fue evaluada mediante el análisis de Coeficiente de Correlación Intraclase (CCI). Asimismo, se efectuó un ANOVA de medidas repetidas para detectar posibles sesgos sistemáticos en el registro de las coordenadas (Zar, 1999; Klingenberg, 2016). En conjunto, el CP1 y CP2 explicaron el 29,39\% del total de la variación en la muestra de 15 individuos. Los resultados indicaron un excelente acuerdo en la distribución de los individuos a lo largo de los componentes principales de cada serie (Tabla 6.1). Los resultados del ANOVA indicaron que no se detectaron diferencias significativas en la posición de los individuos en los componentes de ambas series.

Tabla 6.1. Análisis del error en la digitalización

\begin{tabular}{cccc}
\hline \multirow{2}{*}{ Componentes } & \multicolumn{3}{c}{ Serie 1 - Serie 2 } \\
\cline { 2 - 4 } & $\mathrm{CCl}$ & $\mathrm{F}$ & $\mathrm{p}$ \\
\hline CP 1 & 0,98 & 0,97 & 0,341 \\
CP 2 & 0,98 & 3,04 & 0,1 \\
\hline
\end{tabular}




\subsubsection{Modificaciones culturales del cráneo}

Las poblaciones de las que proceden las muestras empleadas se caracterizaron por la práctica de modificaciones culturales del cráneo (ver Capítulo 4; Fig. 6.4). Para determinar la presencia de cráneos con modificaciones culturales se realizó, en primer lugar, un diagnóstico morfoscópico siguiendo los criterios de Dembo e Imbelloni (1938). Luego se procedió al análisis cuantitativo de la forma (i.e. shape) a partir de las coordenadas de puntos digitalizadas en la base y la bóveda craneal (ver Anexo 2). Sobre estas coordenadas se efectuó un análisis de componentes principales con el fin de evaluar si los individuos que presentaban modificaciones culturales de acuerdo a los criterios morfoscópicos se diferenciaban en el espacio de forma.

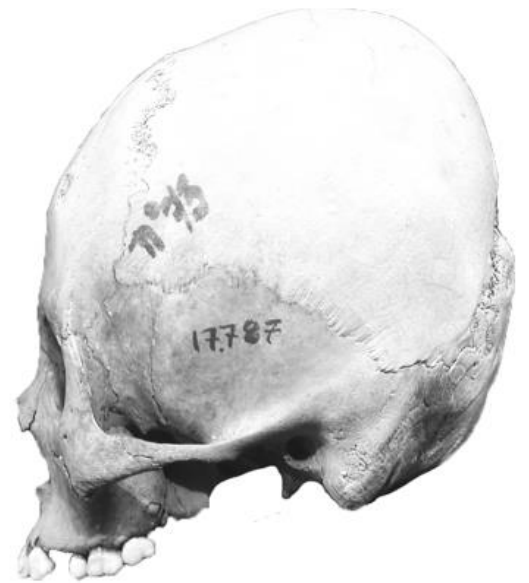

Fig. 6.4. Foto en norma lateral izquierda de cráneo de subadulto de Pampa Grande con modificación craneofacial tipo tabular

A continuación se presentan los resultados obtenidos para ambas muestras. En la muestra de PG se identificaron 3 subadultos y 7 adultos con modificaciones culturales determinadas por criterios morfoscópicos. El análisis de componentes principales indica que los subadultos y 6 de los adultos se separan a lo largo de los dos primeros componentes (Fig. 6.5a,b). Con relación a Ch, 2 subadultos y 2 adultos fueron identificados con modificaciones culturales por criterios morfoscópicos. Sin embargo, no se observaron diferencias en la forma del neurocráneo entre los individuos con y sin modificación cultural a lo largo de los dos primeros componentes del análisis de componentes principales (Fig. 6.5c,d). A partir de los resultados obtenidos, se decidió excluir sólo a los individuos de Pampa Grande con modificaciones culturales del cráneo de los análisis de forma (i.e. shape) del cráneo completo, para evitar así la introducción de variación por acción cultural en los análisis morfológicos. 
a)

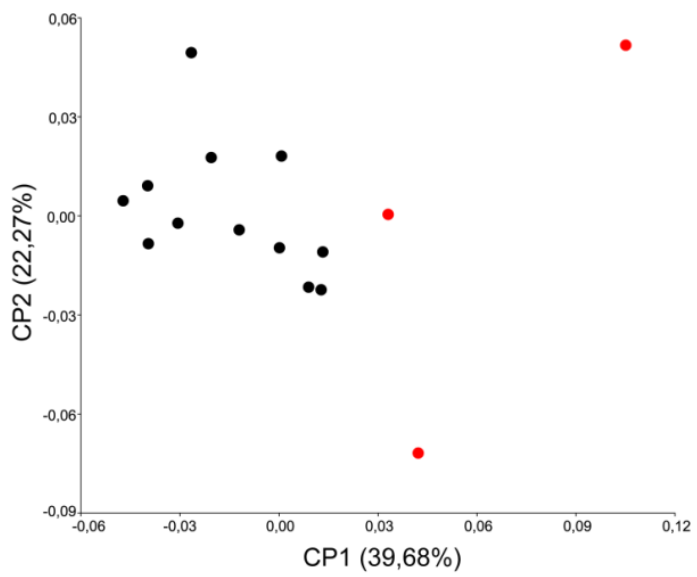

c)

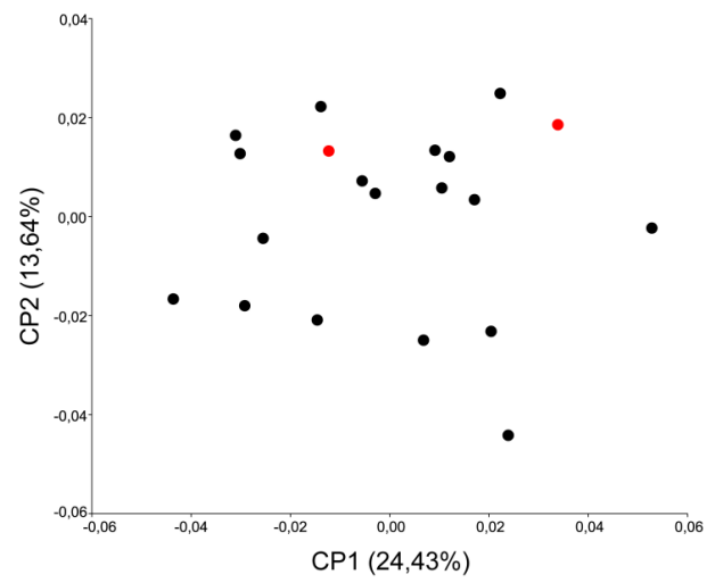

b)

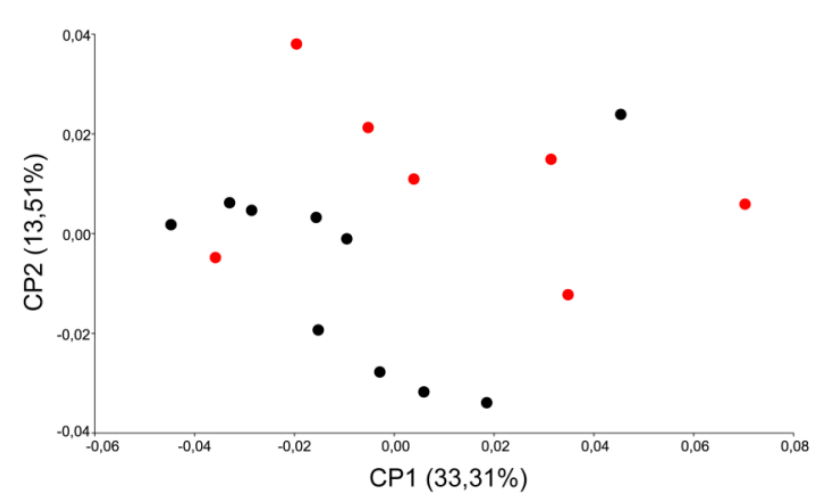

d)

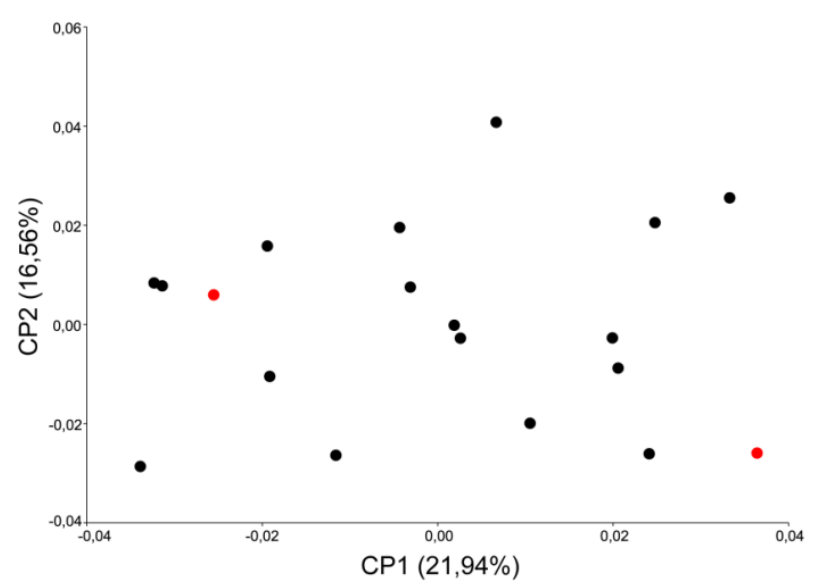

Fig. 6.5. Análisis de la variación en forma de los cráneos de subadultos (a) y adultos (b) de Pampa Grande, y de los subadultos (c) y adultos (d) de Chubut, a partir de las coordenadas de puntos digitalizadas en la base y la bóveda craneal. En rojo se marcan los individuos identificados por diagnóstico morfoscópico con modificaciones culturales

\subsection{Métodos multivariados para el análisis de la morfología craneofacial}

Se efectuaron análisis multivariados para describir la variación intra e inter-poblacional. En este sentido, a fin de evaluar cambios en tamaño asociados a la edad en los individuos subadultos, se aplicó un análisis de correlación entre CSz y el score de desarrollo dental. A su vez, para el análisis de cambios en forma (i.e. shape) asociados a los cambios en tamaño (i.e. cambios alométricos) se empleó un análisis de regresión multivariada (Monteiro, 1999). Finalmente, para visualizar cambios en shape a lo largo de la ontogenia en cada muestra, así como diferencias morfológicas entre adultos y subadultos de las dos muestras, se empleó un Análisis de Componentes Principales. Los cambios en forma fueron representados gráficamente mediante morphings (Klingenberg, 2013). Los análisis se efectuaron para el cráneo completo, y para las regiones faciales superior y media. Se emplearon los programas MorphoJ (Klingenberg, 2011) y R 3.1.1 (R Core Team, 2014). 


\section{Análisis histológicos}

Resultados de los análisis histológicos de las superficies faciales óseas

\section{Contenido}

7.1. Completitud de la información histológica de las superficies faciales

7.2. Patrones de modelado óseo: mapas generales en individuos subadultos y adultos

7.2.1. Patrones generales de modelado óseo en la muestra de Pampa Grande

Glabela

Supraorbital

Malar

Maxilar

7.2.2. Patrones generales de modelado óseo en la muestra de Chubut

Glabela

Supraorbital

Malar

Maxilar

7.3. Variación individual de los patrones de modelado óseo

7.3.1. Patrones de modelado óseo individuales en la muestra de Pampa Grande

Glabela

Supraorbital

Malar

Maxilar

7.3.2. Patrones de modelado óseo individuales en la muestra de Chubut

Glabela

Supraorbital

Malar

Maxilar

7.4. Variación inter-muestral de los patrones de modelado óseo de la región facial

7.4.1. Comparación de los patrones generales de modelado óseo de los individuos subadultos

7.4.2. Comparación de los patrones generales de modelado óseo de los individuos adultos

7.5. Resultados destacados 
En el presente capítulo se presenta el patrón de modelado óseo de los individuos de las muestras de Pampa Grande y de Chubut caracterizados a través de los mapas generales obtenidos para glabela, supraorbital, malar y maxilar. En primer lugar, se indica el porcentaje de información relevada e imputada sobre la cual se construyeron los mapas de modelado óseo. En segundo lugar, se realiza una aproximación a la variación intra-muestral en el modelado óseo. Se presentan los mapas generales de cada estructura anatómica por muestra, divididos en dos grandes grupos etarios, subadultos y adultos. A su vez, se presentan los mapas individuales de modelado óseo. En tercer lugar, se realiza una aproximación a la variación inter-muestral del modelado óseo, comparando la información procedente de aquellos individuos con más datos relevados (i.e. más del $25 \%$ de la superficie de cada réplica con datos de formación o reabsorción ósea).

\subsection{Completitud de la información histológica de las superficies faciales}

En la Tabla 7.1 se presenta el porcentaje de información histológica (i.e. formación y reabsorción ósea) relevada por región anatómica para cada individuo. En general, se registraron porcentajes elevados de información presente (i.e. más del $25 \%$ ), principalmente en los individuos subadultos de Chubut, mientras que la menor cantidad de datos fue registrada para los individuos adultos de Chubut. Con relación a las regiones anatómicas, la información recuperada es dispar entre submuestras. El malar y el maxilar exhiben elevados porcentajes de información presente en los subadultos de las dos muestras, disminuyendo en los individuos adultos. La glabela presenta un alto porcentaje de datos relevados en los individuos adultos de la muestra de Pampa Grande y subadultos de Chubut, mientras es muy reducido en subadultos de Pampa Grande y adultos de Chubut. Finalmente, el supraorbital exhibió bajos porcentajes de información presente en todas las submuestras.

A partir del porcentaje de información presente en el relevamiento histológico (Tabla 7.1), se establecieron dos categorías de agrupamiento para obtener los mapas generales: por un lado, una que incluye el total de los individuos -Mapa general total- $y$, por el otro, una con sólo aquellos individuos que presentaban más del $25 \%$ de datos con información de modelado óseo -Mapa general restrictivo-. 
Tabla 7.1. Porcentaje de información histológica relevada

\begin{tabular}{|c|c|c|c|c|}
\hline & Glabela & Supraorbital & Malar & Maxilar \\
\hline \multicolumn{5}{|l|}{ Pampa Grande } \\
\hline \multicolumn{5}{|l|}{ Subadultos } \\
\hline 17713 & 46,77 & 56,42 & 23,21 & 4,63 \\
\hline 17714 & 0 & 6,09 & 0 & 0 \\
\hline 17766 & 0 & 20 & 29,47 & 81,11 \\
\hline 17769 & 21,01 & 22,30 & 53,34 & 86,83 \\
\hline 17770 & 1,77 & 44,82 & 45,27 & 54,82 \\
\hline 17772 & 4,15 & 26,27 & 31,46 & 50 \\
\hline 17774 & 0 & 4,09 & 17,14 & 78,62 \\
\hline 17775 & 0 & 0 & 15,81 & 33 \\
\hline 17776 & 41,97 & 51,97 & 60,70 & 36,42 \\
\hline 17778 & 9,18 & 14,84 & 36,96 & 20,81 \\
\hline 17780 & 79,23 & 73,02 & 70,58 & 93,92 \\
\hline 17781 & 94,66 & 58,68 & 87,47 & 70,08 \\
\hline 17782 & 3,73 & 18,99 & 5,50 & 14,26 \\
\hline 17783 & 9,59 & 7,73 & 38,54 & 70,36 \\
\hline 17786 & 6,41 & 19,90 & 38,34 & 20,96 \\
\hline 17787 & 4,54 & 0 & 37,77 & 90,68 \\
\hline \multicolumn{5}{|l|}{ Adultos } \\
\hline 17688 & 11,89 & 8,56 & 39,45 & 23,81 \\
\hline 17690 & 6,29 & 10,60 & 18,80 & 27,45 \\
\hline 17695 & 73,87 & 85,81 & 52,76 & 4,48 \\
\hline 17697 & 5,31 & 8,48 & 51,94 & 11,49 \\
\hline 17700 & 33,84 & 0 & 38,21 & 41,08 \\
\hline 17706 & 78,33 & 29,41 & 31,20 & 24,33 \\
\hline 17716 & 4,11 & 0 & 22,85 & 8,84 \\
\hline 17722 & 4,28 & 4,48 & 23,43 & 26,29 \\
\hline 17723 & 0 & 6,03 & 0 & 18,72 \\
\hline 17724 & 58,33 & 25,94 & 22,49 & 80,42 \\
\hline 17726 & 39,01 & 50,11 & 26,89 & 15,54 \\
\hline 17732 & 20,32 & 7,94 & 51,37 & 3,24 \\
\hline 17735 & 41,59 & 3,85 & 17,37 & 18,97 \\
\hline 17737 & 0 & 12,86 & 33,70 & 55,35 \\
\hline 17739 & 0 & 0 & 10,92 & - \\
\hline 17744 & 33,42 & 70,18 & 39,83 & 69,05 \\
\hline 17749 & 62,19 & 51,13 & 76,20 & 6,95 \\
\hline \multicolumn{5}{|l|}{ Chubut } \\
\hline \multicolumn{5}{|l|}{ Subadultos } \\
\hline 1008 & 24,19 & 15,84 & 69,14 & 19,86 \\
\hline 1009 & 54,53 & 74,40 & 57,26 & 70,79 \\
\hline 1010 & 52,17 & 44,23 & 59,33 & 35,22 \\
\hline 1020 & 83,76 & 85,80 & 40,19 & 32,81 \\
\hline 1032 & 37,81 & 11,43 & 53,55 & 52,84 \\
\hline 1033 & 0 & 0 & 4,15 & 14,17 \\
\hline
\end{tabular}




\begin{tabular}{|c|c|c|c|c|}
\hline & & & & \\
\hline 1041 & 47,29 & 60,94 & 51,76 & 50,50 \\
\hline 1050 & 7,29 & 4,40 & 21,23 & 49,73 \\
\hline 1068 & 0 & 5,34 & 2,84 & 0 \\
\hline 1209 & 79,23 & 54,59 & 63,32 & 62,55 \\
\hline 1211 & 4,04 & 3,33 & 32,29 & 52,14 \\
\hline 1216 & 73,66 & 26,43 & 63,52 & 79,54 \\
\hline 1218 & 94,91 & 93,54 & 79,06 & 72,75 \\
\hline 1220 & 63,64 & 43,75 & 45,50 & 64,10 \\
\hline 1221 & 85,64 & 35,18 & 32,86 & 20,45 \\
\hline 1263 & 23,27 & 13,14 & 19,89 & 52,64 \\
\hline 1264 & 67,89 & 6,74 & 16,11 & 86,40 \\
\hline 1266 & 0 & 0 & 2,79 & 4,50 \\
\hline 1267 & 20,49 & 25,09 & 28,72 & 26,39 \\
\hline 1275 & 7,90 & 31,44 & 60,06 & 74,32 \\
\hline \multicolumn{5}{|l|}{ Adultos } \\
\hline 1014 & 31,36 & 40,17 & 56,40 & - \\
\hline 1016 & 0 & 21,64 & 18,45 & - \\
\hline 1081 & 5,93 & 0 & 3,82 & 55,50 \\
\hline 1082 & 0 & 0 & 0 & 0 \\
\hline 1083 & 10,35 & 16,82 & 14,38 & 29,97 \\
\hline 1098 & 25,98 & 86,17 & 11,24 & 63,84 \\
\hline 1100 & 7,84 & 9,75 & 0 & 9,74 \\
\hline 1102 & 0 & 0 & 14,41 & - \\
\hline 1104 & 17,12 & 26,57 & 26,50 & 13,70 \\
\hline 1106 & 0 & 6,58 & 9,68 & 12,57 \\
\hline 1111 & 27,30 & 43,40 & 19,12 & 30,65 \\
\hline 1112 & 1,88 & 0 & 15,60 & 2,65 \\
\hline 1115 & 0 & 0 & 0 & 8,80 \\
\hline 1120 & 2,52 & 0 & 0 & - \\
\hline 1122 & 69,57 & 85,37 & 82,95 & - \\
\hline 1131 & 84,09 & 87,42 & 48,11 & 72,50 \\
\hline 1132 & 3,78 & 7,26 & 69,67 & 35,35 \\
\hline 1136 & 5,83 & 3,07 & 3,60 & 40,64 \\
\hline 1268 & 5,29 & 0 & 13,02 & 39,44 \\
\hline \multicolumn{5}{|l|}{ Mediana } \\
\hline PG subadultos & 9,38 & 21,15 & 36,96 & 54,82 \\
\hline PG adultos & 33,63 & 11,73 & 32,45 & 21,39 \\
\hline Ch subadultos & 52,17 & 28,94 & 42,84 & 52,14 \\
\hline Ch adultos & 9,10 & 24,11 & 15,60 & 30,65 \\
\hline
\end{tabular}

En las Figuras 7.1 y 7.2 se presentan los histogramas que resumen la cantidad de datos imputados por individuo para cada región anatómica para las muestras de Pampa Grande y Chubut, respectivamente. En la muestra de Pampa Grande, la mayoría de los individuos con 
datos imputados fueron los que exhibieron un bajo porcentaje de información histológica presente (Fig. 7.1, Tabla 7.1). Los individuos que presentaron entre el $25-30 \%$ de información relevada (i.e. cercanos al límite de corte para incluirlos en los mapas restrictivos), en general, cuentan con menos del $25 \%$ de datos imputados. Finalmente, no habría asociación entre el porcentaje de información relevada y la frecuencia de datos imputados, presentándose frecuencias similares de imputación para diferentes porcentajes de datos relevados (Fig.7. $1 a, c)$. Por otro lado, la región ósea con mayor porcentaje de datos imputados fue la glabela en subadultos y el maxilar en adultos, tanto por la cantidad de individuos como por la frecuencia de datos perdidos (Fig. 7.1a,d). Por el contrario, el maxilar de subadultos y el malar de adultos fueron las regiones con menor porcentaje de datos imputados (Fig. 7.1c,d). Finalmente, con relación al maxilar de adultos y subadultos, se observa que hay individuos con altos porcentajes de información histológica relevada que presentan a su vez imputación de datos (Tabla 7.1, Fig. 7.1d). Esto se debe a que la información presente en el maxilar se distribuye de manera agregada.
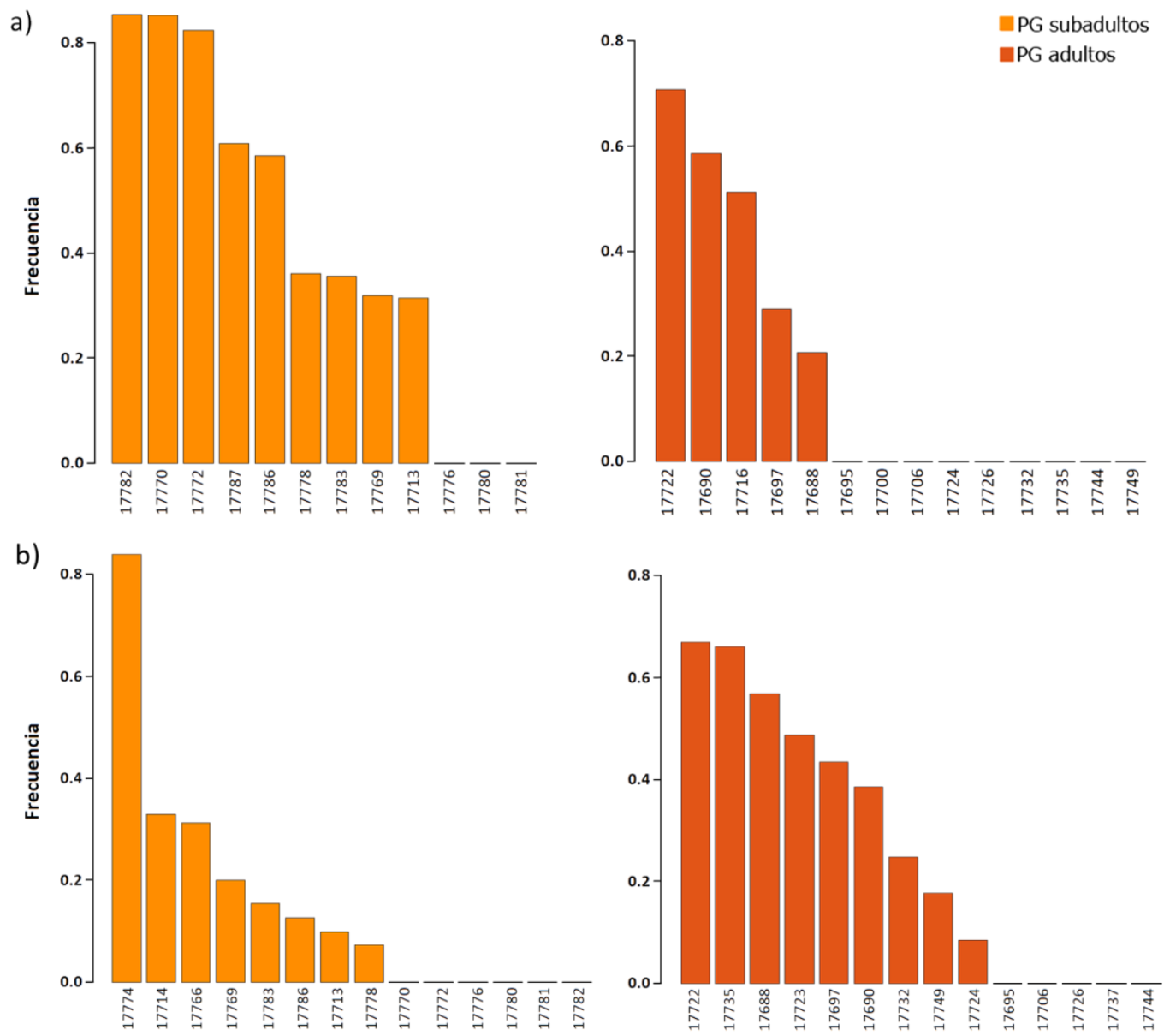

Continúa en la siguiente página 
c)

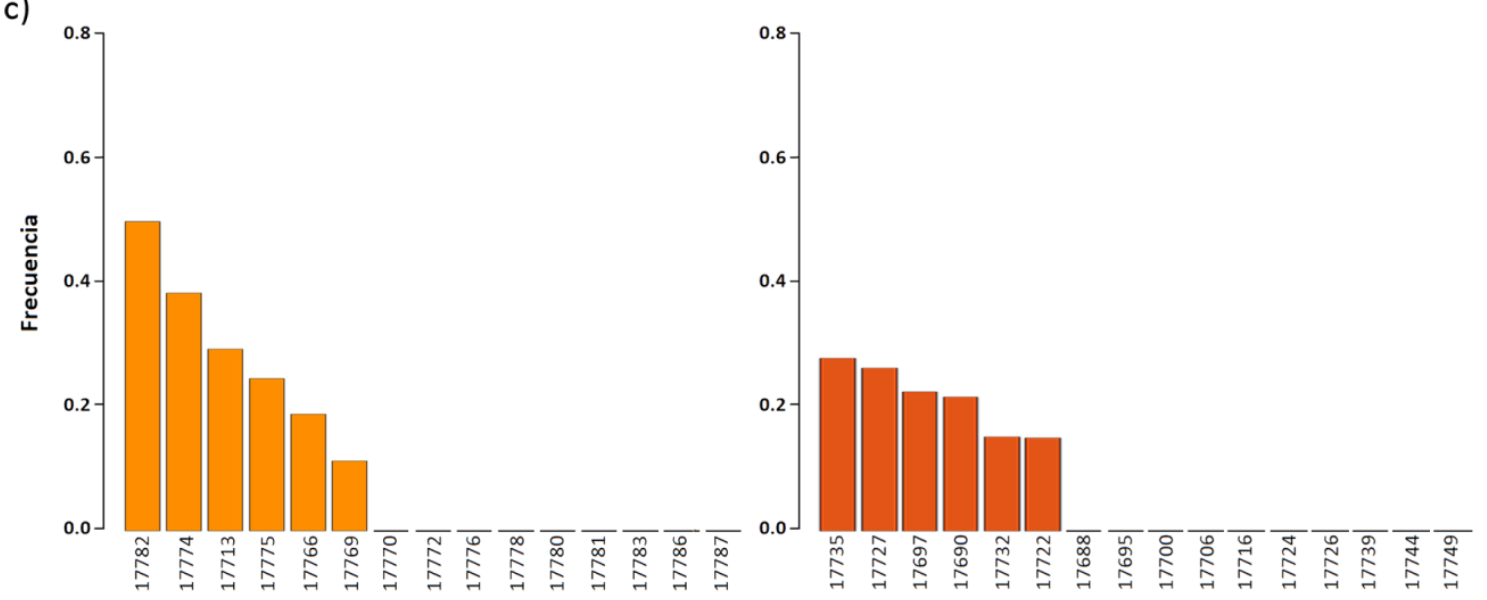

d)
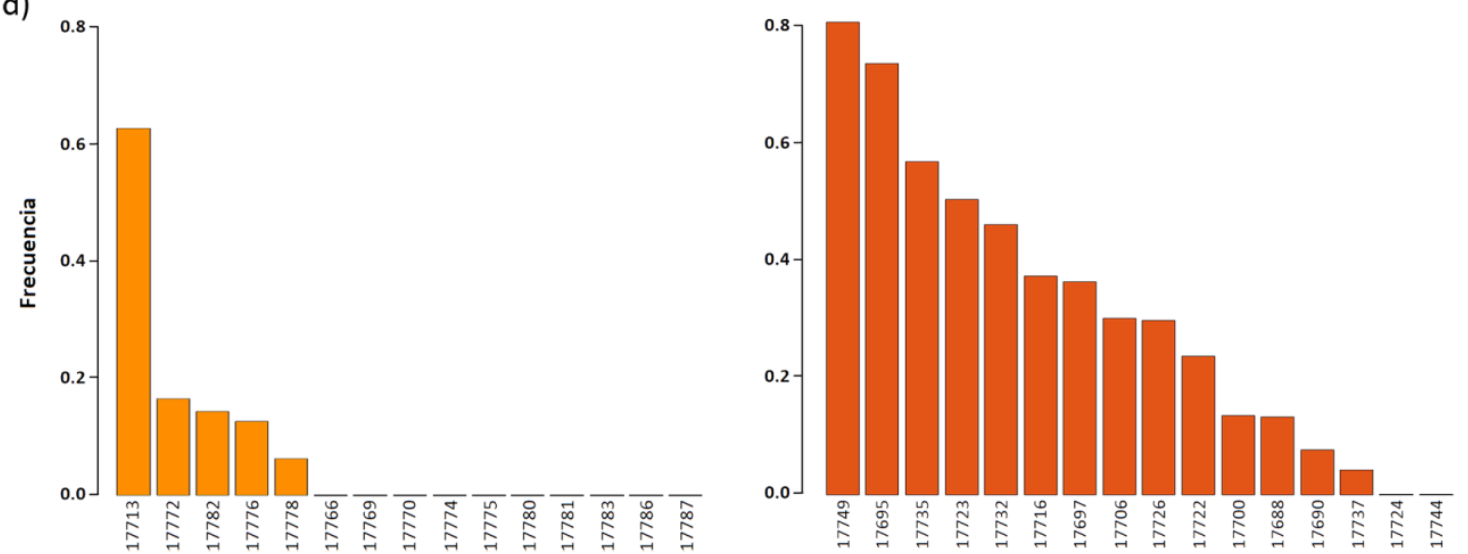

Fig. 7.1. Frecuencia de datos imputados por individuo para glabela (a), supraorbital (b), malar (c) y maxilar (d) de la muestra de Pampa Grande

En la Figura 7.2 se presentan las frecuencias de datos imputados para subadultos y adultos de la muestra de Chubut. En general, aquellos individuos que presentan menos del $25 \%$ de información relevada a nivel histológico requirieron de la imputación de datos (Tabla 7.1). Los individuos que presentaron entre el 25-30\% de información relevada, en general, cuentan con menos del $25 \%$ de datos imputados (Tabla 7.1, Fig. 7.2). Nuevamente, se observa que el porcentaje de pérdida ósea no se relaciona necesariamente con la frecuencia de datos imputados, dándose el caso de individuos con similar porcentaje de información registrada, pero diferentes frecuencias de imputación (Tabla 1, Fig. 7.2b). Respecto a las regiones óseas, en todos los casos la frecuencia de imputación fue mayor en adultos que en subadultos, tanto en número de individuos como en porcentaje de datos imputados (Fig. 7.2a-d). Las regiones con más imputaciones fueron el supraorbital y el malar para subadultos, y la glabela para adultos; mientras que la región con menos datos imputados fue el maxilar para ambos grupos etarios. Al igual que en la muestra de Pampa Grande, fue necesario imputar datos del maxilar en individuos con altos porcentajes de información relevada (Fig. 7.2d, Tabla 7.1). 

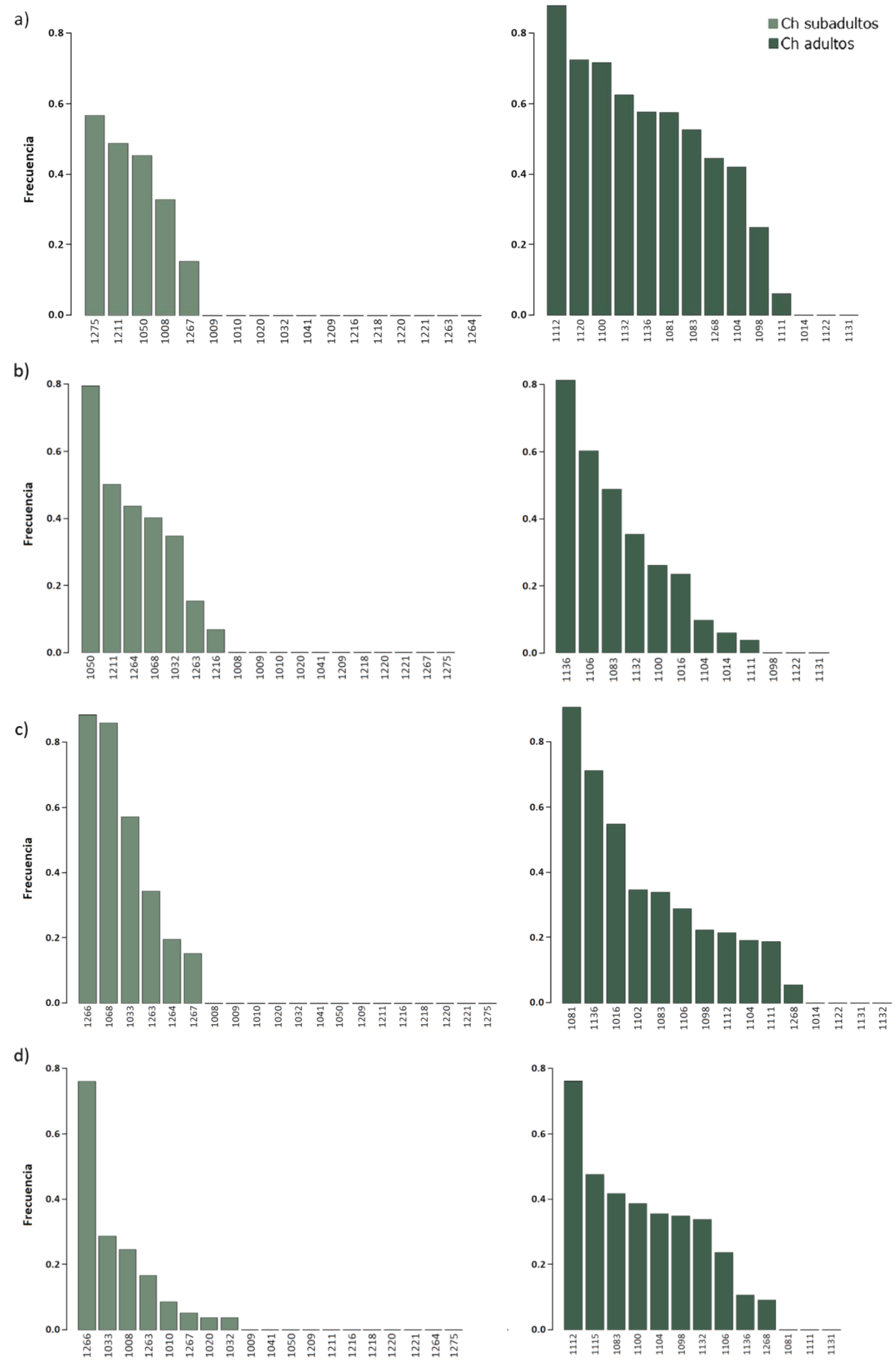

Fig. 7.2. Frecuencia de datos imputados por individuo para glabela (a), supraorbital (b), malar (c) y maxilar (d) de la muestra de Chubut 
7.2. Patrones de modelado óseo: mapas generales en individuos subadultos y adultos

\subsubsection{Patrones generales de modelado óseo en la muestra de Pampa Grande}

\section{Glabela}

En la Figura 7.3-1 se presentan los mapas generales total y restrictivo de la glabela para subadultos y adultos de la muestra de Pampa Grande. La glabela de subadultos se caracteriza por la presencia uniforme de actividad de formación. Esto es compartido por casi todos los individuos, si se tiene en cuenta la escasa variación registrada (Fig. 7.3, 1).

En adultos, se mantiene el patrón observado en subadultos, pero con un incremento del rango de variación entre individuos (Fig. 7.3, 1c,d). Los laterales de la glabela representan dos áreas que exhiben alternativamente ambos tipos de actividad de remodelado óseo (Fig. 7.3, 1c). Dichas áreas presentan gran variación así como el área ubicada en la porción superior de la glabela (Fig. 7.3, 1d).

\section{Supraorbital}

En la Figura 7.3-2 se presentan los mapas generales para la región supraorbital. En subadultos, el patrón de modelado óseo es igual al registrado en la glabela, caracterizado por la homogeneidad de formación ósea y escasa variación entre individuos (Fig. 7.3, 2a,b).

Sin embargo, en adultos se registra un patrón diferente al de subadultos. Se diferencian los dos extremos del supraorbital, presentando el par nasal una continuación del patrón observado en glabela, caracterizado por presencia de formación ósea (Fig. 7.3, 2c,d). Por el contrario, si se considera el mapa general total el par frontal se caracteriza por la alternancia de ambas actividades de remodelado óseo con áreas de actividad de formación y de reabsorción ósea más definidas (Fig. 7.3, 2d). Si se considera el mapa restrictivo, las áreas de reabsorción ósea pasan a tener una delimitación más precisa diferenciándose una en el borde orbital y otra, en la región superior del arco superciliar (Fig. 7.3, 2c). Respecto al rango de variación, el mapa restrictivo registró menor grado de variación y acotado a áreas menores principalmente, el borde orbital y parte del arco superciliar y del par frontal-, que el mapa general total (Fig. 7.3, 2c,d). 
1a) PG-Sad $>25 \%$

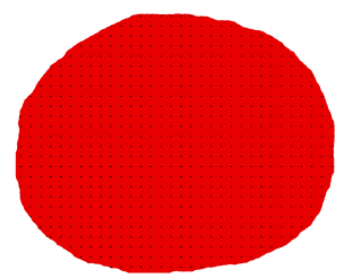

1b) PG-Sad

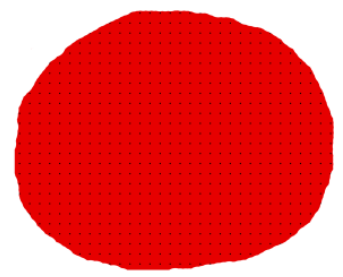

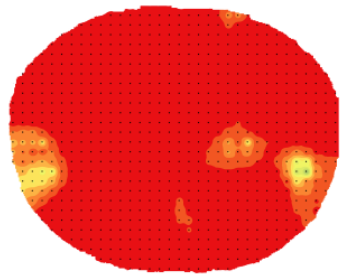

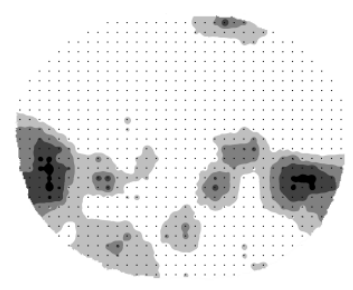

1d) PG-Ad
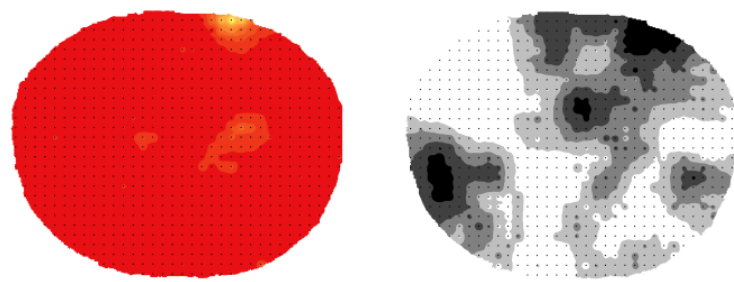

2c)
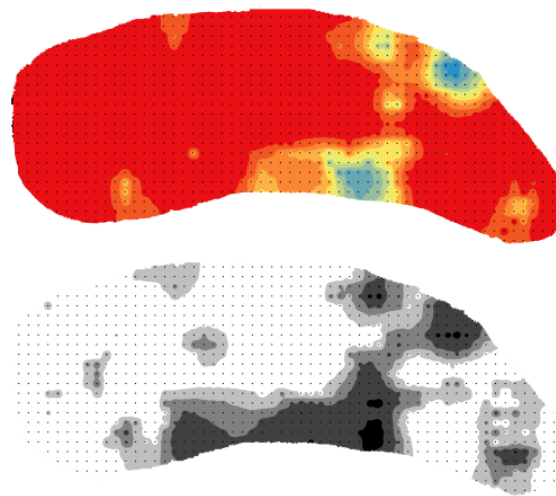

2a)

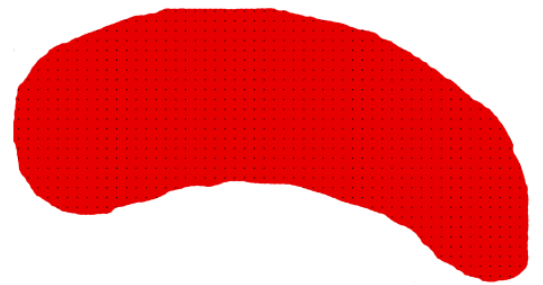

2b)

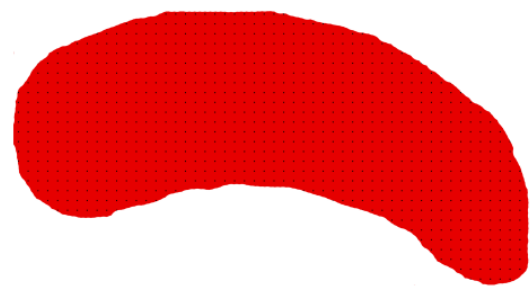

:3:

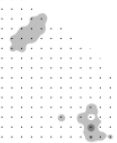

2d)
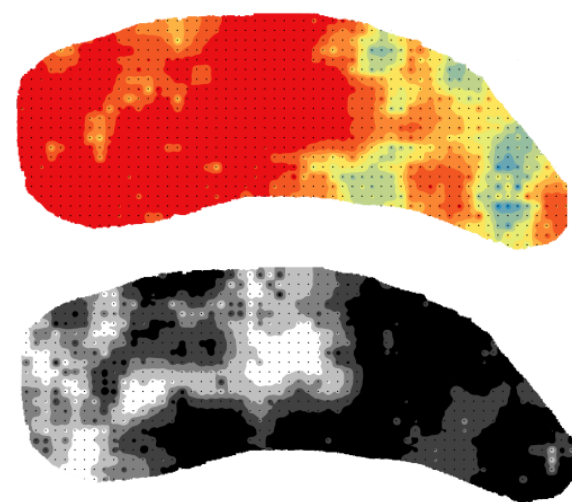

Fig. 7.3. Mapas generales de la glabela (1) y el supraorbital (2) de subadultos (a y b) y adultos (c y d) de Pampa Grande: a y c, mapa general restrictivo (>25\% de información); b y d, mapa general total. Los mapas de colores representan el patrón de modelado óseo estimado a partir de la mediana. Los mapas grises representan los rangos de variación de la información entre individuos. Los puntos indican el centro de las celdas (referencias al final de la figura) 
En la Figura 7.3-3 se presentan los mapas generales del malar. Los individuos subadultos muestran predominancia de actividad de formación, salvo para la región inferior del borde orbital, donde se registran pequeñas áreas de reabsorción (Fig. 7.3, 3a,b). El borde orbital es una región de gran variación, característica que se extiende hasta la región adyacente del borde maxilar. El proceso temporal también presenta gran variación entre individuos (Fig. 7.3, $3 a, b)$.

En los individuos adultos se observa predominancia de formación en toda la superficie del malar, con excepción del borde maxilar, que se caracteriza por presentar reabsorción ósea (Fig. 7.3, 3c,d). Dicha región se caracteriza por ser de gran variación. Otras regiones con variación, pero en menor extensión y magnitud, son las áreas del borde masetero y de la apófisis marginal, seguidos por los procesos temporal y frontal (Fig. 7.3, 3c). La extensión y magnitud de variación en estas áreas es mayor en el mapa general total que en el restrictivo (Fig. 7.3, 3d).

\section{Maxilar}

En la Figura 7.3-4 se presentan los mapas generales obtenidos para el maxilar. En subadultos es posible diferenciar tres áreas de acuerdo al tipo de actividad de modelado óseo predominante (Fig.7.3, 4a,b). La primera corresponde a la región del proceso frontal, caracterizada por el predominio de formación ósea. Es un área que se mantiene constante, salvo en la región adyacente a la sutura frontomaxilar. La segunda área se extiende entre la fosa canina y el proceso cigomático. Si bien en esta región se observa formación, ya no predomina como en el proceso frontal. Incluso, se observan pequeñas áreas de alternancia de actividad o con reabsorción ósea. Finalmente, la tercera área corresponde a las regiones del proceso alveolar y de la fosa incisiva, y se caracteriza por la predominancia de reabsorción. Las segunda y tercera áreas son zonas de gran variación, tanto en extensión como en magnitud (Fig. 7.3, 4a,b).

En adultos, las tres áreas delimitadas en subadultos se presentan como áreas más bien continuas, manteniéndose una diferenciación más clara para el proceso alveolar (Fig. 7.3, $4 c, d)$. El proceso frontal presenta formación ósea, aunque ya no predomina como en subadultos. Las regiones de la fosa canina y del proceso cigomático también presentan principalmente formación, pero con áreas de reabsorción. Algunas de estas áreas se corresponden a las observadas en subadultos, ubicadas por encima del foramen infraorbitario 
3a) PG-Sad $>25 \%$
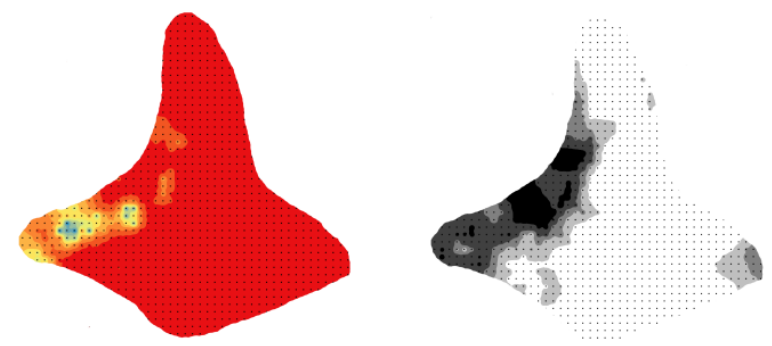

3c) PG-Ad $>25 \%$
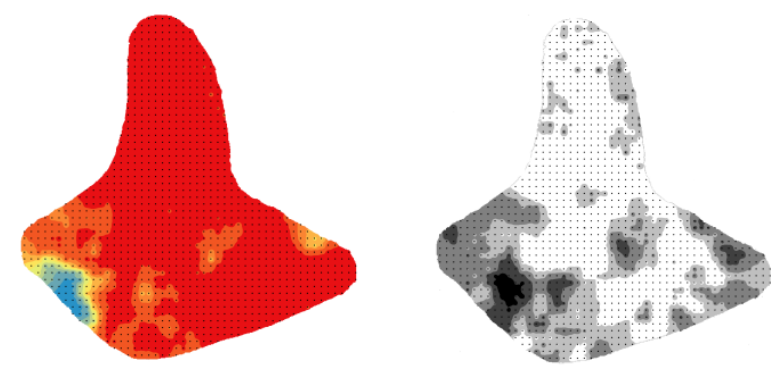

4a) PG-Sad $>25 \%$

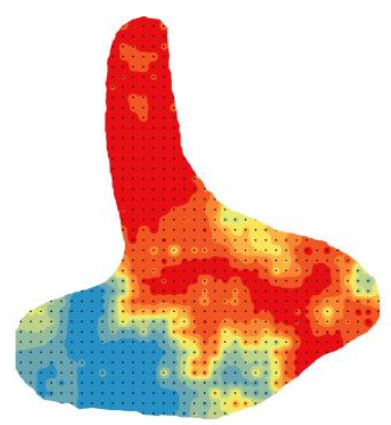

4c) PG-Ad $>25 \%$

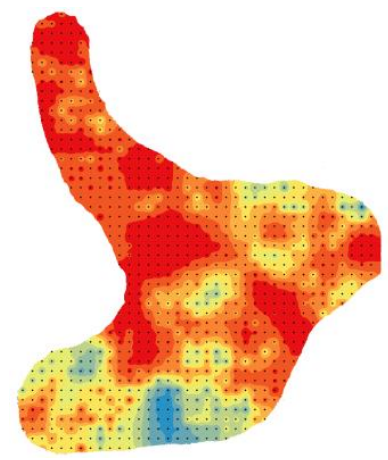

Reabsorción ósea

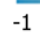

3b) PG-Sad
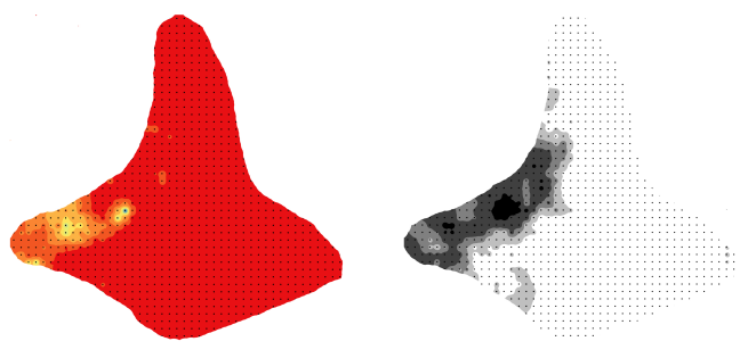

3d) PG-Ad
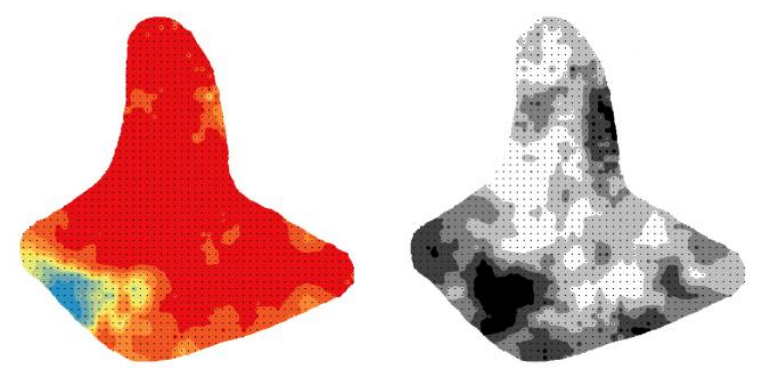

4b) PG-Sad
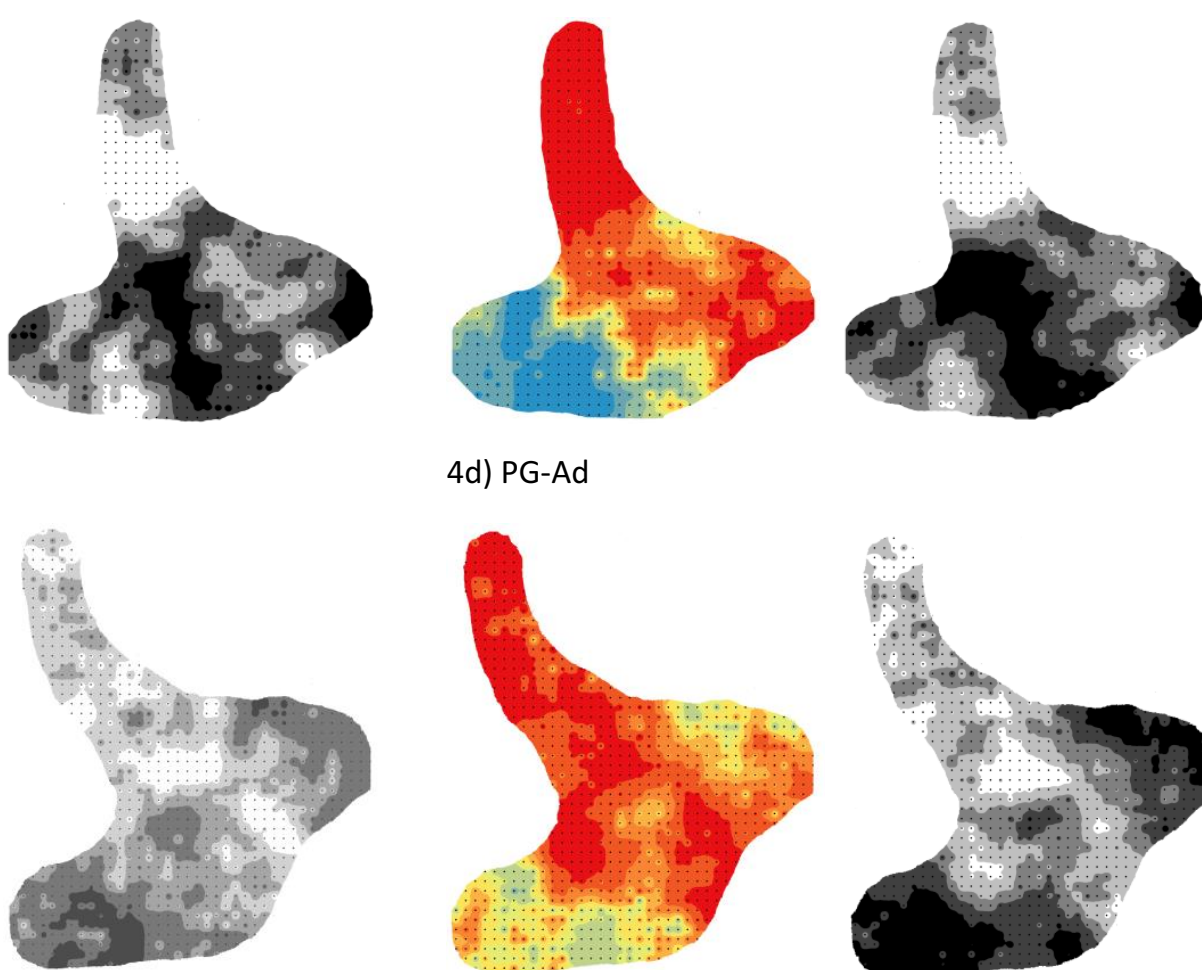

4d) PG-Ad
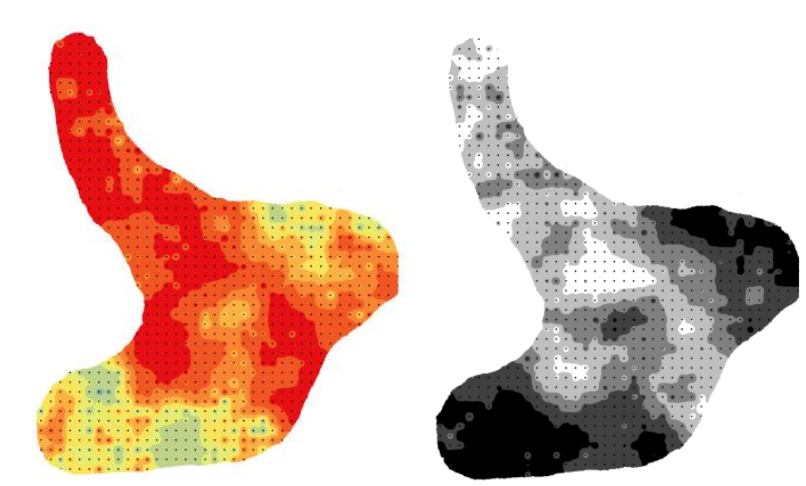

Formación ósea

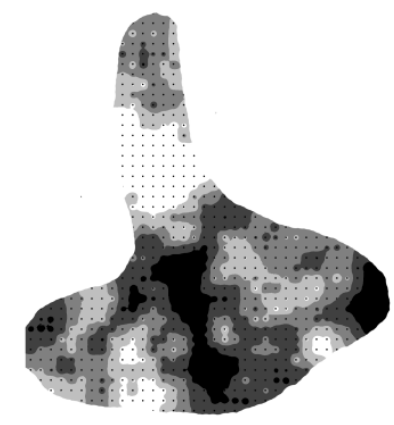

Rango de variación

Fig. 7.3 (continuación). Mapas generales del malar (3) y el maxilar (4) de subadultos (a y b) y adultos (c y d) de Pampa Grande: a y c, mapa general restrictivo ( $25 \%$ de información); b y d, mapa general total. Los mapas de colores representan el patrón de modelado óseo estimado a partir de la mediana. Los mapas grises representan los rangos de variación de la información entre individuos. Los puntos indican el centro de las celdas 
y en la parte superior del proceso cigomático. La región del proceso alveolar presenta reabsorción ósea en menor extensión que lo observado para subadultos y corresponde a áreas de gran variación. La región de la fosa incisiva presenta formación ósea (Fig. 7.3, 4c,d). Respecto a los niveles de variación registrados, las regiones de los procesos alveolar y cigomático fueron las de mayor variación, principalmente al considerar todos los individuos (Fig.7.3, 4c,d).

\subsubsection{Patrones generales de modelado óseo en la muestra de Chubut}

\section{Glabela}

En la Figura 7.4-1 se presentan los mapas generales total y restrictivo para la glabela de los individuos subadultos y adultos de la muestra de Chubut. Los subadultos en general se caracterizan por la predominancia de formación ósea, salvo por la presencia de pequeñas y difusas áreas con alternancia de actividad, ubicadas en la porción inferior de la glabela. No se registran altos niveles de variación (Fig. 7.4, 1a,b).

Los individuos adultos se caracterizan por presentar formación ósea, salvo en los laterales adyacentes al par nasal del supraorbital, que se definen en el mapa restrictivo como áreas de reabsorción ósea (Fig. 7.4, 1c,d). En adultos, las áreas variables de la glabela se caracterizan por su gran magnitud y extensión (Fig. 7.4, 1c,d). La extensión de las áreas de variación se reduce al considerar el mapa restrictivo, aumentando incluso el área constante en la porción superior y diferenciándose una nueva área sin variación en la porción inferior de la glabela (Fig. $7.4,1 c)$.

\section{Supraorbital}

En la Figura 7.4-2 se presentan los mapas generales para el supraorbital. En individuos subadultos, al igual que para la glabela, se observa presencia de formación ósea a lo largo de toda la superficie (Fig. 7.4, 2a,b). Sin embargo, al considerar el mapa restrictivo se aprecia la presencia de pequeñas áreas difusas con alternancia de actividad, localizadas principalmente en el borde orbital (Fig. 7.4, 2a). El supraorbital presenta variación en casi la totalidad de su superficie, a excepción de las áreas constantes adyacentes a los extremos del arco superciliar (Fig. 7.4, 2b). Al considerar el mapa general restrictivo la extensión del área constante correspondiente al par frontal aumenta desde el arco superciliar al borde orbital (Fig. 7.4, 2a). 
1a) $\mathrm{Ch}-\mathrm{Sad}>25 \%$
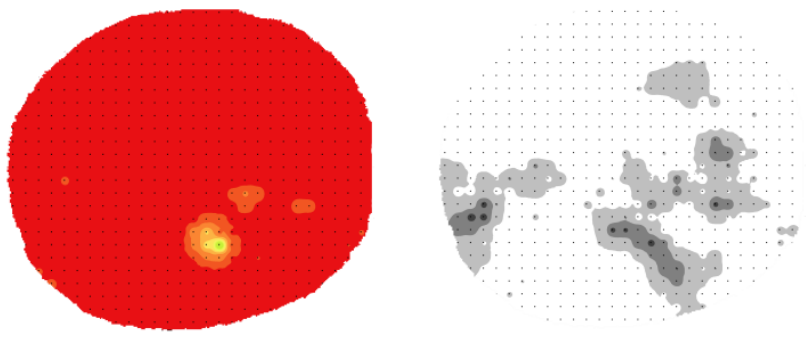

1b) Ch-Sad
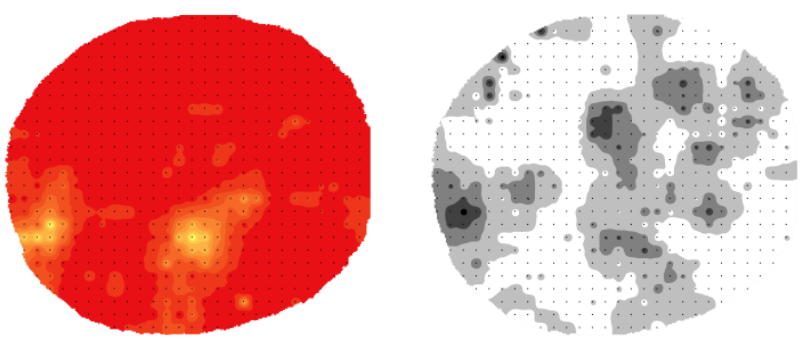

1c) Ch-Ad $>25 \%$
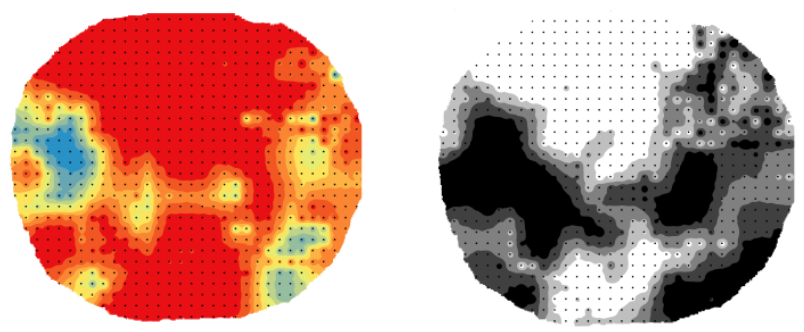

1d) Ch-Ad
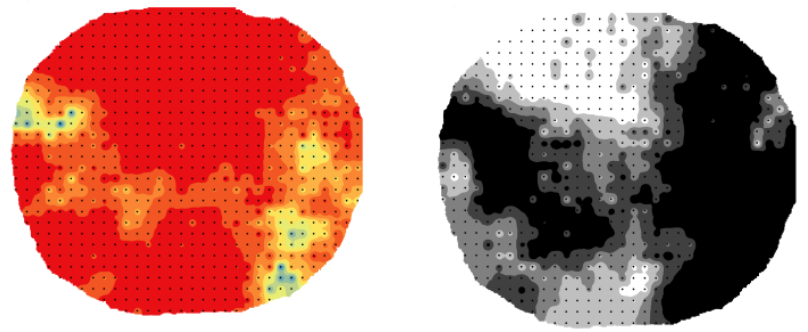

2a)
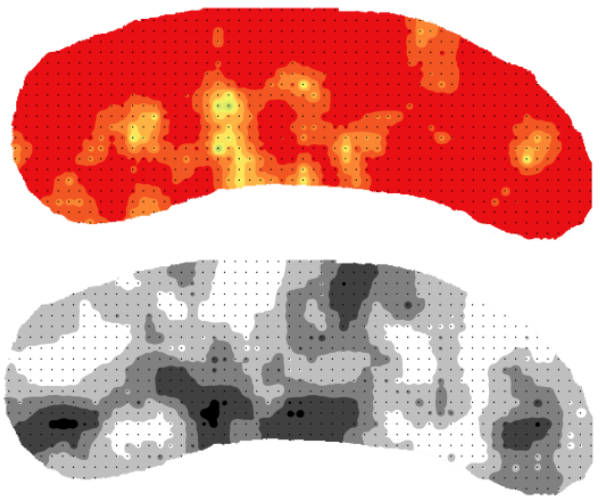

2b)

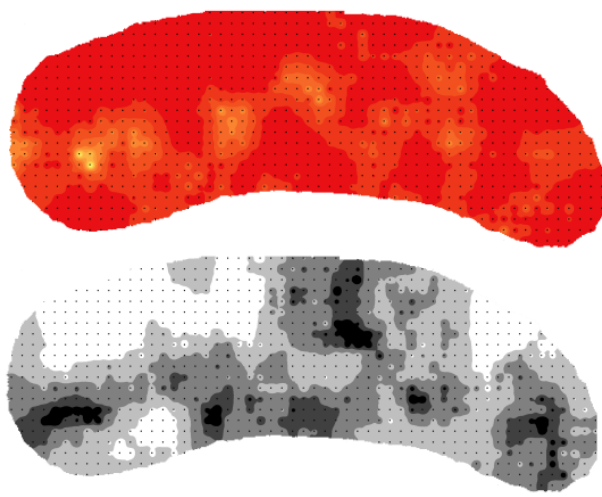

2c)

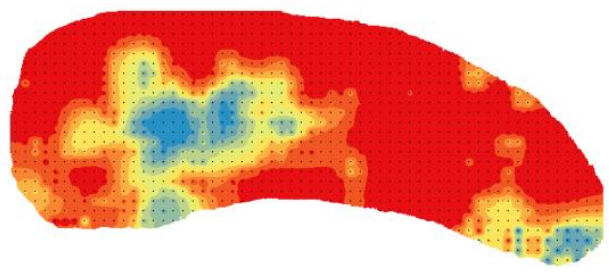

2d)

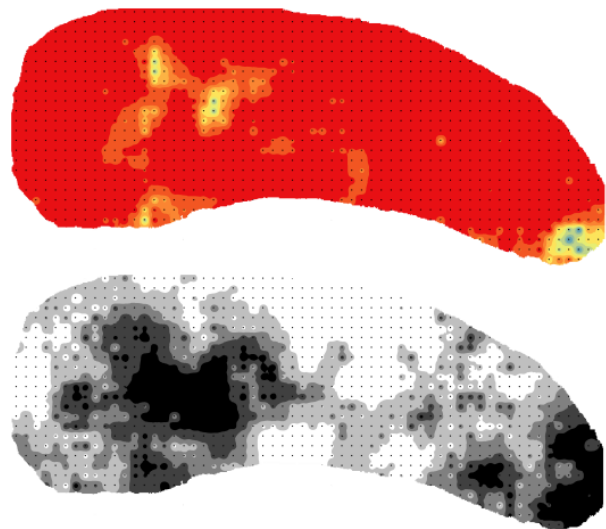

Fig. 7.4. Mapas generales de la glabela (1) y el supraorbital (2) de subadultos (a y b) y adultos (c y d) de Chubut: a y c, mapa general restrictivo (>25\% de información); b y d, mapa general total. Los mapas de colores representan el patrón de modelado óseo estimado a partir de la mediana. Los mapas grises representan los rangos de variación de la información entre individuos. Los puntos indican el centro de las celdas (referencias al final de la figura) 
En individuos adultos, el patrón de modelado óseo observado en el mapa general restrictivo difiere significativamente del mapa general total. El mapa restrictivo se caracteriza por predominancia de formación ósea con presencia de una importante área de reabsorción ubicada entre el par nasal y la región central del supraorbital, alcanzando el borde orbital. Un área menor se sitúa en el par frontal (Fig. 7.4, 2c). Por el contrario, el mapa general total se caracteriza por la predominancia de formación en casi toda la superficie. Deja de observarse el área mayor de reabsorción y se reduce el área menor situada en el par frontal (Fig. 7.4, 2d). El par nasal y frontal son áreas de gran variación, mientras que la región central del supraorbital se mantiene constante (Fig. 7.4, 2c,d).

$\underline{\text { Malar }}$

En la Figura 7.4-3 se presentan los mapas generales del malar. En subadultos se delimitan tres áreas de acuerdo a la actividad de moldeado óseo. Dos áreas corresponden a reabsorción ósea, una ubicada en el borde orbital inferior y la otra, principalmente en el proceso temporal (Fig. 7.4, 3a,b). Al considerar el mapa restrictivo esta última área aumenta su extensión a lo largo del borde masetero (Fig. 7.4, 3a). El resto de la superficie del malar se caracteriza por presentar formación ósea. La predominancia de cada actividad por área se hace más notoria en el mapa restrictivo (Fig. 7.4, 3a). Las áreas con reabsorción ósea y áreas contiguas exhiben gran nivel de variación (Fig. 7.4, 3a,b).

El patrón de modelado óseo observado en individuos subadultos se mantiene parcialmente en adultos. Las regiones del proceso temporal y del borde masetero presentan reabsorción ósea (Fig. 7.4, 3c,d). El área con reabsorción registrada en el borde orbital presenta una extensión menor y se localiza en el extremo inferior del borde, visible sólo al considerar el mapa restrictivo (Fig. 7.4, 3c). En la apófisis marginal se presenta reabsorción ósea. El resto de la superficie del malar se mantiene con formación ósea (Fig. 7.4, 3c,d). Respecto a la variación entre individuos, nuevamente las áreas con reabsorción ósea son las que presentan mayor grado de variación (Fig. 7.4, 3c,d). Si se considera el mapa general total, se observa que la porción superior del malar también es muy variable (Fig. 7.4, 3d).

\section{Maxilar}

En la Figura 7.4-4 se presentan los mapas generales del maxilar. En subadultos es posible diferenciar tres áreas de acuerdo al tipo de actividad de modelado óseo. Una, correspondiente al proceso frontal, caracterizada por la presencia de formación ósea. Otra, correspondiente al proceso alveolar y a la fosa incisiva, muestra la presencia de reabsorción. Y una tercera área, 
3a) Ch-Sad $>25 \%$
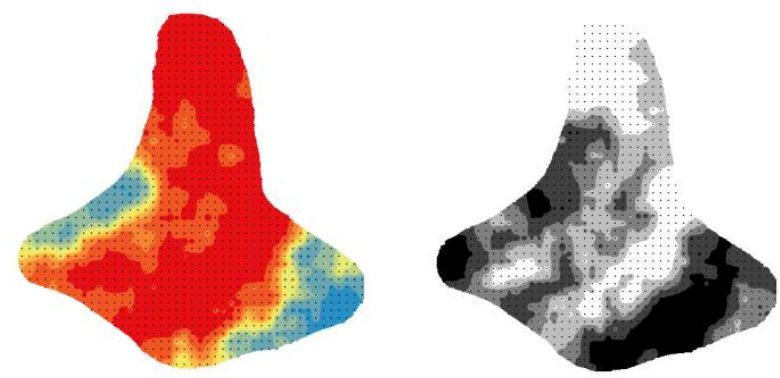

3c) Ch-Ad $>25 \%$

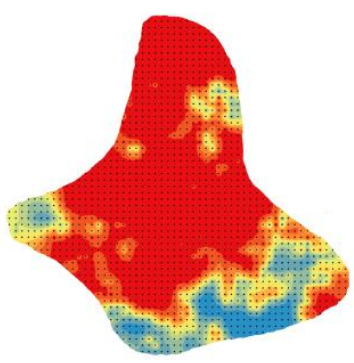

4a) Ch-Sad $>25 \%$

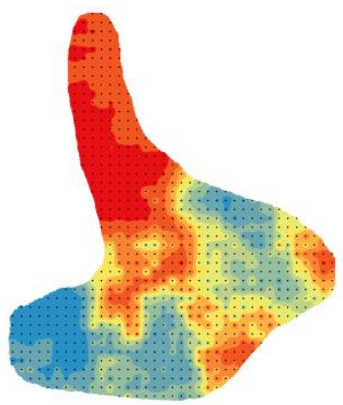

4c) $\mathrm{Ch}-\mathrm{Ad}>25 \%$

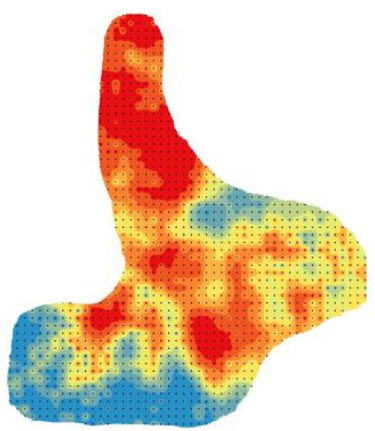

Formación ósea
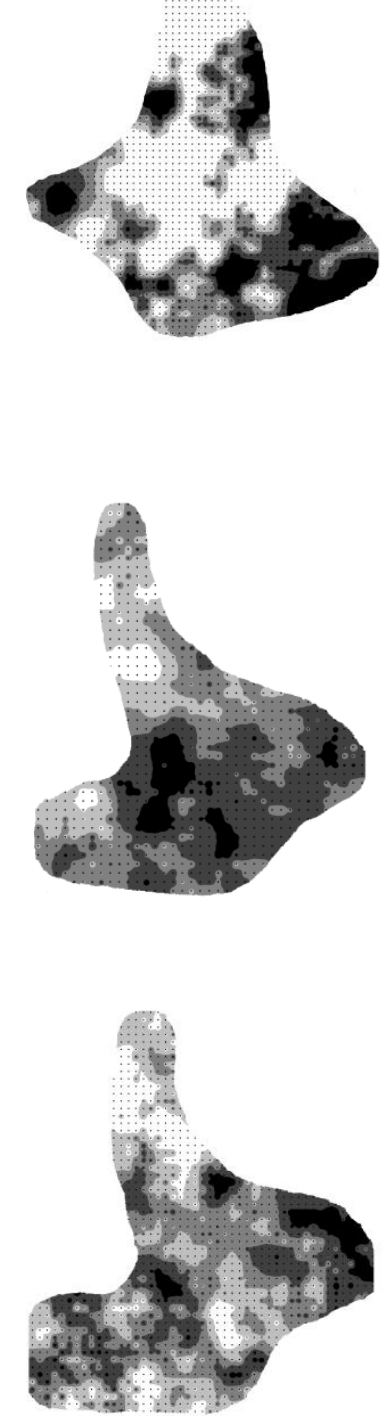

4b) Ch-Sad

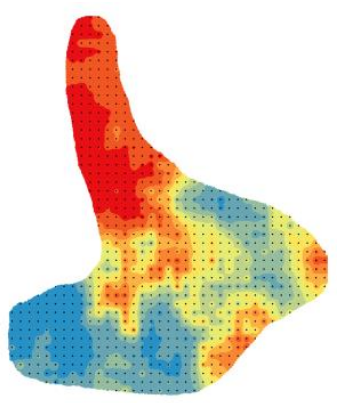

4d) Ch-Ad

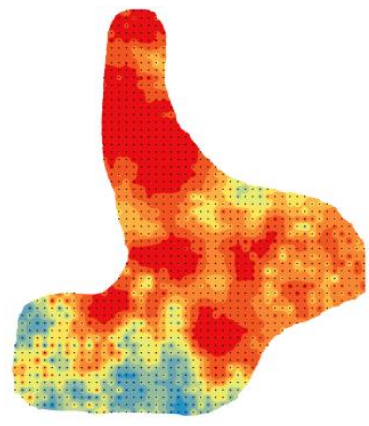

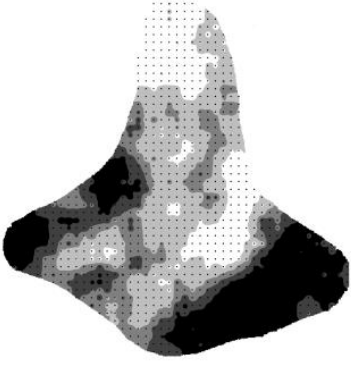

3d) Ch-Ad
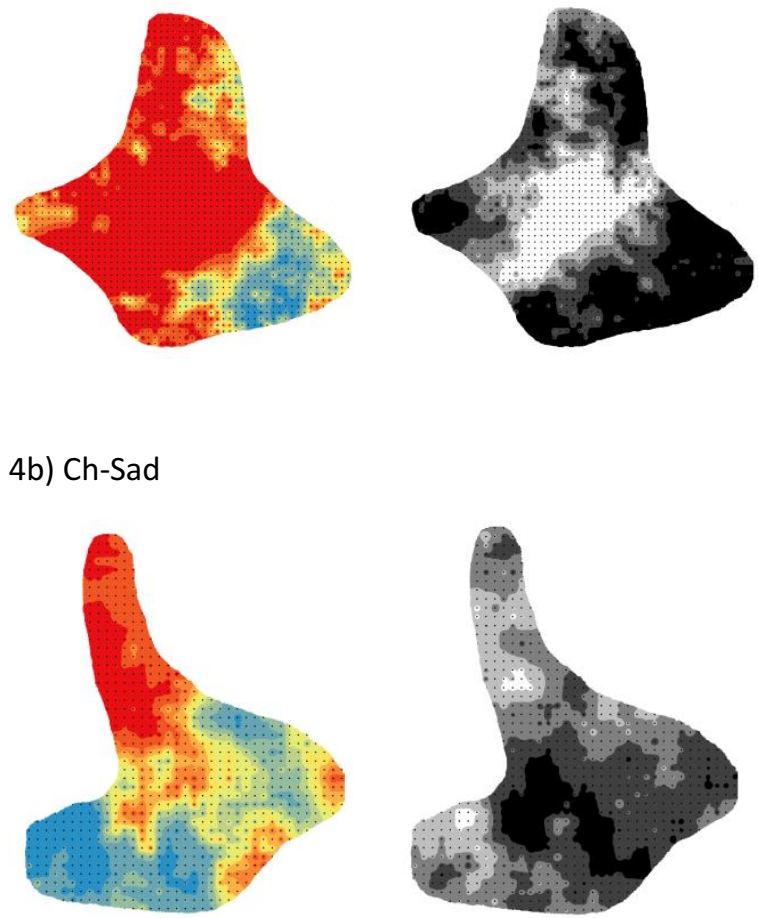

92

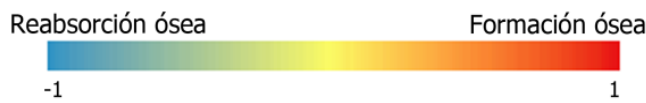

Fig. 7.4 (continuación). Mapas generales del malar (3) y el maxilar (4) de subadultos (a y b) y adultos (c y d) de Chubut: a y c, mapa general restrictivo (>25\% de información); b y d, mapa general total. Los mapas de colores representan el patrón de modelado óseo estimado a partir de la mediana. Los mapas grises representan los rangos de variación de la información entre individuos. Los puntos indican el centro de las celdas 
ubicada entre las dos anteriores, correspondiente a las zonas de la fosa canina y el proceso cigomático, se caracteriza por presentar formación y reabsorción (Fig. 7.4, 4a,b). En esta última área, la formación se ubica adyacente a la apertura piriforme, al extremo del proceso cigomático y a la región entre el proceso cigomático y alveolar, mientras que la reabsorción se sitúa alrededor del foramen infraorbitario y en el proceso cigomático. Casi la totalidad del maxilar de los individuos subadultos presenta variación en el tipo de actividad, siendo la región de la fosa canina la que presenta mayor magnitud de variación (Fig. 7.4, 4a,b).

En individuos adultos se mantiene en cierto grado el patrón observado en subadultos, aunque los límites entre las áreas son menos marcadas. Si se considera el mapa general total es posible diferenciar dos y no tres áreas de remodelado óseo (Fig. 7.4, 4d). El proceso frontal mantiene la presencia de formación ósea. El proceso alveolar presenta principalmente reabsorción, pero en menor extensión, observándose formación en la fosa incisiva en el mapa general total. Hay formación en el área adyacente a la apertura piriforme. Las regiones de la fosa canina y del proceso cigomático presentan predominancia de formación ósea con áreas de reabsorción (Fig. 7.4, 4c,d). La presencia de reabsorción ósea es definida en el mapa restrictivo, abarcando las regiones del proceso cigomático y el foramen infraorbitario (Fig. 7.4, 4c). El maxilar es altamente variable en toda su extensión como en subadultos, salvo para la parte central del proceso frontal que es constante y en la fosa incisiva que presenta mayor grado de variación que en los individuos subadultos (Fig. 7.4, 4c,d).

\subsection{Variación individual de los patrones de modelado óseo}

Los mapas generales construidos a partir del rango intercuartil indicaron altos niveles de variación, especialmente para algunas estructuras, dentro de los grupos de individuos subadultos y adultos. Con el fin de analizar en mayor profundidad la variación dentro de estos dos grupos etarios, en este apartado se presentan los mapas de modelado óseo individuales de los 6 grupos de edad conformados previamente. Asimismo, para los individuos subadultos se evalúa la relación entre el modelado óseo y la edad mediante una regresión de los primeros componentes principales obtenidos a partir de los datos de formación y reabsorción con el score de edad dental.

\subsubsection{Patrones de modelado óseo individuales en la muestra de Pampa Grande}

\section{Glabela}

En la Figura 7.5 se presenta el patrón de modelado óseo de la glabela obtenido para cada individuo. El mapa general total de subadultos fue reconstruido con datos procedentes de 

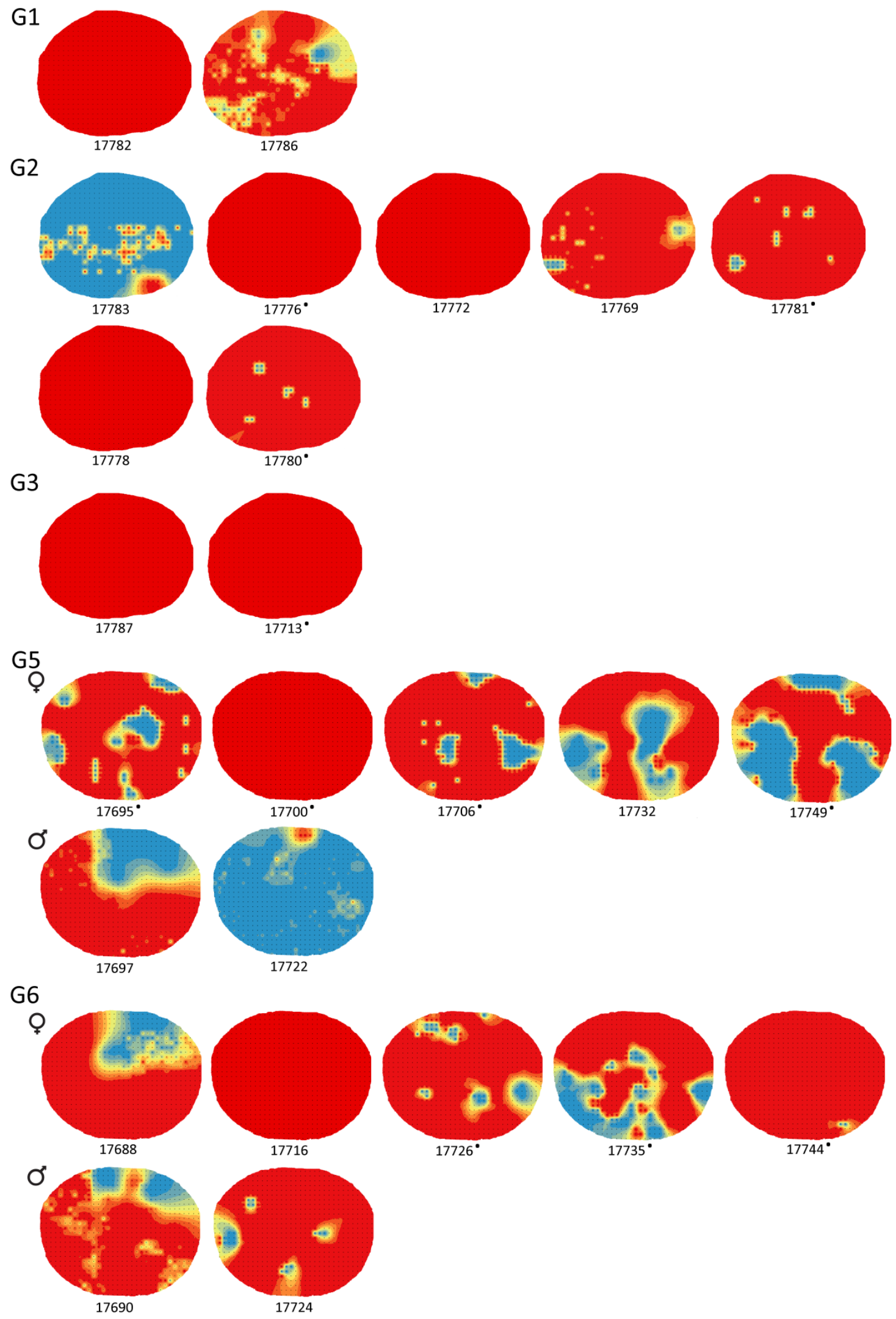

Fig. 7.5. Mapas individuales de modelado óseo de la glabela de la muestra de Pampa Grande. Los individuos subadultos se ordenan por orden creciente de edad y los adultos, por sexo. Se señalan con puntos los individuos con $>25 \%$ de información de modelado óseo. Algunas imputaciones generaron cambios de información con valores opuestos entre celdas adyacentes de manera sucesiva. Referencias de colores en las Figuras 7.3 
todos los grupos etarios, mientras que el mapa restrictivo sólo incluyó información correspondiente al intervalo entre 4,5 y 14,4 años (Fig. 7.5, G2 y G3). En adultos, el mapa restrictivo incluyó información de individuos femeninos solamente (Fig. 7.5, G5 y G6).

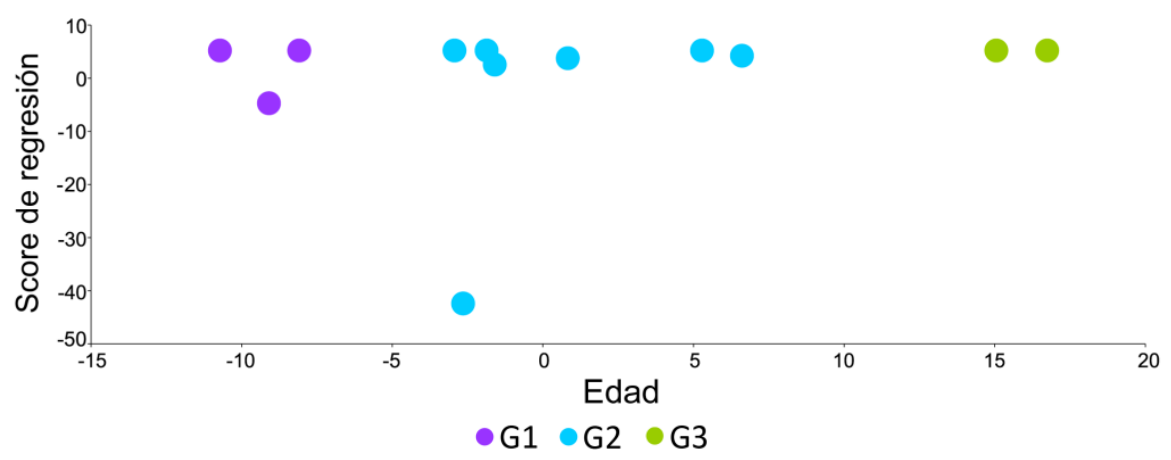

Fig. 7.6. Cambios en forma por modelado óseo en glabela de subadultos de Pampa Grande en función de la edad. La edad se obtuvo del score del CP1 del desarrollo dental. La forma corresponde al score del CP1 del modelado óseo

En subadultos, los individuos presentaron similar patrón de modelado óseo, a excepción de un individuo del G2 (Fig. 7.6). A lo largo de los dos primeros grupos de individuos subadultos se observan, en general, áreas aisladas de reabsorción sobre superficies predominantes de formación. Esta distribución de las áreas es aleatoria y no se asocia a ninguna región en particular (Fig. 7.5, G1 y G2). En los individuos entre 10,5.-14,4 (G3) el patrón corresponde solo a formación ósea (Fig. 7.5, G3). En individuos adultos, a diferencia de subadultos, se registra una proporción mayor de reabsorción ósea. Las áreas de reabsorción son más frecuentes y de mayor extensión, pero su distribución sigue siendo aleatoria (Fig. 7.5, G5 y G6). Con relación al incremento de edad, no hay una diferenciación en cantidad y distribución de actividad ósea entre las categorías adulto joven y medio.

\section{Supraorbital}

En la Figura 7.7 se presenta el patrón de modelado óseo individual del supraorbital. A diferencia de lo observado en la glabela, el mapa restrictivo de subadultos (Fig. 7.3, 1a) incluyó individuos asignados a los diferentes grupos etarios, mientras que en adultos se construyó con información proveniente de individuos de ambos sexos (Fig. 7.3, 1c).

En los individuos subadultos no se observan cambios en el patrón de modelado a través de los grupos etarios. Sólo dos individuos se diferencian del patrón general (Fig. 7.8). La información que predomina es la de formación, con presencia de reabsorción en pocos individuos (Fig. 7.7, G1-G3). En adultos, se observa la presencia de áreas de reabsorción de 

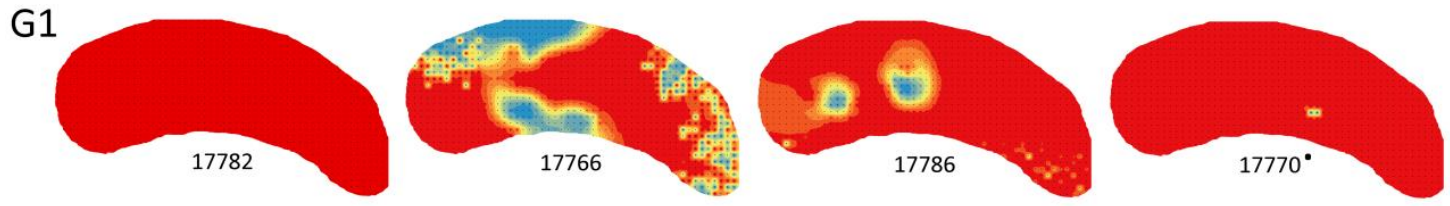

G2
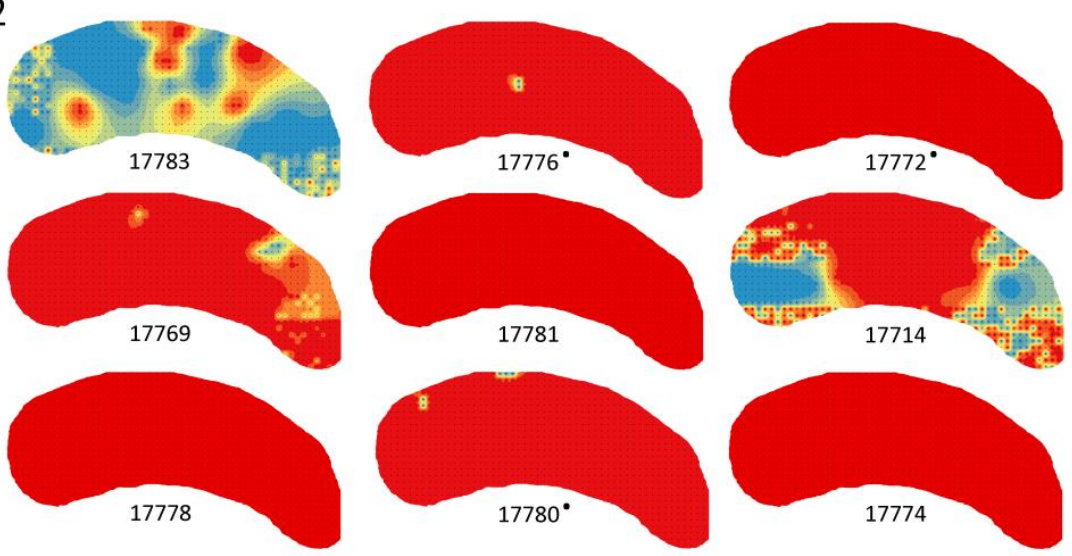

G3

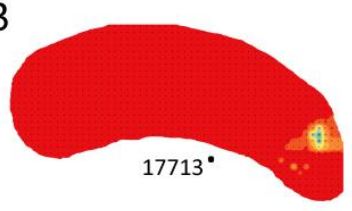

G5
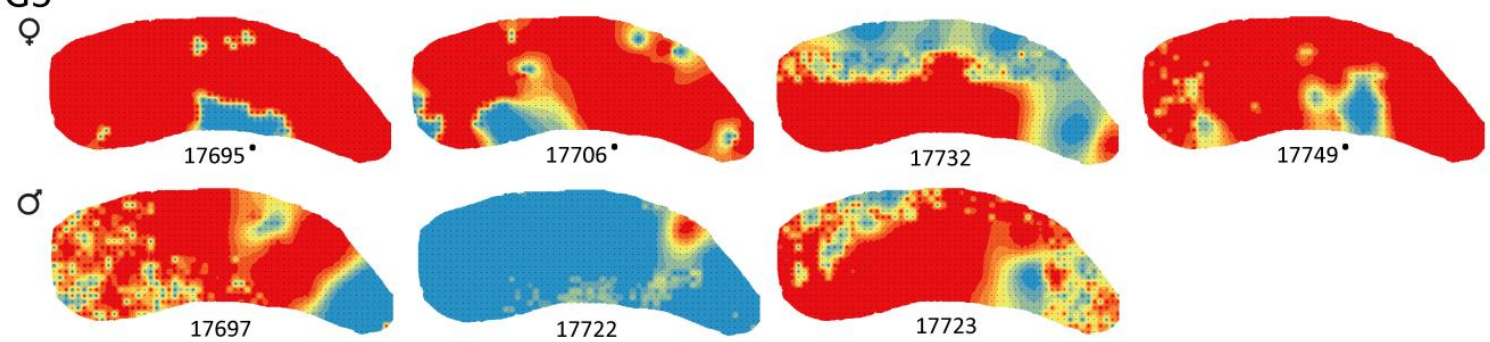

G6
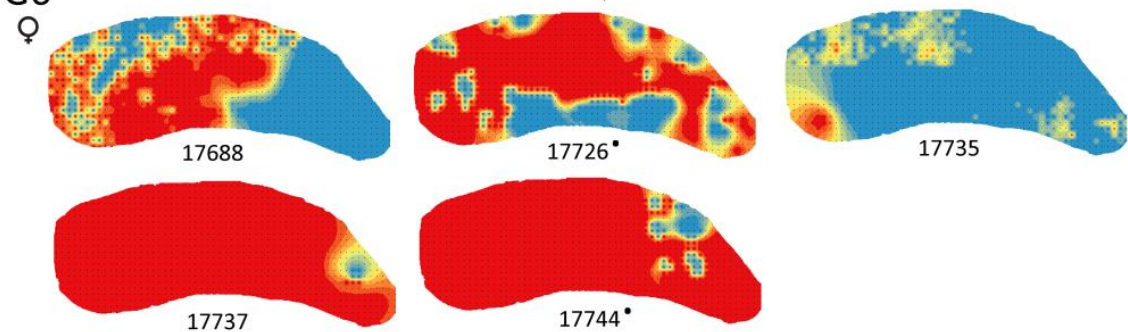

○
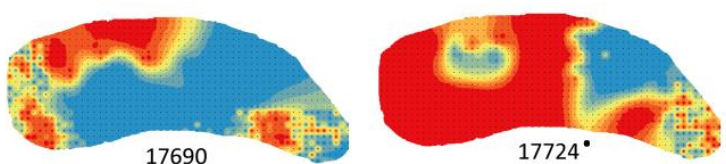

Fig. 7.7. Mapas individuales de modelado óseo del supraorbital de Pampa Grande. Los subadultos se ordenan por orden creciente de edad y los adultos, por sexo. Se señalan con puntos los individuos con $>25 \%$ de información de modelado óseo. Algunas imputaciones generaron cambios de información con valores opuestos entre celdas adyacentes de manera sucesiva. Referencias de colores en la Figura 7.3 
gran extensión en gran parte de los individuos (Fig. 7.7, G5 y G6). Sin embargo, la extensión de las áreas de reabsorción es menor en aquellos individuos con más información relevada. Si se considera sólo a los individuos con más información presente, se visualiza un incremento de reabsorción en la superficie a nivel general. Esta caracterización se da indistintamente en ambos sexos. Finalmente, como se observara en el mapa general total (Fig. 7.3, 1d), la superficie del supraorbital presenta una alternancia de actividades de remodelado óseo, salvo para el par frontal, que tiende a presentar en mayor proporción reabsorción en ambos grupos etarios.

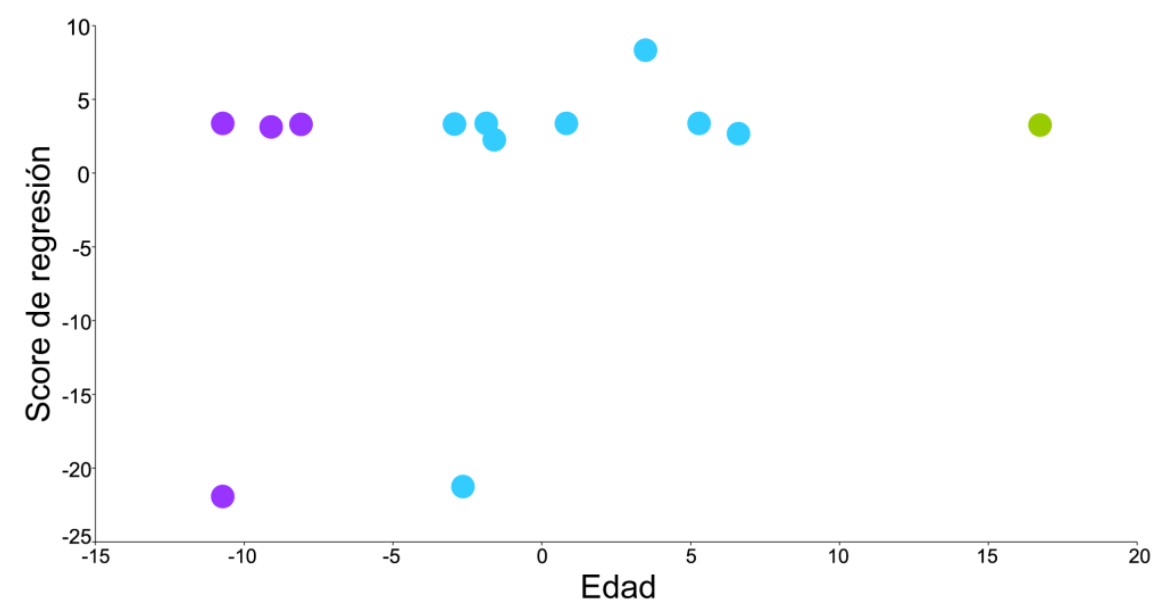

Fig. 7.8. Cambios en forma por modelado óseo en supraorbital de subadultos de Pampa Grande en función de la edad. La edad se obtuvo del score del CP1 del desarrollo dental. La forma corresponde a los scores del CP1 y CP2 del modelado óseo (referencia en Fig. 7.6)

$\underline{\text { Malar }}$

En la Figura 7.9 se observa el patrón de modelado óseo individual para el malar. Los mapas generales restrictivos obtenidos previamente (Fig. 7.3, 3a,c) incluyeron información de todo el rango etario y de ambos sexos.

El patrón de modelado óseo presenta cambios asociados a la edad. En general, los individuos entre 4,5-14,4 difieren de aquellos de hasta 4,4 años incluidos en el G1 (Fig. 7.9). A partir de los mapas individuales, se puede observar en subadultos una predominancia de formación para el primer grupo, con áreas de diferente extensión sobre el borde orbital (Fig. 7.9, G1). Posteriormente, la presencia de reabsorción se incrementa, principalmente en extensión, sobre el borde orbital (Fig. 7.9, G2). La extensión de la reabsorción disminuye en el tercer grupo etario, aunque su localización sigue siendo en la región anterior del malar (Fig. 7.9, G3). En adultos jóvenes se incrementa nuevamente la presencia de reabsorción ósea, 
G1
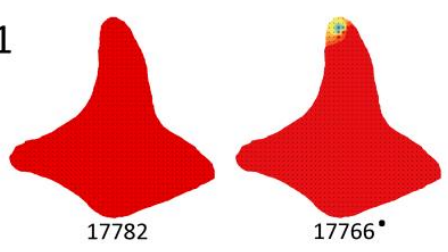

G2
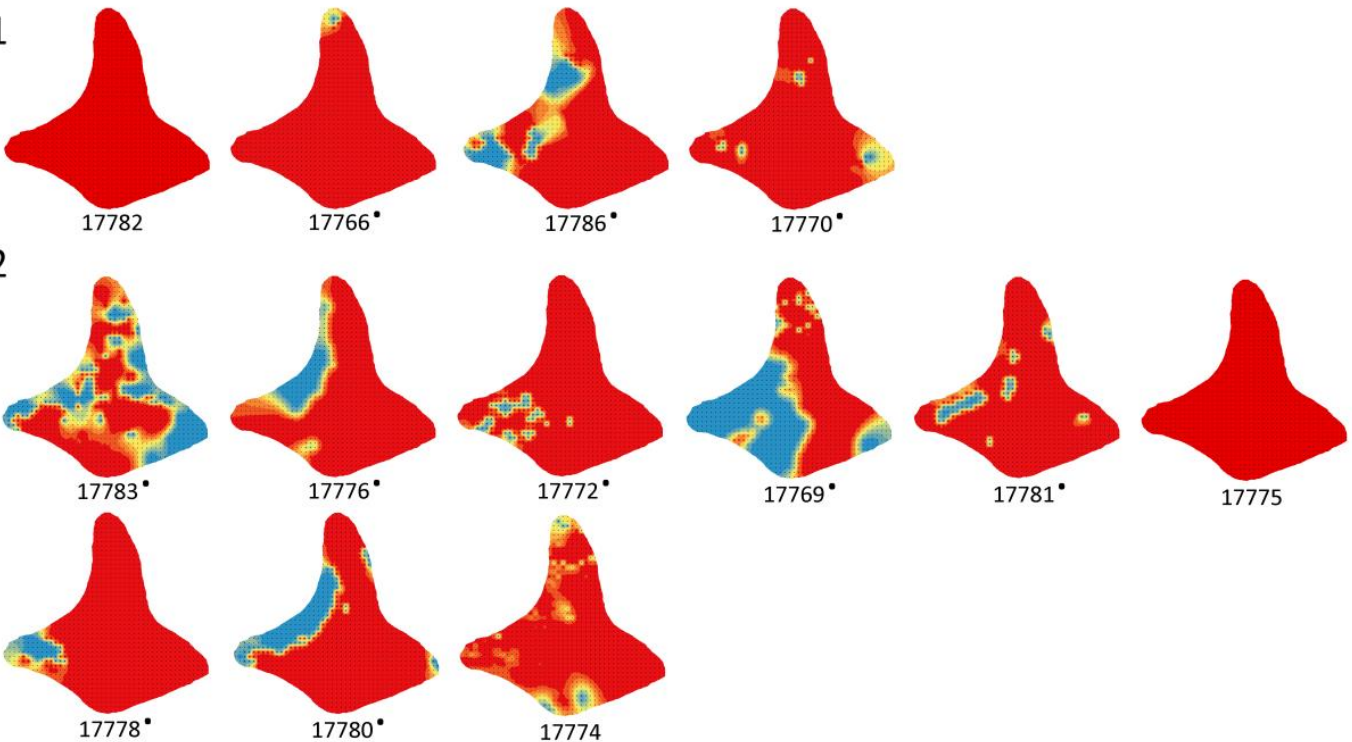

G3
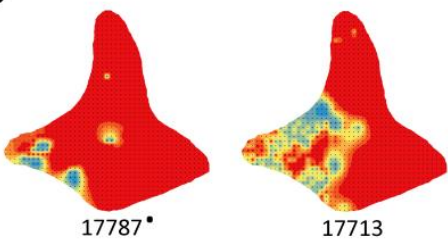

G5
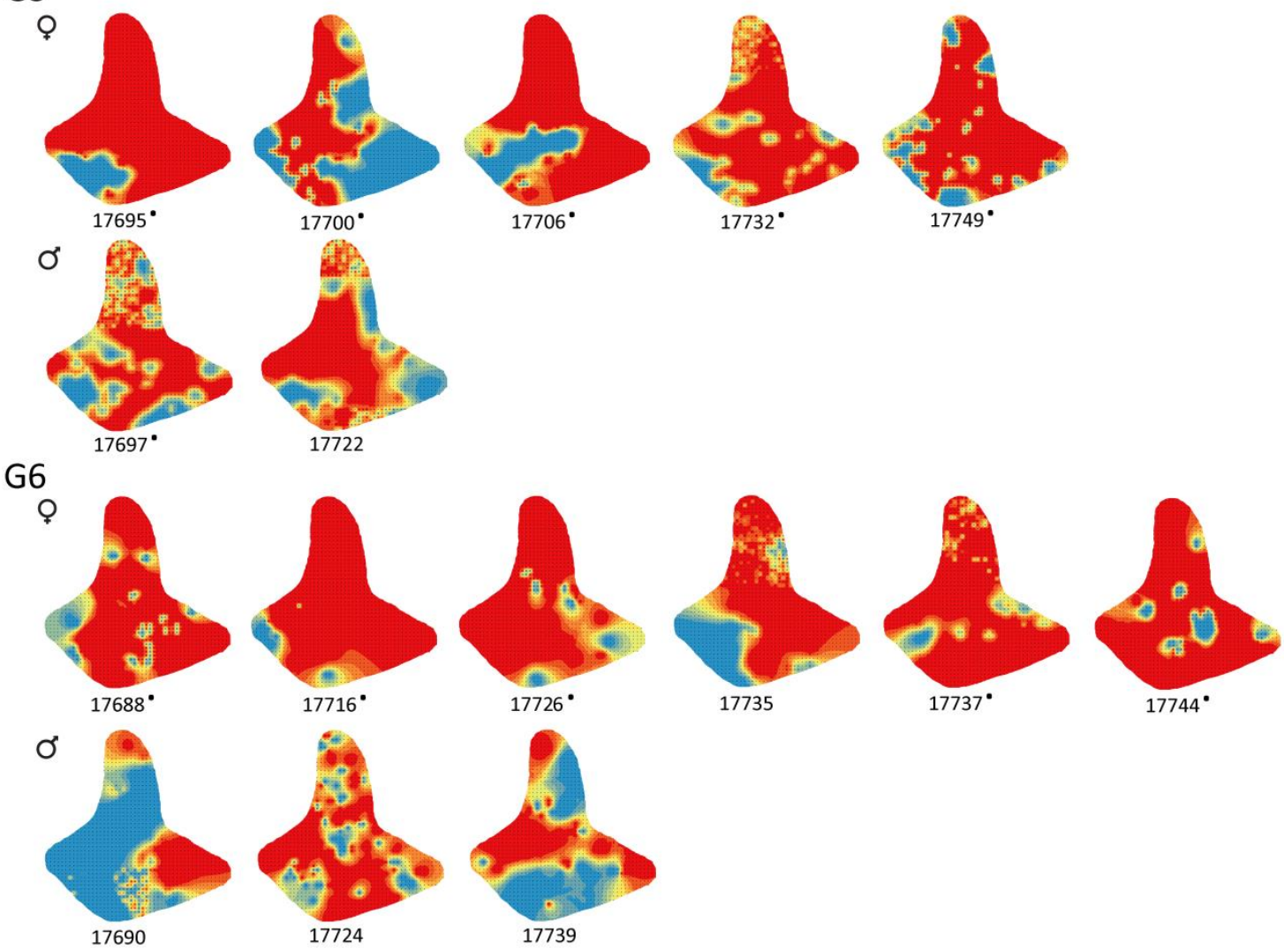

Fig. 7.9. Mapas individuales de modelado óseo del malar de Pampa Grande. Los subadultos se ordenan por orden creciente de edad y los adultos, por sexo. Se señalan con puntos los individuos con $>25 \%$ de información de modelado óseo. Algunas imputaciones generaron cambios de información con valores opuestos entre celdas adyacentes de manera sucesiva. Referencias de colores en la Figura 7.3 
extendiéndose su localización a la región posterior del malar. Se restringe la presencia de reabsorción sobre el borde orbital y, por el contrario, se hace más frecuente en el borde maxilar (Fig. 7.9, G5). En el último grupo se vuelve a observar un incremento de formación ósea con algunas áreas de reabsorción ósea distribuidas aleatoriamente (Fig. 7.9, G6). Los individuos con predominancia de reabsorción corresponden a individuos con poca información histológica relevada.

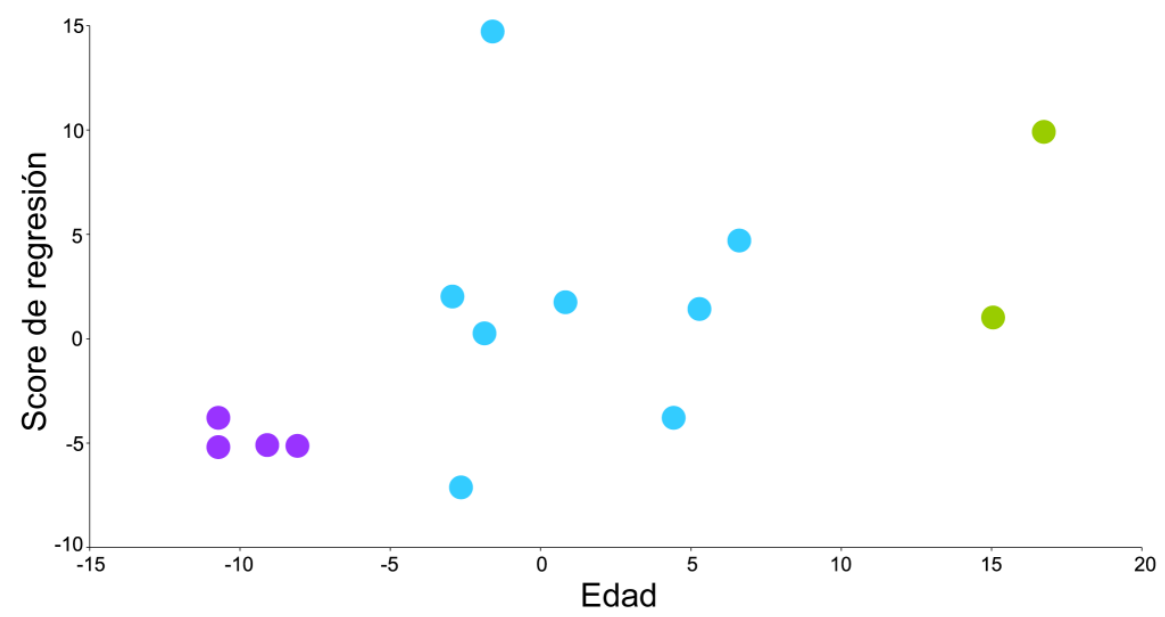

Fig. 7.10. Cambios en forma por modelado óseo en malar de subadultos de Pampa Grande en función de la edad. La edad se obtuvo del score del CP1 del desarrollo dental. La forma corresponde a los scores del CP1 al CP5 del modelado óseo (referencia en Fig. 7.6)

\section{Maxilar}

En la Figura 7.11 se presenta el patrón de modelado óseo individual para el maxilar. Los mapas restrictivos (Fig. 7.3, 3a,c) incluyeron información proveniente de todos los grupos etarios y, en adultos, de ambos sexos.

Respecto al patrón de modelado óseo, se pueden observar cambios asociados a la edad. En general, el patrón de modelado es similar en los individuos hasta 10,4 años (G1 y G2), mientras que se modifica en los individuos de 10,5-14,4 (G3; Fig. 7.12). A partir de los mapas individuales se puede observar que, inicialmente, el patrón se caracteriza por la predominancia de formación con presencia de reabsorción ósea en la región anterior del maxilar (Fig. 7.11, G1). En el siguiente grupo etario, las áreas con reabsorción son más extensas y, a su vez, aparecen áreas con reabsorción ósea en la región del proceso frontal (Fig. 7.11, G2). La extensión de la reabsorción en el cuerpo del maxilar se mantiene en el G3, sin embargo, cambia en el proceso frontal que presenta exclusivamente formación (Fig. 7.11, G3). En adultos jóvenes (G5), se mantiene la presencia reabsorción en la región del proceso alveolar, 
G1

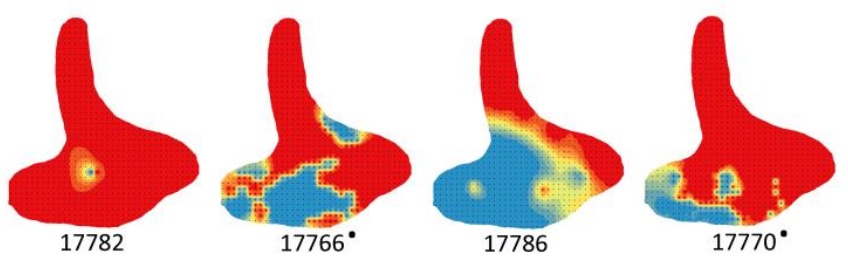

G2
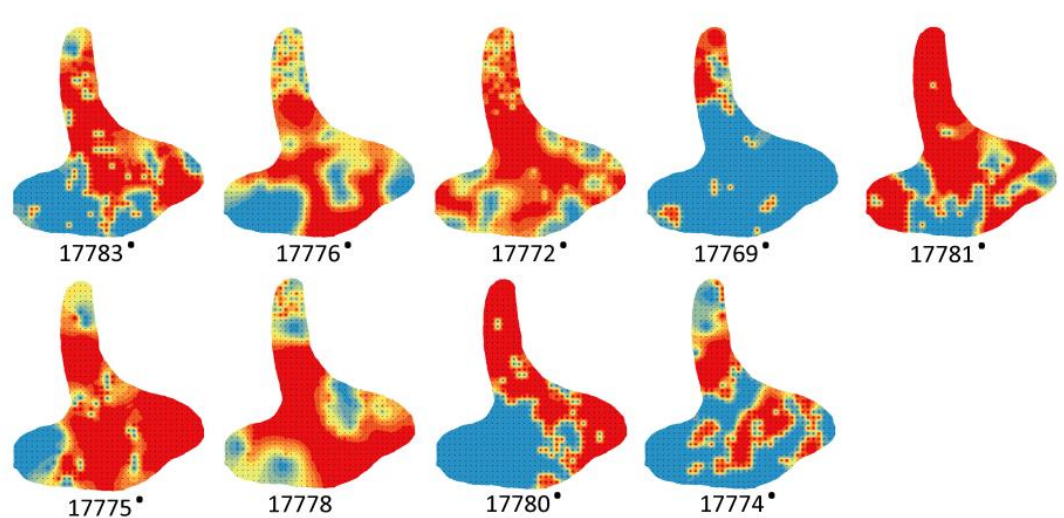

G3

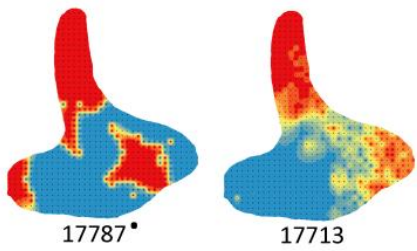

G5
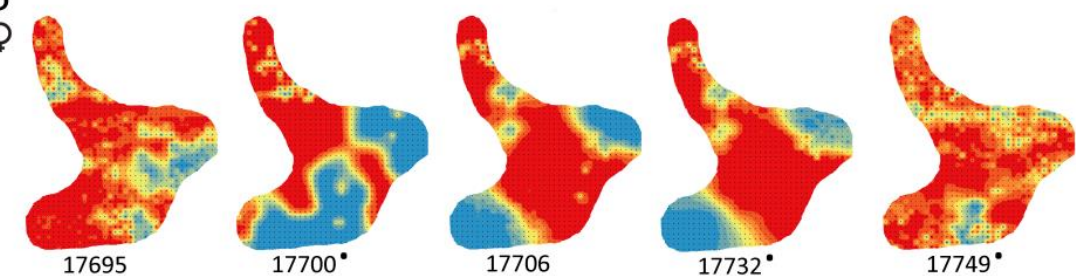

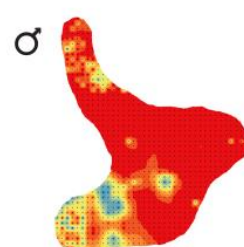

17697

G6
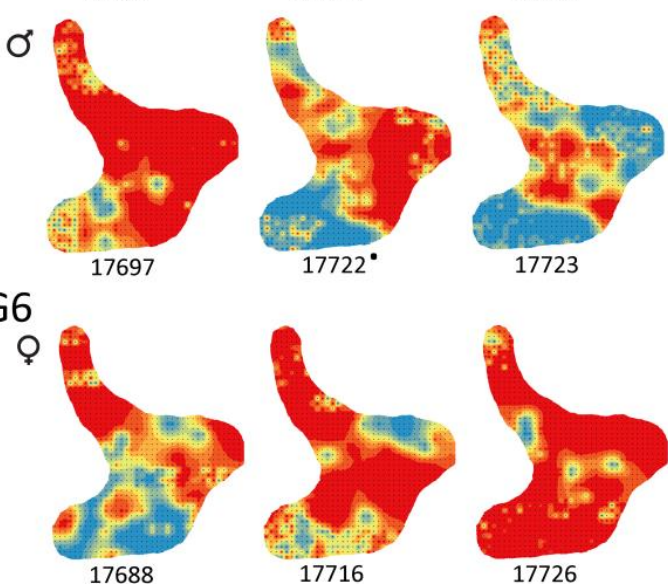

17723
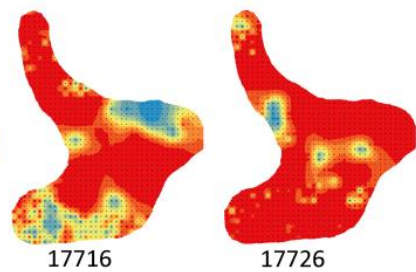
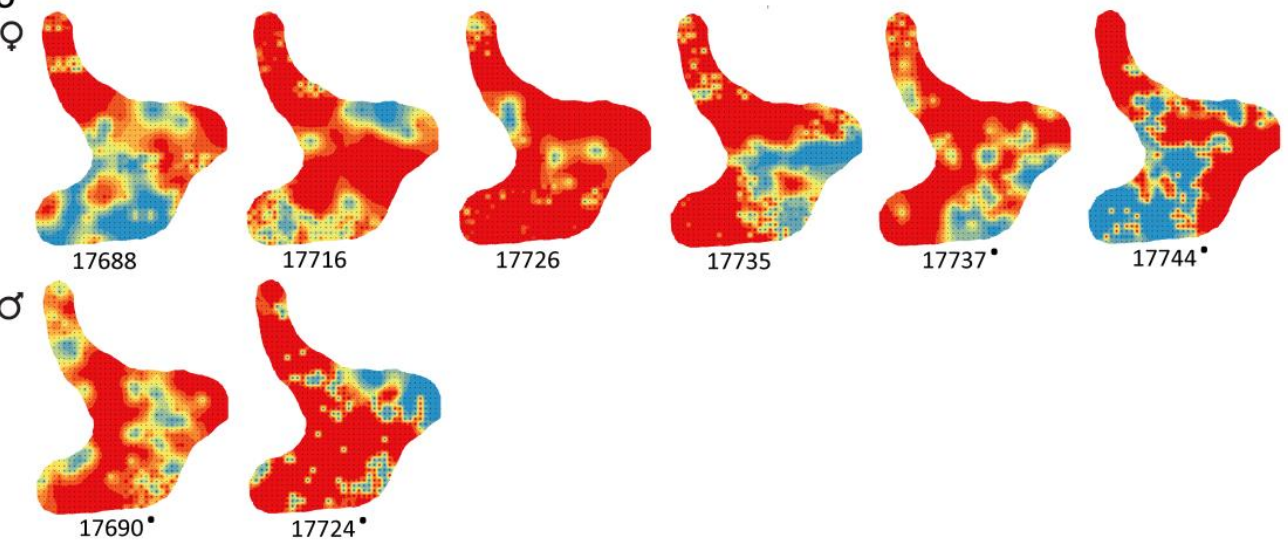

Fig. 7.11. Mapas individuales de modelado óseo del maxilar de Pampa Grande. Los subadultos se ordenan por orden creciente de edad y los adultos, por sexo. Se señalan con puntos los individuos con $>25 \%$ de información de modelado óseo. Algunas imputaciones generaron cambios de información con valores opuestos entre celdas adyacentes de manera sucesiva. Referencias de colores en la Figura 7.3 
pero a diferencia del grupo etario anterior, en la fosa canina empieza a predominar la formación ósea. En el proceso frontal se mantiene la predominancia de formación con algunas áreas de reabsorción ósea. Finalmente, para el proceso cigomático varía entre predominancia de formación o de reabsorción entre individuos (Fig. 7.11, G5). En los adultos medio (G6), nuevamente hay predominancia de formación ósea sobre reabsorción. La región anterior del maxilar se caracteriza por presentar principalmente formación. En el borde alveolar se registra reabsorción, asociada a la porción posterior. El proceso frontal mantiene la caracterización observada en adultos jóvenes, con predominancia de formación y áreas de reabsorción. En el resto de la superficie del maxilar, ambas actividades de remodelado óseo se presentan indistintamente, con diferencias en extensión y en distribución. Dos áreas de reabsorción más o menos constantes se ubican en la región contigua a la apertura piriforme, correspondiente al alar, y en la región del foramen infraorbitario (Fig. 7.11, G6).

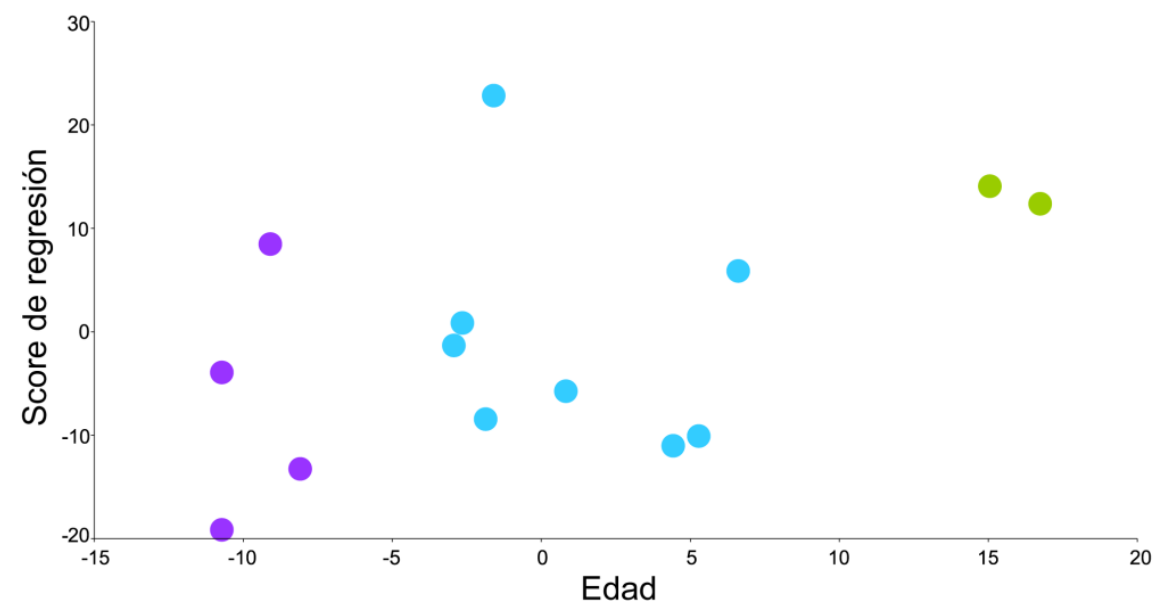

Fig. 7.12. Cambios en forma por modelado óseo en maxilar de subadultos de Pampa Grande en función de la edad. La edad se obtuvo del score del CP1 del desarrollo dental. La forma corresponde a los scores del CP1 al CP6 del modelado óseo (referencia Fig. 7.6)

\subsubsection{Patrones de modelado óseo individuales en la muestra de Chubut}

Glabela

En la Figura 7.13 se presenta el patrón de modelado óseo individual de la glabela. Los mapas generales restrictivos cuentan con información de toda la serie ontogenética (Fig. 7.4, 1a,c). Sin embargo, el mapa general restrictivo de adultos (Fig. 7.4, 1c) representa principalmente la información correspondiente a la categoría adulto joven (Fig. 7.13, G5 y G6). 
Respecto a los cambios en el patrón con la edad, en subadultos se observa que los individuos entre 4,5 a 10,4 años presentan gran variación. El patrón cambia de dicho grupo al de 14,5-18 años (Fig. 14). En los mapas individuales de subadultos, si se considera aquellos con más del $25 \%$ de información, se observa que predomina la formación ósea con áreas de reabsorción dispersas. Las áreas de reabsorción se presentan dispersas en toda la superficie y su extensión se incrementa en algunos individuos que presentaron menos del $25 \%$ de información (Fig. 7.13, G1-G4). Si se considera a todos los individuos, se observa que en los individuos de 14,5-18 años la predominancia de reabsorción es mayor que en los grupos precedentes. En adultos, la presencia de actividades de formación y reabsorción ósea es equilibrada, tanto si se incluye al total de los individuos como a aquellos con más información registrada. Para adultos jóvenes, de los 4 individuos que formaron parte del mapa general restrictivo, se puede establecer una predominancia de actividad por sexo: los dos que presentaron mayormente formación son femeninos, mientras que los dos que presentaron predominancia de reabsorción son masculinos (Fig. 7.13, G5). En los adultos medio, si se considera la totalidad de individuos, se observa que el patrón se mantiene, con los femeninos caracterizados por predominancia de formación y los masculinos con predominancia de reabsorción (Fig. 7.13, G6).

G1

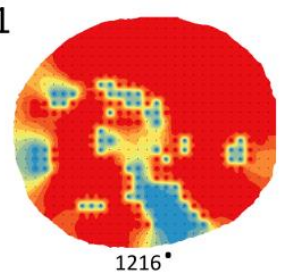

G2
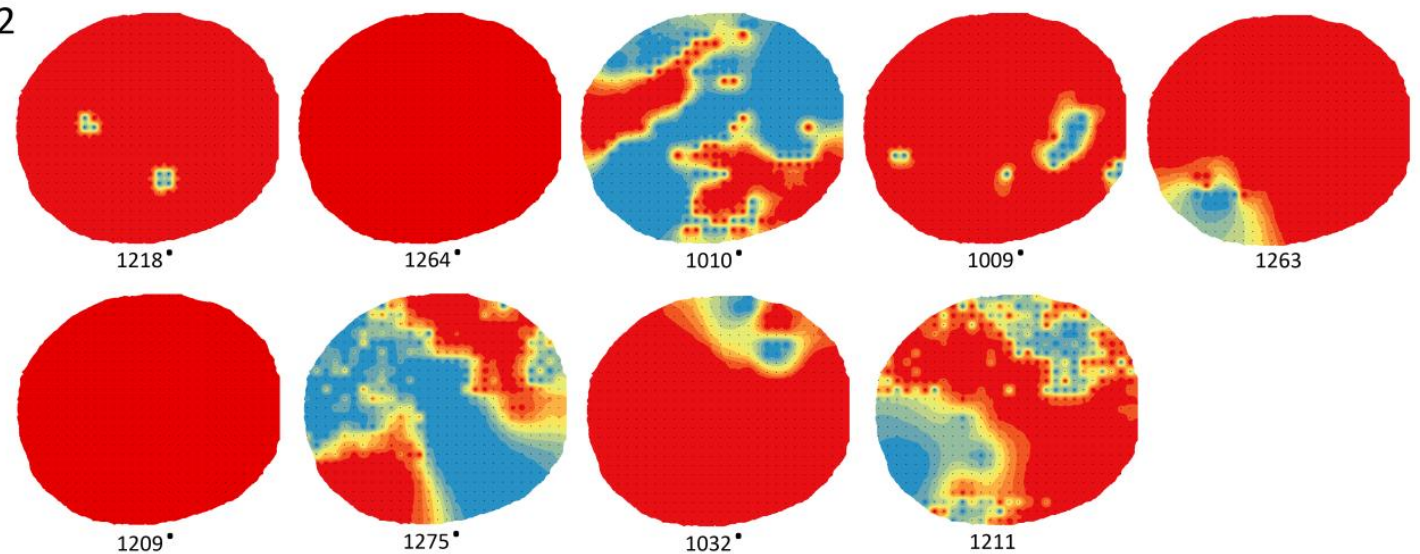

Continúa en la siguiente página 
G3
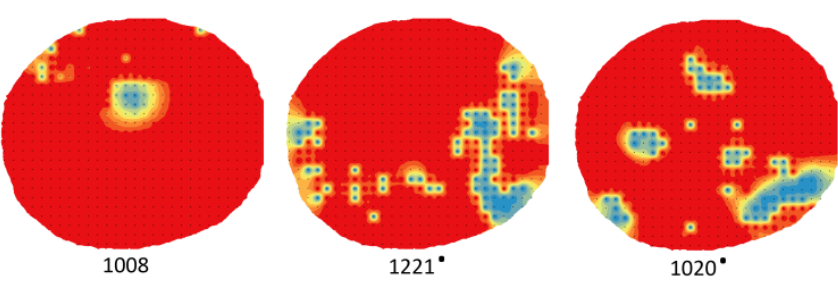

G4
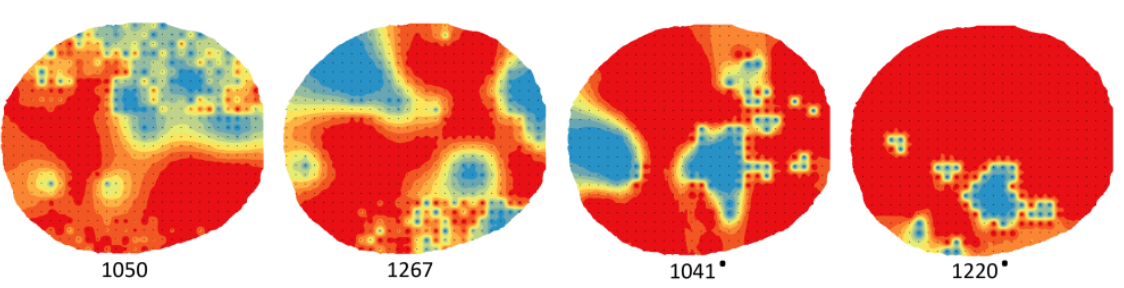

G5

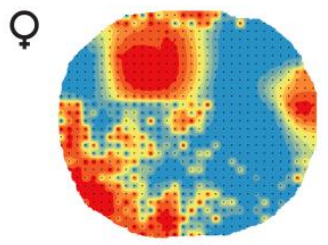

1083
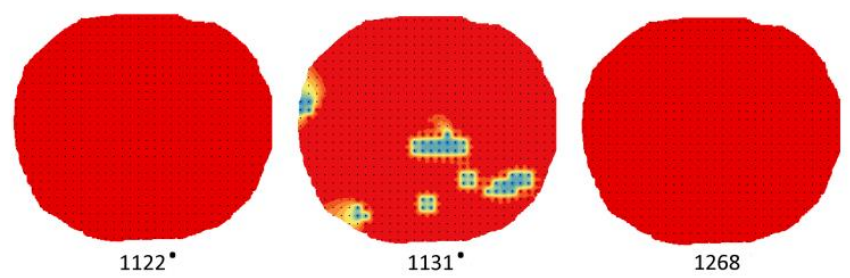

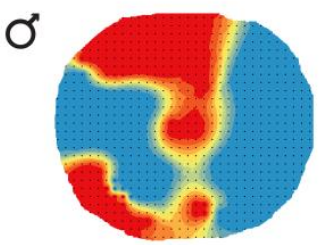

$1014^{\circ}$

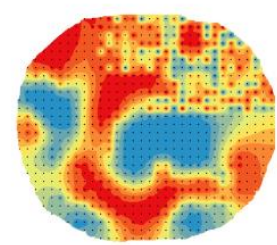

$1098^{\circ}$

G6

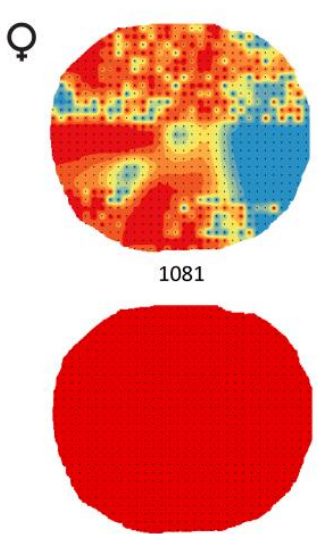

1132

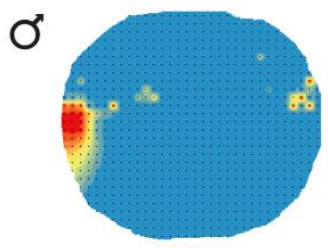

1104

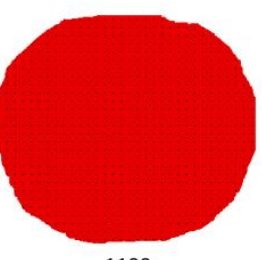

1100

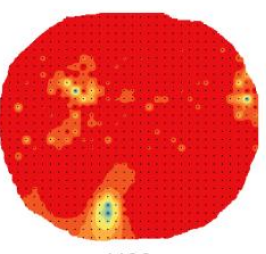

1136

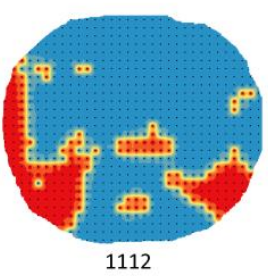

Fig. 7.13. Mapas individuales de modelado óseo de la glabela de Chubut. Los subadultos se ordenan por orden creciente de edad y los adultos, por sexo. Se señalan con puntos los individuos con $>25 \%$ de información de modelado óseo. Algunas imputaciones generaron cambios de información con valores opuestos entre celdas adyacentes de manera sucesiva. Referencias de colores en la Figura 7.4 


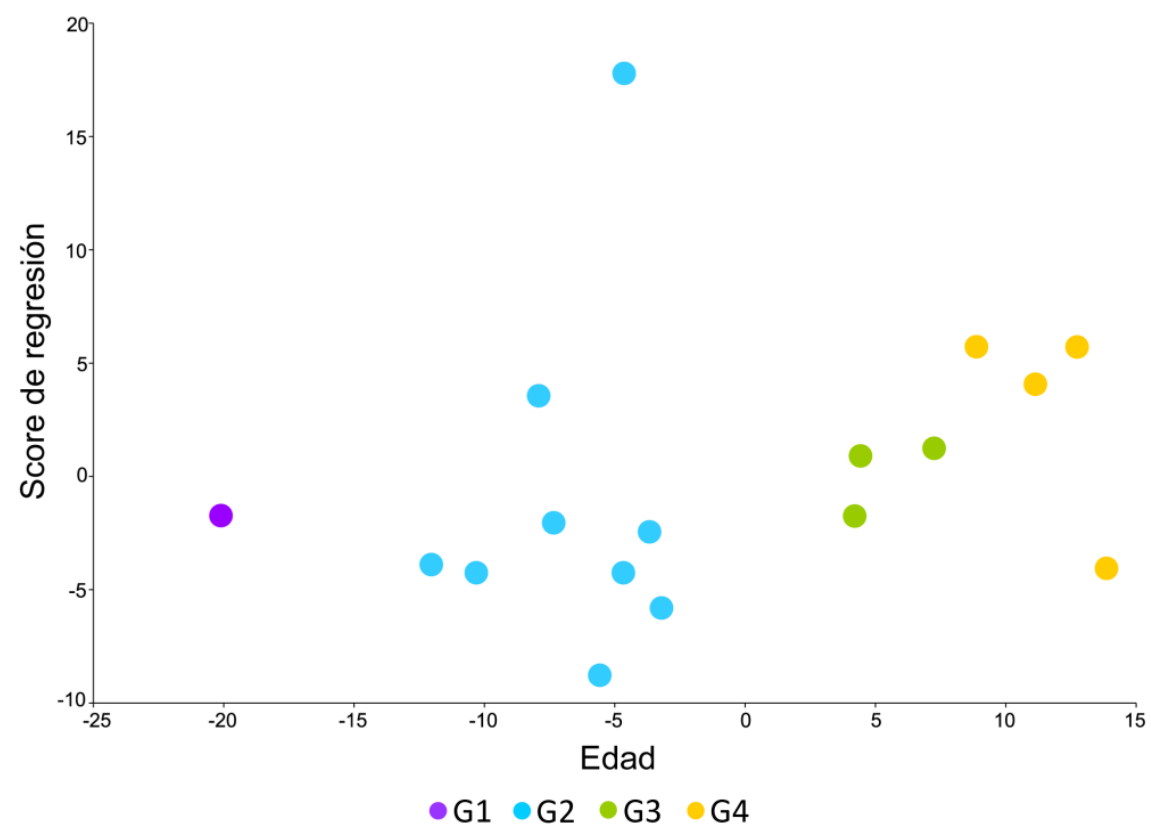

Fig. 7.14. Cambios en forma por modelado óseo en glabela de subadultos de Chubut en función de la edad. La edad se obtuvo del score del CP1 del desarrollo dental. La forma corresponde a los scores del CP1 al CP5 del modelado óseo

\section{Supraorbital}

En la Figura 7.15 se presenta el patrón de modelado óseo individual del supraorbital. Los mapas generales restrictivos incluyen individuos de todos los grupos etarios y, en adultos, datos de ambos sexos (Fig. 7.4, 2a,c). Respecto a los cambios observados en el patrón de modelado óseo, es bastante similar a lo largo de los subadultos, salvo en el G4 donde algunos de los individuos se apartan de la distribución (Fig. 7.16). En los mapas individuales, si se considera el total de los subadultos, se observa predominancia de formación ósea y áreas más o menos extensas de reabsorción hasta los 14,4 años. La distribución de la reabsorción ósea es aleatoria entre individuos y no se observan cambios asociados a las distintas regiones del supraorbital (Fig. 7.15, G1-G3). En los individuos de 14,5 a 18 años hay una distribución similar de las actividades de modelado óseo, que no muestra predominancia en ninguna región (Fig. 7.15, G4). Como se observó en la glabela, los adultos jóvenes femeninos exhiben predominancia de formación, mientras que en los masculinos predomina la reabsorción (Fig. 7.15, G5). En los individuos del grupo adulto medio sólo se mantiene esta relación si se considera a aquellos individuos con más información, mientras que si se considera a la totalidad de adultos, la frecuencia de actividad celular no se diferencia por sexo (Fig. 7.15, G6). 
G1

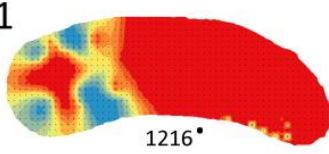

G2
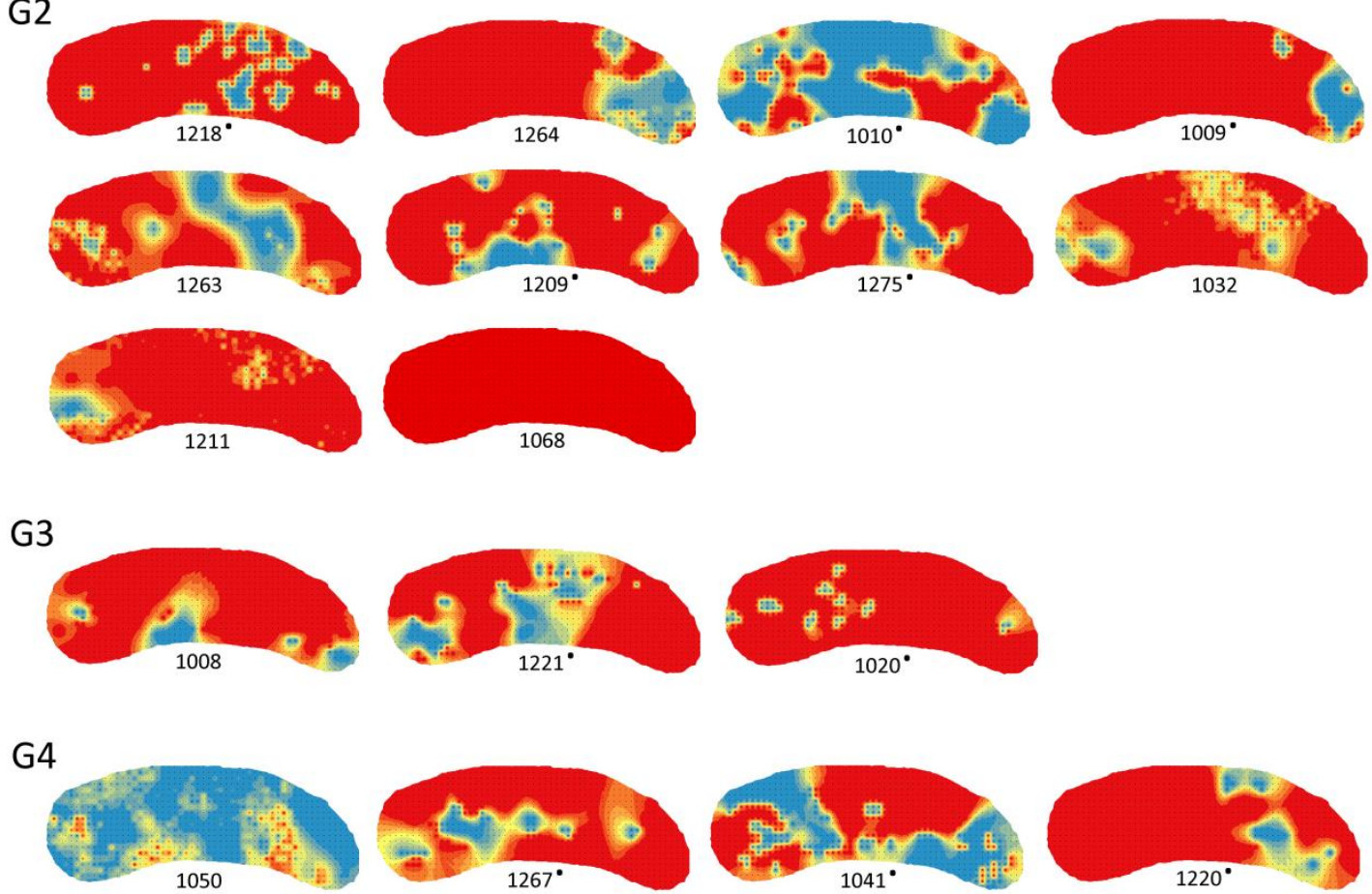

G5
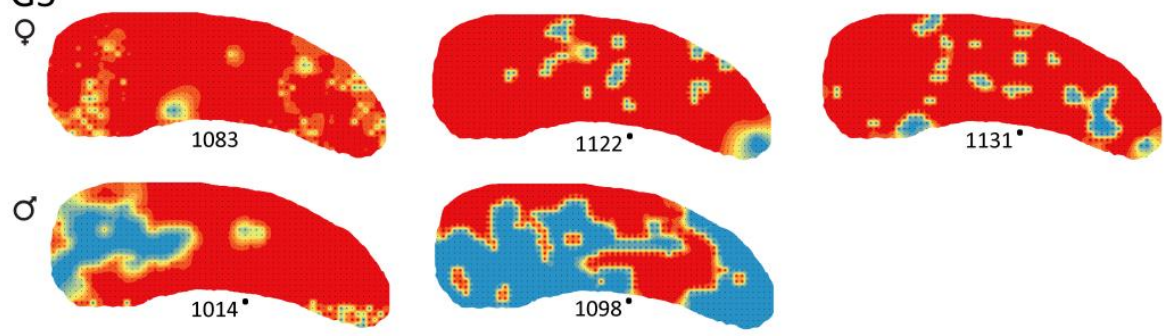

G6
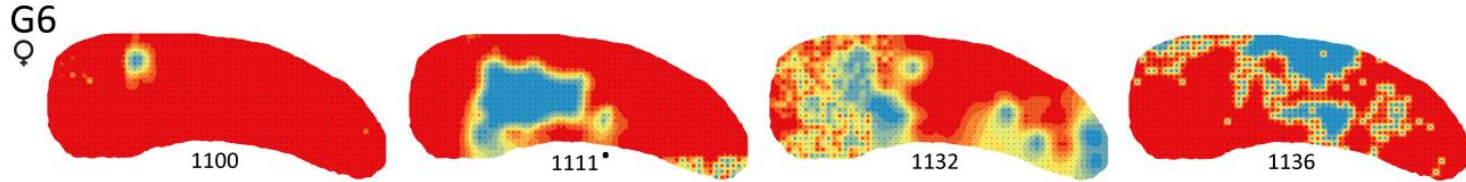

○
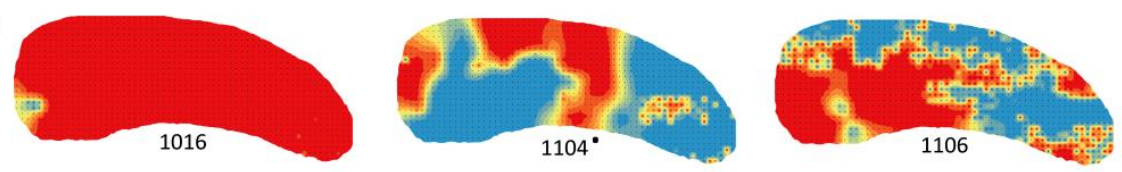

Fig. 7.15. Mapas individuales de modelado óseo del supraorbital de Chubut. Los subadultos se ordenan por orden creciente de edad y los adultos, por sexo. Se señalan con puntos los individuos con $>25 \%$ de información de modelado óseo. Algunas imputaciones generaron cambios de información con valores opuestos entre celdas adyacentes de manera sucesiva. Referencias de colores en la Figura 7.4 


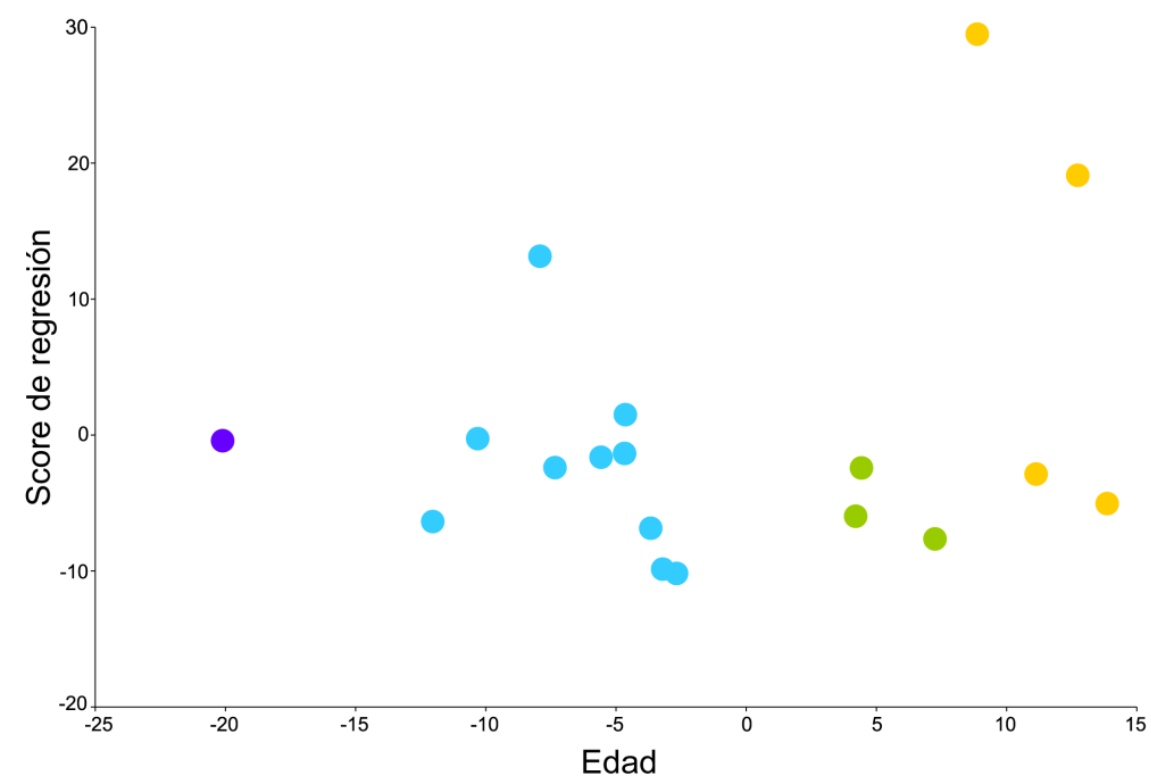

Fig. 7.16. Cambios en forma por modelado óseo en supraorbital de subadultos de Chubut en función de la edad. La edad se obtuvo del score del CP1 del desarrollo dental. La forma corresponde a los scores del CP1 al CP6 del modelado óseo (referencia Fig. 7.14)

Malar

En la Figura 7.17 se presenta el patrón de modelado óseo individual para el malar. Los mapas generales restrictivos contienen información proveniente de todo el rango etario y de ambos sexos (Fig. 7.4, 3a,c). Respecto a la variación observada en los patrones de modelado a través de la edad en subadultos, se observa que los individuos de 14,5-18 años se diferencian de los asignados al intervalo 4,5-14,4 (Fig. 7.18). El malar de subadultos se caracteriza por presentar similar distribución de ambos tipos de actividad ósea (Fig. 7.17, G1-G4). Hay incremento de formación ósea en los grupos G2 y G3 en comparación a G1 y G4. La reabsorción se distribuye a lo largo de toda la superficie inferior del malar, tanto en la región anterior como posterior. Hay algunas áreas de reabsorción en el proceso frontal, pero no son frecuentes. Se observa la presencia de reabsorción principalmente en el borde inferior del borde orbital. Si bien en todos los grupos de edad de subadultos se observa reabsorción en la parte posterior, en G4 hay áreas mayores ubicadas en el borde masetero. En adultos, hay alternancia de actividad entre individuo así como una distribución de ambas actividades en toda la superficie. Los adultos jóvenes muestran, en general, reabsorción asociada al borde orbital, pero no localizada exclusivamente en la adyacencia del borde maxilar como en subadultos (Fig. 7.17). Esta localización de la reabsorción se pierde en los individuos del grupo G6 (Fig. 7.17, G6). La predominancia de reabsorción en la región posterior del malar se mantiene en ambos grupos de edad. Finalmente, si se considera a los individuos con más información, se observa un incremento de reabsorción ósea de adultos joven a medio (Fig. 7.17, G5 y G6). 


$$
\begin{aligned}
& 4 \\
& 4441 \\
& 440 \\
& 444
\end{aligned}
$$



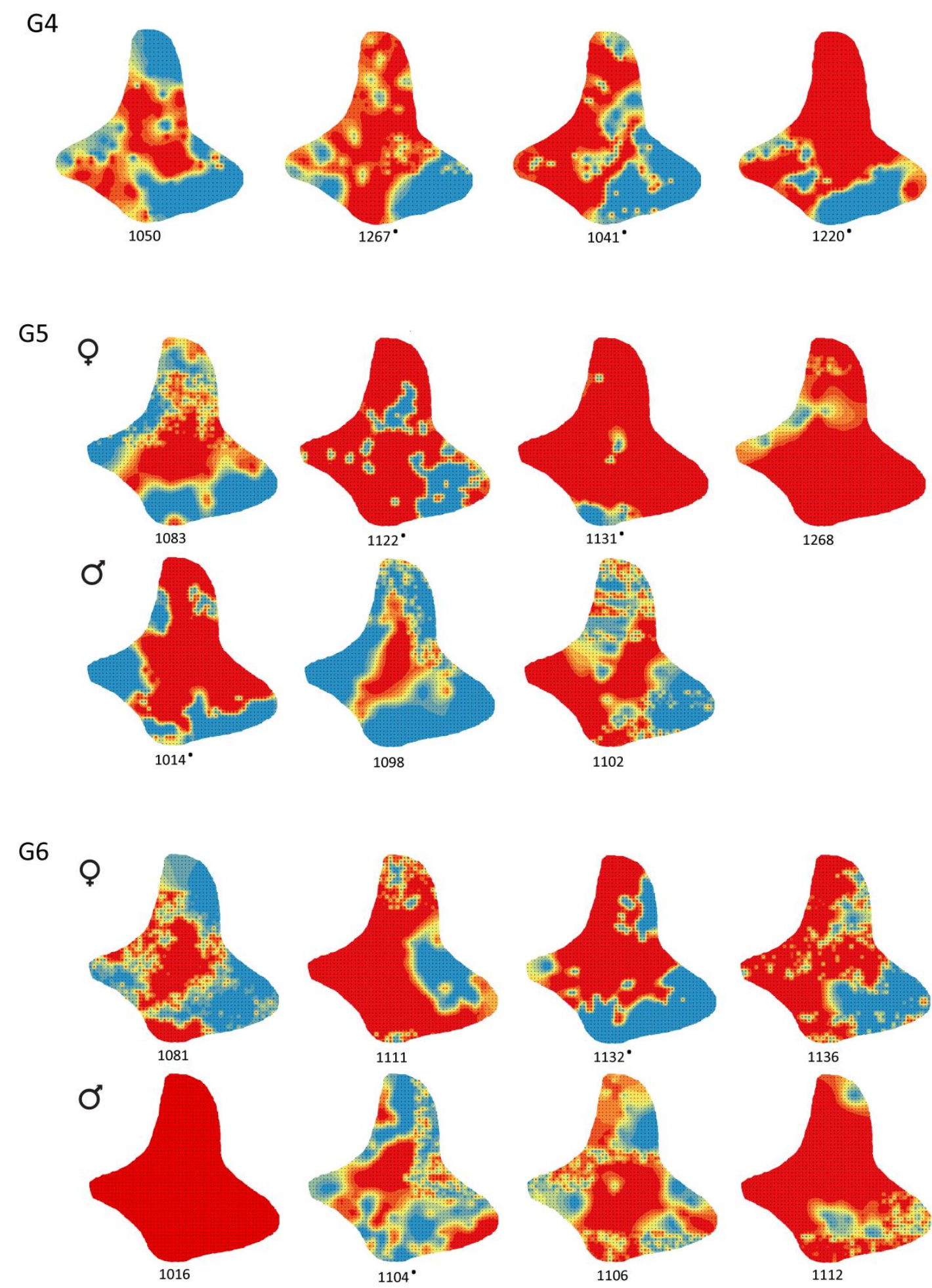

Fig. 7.17. Mapas individuales de modelado óseo del malar de Chubut. Los subadultos se ordenan por orden creciente de edad y los adultos, por sexo. Se señalan con puntos los individuos con $>25 \%$ de información de modelado óseo. Algunas imputaciones generaron cambios de información con valores opuestos entre celdas adyacentes de manera sucesiva. Referencias de colores en la Figura 7.4 


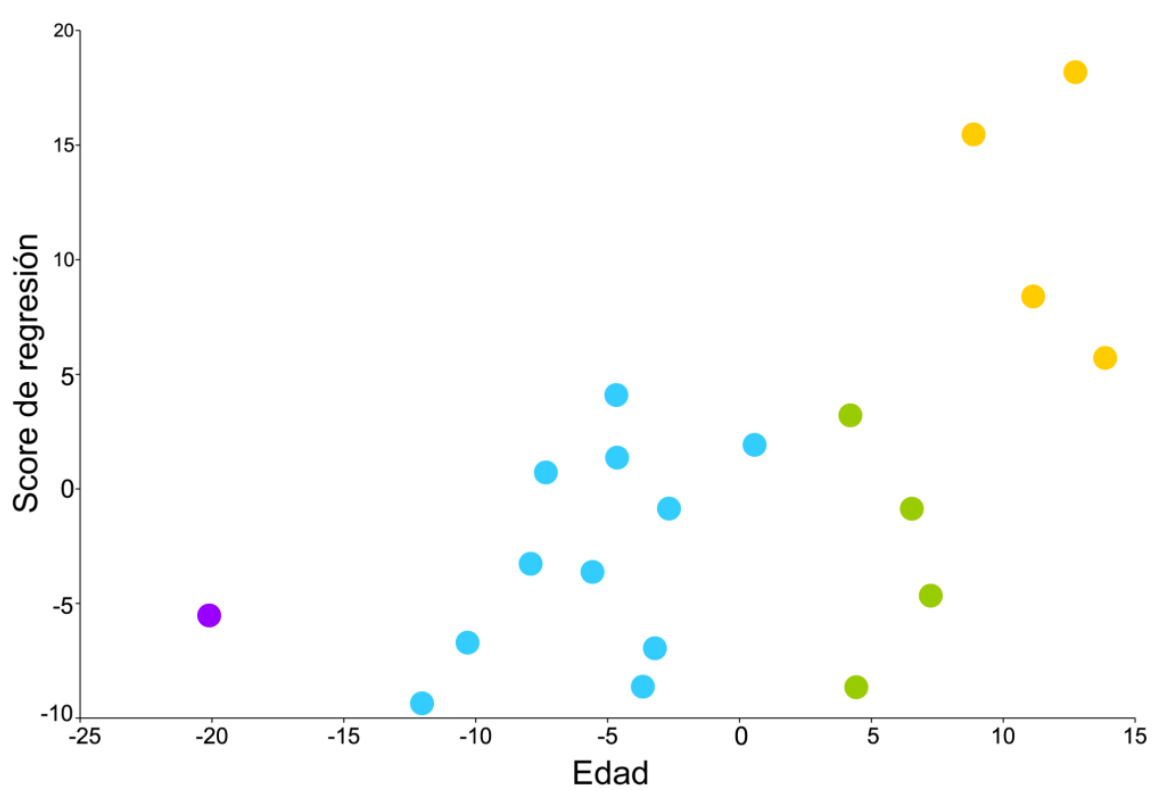

Fig. 7.18. Cambios en forma por modelado óseo en malar de subadultos de Chubut en función de la edad. La edad se obtuvo del score del CP1 del desarrollo dental. La forma corresponde a los scores del CP1 al CP8 del modelado óseo (referencia en Fig. 7.14)

\section{Maxilar}

En la Figura 7.19 se presenta el patrón de modelado óseo individual del maxilar. Los mapas generales restrictivos están conformados por individuos de todas las edades (Fig. 7.4, 4a,c). En adultos, el mapa restrictivo no contiene información asociada a los adultos medio de sexo masculino (Fig. 7.4, 4c). Respecto a la variación con la edad en el patrón de modelado óseo, se pueden observar cambios entre los grupos. Los individuos de 4,5-10,4 años (G2) presentan gran variación. Los individuos de entre 10,5-14,4 años (G3), en general, se asemejan al patrón registrado en parte del grupo G2, mientras que el patrón cambia entre 14,5-18 años (G4). Un individuo del G3 presenta un patrón similar al del G4, así como uno del G4 al patrón general del G3 (Fig. 7.20). En los mapas individuales se observa que en el individuo menor a 4,4 años (G1) se encuentran ambos tipos de actividad de modelado óseo, con formación a lo largo del proceso frontal y de la fosa canina, y reabsorción en los procesos alveolar y cigomático, así como en el foramen infraorbitario (Fig. 7.19, G1). En el siguiente grupo de edad, se expande el área de reabsorción a lo largo de la fosa canina, con áreas de reabsorción más extensas en el proceso frontal (Fig. 7.19, G2). La predominancia de reabsorción es marcada en el G3 a lo largo de toda la superficie del maxilar. Sin embargo, sólo un individuo presenta más del $25 \%$ de información relevada, el cual presenta formación en el proceso frontal (Fig. 7.19, G3). Esta tendencia se revierte en el G4, en el que se observa mayor presencia de formación ósea. En el proceso frontal predomina la formación, mientras que la mayor parte de los individuos -todos 
con más del $25 \%$ de información- presentan reabsorción principalmente en los procesos alveolar y cigomático (Fig. 7.19, G4). En adultos jóvenes femeninos se mantiene el patrón registrado en el G4, mientras que el único masculino presenta mayormente reabsorción todos ellos con más del $25 \%$ de información registrada-. Las regiones de reabsorción corresponden principalmente a los procesos alveolar y cigomático, y al foramen infraorbitario (Fig. 7.19, G5). Finalmente, en los individuos del G6 se observa presencia de ambos tipos de actividad de remodelado óseo, tanto si se considera al total de individuos como a aquellos con más información relevada. La formación ósea sigue predominando en el proceso frontal y la reabsorción ósea en los procesos alveolar y cigomático. Sin embargo, la extensión de cada actividad por área varía entre individuos (Fig. 7.19, G6). Cabe destacar que el individuo que presenta reabsorción en mayor extensión en el G6 corresponde a un adulto mayor, sin embargo, presenta poca información histológica relevada (Tabla 7.1).

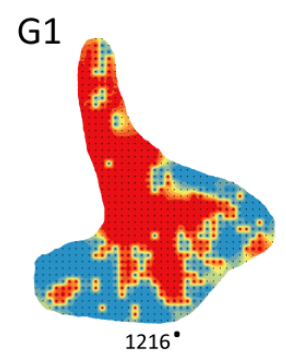

G2
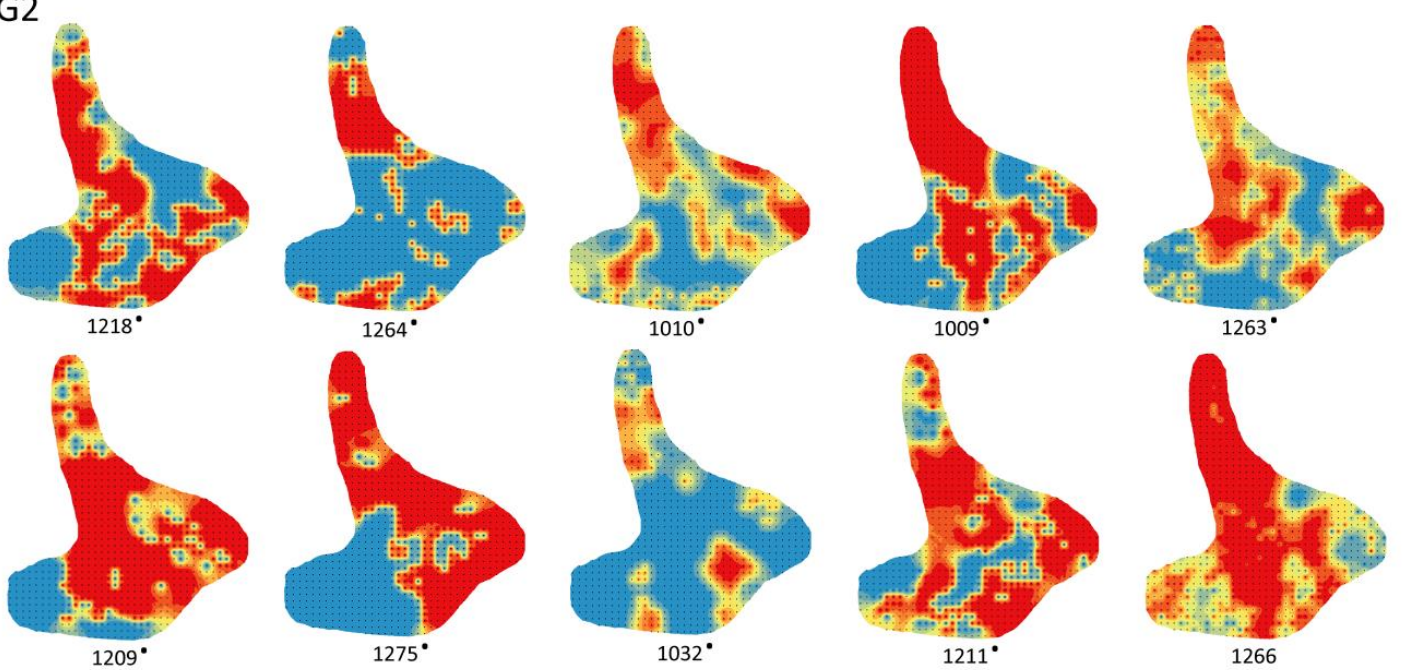

G3
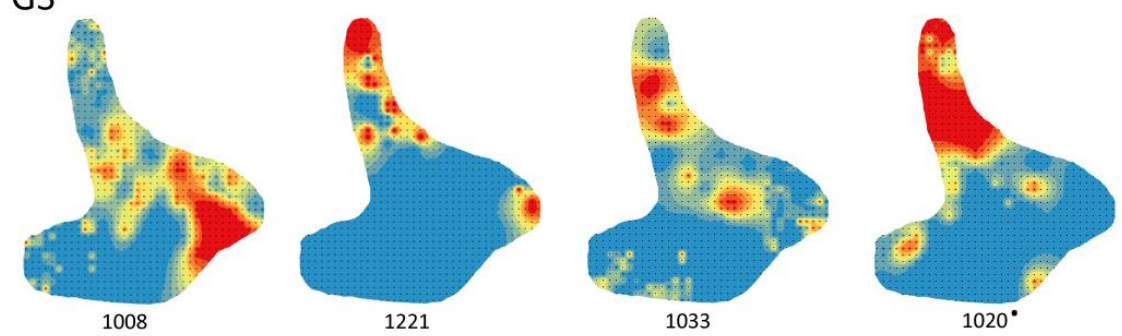

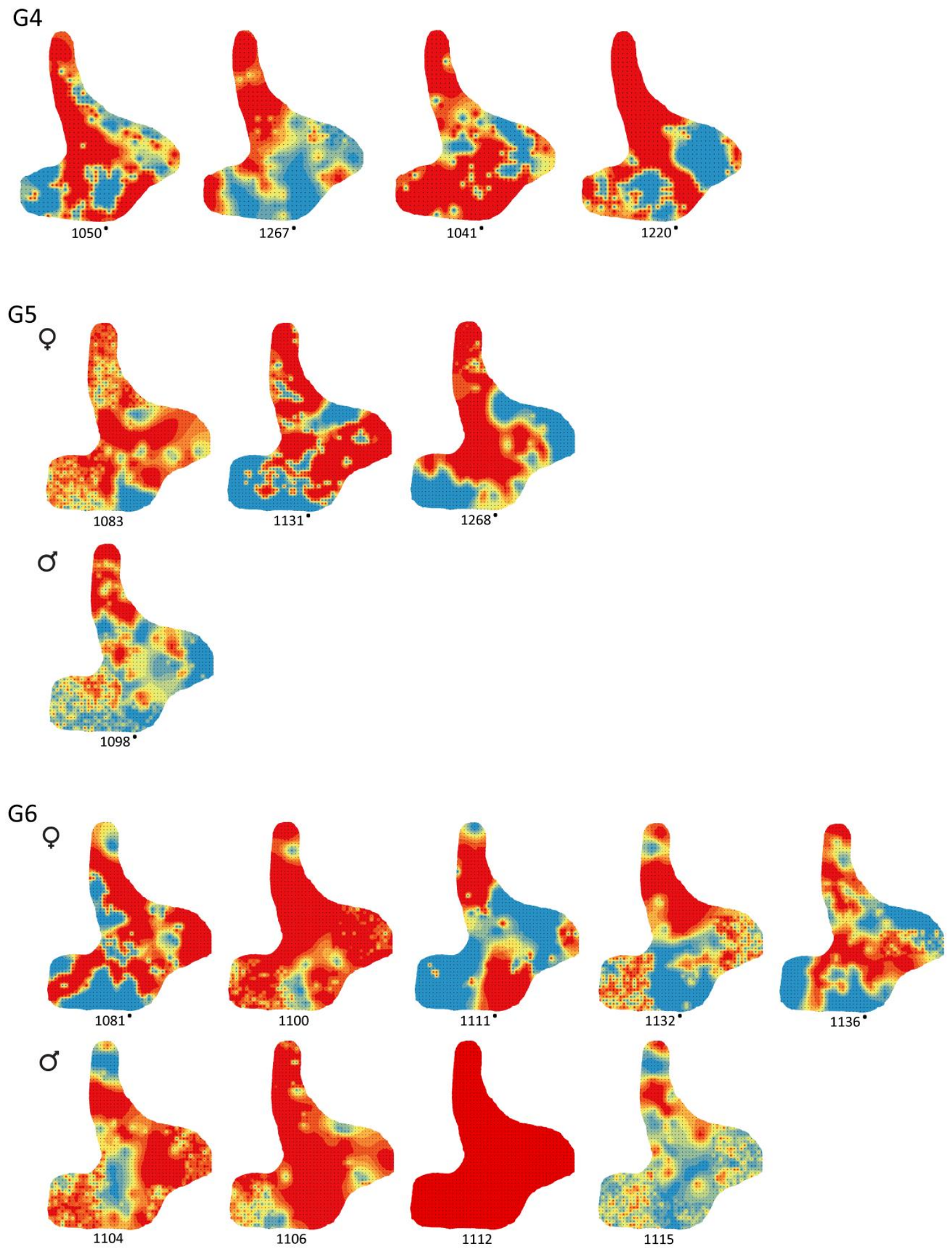

Fig. 7.19. Mapas individuales de modelado óseo del maxilar de Chubut. Los subadultos se ordenan por orden creciente de edad y los adultos, por sexo. Se señalan con puntos los individuos con $>25 \%$ de información de modelado óseo. Algunas imputaciones generaron cambios de información con valores opuestos entre celdas adyacentes de manera sucesiva. Referencias de colores en la Figura 7.4 


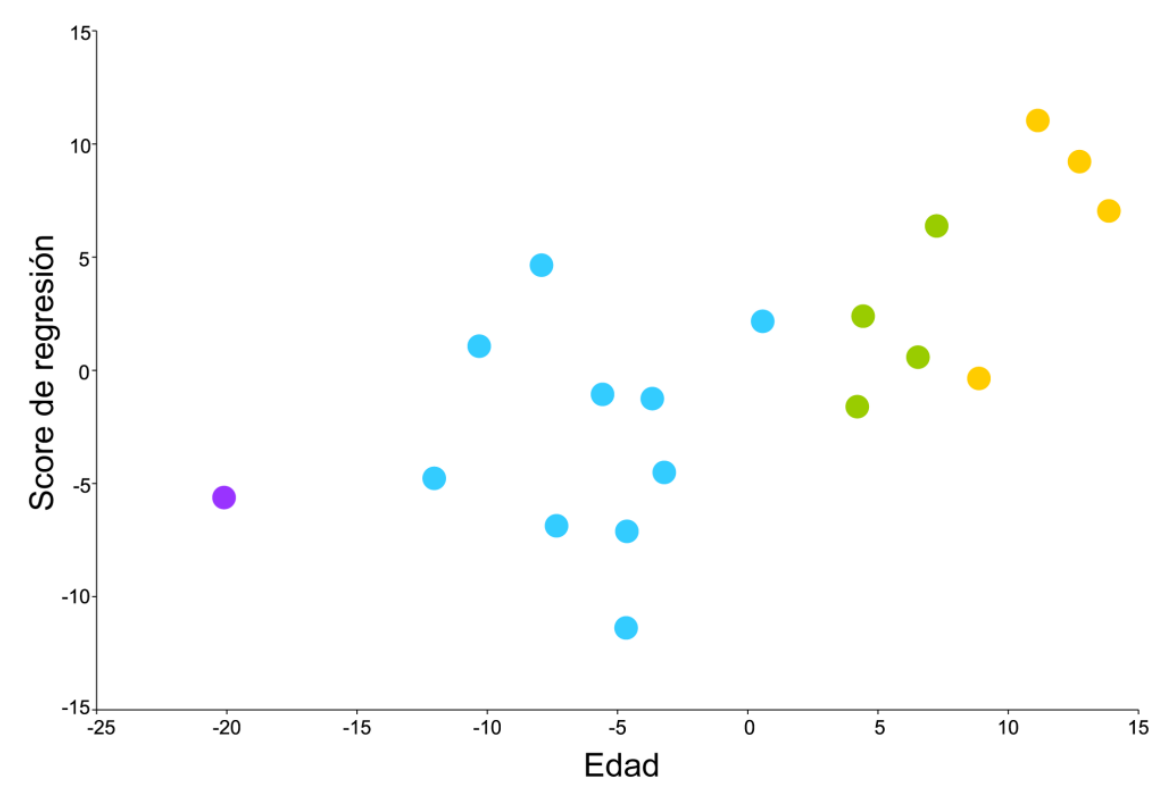

Fig. 7.20. Cambios en forma por modelado óseo en maxilar de subadultos de Chubut en función de la edad. La edad se obtuvo del score del CP1 del desarrollo dental. La forma corresponde a los scores del CP1 al CP8 del modelado óseo (referencia en Fig. 7.14)

\subsection{Variación inter-muestral de los patrones de modelado óseo}

\subsubsection{Comparación de los patrones generales de modelado óseo de los individuos subadultos}

En la Figura 7.21 se presenta el patrón de modelado óseo facial obtenido para los individuos subadultos de las muestras de Pampa Grande y Chubut a partir de los mapas generales restrictivos (Figs. 7.3, 1-4a y 7.4, 1-4a). La región facial superior de ambos grupos es similar, caracterizada en general, por formación ósea. En la muestra de Chubut, se observa reabsorción en el borde inferior del orbital y superior al foramen infraorbitario. En la muestra de Pampa Grande, el área de reabsorción se ubica en una posición inferior.

Respecto a la región facial media, los mapas generales de ambas muestras presentan reabsorción a lo largo del proceso alveolar. Sin embargo, la muestra de Chubut exhibe un área de formación en la región posterior del proceso alveolar. El resto de la región facial media difiere entre ambos grupos. En la muestra de Pampa Grande, la región de la fosa canina y del proceso cigomático del maxilar, y el malar, se caracterizan por presencia de formación. En la muestra de Chubut, en dichas regiones se presentan ambas actividades de modelado óseo. En particular, se registra reabsorción ósea en el área de la fosa canina y del proceso cigomático del maxilar, y en el borde masetero del malar. 


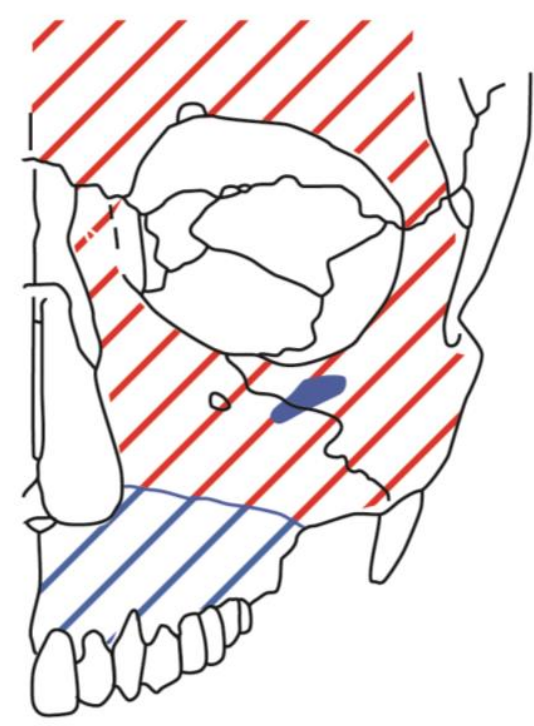

PG-Sad $>25 \%$

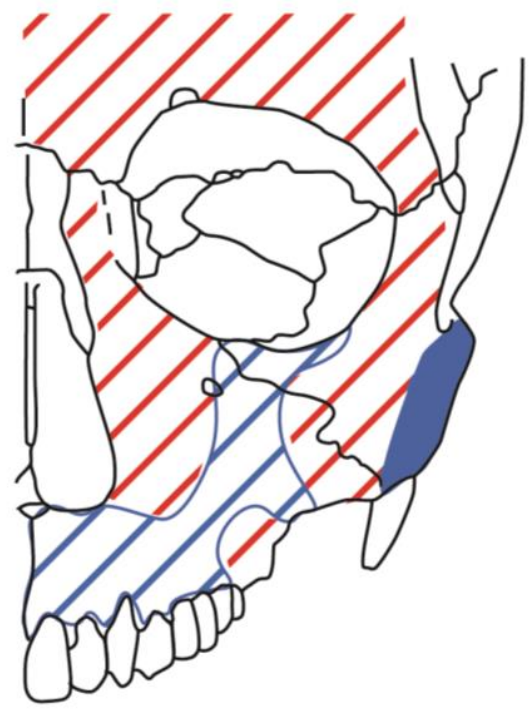

Ch-Sad $>25 \%$

Fig. 7.21. Mapas generales restrictivos de subadultos de Pampa Grande y Chubut. Rojo: formación ósea; azul: reabsorción ósea. Las áreas de modelado óseo pequeñas se marcan lisas para mejor ubicación

\subsubsection{Comparación de los patrones generales de modelado óseo de los individuos adultos}

En la Figura 7.22 se presenta el remodelado óseo facial obtenido para adultos de las muestras de Pampa Grande y Chubut a partir de los mapas generales restrictivos (Figs. 7.3, 1-4c y 7.4, 14c). La región facial superior de ambas muestras se caracteriza por mantener la predominancia de formación ósea, sin embargo, difieren en la distribución de las áreas de reabsorción. En la muestra de Pampa Grande, se presenta reabsorción en el borde orbital y arco superciliar, cercanos al par frontal del supraorbital. En la muestra de Chubut, estas regiones presentan formación. La reabsorción se ubica en la glabela -pequeña área en el centro-, en el par frontal del supraorbital -contiguo a la sutura frontomalar- y entre el par nasal y el centro del supraorbital -área de mayor tamaño-. Una última área se localiza cercana a la sutura frontomaxilar. A su vez, el borde orbital inferior en ambos grupos presenta formación, con áreas de reabsorción en la región inferior. Esta área es continua en la muestra Chubut y se extiende entre la sutura cigomaxilar y el foramen infraorbitario. En la muestra de Pampa Grande, se hallan dos áreas de reabsorción, separadas por un área de formación ósea en la región del foramen infraorbitario. La de mayor tamaño se extiende a través de la sutura cigomaxilar en la región facial media.

La región facial media difiere significativamente entre ambas muestras. El proceso alveolar en la muestra de Pampa Grande se caracteriza por presentar formación ósea en la fosa incisiva y reabsorción en la región posterior al canino, mientras que entre ambas regiones se halla 
ambos tipos de actividad de remodelado óseo. La muestra de Chubut se caracteriza por la presencia de áreas más extensas de reabsorción ósea. El resto del maxilar presenta formación ósea en ambos grupos, con presencia de reabsorción en la región contigua al alar, y en el centro de la fosa canina en Pampa Grande. En la muestra de Chubut, hay alternancia de actividad en la región del proceso cigomático. Respecto al malar, exceptuando el área de reabsorción en la sutura cigomaxilar previamente descripta, Pampa Grande se caracteriza por presentar sólo formación. En cambio, en la muestra de Chubut aparece reabsorción a lo largo del borde masetero y en la apófisis marginal.

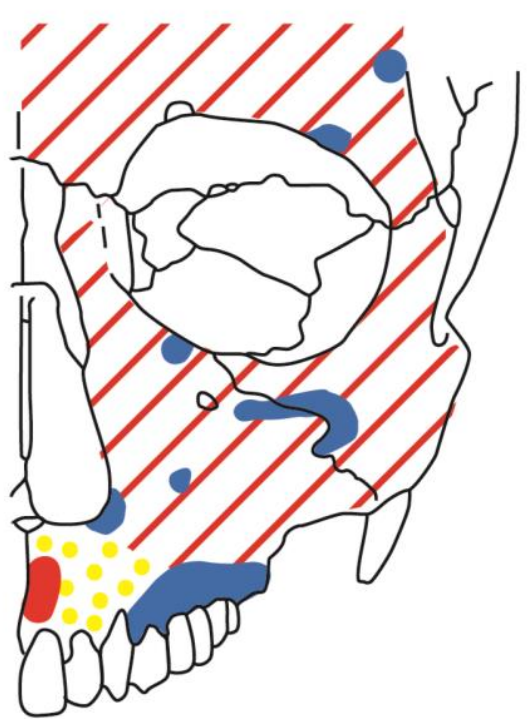

PG-Ad $>25 \%$

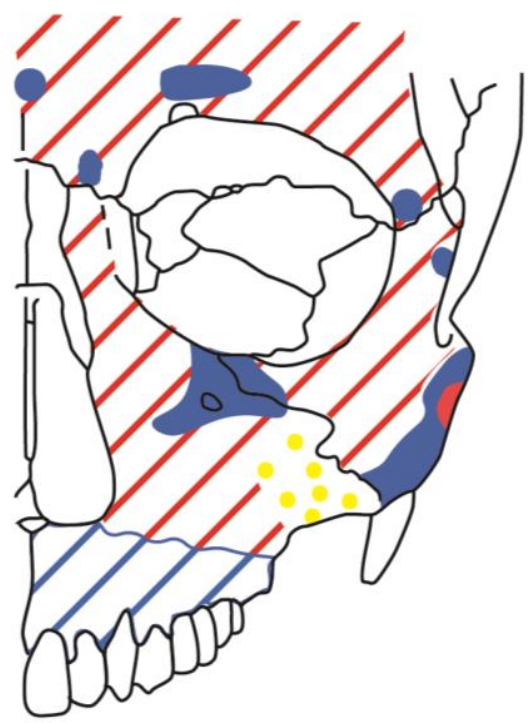

Ch-Ad $>25 \%$

Fig. 7.22. Mapas generales restrictivos de adultos de Pampa Grande y Chubut. Rojo: formación ósea; azul: reabsorción ósea; amarillo: probabilidad de ambas actividades. Las áreas de remodelado óseo pequeñas se marcan lisas para mejor ubicación

\subsection{Resultados destacados}

A continuación, se resumen los principales resultados obtenidos a partir del análisis de la variación intra e inter-muestral en los patrones de modelado óseo de la glabela, el supraorbital, el malar y el maxilar en las dos muestras estudiadas:

Región facial superior

- La región facial superior -que comprende la glabela, el supraorbital, el borde orbital del malar, el proceso frontal del maxilar y la región superior al foramen infraorbitariose caracteriza por la predominancia de formación ósea, y la presencia de reabsorción en el borde orbital inferior. Este patrón general se observó en ambas muestras, tanto 
en individuos subadultos como en adultos, aunque con algunas variaciones. En particular, los subadultos de la muestra de Chubut y los adultos de ambas muestras presentan alternancia de áreas de reabsorción, especialmente, en la región de la sutura fronto-maxilar de la glabela y en el borde inferior del supraorbital.

- Los individuos subadultos de la muestra de Chubut mostraron mayor variación en los patrones de modelado de la región facial superior que los de la muestra de Pampa Grande. Se registró un aumento de variación entre los individuos vinculado a la edad, siendo la etapa del G2 de gran variación.

\section{Región facial media}

- En la región facial media -cuerpo del maxilar y del malar- el patrón de modelado de los individuos subadultos y adultos, tanto de la muestra de Pampa Grande como de la de Chubut, se caracteriza por presentar grandes áreas de formación y reabsorción ósea. Dichas áreas presentan una ubicación más o menos constante a lo largo de la ontogenia de los individuos en ambas muestras, aunque en comparación con la región facial superior, esta región exhibe un mayor grado de variación.

- El malar exhibe predominancia de formación tanto en los individuos subadultos como en los adultos de ambas muestras. Se observaron áreas de reabsorción de tamaño variable en la sutura cigomaxilar, siendo de mayor tamaño en los individuos de la muestra de Chubut, en los que también se destaca un área de reabsorción en la inserción del músculo masetero.

- En el maxilar se diferencian dos grandes regiones: el proceso alveolar y la fosa caninaproceso cigomático. El proceso alveolar se caracteriza por la predominancia de reabsorción en subadultos y adultos de ambas muestras. En subadultos de Chubut, también se presenta formación en la región posterior del proceso, mientras que en adultos de Pampa Grande hay formación en la fosa incisiva. El área de la fosa caninaproceso cigomático se caracteriza por la presencia de formación en Pampa Grande y por ambos tipos de superficie en Chubut. 


\section{Análisis morfológicos}

Resultados de los análisis morfométricos de la superficie craneofacial y de los espacios funcionales

\section{Contenido}

8.1. Variación intra-muestral en Pampa Grande

8.1.1. Variación en tamaño

8.1.2. Variación en forma

\subsubsection{Cambios alométricos}

8.2. Variación intra-muestral en Chubut

8.2.1. Variación en tamaño

8.2.2. Variación en forma

\subsubsection{Cambios alométricos}

8.3. Variación inter-muestral entre Pampa Grande y Chubut

8.3.1. Variación en tamaño

8.3.2. Variación en forma

El presente capítulo contiene los resultados de los análisis de tamaño y forma realizados. Se estructura presentando en primer lugar, la información relevada sobre los individuos de Pampa Grande y a continuación, la obtenida para Chubut; integrando los datos de subadultos y adultos. Se diferenciaron las regiones faciales analizadas a nivel histológico, integradas en tres grupos anatómicos: glabela y supraorbitales, malar y maxilar. En último lugar, se presentan los resultados de las comparaciones efectuadas entre muestras.

\subsection{Variación intra-muestral en Pampa Grande}

\subsubsection{Variación en tamaño}

Se analizaron los cambios de tamaño en relación con la edad en los individuos subadultos (Fig. 8.1). El tamaño centroide craneofacial -CSz total- exhibe incremento con la edad hasta los 14,4 años (G3), observándose el mayor aumento de tamaño hasta los 4,4 años (G1) (Fig. 8.1a). Los senos maxilar y frontal alcanzaron su tamaño final entre 10,5-14,4 años (Fig. 8.1b,c), mientras 
que el orbital y el endocráneo lo hicieron entre 4,5-10,4 años (G2; Fig.8.1d,e). Asimismo, en la Figura 8.1c se observa que el seno frontal aún no se desarrolló en los individuos hasta 4,4 años y en algunos de etapas posteriores.

a)

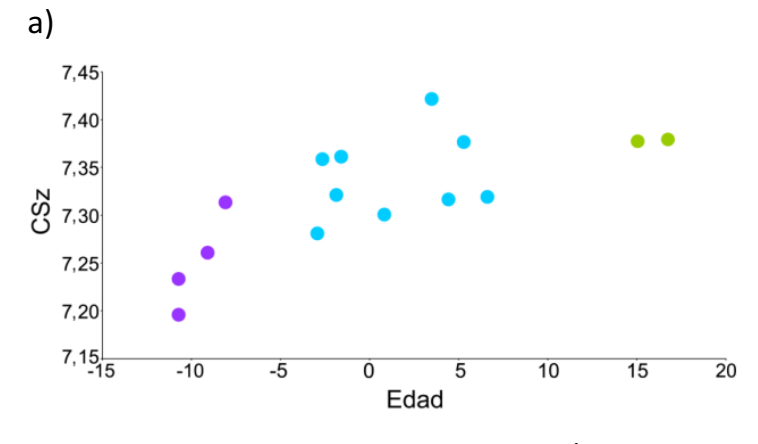

b)

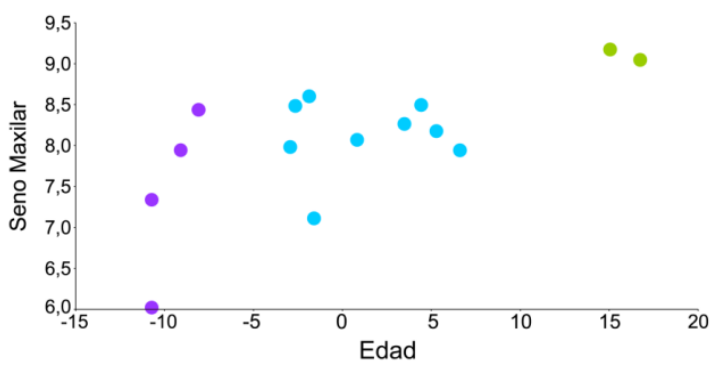

d)

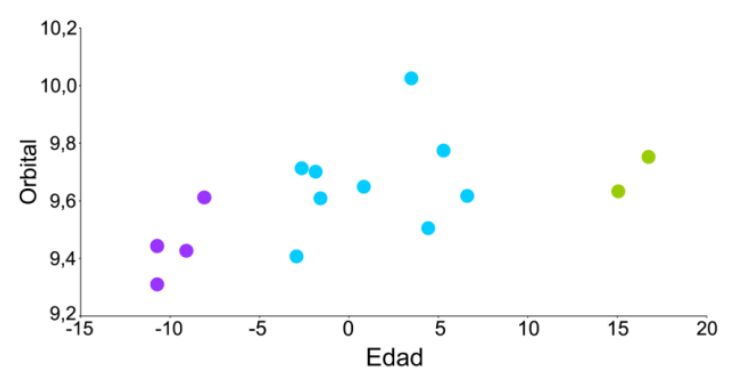

c)
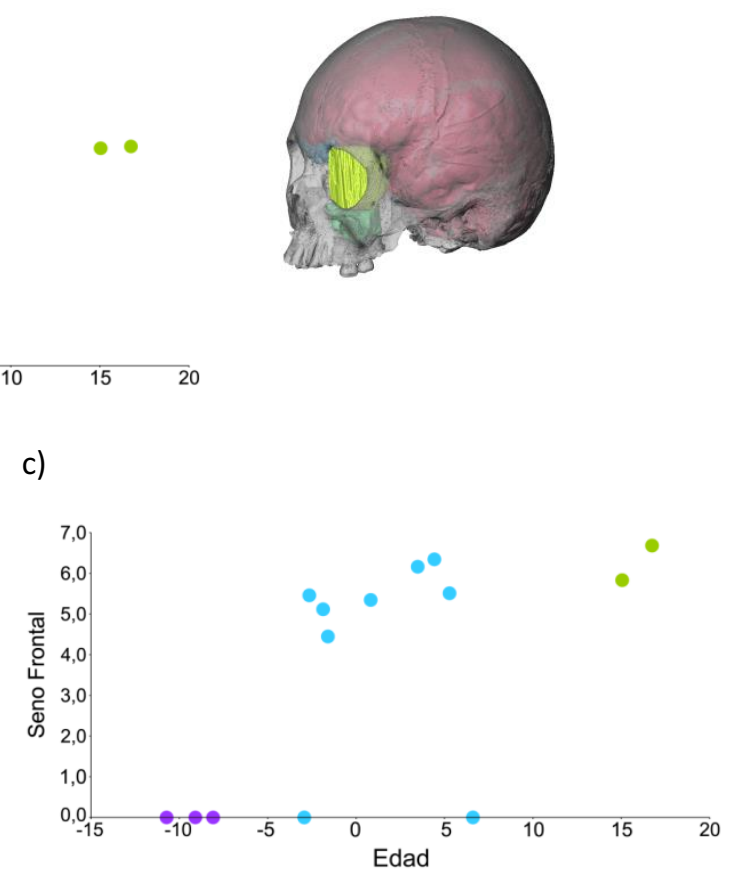

e)

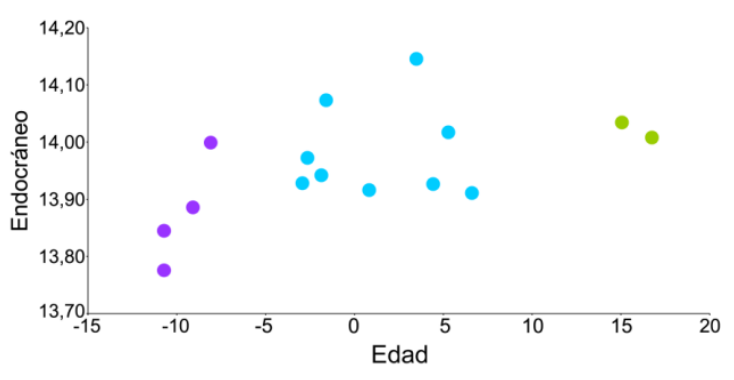

$\bullet \mathrm{G} 1 \bullet \mathrm{G} 2 \bullet \mathrm{G} 3$

Fig. 8.1. Análisis de tamaño en subadultos de Pampa Grande en función de la edad. La edad se obtuvo del score del CP1 del desarrollo dental

El análisis de los cambios en el tamaño craneofacial en relación con las cavidades craneofaciales para los individuos subadultos y adultos, indica que el seno maxilar alcanza el tamaño adulto entre 10,5-14,4 años (Fig.8. 2a), mientras el seno frontal lo hace en la etapa adulto joven (G5; Fig. 8.2b). A su vez, se registra un incremento en el volumen del orbital que continúa en la etapa adulta (Fig. 8.2c). Finalmente, el endocráneo alcanza el tamaño adulto en entre 4,5-10,5 (G2; Fig. 8.2d). 
a)

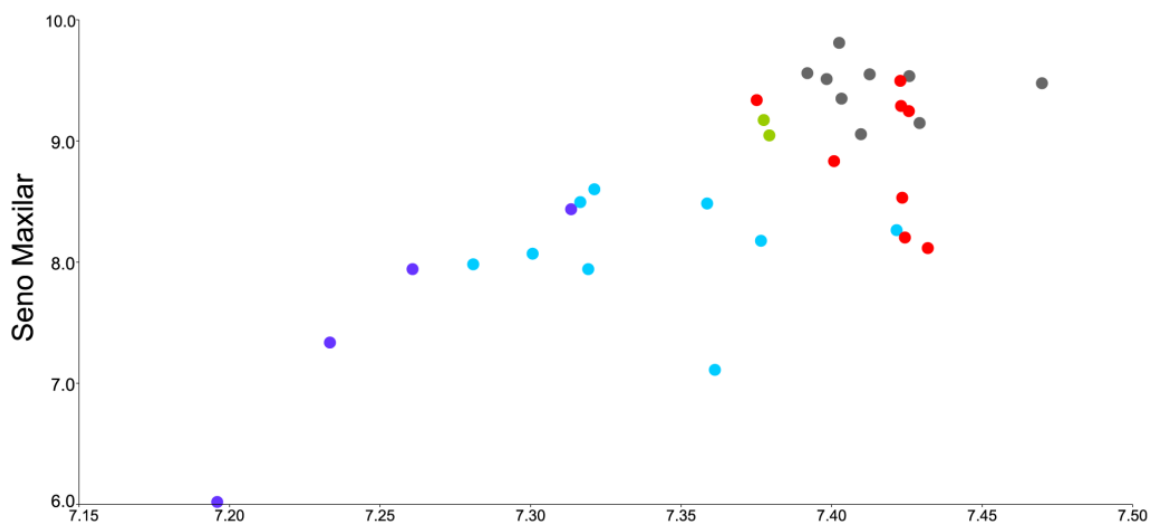

b)

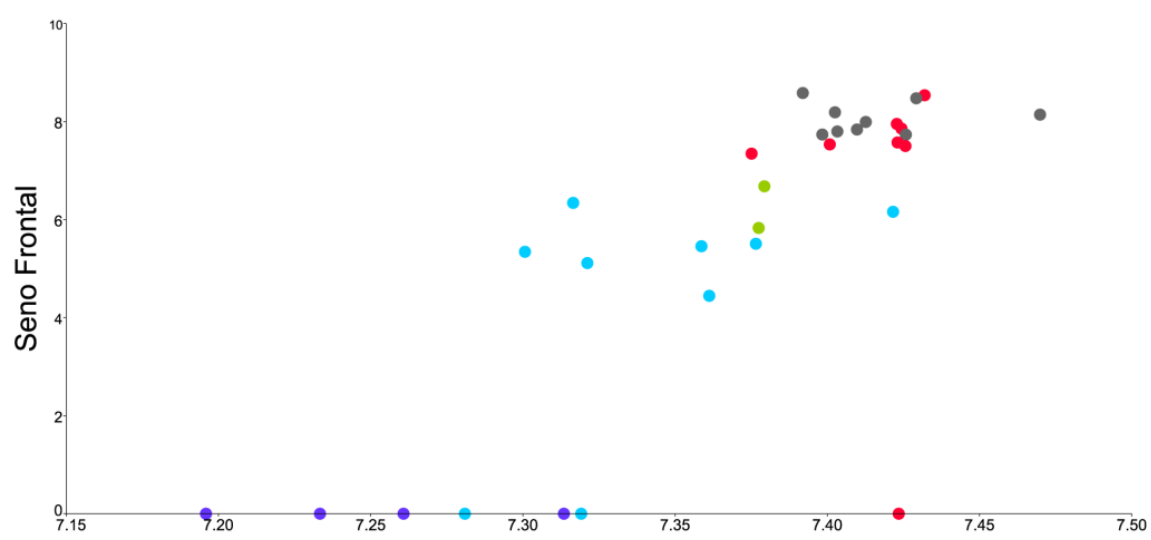

c)

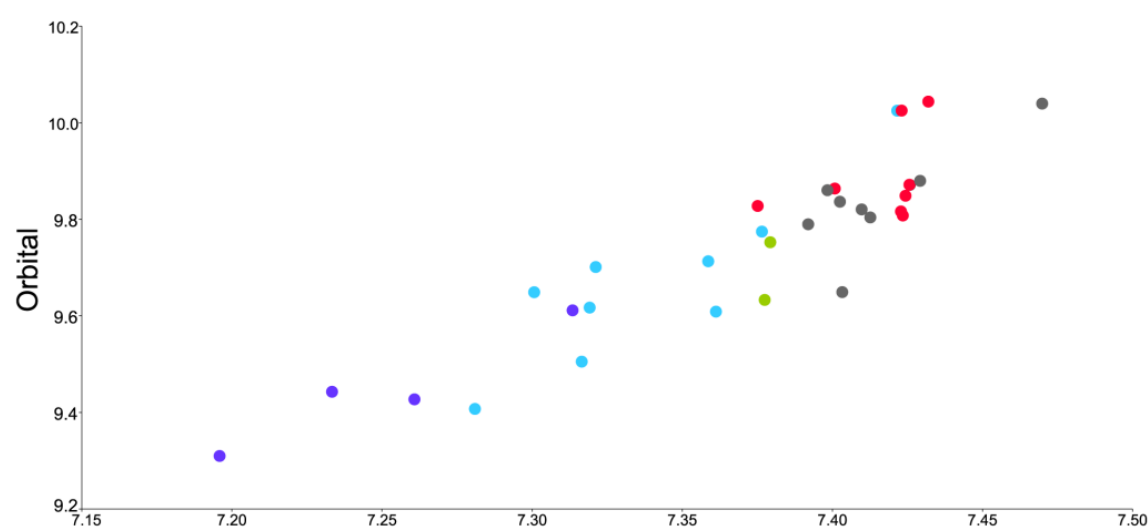

d)

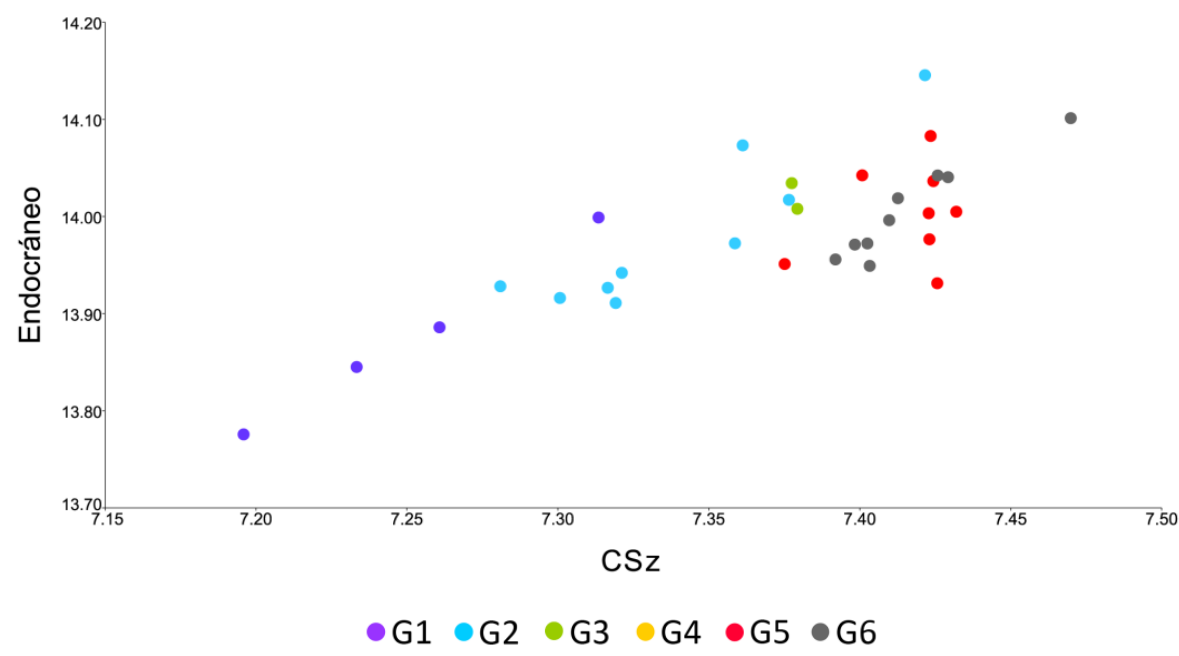

Fig. 8.2. Variación del tamaño de las cavidades craneofaciales en función del tamaño centroide craneofacial (CSz) de los individuos de Pampa Grande 
La Tabla 8.1 resume las correlaciones entre el tamaño centroide del cráneo -CSz total- y de la región facial-CSz facial-, y los volúmenes de las cavidades craneofaciales.

El tamaño centroide facial presentó una correlación significativa con el tamaño total. Los senos paranasales, maxilar y frontal, presentaron una mayor correlación con el tamaño centroide facial que con el total. Por el contrario, el orbital y el endocráneo presentaron una correlación mayor con el tamaño centroide total. Tanto los senos paranasales como el orbital, presentaron valores similares de correlación con el tamaño facial, mientras que el seno frontal y el endocráneo presentaron valores similares al tamaño total. El valor más elevado de correlación corresponde al orbital con el tamaño centroide total y facial, mientras que los valores más bajos se registraron para el seno maxilar con el tamaño total y el endocráneo con el tamaño facial (Tabla 8.1).

Respecto a las cavidades craneofaciales, las mayores correlaciones se observaron entre el orbital y el seno frontal, seguido por el seno frontal con el seno maxilar y el orbital con el endocráneo. Por el contrario, las correlaciones más bajas se observaron entre el endocráneo y los senos paranasales (Tabla 8.1).

Tabla 8.1. Correlaciones entre el tamaño centroide (CSz) total y facial, y los volúmenes de las cavidades del cráneo para la muestra de Pampa Grande

\begin{tabular}{lcccccc}
\hline & CSz total & CSz facial & S. Maxilar & S. Frontal & Orbital & Endocráneo \\
\hline CSz total & 1 & $* *$ & $* *$ & $* *$ & $* *$ & $* *$ \\
CSz facial & 0,96 & 1 & $* *$ & $* *$ & $* *$ & $* *$ \\
S. Maxilar & 0,73 & 0,84 & 1 & $* *$ & $* *$ & $*$ \\
S. Frontal & 0,77 & 0,83 & 0,71 & 1 & $* *$ & $*$ \\
Orbital & 0,91 & 0,85 & 0,63 & 0,74 & 1 & $* *$ \\
Endocráneo & 0,79 & 0,64 & 0,42 & 0,44 & 0,70 & 1 \\
\hline
\end{tabular}

\subsubsection{Variación en forma}

Se analizaron los cambios en forma del cráneo y de las tres estructuras óseas faciales de interés (glabela y supraorbitales, malar y maxilar).

El Componente Principal 1 (CP1) del análisis de componentes principales calculado a partir de las coordenadas Procrustes de todo el cráneo resumió el $44,87 \%$ de la variación total en la forma dentro de la muestra de PG, separando los individuos subadultos de los adultos. En el 
extremo positivo del CP1 se localizaron los grupos de edades menores y en el negativo, los de mayor edad (Fig. 8.3a).

La forma del cráneo de los individuos ubicados hacia el extremo negativo del CP1 se caracteriza por una bóveda redondeada a lo largo de la sutura sagital y del borde occipital, y con un marcado proceso mastoides (Fig. 8.3b). El frontal presenta una tendencia huidiza por encima del arco superciliar. La apófisis cigomática del temporal es ancha y presenta un tubérculo articular desarrollado. La región facial se caracteriza por un malar prominente, que desciende en línea casi recta con relación al orbital; el ángulo del borde temporal es agudo y el proceso frontal ancho y con una apófisis marginal desarrollada. El borde supraorbital es pronunciado. Finalmente, el maxilar exhibe una proyección anterior y una altura relativamente mayor en comparación con la morfología del extremo positivo. En norma anterior se observa que los huesos parietales son rectos y no superan la línea del arco cigomático. En la región facial, el par frontal del supraorbital es marcado y ancho. El malar presenta un marcado proceso frontal, con un borde inferior pronunciado y proyectado externamente. El maxilar presenta un cuerpo recto y una gran apertura y extensión en la región entre el proceso cigomático y el proceso alveolar (Fig. 8.3b).

La forma craneofacial de los individuos en el extremo positivo del CP1 se caracteriza, en general, por presentar una bóveda marcadamente globular en comparación con el extremo negativo, con un occipital más recto (Fig. 8.3b). Asimismo, el frontal se proyecta en sentido anterior. La apófisis cigomática del temporal es angosta. En la región facial, se observa que el cuerpo del malar está retraído, con los procesos frontal y temporal angostos, y un borde temporal de ángulo más abierto. El supraorbital no sobresale. Por último, el maxilar desciende verticalmente y es más corto en comparación con las morfologías ubicadas en el extremo negativo. En norma anterior, los parietales presentan forma redondeada y sobresalen del ancho del arco cigomático. Para la región facial se observa un borde supraorbital poco prominente. El malar presenta un proceso frontal angosto, con un borde inferior recto. El maxilar presenta un ángulo cerrado en la región entre el proceso cigomático y alveolar (Fig. $8.3 b)$.

El ACP sobre las coordenadas Procrustes de las tres regiones faciales estudiadas indica que los individuos subadultos y adultos se diferencian a lo largo del CP1 (Fig. 8.4a-c). En particular, para glabela y supraorbitales, el CP1 resumió el 52,29\% y el CP2 el 12,09\% de la variación total en forma. En el extremo negativo se ubicaron los subadultos y en el extremo positivo, los adultos (Fig. 8.4a). Para el malar, el CP1 resumió el 20,52\% y el CP2 el 13,95\% de la variación. 
En general, los subadultos se ubicaron en el extremo positivo del CP1 y los adultos, en el negativo (Fig. 8.4b). En el maxilar, el CP1 resumió el 41,62\% de la variación y el CP2 el 9,56\%. Los subadultos, ubicados en el extremo negativo, se separan claramente de los adultos, en el extremo positivo (Fig. 8.4c).

a)

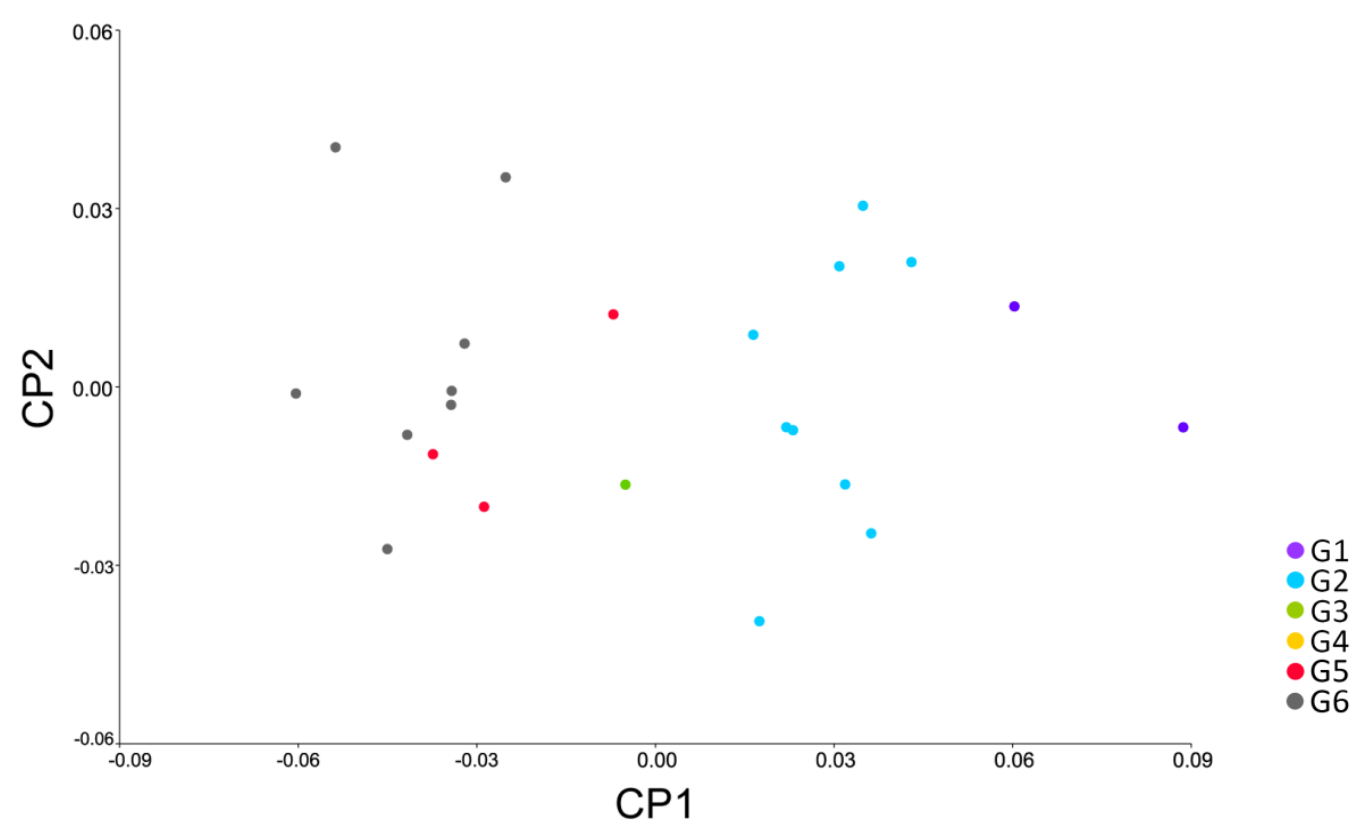

b)
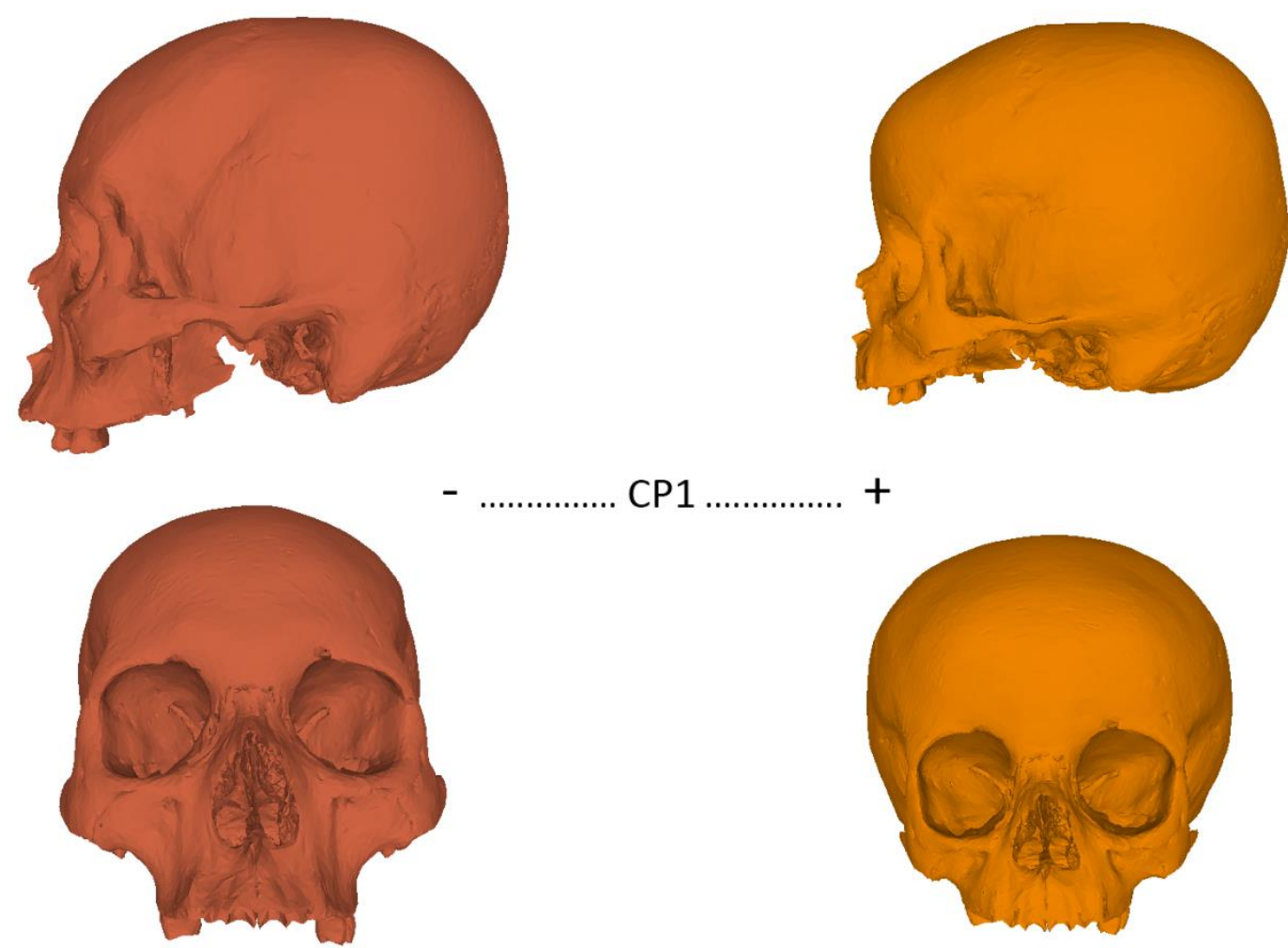

CP1

$+$

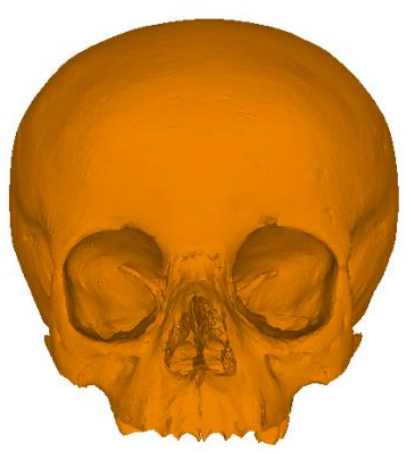

Fig. 8.3. Cambios en la forma craneofacial de Pampa Grande: a) distribución de los individuos en función de los dos primeros Componentes Principales, b) modelos craneofaciales que representan la variación ontogenética resumida en los extremos del CP1 
a)

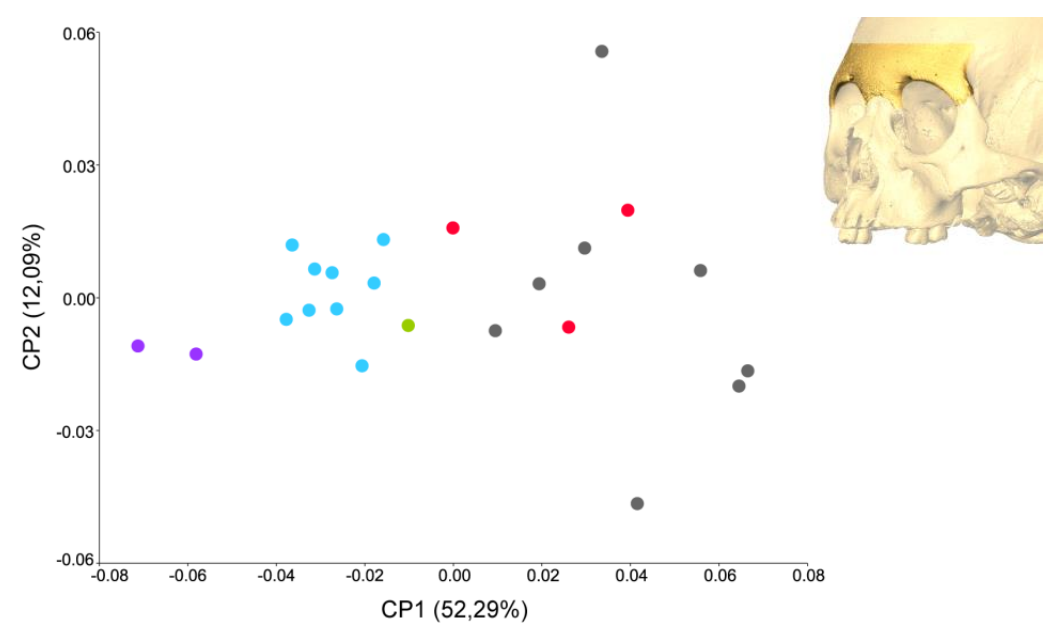

b)
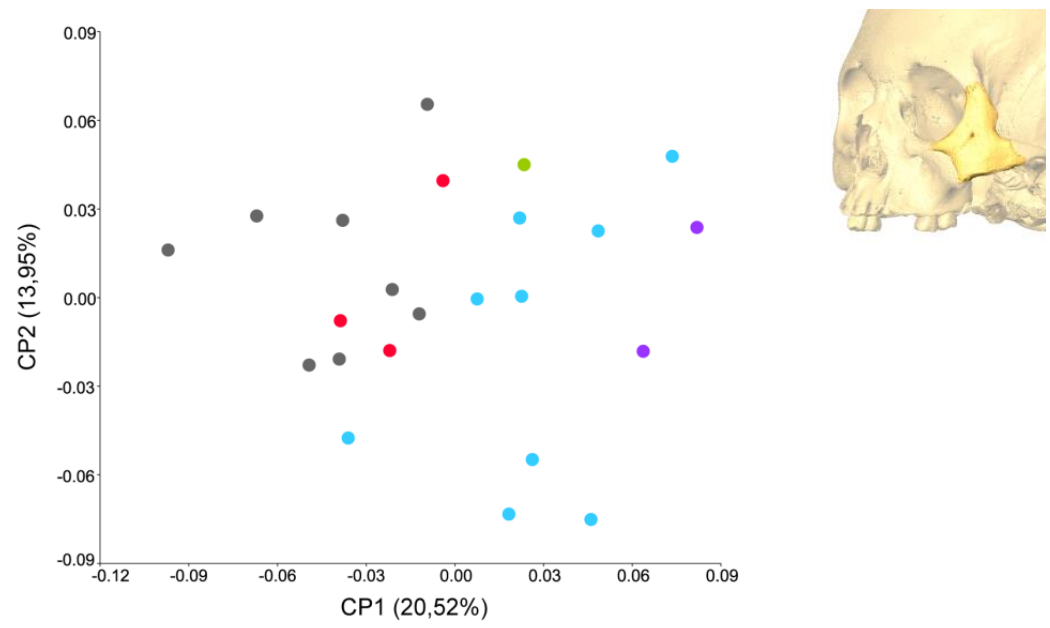

c)
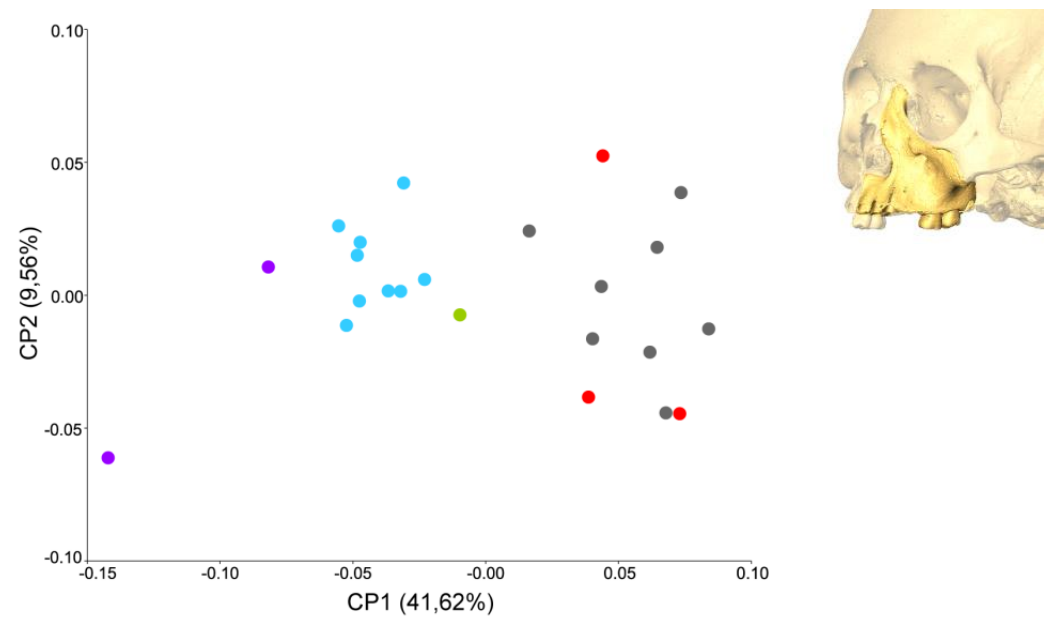

\subsubsection{Cambios alométricos}

El análisis de regresión de las coordenadas de forma Procrustes sobre el tamaño centroide del cráneo que representa los cambios alométricos en la muestra de Pampa Grande indica que el $32,59 \%$ de la variación total en forma es explicada por cambios en el tamaño (Fig. 8.5). Los 
cambios en forma asociados al tamaño son similares a los cambios en forma descriptos por el CP1. Ambos análisis muestran que los cráneos de menor tamaño -lo que coincide con los individuos de menor edad- presentan una morfología craneofacial más globosa mientras los cráneos de mayor tamaño -correspondiente a los individuos de mayor edad- presentan cráneos relativamente más angostos y altos, con una mayor proyección de la región facial.

a)

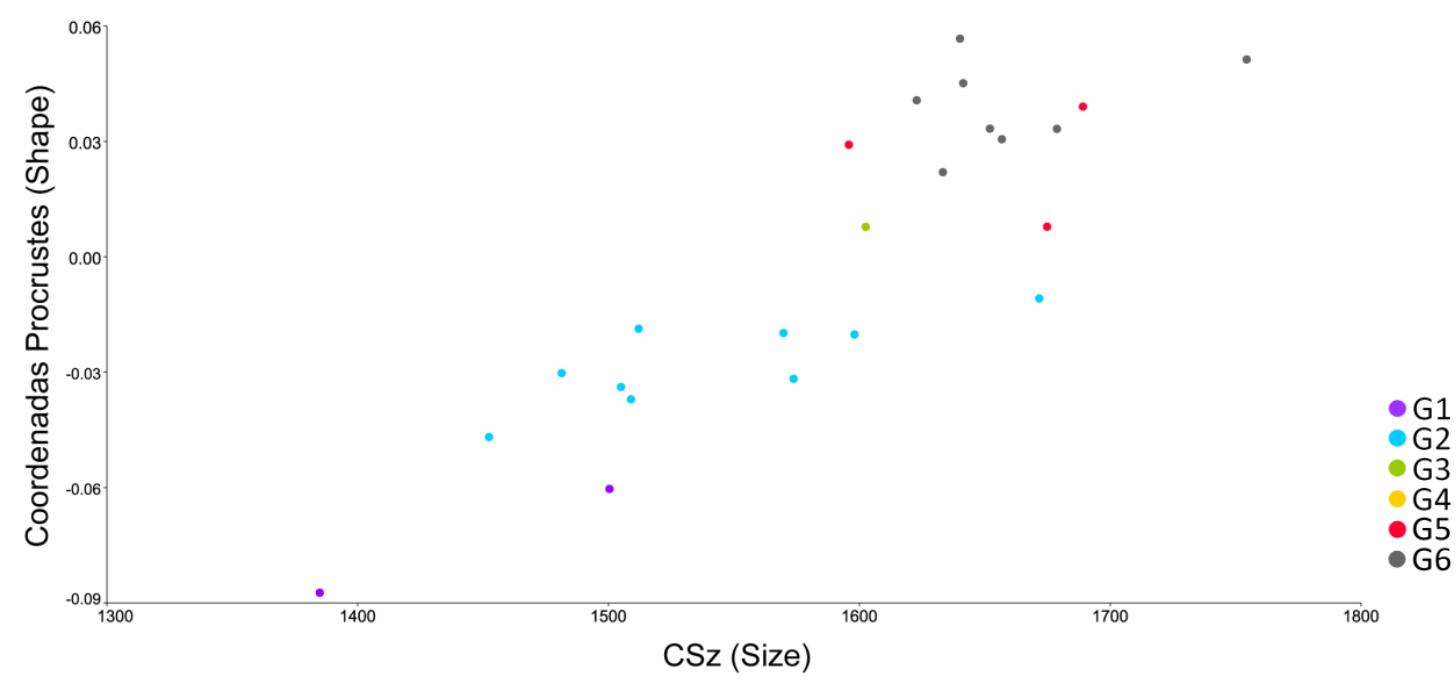

b)
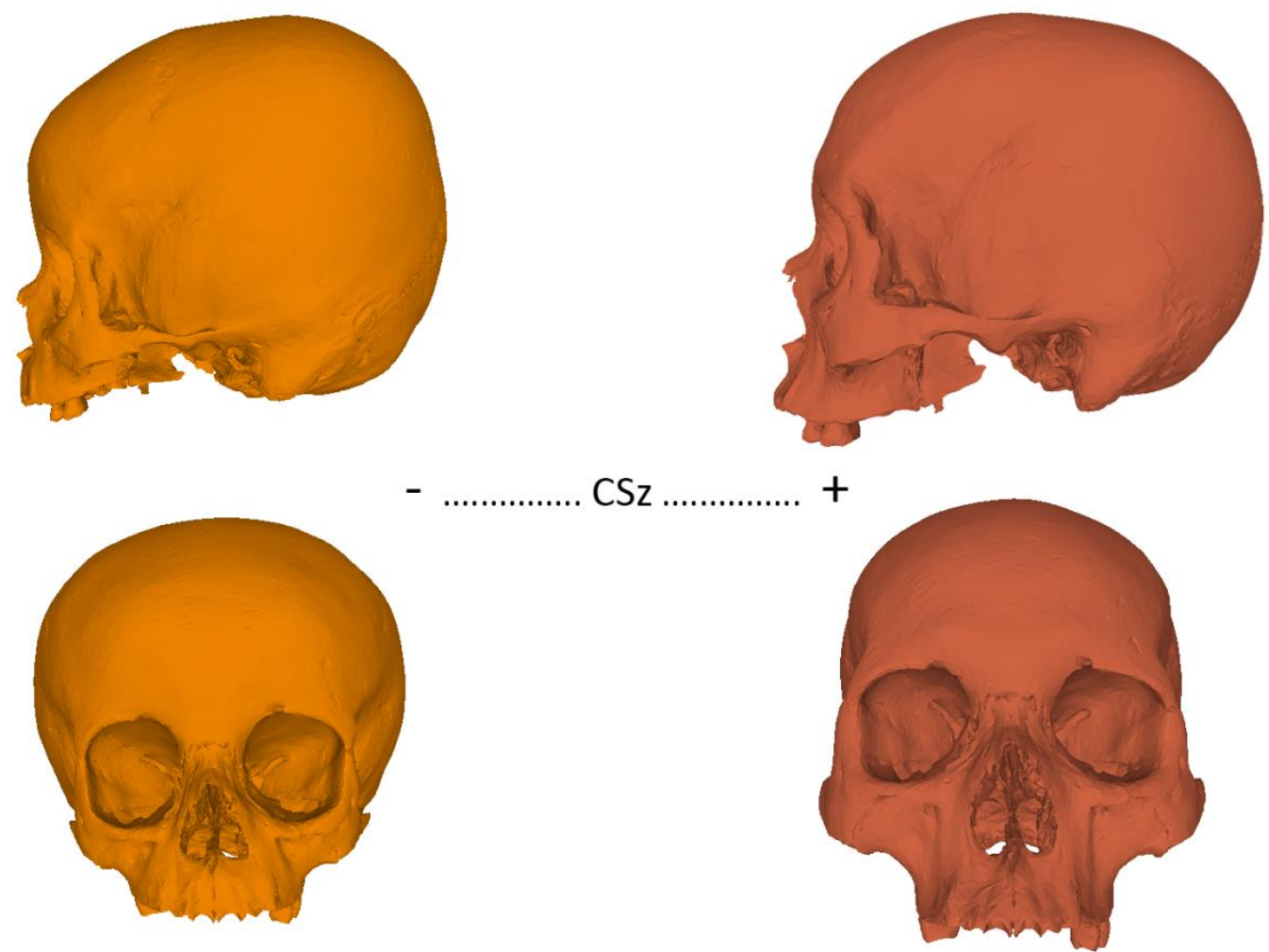

Fig. 8.5. Cambios alométricos en la morfología craneofacial de Pampa Grande: a) distribución de los individuos en función de la recta de regresión, b) modelos craneofaciales que representan la variación resumida en los extremos de la regresión 


\subsection{Variación intra-muestral en Chubut}

\subsubsection{Variación en tamaño}

Se analizaron los cambios de tamaño asociados a la edad en los individuos subadultos (Fig. 8.6). El tamaño centroide craneofacial -CSz total- exhibe un incremento con la edad hasta los 18 años de edad (G4; Fig. 8.6a). Los senos paranasales, el orbital y el endocráneo alcanzan el tamaño final a la misma edad (Fig. 8.6b-e). En seno frontal aún no se ha desarrollado en el individuo menor a 4,5 años así como en otros individuos de etapas posteriores (Fig.8.6).
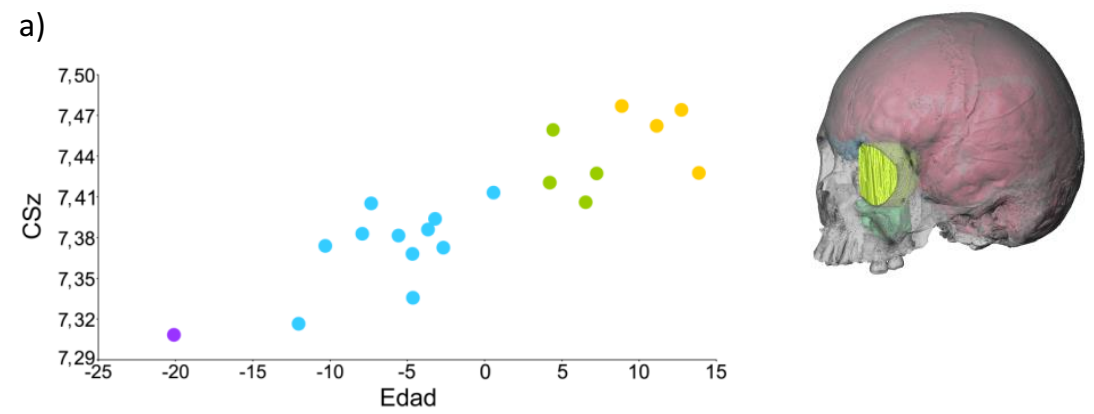

b)

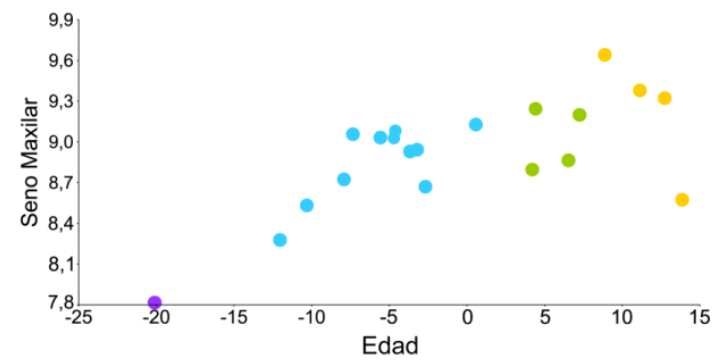

d)

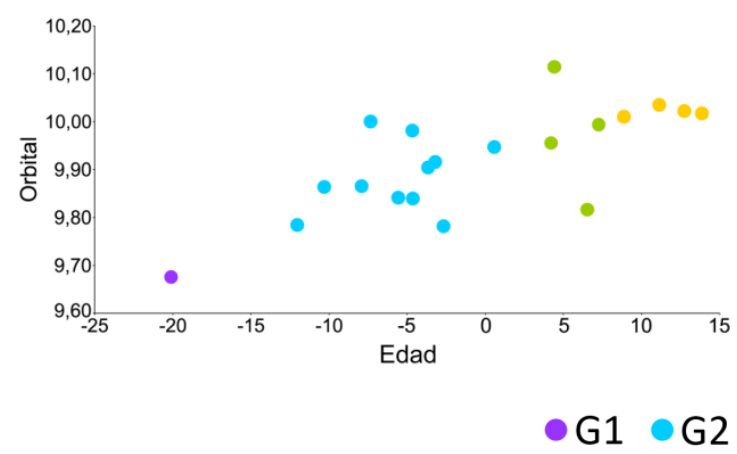

c)

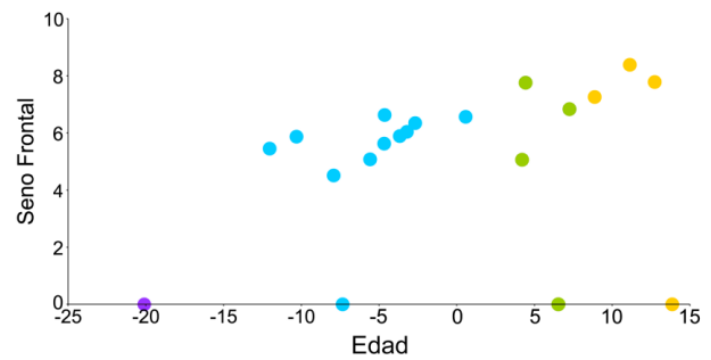

e)

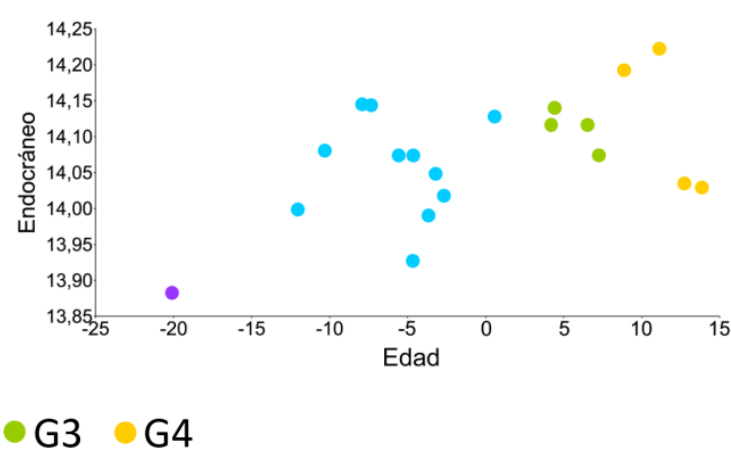

Fig. 8.6. Análisis de tamaño en subadultos de Chubut en función de la edad. La edad se obtuvo del score del CP1 del desarrollo dental 
El análisis de los cambios en el tamaño craneofacial en relación con las cavidades del cráneo en subadultos y adultos indica que los senos paranasales alcanzan el tamaño adulto entre los 14,5 y 18 años (G4; Fig. 8.7a,b). Sin embargo, para el seno maxilar se observa que algunos individuos en la categoría adulto medio se encuentran por debajo del tamaño alcanzado por individuos más jóvenes (Fig. 8.7a). En el orbital, se registra un incremento de volumen aún en etapas adultas, al igual que en la muestra de PG (Fig. 8.7c). Finalmente, el endocráneo alcanza el tamaño adulto entre 4,5-10,4 años (Fig. 8.7d).

a)

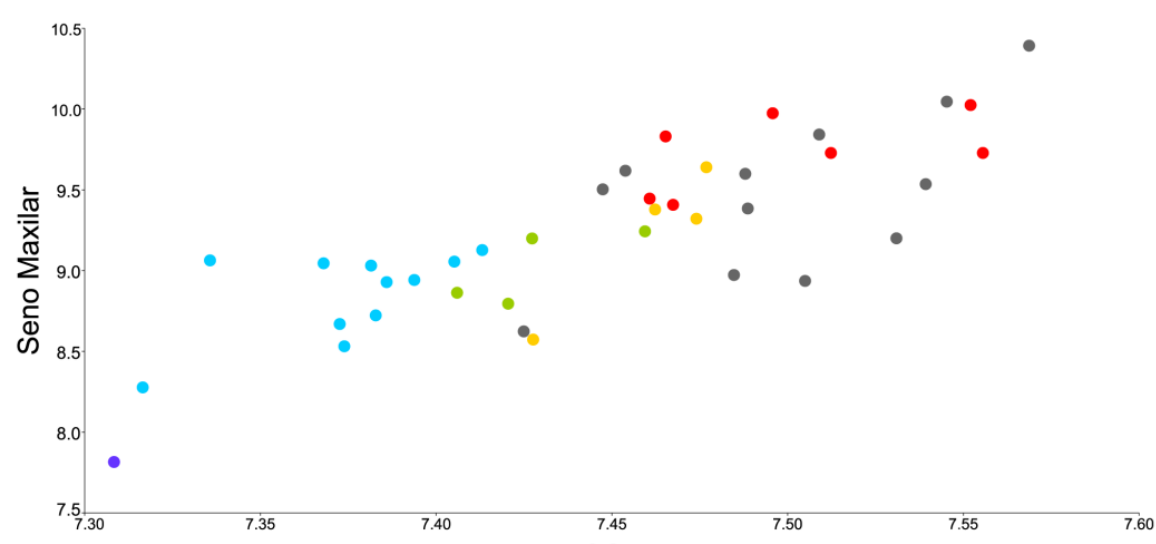

b)

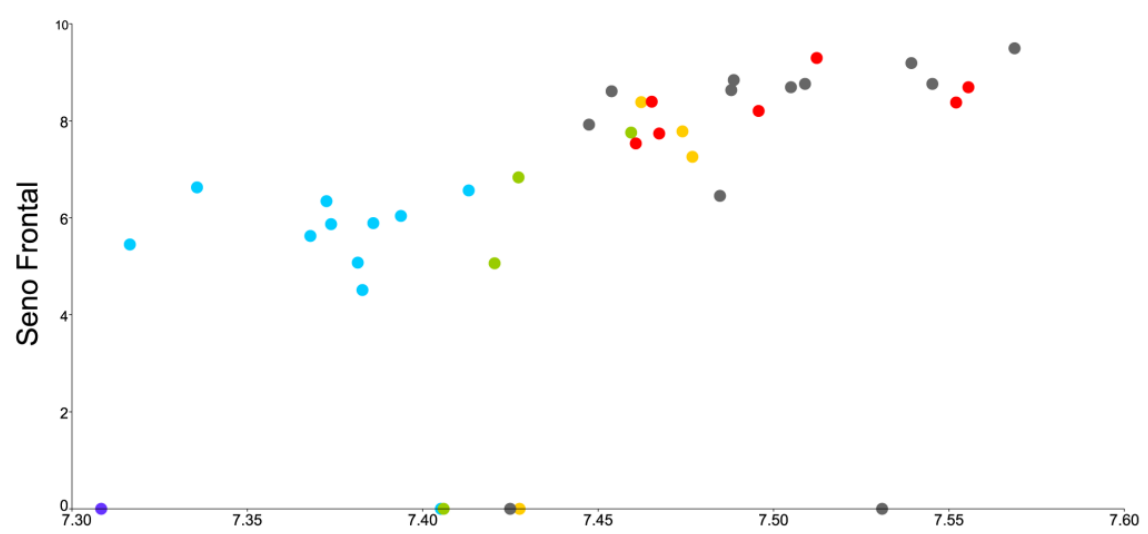

c)

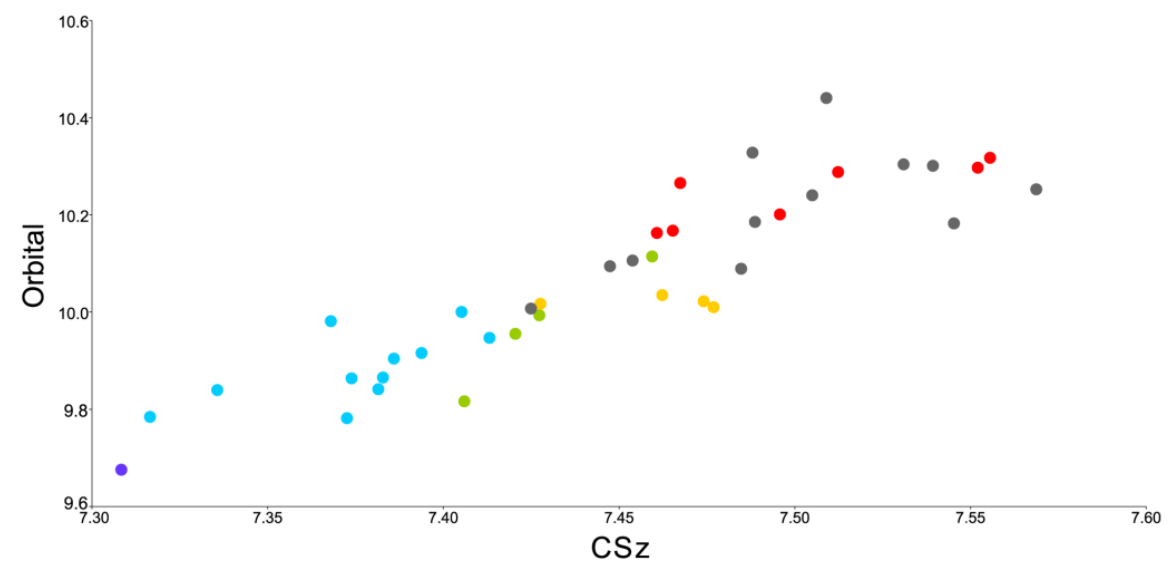

Continúa en la siguiente página 
d)

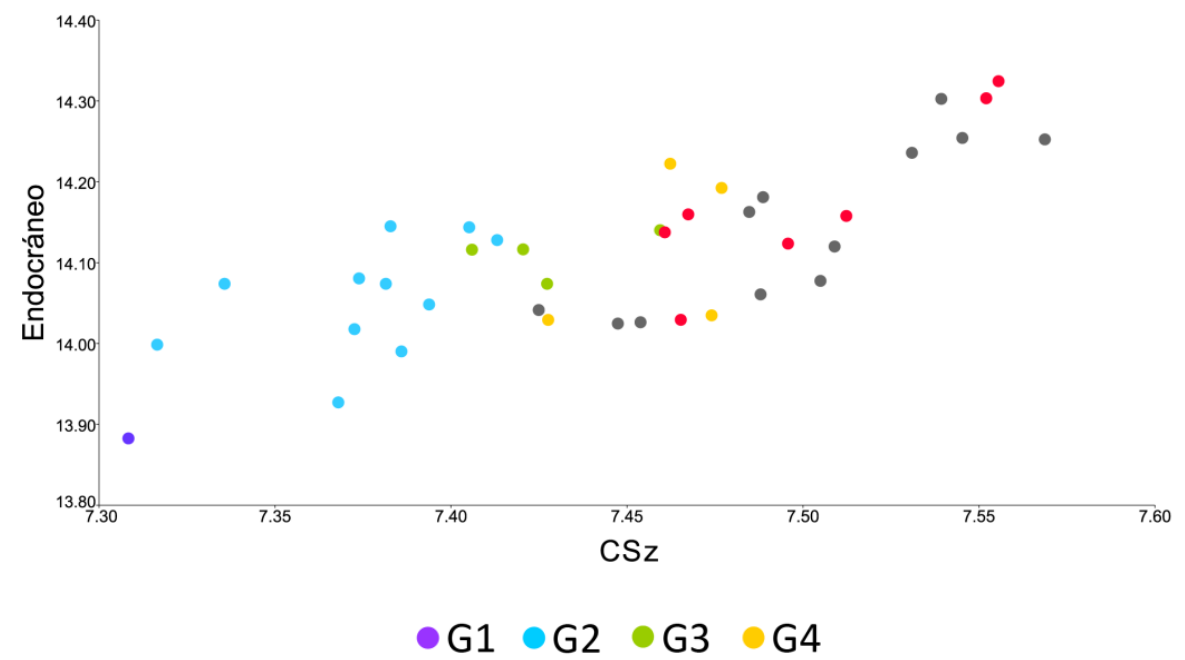

Fig. 8.7. Variación del tamaño de las cavidades craneofaciales en función del tamaño centroide craneofacial (CSz) de los individuos de Chubut

En la Tabla 8.2 se presentan los resultados de las correlaciones entre el tamaño centroide y los volúmenes de las cavidades craneofaciales. El tamaño centroide facial-CSz facial- presentó una correlación significativa con el tamaño centroide total -CSz total-. Los senos paranasales y el orbital presentaron valores similares de correlación con los tamaños total y facial, mientras que el endocráneo presentó una mayor correlación con el tamaño centroide total. La correlación más alta se registró entre el orbital y ambos tamaños centroides, mientras que la menor correlación se registró entre el seno frontal y los tamaños total y facial (Tabla 8.2).

Respecto a las cavidades craneofaciales, la mayor correlación se registró entre el seno maxilar y el orbital, mientras que la más baja fue entre el seno frontal y el endocráneo. El seno maxilar presentó los valores de correlación más altos con todas las cavidades craneofaciales seguido por la correlación del orbital con el endocráneo y finalmente, el seno frontal con el orbital y el endocráneo (Tabla 8.2).

Tabla 8.2. Correlaciones entre el tamaño centroide (CSz) total y facial, y los volúmenes de las cavidades del cráneo para la muestra de Chubut

\begin{tabular}{lcccccc}
\hline & CSz total & CSz facial & S. Maxilar & S. Frontal & Orbital & Endocráneo \\
\hline CSz total & 1 & $* *$ & $* *$ & $* *$ & $* *$ & $* *$ \\
CSz facial & 0,96 & 1 & $* *$ & $* *$ & $* *$ & $* *$ \\
S. Maxilar & 0,82 & 0,80 & 1 & $* *$ & $* *$ & $* *$ \\
S. Frontal & 0,51 & 0,53 & 0,69 & 1 & $* *$ & $*$ \\
Orbital & 0,90 & 0,91 & 0,78 & 0,52 & 1 & $* *$ \\
Endocráneo & 0,76 & 0,61 & 0,62 & 0,34 & 0,60 & 1 \\
\hline
\end{tabular}

$* p<0,05 ; * *<0,01$ 


\subsubsection{Variación en forma}

Se analizaron los cambios en forma del cráneo y de las tres estructuras óseas faciales de interés (glabela y supraorbital, malar y maxilar).

El análisis de componentes principales sobre las coordenadas Procrustes de todo el cráneo indica que el CP1 resume el 39,59\% de la variación total, diferenciándose en los extremos individuos correspondientes a distintas categorías de edad. En el extremo negativo del CP1 se localizan los individuos de menor edad y en el positivo, los de mayor edad (Fig. 8.8a).

Los individuos localizados en el extremo negativo del CP1 presentan cráneos con formas más redondeadas y menos robustas que los del extremo positivo (Fig. 8.8b). En norma lateral se visualiza una bóveda redondeada, con un frontal prominente, un occipital poco prominente y un proceso mastoides corto. La apófisis cigomática del temporal es angosta y el tubérculo articular está poco desarrollado. La región facial se caracteriza por un malar de cuerpo pequeño y retraído posteriormente, con los procesos frontal y temporal angostos. La región supraorbital es plana. Finalmente, el maxilar es corto verticalmente. En norma anterior se observa que el malar tiene una disposición vertical, paralela al plano sagital. El maxilar presenta un cuerpo corto y el arco de la región entre el proceso cigomático y alveolar es cerrado (Fig. 8.8b).

Los individuos ubicados hacia el extremo positivo del CP1 exhiben cráneos marcadamente robustos (Fig. 8.8b). En norma lateral, se observa una bóveda de forma alargada en sentido antero-posterior, con un frontal huidizo por encima del arco superciliar y con un occipital prominente. La apófisis temporal del cigomático es ancha y presenta un tubérculo articular desarrollado. En la región facial se observa un malar robusto, con un cuerpo sobresaliente y grande. El extremo del proceso temporal es ancho y elevado. En la región del supraorbital se observa un reborde prominente. El maxilar se proyecta hacia abajo y adelante. En norma anterior, se observa que la bóveda es más angosta lateralmente con relación a la del extremo negativo. La región facial se caracteriza por presentar un marcado borde supraorbital, destacándose los rebordes de los arcos superciliares y de la glabela. El malar es robusto y se proyecta hacia afuera, en línea recta con los orbitales. El maxilar presenta un cuerpo recto y una gran apertura y extensión en la región entre el proceso cigomático y el proceso alveolar (Fig. 8.8b). 
a)

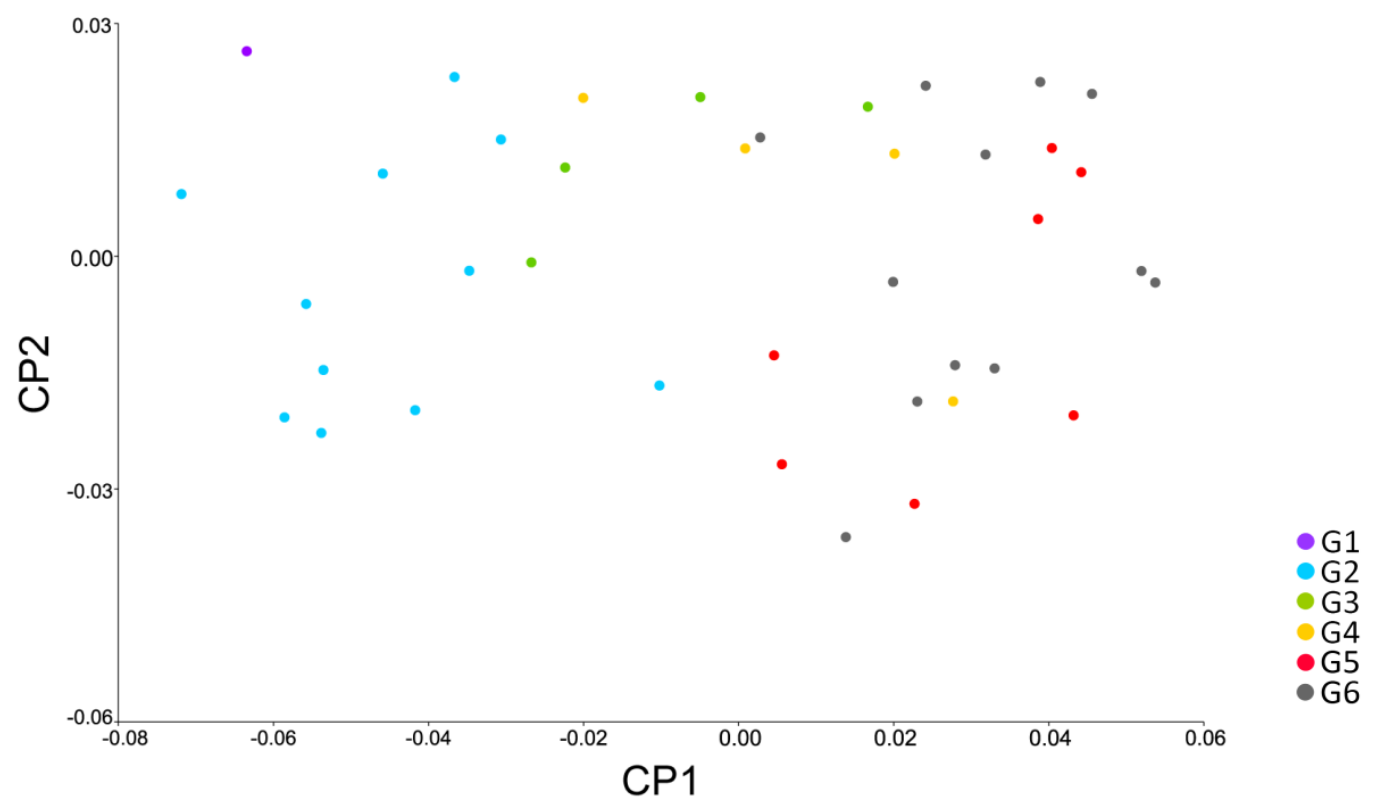

b)
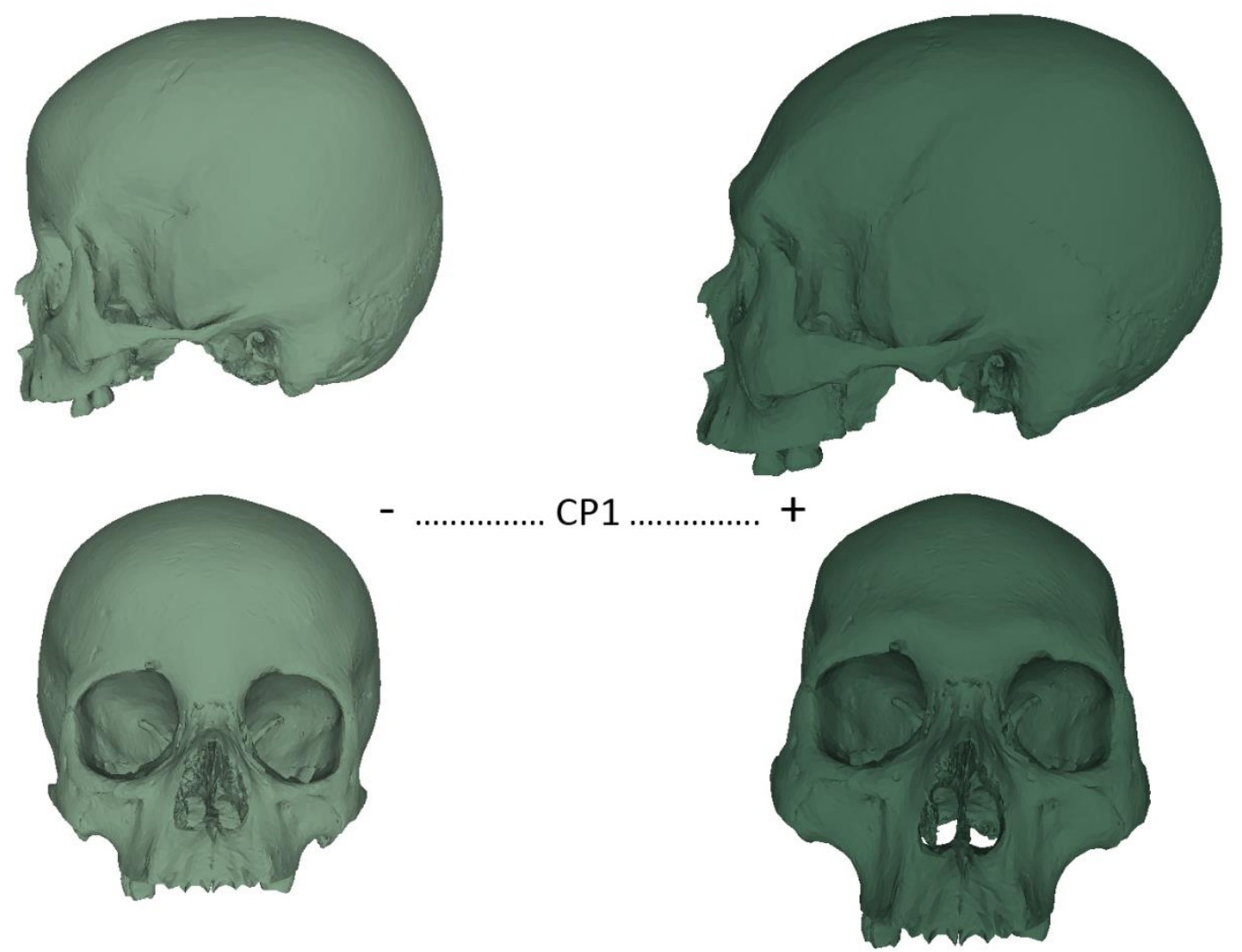

Fig. 8.8. Cambios en la forma craneofacial de Chubut: a) distribución de los individuos en función de los dos primeros Componentes Principales, b) modelos craneofaciales que representan la variación ontogenética resumida en los extremos del CP1

En la Figura 8.9 se presenta la distribución de los individuos a lo largo de los dos primeros componentes del ACP sobre las coordenadas Procrustes de las tres regiones faciales estudiadas (glabela y supraorbitales, maxilar y malar). Los individuos subadultos y adultos se 
separan a lo largo del CP1 en el análisis de la glabela y supraorbital, y en el de maxilar, pero no en el malar (Fig. 8.9a-c). Para glabela y supraorbitales, el CP1 resumió el 55\% y el CP2 el 9,83\% de la variación total en forma. En el extremo negativo se ubicaron los subadultos menores a 14,4 años y en el extremo positivo, los adultos. Los subadultos entre 14,5 y 18 años se distribuyeron entre ambos grupos de edad. Dos individuos correspondientes a la categoría adultos medio de sexo femenino, se agruparon en el cuadrante negativo (Fig. 8.9a). Respecto al malar, el CP1 resumió el $23,73 \%$ y el CP2 el 15,27\% de la variación total en forma. Hacia el extremo positivo del CP1 y CP2 se ubican los individuos hasta 10,4 años. El CP2 tiende a separar los individuos por edad, ubicando en el extremo positivo a los individuos menores a 14,4 años, y en el negativo a partir de 14,5 años. Sin embargo, hay un gran solapamiento entre individuos de distintas edades (Fig. 8.9b). Para el maxilar, el CP1 resumió el 34,84\% de la variación y el CP2 el 10,30\% de la variación total en forma. Los subadultos menores a 14,4 años se ubicaron en el extremo positivo, diferenciándose claramente de los mayores de 14,5, ubicados en el extremo negativo (Fig. 8.9c).

a)
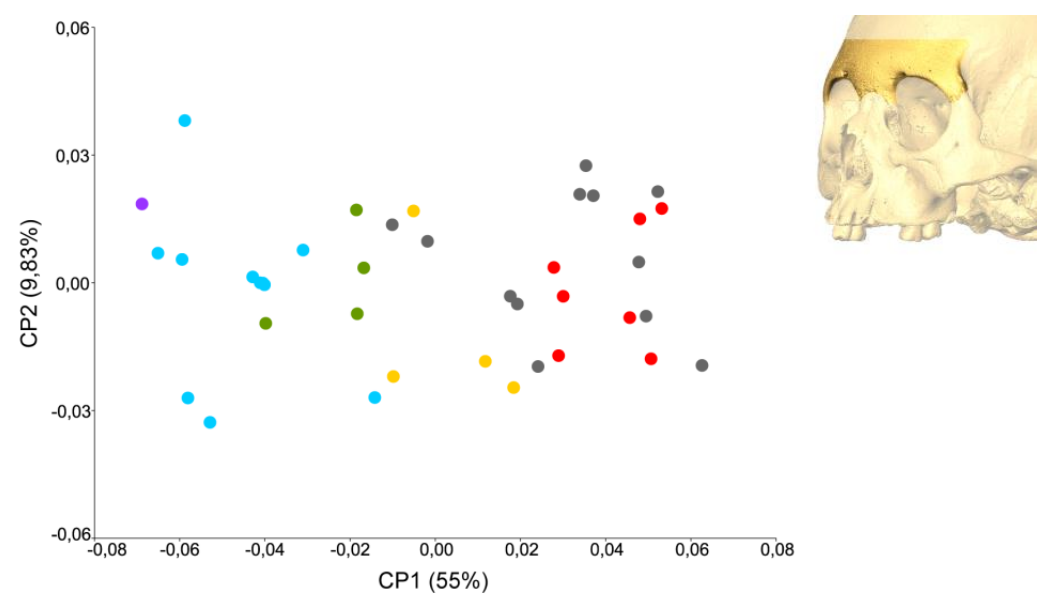

b)
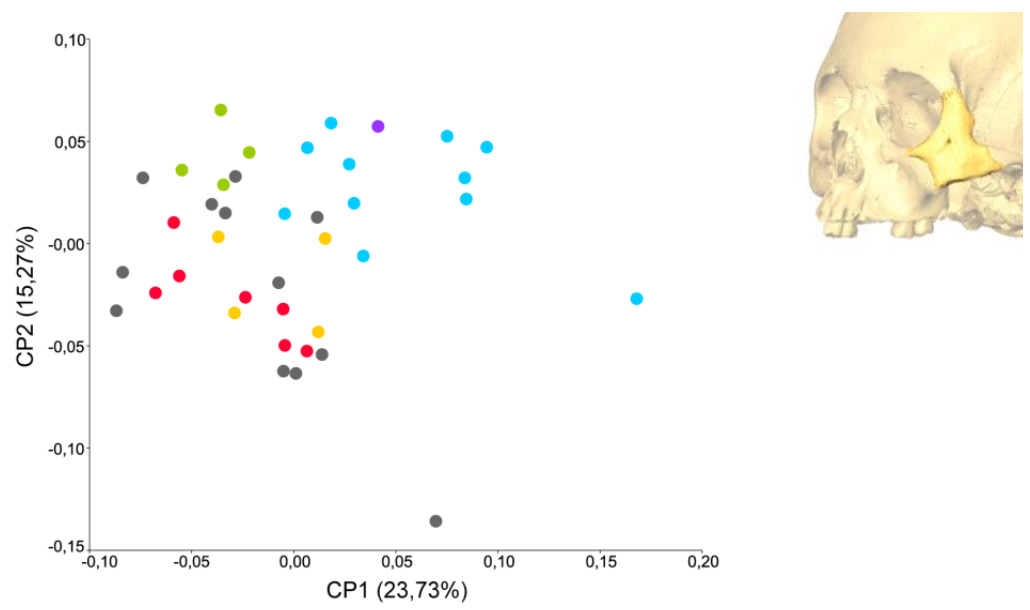

Continúa en la siguiente página 
c)
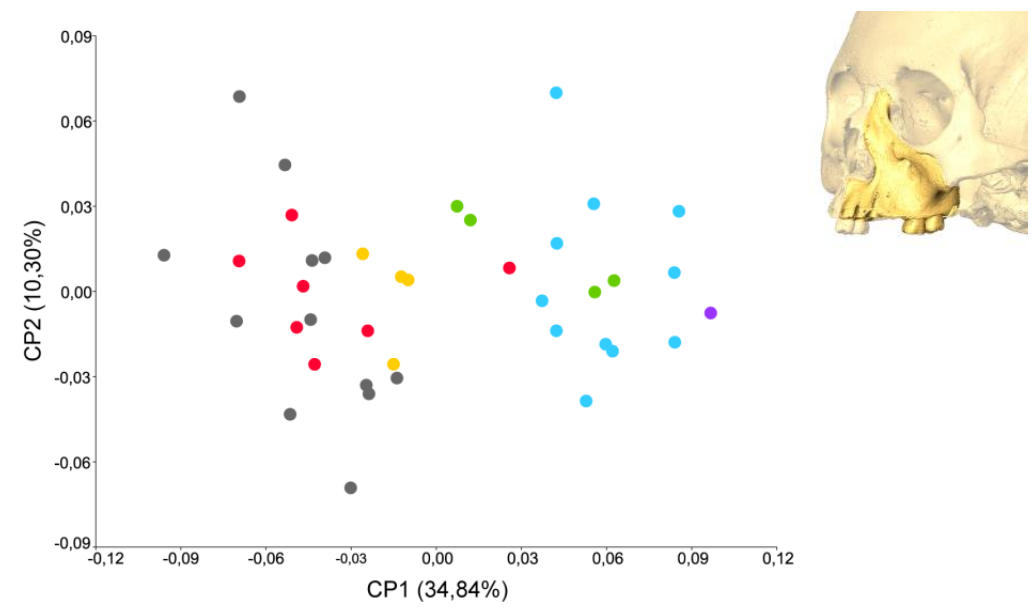

Fig. 8.9. Cambios en la forma de las regiones de glabela y supraorbital (a), malar (b) y maxilar (c) de Chubut

\subsubsection{Cambios alométricos}

El análisis de regresión de las coordenadas de forma Procrustes sobre el tamaño centroide del cráneo que representa los cambios alométricos en la muestra de Chubut indica que el 32,50\% de la variación total en forma es explicada por cambios en el tamaño (Fig. 8.10). Los cambios en forma asociados al tamaño son similares a los observados a lo largo del CP1, presentando los individuos de menor tamaño -lo que coincide con los individuos de menor edad- cráneos más redondeados, mientras que los cráneos de mayor tamaño -correspondientes a los individuos de mayor edad- exhiben un cráneo más alargado y más robusto.

a)

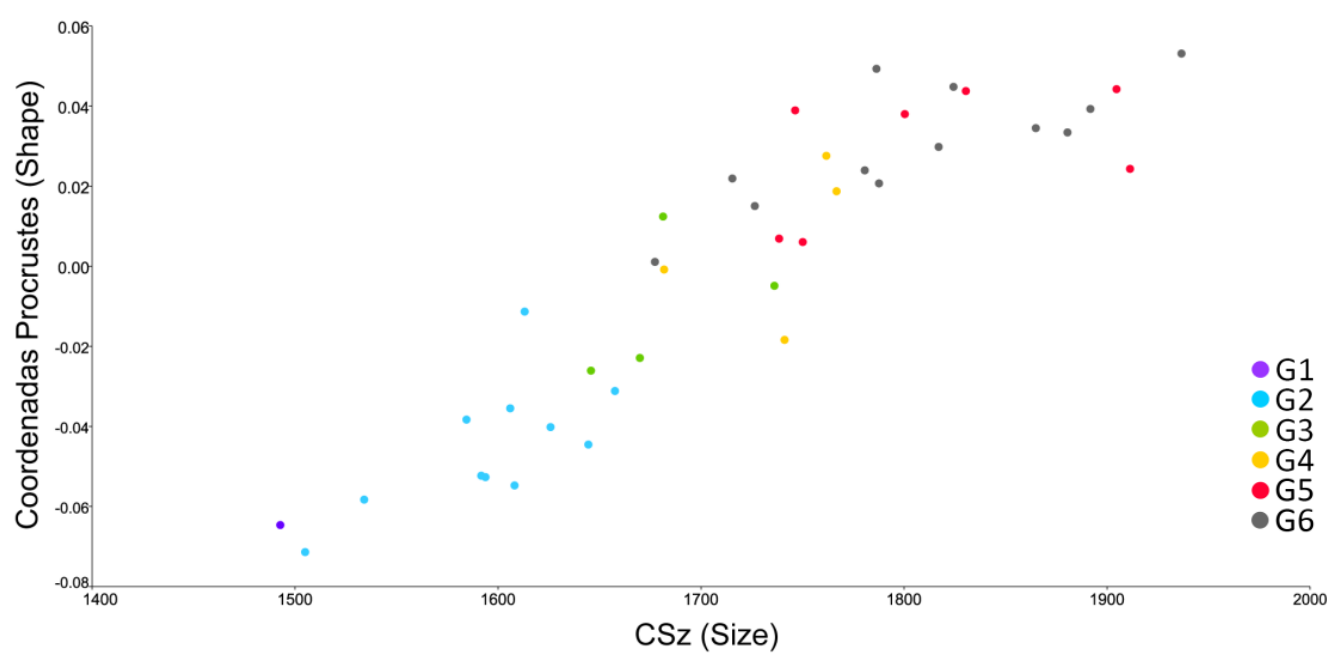


b)

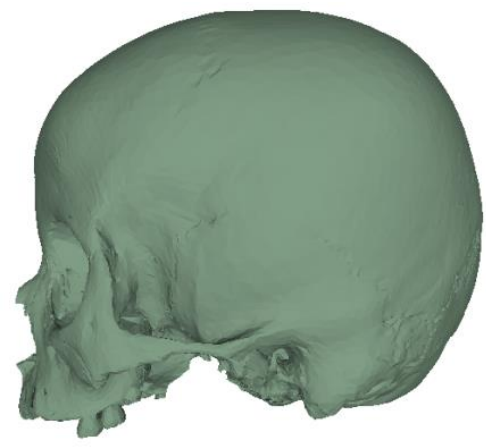

$\mathrm{CSz}$
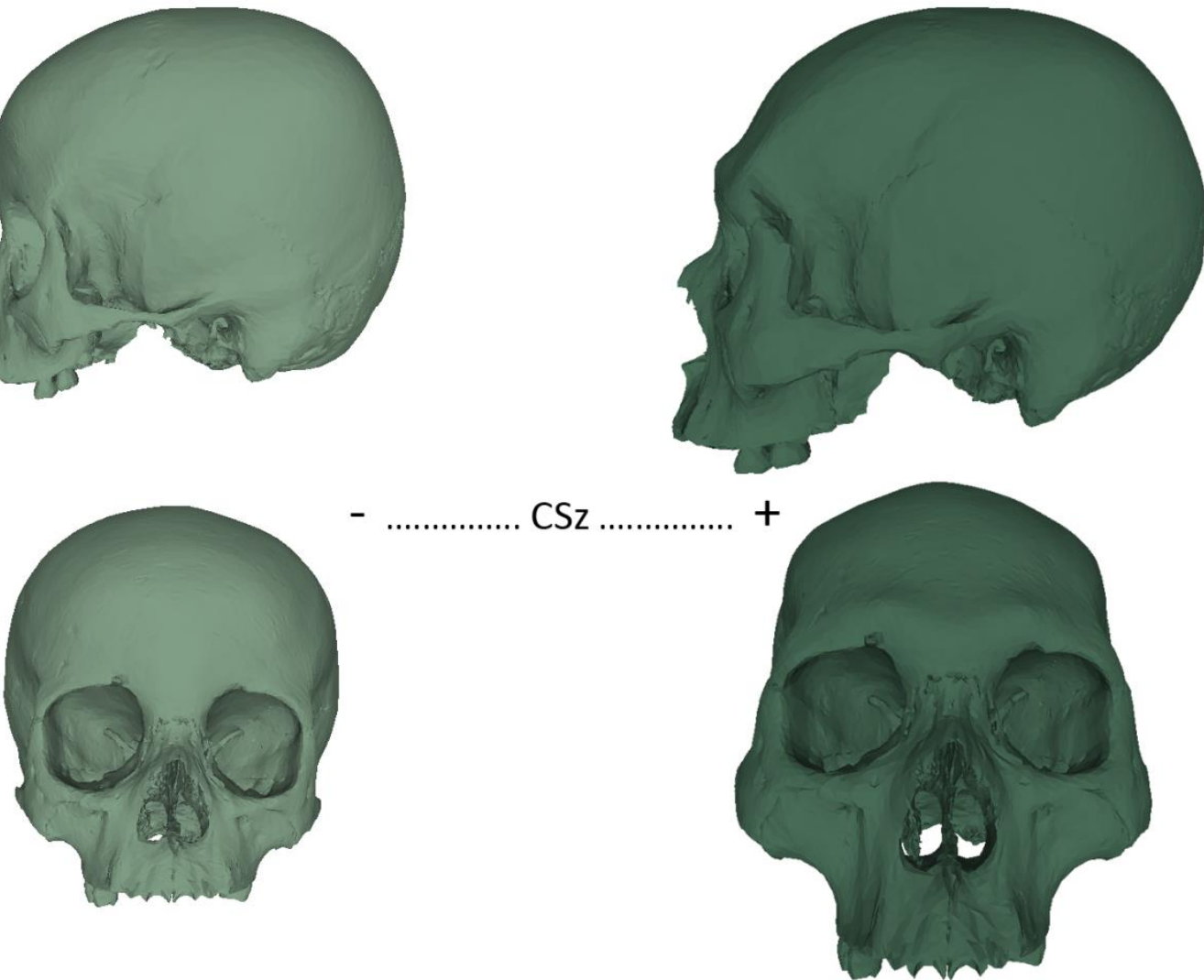

Fig. 8.10. Cambios alométricos en la morfología craneofacial de Chubut: a) distribución de los individuos en función de la recta de regresión, b) modelos craneofaciales que representan la variación resumida en los extremos de la regresión

\subsection{Variación inter-muestral entre Pampa Grande y Chubut}

\subsubsection{Variación en tamaño}

Se analizaron las diferencias de tamaño de las cavidades craneofaciales entre subadultos y adultos de Pampa Grande y Chubut (Fig. 8.11). Respecto a los senos paranasales, los subadultos de Ch presentaron mayor tamaño que los de PG; mientras que en adultos, para el seno maxilar las medianas fueron similares, pero para el seno frontal fue mayor Chubut (Fig. $8.11 a, b)$. Para la cavidad orbital, subadultos y adultos de Ch presentaron medianas mayores que las registradas para Pampa Grande (Fig. 8.11c). Lo mismo se registró para el endocráneo, pero con un mayor rango de dispersión para los adultos de Ch (Fig. 8.11d). 
a)

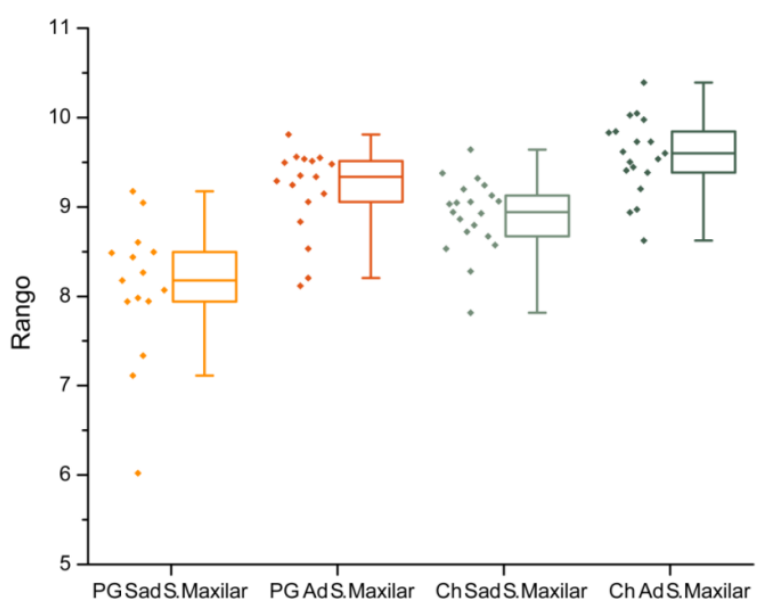

c)

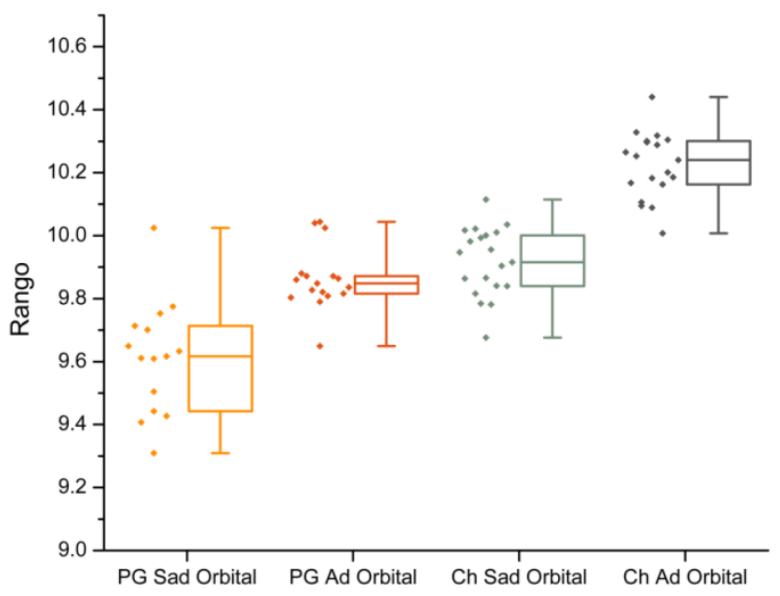

b)

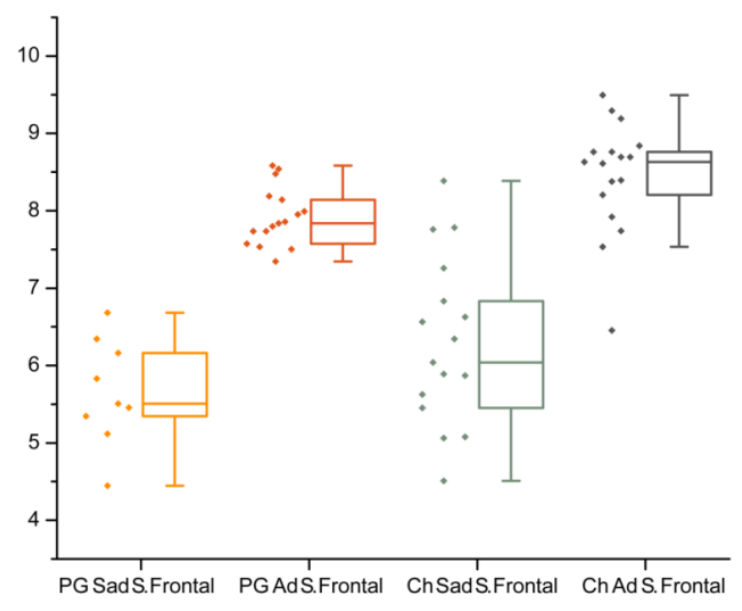

d)

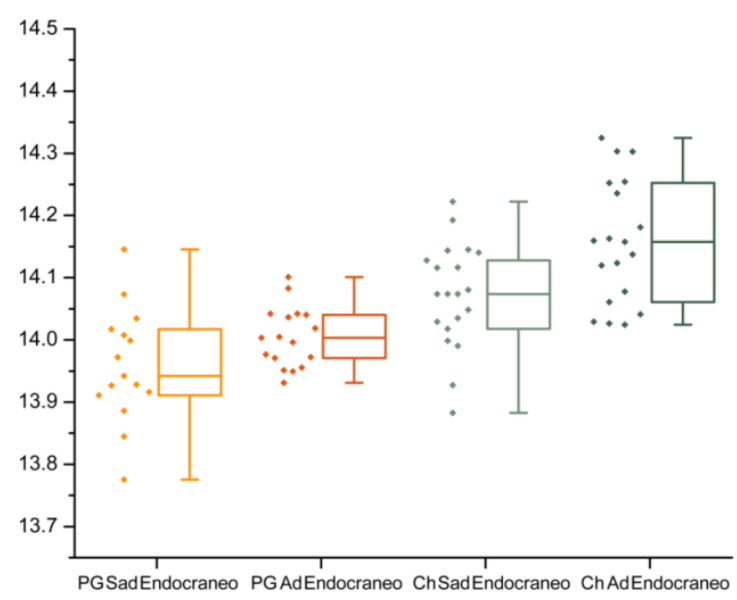

Fig. 8.11. Variación en el tamaño de las cavidades craneofaciales entre subadultos y adultos de Pampa Grande y Chubut: a) seno maxilar, b) seno frontal, c) cavidad orbital, d) endocráneo

\subsubsection{Variación en forma}

El CP1 del análisis de componentes principales resumió el 42,19\% y el CP2 el 8,57\% de la variación total en forma. La variación etaria influyó en el CP1, separando los individuos subadultos de los adultos. El CP2 resumió la variación asociada a diferencias geográficas, separando los individuos por procedencia (Fig. 8.12)

En el extremo negativo del CP2 se ubicaron principalmente individuos de Pampa Grande (Fig. 8.12a). La forma craneofacial es más corta en dirección antero-posterior y más ancha que la del extremo positivo. En norma lateral se visualiza una bóveda redondeada, con un occipital plano. La región supraorbital es plana. El malar presenta menor proyección anterior y el maxilar se proyecta hacia abajo. En norma anterior se observa una bóveda redondeada y un ancho facial mayor en comparación al extremo positivo. El malar se proyecta hacia afuera. El 
a)

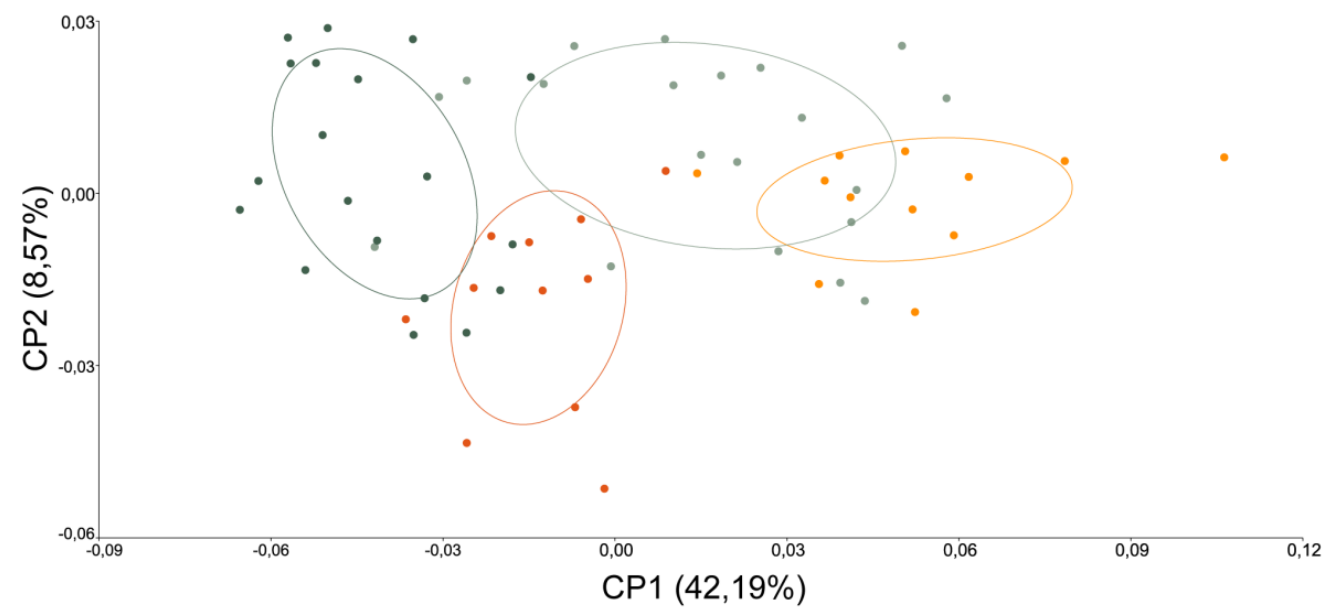

$\square$ PG Sad $\square$ PG Ad $\square$ Ch Sad $\square$ Ch Ad

b)
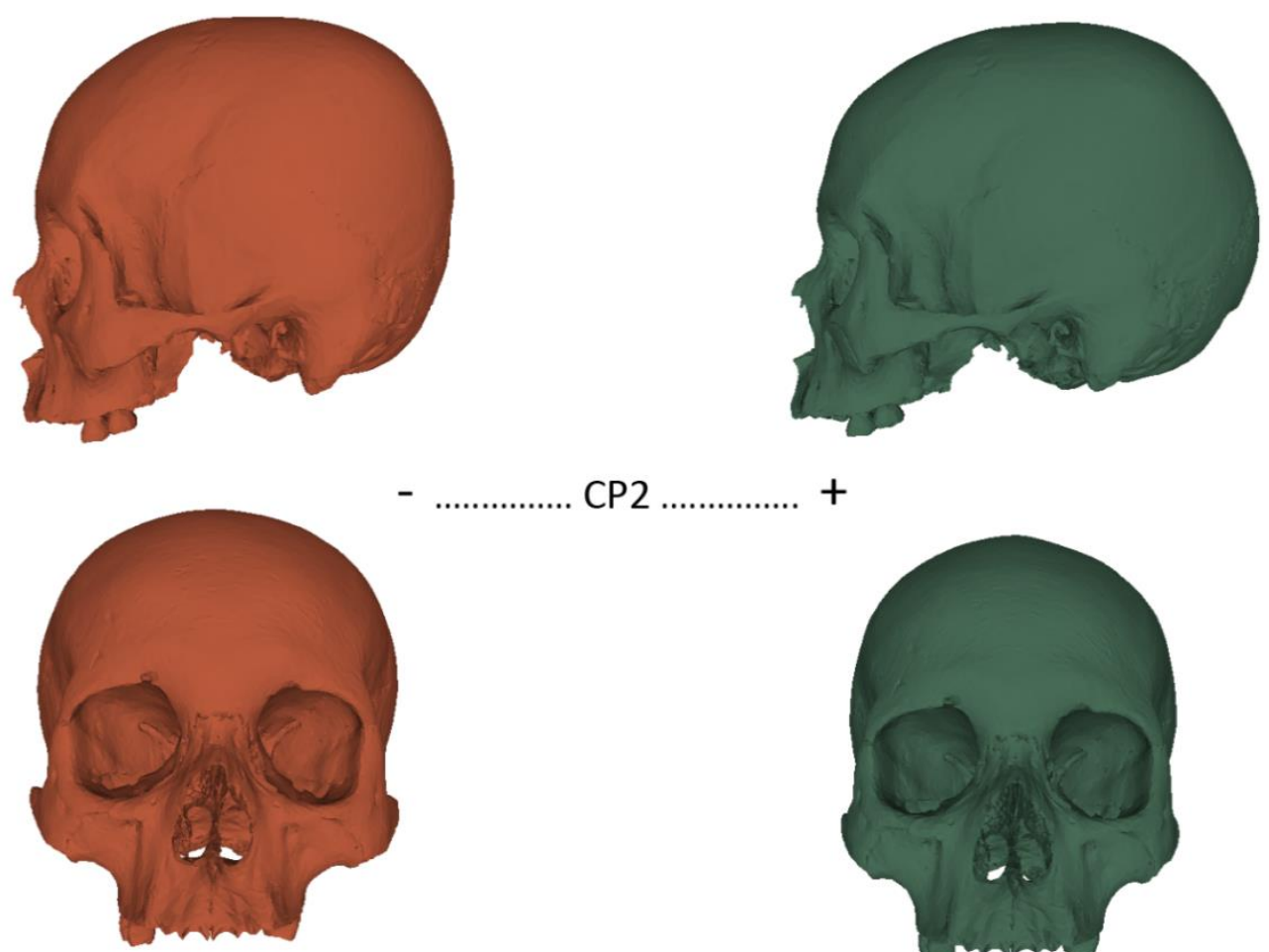

$+$

c)
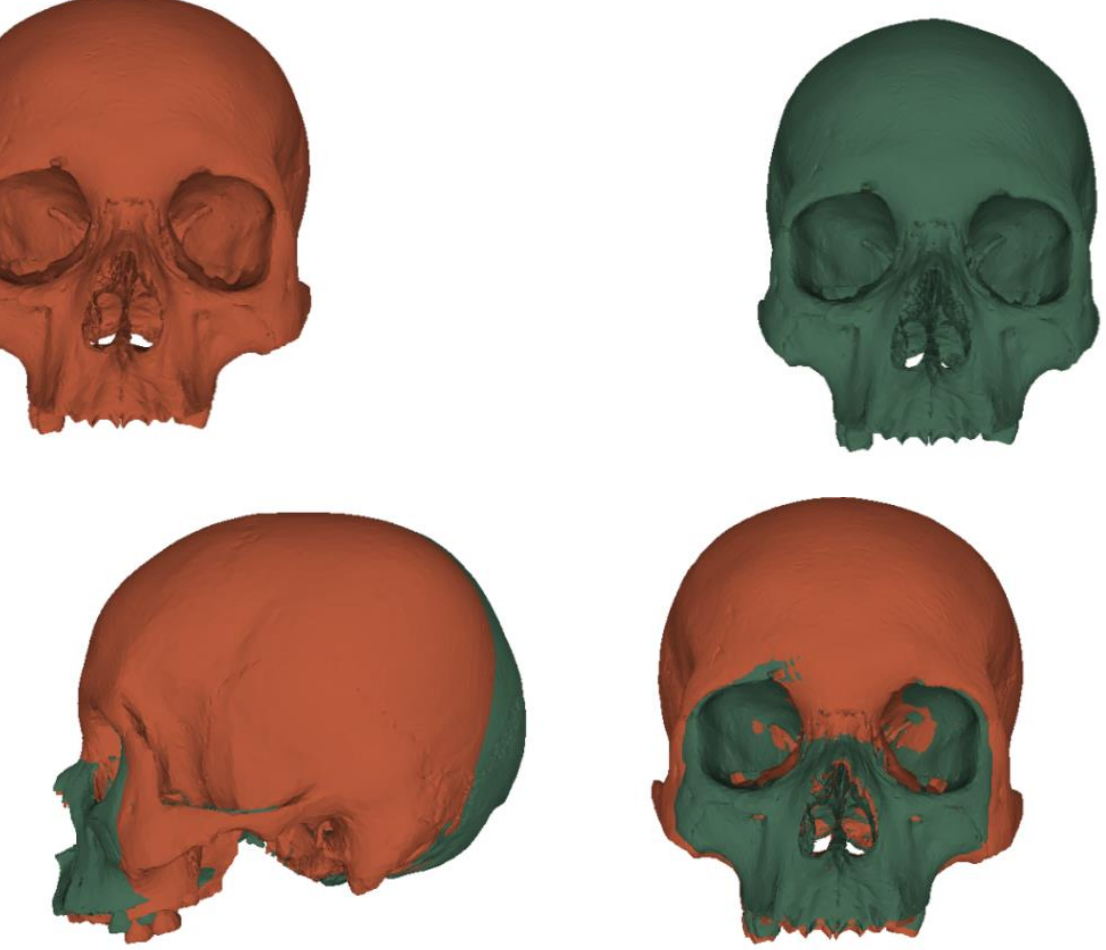

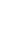

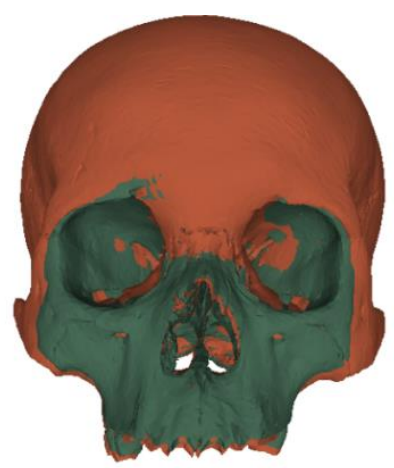

Fig. 8.12. Cambios en la forma craneofacial de Pampa Grande y Chubut: a) distribución de los individuos en función de los dos primeros Componentes Principales, b) modelos craneofaciales que representan la variación por procedencia resumida en los extremos del CP2 (negativo PG, positivo Ch), c) superposición de los modelos craneofaciales negativo (PG) y positivo (Ch) del CP2 
maxilar, de cuerpo recto, presenta una gran apertura en la región entre el proceso cigomático y el proceso alveolar (Fig. 8.12b,c).

En el extremo positivo del CP2 se ubicaron individuos de Chubut (Fig. 8.12a). La forma craneofacial es alargada antero-posteriormente y de menor ancho facial que la obtenida a partir del extremo negativo. En norma lateral se observa una bóveda de forma abovedada, con proyección del occipital. El borde supraorbital, si bien no es muy robusto, es más marcado que en el del extremo negativo. El malar se proyecta hacia adelante, junto al maxilar. El maxilar es corto. En norma anterior se observa una bóveda angosta. El malar no se proyecta tanto hacia afuera como sí sucede en el extremo negativo. El maxilar presenta un cuerpo recto y una gran extensión en la región entre el proceso cigomático y el proceso alveolar (Fig. 8.12b,c). 


\section{Integración de datos histológicos y morfológicos}

Asociación entre la variación en los patrones de modelado óseo y la variación

en la morfología facial

\section{Contenido}

9.1. Variación en los patrones de modelado óseo y la morfología facial en la muestra de Pampa Grande

9.1.1. Variación en tamaño, forma y modelado óseo

Glabela y supraorbitales

Malar

Maxilar

9.2. Variación en los patrones de modelado óseo y la morfología facial en la muestra de Chubut

9.2.1. Variación en tamaño, forma y modelado óseo

Glabela y supraorbitales

Malar

Maxilar

9.3. Resultados destacados

En el presente capítulo se exponen los resultados del análisis conjunto de los datos de modelado óseo y de la morfología craneofacial de las muestras de Pampa Grande y Chubut. Para cada muestra se presentan los análisis de asociación entre el tamaño y la forma facial en relación con los patrones de modelado óseo para tres regiones faciales: 1) glabela y supraorbitales, 2) malar y 3) maxilar. Como variables de tamaño se emplean el tamaño centroide de cada región facial y el volumen de las cavidades craneofaciales asociadas a las superficies replicadas. En particular, se presentan las regresiones entre los patrones de modelado óseo de la glabela y el seno frontal, del maxilar y el seno maxilar, y del supraorbital y del malar y el volumen de la cavidad orbital (u orbital). El grado de asociación entre la forma y el modelado es evaluado a través de la comparación de los componentes principales derivados de las coordenadas Procrustes y de los mapas que resumen la distribución de áreas de formación y reabsorción de cada individuo, así como mediante el análisis de la covariación entre las coordenadas de forma y los componentes de modelado óseo. 
9.1. Variación en los patrones de modelado óseo y la morfología facial en la muestra de Pampa Grande

9.1.1. Variación en tamaño, forma y modelado óseo

\section{Glabela y supraorbitales}

En la Figura 9.1 se presenta la regresión de los primeros componentes principales del patrón de modelado óseo sobre el tamaño centroide de la región de glabela y supraorbitales en los individuos subadultos (a) y adultos (b) de Pampa Grande. El tamaño centroide -CSz- no muestra asociación con el patrón de modelado (Fig. 9.1a,b). Los individuos subadultos exhiben cambios en el tamaño, mientras el patrón de modelado no presenta variación entre individuos, caracterizándose por la formación ósea (Fig. 9.1a). Los individuos adultos presentan variación tanto en el tamaño como en el modelado óseo, aunque ambas variables no están asociadas (Fig. 9.1b).

a)

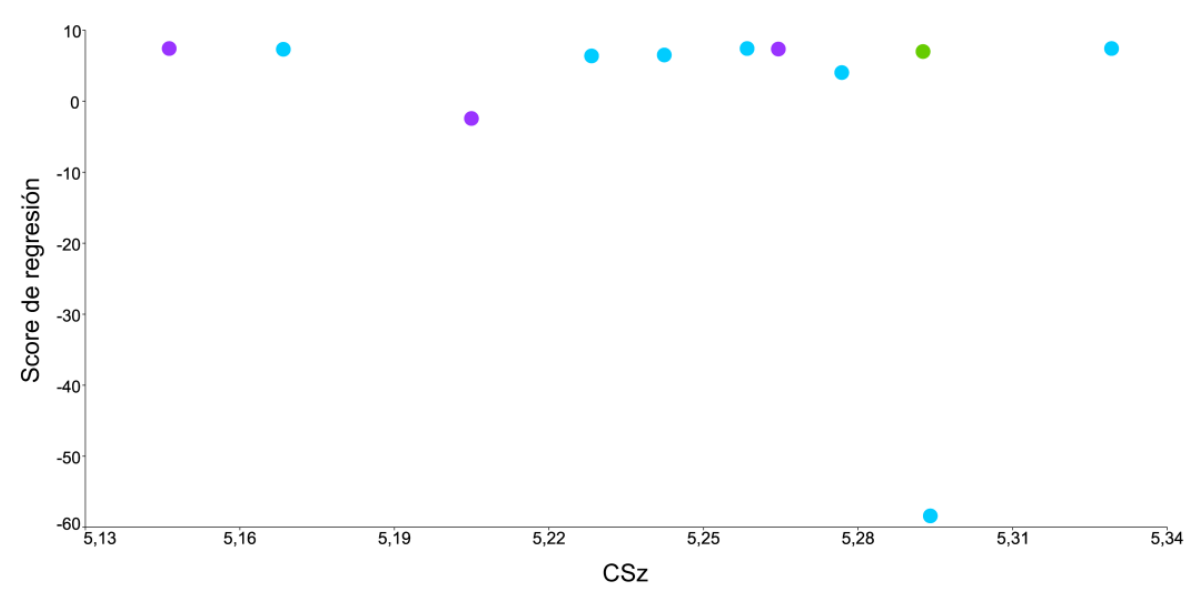

b)

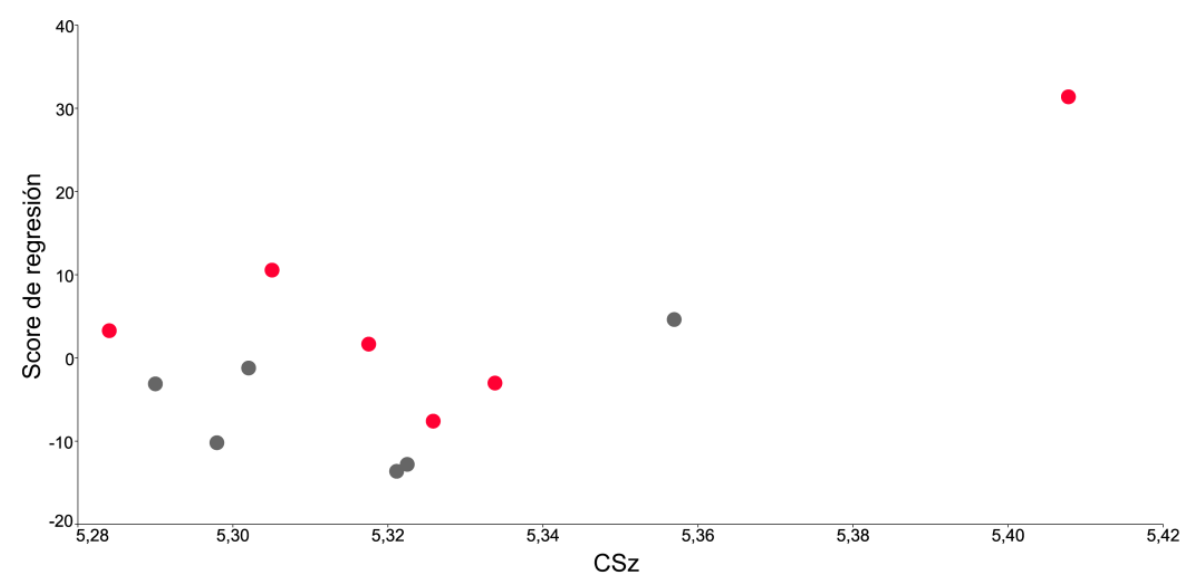

Fig. 9.1. Regresión del modelado óseo (score de regresión) y el tamaño centroide (CSz) de la región de glabela y supraorbitales de subadultos (a) y adultos (b) de Pampa Grande. Valor predictivo de la regresión: a) 6,88\%, b) 6,24\%, (p>0,05) 
Los análisis de regresión entre el patrón de modelado de la glabela y del supraorbital y el volumen del seno frontal y del orbital muestran la falta de asociación entre las variables histológicas y el volumen de estas cavidades (Fig. 9.2). En los subadultos, el patrón de modelado es similar entre individuos de distintas edades, mientras el volumen de ambas cavidades exhibe diferencias entre individuos (Fig. 9.2a,c). Los individuos adultos presentan variación tanto en el modelado óseo como en los volúmenes del seno frontal y el orbital, aunque no hay asociación entre las variables histológicas y morfológicas (Fig. 9.2b,d).

a)

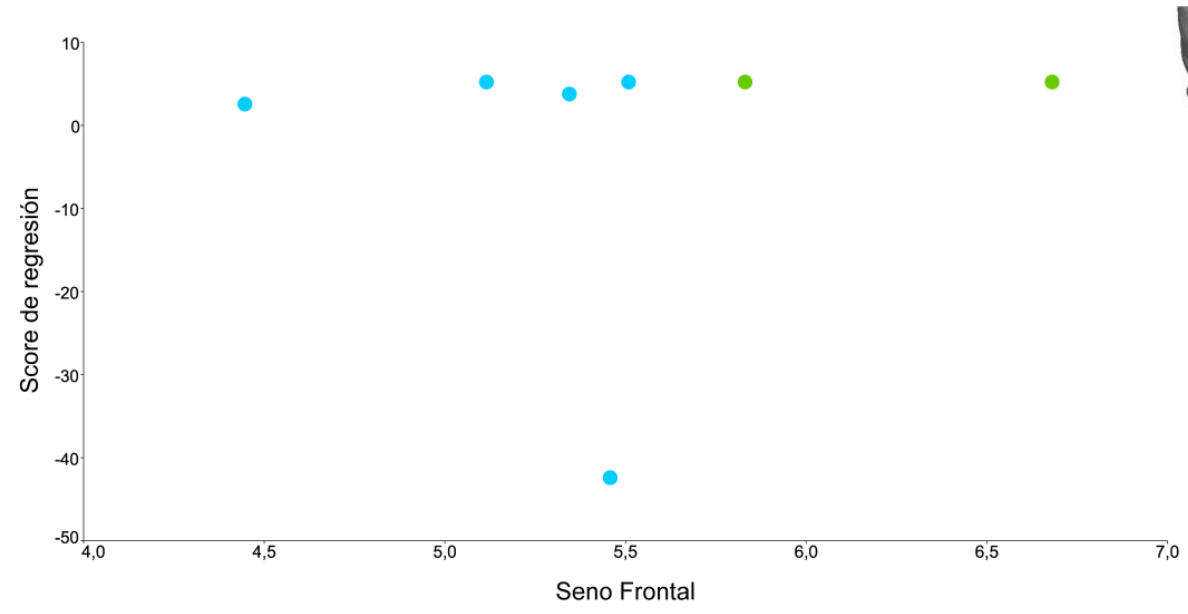

b)

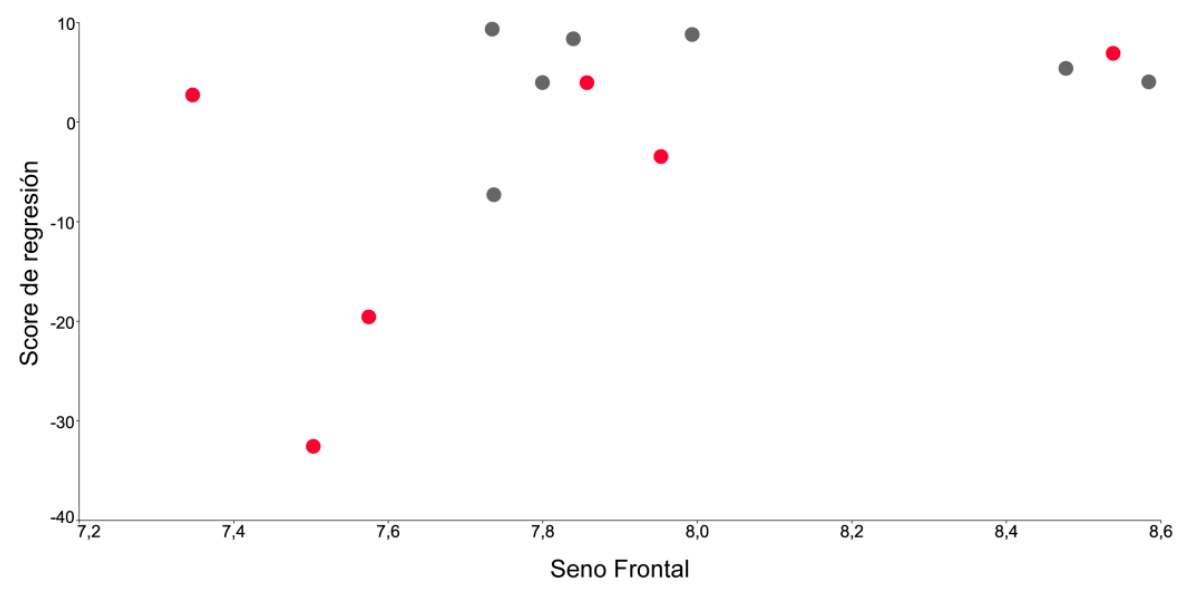

c)

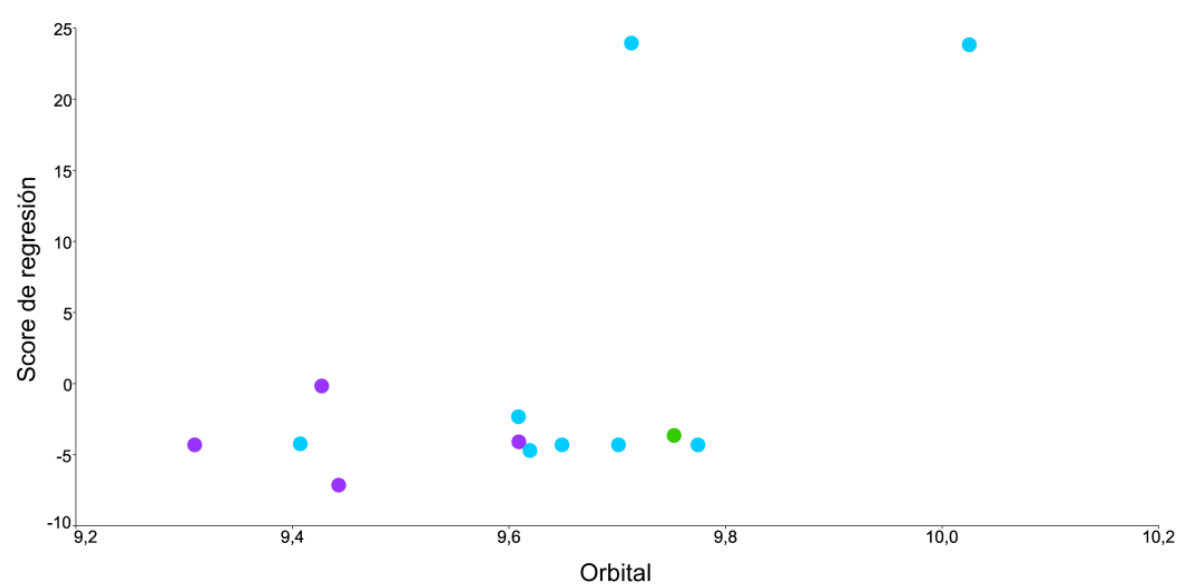

Continíua en la siguiente página 
d)

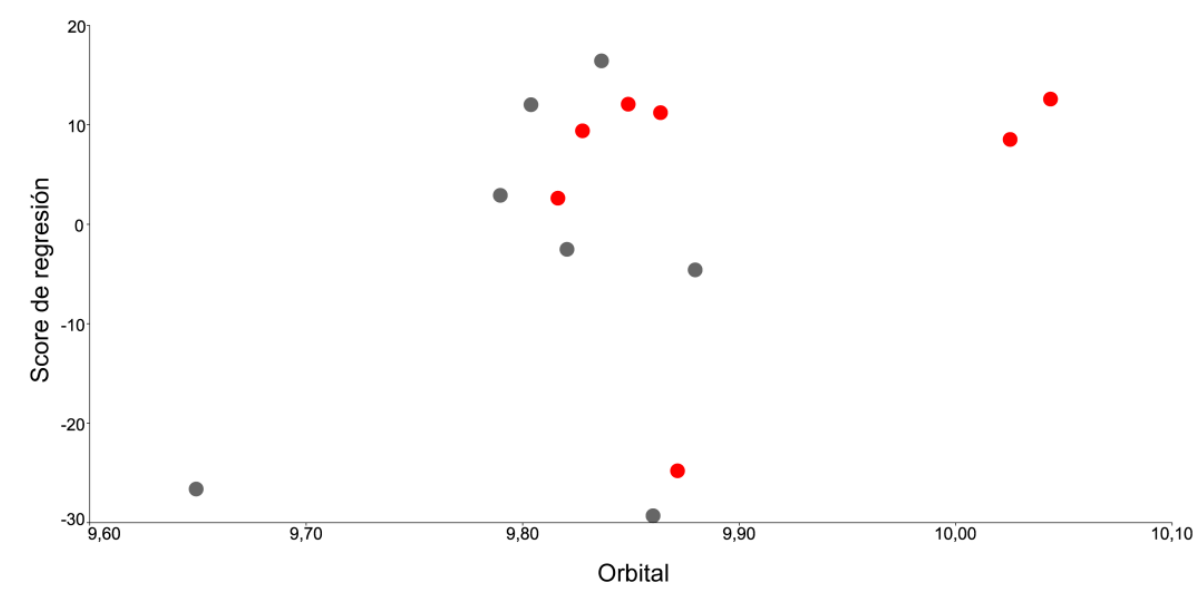

Fig. 9.2. Regresión del modelado óseo (score de regresión) de la región de glabela y supraorbitales y el volumen de las cavidades craneofaciales para la muestra de Pampa Grande: a) seno frontal de subadultos, b) seno frontal de adultos, c) orbital de subadultos, d) orbital de adultos. Valor predictivo de la regresión: a) 0,33\%, b) 9,77\%, c) 15,56\%, d) 6,20\%. (p>0,05)

En la Figura 9.3 se presenta la distribución de los individuos subadultos y adultos de la muestra de Pampa Grande a lo largo de los primeros componentes principales del análisis de la forma de la región de glabela y supraorbitales (Fig. 9.3a,c) y el patrón de modelado óseo de la glabela y del supraorbital. En este análisis sólo se incluyeron los individuos que presentaban datos de modelado tanto para la glabela como el supraorbital.

En los subadultos se registran cambios en forma asociados con la edad a lo largo del CP1 (que explica el $26,18 \%$ de la variación). En el extremo negativo se ubican los individuos menores a 4,4 años (G1), mientras en el positivo se encuentran los individuos entre 10,5-14,4 años (G3). Los individuos entre 4,5-10,4 años (G2) exhiben la mayor dispersión a lo largo del CP1 (Fig. 9.3a). Con respecto el modelado óseo, en el extremo positivo del CP1 (90,57\%) y del CP2 (5,61\%) se agrupan los individuos del G1 al G3, en los que predomina la formación ósea en la superficie, y se separan los individuos que presentan reabsorción (Fig. 9.3b). En el extremo negativo del CP1 se ubica un individuo con predominancia de reabsorción en la glabela y el supraorbital. En líneas generales no se observa una distribución similar de los individuos en los componentes de forma y modelado óseo, algunos individuos se separan en el espacio de modelado óseo, pero se encuentran agrupados en el de forma (Fig. 9.3a,b).

Los adultos jóvenes presentan una distribución más restringida que los adultos medios a lo largo del CP1 de forma (32,96\% de la variación) (Fig. 9.3c). En el extremo negativo del CP1 (41,70\% de la variación) del espacio de modelado se agrupan individuos con predominancia de reabsorción en la glabela y el supraorbital, mientras que en el extremo positivo se encuentran 
aquellos con predominancia de formación (Fig. 9.3d). La distribución de los individuos en ambos espacios difiere, encontrándose individuos con morfologías similares que tienden a diferenciarse en el espacio de modelado óseo (Fig. 9.3c,d).

a)

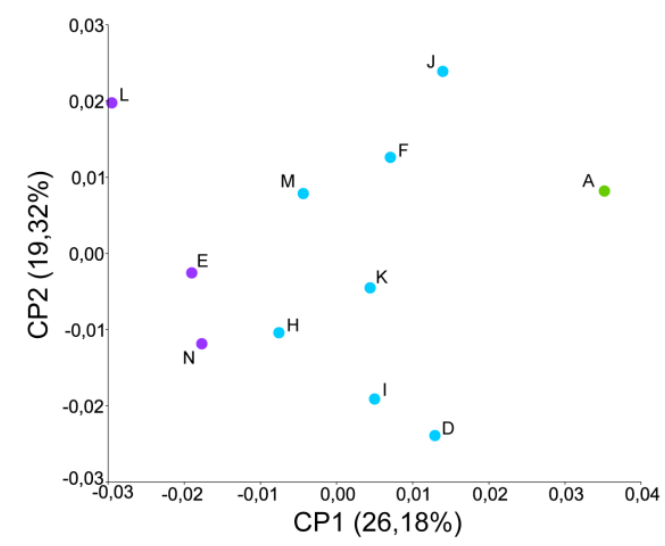

b)

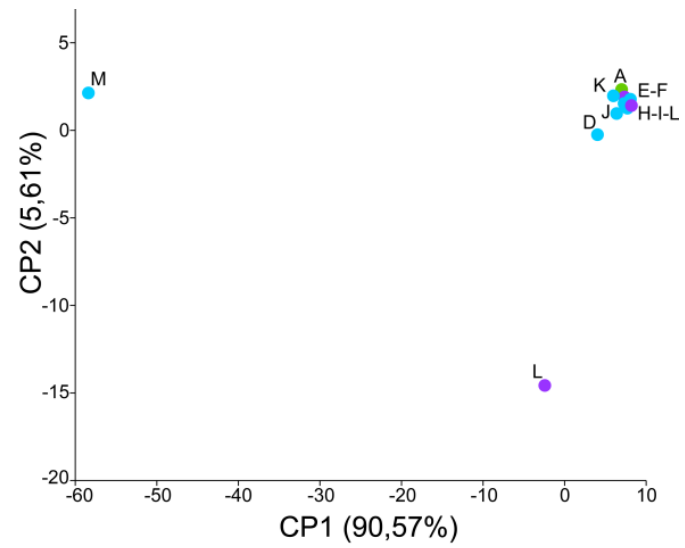

c)

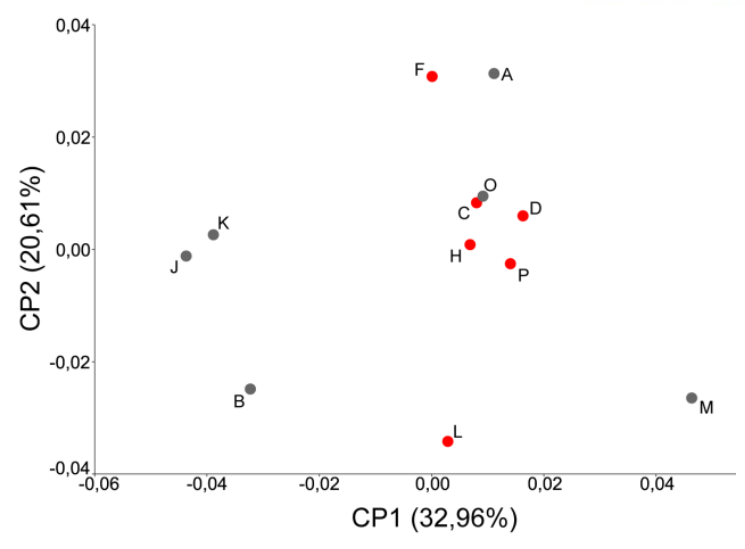

d)

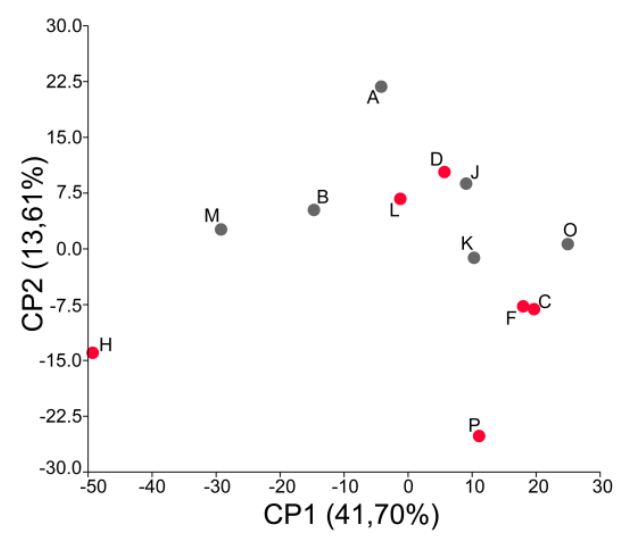

Fig. 9.3. Componentes principales de las variables de forma $(a, c)$ y de modelado óseo $(b, d)$ de la región de glabela y supraorbitales de subadultos (a-b) y adultos (c-d) de la muestra de Pampa Grande. Las letras referencian los mismos individuos entre los dos análisis de subadultos y de adultos

En la Figura 9.4 se presenta el análisis de covariación entre los componentes de forma y de modelado óseo de subadultos (a) y adultos (b) de la muestra de Pampa Grande. Los coeficientes de correlación en ambos casos fueron relativamente altos, pero no significativos ( $r=0,79, p=0,88$ para subadultos; $r=0,73, p=0,78$ para adultos). Los primeros ejes del análisis de PLS, claramente muestran la ausencia de covariación entre ambos tipos de variables para la región de glabela y supraorbitales, tanto en subadultos como en adultos. 
a)

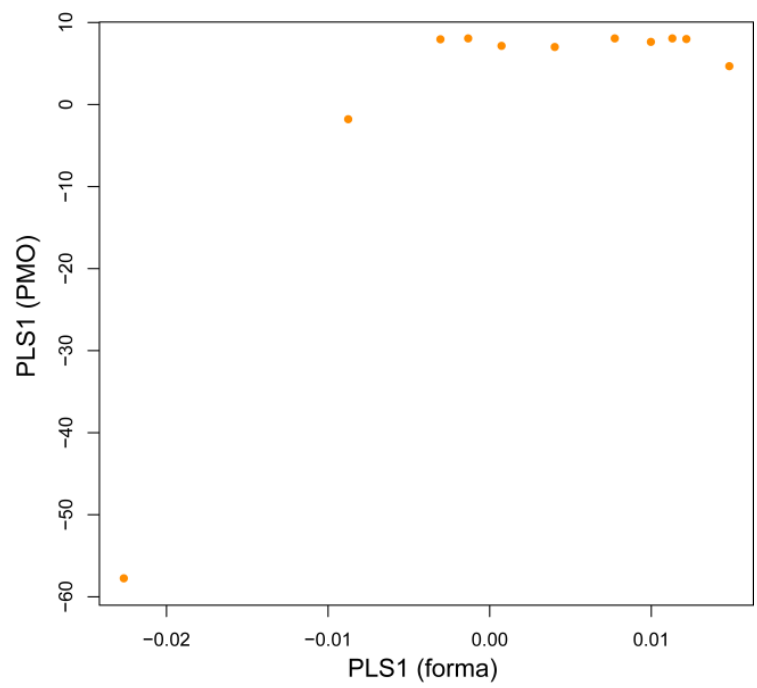

b)

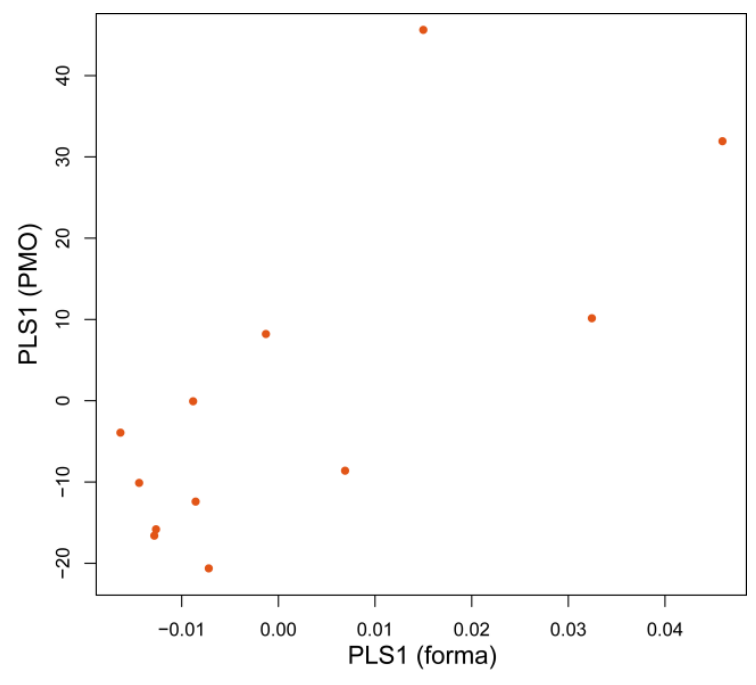

Fig. 9.4. Primeros ejes del análisis de Partial Least Squares (PLS) entre forma y modelado óseo de la región de glabela y supraorbitales en subadultos (a) y adultos (b) de Pampa Grande.

\section{$\underline{\text { Malar }}$}

En la Figura 9.5 se presenta la regresión del patrón de modelado sobre el tamaño centroide del malar. Tanto en subadultos como en adultos se observa que a medida que se incrementa el tamaño los datos del patrón de modelado muestran mayor dispersión (Fig. 9.5a,b). El porcentaje de variación en el patrón de modelado explicado por el tamaño es muy bajo.

a)

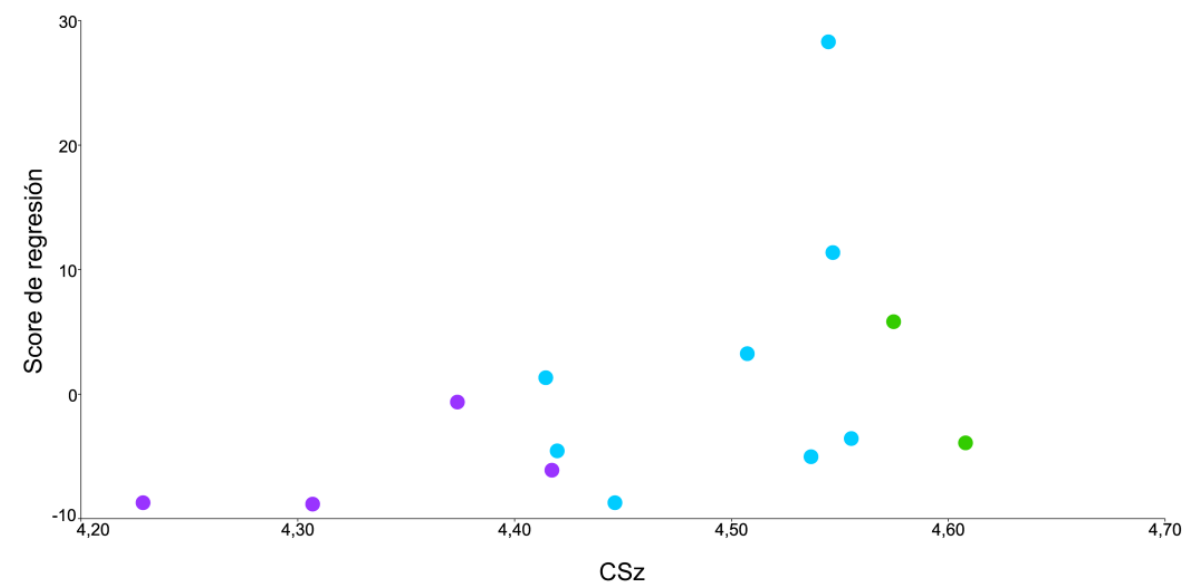


b)

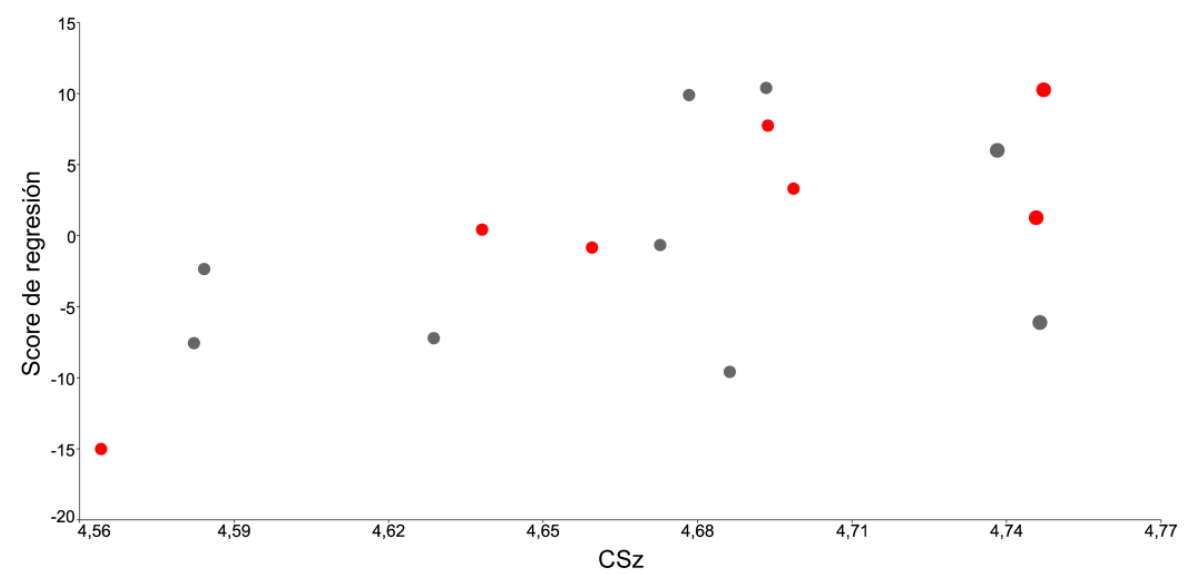

Fig. 9.5. Regresión del modelado óseo (score de regresión) y el tamaño centroide (CSz) del malar de subadultos (a) y adultos (b) de Pampa Grande. Valor predictivo de la regresión: a) 10,88\%, b) $4,25 \%(p>0,05)$

En la Figura 9.6 se presenta la regresión del patrón de modelado del malar sobre el volumen del orbital. Tanto en los individuos subadultos como adultos se registra una falta de asociación entre ambas variables (Fig. 9.6a,b).

a)
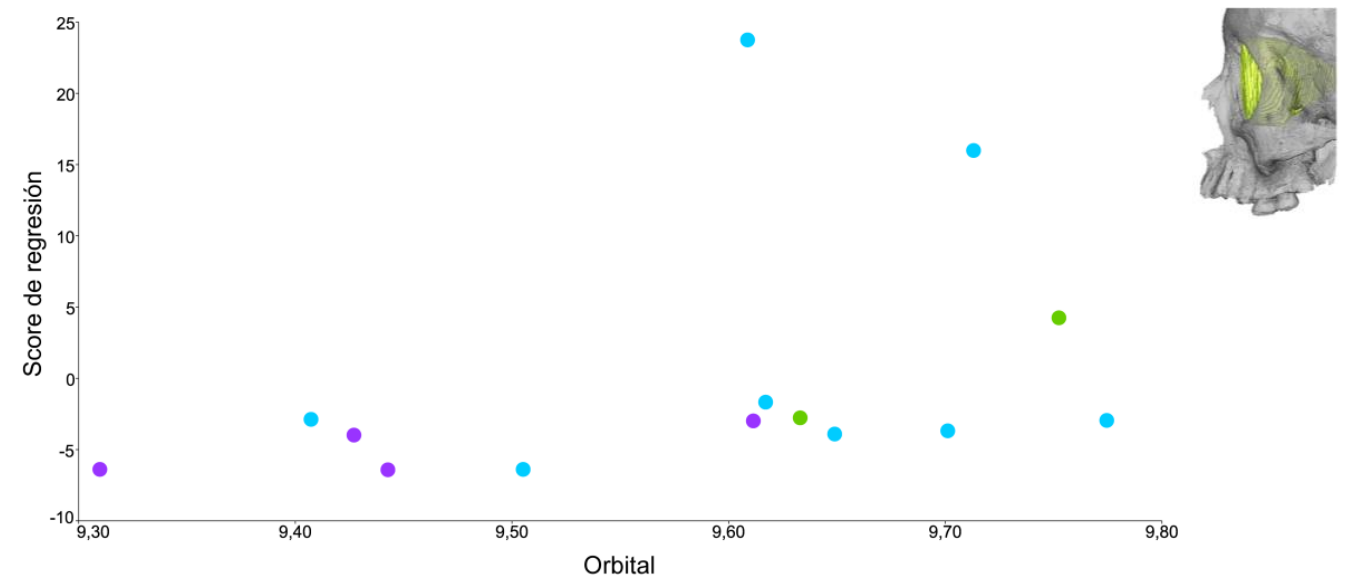

b)

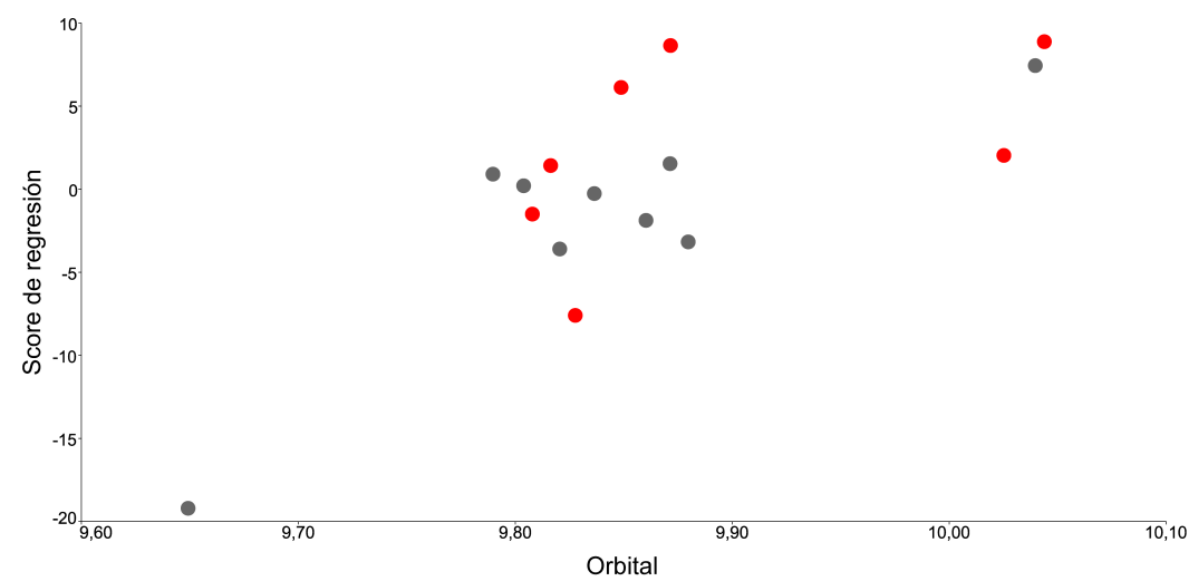

Figura 9.6. Regresión del modelado óseo del malar sobre el volumen del orbital en subadultos (a) y adultos (b) de Pampa Grande. Valor predictivo de la regresión: a) 5,28\%, b) 5,35\% (p>0,05) 
Los resultados del análisis de componentes principales sobre las variables de forma y de modelado óseo del malar de individuos subadultos y adultos se presentan en la Figura 9.7. Los individuos del G2 presentaron mayor variación en forma a lo largo del CP1 (24,37\% de la variación) que el resto de los subadultos (Fig. 9.7a). En el espacio de modelado óseo, los mapas caracterizados por áreas más extensas de reabsorción se ubican en el extremo negativo del CP1 $(42,73 \%)$, mientras en el extremo positivo se encuentran los mapas con predominio de formación (Fig. 9.7b). La distribución de los individuos en el espacio de forma difiere a la observada en el espacio de modelado óseo (Fig. 9.7a,b).

Los individuos correspondientes a la categoría adulto medio presentan menor dispersión a lo largo del CP1 (24,65\%) que los adultos jóvenes (Fig. 9.7c). Respecto al modelado óseo, en el extremo negativo del CP1 $(30,76 \%)$ se ubican los individuos con áreas más extensas de reabsorción. En el extremo negativo del CP2 (18,62\%) se localizan los mapas caracterizados por presentar reabsorción en la región posterior del malar, mientras que en el extremo positivo se localizan aquellos que presentan reabsorción en la región anterior. Asimismo, se observan diferencias vinculadas al sexo, a lo largo del CP1 se diferencian los individuos masculinos -con scores negativos o cercanos a 0- de los femeninos -con scores positivos en su mayoría- (Fig. 9.7d). Al igual que lo observado en subadultos, no se encontraron similitudes en la distribución de los individuos en los espacios de forma y modelado óseo (Fig. 9.7c,d).

a)

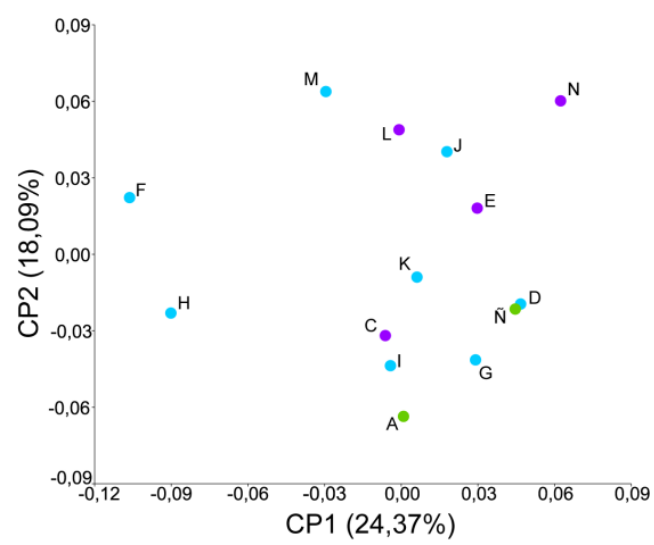

c)

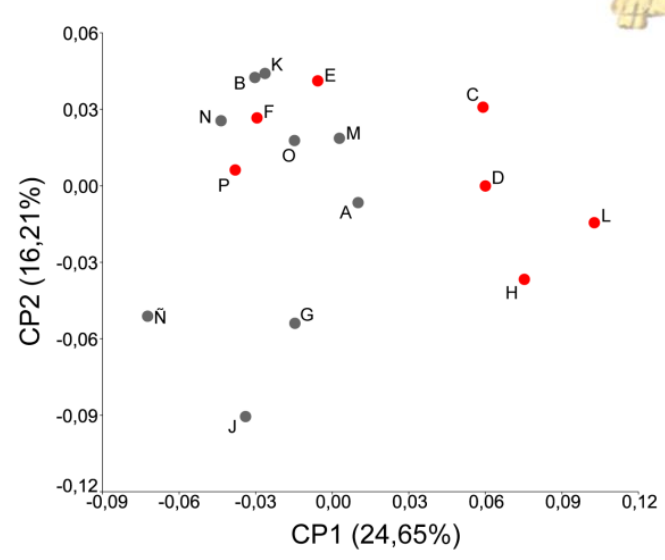


b)

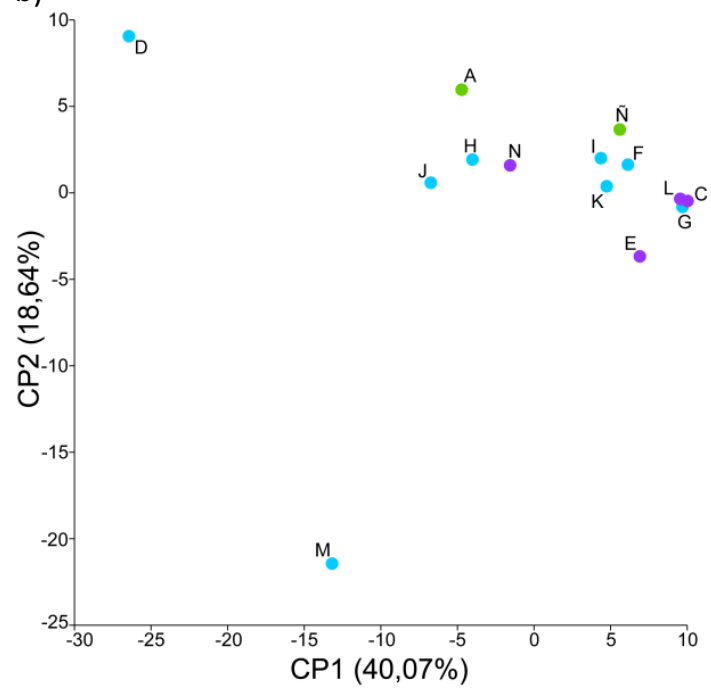

d)

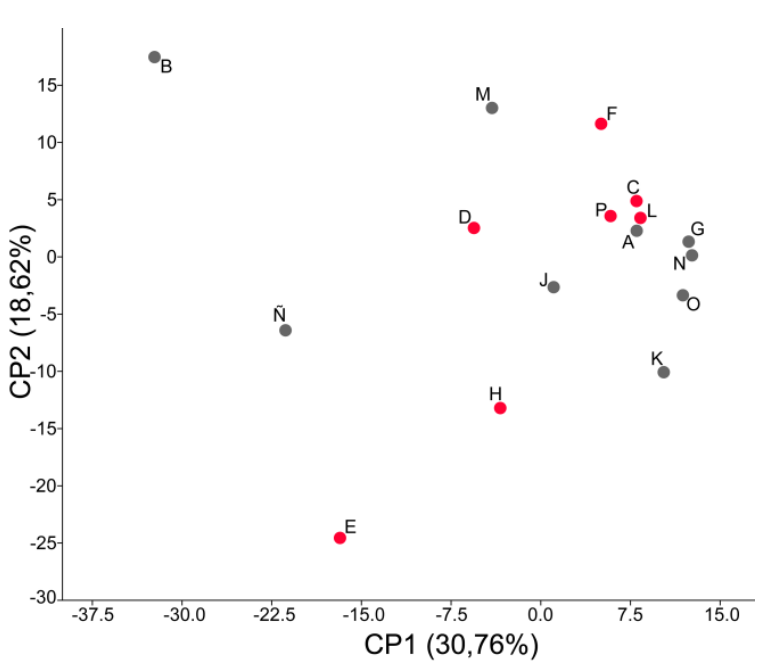

Fig. 9.7. Componentes principales de las variables de forma $(a, c)$ y de modelado óseo (b,d) del malar de subadultos (a-b) y adultos (c-d) de la muestra de Pampa Grande. Las letras referencian los mismos individuos entre los dos análisis de subadultos y de adultos

En la Figura 9.8 se presenta la covariación de los componentes de forma y de modelado óseo del malar en subadultos (a) y adultos (b) de Pampa Grande. En subadultos, el coeficiente de correlación fue de $0,80(p=0,46)$, mientras que en adultos la correlación fue de 0,72 $(p=0,86)$ (Fig. 9.8a,b).

El análisis de PLS del malar de los individuos subadultos indica que en el extremo negativo del primer eje del patrón de modelado se ubican aquellos individuos que presentan mayor proporción de formación y áreas más pequeñas de reabsorción, especialmente en el borde anterior, mientras que en el extremo positivo se encuentran individuos con reabsorción ósea en los bordes anterior y posterior del malar. Las morfologías ubicadas en el extremo negativo del primer eje de forma se caracterizan por un cuerpo más alto y ancho, el proceso frontal más alto y desplazado hacia el lado medial, el proceso temporal relativamente más grande y el orbital relativamente más pequeño que las morfologías del extremo positivo (Fig. 9.8a).

En los individuos adultos, el primer eje del análisis PLS realizado sobre los componentes principales del patrón de modelado óseo separa los individuos de acuerdo al tipo de actividad predominante. En el extremo positivo se localizan los individuos en los que predomina formación, mientras en el negativo se encuentran aquellos que presentan una mayor proporción de reabsorción. La morfología de los malares ubicados en el extremo positivo del primer eje de forma se caracteriza por presentar el proceso frontal y el cuerpo más alto y angosto, y el proceso temporal de mayor tamaño en relación con las morfologías ubicadas en el extremo negativo (Fig. 9.8b). 
a)
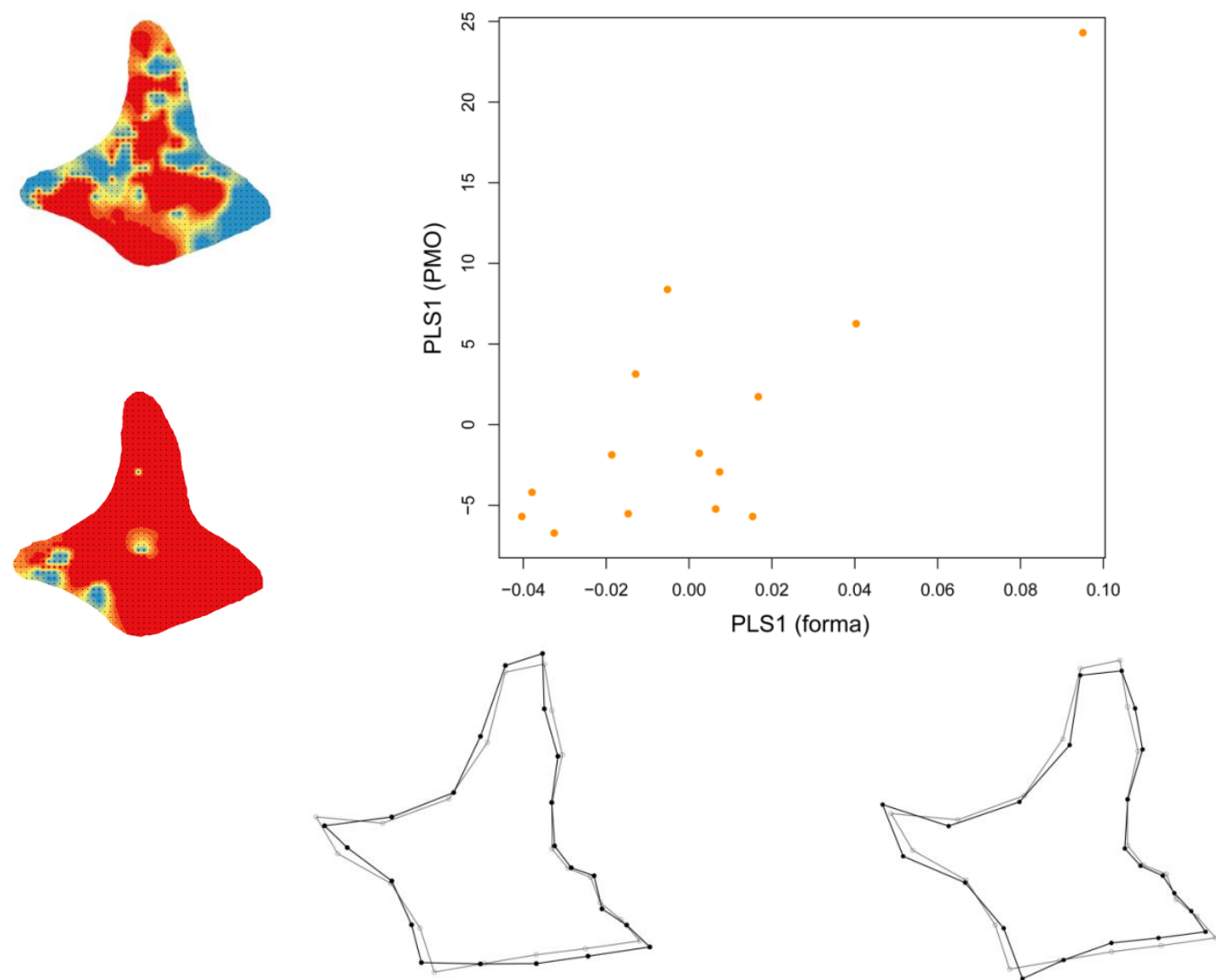

b)
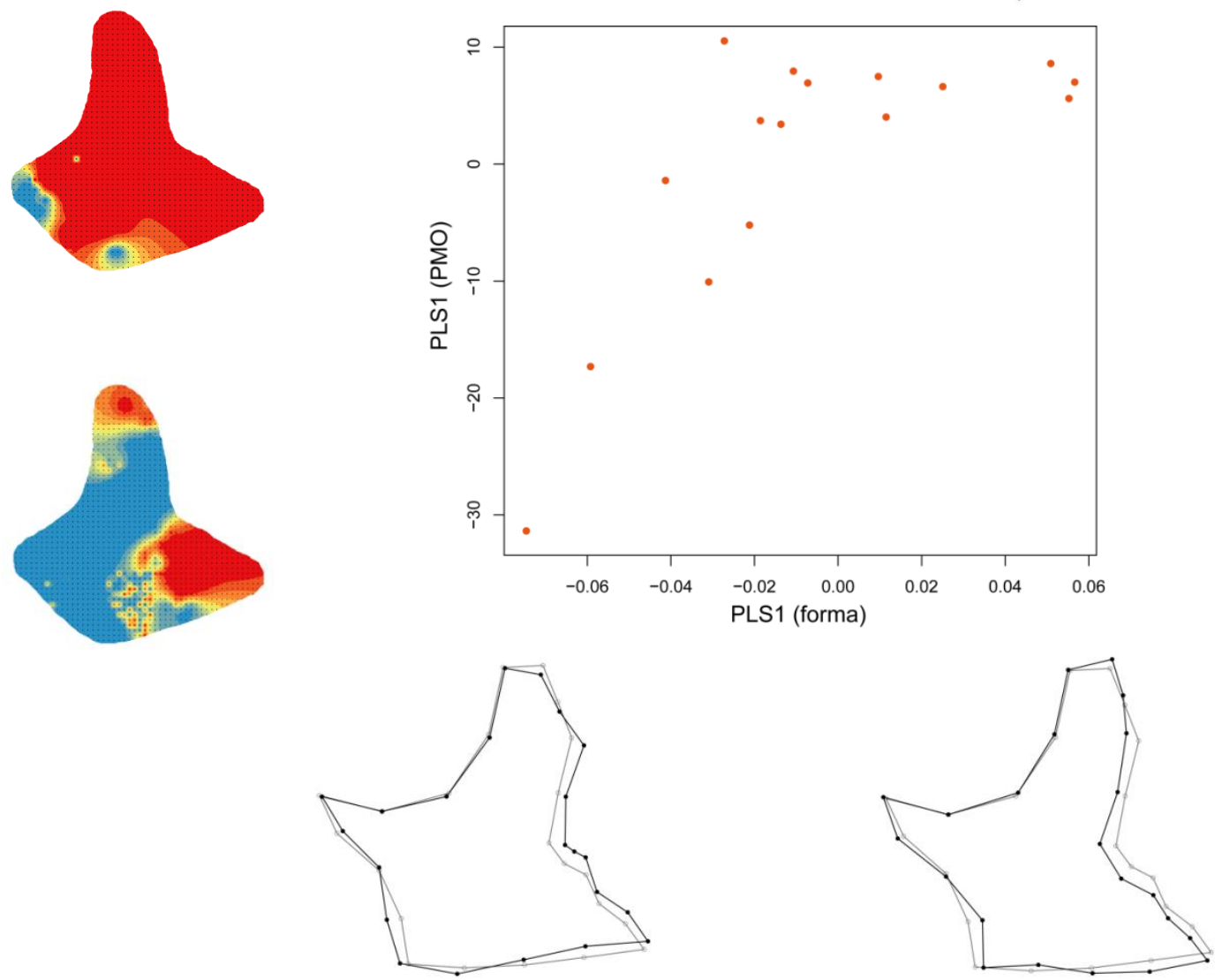

Fig. 9.8. Primeros ejes del análisis de Partial Least Squares (PLS) entre forma y modelado óseo del malar en subadultos (a) y adultos (b) de Pampa Grande. Los análisis se realizaron a partir de las coordenadas de todos los puntos que describen el malar. Para facilitar la visualización de los cambios en forma se emplearon sólo los de contorno. En el wireframe la línea gris representa la forma media, mientras la negra representa las formas en los extremos del PLS1. Los mapas de modelado óseo corresponden a los individuos extremos del PLS 
En la Figura 9.9 se presenta la regresión entre el modelado y el tamaño centroide del maxilar para los individuos subadultos y adultos ( $a, b$ respectivamente). En ninguno de estos dos grupos se observa una fuerte asociación entre ambas variables, tal como lo refleja el bajo porcentaje de variación explicada por el tamaño (Fig. 9.9).

a)

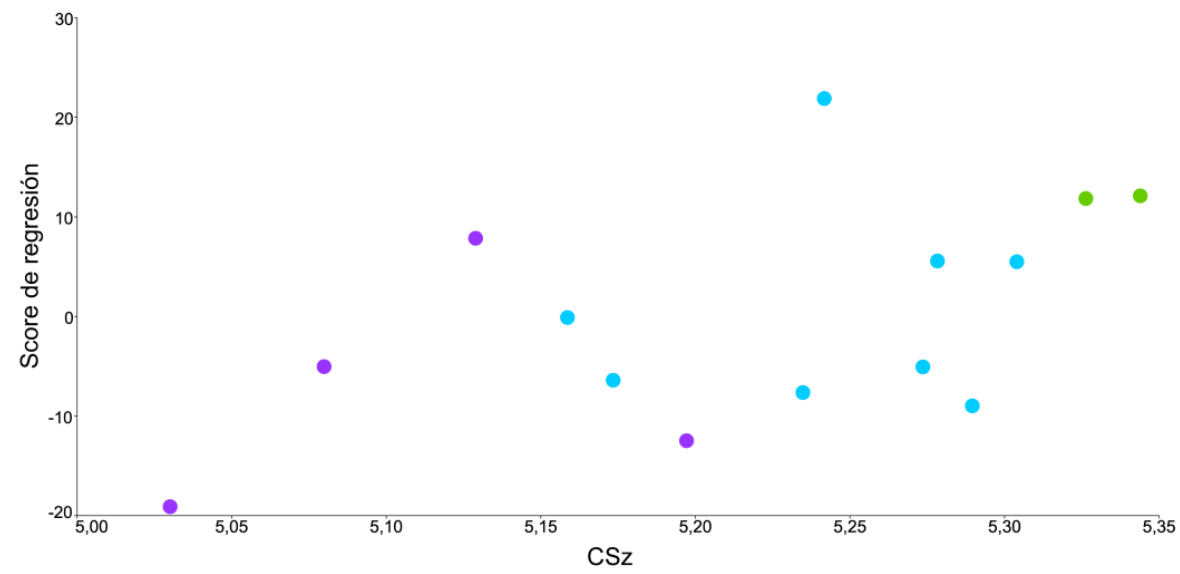

b)

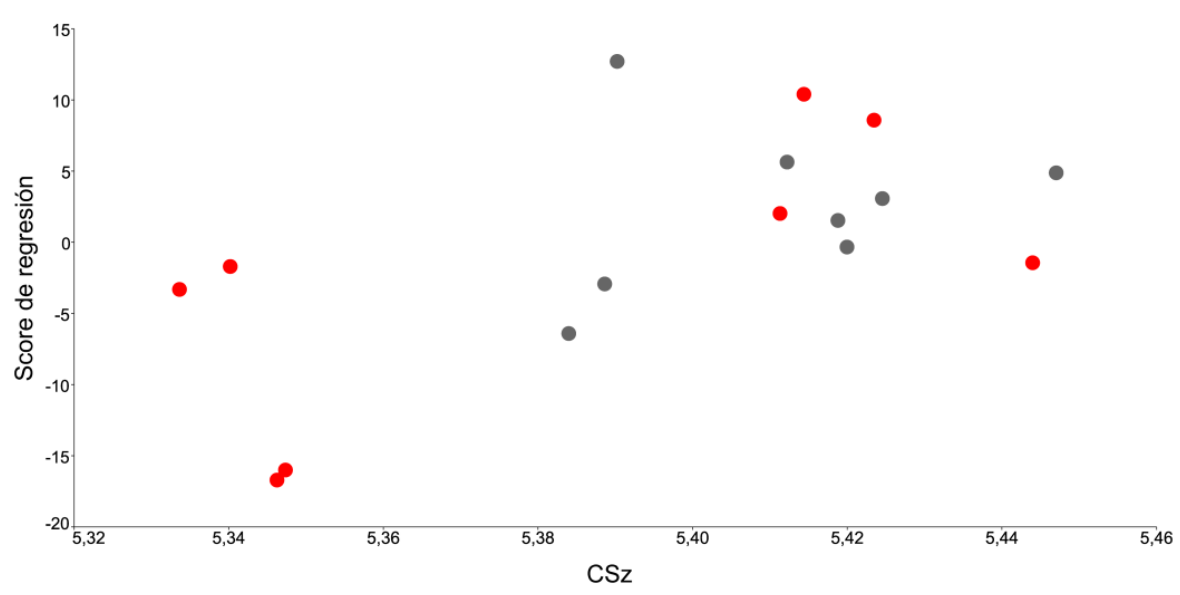

Fig. 9.9. Regresión del modelado óseo y el tamaño centroide del maxilar en subadultos (a) y adultos (b) de Pampa Grande. Valor predictivo de la regresión: a) 11,66\%, b) 8,07\% (p>0,05)

En la Figura 9.10 se presenta la regresión entre el modelado óseo del maxilar y el volumen del seno maxilar en los individuos subadultos y adultos de Pampa Grande. En ambos grupos de edad se evidencia la baja asociación entre el modelado y los cambios en el tamaño del seno maxilar. En los subadultos se destaca el individuo que presenta el menor volumen y se diferencia del resto en el score de regresión (Fig. 9.10a). 
a)

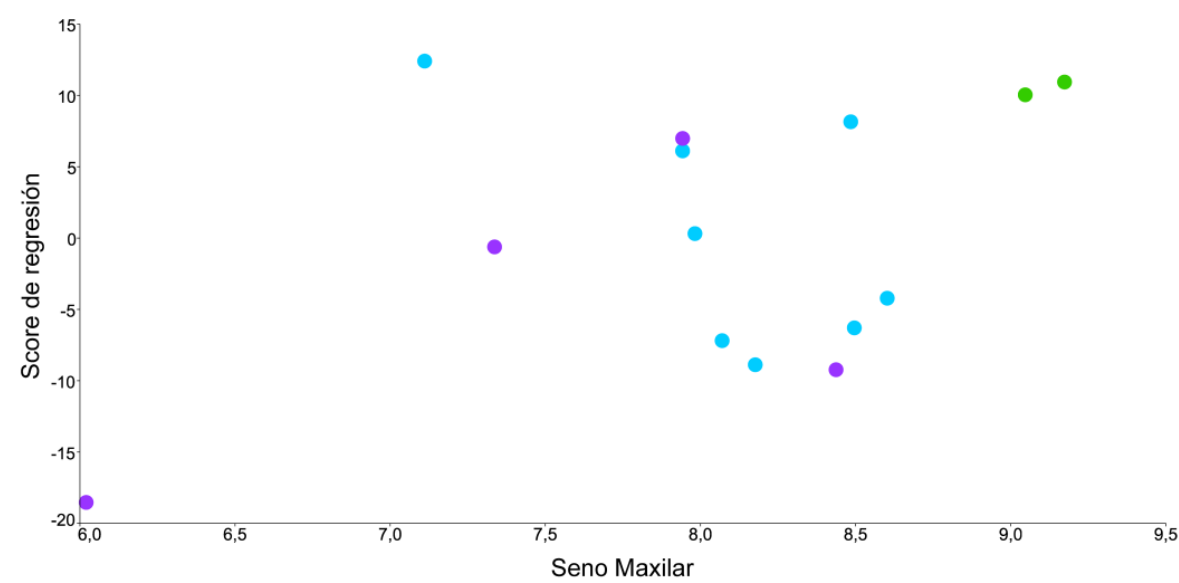

b)

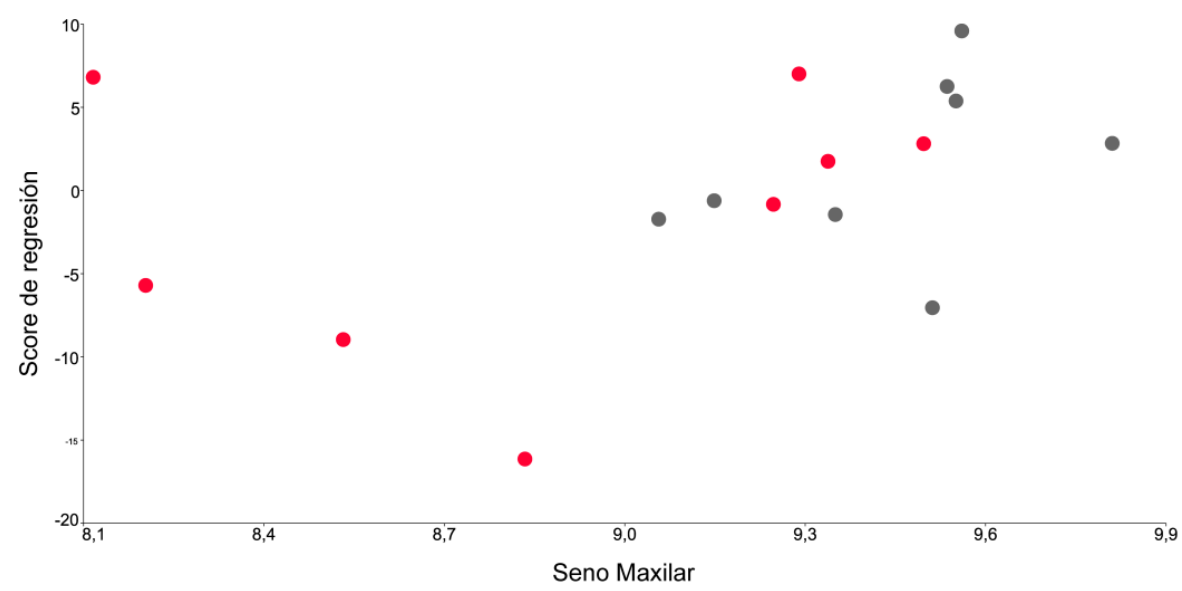

Figura 9.10. Regresión del modelado óseo del maxilar y el volumen del seno maxilar en subadultos (a) y adultos (b) de Pampa Grande. Valor predictivo de la regresión: a) 5\%, b) 2,05\% (p>0,05)

En la Figura 9.11 se representan los dos primeros componentes del análisis de la variación en la forma $(a, c)$ y el patrón de modelado óseo $(b, d)$ del maxilar. Los individuos subadultos presentan cambios en forma asociados con la edad a lo largo del CP1 (34,53\% de la variación), ubicándose los individuos de menor edad en los scores negativos y los del G3 en el extremo positivo. Los individuos del G1 presentan la mayor dispersión a lo largo del CP1 y los del G3, la menor (Fig. 9.11a). En el espacio del modelado óseo, los individuos con predominancia de reabsorción se localizan en el extremo negativo del CP1 (43,44\%) (Fig. 9.11b). Estos cambios a lo largo del primer eje son particularmente remarcables en el área del proceso alveolar que exhibe predominancia de formación en el extremo positivo y de reabsorción en el negativo. A diferencia de lo observado para las otras regiones, el maxilar de los subadultos se caracteriza por la similitud en la distribución de los individuos en el espacio de forma y el espacio de modelado. Aquellos individuos que se encuentran cercanos en forma a lo largo del CP1, se agrupan en el espacio de modelado a lo largo del CP2 (que explica el 13,35\% de la variación) 
(Fig. 9.11a,b). En este eje se observan cambios en el patrón de modelado óseo en el área correspondiente al proceso frontal, con predominancia de formación en el extremo positivo e incremento de reabsorción en dirección al extremo negativo del CP2.

El primer eje del análisis de componentes principales de las variables de forma en los individuos adultos separa dos grandes grupos, sin embargo, esa separación no se asocia a la edad o al sexo. En el CP2, los adultos jóvenes presentan menor dispersión que los del grupo adulto medio (Fig. 9.11c). En el espacio de modelado óseo, aquellos individuos que presentaron predominancia de formación en los procesos frontal y alveolar se ubicaron en el extremo positivo del CP1 (30,78\%), mientras que en el extremo negativo se ubicaron aquellos con mayor proporción de reabsorción ósea. A lo largo del CP2 $(17,84 \%)$ se diferencian los individuos que presentan predominancia de formación en el área de la fosa canina y el proceso cigomático, ubicándose en el extremo positivo, mientras aquellos en los que predomina la reabsorción se localizan en el extremo negativo (Fig. 9.11d). Los individuos que se agruparon en el extremo positivo del CP2 (15,06\%) del espacio de forma, se agruparon en el extremo negativo del CP2 $(17,84 \%)$ del espacio de modelado; mientras que los que se ubicaron en el extremo negativo del CP2 de forma o cercanos al score 0 , se distribuyeron desde el score de - 5 del CP2 de modelado al extremo positivo. Sin embargo, dentro de cada cuadrante se observa que formas similares se asocian a patrones de modelado óseo diferentes, o por el contrario, formas diferentes presentaron similar patrón de modelado (Fig. 9.11c,d).

a)

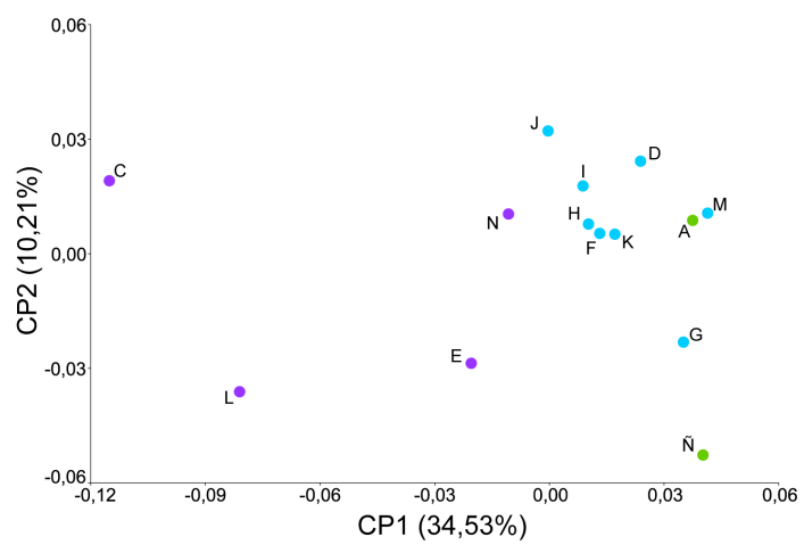

c)

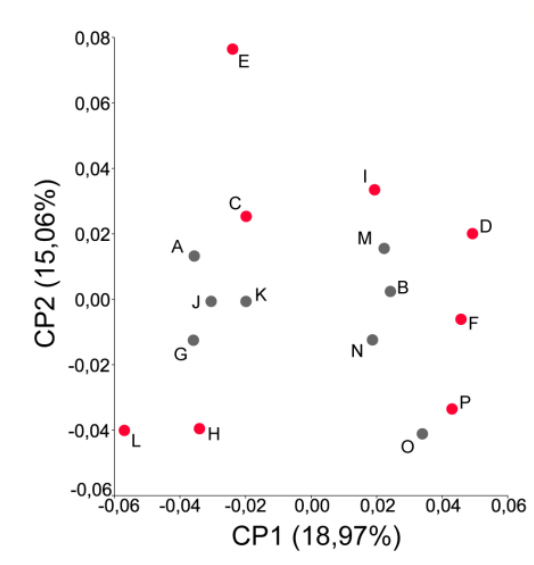


b)

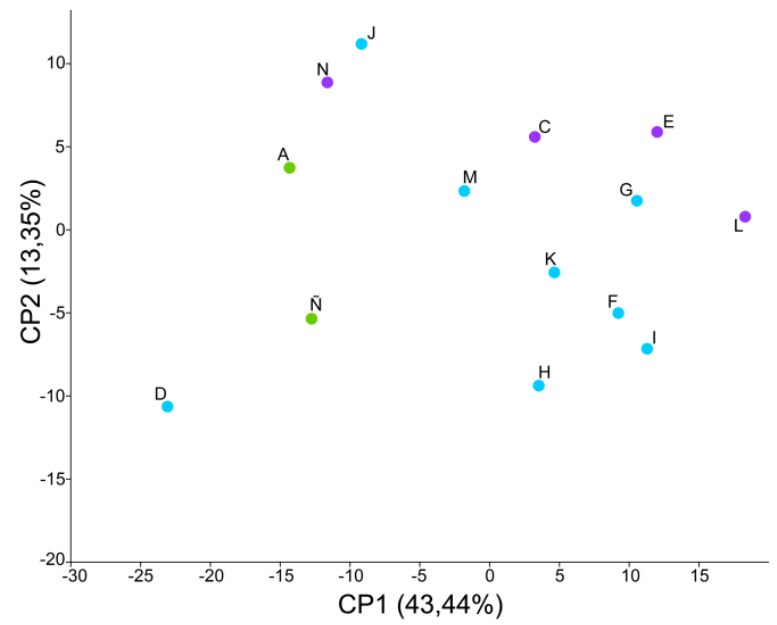

d)

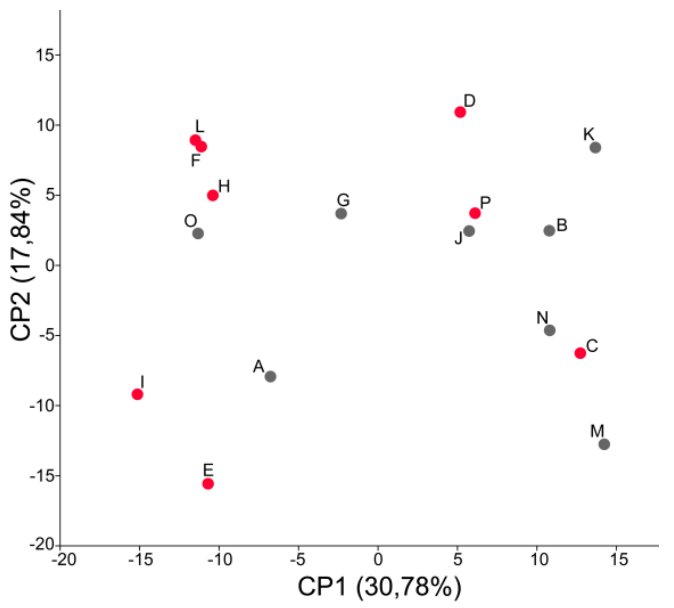

Fig. 9.11. Componentes principales de las variables de forma $(a, c)$ y de modelado óseo $(b, d)$ del maxilar de subadultos (a-b) y adultos ( $c-d$ ) de la muestra de Pampa Grande. Las letras referencian los mismos individuos entre los dos análisis de subadultos y de adultos

En la Figura 9.12 se presenta la covariación entre los componentes de forma y de modelado óseo del maxilar en subadultos (a) y adultos (b) de Pampa Grande. Para los individuos subadultos el coeficiente de correlación fue de 0,74 ( $p=0,45$; Fig. 9.12a), mientras que para los adultos la correlación fue de 0,91 ( $p=0,06$; Fig. 9.12b). Aun cuando el valor obtenido para los subadultos no fue significativo, los dos primeros ejes del análisis de PLS muestran que la variación entre ambos conjuntos de datos de encuentra asociada. Este patrón es más marcado en los individuos adultos.

El primer eje del análisis de PLS de los individuos subadultos, que resume la covariación de la forma con el patrón de modelado, muestra que los individuos con predominancia de formación en el maxilar se ubican en el extremo negativo, mientras aquellos localizados en el extremo opuesto presentan mayor proporción de reabsorción. En el primer eje de las variables de forma se distinguen hacia el extremo negativo morfologías caracterizadas por: un proceso frontal más elevado y ancho en la parte superior, desplazado hacia el lado medial; un proceso cigomático de mayor longitud, pero más angosto; un proceso alveolar desplazado hacia arriba; y un cuerpo maxilar más rectangular (de mayor longitud y más angosto) (Fig. 9.12a).

En los individuos adultos, el primer eje del modelado óseo separa los individuos con mayor proporción de formación hacia el extremo positivo y los que presentan más reabsorción hacia el negativo. Con respecto a los cambios en forma asociados al modelado óseo, se observa que las morfologías en el extremo positivo del primer eje presentan: un proceso frontal más ancho en la base y angosto en la parte superior; un proceso cigomático más ancho; el proceso alveolar desplazado hacia arriba; el cuerpo del maxilar desplazado hacia el lateral (Fig. 9.12b). 
a)
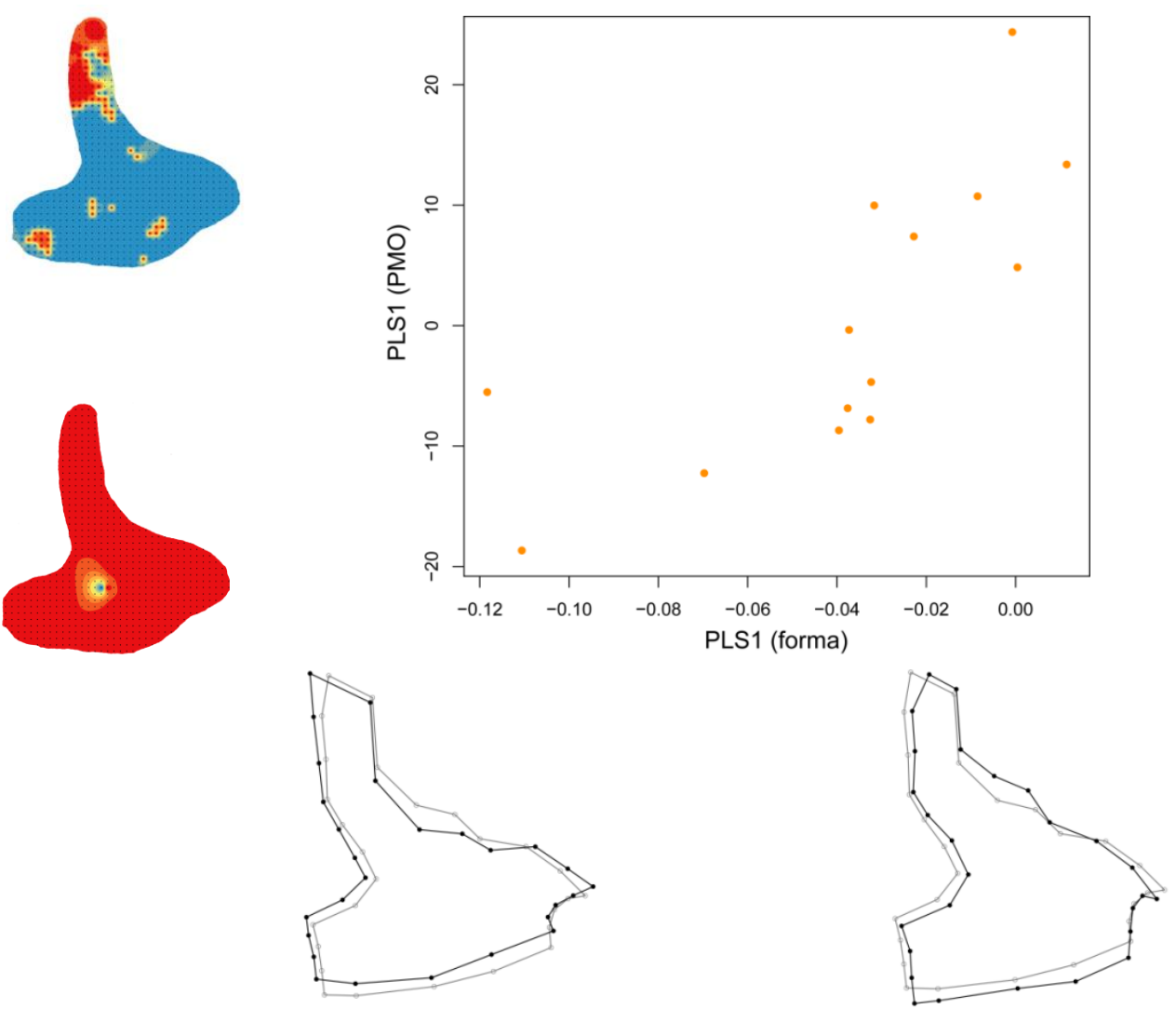

b)
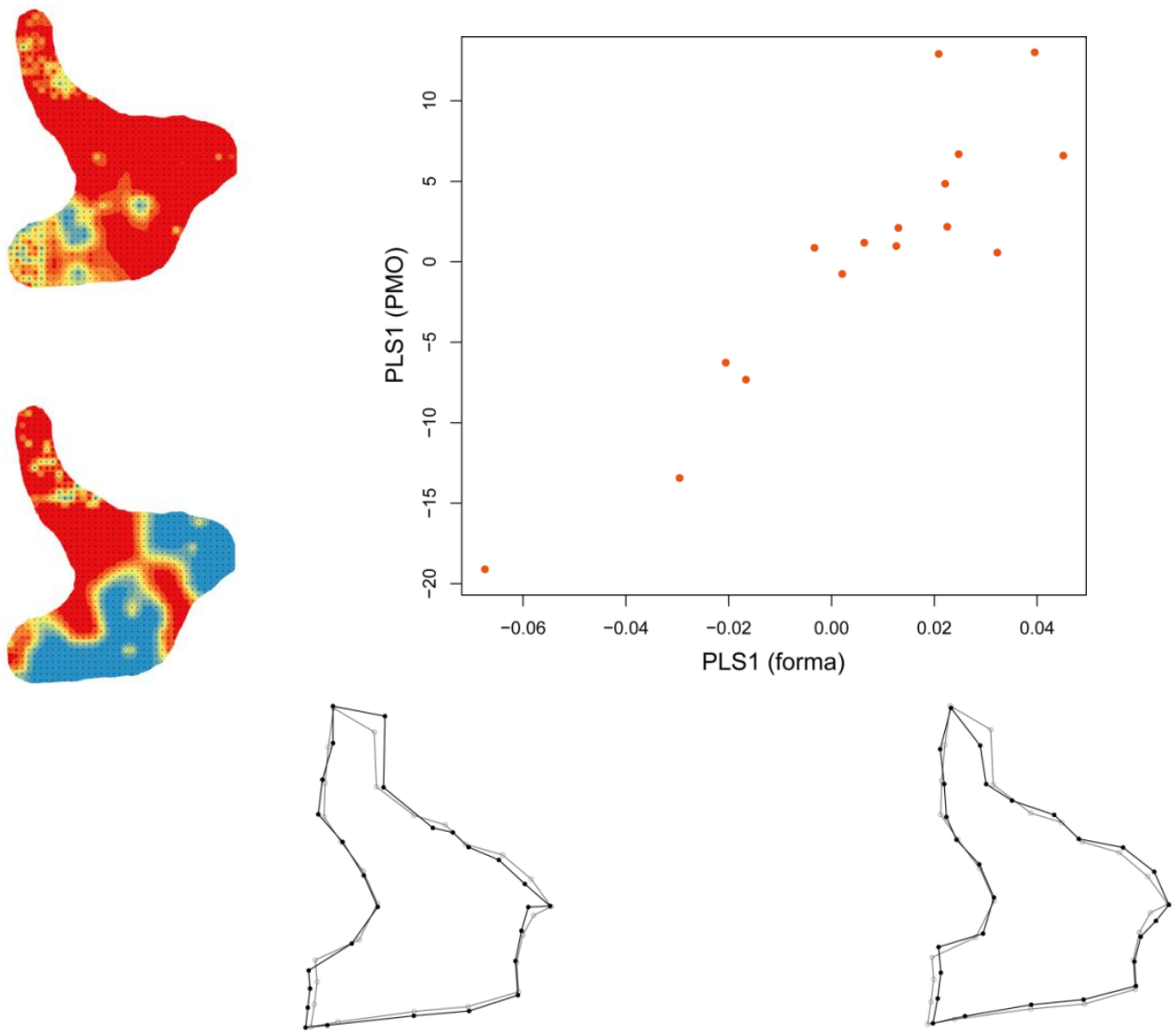

Fig. 9.12. Primeros ejes del análisis de Partial Least Squares (PLS) entre forma y modelado óseo del maxilar en subadultos (a) y adultos (b) de Pampa Grande. Los análisis se realizaron a partir de las coordenadas de todos los puntos que describen el maxilar. Para facilitar la visualización de los cambios en forma se emplearon sólo los de contorno. En el wireframe la línea gris representa la forma media, mientras la negra representa las formas en los extremos del PLS1. Los mapas de modelado óseo corresponden a los individuos extremos del PLS 


\subsection{Variación en los patrones de modelado óseo y la morfología facial en la muestra de Chubut}

\subsubsection{Variación en tamaño, forma y modelado óseo}

\section{Glabela y supraorbitales}

En la Figura 9.13 se presenta la regresión entre el patrón de modelado óseo y el tamaño centroide de la región de glabela y supraorbitales de los individuos subadultos (a) y adultos (b) de Chubut. En los subadultos no se encontró asociación entre el tamaño centroide -CSz- y el patrón de modelado. En los adultos se observan diferencias en el patrón de modelado entre los individuos de menor y mayor tamaño centroide, siendo el porcentaje de variación explicado por el tamaño relativamente elevado aunque no significativo (22,35\%; Fig. 9.13b).

a)

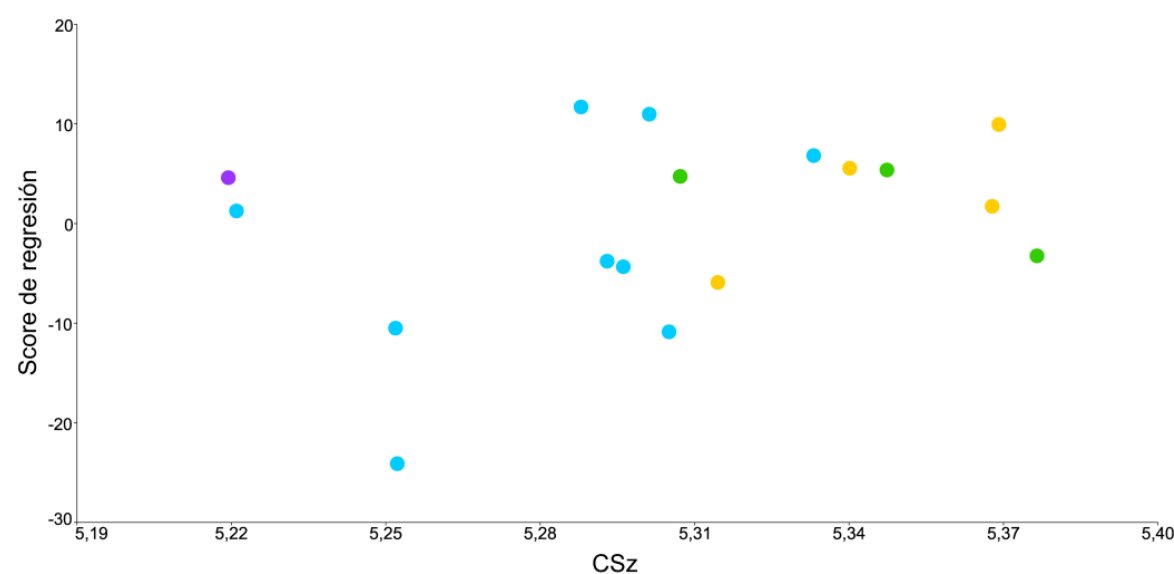

b)

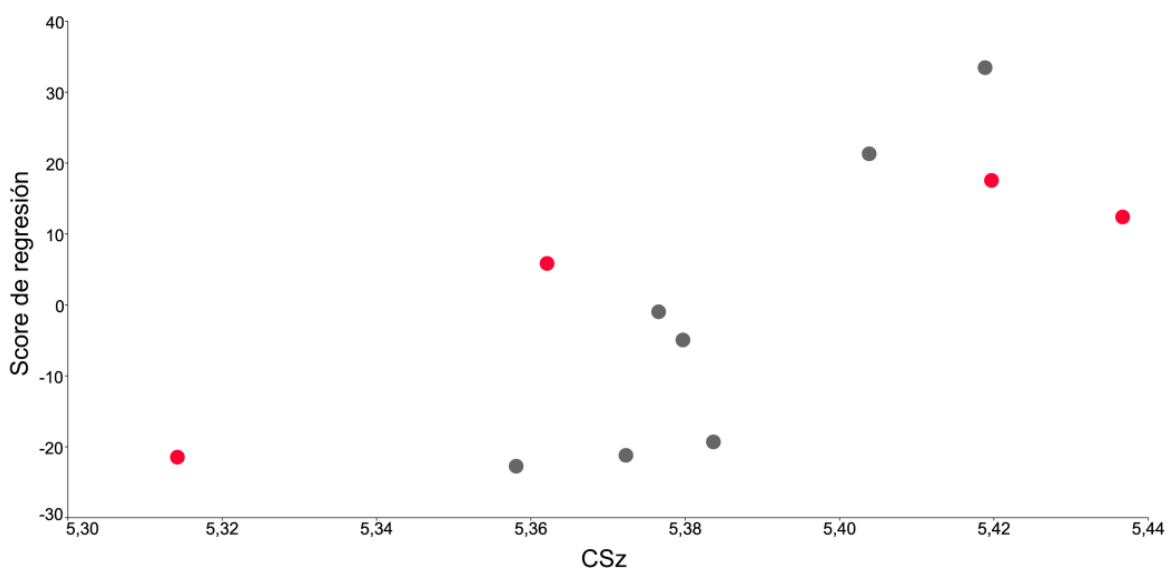

Fig. 9.13. Regresión del modelado óseo (score de regresión) y el tamaño centroide (CSz) de la región de glabela y supraorbitales de subadultos (a) y adultos (b) de Chubut. Valor predictivo de la regresión: a) $1,57 \%$, b) $22,35 \%$. (p>0,05)

Con respecto a la relación entre los patrones de modelado de la región de glabela y supraorbitales y el volumen de las cavidades craneofaciales, se encontró asociación entre los 
datos histológicos de la glabela y el tamaño del seno frontal en los individuos subadultos, con cambios en el patrón asociados al incremento de tamaño del seno frontal (Fig. 9.14a). Por el contrario, en los adultos no se registró asociación entre ambas variables (Fig. 9.14b). La tendencia opuesta se registró para la asociación entre el modelado del supraorbital con el volumen del orbital, encontrándose mayor asociación con el modelado óseo para los individuos adultos que para los subadultos (Fig. 9.14d y c, respectivamente).

a)

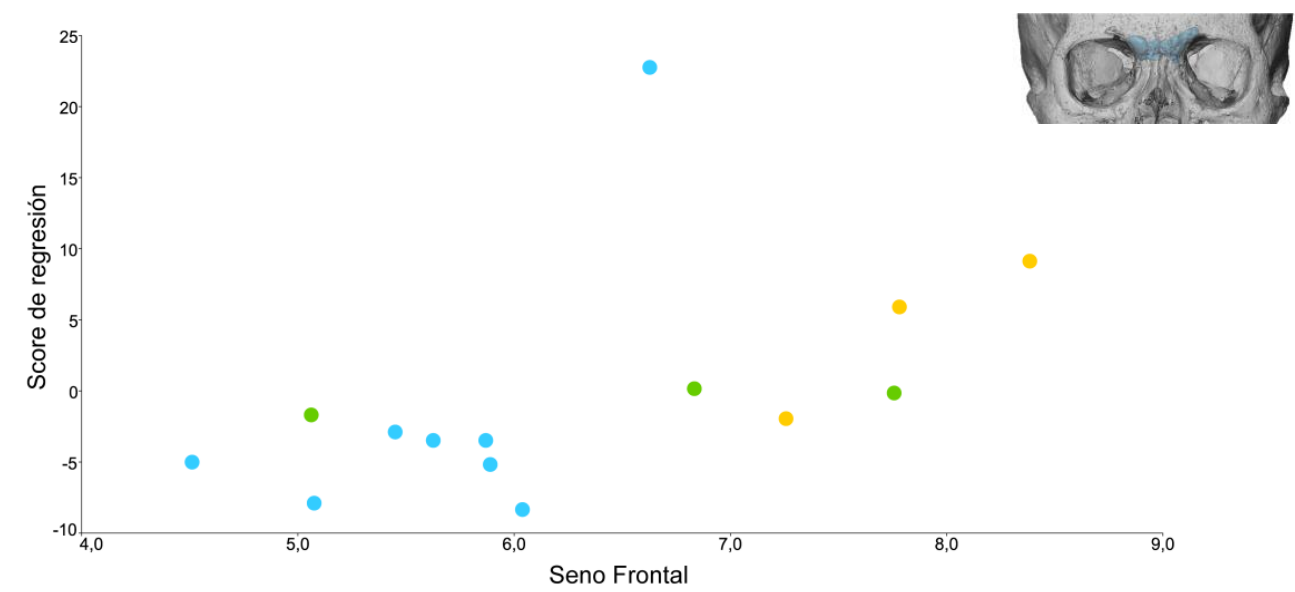

b)

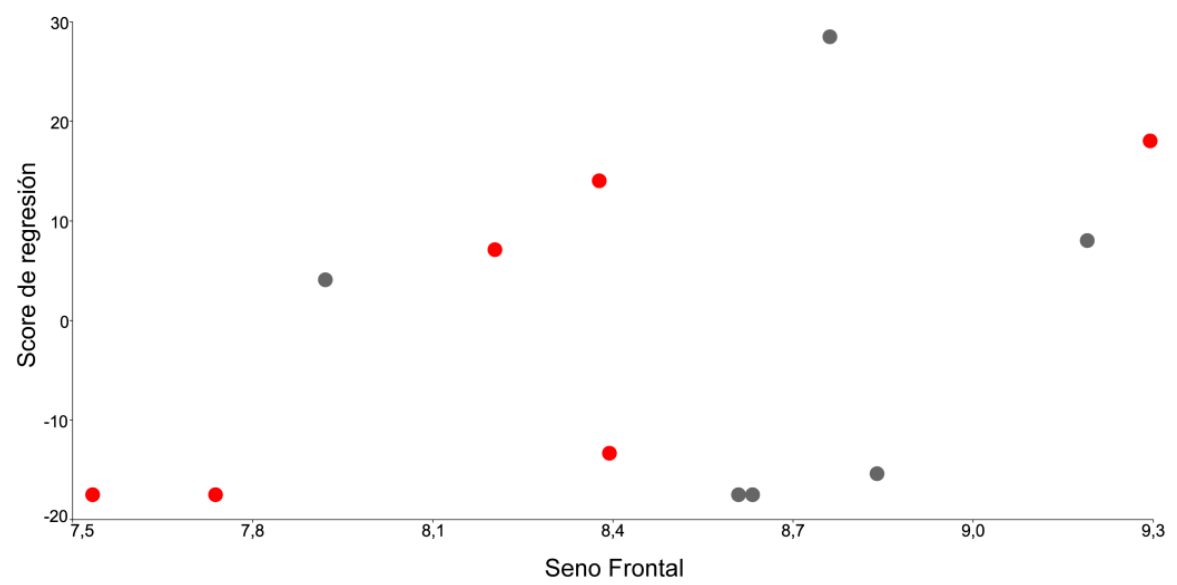

c)

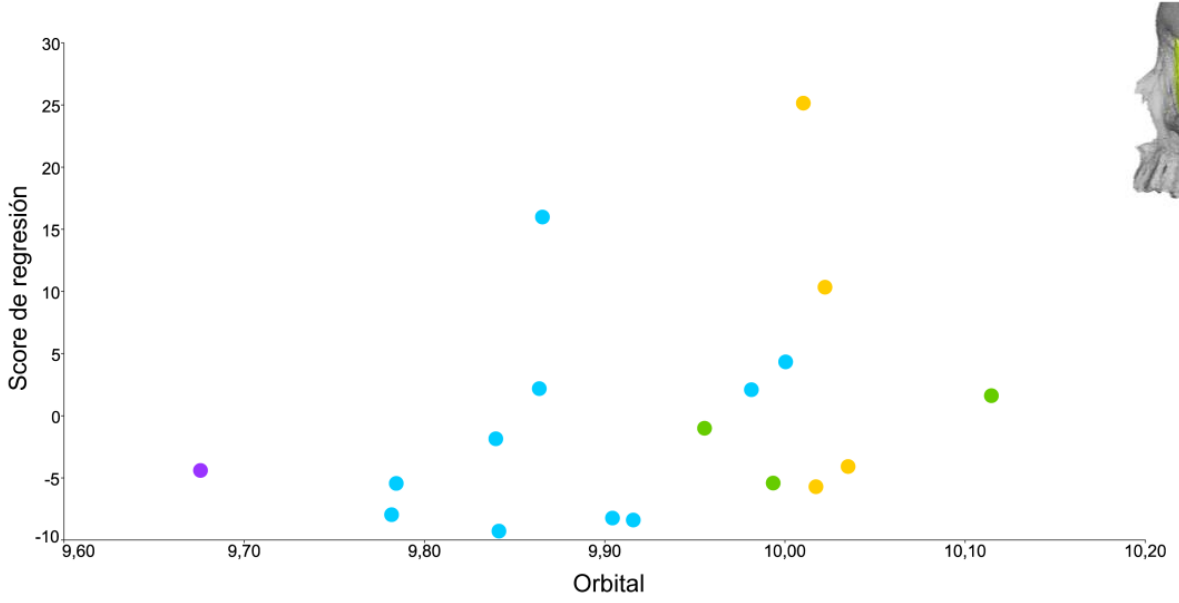

Continúa en la siguiente página 
d)

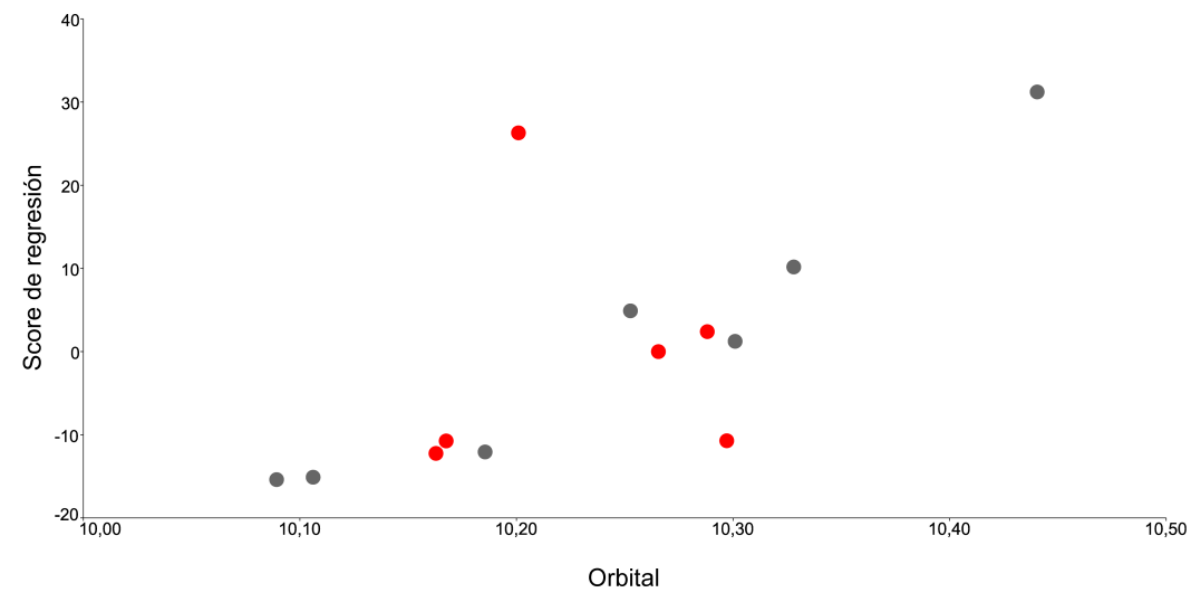

Fig. 9.14. Regresión del modelado óseo (score de regresión) de la región de glabela y supraorbitales y el volumen de las cavidades craneofaciales para la muestra de Chubut: a) seno frontal de subadultos, b) seno frontal de adultos, c) orbital de subadultos, d) orbital de adultos. Valor predictivo de la regresión: a) $8,02 \%$, b) $12,52 \%$, c) 2,59\%, d) 23,60\% (p>0,05)

En la Figura 9.15 se resumen la variación en la forma $(a, b)$ y en el patrón de modelado óseo (b,d) de la región de glabela y supraorbitales en individuos subadultos (a-b) y adultos (c-d) de Chubut. Se incluyeron los individuos de los que se tenían datos de modelado para glabela y supraorbital en conjunto.

El análisis de componentes principales muestra cambios en forma asociados con la edad a lo largo del CP1 (que explica el 42,05\% de la variación), ubicándose en el extremo negativo individuos de los grupos G1 y G2, y en el positivo del G4. Los individuos del G2 presentaron la mayor dispersión a lo largo del CP1 (Fig. 9.15a). En el espacio de modelado óseo los individuos con predominancia de reabsorción se ubicaron en el extremo negativo del CP1 (32,88\%), mientras en el positivo, aquellos con predominancia de formación (Fig. 9.15b). Algunos individuos que se agrupan en el CP1 de forma lo hacen en el CP2 de modelado, otros que se agruparon en el CP2 de forma se encuentran cercanos en el CP1 de modelado (Fig. 9.15a,b).

Los adultos jóvenes presentaron una distribución más restringida a lo largo del CP1 $(29,62 \%)$. En el extremo negativo se ubicaron individuos femeninos del G6 y en el positivo, femeninos y masculinos del G5 y del G6 (Fig. 9.15c). En el espacio de modelado, los individuos con mayor predominancia de reabsorción en glabela y supraorbital se agruparon en el extremo negativo del CP1 (39,29\% de la variación), mientras que en el extremo positivo, se agruparon aquellos con predominancia de formación (Fig. 9.15d). En general, los individuos que se agrupan en el CP2 de forma (22,01\%), tienden a estar cercanos en el CP1 de modelado (Fig. $9.15 c, d)$. 
a)

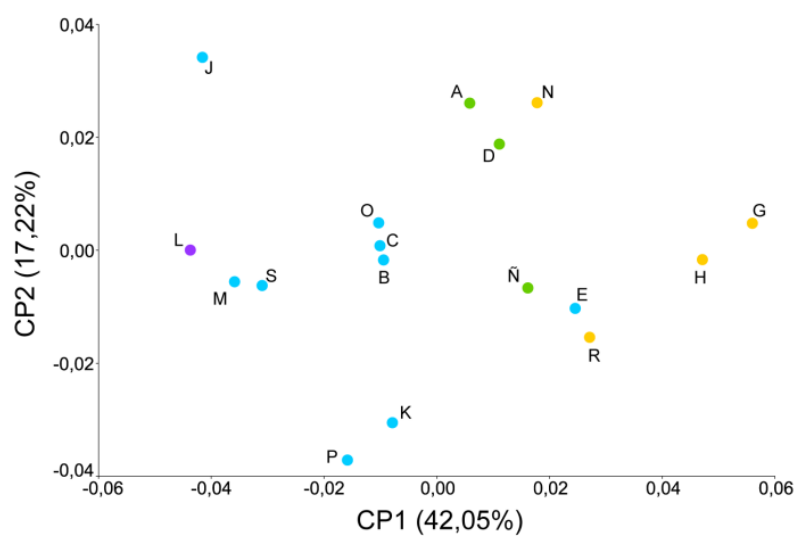

b)

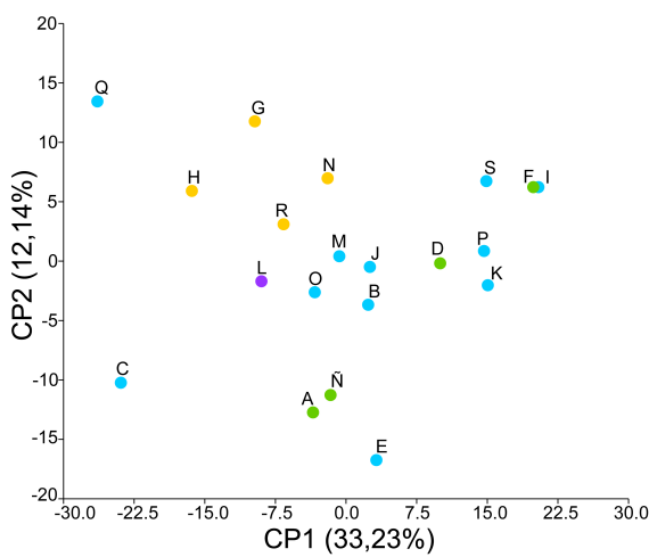

c)

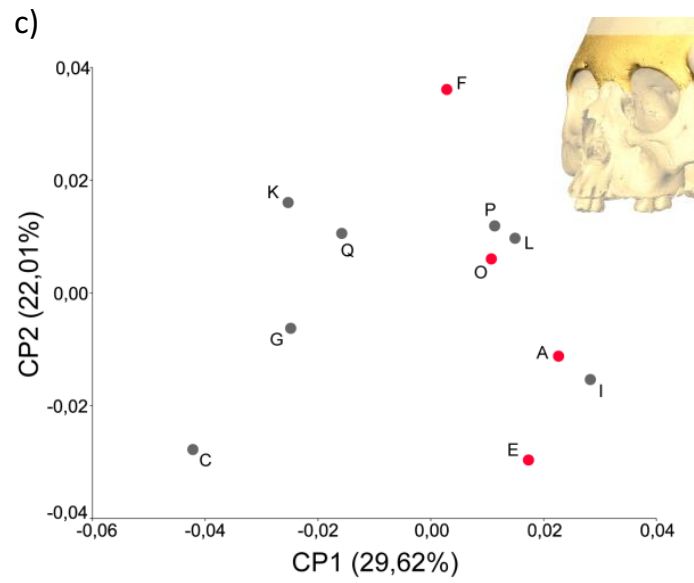

d)

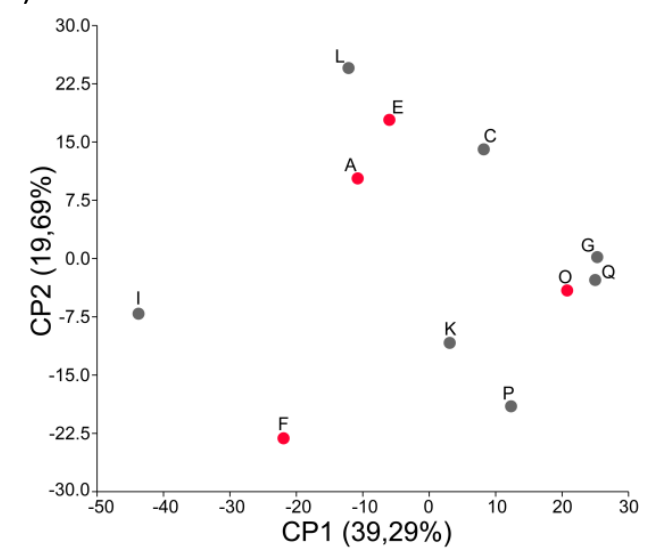

Fig. 9.15. Componentes principales de las variables de forma $(a, c)$ y de modelado óseo $(b, d)$ de la región de glabela y supraorbitales de subadultos $(a-b)$ y adultos (c-d) de la muestra de Chubut. Las letras referencian los mismos individuos entre los dos análisis de subadultos y de adultos

En la Figura 9.16 se presenta la covariación entre los componentes de forma y de modelado óseo de la región de glabela y supraorbitales en subadultos (a) y adultos (b) de Chubut. En ambos grupos de edad el coeficiente de correlación fue bajo y no significativo ( $r=0,54$ y $p=0,92$ para subadultos; $r=0,79$ y $p=0,66$ para adultos).
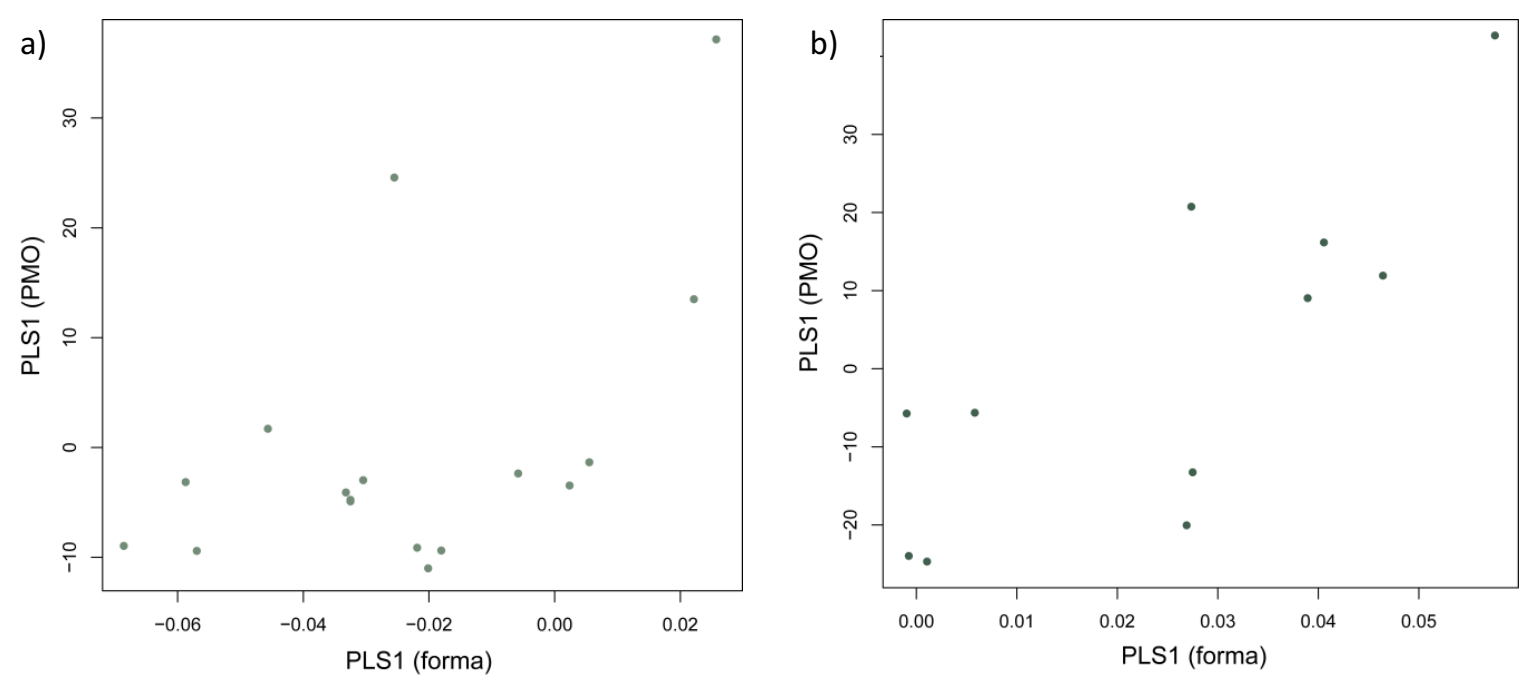

Fig. 9.16. Primeros ejes del análisis de Partial Least Squares (PLS) entre forma y modelado óseo de la región de glabela y supraorbitales en subadultos (a) y adultos (b) de Chubut. 
En la Figura 9.17 se presentan los resultados de la regresión entre el patrón de modelado y el tamaño centroide para el malar. En los individuos subadultos se observan cambios en el patrón con el tamaño, aunque la dispersión de los valores es alta y el porcentaje de variación explicado es muy bajo (Fig. 9.17a). Los individuos adultos no exhiben asociación entre ambas variables (Fig. 9.17b).

a)

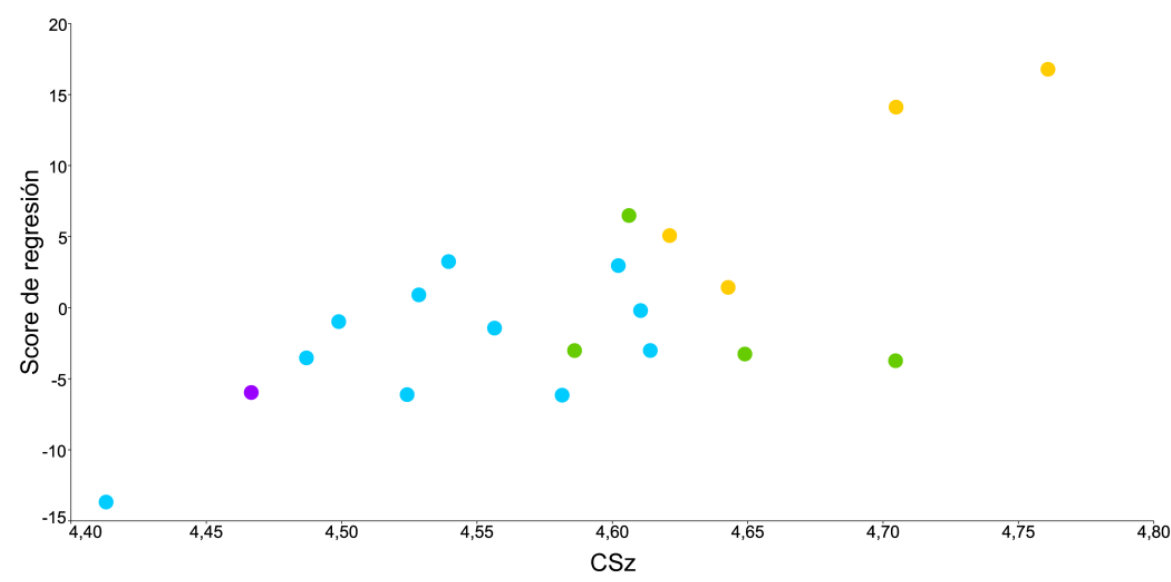

b)

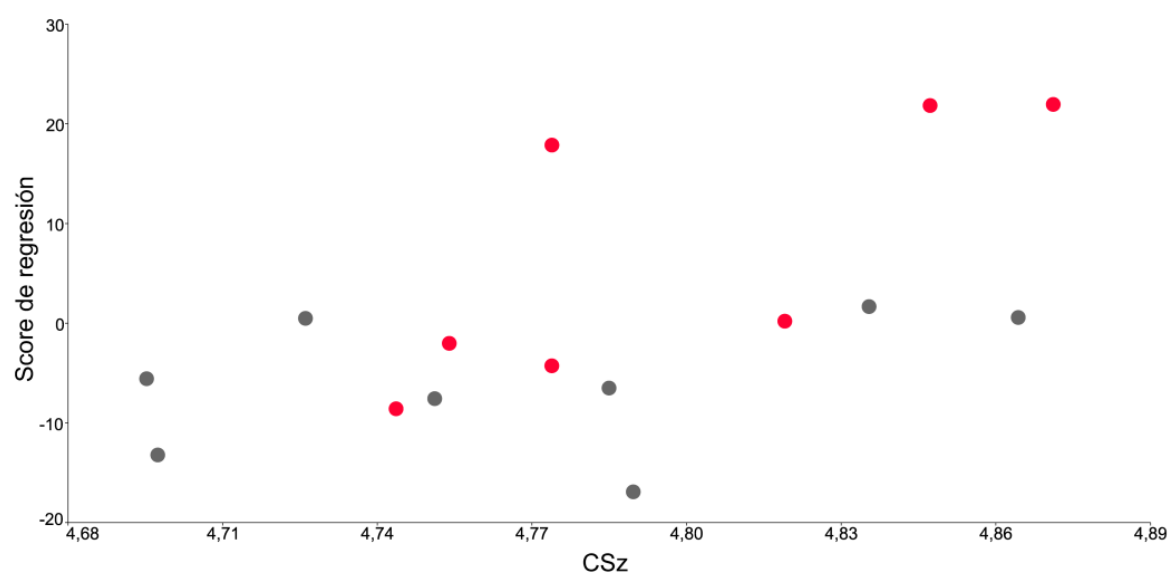

Fig. 9.17. Regresión del modelado óseo (score de regresión) y el tamaño centroide (CSz) del malar de subadultos (a) y adultos (b) de Chubut. Valor predictivo de la regresión: a) 5,49\%, b) 6,93\% $(p>0,05)$

En la Figura 9.18 se presenta la regresión entre el modelado óseo del malar y el volumen del orbital. En los individuos subadultos, no se registró asociación entre ambas variables (Fig. 9.18a). Si bien en los adultos se observa que los individuos con menor volumen del orbital presentan un patrón diferente a los de mayor volumen, el porcentaje de variación en el modelado explicado por el tamaño es muy bajo (Fig. 9.18b). 
a)

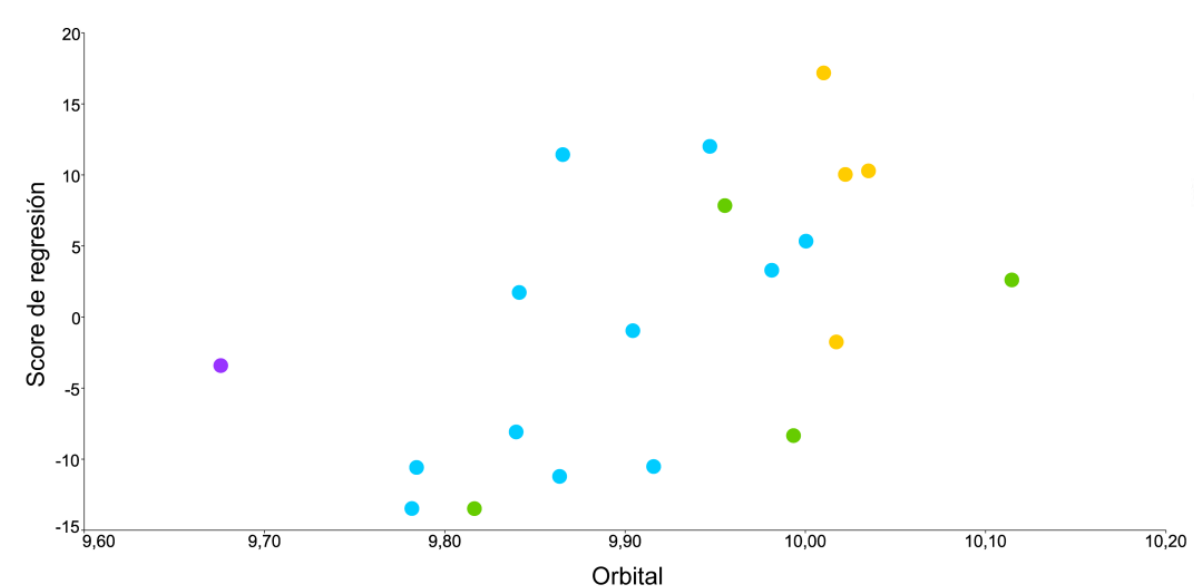

b)

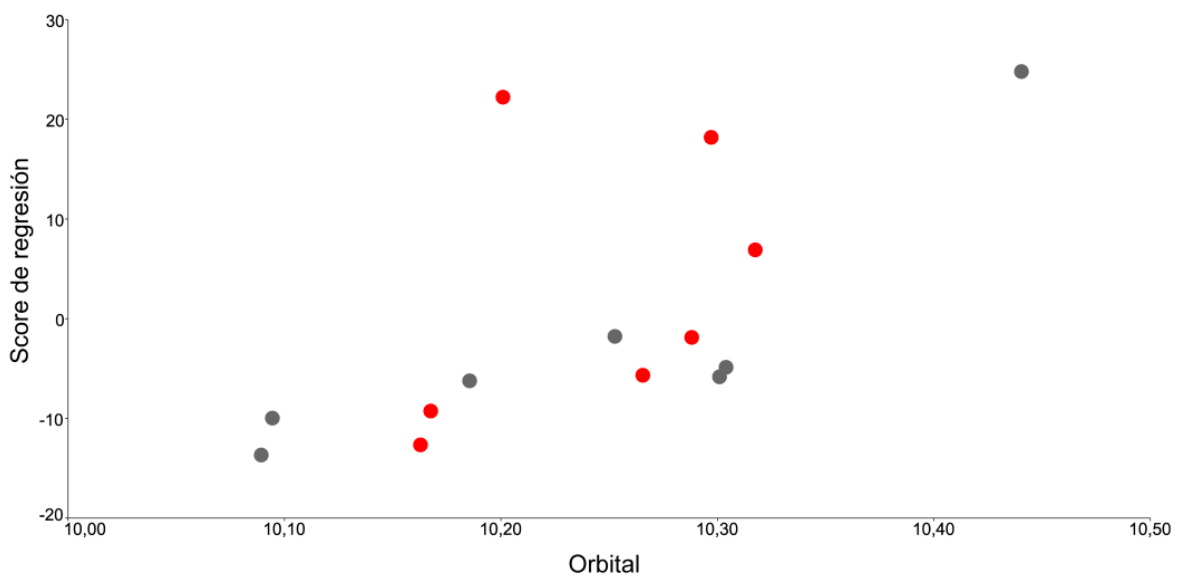

Figura 9.18. Regresión del modelado óseo del malar sobre el volumen del orbital en subadultos (a) y adultos (b) de Chubut. Valor predictivo de la regresión: a) 6,23\%, b) 9,53\% ( $p>0,05)$

La Figura 9.19 muestra los dos primeros componentes del análisis de las variables de forma del malar y del patrón de modelado óseo en individuos subadultos y adultos de Chubut. Los individuos del G2 presentaron mayor variación en forma a lo largo del CP1 $(32,22 \%)$ que el resto de los grupos de edad (Fig. 9.19a). En el espacio de modelado óseo, los individuos con predominancia de reabsorción en la superficie del malar se distribuyen en el extremo negativo del CP1 $(33,23 \%)$, mientras en el extremo positivo se ubican los individuos que presentan predominancia de formación (Fig. 9.19b). La distribución de los individuos en los dos primeros componentes del espacio de forma y de modelado se diferencia claramente (Fig. 9.19a,b).

Los individuos adultos jóvenes presentan menor dispersión a lo largo del CP1 (31,92\%) del espacio de forma (Fig. 9.19c). En los componentes del modelado óseo se observa que los individuos con predominancia de reabsorción se localizan en el extremo negativo del CP1 $(34,47 \%)$, mientras en el extremo positivo se encuentran los individuos con predominancia de formación (Fig. 9.19d). Al igual que en los subadultos, no se encontró similitud en el ordenamiento de los individuos en los dos primeros componentes de los espacios de forma y modelado (Fig. 9.19c,d). 
a)

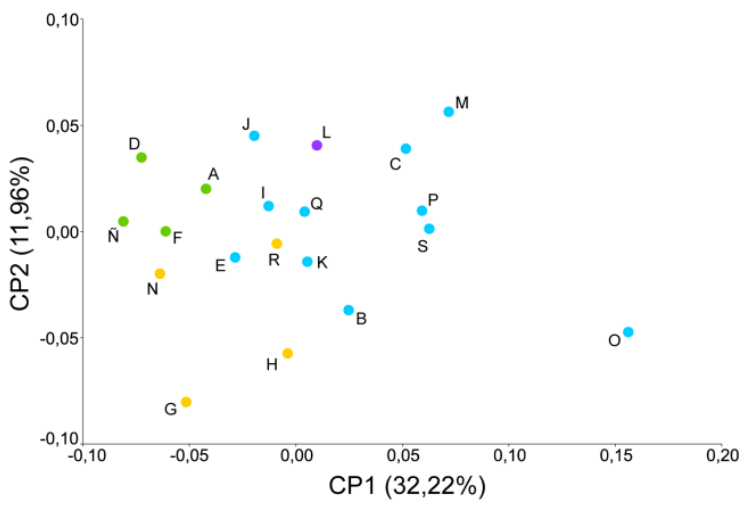

b)

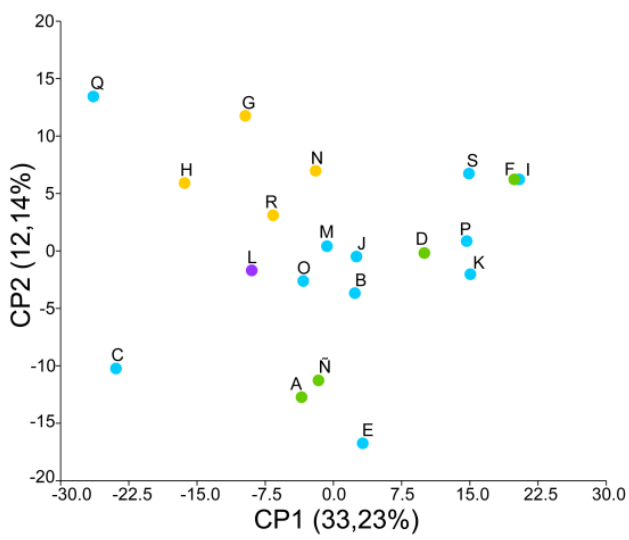

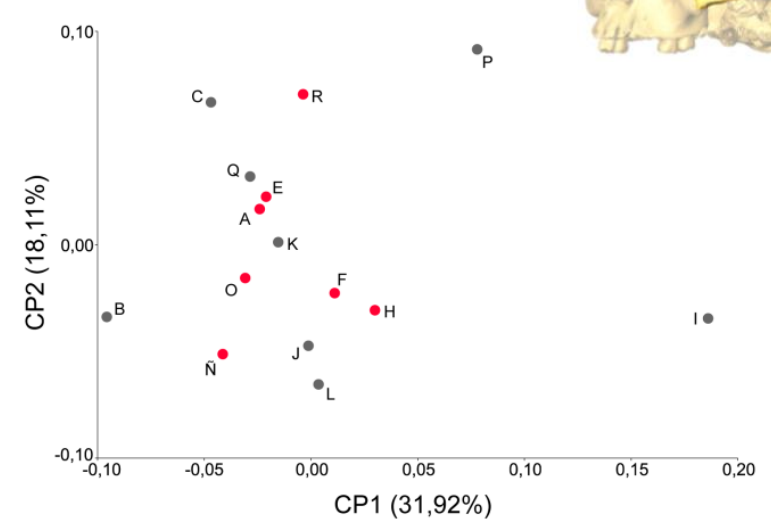

d)

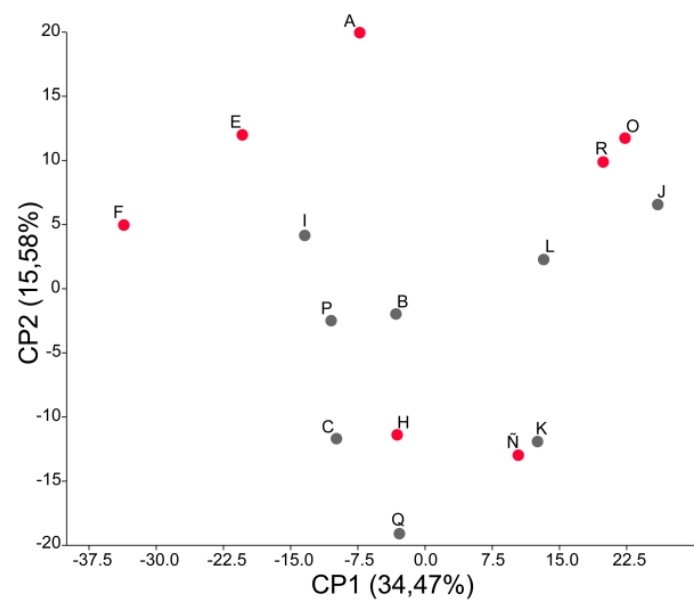

Fig. 9.19. Componentes principales de las variables de forma $(a, c)$ y de modelado óseo (b,d) del malar de subadultos (a-b) y adultos ( $c-d$ ) de la muestra de Chubut. Las letras referencian los mismos individuos entre los dos análisis de subadultos y de adultos

En la Figura 9.20 se presentan los resultados del análisis de PLS entre los componentes de forma y de modelado óseo del malar de subadultos (a) y adultos (b) de Chubut. Para los subadultos, el coeficiente de correlación fue de $0,77(p=0,07)$, mientras para adultos, la correlación fue de 0,72 y no significativa $(p=0,56)$.

El análisis de PLS de los malares de individuos subadultos de la muestra de Chubut indica que en el extremo negativo del primer eje del patrón de modelado se ubican aquellos individuos que presentan grandes áreas de reabsorción en el borde masetero, el proceso frontal y el borde inferior del orbital, mientras que en el extremo positivo se ubican aquellos con mayor proporción de formación. La morfología de los malares que se ubican en el extremo negativo del primer eje de forma presentan un proceso frontal corto $\mathrm{y}$ ancho, el cuerpo 
desplazado hacia atrás y relativamente más alto y un proceso temporal más ancho, mientras que los ubicados en el extremo positivo se caracterizan por presentar un proceso frontal relativamente alto y estrecho y el cuerpo desplazado hacia la línea media (Fig. 9.20a).

En los individuos adultos, el primer eje del análisis PLS realizado sobre los componentes principales del patrón de modelado óseo separa los individuos de acuerdo al tipo de actividad predominante. En el extremo negativo se localizan los individuos en los que predomina formación, mientras en el positivo se encuentran aquellos que presentan una mayor proporción de reabsorción. La morfología de los malares ubicados en el extremo negativo del primer eje de forma se caracteriza por el desplazamiento medial del proceso frontal, el cuerpo más alto y angosto, y el proceso temporal relativamente más grande que las formas ubicadas en el extremo negativo (Fig. 9.20b).

a)
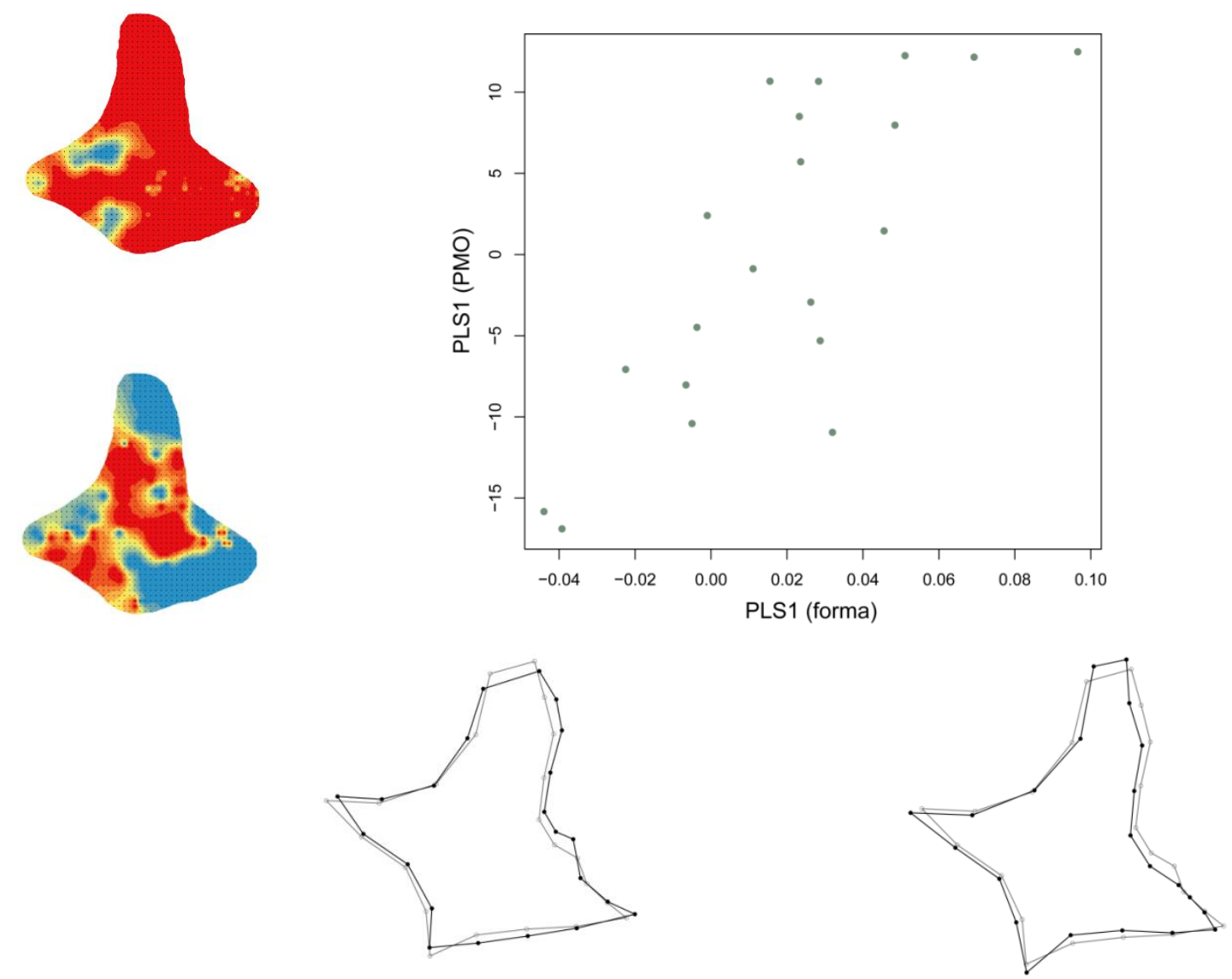

Continúa en la siguiente página 
b)
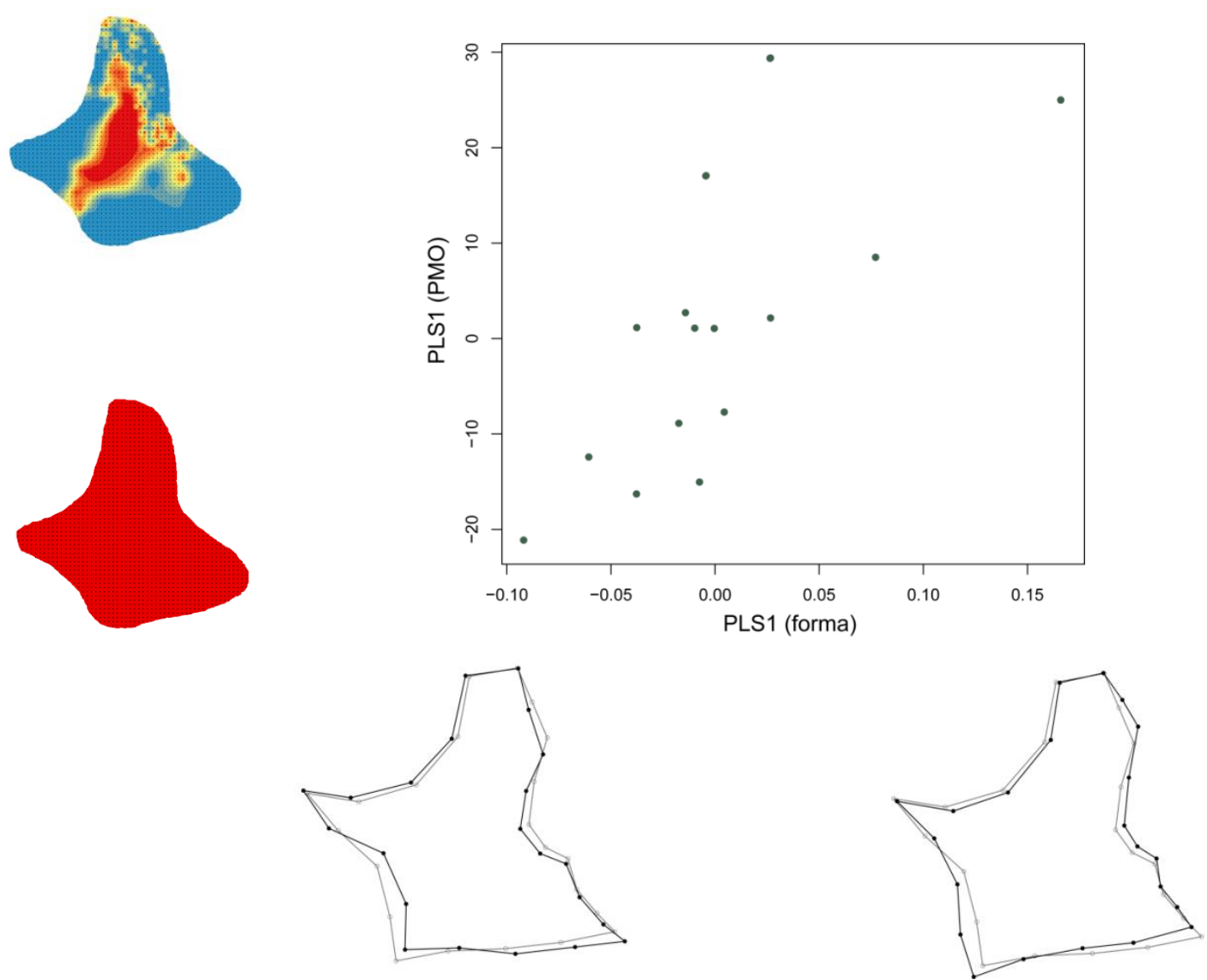

Fig. 9.20. Primeros ejes del análisis de Partial Least Squares (PLS) entre forma y modelado óseo del malar en subadultos (a) y adultos (b) de Chubut. Los análisis se realizaron a partir de las coordenadas de todos los puntos que describen el malar. Para facilitar la visualización de los cambios en forma se emplearon sólo los de contorno. En el wireframe la línea gris representa la forma media, mientras la negra representa las formas en los extremos del PLS1. Los mapas de modelado óseo corresponden a los individuos extremos del PLS

\section{$\underline{\text { Maxilar }}$}

Los resultados de la regresión del patrón de modelado sobre el tamaño centroide del maxilar se presentan en la Figura 9.21. En los individuos subadultos se observa una tendencia en el modelado a cambiar en asociación con el incremento en el tamaño, aunque el porcentaje de variación explicado por el modelo de regresión es bajo (Fig. 9.21a). En los adultos no se encontró relación entre ambas variables, tamaños similares del maxilar exhiben patrones diferentes de modelado óseo (Fig. 9.21b). 
a)

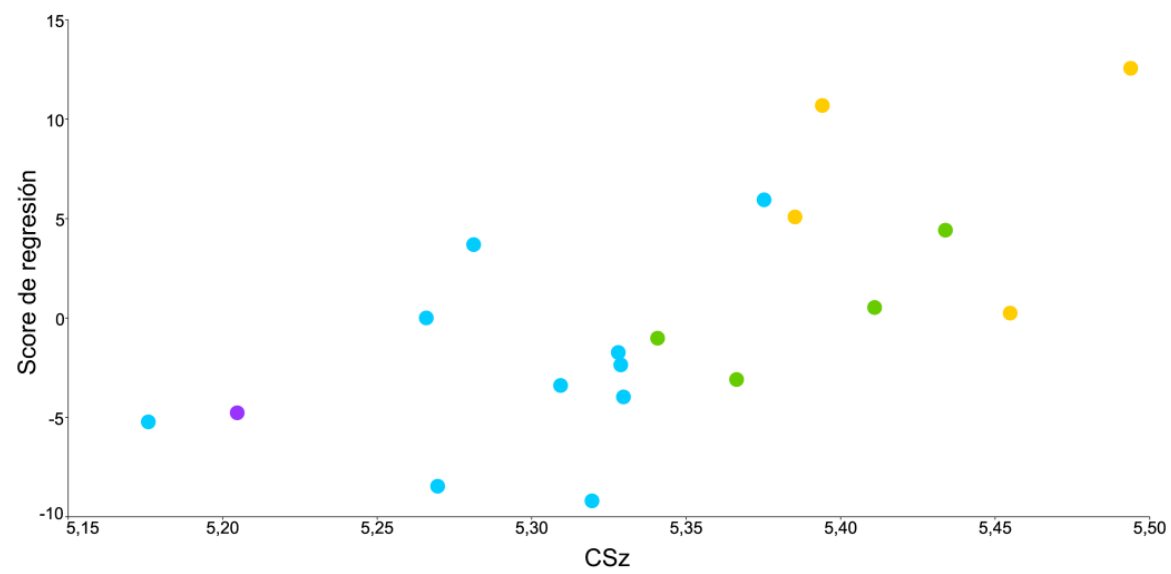

b)

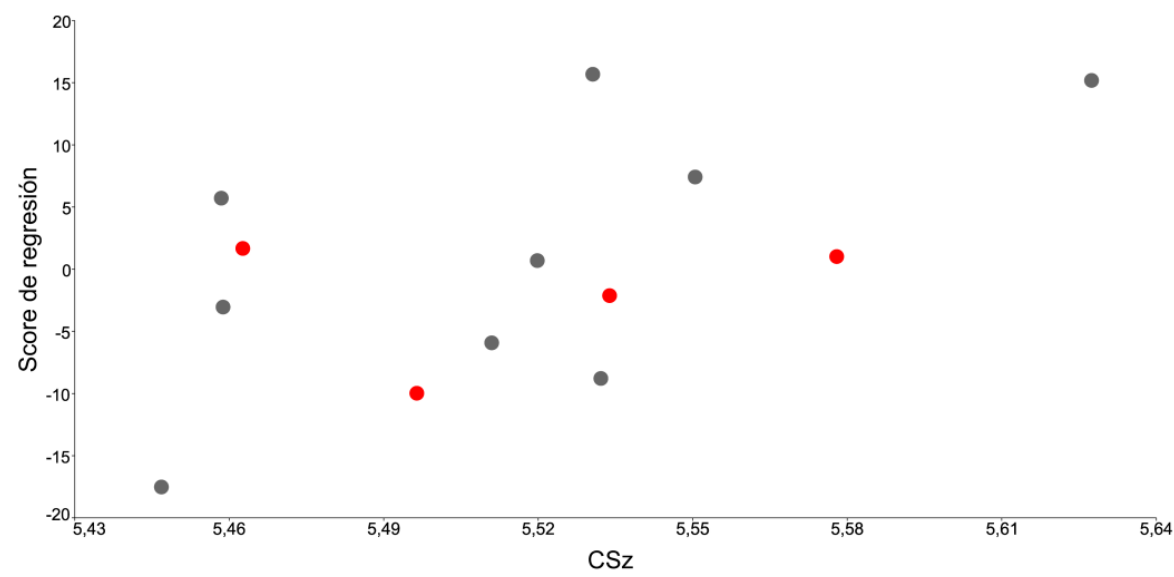

Fig. 9.21. Regresión del modelado óseo y el tamaño centroide del maxilar en subadultos (a) y adultos (b) de Chubut. Valor predictivo de la regresión: a) 4,68\%, b) 5,21\% (p>0,05)

En la Figura 9.22 se presentan los cambios en el modelado óseo del maxilar en relación con el volumen del seno maxilar. Los individuos subadultos muestran diferencias en el patrón de modelado asociadas con el tamaño. Por el contrario, en los adultos el patrón de modelado óseo no presenta relación con la variación en el volumen del seno maxilar.

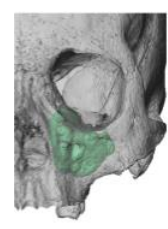

a)

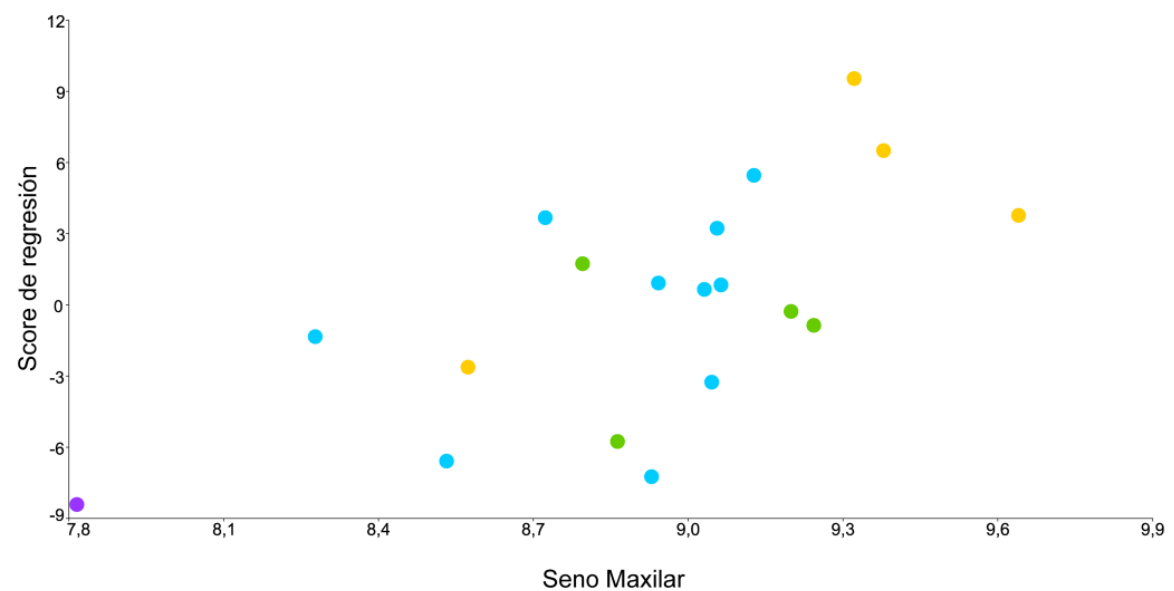


b)

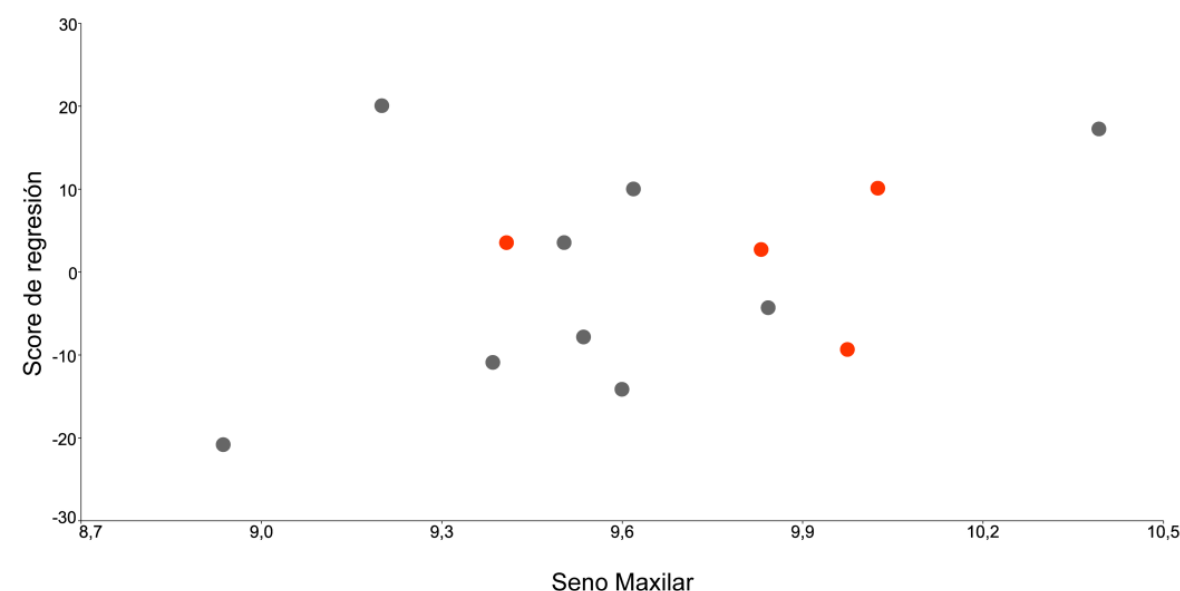

Figura 9.22. Regresión del modelado óseo del maxilar y el volumen del seno maxilar en subadultos (a) y adultos (b) de Chubut. Valor predictivo de la regresión: a) 3,09\%, b) 4,44\%. (p>0,05)

La distribución de los individuos subadultos y adultos en el espacio de las variables de forma y de modelado del maxilar se presenta en la Figura 9.23. En los individuos subadultos, los cambios en forma a lo largo del CP1 $(24,71 \%)$ se asocian con la edad, los individuos de menor y mayor edad se ubican en extremos opuestos de este eje. Los individuos del G2 y del G3 presentaron la mayor dispersión a lo largo de CP1 (Fig. 9.23a). En el espacio de modelado óseo, los patrones caracterizados por la predominancia de reabsorción se ubican en el extremo negativo del CP1 $(33,86 \%)$, mientras en el extremo positivo se encuentran los patrones con predominancia de formación (Fig. 9.23b). Con respecto a la distribución de los individuos en los espacios de forma y modelado, se observa que sólo algunos individuos se agrupan a lo largo de ambos componentes (Fig. 9.23a,b).

Los individuos de la categoría adulto medio exhiben mayor dispersión a lo largo del CP1 (25,96\%) del espacio de forma que los adultos jóvenes (Fig. 9.23c). En el espacio del patrón de modelado óseo, el CP1 $(31,85 \%)$ separa los individuos con predominancia de reabsorción (en el extremo negativo) de los que exhiben predominancia de formación (extremo positivo) (Fig. 9.23b). Los individuos con formas similares tendieron a agruparse en el CP2 de modelado (20,26\%), no así a lo largo del CP1 (Fig. 9.23c,d). 
a)

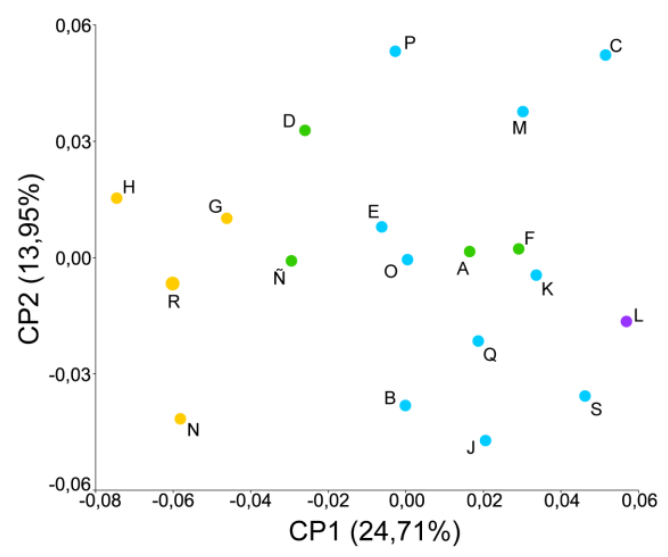

b)

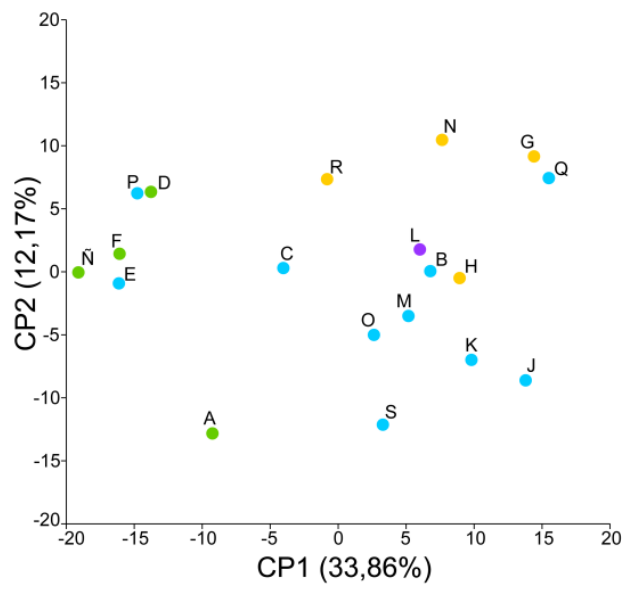

c)

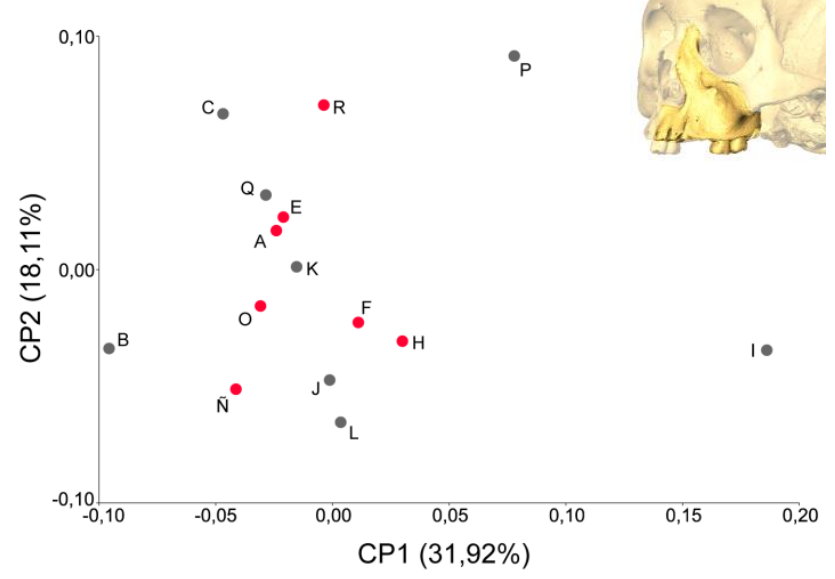

d)

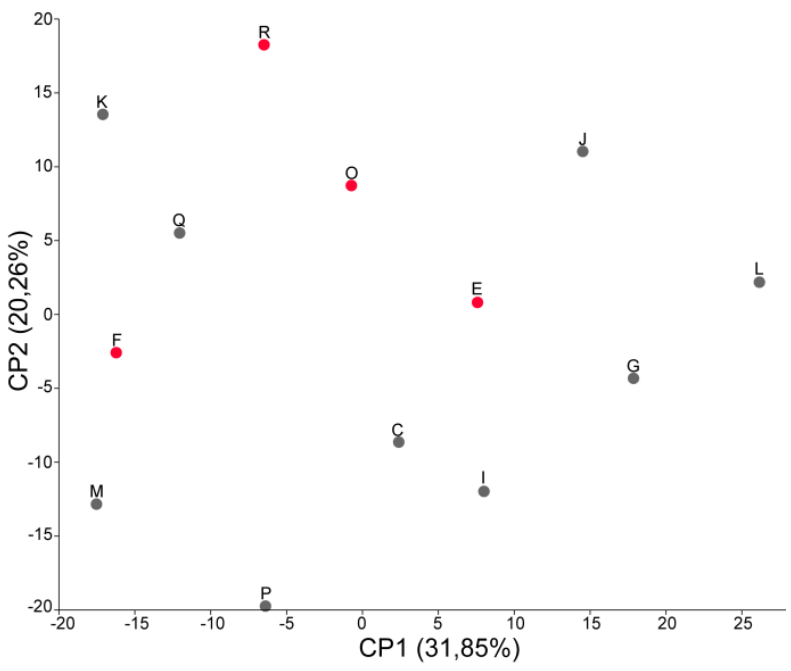

Fig. 9.23. Componentes principales de las variables de forma $(a, c)$ y de modelado óseo $(b, d)$ del malar de subadultos (a-b) y adultos (c-d) de la muestra de Chubut. Las letras referencian los mismos individuos entre los dos análisis de subadultos y de adultos

El análisis de PLS entre los componentes de forma y de modelado óseo del maxilar en subadultos (a) y adultos (b) de Chubut (Figura 9.23) indica una alta correlación entre las variables morfométricas e histológicas en ambos grupos de edad. En subadultos, el coeficiente de correlación fue de $0,83(p=0,10)$, mientras en adultos, la correlación fue de $0,90(p=0,08)$.

En los individuos subadultos, el primer eje que resume los cambios en el modelado asociados con la forma indica que en el extremo positivo se agrupan los individuos que presentan mayor proporción de formación, mientras aquellos en el extremo negativo exhiben un porcentaje mayor de reabsorción. Con respecto a la variación en forma, las morfologías en el extremo positivo presentan un proceso frontal más corto y ancho en la parte superior; un proceso alveolar desplazado hacia arriba y el cuerpo maxilar más alto y desplazado hacia la línea media (Fig. 9.23a). 
a)
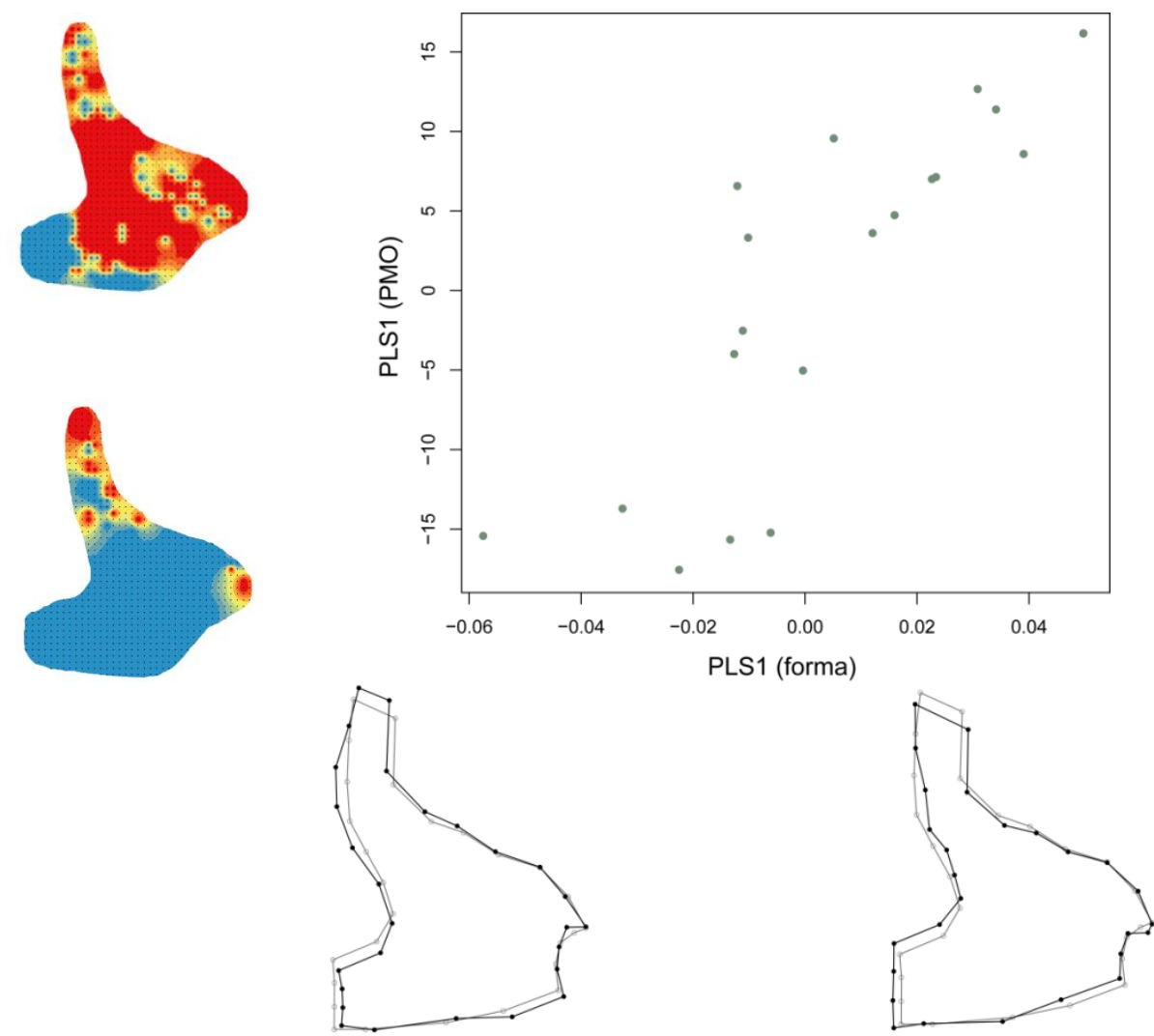

b)
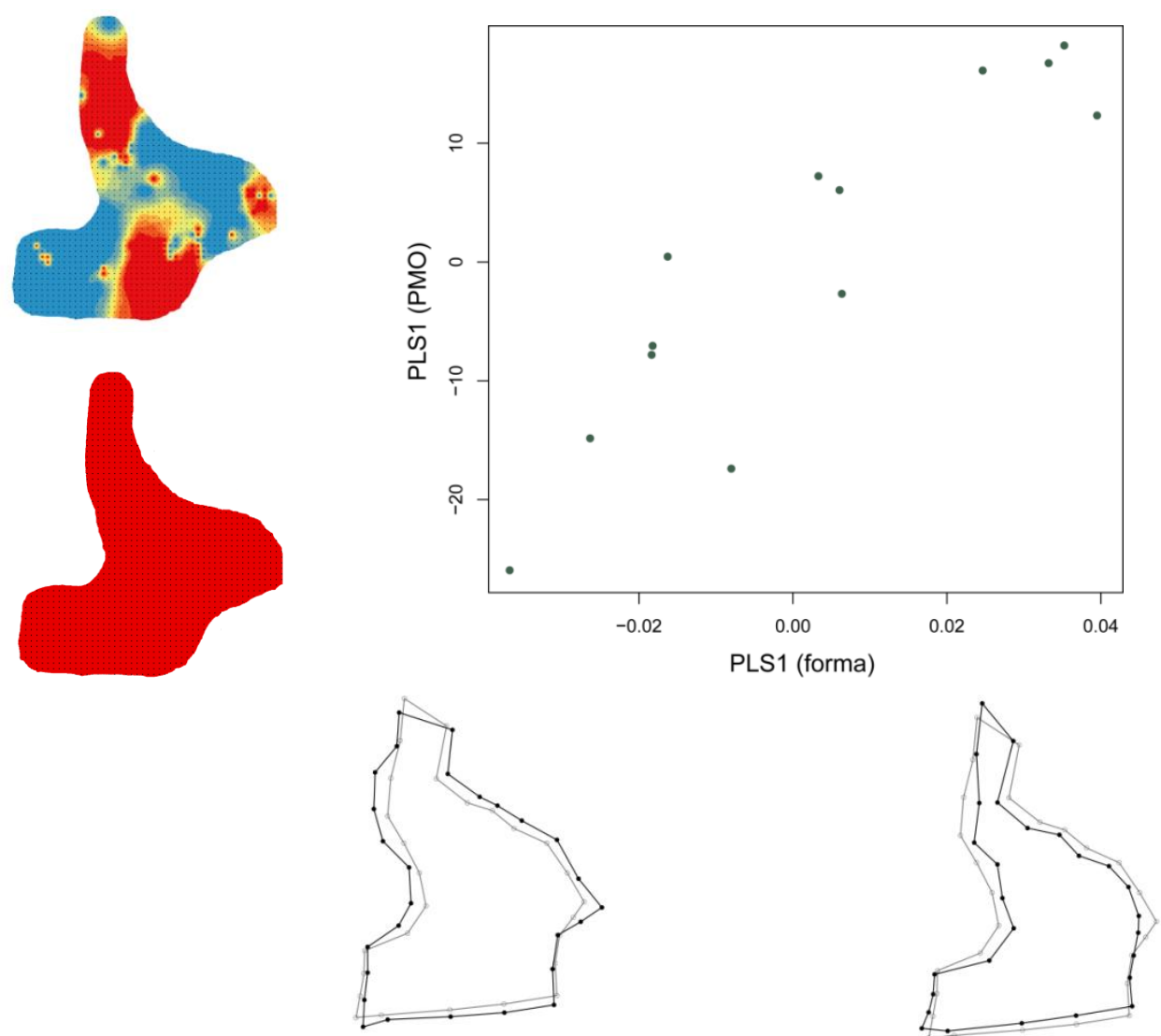

Fig. 9.23. Primeros ejes del análisis de Partial Least Squares (PLS) entre forma y modelado óseo del maxilar en subadultos (a) y adultos (b) de Chubut. Los análisis se realizaron a partir de las coordenadas de todos los puntos que describen el maxilar. Para facilitar la visualización de los cambios en forma se emplearon sólo los de contorno. En el wireframe la línea gris representa la forma media, mientras la negra representa las formas en los extremos del PLS1. Los mapas de modelado óseo corresponden a los individuos extremos del PLS 
El análisis de PLS sobre el maxilar de los individuos adultos separa en el extremo negativo del primer eje de modelado aquellos individuos con predominancia de formación y en el positivo, los mapas caracterizados por mayores superficies de reabsorción. El primer eje que resume la covariación en forma, muestra que las morfologías en el extremo negativo presentan el proceso frontal más ancho y corto, el proceso alveolar desplazado hacia abajo, y el cuerpo del maxilar más cuadrangular (Fig. 9.23b).

\subsection{Resultados destacados}

A continuación, se resumen los principales resultados obtenidos del análisis de la asociación entre los patrones de modelado óseo y la variación en el tamaño y la forma de regiones faciales en los individuos subadultos y adultos de las dos muestras estudiadas:

- En los individuos subadultos y adultos de Pampa Grande y Chubut los patrones de modelado óseo de las tres regiones faciales -glabela y supraorbitales, malar y maxilarexhibieron baja o nula asociación con la variación en tamaño, tanto del tamaño centroide de las estructuras como de los volúmenes de las cavidades craneanas asociadas.

- El patrón de modelado tampoco mostró una asociación consistente con la forma de las regiones faciales en los individuos subadultos. En ambas muestras, los individuos presentaron patrones de distribución diferentes en los espacios de forma y modelado. Asimismo, se observó, en general, una baja covariación entre ambos conjuntos de variables. Una excepción fue el malar de la muestra de Chubut para el que se obtuvo un valor elevado y significativo de covariación entre los datos histológicos y las variables de forma. Por otro lado, el maxilar de ambas muestras presentó una buena asociación entre forma y patrón de modelado, aunque no significativa.

- En los individuos adultos se encontró un patrón similar a los subadultos. La región de glabela y supraorbitales mostraron baja asociación entre el modelado y la forma, mientras que el malar y el maxilar presentaron valores más altos y significativos de asociación. 


\section{Discusión}

Discusión general de los principales resultados

\section{Contenido}

10.1. Desarrollo de una aproximación metodológica cuantitativa para el análisis de los patrones de modelado óseo

10.2. Variación intra e inter-poblacional en los patrones de modelado óseo

10.3. Integración de datos craneofaciales histológicos y morfométricos

Este capítulo se estructura siguiendo el orden propuesto en los objetivos específicos y, en particular, las hipótesis planteadas en el capítulo 2. En el apartado 10.1 se discuten las fortalezas y limitaciones de la aproximación metodológica desarrollada para evaluar la precisión en el registro de variables histológicas, para obtener y analizar los patrones de modelado óseo de la superficie facial mediante técnicas cuantitativas y las técnicas empleadas para la integración de datos histológicos y morfométricos. En los apartados 10.2 y 10.3 se discuten los resultados obtenidos a partir del análisis de los patrones de modelado óseo y de la morfología del esqueleto facial de las dos muestras del sur de sudamérica analizadas, con especial énfasis en la comparación entre individuos a lo largo de la ontogenia y entre muestras.

\subsection{Desarrollo de una aproximación metodológica cuantitativa para el análisis de los patrones de} modelado óseo

Los trabajos que abordan la reconstrucción de los patrones de modelado óseo a partir del registro de rasgos histológicos sobre las superficies craneofaciales han seguido, en líneas generales, la aproximación metodológica propuesta en los inicios de estos estudios hacia la década de 1970 (Bromage, 1985, 1989; McCollum, 2001, 2008; Mowbray, 2005; MartinezMaza et al., 2006, 2013, 2016; Kranioti, 2009). Hasta el presente, solo se han planteado algunas alternativas para evaluar la viabilidad de diferentes instrumentos de observación para el registro de las microestructuras y técnicas de preparación de las muestras con el fin de maximizar la información, incrementar la exactitud, y reducir tiempos y costos (Pfefferkorn y Boyde, 1974; Pameijer, 1978; Bromage, 1985; Bromage y Boyde, 2008; Martinez-Maza et al., 2010). 
Sin embargo, aún continúan sin abordarse importantes problemas que requieren el desarrollo de soluciones específicas. Particularmente, los obstáculos más importantes para la realización de este tipo de estudio son la ausencia de diseños para la evaluación del error de medición en el registro de variables microestructurales (Brachetta-Aporta, 2016), y el empleo de variables cualitativas tanto para describir como para comparar los patrones de modelado entre individuos (McCollum, 2008; Brachetta-Aporta et al., 2018), así como para correlacionar los patrones de modelado óseo con datos cuantitativos (e.g. variables morfométricas) (O'Higgins y Jones, 1998; Martinez-Maza et al., 2013; Brachetta-Aporta et al., 2014, 2016; Freidline et al., 2017). Hasta el presente, estos problemas han sido escasamente abordados y, en consecuencia, han limitado la realización de análisis rigurosos y sistemáticos.

En primer lugar, dado que la precisión en el registro de las variables histológicas es fundamental para la obtención de patrones de modelado confiables, en el marco de este trabajo se propuso la evaluación del error de observación asociado a la identificación de las áreas de formación y reabsorción ósea de la superficie de la región facial. Con este fin se efectuó un diseño experimental de medidas repetidas para controlar la consistencia en la identificación del tipo y de la extensión asignada a las actividades de modelado óseo a nivel intra-observador. Los resultados mostraron un incremento en la concordancia en la identificación de las áreas de formación y reabsorción ósea a lo largo de las series de observaciones en tres estructuras analizadas -glabela, malar y maxilar-. Esto indica la importancia del entrenamiento para el registro de la actividad de modelado en las superficies óseas. La eficacia del registro, basada en la precisión y exactitud con que se identifican las variables (Jindrová et al., 2012), aumentó con la experiencia del observador. Sin embargo, el aumento en la consistencia no fue similar en los dos tipos de superficies -i.e. formación, reabsorción- relevadas ni en las tres estructuras anatómicas analizadas. Particularmente, la identificación de las superficies de reabsorción presentó menor consistencia que la de las superficies de formación, a pesar de ser reconocida como una superficie fácilmente identificable dada su topografía característica de pozos o lagunas (Boyde, 1972). Sin embargo, esta última afirmación se ha basado en el análisis de superficies en especímenes altamente preservados o especialmente preparados para el análisis en el microscopio electrónico de barrido (Boyde, 1972; Boyde y Jones, 1972; Bromage, 1984). Posiblemente, la presencia de procesos pre y post-depositacionales que desintegran y producen pérdida ósea pueden generar alteraciones en las superficies de los huesos que dificultan la identificación de las lagunas de Howship, sobre todo en aquellas superficies más expuestas. Dado que algunas 
alteraciones tafonómicas implican pérdida ósea al igual que la reabsorción, es posible que la identificación y asignación de lagunas a la actividad de osteoclastos se vea dificultada.

El análisis realizado en el marco de este trabajo de tesis constituye la primer evaluación sistemática del error de observación en rasgos microestructurales de superficies óseas, por lo tanto, los resultados obtenidos resultan difíciles de comparar con estudios previos (BrachettaAporta, 2016). Por el contrario, el error asociado al análisis de cortes histológicos del hueso cortical ha recibido mayor atención y los estudios realizados coinciden en señalar que distintos rasgos histológicos exhiben niveles variables de error intra e inter-observador, incluso en aquellos considerados con menores dificultades para su identificación (Compston et al., 1986; Lynnerup et al., 1998; Keough et al., 2009). Las muestras empleadas en estos casos son modernas por lo que los factores tafonómicos pueden ser descartados, atribuyéndose las diferencias encontradas, principalmente, a la definición de las variables y a las particularidades intrínsecas de cada rasgo. En este sentido, futuros estudios que evalúen el error en el registro de superficies en muestras modernas así como el desarrollo de diseños experimentales bajo condiciones controladas, contribuirán a discutir la influencia de los procesos tafonómicos en la observación de rasgos histológicos microestructurales.

Con relación a las diferencias entre estructuras anatómicas, el maxilar presentó los mayores niveles de error intra-observador. Este resultado podría deberse a las irregularidades que presenta su superficie, a diferencia del relieve plano que exhiben el resto de las estructuras. Las superficies más abruptas dificultan el ajuste del foco en los microscopios ópticos como el utilizado aquí, lo que puede ser una causa del incremento del error. Si bien en general se plantea que el tipo de instrumental empleado en las observaciones histológicas no representa una fuente que contribuya en gran medida al error (Compston et al., 1986; Lynnerup et al., 1998), estas observaciones se han realizado sobre cortes, en los que las superficies analizadas son planas, o sobre reconstrucciones bi-dimensionales visualizadas en computadora. En consecuencia, es necesaria una evaluación sistemática del tipo de instrumental como fuente de error en análisis de modelado óseo de superficie, particularmente por la variedad de microscopios empleados en la práctica.

La experiencia realizada destacó la importancia del aprendizaje controlado a través de un diseño de medidas repetidas para identificar las principales dificultades y reconocer diferentes fuentes de error. Sin embargo, aún resta evaluar y mejorar la precisión con que se obtienen los datos para garantizar la consistencia de las observaciones de superficies entre observadores (Perez et al., 2004). El control de esta fuente de error es especialmente importante dado que 
los estudios en este campo son escasos y costosos en términos del tiempo requerido para generar los datos, y en consecuencia, resulta necesario el empleo de datos generados por diversos investigadores con fines comparativos.

En segundo lugar, se desarrolló una aproximación cuantitativa como alternativa al empleo de análisis cualitativos para la descripción, comparación y análisis de los patrones de modelado óseo entre individuos (e.g. Kurihara et al., 1980; Bromage, 1989; Martinez-Maza et al., 2006, 2013, 2016; McCollum, 2008; Kranioti et al., 2009; Lacruz et al., 2015a,b). Para obtener una descripción completa de los mapas individuales se aplicaron técnicas de estadística espacial y de imputación de datos perdidos. De acuerdo a los resultados obtenidos, los mapas de modelado exhiben una estructuración espacial de los datos de formación y reabsorción ósea caracterizada por la similitud de información entre áreas adyacentes, mientras que para distancias mayores la información tendió a diferir. Dada esta estructuración espacial se utilizó el algoritmo de la distancia inversa ponderada (Fortin y Dale, 2005) para realizar la interpolaciones de datos perdidos. Las simulaciones realizadas sugieren que la interpolación espacial de datos permite reconstruir de manera confiable la información perdida en aquellos casos en que se cuenta con un mínimo del $25 \%$ del área con datos presentes y datos perdidos con una distribución espacial de tipo aleatoria. En los mapas que presentan áreas extensas sin información la interpolación espacial presenta algunos problemas, siendo más recomendable emplear algoritmos de imputación de datos que tienen en cuenta la información presente en la muestra. En resumen, los análisis efectuados brindan herramientas para la elección de criterios claros y explícitos para la estimación de datos en las áreas con ausencia de información histológica. Esto es relevante dado que representa un problema común en el análisis de superficies óseas de restos arqueológicos y fósiles debido al efecto de alteraciones tafonómicas (Bromage, 1989).

Asimismo, el análisis de la estructuración espacial permitió reconocer que las áreas de formación y reabsorción ósea en las estructuras faciales analizadas se distribuyen de forma heterogénea a lo largo de la superficie. Esta distribución espacial presentó una clara asociación con el porcentaje de información presente para la reconstrucción. La eliminación progresiva de celdas con información a través de las simulaciones resultó, luego de la interpolación espacial, en mapas con grandes áreas homogéneas de formación y reabsorción ósea. Diversos estudios han mostrado, a partir del análisis de individuos modernos de edades similares, la alternancia de actividades de modelado en la región facial (Kurihara et al., 1980; McCollum, 2008; Kranioti et al., 2009; Martinez-Maza et al., 2013, 2016). Por el contrario, los mapas de modelado óseo generados para muestras fósiles presentan patrones de distribución con áreas extensas y 
homogéneas para cada tipo de rasgo microestructural (Bromage, 1989; Lacruz et al., 2015a,b). Por lo tanto, resulta fundamental tomar en consideración el porcentaje de información a partir del cual se realizan las estimaciones de las áreas de cada tipo de superficie ósea para determinar en qué medida las diferencias entre individuos y especies son producto de la biología celular o de la reconstrucción efectuada.

Como se mencionó previamente, las aproximaciones cualitativas también presentan limitaciones para realizar análisis comparativos de los mapas de modelado óseo correspondientes a varios individuos. En general, se basan en la representación de la distribución de áreas de formación y reabsorción ósea sobre esquemas de las estructuras craneofaciales a partir de los cuales se realizan comparaciones descriptivas (e.g. Kurihara et al., 1980; Bromage, 1989; Martínez-Maza et al., 2006, 2013, 2016; McCollum, 2008; Kranioti et al., 2009; Lacruz et al., 2015a,b). En este trabajo se combinaron técnicas de la morfometría geométrica y herramientas de sistemas de información geográfica para obtener mapas homólogos para un conjunto de individuos y registrar de forma automática el tipo de actividad presente en la superficie representada en dichos mapas. A partir de la información cuantificada para cada celda de los mapas de las cuatro estructuras faciales analizadas se estimaron medidas de tendencia central (i.e. mediana) y de dispersión (i.e. rango intercuartil). De esta manera se generaron mapas de modelado óseo representativos de cada grupo de edad para las dos muestras analizadas. Por lo tanto, la aproximación desarrollada aquí facilita la identificación de las áreas de mayor y menor variación, y posibilita la aplicación de técnicas estadísticas multivariadas para el análisis de los cambios registrados a lo largo de la ontogenia, entre individuos del mismo rango etario, así como a nivel poblacional e inter-específico.

Finalmente, la cuantificación de la información histológica también permitió el análisis integrado de los patrones de modelado con las variables morfométricas empleadas para el registro del tamaño y la forma craneofacial mediante el empleo de técnicas estadísticas multivariadas. Previamente, se ha reconocido que no se cuenta con las herramientas analíticas necesarias para examinar la variación en el modelado óseo con suficiente grado de detalle, recurriendo a generalizaciones que tienden a simplificar las diferencias entre individuos (Lacruz et al., 2013; Freidline et al., 2017). En efecto, hasta el presente trabajo, los estudios que utilizaron datos de superficies óseas y datos morfométricos se han limitado a analizar los niveles histológico y anatómico de forma independiente (O'Higgins et al., 1991; O'Higgins y Jones, 1998; Brachetta-Aporta et al., 2014, 2016; Martinez-Maza et al., 2016; Freidline et al., 2017), lo que limita la posibilidad de establecer de qué manera y en qué medida se vinculan la variación del modelado óseo con los cambios en forma y tamaño. Los análisis propuestos aquí 
ofrecen la oportunidad de evaluar la relación entre los cambios en la morfología craneofacial y los mecanismos del modelado óseo subyacentes. En este sentido, contribuirá al estudio de los procesos del desarrollo involucrados en la generación de estructuras morfológicas y su evolucionabilidad (Atchley y Hall, 1991; Hall, 2003) y a la delimitación de módulos en morfologías complejas como el cráneo de primates, a partir de identificar niveles jerárquicos de integración anidados (Ackermann, 2005; Bastir, 2008). Asimismo, el análisis conjunto de los niveles histológico y anatómico permitirá analizar las respuestas óseas, en la formación y reabsorción, a cambios y demandas funcionales y del crecimiento óseo. En particular, podrían evaluarse hipótesis acerca de los procesos involucrados en la variación morfológica a lo largo de la ontogenia tal como la hipótesis de Enlow (Enlow, 1963; Enlow y Hans, 1996) que plantea que el remodelado óseo por crecimiento (i.e. modelado óseo) en gran medida compensa los desplazamientos.

En resumen, en este trabajo se mostró que la cuantificación de la información histológica presenta claras ventajas frente a la aproximación cualitativa tradicional en cuanto a las posibilidades de resumir y analizar la información. Los resultados obtenidos en esta tesis indican que es particularmente útil para efectuar análisis comparativos dentro y entre muestras numerosas, así como para integrar conjuntos de datos que capturan distintos niveles de la variación fenotípica (e.g. histológico y morfológico).

\subsection{Variación intra e inter-poblacional en los patrones de modelado óseo}

Los resultados del análisis del modelado óseo obtenidos para las muestras de Pampa Grande y Chubut analizadas en este trabajo apoyan parcialmente la primera de las hipótesis planteadas Los patrones de modelado óseo del esqueleto facial no se mantienen constantes a través de la ontogenia de los individuos-. Mientras que algunas áreas de la región facial exhibieron cambios con la edad, otras se caracterizaron por presentar un patrón de modelado óseo general constante a lo largo de la ontogenia. Las regiones de la glabela, supraorbital, proceso frontal del maxilar y gran parte del hueso malar mostraron predominancia de formación, tanto en los individuos subadultos como adultos de ambas muestras. Este patrón se mantuvo relativamente constante a través de los grupos de edad, con mayores variaciones para la muestra de Chubut. En particular, se registró reabsorción en la porción inferior del borde orbital de los subadultos de ambas muestras, en el borde maxilar del malar en los individuos adultos de Pampa Grande, y en el borde masetero y la apófisis marginal de adultos de Chubut. Por otro lado, el proceso alveolar del maxilar se caracterizó por la predominancia de reabsorción, mientras que la fosa canina y el proceso cigomático presentaron los dos tipos de 
actividad de modelado óseo. En ambas muestras estas áreas registraron un aumento de la presencia de formación con la edad, en particular en la fosa incisiva de los adultos de Pampa Grande y en la fosa canina de los adultos de Chubut.

Estudios transversales en restos de humanos modernos han identificado cambios postnatales en el patrón de modelado óseo facial desde edades tempranas hasta la adultez (Kurihara et al., 1980; McCollum, 2001, 2008; Martinez-Maza et al., 2013). Se ha propuesto que las demandas de crecimiento generan cambios en los campos de formación y reabsorción ósea, modificándose la extensión, localización y tasa de las actividades de modelado (Enlow y Hans, 1996; O'Higgins y Jones, 1998). En particular, se considera que el hueso frontal se caracteriza por la presencia de formación ósea en la tabla externa y reabsorción en la tabla interna como consecuencia de la expansión anterior del lóbulo frontal del cerebro. Con el cese del crecimiento del cerebro ( 6 años) y de la actividad de reabsorción interna se generaría el espacio del seno frontal (Moss y Young, 1960; Enlow y Hans, 1996). Este patrón de formación se mantendría hasta etapas adultas (Martinez-Maza et al., 2013). Los resultados obtenidos aquí coinciden en señalar la predominancia de formación para la glabela y el supraorbital, que se establece en los primeros grupos de edad y se mantiene a lo largo de la ontogenia.

De acuerdo al modelo de Enlow los orbitales se caracterizarían por su verticalización a medida que se incrementa la cavidad, acompañando los desplazamientos hacia abajo y adelante del complejo nasomaxilar (Enlow, 1966; Enlow y Hans, 1996). Los desplazamientos se compensarían mediante depositación ósea en el proceso frontal del maxilar, a la vez que la presencia de reabsorción en el borde orbital del malar y en la región superior al foramen infraorbitario contribuiría en el incremento del volumen orbital (Enlow y Bang, 1965; Enlow y Hans, 1996). A partir de un estudio transversal que incluye un rango amplio de categorías etarias, Martinez-Maza (2007) reconoce una extensión restringida de las áreas de reabsorción a lo largo del borde orbital del malar en subadultos, y un predominio de áreas de formación en los adultos, abarcando casi todo el borde orbital a excepción de pequeños parches de reabsorción en el malar y maxilar. En la presente tesis también se halló una distribución más restringida para la actividad de reabsorción, registrándose en el borde orbital del malar con mayor extensión en el grupo de edad que abarca entre 4,5 a 10,4 años para Pampa Grande y entre 4,5 y 14,4 años para Chubut, y en la región superior al foramen infraorbitario del maxilar de Chubut. La mayor extensión de reabsorción para los rangos mencionados es similar a lo observado en la mayoría de los subadultos analizados hasta el presente (Enlow y Bang, 1965; Martinez-Maza et al., 2013). Incluso Martinez-Maza y colaboradores (2013) observaron sólo presencia de reabsorción en los individuos de 7, 8 y 11 años, y formación en los de 10 y 17 
años de edad. En adultos, el patrón de modelado general se mantuvo similar el observado en subadultos.

En el caso del malar se ha propuesto que durante el crecimiento este hueso atraviesa por un proceso de posicionamiento posterior y verticalización (Enlow, 1966). Los desplazamientos pasivos en dirección anterior e inferior son compensados por reabsorción anterior principalmente, borde maxilar- y depositación posterior -incluyendo los procesos frontal y temporal- (Enlow y Bang, 1965; Enlow y Hans, 1996; Martinez-Maza et al., 2013). Esta compensación espacial cesa al alcanzarse la longitud final del arco dental (Enlow y Hans, 1996). A su vez, la presencia de formación en el borde del masetero en los subadultos contribuiría al crecimiento vertical, mientras la depositación en la superficie externa y reabsorción en la interna, contribuirían al crecimiento lateral del hueso (Enlow y Hans, 1996). En adultos, la verticalización facial se vería acentuada a través de la presencia de formación en toda la superficie del malar, con presencia de reabsorción restringida al borde masetero posiblemente como consecuencia de fuerzas masticatorias (Martinez-Maza et al., 2013). En las muestras de Pampa Grande y de Chubut se observó un patrón similar, caracterizado por la mayor presencia de formación ósea en la superficie externa del hueso y en el proceso frontal (salvo en el G4 de Chubut), y la presencia de reabsorción en el borde masetero de subadultos y adultos de Chubut. Respecto a la región anterior -borde maxilar-, se caracterizó por presentar formación ósea, con mayor presencia de reabsorción en el grupo de edad entre 10,5 y 14,4 años, y adultos de Pampa Grande.

Finalmente, el maxilar es la estructura facial que mayor atención ha recibido en estudios a nivel histológico. Se considera que la verticalización del maxilar durante el crecimiento es el resultado de un proceso simultáneo de desplazamiento primario en dirección anterior e inferior, compensado por un crecimiento y prolongación posterior (Enlow, 1966; Enlow y Hans, 1996). La depositación continua sobre la tuberosidad contribuiría a la elongación horizontal del arco dental, a la vez que en combinación con la presencia de reabsorción en la superficie endóstica, generaría el espacio del seno maxilar. La presencia de reabsorción anterior contribuiría, junto con la depositación en el proceso frontal, al desplazamiento inferior del arco, registrándose un incremento de la actividad desde el tercer mes de vida postnatal hasta los 14 años (Enlow y Bang, 1965; Kurihara et al., 1980; Enlow y Hans, 1996). A pesar del incremento en extensión de la actividad de reabsorción a lo largo de la ontogenia observado en cortes histológicos (Kurihara et al., 1980), los análisis de la superficie indican la existencia de proporciones similares de formación y reabsorción en el periodo de 1 a 20 años (McCollum, 2001, 2008). Sin embargo, estudios más recientes reconocen en las superficies un patrón 
similar al propuesto a partir de cortes para edades entre los 7 y 17 años, modificándose en adultos con una mayor presencia de formación (Martinez-Maza et al., 2013). En la presente tesis, se registró una gran variación en el patrón de modelado a lo largo de la trayectoria ontogenética para ambas muestras. La presencia de reabsorción anterior fue mayor en el grupo de edad entre 10,5 y 14,4 años de Pampa Grande, y entre 4,5 y 10,4 años para Chubut, restringiéndose al proceso alveolar en etapas anteriores y posteriores. En Chubut, se observó reabsorción también en algunas áreas de la fosa canina y el proceso cigomático. En adultos, la extensión de las áreas de reabsorción se limitaría aún más, observándose la presencia de formación inclusive en la fosa incisiva para la muestra de Pampa Grande. Esta caracterización marcada por una mayor variación en la extensión de las áreas de reabsorción puede estar, en parte, influenciada por el mayor grado error de observación que exhibió este tipo de superficies, por lo que futuros análisis evaluar la concordancia con las descripciones realizadas en este trabajo.

Los resultados obtenidos apoyan una diferenciación en los patrones de modelado entre la región facial superior y la media, indicando que desde el punto de vista histológico estas dos regiones presentan un comportamiento modular. Las diferencias entre los patrones y los niveles de variación registrados para cada hueso indican que las fases del modelado óseo (i.e. activación, reabsorción y formación) no se suceden en el mismo sentido en ambas regiones. Mientras que la región facial superior se caracterizó por el predominio de las superficies de formación y los bajos niveles de variación entre individuos, la región media presentó mayor alternancia espacial de formación y reabsorción, así como mayor variación inter-individual. En este sentido, las demandas funcionales y del desarrollo de la región superior generarían un continuo de depositación ósea y, por el contrario, un mayor recambio óseo en la región media. Estas diferencias pueden corresponderse con una sensibilidad diferencial a factores con efectos locales (e.g. matrices funcionales; cargas masticatorias) y sistémicos (e.g. clima, nutrición, hormonas), produciendo diferencias en el comportamiento celular (Atchley y Hall, 1991; González-José et al., 2005; Sardi y Ramirez-Rozzi, 2007; Lieberman, 2011b; BarbeitoAndrés, 2014). Un análisis reciente de los módulos anatómicos y funcionales de la cabeza humana mediante la cuantificación de redes anatómicas (anatomical network analysis, AnNA por sus siglas en inglés) ha permitido establecer módulos musculoesqueléticos independientes correspondientes a la región facial superior y media (Esteve-Altava et al., 2015), coincidiendo con los resultados de este trabajo.

Asimismo, los huesos malar y maxilar presentaron áreas de formación y reabsorción delimitadas de forma relativamente clara. Estas áreas podrían considerarse módulos de menor 
jerarquía, en tanto que pueden estar respondiendo a factores cuya demanda funcional y de desarrollo genera un impacto local restringido a un área particular del hueso (e.g. cargas masticatorias, desarrollo dental) (Atchley y Hall, 1991; Cheverud, 1996; Ackermann, 2005). En particular, el tejido óseo tiene la capacidad de responder a estímulos causados por tensiones externas aún finalizado el período de crecimiento, siendo el intervalo comprendido entre la pubertad y los primeros años de la adultez uno de los más sensibles a las cargas mecánicas (Gosman, 2012; Martin et al., 2015), intervalo que se correspondió con los períodos de mayor alternancia en el patrón de modelado en el malar y el maxilar de Pampa Grande y Chubut.

La segunda hipótesis formulada en este trabajo es la siguiente: Los patrones de modelado óseo del esqueleto facial difieren entre las poblaciones humanas modernas. Los análisis realizados para su evaluación indican variación intra-específica en los patrones de modelado óseo de la región facial. Las dos muestras del sur de Sudamérica analizadas aquí exhibieron diferencias en el patrón de modelado, especialmente en las áreas asociadas a la masticación y a la inserción muscular de la región facial media. En particular, la muestra de Chubut se caracterizó por la presencia de actividad de reabsorción en dichas áreas, lo que sugiere que el impacto biomecánico sería un factor importante en el patrón de modelado óseo, asociándose la reabsorción a respuesta a las tensiones ejercidas por los músculos de la masticación (Enlow y Hans, 1996; Currey, 2003; Rayfield, 2007; Gosman, 2012). Los mayores niveles de fuerza ejercidos durante la masticación en individuos de Chubut, producto de dietas más abrasivas y duras, y del empleo de la boca como herramienta (Bernal et al., 2006; Menéndez et al., 2014), se corresponden con la presencia desde subadultos de reabsorción en el borde masetero del malar, la aparición de reabsorción en la apófisis marginal en adultos y la extensión de reabsorción a lo largo de la ontogenia en el proceso alveolar del maxilar. Esto coincide con el mayor grado de desgaste oclusal registrado para la dentición decidua y permanente en subadultos y adultos de Chubut. Modelizaciones de fuerzas que simulan la masticación en humanos, han identificado a la región de inserción del masetero y el área adyacente al punto de mordida (i.e. fosa incisiva) como algunas de las zonas de mayor deformación (Toro-lbacache y O'Higgins, 2016). El incremento de la actividad de reabsorción en áreas locales del hueso indicaría un mayor recambio óseo que evitaría la acumulación de microdaños en el tejido como consecuencia de tensiones continuas (Currey, 2003; Stout y Crowder, 2012).

La presencia de reabsorción en el borde masetero del malar sólo se había registrado previamente en restos de adultos contemporáneos (Martinez-Maza et al., 2013). Sin embargo, en subadultos la caracterización siempre correspondió a presencia de formación (Enlow y Bang, 1965; Enlow y Hans, 1996; Martinez-Maza et al., 2013). Asimismo, la presencia de 
reabsorción en la fosa incisiva en adultos no se había observado previamente. El análisis del modelado óseo de los individuos de Chubut corresponde al primero efectuado sobre una muestra correspondiente a cazadores-recolectores. Hasta el presente, las muestras analizadas solo han incluido individuos que consumieron dietas blandas, tanto de contextos arqueológicos (Bromage, 1982) como contemporáneos (Enlow y Bang, 1965; Kurihara et al., 1980; McCollum, 2008; Martinez-Maza et al., 2013). Las diferencias ecológicas tendrían un rol importante en el tipo de patrón de modelado óseo registrado en la región facial media y, por ende, en la morfología facial resultante. Esta consideración debe ser tenida en cuenta tanto en análisis poblacionales, como inter-específicos. Por un lado, la afirmación de que existe un patrón de modelado óseo común para los humanos modernos (Enlow, 1966; Martinez-Maza et al., 2006) no encuentra sustento en los datos, al menos para la región facial media. Por otro lado, la consideración del patrón de modelado óseo como clave para establecer relaciones filogenéticas (e.g. Bromage, 1989; Martinez-Maza et al., 2011, 2016; Lacruz et al., 2013, $2015 a, b)$ debe ser revisado en función de las particularidades de los nichos ecológicos de cada especie (Marcé-Nogué et al., 2017).

Con relación a la región facial superior, se observó que la constancia en el patrón de formación observada en las trayectorias ontogenéticas de Pampa Grande y Chubut para las regiones de la glabela, supraorbital, proceso frontal del maxilar y del malar, son consistentes también con las documentadas para restos modernos de procedencia europea y norteamericana (Enlow y Hans, 1996; Martinez-Maza et al., 2013). Por el contrario, el borde orbital inferior presentó diferencias entre los individuos de ambas muestras. Los subadultos y adultos de Pampa Grande se caracterizaron por presentar formación en el borde orbital del malar. Para Chubut también se observó mayor proporción de formación en adultos, pero no así en subadultos. Previamente, sólo se había registrado formación para adultos contemporáneos (Martinez-Maza et al., 2013), mientras que la presencia de reabsorción en subadultos había sido interpretada como contribución a la localización posterior del malar y crecimiento de la cavidad orbital (Enlow, 1966; Enlow y Hans, 1996; Martinez-Maza et al., 2013). La similitud en el modelado óseo entre diferentes muestras permite sostener la idea de un patrón común de la especie para la región facial superior, caracterizado por la depositación ósea. Sólo el borde orbital inferior debería ser excluido de esta caracterización, posiblemente como consecuencia de una mayor interacción con la región facial media, a diferencia del resto de las estructuras óseas de la región superior.

La constancia en el patrón de modelado entre las muestras de Pampa Grande y Chubut para la región facial superior, y las diferencias observadas en la región facial media, refuerzan 
la hipótesis de que ambas regiones responderían a interacciones funcionales y de desarrollo diferentes. Sin embargo, los límites de cada módulo son imprecisos.

\subsection{Integración de datos craneofaciales histológicos y morfométricos}

Finalmente, se planteó como hipótesis que "La distribución y extensión de las áreas de formación y reabsorción ósea se asocia con la variación en la morfología del esqueleto facial en la ontogenia". Los resultados obtenidos para la covariación entre el modelado óseo y las morfologías óseas sugieren que las variaciones ontogenéticas registradas en la forma del malar y del maxilar se asocian a cambios en el patrón de modelado óseo, mientras que para la glabela y el supraorbital los cambios en forma registrados a lo largo de la ontogenia no se asocian a variaciones en el modelado óseo.

Los cambios en forma de la región facial superior mostraron una proyección anterior de la glabela y los supraorbitales con el aumento de edad, destacándose la presencia de un reborde superciliar marcado en los individuos adultos de Chubut. También se observó un incremento de tamaño del encéfalo, la cavidad orbital y del seno frontal con la edad en ambas muestras, siendo mayores los tamaños en los individuos de Chubut desde la etapa subadultos. Previamente, en estudios morfométricos se han reconocido diferencias en la forma facial entre las muestras de Pampa Grande y Chubut, las cuales se asocian en parte al tamaño (BarbeitoAndrés et al., 2011; Gonzalez et al., 2011). En particular, para la región facial superior, se ha registrado mayor tamaño del orbital en individuos de Chubut desde edades tempranas en la ontogenia (Barbeito-Andrés et al., 2011). Por el contrario, como se mencionó en el apartado anterior, el patrón de modelado óseo mostró consistentemente formación ósea. A su vez, la presencia de formación en el borde orbital del malar para Chubut no concuerda con lo esperado para un tamaño orbital mayor, donde un incremento de tamaño de la cavidad orbital generaría depositación interna y reabsorción en el borde inferior y lateral del orbital -i.e. incremento por principio de la V- (Enlow y Hans, 1996). En consecuencia, la distribución espacial de las actividades de modelado óseo no daría cuenta de las diferencias en tamaño y robustez en la región facial superior a lo largo de la ontogenia y entre muestras. A partir de datos morfométricos en 2D se ha propuesto que las diferencias en la forma facial entre Pampa Grande y Chubut responderían principalmente a una prolongación de la trayectoria de crecimiento en Chubut (Gonzalez et al., 2010, 2011). Sin embargo, a nivel histológico se observó una continuidad en la depositación ósea desde subadultos a adultos en ambas muestras. Con base en estos resultados es posible plantear que las diferencias de tamaño y robustez facial son producto de variaciones en la tasa de depositación ósea (i.e. cantidad de 
hueso nuevo producido por unidad de tiempo; Martin et al., 2015) y no en la distribución o extensión de las áreas de formación. Una mayor tasa de actividad de formación en Chubut conduciría al mayor desarrollo de la glabela y los supraorbitales.

Por otro lado, resta discutir la persistencia de grandes áreas de la depositación ósea una vez finalizado el crecimiento, en etapas adultas. Previamente, se ha sugerido que la presencia de formación en la región facial superior sería consecuencia de un mayor énfasis de la dirección de crecimiento horizontal en humanos (Martinez-Maza et al., 2013). Sin embargo, en los individuos que han completado su crecimiento es necesario considerar otros factores como las cargas mecánicas y la influencia de hormonas. En particular, se reconoce que los andrógenos tienen un impacto en el incremento de formación perióstica del hueso (Kini y Nandeesh, 2012). Esta hormona se asocia a su vez, al desarrollo de caracteres secundarios masculinos (Davey y Grossmann, 2016), siendo el desarrollo de la glabela y del margen supraorbital, dos de los caracteres utilizados en la diferenciación sexual de cráneos (Buikstra y Ubelaker, 1994). En este sentido, la presencia de depositación en adultos para la región facial superior podría responder a cambios en forma asociados al desarrollo de caracteres morfológicos secundarios. Esta consideración podría extenderse a individuos femeninos, en tanto que se reconoce una masculinización de los cráneos femeninos con el incremento de edad (Buikstra y Ubelaker, 1994).

Respecto a la región facial media, los cambios en forma del malar a través de la ontogenia en ambas muestras se caracterizaron por el desarrollo prominente del hueso y su proyección anterior, posicionándose en línea recta con los orbitales (i.e. verticalización). En Pampa Grande, se observó también una mayor proyección lateral. Las diferencias en forma entre Pampa Grande y Chubut estarían establecidas tempranamente en la ontogenia, asociadas a diferencias de tamaño (Gonzalez et al., 2010; Barbeito-Andrés et al., 2011). Los individuos de Chubut presentarían mayores tamaños para la región del malar, manteniéndose la diferencia a lo largo de las edades (Barbeito-Andrés et al., 2011). Diferencias en la extensión en las trayectorias de crecimiento podrían haber contribuido a la diferenciación en forma (Gonzalez et al., 2011). A nivel del modelado óseo, se observó que entre las muestras se presentaron dos patrones de modelado óseo diferentes, con presencia de reabsorción en el borde masetero para Chubut. Estas diferencias en el patrón estuvieron presentes desde subadultos y se mantuvieron constantes a través de la ontogenia, lo que sustenta una diferencia de forma establecida tempranamente en la ontogenia. La presencia de formación en el cuerpo y proceso frontal del malar se asoció a una mayor altura del hueso. Sin embargo, en Chubut se registró una disminución de la formación a partir del G4 (14,5 a 18 años) que se mantuvo en adultos 
jóvenes. En consecuencia, es posible que las diferencias en tamaño entre muestras se asocien a variaciones en la tasa de formación y no a la extensión del patrón de modelado en la ontogenia. Por otro lado, la presencia de formación en la superficie externa del malar se asocia a una proyección lateral del hueso, donde la depositación en la superficie externa del arco cigomático y reabsorción en la interna, expandirían la región (Enlow y Bang, 1965; Enlow y Hans, 1996). La mayor extensión y distribución de formación en Pampa Grande podría subyacer, en este sentido, a la mayor proyección lateral registrada en los individuos adultos. Finalmente, se considera que la presencia de reabsorción en la región anterior del malar contribuye a la retracción posterior del hueso que, junto a la presencia de formación en la región posterior del hueso y en el proceso frontal, produce la verticalización del malar (Enlow y Bang, 1965; Enlow y Hans, 1996; Martinez-Maza et al., 2013). En Pampa Grande y Chubut se observó que la verticalización facial se asoció a la presencia de formación en la región anterior del malar. A su vez, los subadultos de Chubut presentaron reabsorción posterior. Por lo tanto, la verticalización facial no estaría vinculada a un tipo específico de patrón de modelado.

Con relación al maxilar, se registraron cambios de forma con la edad, resultando en un cuerpo más rectangular en adultos, con una importante extensión en la altura relativa en Pampa Grande, y con ampliación de la región ubicada entre los procesos cigomático y alveolar en ambas muestras. También se observó una proyección anterior del hueso. Respecto al tamaño, se registró un incremento del seno maxilar con la edad en ambas muestras, siendo mayor el tamaño en los subadultos de Chubut y similares las medianas entre los adultos de ambas muestras. Estudios previos han planteado que las diferencias en la forma del maxilar entre Pampa Grande y Chubut se establecen tempranamente la ontogenia (Barbeito-Andrés et al., 2011; Gonzalez et al., 2011). El tamaño, por otro lado, sería similar en subadultos menores a 5 años, seguido de un incremento diferencial en ambas muestras que resultaría en el mayor tamaño alcanzado por los individuos de la muestra de Chubut (Barbeito-Andrés et al., 2011). Se ha planteado que la extensión en la trayectoria de crecimiento contribuiría a la variación alométrica observada entre estas muestras (Gonzalez et al., 2011). El patrón de modelado óseo coincide con esta caracterización. Se registró un patrón similar entre Pampa Grande y Chubut en subadultos, mientras que los adultos exhiben un patrón particular en cada muestra. Incluso, el patrón de modelado observado en el grupo que incluye individuos entre 10,5 a 14,4 años en ambas muestras es similar al registrado por otros autores para subadultos (Enlow y Bang, 1965; Enlow y Hans, 1996; Martinez-Maza et al., 2013).

La presencia de formación ósea se asoció a un proceso frontal relativamente más ancho y, para Chubut, también más corto; y a un desplazamiento del proceso alveolar hacia arriba para 
Pampa Grande y subadultos de Chubut. Esto concuerda con la expectativa de un mayor desplazamiento hacia abajo del complejo nasomaxilar producto de la presencia de reabsorción anterior (Enlow y Bang, 1965; Enlow y Hans, 1996; Martinez-Maza et al., 2013). Sin embargo, en Pampa Grande se observó una mayor proyección inferior asociada a formación, mientras que en Chubut se registró una mayor proyección anterior con presencia de reabsorción. Dado que las diferencias en el patrón de modelado entre ambas muestras se establecieron tardíamente en la ontogenia y que la muestra de Chubut presentó mayor del área de reabsorción en adultos, es posible que ambas muestras presenten variaciones en forma producto no solo del patrón de modelado, sino también de la tasa de actividad celular. Otra alternativa, es que exista una contribución diferencial en el modelado óseo de la región de la tuberosidad del maxilar. A pesar de ser considerada una estructura clave en el desarrollo del maxilar (Enlow y Hans, 1996), ha recibido menor atención en comparación a la región anterior. Se considera que la elongación horizontal del arco maxilar se asociaría a una depositación continua sobre la superficie perióstica de la tuberosidad (Enlow y Bang, 1965; Enlow y Hans, 1996). Sin embargo, también se ha observado variación en el patrón de modelado de la tuberosidad atribuida a variaciones producto del desarrollo dental (Martinez-Maza, 2007). En este sentido, se requieren futuros estudios cuyos objetivos se orienten a la evaluación de esta región. 


\section{Consideraciones finales}

La presente tesis constituye el primer estudio acerca de los procesos y mecanismos del desarrollo óseo, a nivel histológico, involucrados en la diferenciación morfológica facial en poblaciones humanas del sur de Sudamérica. El objetivo general fue contribuir al conocimiento de la variación en los procesos de modelado óseo y su relación con la variación morfológica dentro y entre poblaciones humanas. Con este fin se integraron datos histológicos del modelado facial derivados del análisis de superficies óseas con información sobre el tamaño y forma del esqueleto facial obtenida mediante análisis morfométricos tridimensionales de coordenadas de landmarks y semilandmarks, y de reconstrucciones de espacios funcionales internos del cráneo.

Los estudios sobre la variación intra e inter-poblacional en el modelado óseo y su vinculación con el desarrollo de rasgos morfológicos complejos durante la ontogenia presentan un conjunto de limitaciones. Por un lado, se destacan algunos problemas de muestreo dado que las poblaciones representadas hasta el presente han sido muy escasas, la descripción de la histología de superficies óseas se ha enfocado en estructuras faciales particulares y la representación de algunas edades ha sido muy baja o nula. En este trabajo se incorporaron muestras arqueológicas de procedencias geográficas aún no estudiadas y que contaron con series ontogenéticas más extensas, incluyendo individuos de la categoría adulto medio -un rango etario no analizado previamente-. Por otro lado, un número importante de obstáculos han sido de tipo metodológico. En este sentido, el presente trabajo aporta el desarrollo de una metodología cuantitativa que demostró su eficacia para evaluar, de forma precisa y exhaustiva, los cambios en el modelado óseo a través de la ontogenia y las diferencias entre muestras. Asimismo, el empleo de una aproximación no invasiva de imágenes de tomografía computada permitió combinar la descripción de rasgos estructurales y funcionales del esqueleto craneofacial mediante la reconstrucción tridimensional de la superficie externa y de los espacios internos del cráneo. A su vez, fue posible obtener una estimación más detallada del desarrollo dental en individuos subadultos que, junto al empleo de análisis multivariados, resultó en una mejor distinción de los individuos en función del grado desarrollo.

Particularmente, a partir de la incorporación de información sobre la variación espacial de las áreas de formación y reabsorción se concluyó que la región facial superior y media 
representarían dos módulos que se mantienen a lo largo de la ontogenia. Caracterizándose el primero por la constancia en el patrón de modelado a través de los grupos de edad, mientras que la región media exhibió altos niveles de variación en la ontogenia. Asimismo, se detectaron módulos de menor jerarquía, posiblemente asociados a factores locales biomecánicos. Estos módulos planteados en el nivel histológico pueden contribuir a identificar los procesos funcionales y del desarrollo que modelan la morfología del esqueleto facial.

A partir de análisis comparativos entre muestras pudo establecerse la existencia de diferencias inter-poblacionales en el patrón de modelado óseo, especialmente para la región facial media. La principal variación se encontró en áreas vinculadas a la masticación y a inserciones musculares, presentando la muestra de cazadores-recolectores analizada aquí una mayor proporción de superficies de reabsorción. Este resultado sugiere que los factores biomecánicos vinculados a la masticación podrían tener un rol importante en la conformación de los patrones de modelado óseo a nivel inter-poblacional. Sin embargo, dado que este es el único estudio que incluye individuos cuyas dietas se habrían caracterizado por altos niveles de abrasividad y/o dureza, resta determinar en qué medida estos hallazgos son generalizables a otras poblaciones con dietas similares. En cualquier caso, los resultados presentados aquí tienen importantes implicancias para el análisis del modelado óseo facial tanto a nivel intra como inter-específico ya que señalan la necesidad de contemplar el efecto de factores ecológicos sobre el establecimiento de los patrones observados.

La integración de datos cuantitativos que describen el modelado óseo y la morfología craneofacial a través de análisis estadísticos multivariados ha permitido evaluar, por primera vez, en qué medida la variación morfológica a lo largo de la ontogenia se corresponde con cambios en la distribución de las áreas de formación y reabsorción. En particular, fue posible evaluar las implicancias derivadas de las formulaciones de los modelos clásicos de Moss y Enlow sobre los procesos que operan durante el crecimiento y desarrollo craneofacial. Los resultados de este trabajo sugieren que el crecimiento de las cavidades craneanas no tiene un rol relevante en los patrones de modelado óseo, al menos en el rango etario analizado aquí. Por otro lado, se encontró una fuerte asociación entre los cambios en forma del malar y el maxilar con la variación en la extensión y distribución de áreas de actividad celular, aunque en el caso del malar no se corresponden con las expectativas del modelo de Enlow. Por el contrario, la glabela y los supraorbitales no presentaron asociación con el patrón de modelado, esto sugiere que los cambios en forma a lo largo de la ontogenia serían modelados por la tasa de formación ósea antes que por cambios en la distribución espacial de los dos tipos de actividad celular. Las diferencias en forma y tamaño de los arcos supraorbitales y del malar se 
establecerían tempranamente en la ontogenia, mientras que en el maxilar esto tendría lugar más tardíamente.

Los resultados obtenidos en este trabajo generaron nuevas preguntas de investigación que señalan algunas perspectivas futuras que contribuirán al estudio de las dinámicas de modelado en las superficies óseas en el marco de problemas sobre la diferenciación craneofacial a nivel intra e inter-poblacional.

En primer lugar, es necesario evaluar el impacto de las dificultades metodológicas para diferenciar las superficies que representan quiescencia celular de aquellas ocasionadas por alteraciones tafonómicas. Esta dificultad podría conducir a una sobreestimación de la actividad de osteoblastos y osteoclastos en los mapas de modelado óseo, especialmente en los individuos adultos que exhiben una desaceleración progresiva en la depositación de la matriz ósea. En esta tesis, se registró el estado de preservación de los restos y se evaluó su asociación con el porcentaje de información de modelado relevada, no encontrándose una relación significativa entre ambas variables. Sin embargo, se requieren nuevos estudios empleando diseños experimentales que permitan evaluar la pérdida de microestructuras en superficies óseas en función del tipo y grado de alteración tafonómica, tipo de pieza ósea afectada, edad del individuo, y tipo de microestructura expuesta -i.e. fibras de colágeno, lagunas de Howship-

En tercer lugar, la variación inter-poblacional observada aquí en los patrones de modelado óseo señala la necesidad de incorporar nuevas muestras a este tipo de estudios, en particular, procedentes de poblaciones expuestas a diferentes factores ecológicos (e.g. composición y dureza de las dietas). En este sentido, las muestras arqueológicas de poblaciones humanas constituyen un importante referente que ha sido escasamente analizado. En cuarto lugar, el reducido número de estudios que incorporan series ontogenéticas amplias para todas las estructuras faciales analizadas aquí limita la posibilidad de realizar análisis comparativos. La ampliación de muestras de referencia que incluyan individuos subadultos con edades menores a 5 y mayores a 11 años de edad contribuiría a evaluar los cambios a lo largo de toda la trayectoria ontogenética. En particular, facilita el registro de la variación en el patrón de modelado vinculada a los procesos de formación y erupción dental (e.g. erupción del segundo molar) y a los cambios hormonales asociados el empuje puberal. Asimismo, en individuos adultos es necesario incorporar muestras equilibradas por sexo. Si bien en trabajos previos no se han encontrado diferencias en el modelado asociadas al sexo (Wealthall, 2002; Freidline et al., 2017), el impacto de hormonas sexuales sobre el modelado puede ser una de las causas principales en la diferenciación observada en la región facial superior. 
Finalmente, los resultados de este trabajo sugieren que los factores locales biomecánicos habrían tenido un importante rol en la variación del modelado óseo entre poblaciones. La evaluación de esta hipótesis requiere profundizar el análisis de las fuerzas de carga a las que estuvieron sometidos los individuos de muestras procedentes de poblaciones con dietas marcadamente diferentes en cuanto a su dureza. En este sentido, las aproximaciones con técnicas de análisis de elementos finitos que facilitan la modelización de distintas propiedades de las estructuras incluyendo descripciones geométricas -e.g. el tamaño y forma de diferentes estructuras del cráneo- y de composición de los materiales óseo y muscular -e.g. fracción mineral y orgánica del hueso- han mostrado ser de gran utilidad en estudios de diferenciación morfológica. 
Anexo 1. Planilla registro de individuos

\section{REGISTRO DE INDIVIDUOS}

Sitio/localidad:

Colección:

Individuo:

Fecha:

Observaciones:

\section{Adultos}

Edad: Cierre de suturas: Sitios lateral-anteriores

\begin{tabular}{|c|c|c|c|}
\hline \multicolumn{4}{|l|}{ 1. Pterion } \\
\hline \multicolumn{4}{|c|}{ 2. Sutura coronaria } \\
\hline \multicolumn{4}{|c|}{ 3. Esfeno-frontal } \\
\hline \multicolumn{4}{|c|}{ 4. Esfeno-temporal inferior } \\
\hline \multicolumn{4}{|c|}{ 5. Esfeno-temporal superior } \\
\hline \multicolumn{4}{|c|}{ Edad estimada (años): } \\
\hline $\begin{array}{c}\text { Juvenil } \\
\text { (hasta 20) }\end{array}$ & $\begin{array}{c}\text { Adulto joven } \\
(20-34)\end{array}$ & $\begin{array}{l}\text { Ad. medio } \\
(35-49)\end{array}$ & $\begin{array}{l}\text { Ad. senil } \\
(50+)\end{array}$ \\
\hline
\end{tabular}

Códigos: PNO: Presente pero no observable; A: Ausente; 0: Abierto; 1: Cierre mínimo; 2: Cierre significativo; 3: Obliteración completa. Fuente: Meindl y Lovejoy (1985)

Sexo
\begin{tabular}{|l|l|l|l|l|l|}
\hline 1. Cresta nucal & & & & & \\
\hline 2. Proceso mastoideo & & & & & \\
\hline 3. Margen supraorbital & & & & & \\
\hline 4. Glabela & & & & & \\
\hline Sexo:
\end{tabular}

Códigos: 1: Femenino; 2: Probable femenino; 3: Sexo ambiguo; 4: Probable masculino; 5: Masculino. Fuente: Buikstra y Ubelaker (1994)
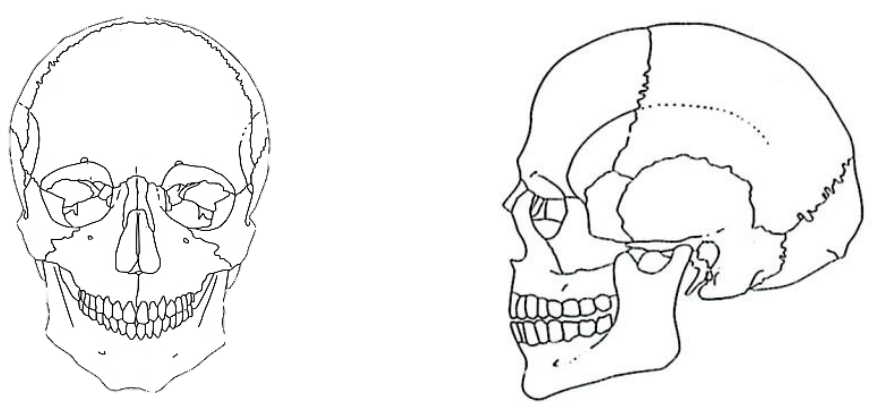

Subadultos

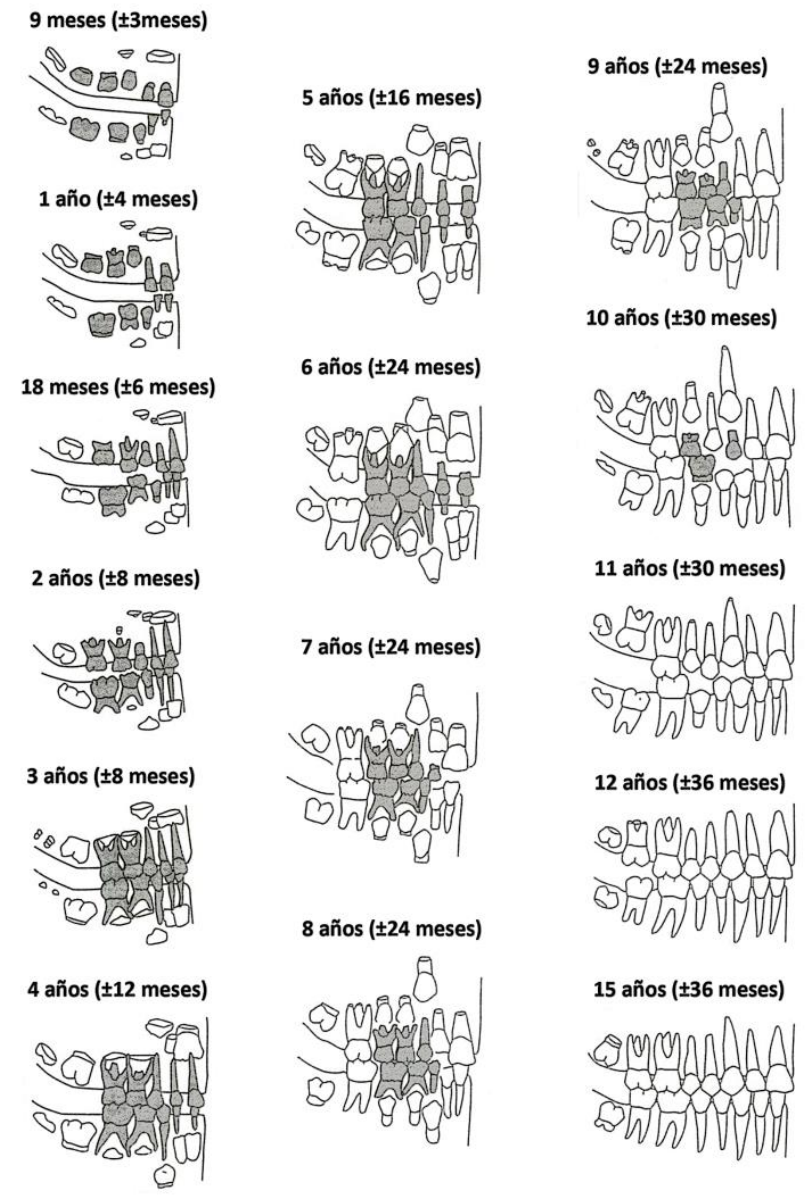

Fuente: Buikstra y Ubelaker (1994) -imágenes seleccionadas-

\section{Integridad y Variables Tafonómicas}

\begin{tabular}{|c|c|c|c|c|c|c|c|c|c|c|}
\hline & $\mathrm{PO}$ & $\mathrm{Fg}$ & $\mathrm{FP}$ & $\mathrm{M}$ & $\mathrm{CO}_{3}$ & $\mathrm{MnO}_{2}$ & $\mathrm{Cu}$ & $\mathrm{R}$ & $\mathrm{Z}$ & A \\
\hline Norma Anterior & & & & & & & & & & \\
\hline Norma Superior & & & & & & & & & & \\
\hline Norma Posterior & & & & & & & & & & \\
\hline Norma Inferior & & & & & & & & & & \\
\hline N. Lateral Derecha & & & & & & & & & & \\
\hline N. Lateral Izquierda & & & & & & & & & & \\
\hline
\end{tabular}

Ref: PO: Pérdida Ósea (\%); Fg: Fragmentación; FP: Fracturas Post-depositacionales; M: Meteorización (estadíos 1-5); $\mathrm{CO}_{3}$ : Carbonato; $\mathrm{MnO}_{2}$ : Óxido de Manganeso; Cu: Óxido de Cobre; R: Marcas de Raíces; Z: Marcas de Animales (C: Carnívoros, R: Roedores); A: Marcas Antrópicas Modernas. Fuente: Gordón (2011) 

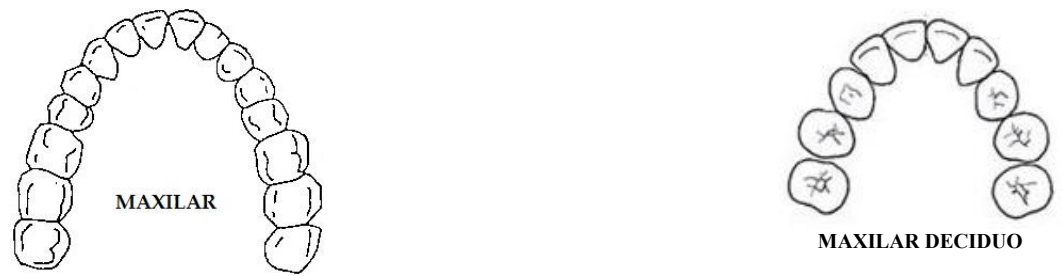

MAXILAR DECIDUO

DIENTE PRESENCIA GRADO DESG FRACTURA CARIES ABSCESOS PERIODONTITIS LABIACIÓN

Maxilar superior Derecho Permanente

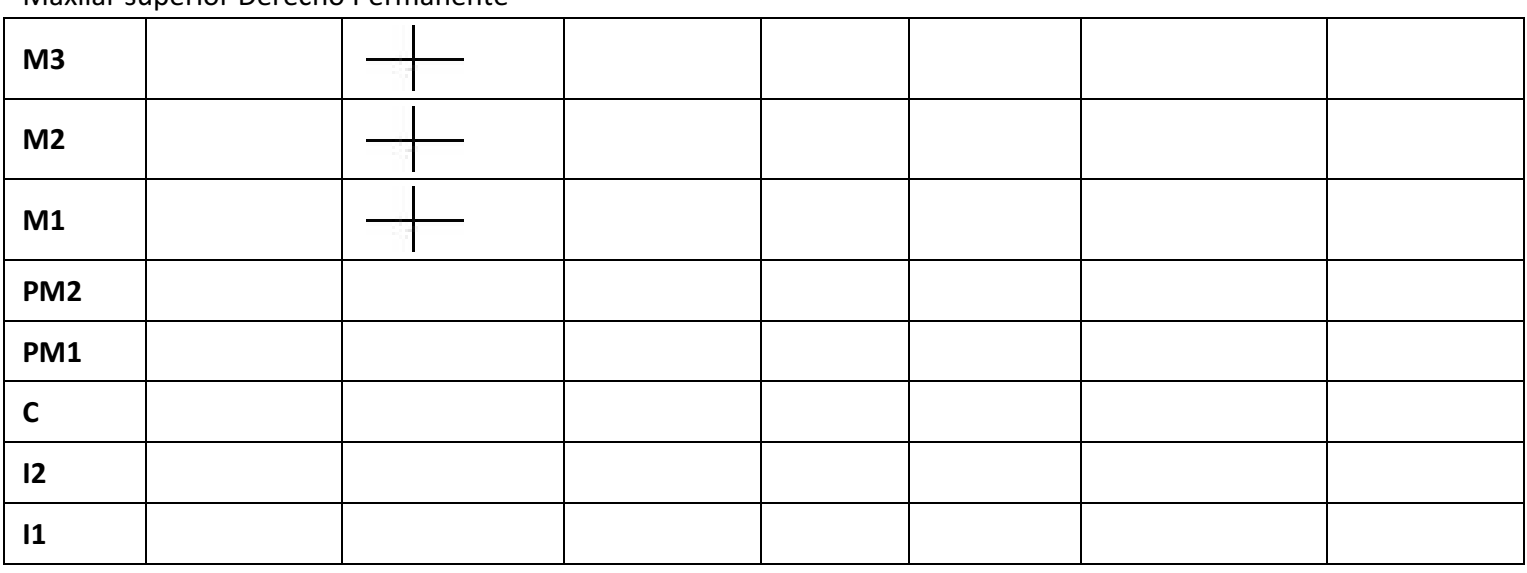

Maxilar superior Izquierdo Permanente

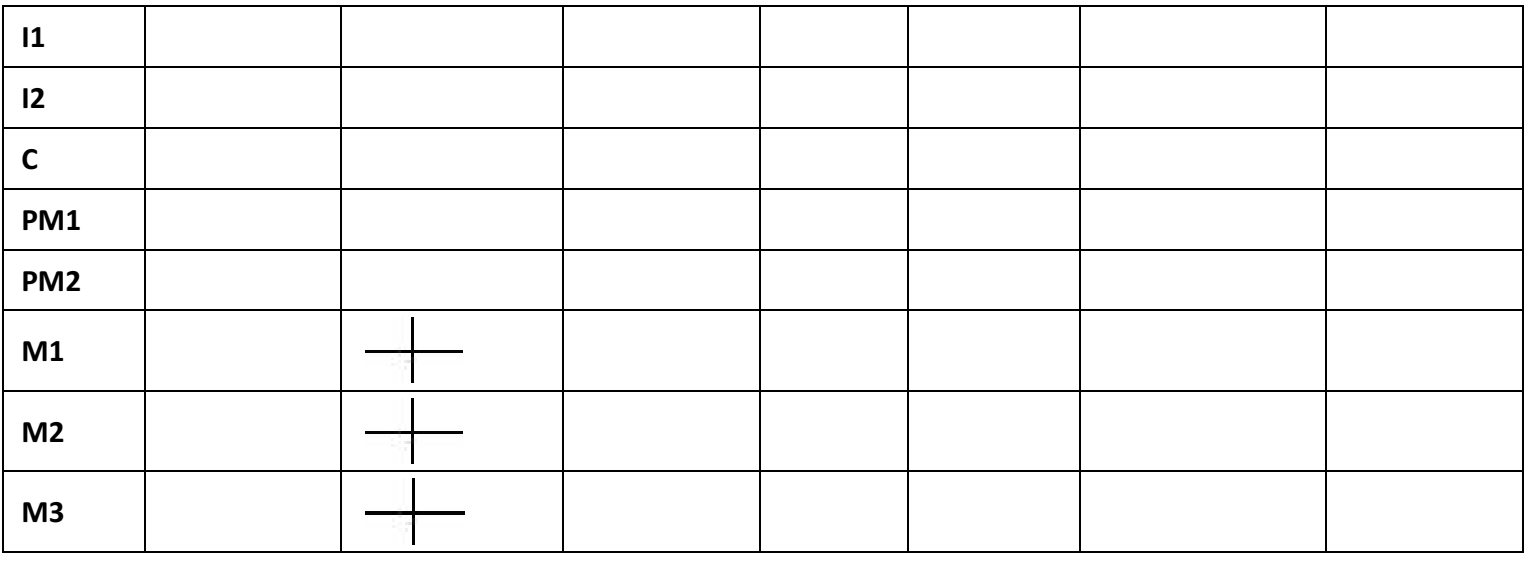

Maxilar superior Derecho Deciduo

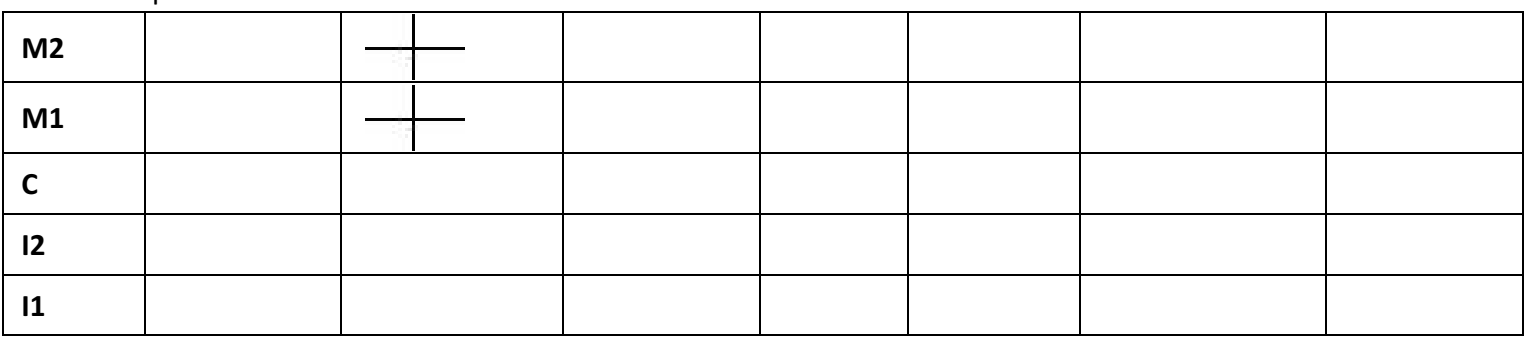

Maxilar superior Izquierdo Deciduo

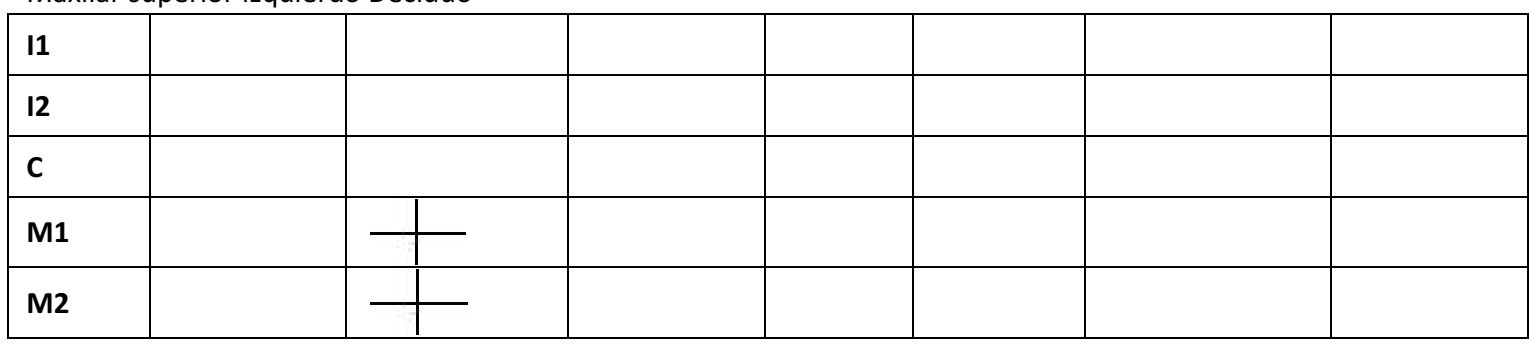

Cód. Presencia: 1: Presente, pero no en oclusión; 2: Presente, desarrollo completo; 3: Perdido, no asociado al hueso alveolar; 4: Perdido, con reabsorción alveolar (pérdida ante-mortem); 5: Perdido, sin reabsorción alveolar (pérdida post-mortem); 6: Perdido, ausencia congénita; 7: Presente, imposible de medir por el daño, pero otras observaciones pueden registrarse; 8: Presente, pero no observable (i.e. dientes encapsulados). Fuente: Buikstra y Ubelaker (1994) 
Anexo 2. Definición de landmarks (L), semilandmarks (sml) y curvas (c) digitalizados en el cráneo

\section{NEUROCRÁNEO}

Punto

Definición

Número

\section{Curvas sagital}

\begin{tabular}{|c|c|c|}
\hline C. 0 Frontal & $\begin{array}{l}\text { Desde el Nasion }{ }^{(a)} \text { al Bregma }{ }^{(a)} \text {. La curva está conformada por los dos } \\
\text { landmarks mencionados más } 10 \text { sml equidistantes }\end{array}$ & $1-12$ \\
\hline C. 0 Parietal & $\begin{array}{l}\text { Desde el Bregma }{ }^{(a)} \text { al Lambda }{ }^{(a)} \text {. Incluye } 8 \mathrm{sml} \text { equidistantes a lo largo } \\
\text { de la sutura sagital }\end{array}$ & $12-21$ \\
\hline C. 0 Occipital & Desde el Lambda ${ }^{(a)}$ al Opistion ${ }^{\text {(c) }}$. Incluye $6 \mathrm{sml}$ equidistantes & $21-28$ \\
\hline
\end{tabular}

\section{Curvas lateral izquierdo}

Desde el Orbital 1 al Coronal 1. Incluye $8 \mathrm{sml}$ equidistantes.

- Los puntos Orbitales se encuentran ubicados a lo largo del borde

C. 1 Frontal orbital superior, equidistantes entre Orbital 1 y Frontomalar anterior ${ }^{\text {(c) }}$

- Los puntos Coronales se encuentran ubicados a lo largo de la sutura coronal, equidistantes entre Bregma y Esfenion ${ }^{(b)}$, estando el Coronal 5 sobre la intersección de la línea temporal superior con la sutura coronal

\begin{tabular}{lll} 
C. 2 Frontal & Desde el Orbital 2 al Coronal 2. Incluye 8 sml equidistantes & $39-48$ \\
\hline & Desde el Coronal 2 al Lambdoidea 1. Incluye 6 sml equidistantes \\
C. 1 Parietal & $\begin{array}{l}\text { - Los puntos Lambdoidea se encuentran ubicados a lo largo de la sutura } \\
\text { lambdoidea, equidistantes entre Lambda y Asterion }{ }^{(b, c)}\end{array}$
\end{tabular}

Desde el Lambdoidea 1 al Foramen magnum izquierdo. Incluye 6 sml equidistantes.

C. 1 Occipital

- El Foramen magnum izquierdo se ubica en el borde lateral-posterior del agujero occipital, equidistante entre Opistion y Foramen magnum lateral

\begin{tabular}{llr}
\hline C. 3 Frontal & Desde el Orbital 3 al Coronal 3. Incluye 8 sml equidistantes & $63-72$ \\
\hline C. 4 Frontal & Desde el Orbital 4 al Coronal 4. Incluye 8 sml equidistantes & $73-82$ \\
\hline C. 2 Parietal & Desde el Coronal 4 al Lambdoidea 2. Incluye 6 sml equidistantes & $82-89$ \\
\hline C. 2 Occipital & $\begin{array}{l}\text { Desde el Lambdoidea } 2 \text { al Foramen magnum lateral. Incluye } 6 \text { sml } \\
\text { equidistantes. }\end{array}$ & $\begin{array}{l}\text { - El Foramen magnum lateral está ubicado en el borde lateral del } \\
\text { foramen, en el límite posterior del cóndilo occipital }\end{array}$ \\
\hline
\end{tabular}




\begin{tabular}{llc} 
Orbital 5 (sml) & $\begin{array}{l}\text { Ubicado en el borde orbital superior, equidistante entre Orbital } 4 \text { y } \\
\text { Frontomalar anterior }\end{array}$ & 97 \\
\hline $\begin{array}{l}\text { Frontal izquierdo } \\
\text { (sml) }\end{array}$ & Ubicado equidistante entre Orbital 5 y Frontotemporal ${ }^{\text {(a) }}$ & $98-106$ \\
\hline C. 5 Frontal & Desde el Frontotemporal ${ }^{\text {(a) }}$ al Coronal 5. Incluye 6 sml equidistantes & $106-113$ \\
\hline C. 3 Parietal & Desde el Coronal 5 al Lambdoidea 3. Incluye 6 sml equidistantes & $113-120$ \\
\hline C. 2 Occipital & Desde el Lambdoidea 3 al Cóndilo externo. Incluye 6 sml equidistantes \\
\hline C. 4 Parietal & digitalizado sobre el occipital & $121-128$
\end{tabular}

\section{Curvas lateral derecho}

Se repite procedimiento en base al orden dado para el lateral izquierdo: 129-228

\begin{tabular}{|c|c|c|}
\hline $\begin{array}{l}\text { Ala del esfenoide } \\
\text { anterior (sml) }\end{array}$ & $\begin{array}{l}\text { Ubicado equidistante entre los puntos Frontomalar posterior (230) y } \\
\text { Fisura orbitaria anterior-superior (Facial, 59) }\end{array}$ & 229 \\
\hline $\begin{array}{l}\text { Frontomalar } \\
\text { posterior (L) }\end{array}$ & $\begin{array}{l}\text { Ubicado en la intersección entre los huesos frontal, malar y el ala mayor } \\
\text { del esfenoides }\end{array}$ & 230 \\
\hline $\begin{array}{l}\text { Ala del esfenoide } \\
\text { superior (sml) }\end{array}$ & $\begin{array}{l}\text { Ubicado equidistante entre los puntos Frontomalar posterior (230) y } \\
\text { Esfenion (232) }\end{array}$ & 231 \\
\hline Esfenion (L) & Punto de encuentro de la sutura coronal con la sutura esfenoparietal (b) & 232 \\
\hline Pterion (L) & $\begin{array}{l}\text { Punto de unión de los huesos parietal, temporal y esfenoides, ubicado } \\
\text { sobre el hueso esfenoidal. En caso de no haber un punto único se debe } \\
\text { ubicar en la mitad de la sutura esfenoparietal }\end{array}$ & 233 \\
\hline $\begin{array}{l}\text { Escama temporal } \\
\text { superior (sml) }\end{array}$ & $\begin{array}{l}2 \text { puntos distribuidos equidistantes a lo largo de la sutura escamosa, del } \\
\text { Pterion (233) al Asterion (236). Digitalizados sobre la escama del } \\
\text { temporal }\end{array}$ & 234-235 \\
\hline Asterion (L) & $\begin{array}{l}\text { Punto de intersección de los huesos parietal, temporal y occipital, } \\
\text { digitalizado sobre el temporal }^{(b, c)}\end{array}$ & 236 \\
\hline Temporo occipital (L) & Punto más anterior en la sutura temporal en la base del cráneo (d) & 237 \\
\hline
\end{tabular}


Ubicado en la intersección de la base de la apófisis cigomática con el ala

Escamotimpánico (L) mayor del esfenoides y el occipital, sobre la cisura escamotimpánica. De

posición medial respecto a la cavidad glenoidea

\begin{tabular}{llc}
\hline Basion (L) & Punto en el borde anterior del foramen magnum sobre la línea media (a) & 239 \\
\hline Sml Basal (sml) & 2 puntos equidistantes desde el Basion (239) al Esfenobasion (242) & $240-241$ \\
\hline Esfenobasion (L) & Sobre la sutura esfenooccipital (o esfenobasion) sobre la línea media & 242 \\
\hline $\begin{array}{l}\text { Escama temporal } \\
\text { anterior (sml) }\end{array}$ & $\begin{array}{l}\text { 2 puntos distribuidos equidistantes a lo largo de la sutura temporal, del } \\
\text { Escamotimpánico (238) al Pterion (233) }\end{array}$ & $243-244$ \\
\hline Cigomático (L) & Ubicado en el borde superior de la apófisis cigomática, en línea vertical & 245 \\
\hline $\begin{array}{l}\text { con el Prominencia cigomática (246) } \\
\text { cigomática (L) }\end{array}$ & Ubicado en la prominencia inferior de la apófisis cigomática \\
\hline $\begin{array}{l}\text { Escotadura } \\
\text { cigomática } \\
\text { posterior (L) }\end{array}$ & \begin{tabular}{l} 
Ubicado en la escotadura posteroinferior de la apófisis cigomática \\
\hline \begin{tabular}{l} 
Porion (L) \\
\hline
\end{tabular}
\end{tabular} \\
\hline
\end{tabular}

\section{Superficie temporal izquierda}

\begin{tabular}{llr}
\hline Temporal I (sml) & $\begin{array}{l}5 \text { puntos equidistantes desde el Escama temporal anterior (244) al } \\
\text { Escama temporal superior (234) }\end{array}$ & $249-253$ \\
\hline Temporal II (sml) & $\begin{array}{l}5 \text { puntos equidistantes desde el Escama temporal anterior (243) al } \\
\text { Escama temporal superior (235) }\end{array}$ & $254-258$ \\
\hline Temporal III (sml) & 3 puntos equidistantes desde el Porion (248) al Asterion (236) & $259-261$ \\
\hline
\end{tabular}

\section{Bóveda lateral derecha y Superficie temporal derecha}

Se repite procedimiento en base al orden dado para el lado izquierdo, sin incluir Basion (239), Sml Basal

(240-241) y Esfenobasion (242): 262-290 
FACIAL

Punto

Definición

Número

\begin{tabular}{|c|c|c|}
\hline \multicolumn{3}{|l|}{ Sagital frontal } \\
\hline Prostion (L) & $\begin{array}{l}\text { Punto más anterior del maxilar, en la línea media del borde alveolar } \\
\text { de los incisivos centrales }\end{array}$ & 1 \\
\hline $\begin{array}{l}\text { Sml Subespinal } \\
\text { (sml) }\end{array}$ & Ubicado equidistante desde el Prostion (1) al Nasoespinal (4) & $2-3$ \\
\hline Nasoespinal (L) & $\begin{array}{l}\text { Punto ubicado en la intersección entre el borde inferior de la } \\
\text { apertura nasal (piriforme) y el plano sagital (a) }\end{array}$ & 4 \\
\hline $\begin{array}{l}\text { Contorno nasal } \\
\text { inferior izquierdo } \\
\text { (sml) }\end{array}$ & $\begin{array}{l}\text { Punto equidistante entre el Nasoespinal (4) y el Alar izq. (6), } \\
\text { digitalizado sobre el contorno de la apertura nasal izquierda }\end{array}$ & 5 \\
\hline Alar izq. (L) & $\begin{array}{l}\text { Punto más lateral izquierdo de la apertura nasal en el plano } \\
\text { transversal }^{\text {(a) }}\end{array}$ & 6 \\
\hline $\begin{array}{l}\text { Sml Contorno nasal } \\
\text { superior izq. (sml) }\end{array}$ & $\begin{array}{l}2 \text { puntos equidistantes desde el Alar izq. (6) al Nasomaxilar izq. (9), } \\
\text { digitalizado sobre el contorno de la apertura nasal izquierda }\end{array}$ & $7-8$ \\
\hline Nasomaxilar izq. (L) & $\begin{array}{l}\text { Sobre la apertura nasal izquierda, en la intersección inferior de la } \\
\text { sutura nasal con el maxilar, digitalizado sobre el maxilar }\end{array}$ & 9 \\
\hline Sml Nasal izq. (sml) & $\begin{array}{l}2 \text { puntos equidistantes ubicados en la sutura naso-maxilar izquierda, } \\
\text { desde el Nasomaxilar izq. (9) al Nasofrontal izq. (12) }\end{array}$ & $10-11$ \\
\hline Nasofrontal izq. (L) & $\begin{array}{l}\text { Punto de articulación entre el nasal izquierdo, el frontal y la apófisis } \\
\text { del maxilar }\end{array}$ & 12 \\
\hline Nasofrontal der. (L) & $\begin{array}{l}\text { Punto de articulación entre el nasal derecho, el frontal y la apófisis } \\
\text { del maxilar }\end{array}$ & 13 \\
\hline Sml Nasal der. (sml) & $\begin{array}{l}2 \text { puntos ubicados equidistantes desde el Nasofrontal der. (13) al } \\
\text { Nasomaxilar der. (16) }\end{array}$ & $14-15$ \\
\hline $\begin{array}{l}\text { Nasomaxilar der. } \\
\text { (L) }\end{array}$ & $\begin{array}{l}\text { Sobre la apertura nasal derecha, en la intersección inferior de la } \\
\text { sutura nasal con el maxilar, digitalizado sobre el maxilar }\end{array}$ & 16 \\
\hline $\begin{array}{l}\text { Sml Contorno nasal } \\
\text { superior der. (sml) }\end{array}$ & $\begin{array}{l}2 \text { puntos equidistantes desde el Nasomaxilar der. (16) al Alar der. } \\
\text { (19), digitalizado sobre el contorno de la apertura nasal derecha }\end{array}$ & 17-18 \\
\hline Alar der. (L) & $\begin{array}{l}\text { Punto más lateral derecho de la apertura nasal en el plano } \\
\text { transversal }^{\text {(a) }}\end{array}$ & 19 \\
\hline
\end{tabular}




\begin{tabular}{|c|c|c|}
\hline $\begin{array}{l}\text { Contorno nasal } \\
\text { inferior derecho } \\
\text { (sml) }\end{array}$ & $\begin{array}{l}\text { Punto equidistante entre el Alar der. (19) y el Nasoespinal (4), } \\
\text { digitalizado sobre el contorno de la apertura nasal derecha }\end{array}$ & 20 \\
\hline \multicolumn{3}{|l|}{ Orbital izquierdo } \\
\hline Dacrion izq. (L) & $\begin{array}{l}\text { Punto de intersección de la sutura maxilolagrimal izquierda y el } \\
\text { hueso frontal. Usualmente hay un pequeño foramen presente }\end{array}$ & 21 \\
\hline $\begin{array}{l}\text { Orbital medial } \\
\text { inferior (sml) }\end{array}$ & $\begin{array}{l}\text { Punto equidistante entre el Dacrion izq. (21) y el Maxilolagrimal izq. } \\
\text { (23) }\end{array}$ & 22 \\
\hline $\begin{array}{l}\text { Maxilolagrimal izq. } \\
\text { (L) }\end{array}$ & $\begin{array}{l}\text { Punto ubicado en la intersección del extremo inferior del hueso } \\
\text { lagrimal con el maxilar, sobre la sutura, digitalizado en el contorno } \\
\text { orbital izquierdo }^{\text {(b) }}\end{array}$ & 23 \\
\hline Cigoorbital izq. (L) & $\begin{array}{l}\text { Intersección del margen orbital izquierdo y la sutura cigomaxilar, } \\
\text { sobre el maxilar }{ }^{\text {(b) }}\end{array}$ & 24 \\
\hline $\begin{array}{l}\text { Sml Orbital lateral } \\
\text { inferior (sml) }\end{array}$ & $\begin{array}{l}3 \text { puntos equidistantes desde el Cigoorbital izq. (24) al Frontomalar } \\
\text { anterior (28) }\end{array}$ & $25-27$ \\
\hline $\begin{array}{l}\text { Frontomalar } \\
\text { anterior (L) }\end{array}$ & $\begin{array}{l}\text { Punto ubicado en el extremo anterior de la sutura frontomalar, } \\
\text { digitalizado sobre el malar izquierdo } \\
\text { (c) }\end{array}$ & 28 \\
\hline
\end{tabular}

\section{Contorno facial izquierdo}

\begin{tabular}{|c|c|c|}
\hline $\begin{array}{l}\text { Frontomalar } \\
\text { temporal (L) }\end{array}$ & $\begin{array}{l}\text { Punto ubicado más lateralmente en la sutura frontomalar, } \\
\text { digitalizado en el malar izq. }\end{array}$ & 29 \\
\hline Yugal I (sml) & $\begin{array}{l}\text { Punto equidistante entre el Frontomalar temporal (29) y el punto } \\
\text { Prominencia yugal (31) }\end{array}$ & 30 \\
\hline $\begin{array}{l}\text { Prominencia yugal } \\
\text { (L) }\end{array}$ & Punto en la prominencia posterior del malar izquierdo ${ }^{(b)}$ & 31 \\
\hline Yugal II (sml) & $\begin{array}{l}\text { Punto equidistante entre el punto Prominencia yugal (31) y el Yugal } \\
\text { izq. (32) }\end{array}$ & 32 \\
\hline Yugal izq. (L) & $\begin{array}{l}\text { Sobre la escotadura posterior del malar, entre los puntos } \\
\text { Prominencia yugal (31) y Cigotemporal superior }(35)^{(b, c)}\end{array}$ & 33 \\
\hline Yugal III (sml) & $\begin{array}{l}\text { Punto equidistante entre el Yugal izq. (32) y el Cigotemporal superior } \\
\text { (35) }\end{array}$ & 34 \\
\hline $\begin{array}{l}\text { Cigotemporal } \\
\text { superior (L) }\end{array}$ & $\begin{array}{l}\text { Ubicado en el extremo superior de la sutura cigotemporal izquierda, } \\
\text { digitalizado sobre el malar }\end{array}$ & 35 \\
\hline
\end{tabular}




\begin{tabular}{|c|c|c|}
\hline $\begin{array}{l}\text { Sml Cigotemporal } \\
\text { medio (sml) }\end{array}$ & $\begin{array}{l}2 \text { puntos ubicados equidistante desde el Cigotemporal superior (35) } \\
\text { al Cigotemporal inferior (38), sobre la sutura cigotemporal izquierda }\end{array}$ & $36-37$ \\
\hline $\begin{array}{l}\text { Cigotemporal } \\
\text { inferior (L) }\end{array}$ & $\begin{array}{l}\text { Ubicado en el extremo inferior de la sutura cigotemporal, } \\
\text { digitalizado sobre el malar }\end{array}$ & 38 \\
\hline $\begin{array}{l}\text { Sml Borde } \\
\text { posteroinferior del } \\
\text { malar (sml) }\end{array}$ & $\begin{array}{l}3 \text { puntos equidistantes desde el Cigotemporal inferior (38) al } \\
\text { Cigomaxilar inferior (42), ubicados sobre el borde posteroinferior del } \\
\text { malar izquierdo }\end{array}$ & $39-41$ \\
\hline $\begin{array}{l}\text { Cigomaxilar } \\
\text { inferior (L) }\end{array}$ & $\begin{array}{l}\text { Punto en el extremo inferior de la sutura cigomaxilar, sobre el } \\
\text { maxilar }\end{array}$ & 42 \\
\hline $\begin{array}{l}\text { Sml Cigomaxilar } \\
\text { (sml) }\end{array}$ & $\begin{array}{l}3 \text { puntos equidistantes desde el Cigomaxilar inferior (42) al } \\
\text { Cigoorbital izq. (24), sobre la sutura cigomaxilar izquierda }\end{array}$ & $43-45$ \\
\hline $\begin{array}{l}\text { Sml Arcada } \\
\text { maxilar (sml) }\end{array}$ & $\begin{array}{l}3 \text { puntos equidistantes desde el Cigomaxilar inferior (42) al punto } \\
\text { Prolongación de la arcada maxilar (52), sobre la curva del maxilar }\end{array}$ & $46-48$ \\
\hline $\begin{array}{l}\text { Interincisivo } \\
\text { izquierdo (L) }\end{array}$ & $\begin{array}{l}\text { Ubicado entre los incisivos } 11 \text { y } 12 \text { izquierdos, digitalizado sobre el } \\
\text { borde alveolar }\end{array}$ & 49 \\
\hline Postcanino izq. (L) & $\begin{array}{l}\text { Punto sobre el borde alveolar externo ubicado por detrás del canino } \\
\text { izquierdo }\end{array}$ & 50 \\
\hline $\begin{array}{l}\text { Alveolar anterior } \\
\text { (sml) }\end{array}$ & $\begin{array}{l}\text { Ubicado equidistante entre los puntos Postcanino izq. (50) y } \\
\text { Prolongación de la arcada maxilar (52), sobre el borde alveolar }\end{array}$ & 51 \\
\hline $\begin{array}{l}\text { Prolongación } \\
\text { arcada maxilar (L) }\end{array}$ & $\begin{array}{l}\text { Ubicado en la intersección entre la arcada maxilar y los molares, } \\
\text { digitalizado sobre el borde alveolar. Aproximadamente a la altura del } \\
\text { segundo molar en adultos o primer molar permanente en subadultos }\end{array}$ & 52 \\
\hline $\begin{array}{l}\text { Sml Alveolar } \\
\text { posterior (sml) }\end{array}$ & $\begin{array}{l}2 \text { puntos equidistantes desde el punto Prolongación de la arcada } \\
\text { maxilar (52) al Postmolar izq. (55) }\end{array}$ & $53-54$ \\
\hline Postmolar izq. (L) & $\begin{array}{l}\text { Ubicado sobre el borde alveolar posterior, por detrás del último } \\
\text { molar erupcionado }\end{array}$ & 55 \\
\hline $\begin{array}{l}\text { Sml Tuberomalar } \\
\text { (sml) }\end{array}$ & $\begin{array}{l}2 \text { puntos equidistantes sobre la sutura tuberomalar, desde el } \\
\text { Cigomaxilar inf. (42) al punto Fisura orbitaria anterior-inferior (58) }\end{array}$ & $56-57$ \\
\hline $\begin{array}{l}\text { Fisura orbitaria } \\
\text { anterior-inferior (L) }\end{array}$ & $\begin{array}{l}\text { Ubicado en la intersección de la sutura tuberomalar con la fisura } \\
\text { orbitaria superior del esfenoides. Digitalizado sobre la tuberosidad }\end{array}$ & 58 \\
\hline $\begin{array}{l}\text { Fisura orbitaria } \\
\text { anterior-superior } \\
\text { (L) }\end{array}$ & $\begin{array}{l}\text { Ubicado en la intersección de la sutura malar-esfenoidal y la fisura } \\
\text { orbitaria. En caso de que la sutura malar-esfenoidal confluya con la } \\
\text { sutura tuberomalar, colocar por arriba del punto Fisura orbitaria } \\
\text { anterior-inferior (58) }\end{array}$ & 59 \\
\hline
\end{tabular}


Ubicado en la fisura orbitaria superior del esfenoides, anterior al Surco infraorbitario surco infraorbitario. Digitalizado sobre el borde formado entre el (L) piso del orbital y la pared de la tuberosidad

\begin{tabular}{llc}
$\begin{array}{l}\text { Fisura } \\
\text { pterigomaxilar } \\
\text { superior (L) }\end{array}$ & $\begin{array}{l}\text { Ubicado en la fisura orbitaria superior, sobre la sutura fronto- } \\
\text { esfenoidal. Digitalizado sobre la tuberosidad izquierda }\end{array}$ & 61 \\
\hline $\begin{array}{l}\text { Fisura } \\
\text { pterigomaxilar } \\
\text { inferior (L) }\end{array}$ & Ubicado en el extremo inferior de la fisura pterigomaxilar izquierda & 62 \\
\hline $\begin{array}{l}\text { Apófisis pterigoides } \\
\text { medio (sml) }\end{array}$ & $\begin{array}{l}\text { Punto equidistante entre los puntos Fisura pterigomaxilar inferior } \\
\text { (6) y Apófisis pterigoides inferior (64), digitalizado sobre la }\end{array}$ & 63 \\
\hline $\begin{array}{l}\text { tupófisis pterigoides } \\
\text { inferior (L) }\end{array}$ & $\begin{array}{l}\text { Ubicado en la intersección entre el extremo inferior de la apófisis } \\
\text { pterigoides y la tuberosidad izquierda, digitalizado sobre la } \\
\text { tuberosidad }\end{array}$ &
\end{tabular}

\section{Orbital derecho}

\begin{tabular}{|c|c|c|}
\hline Dacrion der. (L) & $\begin{array}{l}\text { Punto de intersección de la sutura maxilolagrimal derecha y el hueso } \\
\text { frontal. Usualmente hay un pequeño foramen presente }\end{array}$ & 65 \\
\hline $\begin{array}{l}\text { Orbital medial } \\
\text { inferior (sml) }\end{array}$ & $\begin{array}{l}\text { Punto equidistante entre el Dacrion der. (65) y el Maxilolagrimal der. } \\
\text { (67) }\end{array}$ & 66 \\
\hline $\begin{array}{l}\text { Maxilolagrimal der. } \\
\text { (L) }\end{array}$ & $\begin{array}{l}\text { Ubicado en la intersección del extremo inferior del hueso lagrimal } \\
\text { con el maxilar, sobre la sutura, digitalizado en el contorno orbital } \\
\text { derecho }^{(b)}\end{array}$ & 67 \\
\hline Cigoorbital der. (L) & $\begin{array}{l}\text { Intersección del margen orbital derecho y la sutura cigomaxilar, } \\
\text { sobre el maxilar }{ }^{\text {(b) }}\end{array}$ & 68 \\
\hline $\begin{array}{l}\text { Sml Orbital lateral } \\
\text { inferior (sml) }\end{array}$ & $\begin{array}{l}3 \text { puntos equidistantes desde el Cigoorbital der. (66) al Frontomalar } \\
\text { anterior (70) }\end{array}$ & $69-71$ \\
\hline $\begin{array}{l}\text { Frontomalar } \\
\text { anterior (L) }\end{array}$ & $\begin{array}{l}\text { Ubicado en el extremo anterior de la sutura frontomalar, digitalizado } \\
\text { sobre el malar derecho }{ }^{\text {(c) }}\end{array}$ & 72 \\
\hline \multicolumn{3}{|c|}{ Contorno facial derecho } \\
\hline $\begin{array}{l}\text { Frontomalar } \\
\text { temporal (L) }\end{array}$ & $\begin{array}{l}\text { Punto ubicado más lateralmente en la sutura frontomalar, } \\
\text { digitalizado en el malar derecho }\end{array}$ & 73 \\
\hline Yugal I (sml) & $\begin{array}{l}\text { Punto equidistante entre el Frontomalar temporal (72) y el punto } \\
\text { Prominencia yugal (75) }\end{array}$ & 74 \\
\hline
\end{tabular}


Prominencia yugal Punto en la prominencia posterior del malar derecho ${ }^{(b)}$

(L)

\begin{tabular}{|c|c|c|}
\hline Yugal II (sml) & $\begin{array}{l}\text { Punto equidistante entre el punto Prominencia yugal (75) y el Yugal } \\
\text { der. (77) }\end{array}$ & 76 \\
\hline Yugal der. (L) & $\begin{array}{l}\text { Punto sobre la escotadura posterior del malar, entre los puntos } \\
\text { Prominencia yugal (75) y Cigotemporal superior }(79)^{(b, c)}\end{array}$ & 77 \\
\hline Yugal III (sml) & $\begin{array}{l}\text { Punto equidistante entre el Yugal der. (77) y el Cigotemporal } \\
\text { superior (79) }\end{array}$ & 78 \\
\hline $\begin{array}{l}\text { Cigotemporal } \\
\text { superior (L) }\end{array}$ & $\begin{array}{l}\text { Ubicado en el extremo superior de la sutura cigotemporal derecha, } \\
\text { digitalizado sobre el malar }\end{array}$ & 79 \\
\hline $\begin{array}{l}\text { Cigotemporal } \\
\text { medio (sml) }\end{array}$ & $\begin{array}{l}2 \text { puntos equidistante desde el Cigotemporal superior (79) al } \\
\text { Cigotemporal inferior (82), sobre la sutura cigotemporal derecha }\end{array}$ & $80-81$ \\
\hline $\begin{array}{l}\text { Cigotemporal } \\
\text { inferior (L) }\end{array}$ & $\begin{array}{l}\text { Ubicado en el extremo inferior de la sutura cigotemporal, } \\
\text { digitalizado sobre el malar }\end{array}$ & 82 \\
\hline $\begin{array}{l}\text { Sml Borde } \\
\text { posteroinferior del } \\
\text { malar (sml) }\end{array}$ & $\begin{array}{l}3 \text { puntos equidistantes desde el Cigotemporal inferior (82) al } \\
\text { Cigomaxilar inferior (86), ubicados sobre el borde posteroinferior del } \\
\text { malar derecho }\end{array}$ & $83-85$ \\
\hline $\begin{array}{l}\text { Cigomaxilar } \\
\text { inferior (L) }\end{array}$ & $\begin{array}{l}\text { Punto en el extremo inferior de la sutura cigomaxilar, sobre el } \\
\text { maxilar }\end{array}$ & 86 \\
\hline $\begin{array}{l}\text { Sml Cigomaxilar } \\
(\mathrm{sml})\end{array}$ & $\begin{array}{l}3 \text { puntos equidistantes desde el Cigomaxilar inferior (86) al } \\
\text { Cigoorbital der. (68), sobre la sutura cigomaxilar derecha }\end{array}$ & $87-89$ \\
\hline $\begin{array}{l}\text { Sml Arcada } \\
\text { maxilar (sml) }\end{array}$ & $\begin{array}{l}3 \text { puntos equidistantes desde el Cigomaxilar inferior (86) al punto } \\
\text { Prolongación de la arcada maxilar (96), sobre la curva del maxilar }\end{array}$ & $90-92$ \\
\hline $\begin{array}{l}\text { Interincisivo } \\
\text { derecho (L) }\end{array}$ & $\begin{array}{l}\text { Ubicado entre los incisivos } 11 \text { y } 12 \text { izquierdos, digitalizado sobre el } \\
\text { borde alveolar }\end{array}$ & 93 \\
\hline Postcanino der. (L) & Punto sobre el borde alveolar externo, por detrás del canino derecho & 94 \\
\hline $\begin{array}{l}\text { Alveolar anterior } \\
\text { (sml) }\end{array}$ & $\begin{array}{l}\text { Ubicado equidistante entre el Postcanino der. (94) y el punto } \\
\text { Prolongación de la arcada maxilar (96), sobre el borde alveolar }\end{array}$ & 95 \\
\hline $\begin{array}{l}\text { Prolongación } \\
\text { arcada maxilar (L) }\end{array}$ & $\begin{array}{l}\text { Ubicado en la intersección entre la arcada maxilar y los molares, } \\
\text { digitalizado sobre el borde alveolar. Aproximadamente a la altura del } \\
\text { segundo molar en adultos o primer molar permanente en subadultos }\end{array}$ & 96 \\
\hline $\begin{array}{l}\text { Sml Alveolar } \\
\text { posterior (sml) }\end{array}$ & $\begin{array}{l}2 \text { puntos equidistantes desde el punto Prolongación de la arcada } \\
\text { maxilar (96) al Postmolar der. (99) }\end{array}$ & $97-98$ \\
\hline
\end{tabular}




\begin{tabular}{|c|c|c|}
\hline Postmolar der. (L) & $\begin{array}{l}\text { Ubicado sobre el borde alveolar posterior, por detrás del último } \\
\text { molar erupcionado }\end{array}$ & 99 \\
\hline $\begin{array}{l}\text { Sml Tuberomalar } \\
\text { (sml) }\end{array}$ & $\begin{array}{l}2 \text { puntos equidistantes sobre la sutura tuberomalar, desde el } \\
\text { Cigomaxilar inferior (86) al punto Fisura orbitaria anterior-inferior } \\
(102)\end{array}$ & $100-101$ \\
\hline $\begin{array}{l}\text { Fisura orbitaria } \\
\text { anterior-inferior (L) }\end{array}$ & $\begin{array}{l}\text { Ubicado en la intersección de la sutura tuberomalar con la fisura } \\
\text { orbitaria superior del esfenoides. Digitalizado sobre la tuberosidad }\end{array}$ & 102 \\
\hline $\begin{array}{l}\text { Fisura orbitaria } \\
\text { anterior-superior } \\
\text { (L) }\end{array}$ & $\begin{array}{l}\text { Ubicado en la intersección de la sutura malar-esfenoidal y la fisura } \\
\text { orbitaria. En caso de que la sutura malar-esfenoidal confluya con la } \\
\text { sutura tuberomalar, colocar por arriba del punto Fisura orbitaria } \\
\text { anterior-inferior (102) }\end{array}$ & 103 \\
\hline $\begin{array}{l}\text { Surco infraorbitario } \\
\text { (L) }\end{array}$ & $\begin{array}{l}\text { Ubicado en la fisura orbitaria superior del esfenoides, anterior al } \\
\text { surco infraorbitario. Digitalizado sobre el borde formado entre el } \\
\text { piso del orbital y la pared de la tuberosidad }\end{array}$ & 104 \\
\hline $\begin{array}{l}\text { Fisura pterigo- } \\
\text { maxilar superior (L) }\end{array}$ & $\begin{array}{l}\text { Ubicado en la fisura orbitaria superior, sobre la sutura fronto- } \\
\text { esfenoidal. Digitalizado sobre la tuberosidad izquierda }\end{array}$ & 105 \\
\hline $\begin{array}{l}\text { Fisura pterigo- } \\
\text { maxilar inferior }(\mathrm{L})\end{array}$ & Ubicado en el extremo inferior de la fisura pterigomaxilar derecha & 106 \\
\hline $\begin{array}{l}\text { Apófisis pterigoides } \\
\text { medio (sml) }\end{array}$ & $\begin{array}{l}\text { Punto equidistante entre los puntos Fisura pterigomaxilar inferior } \\
\text { (106) y Apófisis pterigoides inferior (108), digitalizado sobre la } \\
\text { tuberosidad derecha }\end{array}$ & 107 \\
\hline $\begin{array}{l}\text { Apófisis pterigoides } \\
\text { inferior (L) }\end{array}$ & $\begin{array}{l}\text { Ubicado en la intersección entre el extremo inferior de la apófisis } \\
\text { pterigoides y la tuberosidad derecha, digitalizado sobre la } \\
\text { tuberosidad }\end{array}$ & 108 \\
\hline \multicolumn{3}{|c|}{ Superficie facial izquierda } \\
\hline Malar I (sml) & $\begin{array}{l}4 \text { puntos equidistantes desde el sml Cigomaxilar (43) al Cigotemporal } \\
\text { medio (37) }\end{array}$ & $109-112$ \\
\hline Malar II (sml) & $\begin{array}{l}3 \text { puntos equidistantes desde el sml Cigomaxilar (44) al sml } \\
\text { Cigotemporal medio (36) }\end{array}$ & $113-115$ \\
\hline Malar III (sml) & $\begin{array}{l}3 \text { puntos equidistantes desde el sml Cigomaxilar (45) al sml Yugal III } \\
\text { (34) }\end{array}$ & $116-118$ \\
\hline Malar IV (sml) & $\begin{array}{l}2 \text { puntos equidistantes desde el sml Orbital lateral inferior (25) al } \\
\text { Yugal (33) }\end{array}$ & $119-120$ \\
\hline Malar V (sml) & $\begin{array}{l}2 \text { puntos equidistantes desde el sml Orbital lateral inferior (26) al sml } \\
\text { Yugal II (32) }\end{array}$ & $121-122$ \\
\hline
\end{tabular}


2 puntos equidistantes desde el sml Orbital lateral inferior (27) al

Malar VI (sml) punto Prominencia yugal (31)

123-124

\begin{tabular}{|c|c|c|}
\hline Malar VII (sml) & $\begin{array}{l}\text { Punto equidistante entre el Frontomalar anterior (28) y sml Yugal I } \\
\text { (30) }\end{array}$ & 125 \\
\hline Maxilar I (sml) & $\begin{array}{l}5 \text { puntos equidistantes desde el sml Subespinal (2) al sml Arcada } \\
\text { maxilar (48) }\end{array}$ & $126-130$ \\
\hline Maxilar II (sml) & $\begin{array}{l}5 \text { puntos equidistantes desde el sml Subespinal (3) al sml Arcada } \\
\text { maxilar (47) }\end{array}$ & $131-135$ \\
\hline Maxilar III (sml) & $\begin{array}{l}4 \text { puntos equidistantes desde el Contorno nasal inferior (5) al sml } \\
\text { Arcada maxilar (46) }\end{array}$ & $136-139$ \\
\hline Maxilar IV (sml) & 4 puntos equidistantes desde el Alar izq. (6) al sml Cigomaxilar (43) & $140-143$ \\
\hline Maxilar V (sml) & $\begin{array}{l}4 \text { puntos equidistantes desde el Contorno nasal superior (7) al } \\
\text { Cigomaxilar medio (44) }\end{array}$ & $144-147$ \\
\hline Maxilar VI (sml) & $\begin{array}{l}3 \text { puntos equidistantes desde el Contorno nasal superior (8) al } \\
\text { Cigoorbital (24) }\end{array}$ & $148-150$ \\
\hline Maxilar VII (sml) & $\begin{array}{l}2 \text { puntos equidistantes desde el Nasomaxilar izq. (9) al } \\
\text { Maxilolagrimal izq. (23) }\end{array}$ & $151-152$ \\
\hline Maxilar VIII (sml) & $\begin{array}{l}\text { Punto equidistantes entre el sml Nasal izq. (10) y el sml Orbital } \\
\text { medial inferior (22) }\end{array}$ & 153 \\
\hline Maxilar IX (sml) & Punto equidistante entre el sml Nasal izq. (11) y el Dacrion izq. (21) & 154 \\
\hline Tuberosidad I (sml) & $\begin{array}{l}3 \text { puntos equidistantes desde el sml Arcada maxilar (48) al punto } \\
\text { Apófisis pterigoides inferior (64) }\end{array}$ & $155-157$ \\
\hline $\begin{array}{l}\text { Tuberosidad II } \\
\text { (sml) }\end{array}$ & $\begin{array}{l}3 \text { puntos equidistantes desde el sml Arcada maxilar (47) al punto } \\
\text { Apófisis pterigoides medio (63) }\end{array}$ & $158-160$ \\
\hline $\begin{array}{l}\text { Tuberosidad III } \\
(\mathrm{sml})\end{array}$ & $\begin{array}{l}4 \text { puntos equidistantes desde el sml Arcada maxilar (46) al punto } \\
\text { Fisura pterigomaxilar inferior (62) }\end{array}$ & $161-164$ \\
\hline $\begin{array}{l}\text { Tuberosidad IV } \\
\text { (sml) }\end{array}$ & $\begin{array}{l}4 \text { puntos equidistantes desde el Cigomaxilar inferior (42) al punto } \\
\text { Fisura pterigomaxilar superior (61) }\end{array}$ & $165-168$ \\
\hline $\begin{array}{l}\text { Tuberosidad V } \\
(\mathrm{sml})\end{array}$ & $\begin{array}{l}2 \text { puntos equidistantes desde el sml Tuberomalar (56) al Surco } \\
\text { infraorbitario (60) }\end{array}$ & $169-170$ \\
\hline $\begin{array}{l}\text { Tuberosidad VI } \\
\text { (sml) }\end{array}$ & $\begin{array}{l}\text { Punto equidistante entre el sml Tuberomalar (57) y el borde anterior } \\
\text { de la fisura pterigomaxilar (entre los puntos Fisura orbitaria anterior } \\
\text { inferior -58-y Surco infraorbitario -60-) }\end{array}$ & 171 \\
\hline
\end{tabular}




\begin{tabular}{|c|c|c|}
\hline \multicolumn{3}{|c|}{ Superficie facial derecha } \\
\hline Malar I (sml) & $\begin{array}{l}4 \text { puntos equidistantes desde el sml Cigomaxilar (87) al Cigotemporal } \\
\text { medio (81) }\end{array}$ & $172-175$ \\
\hline Malar II (sml) & $\begin{array}{l}3 \text { puntos equidistantes desde el sml Cigomaxilar (88) al sml } \\
\text { Cigotemporal medio (80) }\end{array}$ & $176-178$ \\
\hline Malar III (sml) & 3 puntos equidistantes del sml Cigomaxilar (89) al sml Yugal III (78) & $179-181$ \\
\hline Malar IV (sml) & $\begin{array}{l}2 \text { puntos equidistantes desde el sml Orbital lateral inferior (69) al } \\
\text { Yugal (77) }\end{array}$ & $182-183$ \\
\hline Malar V (sml) & $\begin{array}{l}2 \text { puntos equidistantes desde el sml Orbital lateral inferior (70) al sml } \\
\text { Yugal II (76) }\end{array}$ & $184-185$ \\
\hline Malar VI (sml) & $\begin{array}{l}2 \text { puntos equidistantes desde el sml Orbital lateral inferior (71) al } \\
\text { punto Prominencia yugal (75) }\end{array}$ & 186-187 \\
\hline Malar VII (sml) & $\begin{array}{l}\text { Punto equidistante entre el Frontomalar anterior (72) y el sml Yugal I } \\
\text { (74) }\end{array}$ & 188 \\
\hline Maxilar I (sml) & $\begin{array}{l}5 \text { puntos equidistantes desde el sml Subespinal (2) al sml Arcada } \\
\text { maxilar (92) }\end{array}$ & 189-193 \\
\hline Maxilar II (sml) & $\begin{array}{l}5 \text { puntos equidistantes desde el sml Subespinal (3) al sml Arcada } \\
\text { maxilar (90) }\end{array}$ & 195-197 \\
\hline Maxilar III (sml) & $\begin{array}{l}4 \text { puntos equidistantes desde el Contorno nasal inferior (20) al sml } \\
\text { Arcada maxilar (90) }\end{array}$ & 199-202 \\
\hline Maxilar IV (sml) & 4 puntos equidistantes desde el Alar der. (19) al sml Cigomaxilar (87) & 203-206 \\
\hline Maxilar V (sml) & $\begin{array}{l}4 \text { puntos equidistantes desde el Contorno nasal superior (18) al } \\
\text { Cigomaxilar medio (88) }\end{array}$ & $207-210$ \\
\hline Maxilar VI (sml) & $\begin{array}{l}3 \text { puntos equidistantes desde el Contorno nasal superior (17) al } \\
\text { Cigoorbital (68) }\end{array}$ & $211-213$ \\
\hline Maxilar VII (sml) & $\begin{array}{l}2 \text { puntos equidistantes desde el Nasomaxilar der. (16) al } \\
\text { Maxilolagrimal der. (67) }\end{array}$ & $214-215$ \\
\hline Maxilar VIII (sml) & $\begin{array}{l}\text { Punto equidistante entre el sml Nasal der. (15) y el sml Orbital } \\
\text { medial inferior (66) }\end{array}$ & 216 \\
\hline Maxilar IX (sml) & Punto equidistante entre el sml Nasal der. (13) y el Dacrion der. (65) & 217 \\
\hline Tuberosidad I (sml) & $\begin{array}{l}3 \text { puntos equidistantes desde el sml Arcada maxilar (92) al punto } \\
\text { Apófisis pterigoides inferior (108) }\end{array}$ & $218-220$ \\
\hline
\end{tabular}




\begin{tabular}{|c|c|c|}
\hline $\begin{array}{l}\text { Tuberosidad II } \\
\text { (sml) }\end{array}$ & $\begin{array}{l}3 \text { puntos equidistantes desde el sml Arcada maxilar (91) al punto } \\
\text { Apófisis pterigoides medio (107) }\end{array}$ & $221-223$ \\
\hline $\begin{array}{l}\text { Tuberosidad III } \\
\text { (sml) }\end{array}$ & $\begin{array}{l}4 \text { puntos equidistantes desde el sml Arcada maxilar (90) al punto } \\
\text { Fisura pterigomaxilar inferior (106) }\end{array}$ & $224-227$ \\
\hline $\begin{array}{l}\text { Tuberosidad IV } \\
\text { (sml) }\end{array}$ & $\begin{array}{l}4 \text { puntos equidistantes desde el Cigomaxilar inferior (86) al punto } \\
\text { Fisura pterigomaxilar superior (105) }\end{array}$ & $228-231$ \\
\hline $\begin{array}{l}\text { Tuberosidad V } \\
\text { (sml) }\end{array}$ & $\begin{array}{l}2 \text { puntos equidistantes desde el sml Tuberomalar (100) al punto } \\
\text { Surco infraorbitario (104) }\end{array}$ & $232-233$ \\
\hline $\begin{array}{l}\text { Tuberosidad VI } \\
\text { (sml) }\end{array}$ & $\begin{array}{l}\text { Punto equidistante entre el sml Tuberomalar (101) y el borde } \\
\text { anterior de la fisura pterigomaxilar (entre los puntos Fisura orbitaria } \\
\text { anterior inferior -102-y Surco infraorbitario -104-) }\end{array}$ & 234 \\
\hline \multicolumn{3}{|l|}{ Sagital basal } \\
\hline Hormion (L) & $\begin{array}{l}\text { Punto posterior al vómer, en la intersección de éste con el cuerpo } \\
\text { del esfenoide, entre las dos alas del vómer }{ }^{\text {(c) }}\end{array}$ & 235 \\
\hline $\begin{array}{l}\text { Espina nasal } \\
\text { posterior (L) }\end{array}$ & $\begin{array}{l}\text { Punto más posterior del arco alveolar, sobre el palatino en la línea } \\
\text { media (b) }\end{array}$ & 236 \\
\hline $\begin{array}{l}\text { Paladar -estaurion- } \\
\text { (L) }\end{array}$ & $\begin{array}{l}\text { Intersección entre la sutura palatina media y la sutura palatina } \\
\text { transversa }\end{array}$ & 237 \\
\hline
\end{tabular}




\section{INTERNOS}

\begin{tabular}{|c|c|c|}
\hline Punto & Definición & Número \\
\hline Postglabela (L) & $\begin{array}{l}\text { Punto ubicado en la superficie interna del cráneo, a la altura de la } \\
\text { Glabela }^{(c)} \text {. Digitalizado sobre la cresta frontal }\end{array}$ & 1 \\
\hline $\begin{array}{l}\text { Posterior de apófisis } \\
\text { Crista Galli (L) }\end{array}$ & $\begin{array}{l}\text { Punto posterior a la apófisis Crista Galli, digitalizado sobre el } \\
\text { esfenoides }\end{array}$ & 2 \\
\hline Tubérculo selar (L) & $\begin{array}{l}\text { Punto ubicado sobre el tubérculo de la Silla Turca, sobre la línea } \\
\text { media }\end{array}$ & 3 \\
\hline Silla Turca (L) & $\begin{array}{l}\text { Punto ubicado en la fosa hipofisaria de la Silla Turca, sobre la línea } \\
\text { media }\end{array}$ & 4 \\
\hline $\begin{array}{l}\text { Dorso de la Silla } \\
\text { Turca (L) }\end{array}$ & $\begin{array}{l}\text { Punto ubicado sobre la porción dorsal de la Silla Turca, sobre la línea } \\
\text { media }\end{array}$ & 5 \\
\hline $\begin{array}{l}\text { Esfenobasion } \\
\text { interno (L) }\end{array}$ & $\begin{array}{l}\text { Punto ubicado sobre la sutura esfenobasion desde el lado interno, a } \\
\text { la altura del Esfenobasion (141) }\end{array}$ & 6 \\
\hline $\begin{array}{l}\text { Sml Basal interno } \\
\text { (sml) }\end{array}$ & $\begin{array}{l}2 \text { puntos equidistantes en la porción basal interna del hueso } \\
\text { occipital, desde el Esfenobasion interno (6) al borde del agujero } \\
\text { occipital, correspondientes a la altura de los sml Basal (139-140) }\end{array}$ & $7-8$ \\
\hline Orbital profundo (L) & $\begin{array}{l}\text { Punto ubicado en el extremo inferior de la fisura orbitaria superior } \\
\text { del esfenoides, por encima del agujero redondo }\end{array}$ & 9 \\
\hline
\end{tabular}

\section{Fuente}

a. Buikstra y Ubelaker, 1994

b. Howells, 1937; 1973

c. Martin y Saller, 1957

d. Menéndez, 2014

Sin referencia. Este trabajo 


\section{Anexo 3. Elaboración de réplicas de alta resolución}

La elaboración de réplicas de alta resolución involucra una serie de pasos que incluyen: la limpieza del material óseo, la elaboración de un molde negativo de la superficie ósea, la posterior generación del positivo y su metalización. Dado que cada uno de los pasos influye en el resultado final obtenido, a continuación se detalla el protocolo utilizado para la obtención de las réplicas. El mismo está basado en referencias bibliográficas (Martinez-Maza, 2007; Fernández-Jalvo y Marín-Monfort, 2008) y la propia experiencia.

\section{A3.1. Preparación de la superficie a replicar}

Para la elaboración de réplicas de alta resolución se requiere la manipulación directa de los restos óseos, los cuales pueden dañarse si no se manipulan con el cuidado correspondiente. En este sentido, se recomienda revisar las normas de conservación y manejo de piezas óseas de referencia. Asimismo, la superficie ósea a replicar no debe estar muy deteriorada (e.g. astillada, con exfoliación, agrietamiento), ya que efectuar una réplica en ese caso puede incrementar el daño.

Previamente a la elaboración del molde negativo, se debe limpiar la superficie ósea. Para ello, se aconseja el empleo de cepillos de cerdas finas y suaves, que evitan que se marque el hueso y destruyan las microestructuras de actividad celular. No es aconsejable el empleo de cepillos de cerdas duras, como el cepillo dental, salvo que la réplica sea efectuada sobre una superficie de mayor dureza que la ósea (i.e. dientes). Limpiar la superficie con alcohol $60 \%$ y dejar secar. No emplear agua, dado que promueve la contaminación orgánica, ni tampoco alcoholes de mayores concentraciones, ya que producen agrietamiento de los tejidos duros. Una opción para retirar la suciedad difícil de extraer es realizar un primer molde negativo en silicona (ver siguiente apartado).

\section{A3.2. Obtención del molde negativo de la superficie ósea}

Para la generación del molde negativo se utilizan siliconas de baja viscosidad y buen nivel de copiado, como las empleadas para implantes odontológicos. Las siliconas constan de dos componentes (i.e. catalizador y base) que mezclados generan una copia o molde del objeto sobre el que se aplican. Su duración decae con el tiempo y el uso, por lo cual no se recomienda generar más de dos copias a partir de un mismo molde, ni emplear después de un período mayor al de 7 años. Para la obtención del molde negativo, primero se debe extraer la cantidad necesaria para cubrir la superficie a replicar, con proporciones similares de base y catalizador. 
Sobre una superficie plana y no porosa, mezclar ambos componentes con movimientos envolventes y continuos, hasta que no queden vetas en el preparado. Una vez que los componentes entran en contacto, el fraguado es bastante rápido (e.g. minutos), por lo cual se recomienda que entre el mezclado y su aplicación sobre la superficie no se supere el minuto de tiempo. La mezcla debe realizarse con una esteca plástica, no de madera (por su porosidad) ni de metal (dado que después se emplea sobre la superficie del hueso).

Aplicar la silicona sobre la superficie ósea, presionando suavemente para facilitar el contacto con la superficie y el copiado de las microestructuras. Evitar la formación de burbujas. Dejar actuar aproximadamente 5 minutos y retirar, empezando por despegar los bordes. Revisar que no se hayan generado burbujas o que queden rastros de polvo en el molde, ya que estos artefactos dificultan posteriormente el relevamiento de información. El molde negativo de silicona puede ser guardado en un recipiente o bolsa que cierre hermético o bien, ser empleado inmediatamente para la generación del molde positivo (ver siguiente apartado).

\section{A3.3. Generación del molde positivo o réplica de la superficie ósea}

El molde positivo o réplica, se obtiene a partir del empleo de resina epoxi sobre la superficie copiada del molde negativo. Hay dos variantes principales de resina epoxi, las de uso odontológico y las industriales. Se recomienda la de uso odontológico, que presenta mayor grado de copiado.

Para obtener el molde positivo se debe realizar, primero, un reborde en el molde de silicona que servirá de contención para la resina (Fig. A3.1a). El reborde puede realizarse con un tipo de silicona más viscosa, del tipo masilla, o algún otro componente que no interfiera con el secado de la resina. Se puede utilizar una base de cartón, por ejemplo, sobre la cual adherir el molde y etiquetar provisoriamente. Para preparar la resina epoxi se recomienda, en primer lugar, trabajar en un espacio ventilado y con guardapolvo y guantes descartables, ya que el producto es tóxico. La resina cuenta con dos componentes ( $\mathrm{A}$ y $\mathrm{B})$, los cuales deben llevarse a temperatura de hervor previo a mezclar. Se necesitan 3 partes de A por 1 de B, las cuales deben mezclarse con movimientos envolventes, evitando la formación de burbujas. Utilizar la cantidad necesaria para cubrir el molde, sin superar los $12 \mathrm{ml}$ en total, por su fraguado. En caso de necesitar mayor cantidad, es mejor realizar sucesivas operaciones. Realizar la mezcla sobre un contenedor de plástico descartable limpio, con esteca de metal. Si bien la resina tiene un tiempo de fraguado mayor al de la silicona, a medida que se va enfriando y mezclando ambos componentes, el producto se va endureciendo, lo que puede dificultar su distribución homogénea por la superficie del molde negativo. En consecuencia, se 
recomienda no exceder el minuto entre la mezcla e incorporación sobre el molde negativo. Verter la resina sobre el molde negativo en forma de goteo, desde una altura aproximada de $20 \mathrm{~cm}$ o más. Esto permite disminuir la formación de burbujas. Asimismo, es recomendable efectuar pequeños golpes contra una superficie plana de la base del molde de silicona con resina. Esto permitirá que las burbujas formadas suban a la superficie y se puedan eliminar con la esteca metálica. El fraguado completo del molde positivo varía de acuerdo a la temperatura y humedad del ambiente, así como de la cantidad de resina empleada; pudiendo tardar entre un día, en ambientes secos y con calor, hasta aproximadamente una semana, en ambientes húmedos y fríos. El molde positivo resultante mantiene sus propiedades con el paso del tiempo (Fig. A3.1b). Para la limpieza de la esteca metálica o de algún otro elemento que haya estado en contacto con la resina, utilizar acetona.

a)

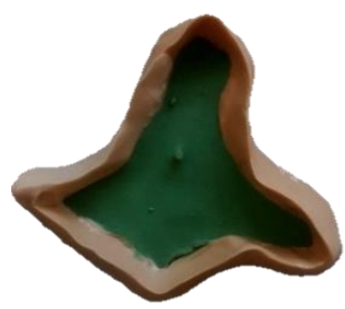

b)

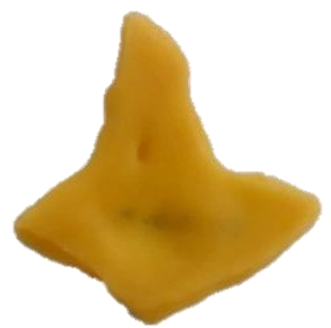

Fig. A3.1. Obtención de la réplica de la superficie externa del hueso malar: a) molde de silicona con reborde de contención; b) molde de resina. En el centro del molde de resina se observa la inscripción realizada en el lado opuesto a la superficie de impresión para la identificación de procedencia

\section{A3.4. Metalizado de la superficie a observar al microscopio}

El último paso para la obtención de una réplica de alta resolución es el metalizado de la superficie que se va a observar al microscopio (Fig. A3.2). El metalizado otorga conductividad eléctrica y térmica a la réplica, posibilitando la observación de la superficie de impresión con microscopio electrónico de barrido o microscopio óptico de luz incidente. Sin embargo, dado que los metalizadores tienen tamaños reducidos, se recomienda que el molde no exceda los $7 \mathrm{~cm}$. En caso de que la superficie ósea a analizar sea mayor, se deberán realizar varios moldes de silicona. Otra opción es cortar en piezas menores el molde de resina (McCollum, 2008).

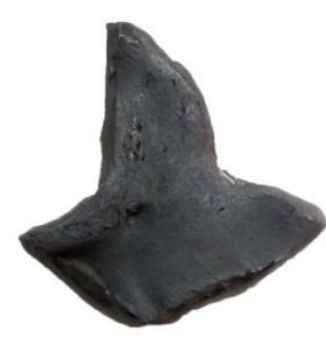

Fig. A3.2. Réplica de malar metalizada 
Anexo 4. Prueba de grillas digitales

El análisis espacial de datos requiere la elección de distintos parámetros que pueden afectar el patrón identificado, y en consecuencia, las inferencias realizadas (Fortin y Dale, 2005). Uno de los aspectos más relevantes a considerar es el tamaño adecuado de las unidades de muestreo, en este caso, el tamaño de las grillas en los mapas de modelado óseo. Se considera que un tamaño muy reducido incrementaría la variación registrada, mientras que un mayor tamaño podría reducirla (Fortin y Dale, 2005). En este trabajo, para establecer el tamaño más adecuado de las grillas se realizaron una serie de pruebas con celdas de dimensiones variables (i.e. ancho por alto, calculados en resolución de pixel). Dado que el objetivo último era generar una metodología que permita realizar comparaciones entre individuos para las mismas regiones óseas, un requisito que se estableció fue la correspondencia espacial anatómica. Es decir, que cada celda contuviera información correspondiente a la misma región, para luego ser comparada entre individuos. En consecuencia, se decidió que cada región ósea mantuviera un tamaño uniforme de celda.

\section{A4.1. Diseño de pruebas y evaluación del registro}

Se seleccionaron cuatro mapas rotados correspondientes a las regiones óseas faciales analizadas en este trabajo (i.e. glabela, supraorbital, malar y maxilar). Los mapas rotados fueron seleccionados de la muestra de individuos adultos de Chubut, teniendo en cuenta que presenten una proporción similar de datos con información histológica (i.e. formación y reabsorción ósea) y datos perdidos. Asimismo, se consideró que los datos presentes tuvieran una distribución aleatoria.

Se generaron cuatro diseños de grillas, estableciendo los tamaños de celda en $5 \times 5,10 \times 10$, $15 \times 15$ y 20x20. Los datos fueron relevados por celda como: -1, para superficies de reabsorción ósea; 1, para superficies de formación ósea; 0 , para superficies con datos perdido. Se determinó un valor por celda en función de la mayor frecuencia registrada. El criterio de interpolación elegido fue el de Inverse Distance Weighting (Distancia Inversa Ponderada). EI procedimiento se efectuó empleando el programa ArcGIS 10 (con licencia de FCNyM).

Los resultados obtenidos indican que los valores interpolados variaron de acuerdo al tamaño de celda empleado (Fig. A4.1). En todos los casos, se observó que las celdas de mayor tamaño (20x20) registraron una menor variación espacial, en comparación con celdas de menor tamaño. Consecutivamente, la variación observada se fue incrementando a medida que se disminuyó el tamaño de las celdas (Fig. A4.1, flechas verdes). 
a)

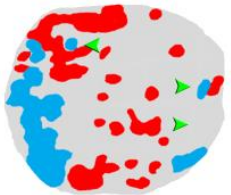

b)

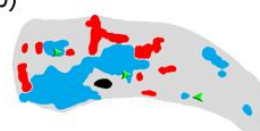

c)

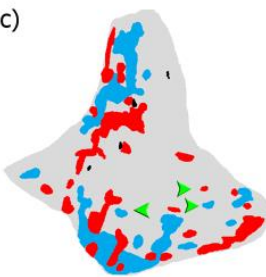

d)

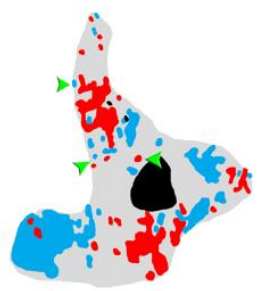

Mapa rotado
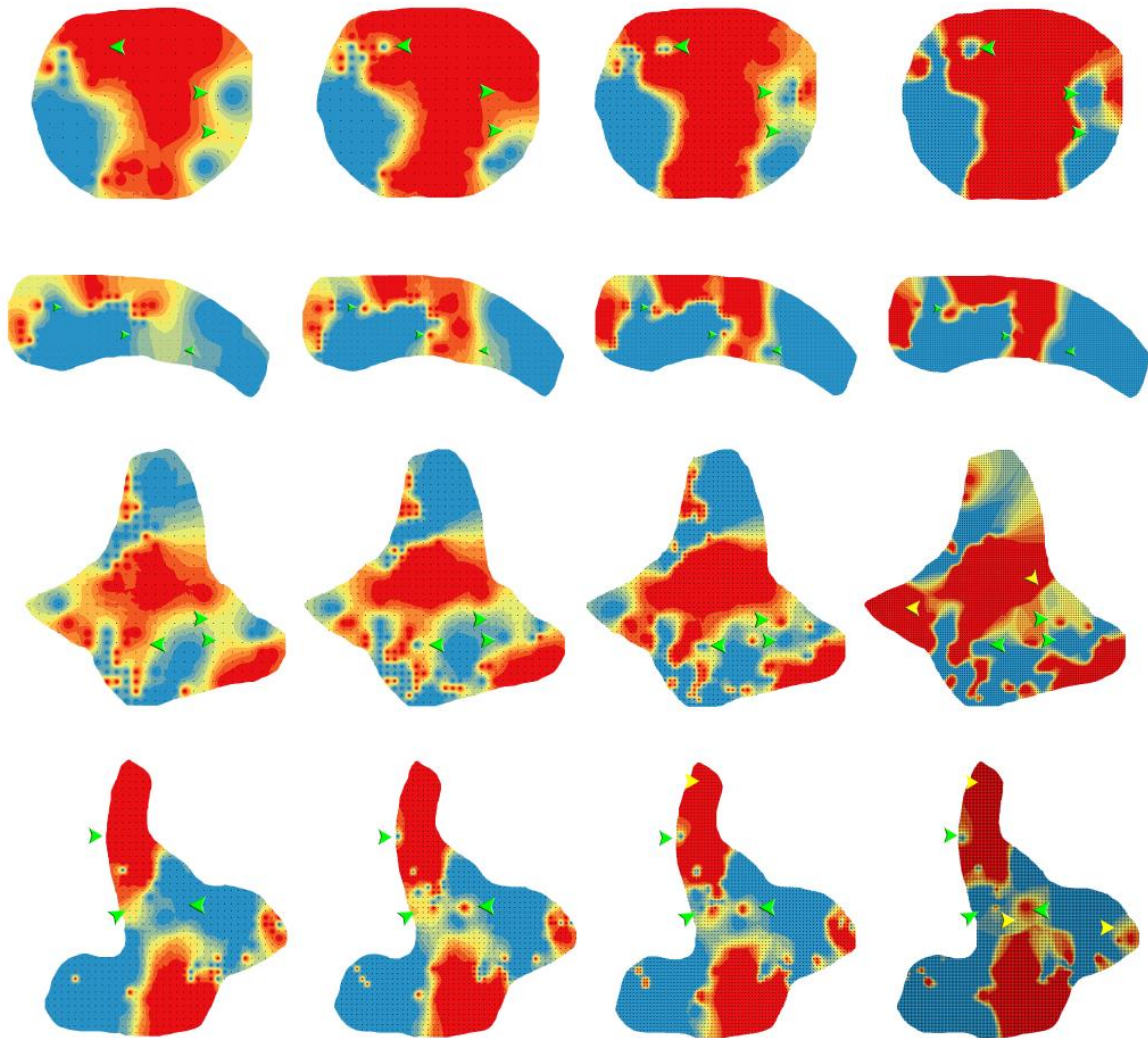

$20 \times 20$

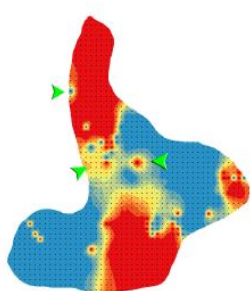

$15 \times 15$

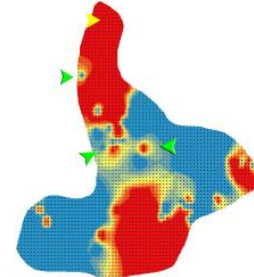

$10 \times 10$

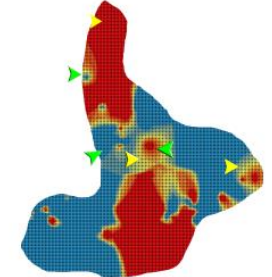

$5 \times 5$

Fig. A4.1. Interpolación de datos obtenida a partir de celdas de tamaño variable en glabela (a), supraorbital (b), malar (c) y maxilar (d). El centro de la celda se visualiza con punto negro. Las flechas verdes indican áreas en las que la información varió en función del tamaño de la celda (20×20, 15×15, $10 \times 10$ y $5 \times 5)$. Las flechas amarillas indican celdas relevadas cuyos datos no se interpolaron. Todos los mapas están en la misma escala

Sin embargo, las celdas de menor tamaño presentaron algunos inconvenientes para el procesamiento de datos. Para las celdas de $5 \times 5$ en el supraorbital, el malar y el maxilar, así como para las celdas de 10x10 en el maxilar, el procedimiento mostró alternancia en el dato registrado (Fig. A4.1, flechas amarillas). La reiteración del procedimiento mostró registros aleatorios de información para algunas de las celdas, no concordando con la información presente en el mapa rotado (Figs. A4.1 y A4.2). No se observó este inconveniente para la glabela, que corresponde al mapa rotado con menor número de celdas con datos (Tabla 4A.1).

a)

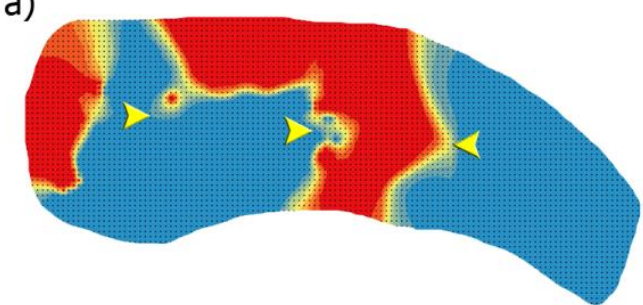

b)

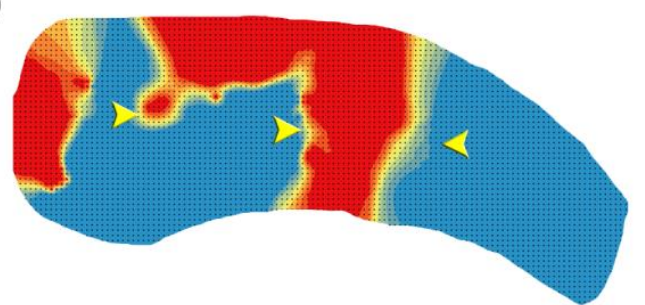

Fig. A4.2. Interpolación con más de 3000 datos. Reiteración del proceso a partir de la misma base de datos ( $a$ y b). El programa genera errores aleatorios, eliminando información en algunas celdas (flechas amarillas) 
Tabla A4.1. Número de celdas con datos por tamaño de grilla

\begin{tabular}{lcccc}
\hline & $20 \times 20$ & $15 \times 15$ & $10 \times 10$ & $5 \times 5$ \\
\hline Glabela & 204 & 358 & 775 & 2989 \\
Supraorbital & 316 & 536 & 1174 & 4523 \\
Malar & 405 & 705 & 1542 & 5970 \\
Maxilar & 739 & 1280 & 2786 & 10837 \\
\hline
\end{tabular}

El error en la interpolación de datos en las grillas con celdas de menor tamaño puede estar asociado a un incremento de la base de datos que debe procesar el programa. En efecto, los diseños que arrojaron errores son aquellos en los que el total de celdas supera las 3000 (Fig. A4.1, Tabla A4.1). Solo la glabela tuvo un número menor, aunque bastante próximo (2989), de celdas debido al menor tamaño de esta región.

Asimismo, otros factores deben ser considerados. La proporción y distribución de los tipos de actividad afectaron la reconstrucción por interpolación. En particular, se observó que los datos distribuidos de manera discontinua y aislada son más propensos a perderse.

En líneas generales, se puede considerar que el tipo y proporción de dato obtenido en el relevamiento depende de cinco factores: 1) distribución de la información registrada en cada mapa (e.g. uniforme, aleatoria o agregada; Fortin y Dale, 2005); 2) tamaño efectivo de la superficie con datos; 3 ) proporción de los datos presentes por región ósea (o porcentaje de datos perdidos); 4) tamaño de la grilla empleado para el relevamiento; y 5) herramienta empleada para procesar los datos. De los cinco factores, sólo los últimos dos pueden ser modificados en base a los objetivos y características estructurales de los datos, mientras que los restantes tres son inherentes a la muestra analizada.

Particularmente, para el relevamiento semiautomático de datos de modelado óseo, se estableció que la mayor eficacia del proceso se da para un tamaño de celda de 10×10 para la glabela, el supraorbital y el malar; y de 15×15 para maxilar. Estos diseños de grilla maximizan las chances de obtener un único tipo de dato por celda, sin alcanzar el límite de procesamiento de datos registrado en las pruebas. 


\section{Bibliografía}

Abràmoff MD, Magelhaes PJ, Ram SJ. 2004. Image processing with ImageJ. Biophotonics International 11: $36-42$.

Abzhanov A, Protas M, Grant BR, Grant PR, Tabin CJ. 2004. Bmp4 and morphological variation of beaks in Darwin's finches. Science 305: 1462-1465.

Ackermann RR. 2005. Ontogenetic integration of the hominoid face. J Hum Evol 48: 175-197.

Ackermann RR, Krovitz GE. 2002. Common patterns of facial ontogeny in the hominid lineage. Anat Rec 269: 142-147.

Adams DC, Rohlf FJ, Slice DE. 2013. A field comes of age: geometric morphometrics in the 21st century. Hystrix 24: 7-14.

AlQahtani SJ. 2008. Atlas of tooth development and eruption. Barts and the London School of Medicine and Dentistry. London: Queen Mary University of London. MClinDent.

AlQahtani SJ, Hector MP, Liversidge HM. 2010. The London atlas of human tooth development and eruption. Am J Phys Anthropol 142: 481-490.

Arnqvist G, Mårtensson T. 1998. Measurement error in geometric morphometrics: empirical strategies to assess and reduce its impact on measures of shape. Acta Zool Acad Sci Hung 44: 73-96.

Arthur W. 2002. The emerging conceptual framework of evolutionary developmental biology. Nature 415: 757-764.

Atchley WR, Hall BK. 1991. A model for development and evolution of complex morphological structures. Biol Rev 66: 101-157.

Azzimonti Renzo JC. 2005. La concordancia entre dos tests clínicos para casos binarios: problemas y solución. Acta Bioquím Clín Latinoam 39: 435-444.

Baffi El, Torres MF. 1993. Una aproximación al análisis de pautas de actividad en una población prehispánica: Las Pirguas (Salta, Argentina). Bol Soc Esp Antrop Biol 14: 63-79.

Baffi EI, Torres MF, Cocilovo JA. 1996. La población prehispánica de Las Pirguas (Salta, Argentina). Un enfoque integral. Rev Arg Antropol Biol 1: 204-218.

Baldini M, Baffi El, Togo J. 1998. Abrigos y cavernas que hacen historia: los hallazgos de Las Pirguas (Pampa Grande, Salta). En: Homenaje a Alberto Rex González, 50 años de aportes al desarrollo y consolidación de la Antropología Argentina. Buenos Aires: Fundación Argentina de Antropología, p. 343-359. 
Baldini MI, Baffi EI, Salaberry MT, Torres MF. 2003. Candelaria: una aproximación desde un conjunto de sitios localizados entre dos cerros de Las Pirguas y el Alto del Rodeo. En: Ortiz G, Ventura B, editores. La mitad verde del mundo andino. Jujuy: EFIUNJU, p. 131-152.

Barbeito-Andrés J. 2014. Integración ontogenética en la morfología craneofacial humana. Tesis Doctoral. La Plata: Universidad Nacional de La Plata.

Barbeito-Andrés J, Pucciarelli HM, Sardi ML. 2011. An ontogenetic approach to facial variation in three Native American populations. HOMO-J Comp Hum Biol 62: 56-67.

Barrientos G, Goñi R, Zangrando A, Del Papa M, García Guraieb S, Arregui MJ, Negro C. 2007. Human taphonomy in southern Patagonia: a view from the Salitroso lake basin (Santa Cruz, Argentina). En: Gutiérrez MA, Miotti L, Barrientos G, Mengoni Goñalons G, Salemme M, editores. Taphonomy and Zooarchaeology in Argentina. Oxford: Archaeopress, p. 187-201.

Bastir M. 2008. A systems-model for the morphological analysis of integration and modularity in human craniofacial evolution. J Anthropol Sci 86: 37-58.

Bastir M, Rosas A, O'Higgins P. 2006. Craniofacial levels and the morphological maturation of the human skull. J Anat 209: 637-654.

Bastir M, Rosas A, Stringer C, Cuétara JM, Kruszynski R, Weber GW, Ross CF, Ravosa MJ. 2010. Effects of brain and facial size on basicranial form in human and primate evolution. J Hum Evol 58: 424431.

Béguelin M, Gómez S. 2011. Restitución de restos humanos: debates actuales y posibles escenarios futuros. X Congreso Argentino de Antropología Social. Buenos Aires: Facultad de Filosofía y Letras, UBA.

Behrensmeyer AK. 1978. Taphonomic and ecologic information from bone weathering. Paleobiology 4: 150-162.

Benavente A, Ato M, López JJ. 2006. Procedimientos para detectar y medir el sesgo entre observadores. Anales de Psicología 22: 161-167.

Bernal V. 2008. Procesos de diferenciación biológica entre poblaciones humanas del Holoceno Tardío de Patagonia: una aproximación desde la variación morfométrica dental. Tesis Doctoral. La Plata: Universidad Nacional de La Plata.

Bernal V, Perez SI, Gonzalez PN. 2006. Variation and causal factors of craniofacial robusticity in Patagonian hunter-gatherers from the late Holocene. Am J Hum Biol 18: 748-765. 
Bernal V, Novellino P, Gonzalez P, Perez SI. 2007. Role of wild plant foods among Late Holocene huntergatherers from Central and North Patagonia (South America): an approach from dental evidence. Am J Phys Anthropol 133: 1047-1059.

Björk A. 1955. Cranial base development: a follow-up x-ray study of the individual variation in growth occurring between the ages of 12 and 20 years and its relation to brain case and face development. Am J Orthod 41: 198-225.

Bookstein FL. 1989. "Size and Shape": a comment on semantics. Syst Zool 38: 173-180.

- 1991. Morphometric tools for landmark data: geometry and biology. Cambridge: Cambridge University Press.

Boyde A. 1972. Scanning electron microscope studies of bone. En: Bourne GH, editor. The biochemistry and physiology of bone. New York: Academic Press, p. 259-310.

Boyde A, Jones SJ. 1972. Scanning electron microscopic studies of the formation of mineralized tissues. En: Slaukin HC, Bavaeta LA, editores. Developmental aspects of oral biology. New York: Academic Press, p. 243-274.

- 1996. Scanning Electron Microscopy of bone: instrument, specimen, and issues. Microsc Res Tech 33: 92-120.

Brachetta-Aporta N. 2016. Error intraobservador en el análisis paleohistológico de superficies craneofaciales. Rev Arg Antrop Biol 18: 1-9.

Brachetta-Aporta N, Martinez-Maza C, Gonzalez P, Bernal V. 2014. Bone modeling patterns and morphometric creaniofacial variation in individuals from two prehistoric human populations from Argentina. Anat Rec 297: 1829-1838.

Brachetta-Aporta N, Gonzalez PN, Bernal V, Martinez-Maza C. 2016. Cambios morfológicos en la mandíbula durante la ontogenia: un aporte desde la histología y la morfometría geométrica. Rev Arg Antrop Biol 18: 1-11.

Brachetta-Aporta N, Gobbo D. 2017. Técnicas de análisis espacial del modelado óseo en superficies craneofaciales. XIII Jornadas Nacionales de Antropología Biológica. Necochea: AABA, p. 129.

Brachetta-Aporta N, Gonzalez P, Bernal V. 2018. A quantitative approach for analysing bone modelling patterns from craniofacial surfaces in hominins. J Anat 232: 3-14.

Bromage TG. 1982. Mapping remodelling reversals with the aid of the scanning electron microscope. Am J Orthod 81: 314-21. 
- 1984. Interpretation of scanning electron microscopic images of abraded forming bone surfaces. Am J Phys Anthropol 64: 161-178.

- 1985. Systematic inquiry in test of negative/positive replica combinations for SEM. J Microsc 137: 209-216.

- 1989. Ontogeny of the early human face. J Hum Evol 18: 751-773.

Bromage TG, Boyde A. 2008. Bone growth remodeling of the early human face. En: Enlow DH, Hans MG, editores. Essentials of facial growth. Philadelphia: WB Saunders, p. 319-344.

Buikstra J, Ubelaker D. 1994. Standards for data collection from human skeletal remains. Fayetteville: Arkansas Archaeological Survey.

Cambra-Moo O, Meneses CN, Rodríguez Barbero MA, García Gil O, Rascón Pérez J, Rello-Varona S, Campo Martín M, González Martín A. 2012. Mapping human long bone compartmentalisation during ontogeny: a new methodological approach. J Struct Biol 178: 338-349.

Cambra-Moo O, Meneses CN, Rodríguez Barbero MA, García Gil O, Rascón Pérez J, Rello-Varona S, D’Angelo M, Campo Martín M, González Martín A. 2014. An approach to the histomorphological and histochemical variations of the humerus cortical bone through human ontogeny. J Anat 224: 634-46.

Carlson DS. 2005. Theories of craniofacial growth in the Postgenomic Era. Semin Orthod 11: 172-183.

Carnese F, Mendisco F, Keyser C, Dejean CB, Dugoujon JM, Bravi CM, Ludes B, Crubézy E. 2010. Paleogenetical study of pre-Columbian samples from Pampa Grande (Salta, Argentina). Am J Phys Anthropol 141: 452-462.

Cheverud JM. 1982. Phenotypic, genetic, and environmental morphological integration in the cranium. Evolution 36: 499-516.

- 1995. Morphological integration in the saddle-back tamarin (Saguinus fuscicollis) cranium. Amer Naturalist 145: 63-89.

- 1996. Developmental integration and the evolution of pleiotropy. Amer Zool 36: 44-50.

- 2007. The relationship between development and evolution through heritable variation. Novartis Found Symp 284: 55-65; discussion 65-70, 110-115.

Cocilovo JA, Varela HH. 2010. La distribución de la deformación artificial del cráneo en el área Andina Centro Sur. Relaciones 35: 41-68.

Cohen J. 1960. A coefficient of agreement for nominal scales. Educ Psychol Meas 20: 37-46.

Compston JE, Vedi S, Stellon AJ. 1986. Inter-observer and intra-observer variation in bone histomorphometry. Calcif Tissue Int 38: 67-70. 
Crespo CM, Russo MG, Hajduk A, Lanata JL, Dejean CB. 2017. Variabilidad mitocondrial en muestras precolombinas de la Patagonia Argentina. Hacia una visión de su poblamiento desde el ADN antiguo. Rev Arg Antrop Biol 19: 1-21.

Currey JD. 2003. The many adaptations of bone. J Biomech 36: 1487-1495.

D’Addona LA, Gonzalez PN, Bernal V. 2016. Variabilidad de las proporciones molares en poblaciones humanas: un abordaje empleando modelos del desarrollo y experimentales. Rev Arg Antrop Biol 18: 1-13.

D’Antoni HL. 1971. Estudios ecológicos de dos regiones de contacto cultural (Valliserrana y Selvas Occidentales). Primera aproximación. Olavarría: Separata de ETNIA 14.

Daegling DJ. 2010. Understanding skull function from a mechanobiological perspective. En: Larsen CS, editor. A Companion to Biological Anthropology, p. 501-515.

Davey RA, Grossmann M. 2016. Androgen receptor structure, function and biology: from bench to bedside. Clin Biochem Rev 37: 3-15.

Dejean CB, Seldes V, Russo MG, Mendisco F, Keyser C, Ludes B, Carnese FR. 2014. Variabilidad genética mitocondrial: comparación de muestras de dos sitios arqueológicos del Noroeste argentino. Rev Arg Antrop Biol 16: 5-16.

Dembo A, Imbelloni J. 1938. Deformaciones intencionales del cuerpo humano de carácter étnico. Humanior A3: 1-348.

Desántolo B, Bernal V. 2016. Los estudios de histología ósea en antropología biológica. Rev Arg Antrop Biol 18: 1-3.

Desántolo B, Inda AM. 2016. Estimación microscópica de edad a partir de la zona cortical del fémur en individuos adultos: revisión metodológica. Rev Arg Antrop Biol 18: 1-12.

Enlow DH. 1962. A study of the post-natal growth and remodeling of bone. Am J Anat 110: 79-101.

- 1963. Principles of bone remodelling. Springfield: Thomas CC Publisher.

— 1966. A comparative study of facial growth in Homo and Macaca. Am J Phys Anthropol 24: 293308.

Enlow DH, Bang S. 1965. Growth and remodeling of the human maxilla. Am J Orthod 51: 446-464.

Enlow DH, DiGangi D, McNamara JA Jr, Mina M. 1988. An evaluation of the morphogenic and anatomic effets of the functional regulator utilizing the counterpart analysis. Eur J Orthod 10: 192-202.

Enlow DH, Hans MG. 1996. Essentials of facial growth. Philadelphia: WB Saunders. 
Esteve-Altava B, Diogo R, Smith C, Boughner JC, Rasskin-Gutman D. 2015. Anatomical networks reveal the musculoskeletal modularity of the human head. Sci Rep 5: 8298.

Feinstein AR, Cicchetti DV. 1990. High agreement but low kappa: I. The problem of two paradoxes. J Clin Epidemiol 43: 543-549.

Ferembach D, Schwidetzky I, Stloukal M. 1977. Raccomandazioni per la determinazione dell'eta e del sesso sullo scheletro. Rivista di Antropologia 60: 5-51.

Fernández-Jalvo Y, Marín Monfort MD. 2008. Experimental taphonomy in museums: preparation protocols for skeletons and fossil vertebrates under the scanning electron microscopy. Geobios 41: 157-181.

Fleiss JL. 1981. Statistical methods for rates and proportions. New York: Wiley.

Fortin MJ, Dale M. 2005. Spatial analysis: a guide for ecologists. New York: Cambridge University Press.

Franklin D. 2010. Forensic age estimation in human skeletal remains: current concepts and future directions. Leg Med 12: 1-7.

Franz-Odendaal TA. 2011. Epigenetics in bone and cartilage development. En: Hallgrímsson B, Hall BK, editores. Epigenetics: linking genotype and phenotype in development and evolution. University of California Press, p. 195-220.

Freidline SE, Martinez-Maza C, Gunz P, Hublin JJ. 2017. Exploring modern human facial growth at the micro- and macroscopic levels. En: Percival CJ, Richtsmeier JT, editores. Building bones: bone formation and development in anthropology. Cambridge University Press, p. 104-127.

Frost HM. 1987. Bone "Mass" and the "Mechanostat": a proposal. Anat Rec 219: 1-9.

García-Gil O, Cambra-Mooa O, Audije Gil J, Nacarino-Meneses C, Rodríguez Barbero MA, Rascón Pérez J, González Martín A. 2016. Investigating histomorphological variations in human cranial bones through ontogeny. Comptes Rendus Palevol 15: 527-535.

García-Mancuso R. 2014. Congruencia entre edad esquelética y desarrollo dentario en una muestra osteológica con edad cronológica documentada. Rev Arg Antrop Biol 16: 103-109.

Gómez Otero J. 2007. Isótopos estables, dieta y uso del espacio en la costa atlántica centro septentrional y el valle inferior del río Chubut (Patagonia argentina). En: Morello F, Martinic M, Prieto A, Bahamonde G, editores. Arqueología de Fuego-Patagonia. Levantando piedras, desenterrando huesos... y develando arcanos. Punta Arenas: Universidad de Magallanes, p. 151161. 
Gómez Otero J, Novellino P. 2011. Diet, nutritional status and oral health in hunter-gatherers from the central-northern coast of Patagonia and the Chubut River lower valley, Argentina. Int J Osteoarchaeol 21: 643-659.

González AR. 1972. Descubrimiento arqueológico en la Serranía de Las Pirguas, Pcia. de Salta. Revista de la Universidad Nacional de La Plata 24: 388-392.

González M. 2013. Procesos de formación y efectos tafonómicos en entierros humanos: el caso del sitio Paso Alsina 1 en Patagonia Nororiental argentina. Magallania 41: 133-154.

Gonzalez PN, Bernal V, Perez SI, Del Papa M, Gordon F, Ghidini G. 2004. El error de observación y su influencia en los análisis morfológicos de restos óseos humanos. Datos de variación discreta. Rev Arg Antrop Biol 6: 35-46.

Gonzalez PN, Perez SI, Bernal V. 2010. Ontogeny of robusticity of craniofacial traits in modern humans: a study of South American populations. Am J Phys Anthropol 142: 367-379.

- 2011. Ontogenetic allometry and cranial shape diversification among human populations from South America. Anat Rec 294: 1864-1874.

González-José R, Ramírez-Rozzi F, Sardi M, Martínez-Abadías N, Hernández M, Pucciarelli HM. 2005. Functional-cranial approach to the influence of economic strategy on skull morphology. Am J Phys Anthropol 128: 757-771.

Gordón F. 2011. Dinámica poblacional, conflicto y violencia en el norte de Patagonia durante el Holoceno Tardío: un estudio arqueológico. Tesis Doctoral. La Plata: Facultad de Ciencias Naturales y Museo, Universidad Nacional de La Plata.

Gosman JH. 2012. Growth and development: morphology, mechanisms, and abnormalities. En: Crowder C, Stout S, editores. Bone histology: an anthropological perspective. Boca Raton: CRC Press, p. 23-44.

Gunz P, Mitteroecker P, Bookstein FL, Weber GW. 2004. Computer-aided reconstruction of incomplete human crania using statistical and geometrical estimation methods. En: Enter the past: computer applications and quantitative methods in archaeology, BAR International Series 1227. Oxford: Archaeopress, p. 92-94.

Gunz P, Mitteroecker P, Bookstein FL. 2005. Semilandmarks in three dimensions. En: Slice DE, editor. Modern morphometrics in physical anthropology, p. 73-98.

Gunz P, Mitteroecker P, Neubauer S, Gerhard WW, Bookstein FL. 2009. Principles for the virtual reconstruction of hominin crania. J Hum Evol 57: 48-62. 
Gunz P, Mitteroecker P. 2013. Semilandmarks: a method for quantifying curves and surfaces. Hystrix 24: 103-109.

Hall BK. 2003. Unlocking the Black Box between genotype and phenotype: cell condensations as morphogenetic (modular) units. Biol \& Philos 18: 219-247.

Hallgrimsson B, Lieberman DE. 2008. Mouse models and the evolutionary developmental biology of the skull. Integr Comp Biol 48: 373-384.

Hallgrimsson B, Jamniczky H, Young N, Rolian C, Parsons T, Boughner J, Marcucio R. 2009. Deciphering the palimpsest: studying the relationship between morphological integration and phenotypic covariation. J Evol Biol 36: 355-376.

Hallgrimsson B, Hall BK. 2011. Epigenetics: the context of development. En: Hallgrímsson B, Hall BK, editores. Epigenetics: linking genotype and phenotype in development and evolution. University of California Press, p. 424-438.

Hammer $\varnothing$, Harper DAT, Ryan PD. 2001. PAST: paleontological statistics software package for education and data analysis. Palaeontol Electronica 4: 1-9.

Hendrikse JL, Parsons TE, Hallgrimsson B. 2007. Evolvability as the proper focus of evolutionary developmental biology. Evol Dev 9: 393-401.

Herring SW. 2011. Muscle-bone interactions and the development of skeletal phenotype: jaw muscles and the skull. En: Hallgrímsson B, Hall BK, editores. Epigenetics: linking genotype and phenotype in development and evolution. University of California Press, p. 221-237.

Hillson S. 2001. Recording dental caries in archaeological human remains. Int J Osteoarchaeol 11: 249289.

Howells WW. 1937. The designation of the principal anthropometric landmarks on the head and skull. Am J Phys Anthropol 22: 477-494.

- 1973. Cranial variation in man. A study of multivariate analysis of patterns of difference among recent human populations. Papers of the Peabody Museum of Archaeology and Ethnology. Cambridge: Harvard University Press.

Humphrey LT. 1998. Growth patterns in the modern human skeleton. Am J Phys Anthropol 105: 57-72.

Ito T, Kawamoto Y, Hamada Y, Nishimura TD. 2015. Maxillary sinus variation in hybrid macaques: implications for the genetic basis of craniofacial pneumatization. Biol J Linn Soc 115: 333-347.

Jamniczky HA, Boughner JC, Rolian C, Gonzalez PN, Powell CD, Schmidt EJ, Parsons TE, Bookstein FL, Hallgrimsson B. 2010. Rediscovering Waddington in the post-genomic age. Operationalising 
Waddington's epigenetics reveals new ways to investigate the generation and modulation of phenotypic variation. Bioessays 32: 553-558.

Jeong HC, Ahn HB. 2015. Comparison of orbital anatomy in Korean and Caucasian patients using computed tomography. J Korean Ophthalmol Soc 56: 1311-1315.

Jindrová A, Tuma, Sládek V. 2012. Intra-observer error of mouse long bone cross section digitization. Folia Zool Brno 61: 340-349.

Jones SJ, Boyde A. 1974. The organization and gross mineralization patterns of the collagen fibres in Sharpey fibre bone. Cell Tissue Res 148: 83-96.

Keough N, L'Abbe' EN, Steyn M. 2009. The evaluation of age-related histomorphometric variables in a cadaver sample of lower socioeconomic status: implications for estimating age at death. Forensic Sci Int 191: 114-119.

Kini U, Nandeesh BN. 2012. Physiology of bone formation, remodeling, and metabolism. En: Fogelman I, Gnanasegaran G, van der Wall H, editores. Radionuclide and hybrid bone imaging. SpringerVerlag Berlin Heidelberg, p. 29-57.

Klingenberg CP. 2008. Morphological integration and developmental modularity. Annu Rev Ecol Evol Syst 39: 115-132.

- 2009. Morphometric integration and modularity in configurations of landmarks: tools for evaluating a priori hypotheses. Evol Dev 11: 405-421.

- 2010a. Evolution and development of shape: integrating quantitative approaches. Nature Reviews Genetics 11: 623-635.

— 2010b. There's something afoot in the evolution of ontogenies. BMC Evol Biol 10: 221.

- 2011. MorphoJ: an integrated software package for geometric morphometrics. Mol Ecol Resour 11: 353-357.

- 2013. Visualizations in geometric morphometrics: how to read and how to make graphs showing shape changes. Hystrix 24: 15-24.

- 2014. Studying morphological integration and modularity at multiple levels: concepts and analysis. Philos Trans R Soc Lond B Biol Sci 369: 20130249.

— 2016. Size, shape, and form: concepts of allometry in geometric morphometrics. Dev Genes Evol 226: 113-137.

Knusel CJ, Robb J. 2016. Funerary taphonomy: an overview of goals and methods. J Archaeol Sci 10: 655-673.

Kontopoulos I, Nystrom P, White L. 2016. Experimental taphonomy: post-mortem microstructural modifications in Sus scrofa domesticus bone. Forensic Sci Int 266: 320-328. 
Kranioti EF, Rosas A, García-Vargas S, Estalrrich A, Bastir M, Peña-Melián A. 2009. Remodeling patterns of occipital growth: a preliminary report. Anat Rec 292: 1764-1770.

Krause WJ. 2001. The art of examining and interpreting histologic preparations. New York: Parthenon Publishing.

Kurihara S, Enlow DH, Rangel RD. 1980. Remodeling reversals in anterior parts of the human mandible and maxilla. Angle Orthod 50: 98-106.

L'Heureux GL. 2014. Indicadores fisiológicos y patológicos bucales en las poblaciones representadas en el sitio Arroyo Seco 2. En: Politis GG, Gutiérrez MA, Scabuzzo C, editores. Estado actual de las investigaciones en el sitio arqueológico Arroyo Seco 2 (partido de Tres Arroyos, Provincia de Buenos Aires, Argentina). Tandil: Universidad Nacional del Centro de la Provincia de Buenos Aires, p. 371-392.

Lacruz RS, Bermúdez de Castro JM, Martinón-Torres M, O’Higgins P, Paine ML, Carbonell E, Arsuaga JL, Bromage TG. 2013. Facial morphogenesis of the Earliest Europeans. PLOS One 8: e65199.

Lacruz RS, Bromage TG, O'Higgins P, Toro-lbacache V, Warshaw J, Berger LR. 2015a. Distinct growth of the nasomaxillary complex in Au. Sediba. Sci Rep 5: 15175.

Lacruz RS, Bromage TG, O’Higgins P, Arsuaga JL, Stringer C, Godinho RM, Warshaw J, Martínez I, GraciaTellez A, Bermúdez de Castro JM, Carbonell E. 2015b. Ontogeny of the maxilla in Neanderthals and their ancestors. Nat Commun 6: 8996.

Lantz CA, Nebenzahl E. 1996. Behavior and interpretation of the $\mathrm{K}$ statistic: resolution of the two paradoxes. J Clin Epidemiol 49: 431-434.

Legendre P, Legendre L. 1998. Numerical Ecology. Amsterdam: Elsevier.

Lehmann-Nitsche R. 1910. Catálogo de la Sección Antropología del Museo de La Plata. Buenos Aires: Imprenta Coni Hnos.

Lema VS. 2009. Criterios de selección en los procesos de manipulación vegetal: el potencial de la información etnobotánica en la interpretación de restos arqueobotánicos de Cucurbita sp. Darwiniana: 35-55.

- 2010. Procesos de domesticación vegetal en el pasado prehispánico del noroeste argentino: estudio de las prácticas más allá de los orígenes. Relaciones 35: 121-141.

- 2011. The possible influence of post-harvest objectives on Cucurbita maxima subspecies maxima and subspecies andreana. Archaeol Anthropol Sci 3:113-139. 
Lieberman DE. 2011a. Epigenetic integration, complexity, and Evolvability of the head: rethinking the Functional Matrix hypothesis. En: Hallgrímsson B, Hall BK, editores. Epigenetics: linking genotype and phenotype in development and evolution. University of California Press, p. 271-289.

— 2011b. The evolution of the human head. Cambridge: Harvard University Press.

Lyman RL. 1994. Vertebrate taphonomy. Cambridge: Cambridge University Press.

Lynnerup N, Thomsen JL, Frohlich B. 1998. Intra- and inter-observer variation in histological criteria used in age at death determination based on femoral cortical bone. Forensic Sci Int 91: 219-230.

Maggiano CM. 2012. Making the mold: a microstructural perspective on bone modeling during growth and mechanical adaptation. En: Crowder C, Stout S, editores. Bone histology: an anthropological perspective. Boca Raton: CRC Press, p. 45-90.

Marcé-Nogué J, Püschel TA, Kaiser TM. 2017. A biomechanical approach to understand the ecomorphological relationship between primate mandibles and diet. Sci Rep 7: 8364.

Martin BR, Burr DB, Sharkey NA, Fyhrie DP. 2015. Skeletal tissue mechanics. New York: Springer.

Martin R, Saller K. 1957. Lehrbuch der anthropologie. Band 1. Gustav Fischer Verlag, Stuttgart.

Martinez-Maza C. 2007. Ontogenia y filogenia del modelado óseo en el esqueleto facial y la mandíbula de los hominoideos. Estudio de la línea filogenética neandertal a partir de las muestras de Atapuerca-SH y El Sidrón. Tesis Doctoral. Madrid: Facultad de Ciencias Biológicas, Universidad Complutense de Madrid.

Martinez-Maza C, Rosas A, García-Vargas S. 2006. Bone paleohistology and human evolution. J Anthropol Sci 84: 33-52.

Martinez-Maza C, Rosas A, Nieto-Diaz M. 2010. Identification of bone formation and resorption surfaces by reflected light microscopy. Am J Phys Anthropol 143: 313-320.

- 2013. Postnatal changes in the growth dynamics of the human face revealed from the bone modelling patterns. J Anat 223: 228-241.

Martinez-Maza C, Freidline SE, Strauss A, Nieto-Diaz M. 2016. Bone growth dynamics of the facial skeleton and mandible in Gorilla gorilla and Pan troglodytes. Evol Biol 43: 63-80.

McCollum MA. 2001. Variation in the growth and modeling of the human maxilla as revealed by scanning electron microscopy. Scanning 23: 71.

— 2008. Nasomaxillary remodeling and facial form in robust Australopithecus: a reassessment. J Hum Evol 54: 2-14. 
McNamara JA Jr, Riolo ML, Enlow DH. 1976. Growth of the maxillary complex in the Rhesus Monkey (Macaca mulatta). Am J Phys Anthropol 44: 15-26.

McNemar Q. 1947. Note of the sampling error of the difference between correlated proportions or percentages. Psychometrika 12: 153-157.

Meindl RS, Lovejoy CO. 1985. Ectocranial suture closure: a revised method for the determination of skeletal age at death based on the lateral-anterior sutures. Am J Phys Anthropol 68: 57-66.

Menéndez L. 2014. Diversificación morfológica craneofacial y diversidad en la dieta: el caso del CentroOeste de Argentina durante el Holoceno tardío. Tesis Doctoral. La Plata: Facultad de Ciencias Naturales y Museo, Universidad Nacional de La Plata.

Menéndez L, Bernal V, Novellino P, Perez SI. 2014. Effect of bite force and diet composition on craniofacial diversification of southern South American human populations. Am J Phys Anthropol 155: 114-127.

Mitteroecker P, Bookstein F. 2008. The evolutionary role of modularity and integration in the hominoid cranium. Evolution 62: 943-958.

Mitteroecker P, Gunz P. 2009. Advances in geometric morphometrics. Evol Biol 36: 235-247.

Mitteroecker P, Gunz P, Windhager S, Schaefer K. 2013. A brief review of shape, form, and allometry in geometric morphometrics, with applications to human facial morphology. Hystrix 24: 59-66.

Monteiro LR. 1999. Multivariate regression models and geometric morphometrics: the search for causal factors in the analysis of shape. Syst Biol 48: 192-199.

Monteiro LR, dos Reis SF. 1999. Princípios de morfometria geométrica. Ribeirao Preto: Holos.

Mosimann JE. 1970. Size allometry: size and shape variables with characterizations of the lognormal and generalized gamma distributions. J Am Stat Assoc 65: 930-945.

Moss ML. 1997a. The Functional Matrix hypothesis revisited. 1. The role of mechanotransduction. Am J Orthod Dentofac Orthop 112: 8-11.

- 1997b. The Functional Matrix hypothesis revisited. 4. The epigenetic antithesis and the resolving synthesis. Am J Orthod Dentofac Orthop 112: 410-417.

Moss ML, Young RW. 1960. A functional approach to craniology. Am J Phys Anthropol 18: 281- 292.

Moss ML, Salentijn L. 1969. The primary role of functional matrices in facial growth. Am J Orthod 55: 566-577. 
Mowbray K. 2005. Surface bone histology of the occipital bone in humans and chimpanzees. Anat Rec 283B: 14-22.

Müller R, Büttner P. 1994. A critical discussion of Intraclass Correlation Coefficients. Stat Med. 13: 24652476.

Muñoz-Muñoz F, Perpiñán D. 2010. Measurement error in morphometric studies: comparison between manual and computerized methods. Ann Zool Fennici 47: 46-56.

Nesser R. 2007. A comparison of statistical and geometric reconstruction techniques: guidelines for correcting fossil hominin crania. Tesis Maestría. Cape Town: Faculty of Science, University of Cape Town.

Neeser R, Ackermann RR, Gain J. 2009. Comparing the accuracy and precision of three techniques used for estimating missing landmarks when reconstructing fossil hominin crania. Am J Phys Anthropol 140: 1-18.

Neubauer S, Gunz P, Hublin JJ. 2009. The pattern of endocranial ontogenetic shape changes in humans. J Anat 215: 240-255.

Norman GR, Streiner DL. 1998. Bioestadística. España: Harcourt Brace Publishers International.

O'Higgins P, Bromage TG, Johnson DR, Moore WJ, McPhie P. 1991. A study of facial growth in the sooty mangabey Cercocebus atys. Folia Primatol 56: 86-94.

O'Higgins P, Jones N. 1998. Facial growth in Cercocebus torquatus: an application of three-dimensional geometric morphometric techniques to the study of morphological variation. J Anat 193: 251272.

O’Higgins P, Bastir M, Kupczik K. 2006. Shaping the human face. Int Congr Ser 1296: 55-73.

O'Higgins P, Fitton LC, Phillips R, Shi JF, Liu J, Gröning F, Cobb SN, Fagan MJ. 2012. Virtual functional morphology: novel approaches to the study of craniofacial form and function. Evol Biol 39: 521535.

Opperman LA. 2000. Cranial sutures as intramembranous bone growth siters. Dev Dyn 219: 472-485.

Opperman LA, Gakunga PT, Carlson DS. 2005. Genetic factors influencing morphogenesis and growth of sutures and synchondroses in the craniofacial complex. Semin Orthod 11: 199-208.

Pameijer $\mathrm{CH}$. 1978. Replica techniques for scanning electron microscopy - a review. Scan Electron Microsc 2: 831-836. 
Parfitt AM. 2002. Targeted and nontargeted bone remodeling: relationship to Basic Multicellular Unit origination and progression (Mini-review). Bone 30: 5-7.

Parker J. 2011. Morphogens, nutrients and the basis of organ scaling. Evol Dev 13: 304-314.

Peña Amaro J. 2007. Competencias y habilidades en histología médica: el potencial formativo de la observación microscópica. Córdoba, España: Universidad de Córdoba.

Perez SI. 2006. Influencia de la deformación artificial del cráneo sobre la morfología facial: implicancias para los estudios de relaciones evolutivas inter-poblacionales. Rev Arg Antrop Biol 8: 37-55.

Perez SI, Gonzalez PN, Bernal V, Del Papa M, Barreiro A, Negro C, Martínez L. 2004. El error de observación y su influencia en los análisis morfológicos de restos óseos humanos. Datos de variación continua. Rev Arg Antrop Biol 6: 61-75.

Perez SI, Bernal V, Gonzalez PN. 2007. Morphological differentiation of aboriginal human populations from Tierra del Fuego (Patagonia): implications for South American peopling. Am J Phys Anthropol 133: 1067-1079.

Perez SI, Monteiro LR. 2009. Nonrandom factors in modern human morphological diversification: a study of craniofacialvariation in southern South American populations. Evolution 63: 978-993.

Perez SI, Lema V, Diniz-Filho JAF, Bernal V, Gonzalez PN, Gobbo D, Pucciarelli HM. 2011. The role of diet and temperature in shaping cranial diversification of South American human populations: an approach based on spatial regression anddivergence rate tests. J Biogeogr 38: 148-163.

Pfefferkorn G, Boyde A. 1974. Review of replica technique for scanning electron microscopy. Scan Electron Microsc 1: 75-82.

Postillone MB. 2016. Estudio de ADN antiguo en muestras precolombinas de Argentina. Tesis Doctoral. La Plata: Facultad de Ciencias Naturales y Museo, Universidad Nacional de La Plata.

Pucciarelli HM, Sardi ML, Jimenez Lopez JC, Serrano-Sánchez C. 2003. Early peopling and evolutionary diversification in America. Quat Int 109-110: 123-132.

Pucciarelli HM, Neves WA, González-José R, Sardi ML, Rozzi FR, Struck A, Bonilla MY. 2006. East-West cranial differentiation in pre-Columbian human populations of South America. HOMO- J Comp Hum Biol 57: 133-150.

R Core Team. 2014. R: a language and environment for statistical computing. R Foundation for Statistical Computing, Vienna, Austria. URL https://www.R-project.org/.

Rayfield EJ. 2007. Finite Element Analysis and understanding the biomechanics and evolution of living and fossil organisms. Annu Rev Earth Planet Sci 35: 541-76. 
Rohlf FJ. 2015. The tps series of software. Hystrix 26: 9-12.

Rohlf FJ, Slice DE. 1990. Extensions of the Procrustes Method for the optimal superimposition of landmarks. Syst Zool 39: 40-59.

Rose DC, Agnew AM, Gocha TP, Stout SD, Field JS. 2012. Technical note: the use of Geographical Information Systems software for the spatial analysis of bone microstructure. Am J Phys Anthropol 148: 648-54.

Sadler TW. 1996. Langman: embriología médica. Buenos Aires: Editorial Médica Panamericana.

Salceda S. 1984. Diagnosis antropológica de los restos óseos humanos aborígenes de Pampa Grande (Guachipas - Salta) y su integración en el cuadro taxonómico racial de la República Argentina. Tesis Doctoral. La Plata: Facultad de Ciencias Naturales y Museo, Universidad Nacional de La Plata.

Sardi ML, Ramírez Rozzi FV. 2005. A cross-sectional study of human craniofacial growth. Ann Hum Biol 32: 390-396.

- 2007. Developmental connections between cranial components and the emergence of the first permanent molar in humans. J Anat 210: 406-417.

Sardi ML, Ramírez-Rozzi F, González-José R, Pucciarelli HM. 2005. South American craniofacial morphology: diversity and implications for Amerindian evolution. Am J Phys Anthropol 128: 747-756.

Scott EC. 1979. Dental wear scoring technique. Am J Phys Anthropol 51: 213-218.

Shapiro F. 2008. Bone development and its relation to fracture repair. The role of mesenchymal osteoblasts and surface osteoblasts. Eur Cell Mater 15: 53-76.

Smith BH. 1984. Patterns of molar wear in hunter-gatherers and agriculturalist. Am J Phys Anthropol 63: 39-56.

Sperber GH. 2001. Craniofacial development. Canada: BC Decker Inc.

Stout S, Crowder C. 2012. Bone remodeling, histomorphology, and histomorphometry. En: Crowder C, Stout S, editores. Bone histology: an anthropological perspective. Boca Raton: CRC Press, p. 121.

Stout SD. 1978. Histological structure and its preservation in ancient bone. Curr Anthr 19: 601-604.

Toro-lbacache V, O'Higgins P. 2016. The effect of varying jaw-elevator muscle forces on a finite element model of a human cranium. Anat Rec 299: 828-839. 
van Buuren S, Groothuis-Oudshoorn K. 2011. mice: Multivariate Imputation by Chained Equations in R. J. Stat. Softw 45: 1-67.

Wagemans PAHM, van de Velde JP, Kuijpers-Jagtman AM. 1988. Sutures and forces: a review. Am J Orthod Dentofac Orthop 94: 129-141.

Wealthall RJ. 2002. Surface remodelling of the facial skeleton in juvenile Macaca mulatta: implications for sexual dimorphism. Folia Primatol 73: 49-53.

Zar JH. 1999. Biostatistical analysis. New York: Prentice Hall.

Zelditch ML, Swiderski DL, Sheets DH, Fink WL. 2004. Geometric morphometrics for biologists: a Primer. London: Academic Press. 